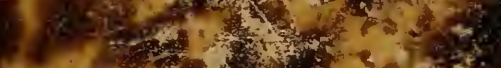

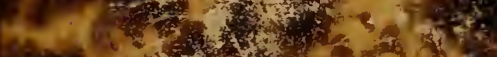

10.

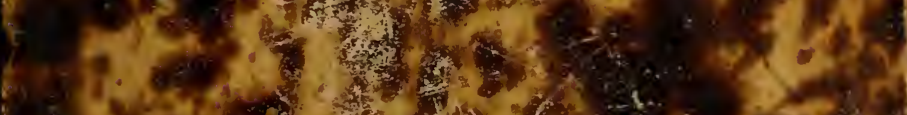
(1)

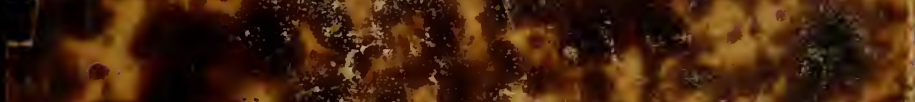

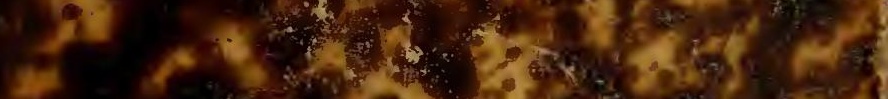
6.

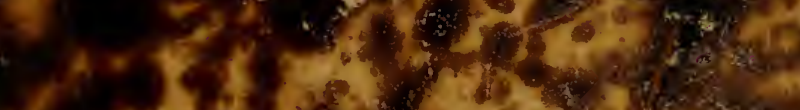
(1) $3=-\mathrm{s}$

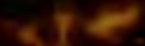
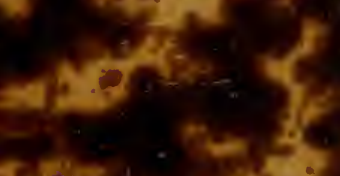

(4) $180^{\circ}$

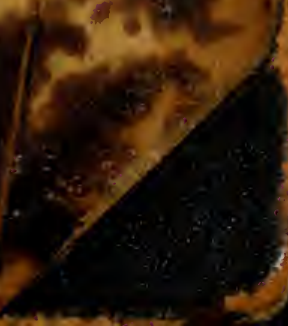




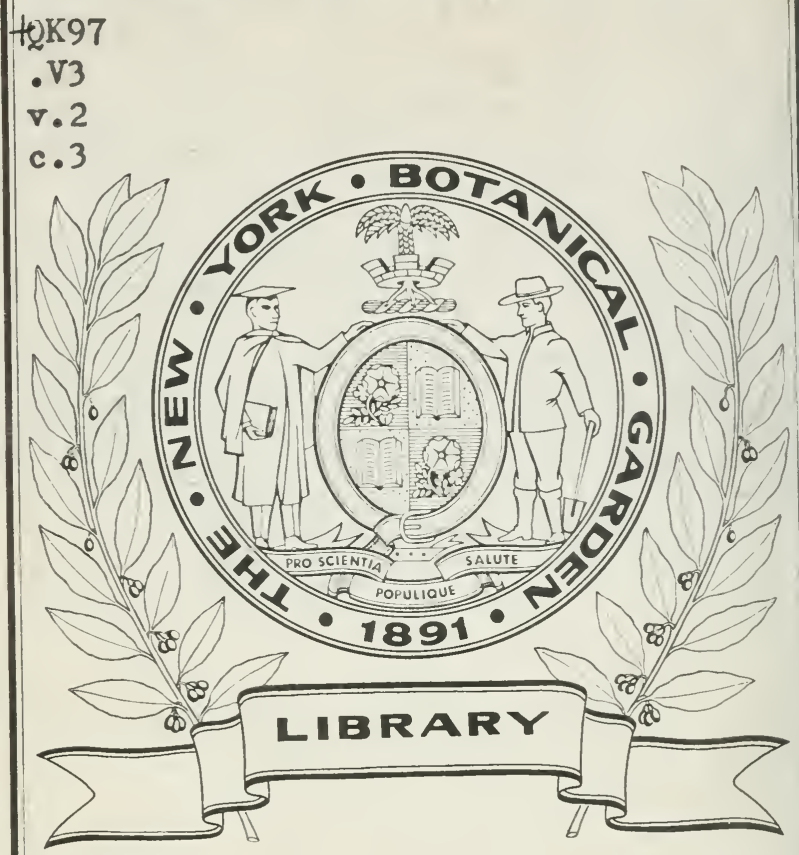






\section{MARTINI VAHLII,}

PROFESS. BOTAN. HAUN, MEMBR, SOCIET. LIT, PLUR,

\section{E N U M ER A T I O \\ P L A N T A R U M,}

VEL AB ALIIS, VEL AB IPSO

OBSERVATARUM,

CUM EARUM

DIFFERENTIIS SPECIFICIS,

SYNONYMIS SELECTIS

ET

DECRIPTIONIBUS SUCCINCTIS.

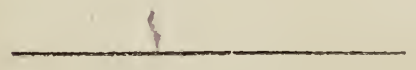

VOLU AT EN II.

HAUNIAE \& LIPSIAE cIว่วcccvi.

Apud Joh. Henr. S chnbothe in Commissis. 
.163

$v_{1} 2$

c. 3 
E N U M E R A T I O

PLA N T A R M.

VOLUMEN SECUNDUM. 


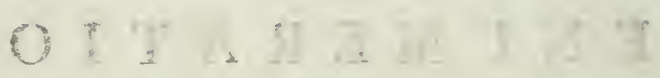

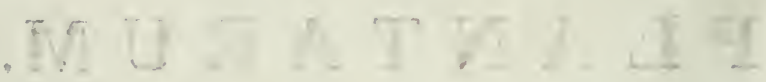

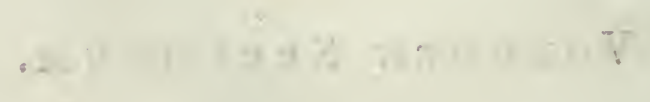

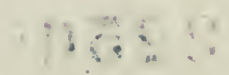




\section{LECTORI BENEVOLO.}

I ars secunda Enumerationis plantarum celeberrimi Vahlii, ad Commelinam usque typis excusa, improvisa auctoris morte fuit interrupta.

Quod absolutum erat, tanta copia specierum novarum abundabat, dubia tam multa tollebat, tot plantas imperfecte cognitas descriptionibus accuratis illustrabat, uno verbo tantis accessionibus botanicen locupletabat, ut chartas scriptas in lucem edendo non levem a botanophilis gratian se inituros defuncti auctoris amici sperarent.

Celeherrimus Vahlius Volumine hoc primum ordinem Classis Triandriae tradere in animo ha- 
buit; in quo elaborando cum ille multum desudasset, melius visum est eum integrum, si fieri posset, edere, et hunc in finem relicta Beati adversaria prelo subjicere.

Comperimus quidem sciagraphiam nondum finitam, descriptiones specierum nonnullarum non satis ad amussin elaboratas esse, et species ad generà, quae condidit nova, non ommes esse relatas: cum vero herbarium locupletissimum Vahlii munificentia Regis patriae conservatum sit, nobisque ad manus fuerit, hoc adjumento deciderata ista vel minus perfecta, comparatis speciminibus herbarīi, suppleri utcunque potuisse, speravimus.

Non diffitemur, opus hocce hac de causa a perfectione procul abesse, qua ornatum prodiisset, si ad finem usque $\mathrm{ab}$ auctore ipso prelo subjectum fuisset, sed melius duximus, opus, quale erat, edere, quam volumen hoc inchoatum et fere absolutum botanophilis invidere, confidimusque justos judices, ubi plurima niteant, levioribus nonnullis maculis non offensum iri. 


\section{P PAEFA TIO.}

Eliminata classe Polygamia, quod ex praefatione voluminis primi patet, Ficum in Trian dria locavimus. Notum quidem nobis erat, ficue plures ad monoeciam pertinere, et fortasse $\mathrm{V}$ ahlius ipse in hac classe locum illis adsignatum roluerat; cum vero genera in herbario suo eo ordine collocaverit, quo usus est in enumeratione plantarum, credidimus, nos, hunc ordinem tanquam normam sequentes, $a b$ animo auctoris non valde discessuros. Eadem de causa genera plurẹ heic sunt praetermissa; Stipulicidam nempe ad Polycarpon, Schoenos plures ad Trisericum, Di. plasiam ad Heptandriam, Cenchros plures ad Lappaginem, Nar̃um âristafum ad Cloridem transtulit.

Post obitum celeberrimi Auctoris plura edita sunt opera botanica, incremento et progressibus botanices inserrientia; hisce adminiculis heic non usi sumus, cum vahliana modo tradere propositum haberemus; ideo nova genera et species ab illustris. Billardiere, Beauvois, Ardrews, Persoon et aliis norissime divulgata in hoc opero frustra quaeris. 
Addenda et Corrigenda in Volumine Primo, a Vahio ipso collecta, ad finem operis addita sunt.

Si hocce Volumen peritis placuerit lectoribus, poterit reliquum opus, sive integrum, sive partes selectas, ex defuncti chartis edi.

Dabamus Hauniae iduum Octobris $18050^{\circ}$

N. Tönder Lund. 'J. WF. Horneman. P. Thonning. 
T R I A N D R I A.

M O N O G Y N I A. 



\section{CLASSIS TII. \\ T R I A N D R I A.}

\section{MONOGYNIA.}

* Flores superi, completi.

?4. VAleriana. Cor. I-petala, saepe calcarata. Sem. calyce corticatum, coronatum.

75. FEDIA.

Cal. 3-4-dentatus. Cor. 5-fida. Caps. coronata, 3-locularis: loculamento I fertili.

89. Axia.

Cal. 3 -fidus. Cor. זo-fida. Sem. x.

+ Boerhaviae nonnullae. Galium trifidum.

** Flores superi, incompleti.

92. Trtpterelta. Cor. h-fida: laciniis alternis minutis; tubo basi ventriceso.

94. Crocus. Cor. 6-partita, aequalis. Stigmata convoluta.

95. WITSENIA. Cor. N-fida. limbo erecto. Stigma subtrifidum. 


\section{TRIANDRIA.}

97. IXIA.

98. Gladiolus.

99. Antholyza.

I00. ARISTEA.

96. MARICA.

IO2. MORAEA.

roI. IRIs.

703. Dilatris.

107. Hanmodorum. Petala 6: 3 interiora supra medium staminifera. Stigma obtusum.

† Narcissus triandrus.

*** Flores inferi, incompleti.

TO5. WACHENDORFIA.

Cor. 6 -petala, inaequalis. locularis. Sem. solitaria.

104. Xiphidium.

Cor. '-petala, aequalis. Caps. 3-locularis. Sem. plura.

93. Heteranthera. Cor. i-petala: limbo 6-partito: laciniis subaequalibus.

86. HEDYCREA.

Stigma peStigma peaciniis indi-

petalis interiStigma varium. 


\section{TRIANDRIA.}

10. Ficus.

79. ROTALA,

78. ORTEGIA.

76. Polychenumo?
Receptac: ventricosum, includens flosculos. ఫ Cal. 3-partitus. \& Cal. 5 -partitus. Utriculus pulposus.

Cal. 3-dentatus. Caps. 3-locularis, polysperma.

Cal. 5-phyllus. Caps. I-locularis, polysperma.

Cal. 5-phyllus. Caps. utricularis, I - sperma.

+ Rivina brasiliensis. Juncus conglomeratus, effusus, bufonius. Laurus triandra.

**** Flores inferi, completi.

77. Loefflingia،

9०. Willichia.

108. Callisia.

106. Commelina.

I09. SYENA.

87 Macrolobium.

88. Outea.

80. HIHPOCRATEA.

81. TONSELla.
Cal. 5-phyllus. Cor. r-petala. Caps. I-locularis, 3-valvis, polysperma.

Cal. 4-fidus. Cor. 4 -fida. Caps. 2locularis, polysperma.

Cal. 3-phyllus. Cor. 3 -petala. Anth. geminae. Caps. 2-10cularis.

Cal. 3-phyllus. Cor. 3 -petala. Nect. staminiforme. Caps. $2-3$-locularis.

Cal. 3-phyllus. Cor. 3 -petala. Caps. I-locularis, 3 -valvis.

Cal. 4 -dentatus. Cor. I-petala. Legum. pedicellatum, I-spermum.

Cal. 5-dentatus. Cor. 6-petala: superius maximum. Stam. 4, I sterile. Germen pedicellatum.

Cal. 5-phyllus. Cor. 5-petala. Caps. 3 , bivalves.

Cal. 5 -ficus. Cor. 5-petala. Nect. suburceolatum. Bacca r-locularis, polysperma. 


\section{TRIANDRIA.}

82. OLAX:

84. Comocladia.

85. Rumphia.

83. Cineorum.

91. OXYвAPHUS.

III. XYRIS.
Cal. margo integer. Cor. 5 -petala: 4 . filamentis connata. Nect. 5-phyllum. Drupa 1 -sperma.

Cal. 3 -partitus. Cor, 3-partita. Drupa putamine bilobo.

Cal. 3-fidus. Cor. 3 -petala. Drupa putamine 3-loculari.

Cal. 3 -4-dentatus. Cor. 3-4-petala: petalis aequalibus. Drupae 3-4, aggregatae.

Cal. 5 -fidtis, campanulatus. Cor. infundibuliformis. Nux I-sperma, calyce insidens.

Cal. cartilagineo-glumaceus, 3 - valvis. Cor. 3 -petala. Caps. I-locularis, 3 - valvis.

+ Eagara spinosa, acuminata. Hirtella triandra. Tradescantia multiflora.

***** Flores glumacei.

II2. Schoenus.

Cal. squamae in spicam fasiculatae, inferiores vacuae. Cor. o. Stylus deciduus.

113. Rynchospora. Cal. squamae in spicam fasciculatae, inferiores vacuae. Cor. 2. Stylus basi persitens. Setae basi seninis.

116. Dichromena. Cal. squamae in spicam undique imbricatae, inferiores vacuae. Cor. 0. Stylus basi persistens. Setae 0.

II. Fimbristylis. Cal. squamae in spicam undique imbricatae. Cor. Stylus basi bulbosus, ciliatus, deciduus.

117. SCIRpus.

Cal. squamae in spicam undique imbricatae. Cor. o. Stylus filiformis, imberbis, deciduus. 


\section{TRIANDRIA.}

125. ERIOPHORUM. Cal. squamae in spicam undique imbricatae. Cor. o. Sern. lana longissima calyculatum.

120. ABILDGAARDIA. Cal. squamae in spicam subdistiche imbricatae. Cor. o. Stylus basi persistens.

121. CYPERUS.

Cal. squamae in spicam distiche imbricatae. Cor. o. Stylus deciduus.

114. MACHAERINA. Cal. squamae in spicam laxe imbricatae, intra singulam Cor. bivalvis. Setae basi seminis.

318. Hypaenyptum. Cal. squamae in spicam arcte imbricatae, intra singulam Cor. bivalvis. Setae 0.

124. Fuirena.

Cal. squamae aristatae, in spicam undique imbricatae, intra singulam Cor. trivalvis.

115. MELANCRAnIs. Squamae in spicam undique imbricatae, intra singulam Spiculae $5-7$ flora. Cal. 2-valvis. Cor. I-valvis.

123. KyLlinga

Flores distincti, in spicam subimbricati. Cal. 2-valvis, -florus. Cor. 2 - vąlvis, calyce major. Stylus bificlus.

127. ReMirea.

Flores distincti, in spicarn congesti. Cal. 2-valvis, I -florus. Cor. 2valvis, calyce minor.

122. MARISCUS.

Flores distincti, in spicam subimbricati. Cal. $=$-valvis. subtriflorus. Corolluclae I-valves, inferior superiorem amplectens. Styl. 3-fidus.

126. MAPANIA.

Flores capitati.

Cal. 6-valvis.

Cor.

o. Sem. 1 .

128. LYGEUM.

Flores gemini calycibus basi in pericarpium bilocularem concrescentibus. Invol. spatha.

122. Cornucoprae. Cal. 2-valvis. Cor. 1-valvis. Invol. infundibuliforme, multiflorun. 


\section{TRIANDRIA.}

130 Pommereulla. Cal. 2 -valvis, 3 - $q$-florus: valvis 4 - fidis, dorso aristatis. Cor. 2 - valvis: altera aristata.

3 3. Cenchrus.

Cal. 2 -valvis, 2 -florus. Cor. 2 -valvis; mutica. Invol. laciniatum, echinatum, 3-4-florum.

32. Nardus.

Cal. x-valvis, r-florus. Cor. I-valvis. Stigma simplex.

33. OrYZOPSIS.

Cal. 2 -valvis, $\mathrm{x}$-florus. Cor. 2 -valvis : exteriore aristata, Nect. 2-phyllum. 


\section{MONOGYNIA.}

74. Valeriana. Cal. superus. Cor. r-pezala, saepe calcarata. Sem. calyce corticatum, pappo dentibusve coronatum.

I. VALERIANA foliis lanceolatis integerrimis, flo- rubiz. ribus monandris caudatis. Lin. syst. veg. 81 . Valeriana rubra. Dod. purg. 9I. pempt. $35 \mathrm{I}$. Polemonii species. Dalech. hist. I 187.

Valeriana rubra latifolia. Bauh. hist. 3. p. 2 I I. Valeriana marina. Rivin. monop.

Habitat in ruderatis Helvetiae, Galliae, Africae borealis et Orientis. 4

Caulis pedalis, subramostu, glaber, uti tota planta. Folia sessilia, bipollicaria, attenuata, obtusiuscula, crassiuscula, nervoso-venosa. Flores in corymbis conferti, sessiles. Pedunculi partiales oppositi, dichotomi.

$V$ ariat flóribus rubris et albis: spontanea foliis latioribus et angustioribus secundum locum fertiliorem vel steriliorem.

2. VALERIANA foliis linearibus integerrimis, flo- angustifolia. ribus monandris caudatis. Wilden. spec. pl. x. p. 175. Cavan. ic. 4. p. 32. t. 353.

Phu aliud angustifolium. Gesn. t. aen. 9. f. 74.

Valeriana rubra angustifolia. Buuh. prodr. 88. hist. 3. p. 2г r. Raii. syll. 25 \%.

Valeriana rubra $\beta$. Lin. spec. $p l .44$.

Valeriana angustifolia. All. fl. ped. $n .2$.

Habitat in Helvetiae, Italiae, Hispaniae montosis. 4

A praecedente vix differt nisi foliis angrustissimis.

3. VALERIANA foliis pinnatifidis, spicis racemo- calcitrapa. sis bipartitis, floribus monandris.

Valeriana annua s. aestiva. Clus. hist. 2. p. 54.

Valeriana sylvestris calcitrapae. Banh. pin. $16 \%$ Moris. hist. 3. s. 7. p. 101. t. I 4. f. 7 .

Valeriana sylvestris, foliis tenuissime divisis. Bauh. pin. 165.

Habitat in Lusitania, Africa septentrionali, Oriente, in Peru, forte ex Europa introducta. ๑.

Tom. II.

A 
Caulis erectus, pedalis, ramosus, laevis, glaberrimus, uti tota planta: Rami oppositi. Folia petiolata, infima cuneata, vix pollicaria, planta adolescente evanescentia: caulina pinnatifida inferiora saepe tri-quadripollicaria, sursum minora; laciniae lanceolatae, intus versus sensim minores, integerrimae vel extrorsum serratae, terminalis major: sub pedunculis linearia, indivisa, integerrima, utrinque attenuata. Pedunculi partiales oppositi,-inferiores bis biparviti, superiores bipartiti. Flores secundi, nulli in divisuris, alterni; fructiferi distantes. Bracteae duae ad basin flortm inferiorum, solitariae superne, subulatae.

oblongifolia. 4. VALERIANA pilosa, foliis radicalibus oblongis dentatis obtusis, caulinis linearibus serrato-incisis. †

Valeriana oblongifolia; floribus triandris, foliis oblongis dentatis, corymbo terminali. Fl. per. т. p. 40. t. $65 . f$ : $a$.

Habitat in alpibus Peruvias.

Radix fibrosa, crassiuscula. Caules plures, fere aphylli, nisi sub floribus, striati; intermedius longior, bipalmaris. Folia radicalia petiolata, remote dentata: floralia sessilia, lineari-lanceolata, profunde serrata. Flores in corymbo congesti, sessiles. Fl. per. l. c.

dioice. 5. VALERIANA foliis radicalibus subspathulatoovatis indivisis, caulinis pinnatifidis laciniis lanceolatis integerrimis subdentatisque obtusiusculis.

mas, «. Phu minimum. Matth. 41. Camerar, epit. 23. f. ad dextram.

Valeriana minor. Rivin monop.

foemina, f. Valeriana quarta omnium minutissima. Trag. 62.

Phu minimum seu Valeriana montana palustris. Camerar. epit. $f$. ad sinistram.

Valeriana flore exiguo. Rivin monop.

Valeriana dioica; floribus triandris dioicis, foliis pinnatis integerrimis. Lin. fl. suec. n. 35. syst. veg. 81. Pollich. pal. n. 30. Fl. dan. t. 687. $\alpha . \beta$.

Habitat in Europae campis uliginosis. 4 
Caulis spithamaeus, uti tota planta glaber. Folia radicalia petiolata, semipollicaria, obtusissima, integerrima : caulina pollicaria, sessilia, duum parium, remota; laciniae infimorum $\bullet b$ longae, obtusiores; superiorum lanceolatae, minus obtusae; terminalis major, intus sensim minores: floralia linearia, indivisa, corymbo breviora. Corymbi ex axillis supremis et apice. trichotomi.

Flores foeminei longe minores quam masculi. Lin.

6. VALERIANA foliis radicalibus ellipticis indivi- thus sis, caulinis pinnatifidis laciniis lanceolatis integerrimis acutis.

Phu magnum. Fuchs. 856. Matth. 39.

Valeriana hortensis flore albo. Rivin monop.

Valerianá phu; floribus triandris, foliis caulinis pinnatis, radicalibus indivisis. Lin. spec. pl. 45 .

Habitat in Alsatia. 4

Caulis sesquipedalis, striatus, uti tota planta glaber. Folia radicalia petiolata, palmaria, basi attenuata, integerrima, venosa: caulina sessilia: floralia linearia, infima longitudine corymbi. Corymbus trichotomus. \$

7. VALERIANA foliis radicalibus spathulato-subro- hyalinorliza. tundis crenatis integris auriculatisque, caulinis pinnatifidis. $\dagger$

Valeriana hyalinorhiza; floribus triandris, foliis radicalibus subrotundis crenatis : caulinis pinnatifido-dentatis, panicula terminali. Fl. per. I. p. 4 I. $t .67 \cdot f . b$.

Habitat in locis aridis arenosis Chili.

Pubescens. Radix tuberosa, obovata. Ryalina, insipida. Caulis semipedalis, purpurascens. Folia radicalia petiolata, intimum utrinque appendiculatum: caulina distantia, connata, lanceolata. Corymbi dichotomi. Calyx obsoletus. Corolla lutea. Semen oblongo-tetragonum, denticulis minimis coronatum. Fl. per. i. $c$. $^{\circ}$

8. VALERIANA foliis inferioribus' ovato-oblongis srispa, dentato-serratis, caulinis subpinnatis; foliolis serratis undulatis. $f$ 
Valeriana crispa; floribus triandris, foliis inferioribus ovato-oblongis serratis: caulinis subpinnatis: foliolis lanceolatis, racemis dichotomis. Fl. per. 1. p. $4 \mathrm{I}$.

Habitat Chili in pratis, arvis et agris.

Radix fibrillosa. Caulis bipedalis, ramosus, fra. gilis, teres, striatus, cavus. Folia petiolata: caulina pinnata subpinnatifidaque; foliola sessilia, reflexa, undulato-crispa, intima sensim minora, terminale maximum. Racemi dichotomi. Fl. per. l. $c$.

interrupta. 9. VALERIANA foliis radicalibus interrupte pinnatifidis: laciniis longioribus subpinnatifidis, caule subaphyllo. $†$

Valeriana interrupta; floribus triandris, foliis pinnatifido-laciniatis interruptis: laciniis dentiformibus, corymbis involucratis. Fl. per. 1. p. 42. t. $-67 \cdot f \cdot a$.

Habitat in alpibus Peruvianis. 4

Succosa, glabra. Radix crassa, bifida. Folia radicalia, nulla in caule nisi duo pinnatifida sub corymbo, Scorzonerae laciniatae haud absimilia. Pedunculi terminales, terni: flores in capitulo sessiles. Bracteae lineares ad singutum fiorem. Corolla alba, quinquefida. Fl. per. $l$. $c$.

lyrata. 10. VALERIANA folìs radicalibus lyratis; laciniis oblongis dentato-serratis terminalibus subpinnatifidis caulinorum lineari-lanceolatis.

Habitat in Peruvia. Ex herbario Iussiaei.

Caulis spithamaeus, diphyllus, glaber. Folia radicalia petiolata, caule dimidio breviora; lacinia terminalis maxima, bipollicaris; lateralibus alternis, profunde obtuseque serratis: caulina sessilia, semipollicaria, omnia glabra. Pedunculi partiales racemosi, trifidi, dichotomi. Facie Valerianae calcitrapae.

pinnatifida. Ir. VALERIANA foliis infimis lanceolatis integerrimis, reliquis pinnatifidis laciniis serrato-incisis, corymbi ramis dichotomis. $t$.

Valeriana pinnatifida; floribús triandris corymbosis, foliis infimis lanceolatis integerrimis, reliquis pinnatifidis laciniatis, panicula brachiata. Fl. per. I. p. 40. t. 6g. f. b. 
Habitat in collibus altis Limae. 4

Succosa. Radix tuberosa, longa. Caulis simplicissimus, striatus, cavus, inferne aphyllus. Folia radicalia longe petiolata: caulina semiamplexicaulia; laciniae serrato-dentatae. Paricula elongata: pedunculi partiales inferiores primum trichotomi dein dichotomi: flos sessilis in dichotomiis. Bracteae lineares sub pedunculis et pedicellis. Flores triandri. Fl. per. l. c.

12. VALEPIANA pilosa, acaulis, foliis pinnatis; globifera. foliolis sinuato-dentatis, capitulis globosis. $t$ Valeriana globifera; floribus triandris, foliis pinnatis foliolis sinuato-dentaiis, bracteis spathulatis, capitulis globosis. Fl. per. 1. p. 43.t.65. f. $b$.

Habitat in Alpibus Peruviae.

Radix crassiuscula, bi-trificla. Scapi plures, semipalmares, teretes, striati. Folia radicalia, petiolata, longitudine fere scapi: foliola sessilia. Flores sessiles in capitulo globoso, Bractea spathulata, submembranacea distincti. Fl. per. $l$. $c_{3}$

33. VALERIANA foliis radicalibus pinnatis, cau- paucitora.

linis ternatis foliolis ovalibus acutis serratis, paniculis laxis paucifloris. $t$

Valeriana pauciflora: caulibus simplicibus, erectis: foliis radicalibus pinnatis; caulinis trifoli: tis; foliolis ovalibus acutis, serratis: pani(ula laxa, pauciflora. Michaux fl. bor. Amer. I. $p . \times 8$.

Erabitat in montosis, umbrosis Americae septentrionalis.

1थ. VALERIANA foliis pinnatifidis: laciniis subin- polystachya. tegerrimis, spicis racemosis subcompositis verticillatis.

Valeriana polystachya; floribus triandris, foliis pinnatis, spica composita verticillata. Smith。 pl. ined. 3. p. 5 I. t. $5 \mathrm{I}$.

Habitat in aquosis Bonariae. Commerson, Thouin. Caulis striatus, glaber, uti tota planta. Folia petiolata, tripollicaria; laciniae oppositae vel alternae, extrorsum versus majores, lanceolatae, obtusiusculae, integerrimae vel dente uno alterove notatae: ultina sub spicis linearia, 
indivisa, spicis breviora. Racemus compositus e spicis oppositis; inferioribus compositis, superioribus simplicibus. Flores sex-octo in singulo verticillo. Bracteae ovatae. Corolla basi vix gibba.

officinalis. 15. VALERIANA foliis omnibus pinnatis, pinnis lanceolatis serratis.

Valeriana montana. Trag. 52.

Valeriana sylvestris major montana. Bauh. pin. I 65.

Valeriana foliis angustis. Riv. monop.

ratifolia. F. Valeriana. Brunsf. herb. 2. p. 90.

Thu germanicum. Fuchs. hist. 857 .

Valeriana officinalis; floribus triandris, foliis omnibus pinnatis. Lin. syst. ver. \&I." Pollich. pal. n. 3 T. Fl. dan. t. $57^{\text {d. }}$

zosusfoli $\%$ foliolis linearihus angustissimis integerrimis.

Habitat in Europae nemoribus paludosis. 4

Caulis bi-quadripedalis, glaber, striatus. Folia petiolata: pinnae oppositae, sessiles, interiores minores. Petioli villosi. Corymbi trichotomi. Bracteae lineares.

italica. 36. VALERIANA foliis rentatis, radicalihus oblongis simplicibus pinnatisque, caulinis pinnatis; foliolis lanceolatis, floribus tetrandris.

Valeriana tuberosa. Imper. hist, nat. 868. Bauh. hist. 3. p. 207.

Valeriana tuberosa oblonga, seu Oenanthes radice. Moris. hist. 3. p. io 1. s. 7. t. 15.f. 4 .

Valeriana tuberosa Imperati. Tournef. cor: 5 .

Valeriana tuberosa Imperati seu Telephii radice. Barrel. ic. 825 .

Valeriana italica; floribus tetrandris, foliis pinnatis dentatis, radicalibus indivisis. Lamarck. illustr. . . p. 92 .

Habitat in montibus Liguriae inque Creta. Ex heróario Jussiaei. 4

Caulis striatus, glaber, uti tota planta. Folia raclicalia longe petiolata, remote dentata; alia simplicia, pollicaria, ovato-oblonga, vel oblonga; alia pinnata cum inpari, bi-trijuga, foliolis oppositis vel alternis, sessilibus, oblongis, terminale reliquis majus, sesquipollicare: caulina quadri-quinquejuga, foliolis subpeticlatis, 


\section{TRIANDRIA. MONOGYNIA.}

intus versus sensim minoribus, lanceolatis, bas: dentatis: floralia simplicia, linearia, integerrima, longitudine corymbi. Inforescentia $V a l$. officinalis.

Omnes qui iconem hujus dederunt, figuram ex Imperato, quamvis haud bonam, mutuarunt. Ab Imperatio et Morisonio conjungitur cum Valeriana filipendulae radice. Bauh. pin. $\mathrm{I}^{6} 5$, quae $V a l$. bulbosa Imperati est, et diversa planta.

17. VALERIANA foliis omnibus pinnatis; foliolis ovato-subrotundis integerrimis.

Valeriana orientalis, sisymbrii Mathiolifolio. Tournef, cor. 6.

Habitat in Oriente. Ex herbario Jussiaei.

Facies Sisymbrii nasturtii. Caulis semipedalis vel pedalis, subtilissime striatus, glaber, uti tota planta. Folia petiolata, pinnata cum impari: foliola bi-trijuga; interiora subpetiolata, alterna, minora; exteriora sessilia, opposita; terminale pollicare, ovata vel ovato-subrotunda obtusissima, obscure nervosa, subavenia: supreme interdum ternata. Flores in corymbo denso, fastigiato, subsimplici, facie Val. officinalis. Bracteae lineares, flore breviores. Stamina tria. Stylus trifildus.

Ex mente Buxbaumii Cent, 2. p. ra. a Valeriana dioica non differt, at omnino distincta.

18. VALERIANA foliis pinnatis; foliolis ovatis sapensis. dentatis. Thunt. prodr, fl. cap 7 .

Habitat in Cap. b. spei.

Caulis sulcatus, glaber, geniculis pilosis. Co. rymbi dichotomi,

19. VALERIANA foliis radicalibus ind̄ivisis corcia paniculati.

tis, caulinis pinnatis; foliolis ovatis denticulatis, paniculae ramis dichotomis. +

Valeriana paniculata; floribus triandris, foliis radicalihus indivisis cordatis: caulinis pinna. tis, panicula diffusa. Fl. per. т. p. 4s, t. zo: f. a.

Habitat in locis uliginosis et petrosis Peruviae.

Villosa. Ractiv ramosa. Caules plures, aggregait, panum foliosi, fere tripedales, simplicisșimi, obsalete alcipiles, striato-sulcati, cavi,

sisymbriifo. lici. 
Folia duo racilcalia, integerrima; inferiora caulina septenato-pinnata; suprema ternata: foliola acuta, interiora minora. Petioli vagi. nantes. Panicula diffusa. Bracteae parvae, oppositae, lineares. Calyx marginalis, decemangulatus. Corollae tubus minimus. Semina oblonga, parum compressa. Pappus decemradiatus. Fl. per. $l$. $c$.

decussata. 2o. VALERIANA foliis pinnatis; foliolis lanceolatis denticulatis subtus incanis, paniculae ramis dichotomis divaricatis. $\uparrow$

Valeriana decussata; floribus triandris, foliis impari-pinnatis: foliolis lanceolatis, intimis minimis, panicula decussata, pedunculis dichotomis. Fl. per.. . p. $4=0, t .70 . f . b$.

Habitat in Peru, in sepibus et locis petrosis.

Caulis herbaceus, subscandens, tripedalis, striatus, leviter pubescens, cavus. Folia breviter petiolata: foliola extus versus sensim majora, remote denticulata, supra pubescentia, subtüs tomentosa. Panicula maxima: pedicelli horizontales. Bracteae lineares, sub pedunculis et pedicellis. Corolla minima, ałba. Semina decem, duodecim radiata. Fl. per. l. c.

soarcens. 2I. VALERIANA foliis ternatis, caule scandente. Loefl. it. 235. Lin. syst. veg. 8 1. †

Habitat in Cumana.

Flores laterales, paniculati, subdichotomo-spicati. Corolla viridi-rosea, tubulata, aequaliter quinquedentata: cientes patuli. Stamina tria. Semina compressa, ovata, striata, pappo plumoso coronata. Loefl. l. $c$.

sanguisor-22. VALERIANA foliis pinnatis; foliolis ovatis bacfolia. dentatis, corymbis compositis. +

Valeriana sanguisorbaefolia; foliis impari pinnatis: pinnulis ovatis dentatis: floribus paniculatis. Cavan. ic. 5. p. 34. t. 456 .

Habitat in Cordilleras.

Caulis vix pedalis, adscendens. Folia plurima radicalia: caulina trium parium; foliola sessilia, opposita, utrinque uni-bidentata: floralia simplicia, linearia, margine scariosa. Semina ovata, pellicula striata vestita, coronata caly- 
ce. infundibuliformi decempartito totidemque. pilis plumosis, longitudine seminum. Cavan. l. $c$.

23. VALERIANA foliis pinnatis; pinnis bi-trifidis-virgata. ve, corymbi ramis dichotomis. t

Valeriana virgata; floribus triandris, folis pinnatis: pinnis bi-trifidis laciniis linearibus, panicula subcorymbosa. Fl. per. 1. p. 42, $t$ 。 66. $f . b$.

Habitat in praeruptis Peruviae.

Glabra, habitus T'agetis minutae. Caulis suffruticosus, triperlalis, ramosissimus, tetragonus, striatus, parum cavus, obsolete pubescens: Pami virgati, erecti. Folia impari pinnata: foliola minuta, nonnulla integra, alia li-trifida, pauciora quadrifida; laciniae lineares, emarginatae vel integrae, supra nitidae. Pedunculi partiales dichotomi. Bracteae oppositae, lineares. Flores ex dichotomiis, sessiles. Semina ovato-oblonga, compressa, linc striata, inde dorso elevata. $\mathrm{Fl}$. per. l. $c_{\text {. }}$

24. VALEPIANA foliis subspathulatis ovatis ob-montana, longis simplicibus extrorsum dentatis, caule pubescente.

Valeriana alpina, scrophulariaefolio. Bauh. prodr. 87. pin. 164.

Valeriana montana subrotundo folio. Bauh. pin. 165 .

Valeriana montana; floribus triandris, foliis ovato-oblongis subdentatis, caule simplicissimo. Lin. syst. veg. 81. Jacqu. vind. 242. fl. austr. 3. $t .269$.

Habitat in alpibus Helreticis, Rhaeticis, Pyre. naeis, Austriacis. 4

Caulis striatus, leviter pubescens. Folia remota, acuta, vel acuminata, olscure venosa, glabra: inferiora oblonga in petiolum acuminata; suprema sub corymbo-lanceolata, integerrima, corymbo longiora. Petioli villosi.

25. VALERIANA foliis simplicibus subintegerrimis, intermedia. radicalibus et inferioribus cordato-oblongis, supremis lanceolatis, caulinis ternis.

Habitat in Pyrenaeis, unde atiulit Hornemann lector horti botanici Hauniensis meritissimus. 4 
Caulis vix pedalis, leviter pubescens, ad folia subcanescens, Folia radicalia plura, petiolata, nonnulla ovalia, obtusissima, plurima cordato-oblonga, vix pollicaria, iniegerrima vel basin versus utrinque dentibus duobus vel tribus: caulina trium parium, remotissima; dwo infima oblonga, intermedia cordata"oblonga, attenuata, petiolata: suprema sessilia. Petioli uti venae majores foliorum e viitis brevissimis canescentes. Corymbus patens.

Distincta mihi videtur $a b$ antecedente, foliis non cordatis dentatis ut in illa, sed lanceolatis, integerrimis.

triperis. 36. VALERIANA foliis dentatis, radicalibus cordatis simplicibus, caulinis ternatis ovato-oblongis, lateralibus lanceolatis.

Valeriana alpina prima. Bauh. prodr:: 86. pin. 165.

Valeriana alpina, Bauh. hist. 3. p. 208.

Valeriana alpina minor, planta palmaris. Flukn. alm. $380 . t .23 \mathrm{r}, f .7$.

Valeriana minima, planta uncialis. Plukn. alm. $380 . t$. $23 \mathrm{r} . f .8$.

Valeriana alpina saxatilis minor, flore albo. Barrel, ic. 742 .

Valeriana tripteris foliis dentatis: radicalibus cordatis; caulinis ternatis ovato-oblongis. Lin. syst. veg. 81. Jacqu. vind. $20 \mathrm{I}$. Fl. austr. 3, t. 268 .

Habitat in alpibus Helvetiae, Austriacis. 2i:

Caulis laevis, glaber. Folia petiolata, sesquipollicaria, acuta, glabra, simpliciter venosa: radicalia et inferiora simplicia: caulina ternata; lateralibus utrinque acutis, per petiolum parum decurrentibus; suprema sub corymbolanceolata, integerrima, corymbo longiora. Peiiolus basi parum ciliatus. Pedunculi dichotomi, glabri; partiales approximati. Bracteae subulatae.

Filloэล $2 \%$. VALEPIANA floribus tetrandris aequalibus, foliis inferioribus auriculatis; superioribus dentatis villosis. Thunb. fl. jap. 32.t. 6. †

Habitat in Japonia.

Tota planta dense hirsuta. Caulis simplex, pedalis. Folia radicalia aggregata, petiolata, pal- 
maria, ovata, auriculato-lyrata; Lobi infimi in medio pctioli duo, alterni, lineares, lineam longi, integri, saepe deficientes; duo in apice petioli, oppositi, semipollicares, ovati, dentati; terminalis naximus, pollicaris, ovatus, in acgualiter inciso-serratus: caulina sessilia, semipollicaria, ozata, acuta, inciso-sublyrata, dentata. Paniculae axillares et terminales, trichotomae. Bracteas lineares, Corolla flavae. Thunb. $l_{\mathrm{s}} \mathrm{c}$.

28. VALERIANA foliis cordatis inaequaliter denta- pyrennica.

tis, inferioribus simplicibus, siperioribus pinnatis ternatisque omnibus petiolatis.

Valeriana maxima alliariae foliis. Moris. hist $t^{-} 3$. p. 102.

Valeriana maxima, pyrenaica, cacaliae folio. Tournef. inst. r. herb. 131. Plutin, alm, 380. t. 232, for.

Valeriana pyrenaica; floribus triandris, foliis caulinis cordatis serratis petiolatis: summis ternatis. Lin. syst. veg. $8 \mathrm{I}$.

Fialitat in Pyrenaeis. 24

Caulis saepe orgyalis, striatus, glaber, inter petiolos villoso-subtomentosus. Folia radicalic sesquipedalia: caulina remota, acuta, glabra, venoso-reticulata; foliola tria-quina; lateralic superiorum lanceolata. Pesioli villosi, canescentes. Peduneuli portiales approximati, dichotomi, villosi. Bracteae subulatae, glabrae. Flores rubri, minores quam in Val. triptcae.

29. VALERIANA foliis cordatis attenuatis inaequa- alliariaefolia. liter dentatis omnibus simplicibus, supericribus sessilibus.

Valeriana orientalis, alliariae folio, flore albo. Tournef. cor. 6. Buxb. cent. 2.p. i 9. t. ir.

Irabitat in Cappadocia. Ex herbario Tournefortii.

Tota glabra. Folia inferiora petiolata, paimaria, venosa: superiora pollicaria. Flores corymbosi.

3c. VALERIANA foliis cortato-ovatis subintegerri- lapathifolis. mis indivisis, superioribus sessilibus.

Nabitat ad fretum Magellanicum. Comnerson, Tlouin. 21 
Caulis pedalis vel ultra, crassitie pennae anserinae, striatus, glaber. Folia tripollicaria, sursum sensim minora, acuta, integerrima, interdum obsolete crenata, obscure venosa, nervosa, nervi supra ad lentem villosi, coeterum glabra: radicalia et inferiora petiolata, quatuor in caule, remota, duo superiora sessilia: floralia infima linearia, obtusa, basi ciliata. Corymbi ex axillis supremis, oppositi, pauciflori; terminales multiflori, trichotomi. Flores triandri.

carnosa. 31. VALERIANA foliis ovalibus dentatis carnosis glaucis. Smith. pl. ined. 3. p. 52 t. 52 .

Valeriana magellanica; foliis spathulatis dentatis, caulibus simplicibus, pedunculis oppositis bifidis, fructu prismatico. Lamarck. illustr. 1. p. 93.

Habitat ad fretum Magellanicum. Commerson, Thouin. 24

Caudex adscendens radicis crassitie pennae anserinae, articulatus, vaginis membranaceis vestitus. Caules plures, semipedales, glabri. Folia subcarnosa, glaberrima: radicalia petiolata, pollicaria, inaequaliter dentato-subsinuata, basi attenuata: caulina trium parium, remota, vix unguicularia, sessilia, basi connata, oblonga, dentata. Petiolus folio duplo longior. Corymbi subracemosi, dichotomi.

tuberosa. 32. VALERIANA foliis obtusis integerrimis, radicalibus lanceolato-oblongis indivisis, caulinis pinnatifidis laciniis linearibus.

Nardus montana. Matth. 35 .

Nardus montana radice olivari. Bauh. pin. 165.

Valeriana tuberosa; floribus triandris, foliis radicalibus lanceolatis integerrimis, reliquis pinnatifidis. Lin. syst. veg. $8 \mathrm{r}$.

B. Nardus montana, longius radicata. Cam. epit. i6.

Nardus montana radice oblonga. Bauk. pin. I65. Habitat in Galloprovincia; Sicilia, Dalmatia. 4 Glabra. Radix crassitie digiti, Caulis palmaris. Folia radicalia petiolata, pollicaria, crassiuscula, subnervosa: caulina plerumque duum parium, bipollicaria, basi connata; laciniac 
integerrimae: floralia longitudine corymbi. Co. rymbus densus, hemisphaericus.

An V aleriana bulbosa. Imper. hist. nat. 869: huc pertinet? folia vero latiora et ovata vel cordata secundum figuram.

Similem mesum communicavit cel. Ramond e Pyrenaeis, diversam radice apice divisa in ramos tres-quatuor e reliquiis petiolorum squamosos, forte specie diversam.

33. VALERIANA foliis radicalibus cordatis, cauli- spica. nis oblongis. +

Valeriana jetamansi; flores triandri; folia integra, duum parium, radicalia petiolata, cordata, reliqua sublanceolata, semina papposa. John in act. bengh. 2. p. 405. 4. p. 433. cum figura.

Habitat in Bengala.

Radix descendens, subramosa, superne setis tecta.

Caulis sex-duodecimpollicaris, basi persistens fibrisque involutus. Folia glabra, duo infima cordato-oblonga, undulata, acuta. Corymbus dichotomus.

Ex mente Johnii est Spica nardus antiquorum.

34. VALERIANA foliis radicalibus ovatis, caulinis elongata. cordatis sessilibus inciso-subhastatis. Lin. spec. pl. 1664. Jackil. Austr. 3. t. $210 .+$

Nardo celticae similis alia, sive Valeriana alpina minor. Lin. am. acad. ז. p. 2 14. ed. Lugdb.

Valeriana elongata; floribus triandris, foliis dentatis subovatis: summis basi hastato-incisis, panicula elongata. Jacqu. vind. 205. t. I.

Habitat in alpibus Schneeberg Austriae inferioris. 4

Caulis spithamaeus. Folia radicalia longius pen tiolata, integerrrima, raro subdentata, obtusa, crassiuscula, nitida: caulina oppositionibus duabus-tribus, amplexicaulia, profunde dentata vel incisa. Racemus erectus, longus: pedunculi partiales oppositi, dichotomi, breviusculi. Bracteae lineares. Lin. l. c.

35. VALERIANA foliis simplicibus integerrimis ci- supina, liatis, radicalibus obovatis, caulinis laaceolatis. 
Valeriana alpina, foliis integris, radice repente inodora. Rai. hist. 1. p. 389 .

Valeriana. montana minor italica, foliis integris, radice repente. Barr. ic. 868 .

Valeriana supina; floxibus tetrandris, caule reperte, foliis radicalibus cuneiformibus, emarginatis, ciliatis. Ard. spec. 2. p. 13.t.|3.

Valeriana supina; floribus tetrandris, involucris hexaphyllis trifloris, foliis integris. Lin. Mant. 27. Wulf. in Jacqu. miscel. 2. p. 114. t. 17. f. 2 .

Kabitat in Alpibus Carinthiae. 4

Radix crassitie pennae anserinae, repens, nuda, superne divisa. Caules pollicares, juniores leviter villosuli. Folia radicalia in rosulam exparsa, petiolata, crassiuscula, avenia: caulina sessilia. Pedunculi ex axillis ultimis et apice, oppositi, altitudine caulis, triflori. Bracteae duae ad basin singuli floris, ciliatae. Corolla rubella. Stamina plerumque tria, interdum quatuor. Semen striatum. Pappus plumosus. Wulfen $i$. $c$.

kaxarilis. 36. VAIERJANA foliis indivisis, radicalibus ellipticis trinerviis integerrimis subdentatisque, caulinis linearibus, corymbis racemosis.

Valeriana sylvestris alpina II. saxatilis. Clus. hist. 2. p. 56.

Narko celticae similis. Bauh. prodr. 88. pin. I65.

Valeriana minima, nardifolia. Bauh. hist. 3. $\mu$. 206.

Valeriana alpina nardo celticae similis inodora. Plukn. alme. 380. t. 232 . f. 2 .

Valeriana saxatilis; floribus triandris, foliis sub. dentatis, radicalibus ovatis; caulinis linearilanceolatis. Lin. syst. veg. 8 I. Jacqu. vind. 204. Fl. austr. 3. t. 267.

Habitat in alpithus Stiriae, Austriae, Baldi, Montalbani Italiae. 4

Radix sujyerne ramentis albidis vestitus. Caulis filiformis, spithamaeus, glaber. Folia radicalia petiolata, pollicaria, obtusa, ope lentis margine villosa: caulina duo in medio caulis, integerrima, oltusa. Flores in corymbo compo- 
sito. Pedunculi bis dichotomi, cum flore sessili in dichotomia. Bracteae pedunculis breviores. Flores divici. Jacqu. l. c.

37. VALERIANA foliis lineari-cuneiformibus inte- saïunçૈ. gerrimis tridentatis, floribus umisellato subm. capitatis.

Saliunca Neapolitana. Dalech. 982.

Nardus ex Apulia. Eauh. pin. I 65.

Valeriana saliunca. All. fl. ped. n. 9. t. ?c. f. r.

Habitat in alpizus Italiae. 24

Planta cespitosa. Radix multiceps. Caulis digitalis vel parum ultra. Folia radicalia in rosam expansa, pollicaria, integerrima, crassiuscula, glaberrima: caulina duum parium, remotissima, linearia, integerrima, interdum tridentata. Flores in apice congesti. Pappus plumosus.

Stamina tria. Semina striata. Odor fortissimus. All. l. $c$.

38. VALERIANA foliis indivisis integerrimis obtu- celtika sis, radicalibus cuneato-oblongis, cauiinis linearibus, floribus racernosis.

Nardus celtica, seu'alpina. Clus. pan. 5 r4. Bauh. hist. 3. p. 205. Moris. 3. s. 7. p. 103. t. x5.f. 25. Nardus celtica altera. Bauh. pin. I66.

Nardus celtica; floribus triandris, foliis oratooblongis obtusis integerrimis. Lin. syst. veg. $8 \mathrm{r}$. Jacqu. collect. I. p. $24 . t$. I.

Valeriana foliis integerrimis, radicalibus ovatis, caulinis linearibus obtusis. Hall. $n$. 209. fide speciminis ab ipso determinati.

Hubitat in alpibus Helvetiae, Valesiae, Austriae. 4

Planta digitalis, glabra. Radix multiceps, squamis fuscis tecta. Folia radicalia semipollicaria, oblonga, basi attenuata, crassiuscula: caulina duo. Pedunculi partiales oppositi, inferiores tri-quadriflori, supremi uniflori.

Flores dioici. Hall.

39. VALERIANA foliis spathulato-oblorigis pube- spathuiata. scentibus, floribus terminalibus sessilibus involucratis, corollis trifidis. $\dagger$

Valeriana spathulata; floribus triandris, foliis spathulatis sublinearibusque ebtusis, corollis 
trifidis, umbella sessili involucrata. Fl. per. 1. p. 40. t. 68. f. b.

Habitat in alpibus Peruvize. 21

Caespitosa. Radix ramosa. Caulis subpalmaris, anceps, inferne foliis numerosis tectus. Folia radicalia confertissima: superiora sparsa, erecto-patentia, integerrima, ope lentis ciliata. Involucrum monophyllun, quadri-sexflorum; laciniis linearibus, actitis. Calyx margo minimus. Corollae limbus trifidus. Semina margine coronata. Fl. per. 7 . c.

connata, 40. VALERIANA foliis lanceolatis connatis integerrimis, corymbis racemosis compactis, caulibus suffruticosis procumbentibus. +

Valeriana connata; floribus triandris, foliis lanceolatis connatis integerrinis, spicis verticillatis. Fl. per. I. p. 39. t. 67. f. a.

Habitat in locis frigidis Peru.

Habitus Polygoni persicariae. Caules plures, ramosissimi, cortice cinereo: Rami assurgentes, virati, articulati, fere vaginati, cavi; teneri, bifariam alternatim pubescentes, obscure helvoli, striati. Folia basi attenuata et ciliata, coeterum glabra. Pedunculus elongatus: partiales oppositi, trifidi: foliolum utrinque basi connatum. Bracteae lanceolatae, obtusae. Calyx marginalis. Stigma emarginatum. Pap. pus pilosus. Fl. per. $l$. $c$.

salicariaefo- 4r. VALERIANA foliis lanceolatis integerrimis seslia. silibus, corymbis terminalibus decompositis.

Habitat in Bonaria Commerson. Ex herbario Jussiaei.

Caulis uti tota planta glaber, inferne radicans, sesquipedalis, simplicissimus, striatus. Folia tri-quadripollicaria, inferiora basin versus attenuata, superiora basi subcordata, avenia, enervia.

pilosa. 42. VALERIANA pilosa, foliis lancenlatis integerrimis margine revolutis, corymbis racemosis. $t$

Valeriana pilosa; floribus triandris, foliis lineari-lanceolatis integerrimis margine revolutis. Fl. per. 1. p. 39. t. 66. f. a.

Habitat in locis frigidis Peru. 
Facies Plantaginis albicantis. Radix ramosa. Caulis solitarius, interdum duo vel tres, erectus, pedalis, striatus, versus medium foliis duobus linearibus. Folia radicalia numerosissima, sesquipalmaria, inaequalia, erecta: floralia linearia. Corymbi superne, oppositi: pedicelli tres-quinque. Flores in capitulo sessiles. Bracteae obovatae inter flores. Calyx marginalis. Stigma emarginatitm. Semina pappo pilosa coronata. Fl. per. $l$. c.

43. VALERIANA foliis cuneato-lanceolatis denti- coarstała. culatis ciliatis, floribus verticillato-spicatis. $\dagger$

Valeriana coarctata; floribus triandris, foliis lanceolato-spathulatis margine denticulatis ciIiatis, spica conica coarctata. Fl. per. I. $p$. 40. t. $68 . f . a$.

Habitat in locis altis frigidis Peru. 24

Radix fusiformis, inferne divisa. Caulis fere ps. dalis, striatus, inferne mudus, superne foliosiss, pubescens villis deciduis. Folia radicalia imbricata, bipalmaria, basin versus attenuata, canaliculata, extus purpurascentia: fioralio terna vel quaterna, lanceolata, uti radicalia denticulata, ciliata, utrinque glabra. Flores sessiles in verticillis; verticillus infinuls distans, reliqui contigui. Bracteae breves, cuneiformes. Semin: oblonga, squamis quinque coronata. Fl. per. l. $c$.

44. VALERIANA foliis cuneato-lanceolatis extror- serrats. sum serratis, floribus verticillato-spicatis. +

Valeriana serrata; floribus triandris, foliis lanceolato - spathulatis, superne serratis, spicis verticillatis. Fl. per. s. p. 40. t. 68. $f$. c.

Habitat in locis frigidis Peruviae. 4

Caespitosa, glabra. Radix crassa. Caules plures, striati, subaphylli; intermedius semipeda. lis, sub flore foliosus. Folia radicalia copiosa: floralia apice serrata. Spica terminalis, sesquipalmaris. Flores sessiles in verticillis multifloris, inferioribus distantibus, superioribus approximatis. Bracteae inter flores, cuneiformes, membranaceae. Semen oblongum, squamis quinque curonatum. El. pex. l. $c$.

TQm. II. 
rigida. 45. VALERIANA acaulis, foliis lanceolatis aggregatis imbricatis expansis sensim decrescentibus.

Valeriana rigida; acaulis, floribus triandris, foliis lineari-lanceolatis coriaceis mucronatis, corollis trifidis. Fl. per. ․ p. 39. t. 65. f. c.

Habitat in alpibus Peruviae. Ex herbario Jussiaei. 4

Folia radicalia, copiosissima; in rosam expansa, imbricata, sesquipollicaria, intus versus sensim minora, integerrima, margine cartilaginea, basin versus ciliata, in acumen subpungens desinentia, coriacea, rigida, avenia, enervia, supra nitida, utrinque oculo armato punctata. Scapi brevisimi vel nulli, in centro foliorum.

Radix fusiformis. Scapi breves, compressi, subancipites, albi, basi attenuati. Flores involucrati: involucro universali, uti partiali monophyllo, bifido, vaginante. Calyx margo minimus. Stigma bifidum. Semina nuda. Fl. per. l. c.

tenuifolia. 46. VALERIANA acaulis, foliis lineari-subulatis aggregatis sessilibus imbricatis expansis, extimis longissimis. $t$

Valeriana tenuifolia; acaulis, floribus triandris, foliis lineari subulatis gracilibus, corollis trifidis. Fl. per, 1. p. 39. t. $65, f . d$.

Habitat in alpibus Peruviae. $\frac{3}{4}$

Radix fusiformis. Folia radicalia, numerosa, in stellam expansa, inaequalia, sessiitia, basi dilatata, membranacea, inferne ciliata, integerrima, apice rigidiusculo, avenia, glabra, nitiia. Reliqua ut in praecedente. Fl. per. l. c.

Differt a praecedente: foliis angustioribus, praesertim extimis longissimis, intimis mult brevioribus.

Haec et praecedens habitu ab omnibus diversissimae.

Habitus. Caulis herbaceus, erectus, teres. Folia opposita.

75. Fedia. Cal. superus, 3-4-dentatus. Cor. 1 -petala, 5 -fida, regularis vel irregularis. Caps. coronata, 3-locularis: loculamento 1. fertili. Gaertn. 
x. FEDIA foliis ovatis nervosis, radicalibus spathu-cornucopiae. latis, caulinis sessilibus.

Valeriana indica. Clus, hist. 2. p. 54.

Valeriana peregrina purpurea albave. Bauh. prodr. 87.

Pseudo valeriana cornucopioides annua purpurea. Moris. hist. 3. s. 7. p. 101. t. I\%.f. 27

Valeriana cornucopiae; floribus diandris ringentibus, foliis ovatis sessilibus. Lin. syst.veg. Q r. Habitat in Hispaniae, Siciliae, Africae septantrionalis, Armeniae arvis. (-).

Caulis pedalis, diffusiss. Folia radicalia, in petiolum acuminata, oblonga, reliqua sessilia, sesquipollicaria, obsolete nervosa, obtusa, integerrina vel suldentata; suprema basi saepe dentato-angulata. Pedunculi terminales, gemini, superne crassiores, apice diphylli. Flores argregati, sessiles.

2. FEDIA foliis cuneiformibus dentatis, fructu li- echinata. neari-tridentato; extimo majore recurvato.

Valerianella cornucopioides echinata. Colums. ecphr. 1. p. 2о5. Garid. t. 97.

Valeriana echinata floribus triandris regularibus, foliis dentatis, fructu lineari tridentato: extimo majore recurvato. Lin. spec. $p l .+7$.

Habitat in Galloprovinciae et Italiae umbrosis.

Caulis subtilissime striatus. Folia sessilia, interdum bipollicaria, obtusa, suprema acutiora et basi saepe denticulis nonnullis subulatis profundis. Pedunculi sursum incrassati. Flores dichotomiae solitarii, sessiles, reliqui in spicas dichotomas, coadunatas, obtusas.

3. FEDIA foliis integerrimis obtusis, inferioribus olitoria. cuneatis, superioribus lineari-lanceolatis, fructu nudo.

Lactuca agnina. 1. Tabern. ic. I67.

Valeriana locusta olitoria. Fl. dan. 738 .

f. foliis summis dentatis.

dentatso.

Phu minimum alterum. Lob. ic. 7 r 7 .

Locusta minor. Rivin. monop.

Valeriana locusta; floribús triandris, caule dichotomo, foliis linearibus. Lin. syst. veg. 82 . a. olitoria. Pollich. pal. n. 32 .

Habitat inter segetes, locis gramineis et in aggeribus Europae. 
Caulis digitalis vel ultra. Folia radicalia plura, semipollicaria, sessilia, integerrima, superiora interdum basi dentata.

dentata. 4. FEDIA foliis lanceolatis integerrimis, fructu tridentato, dentibus binis brevissimis. Wild. spec p?. ז. p. 193.

Valeriana altera nudo et umbilicato semine. Colum. ecphr. I. p. 207.

Valerianella serotina elatior fl. albo semine turgidiore. Moris. hist. 3. s. 7. p. 105. t. 16.f. 3?. Locusta major. Rivin. monop.

Valeriana locusta d dentata. Lin. syst. ves. 82.

Valeriana dentata; foliis oblongis serratis, seminis corona tridentata. Hall. hist. n. 215. Pollich. pal. n. 33 .

Fiabitat inter segetes Germaniae, Galliae. (

Caulis sesquipedalis. Folia superiora basin versus denticulis evidentioribus notantur, uti caulis tactu scabra. Flores exigui, ex albido-clilutissime purpurascentes. Semina tri-quadridentata; dentibus inaequalibus. Flosculis abor. tientibus inque folia crispata degenerantibus, nonstrosa evadit. Pollich. l. c. ж

Variat foliis subcientatis. Wild.

corousta. 5. FEDIA foliis lanceolatis obtusis basi laciniatosubpinnatifidis, fructu sexdentato; dentibus rectis.

Valerianella altera tenuifolia, semine scabiosae stellatae. Colum ccp.rr. 1. p. 20-. t. 200 .

Valeriana caule dichotomo, foliis lanceolatis dentatis, fructu sexdentato. Hort. cliff. I6.

Valeriana locusta $\%$ corolıata. Lin. syst. veg. 82.

Habitat in Lusitania, Italia. (-

Caulis pedalis et ultra, striatus. Folia sessilia, bipollicaria, sursum minora. Capsulae in capitulo globoso sessiles.

vesisaria. 6. FEDIA foliis lanceolatis dentatis, fructu inflato globoso. Will. spec. pl. I. p. I 83.

Valerianeila cretica, fru tu vesicario. Tournef. cor. 6. Bocrh. hort. luedb. 1. p. ? . t. 75 .

Valeriana caule dichotomo, foliis lanceolatis ser. ratis, calycibus inflatis. Hort. Cliff. I6.

Valeriana locusta $\beta$. vesicaria. Inin. spec. $47^{\circ}$

Habitat in Creta. (-) 
Caulis spithamaeus. Fulia sessilia, pollicaria vel ultra, inferiora basin versus angustata, obtusiuscula, versus medium utrinque dentibus duo. Bus vel tribus, suprema integerrima. Flores triandri. Capsulae tres vel quinque in singzilo pedunculo sessires: vix magnitudine Pip. nigri, pubescentes, venosae, umbilicatae. के

ๆ. FEDIA fuliis lanceolatis obtusis basi laciniato- dissoidea. pinnarifidis, fructu duodecimdentato, dentibus uncinatis.

Valerianella annua, semine coronato, major lusitanica. Moris. hist. ?. s. -. p. 19, 1. 16. f. 29 . Valeriana locusta ?. Lin. syst. veg. $\delta 2$.

Habitat in Hispania et Italia.

8. FFDIA foliis spathulato-oblongis subintegris, radiatai fructu pubescente subtetragono apice nudo. Frichaux fl. bor. amer. I. p. 18, †.

Ya'erianella marilandica, fuliis oblongis obtusis. Rai. suppl. 2. p. 4.

Valeriana caule dichotomo, capitulis terminalibus involucro cinctis. Gron. virg. io.

Valeriana locusta \&. rariiata. Lin. syst. veg. $8=$.

Habitat in America boreali.

9. FEDIA foliis pinnatifidis: inferioribus lanceola- pumila. tis supremis linearibus, fructu nudo. +

Phu minimum. Lob. ic. ?

Valerianella semine unbilicato rotundo nudo.

Mioris. hist. 3. s. . . p. $10 \pi$. t. 1 s. f. $3=$.

Valeriana multifida; canle dichotomo, foliis imis dentatis, summis linearibus multifidis. Gouan. hort. $=3$.

Valeriana locusta "punila. Lin. sj’st. z2g. $\$ 2$.

Habiat Monspelii. (a)

Caulis vix trijollicaris. Gouan.

I0. FEDIA foliis imis bipinnatifidis, fructu bir-mixta. suto. +

Valerianella semine umbilicato hirsuto minore. Moris. umb. t. gen. f. 56. 57. moris hist. 3. s. ?. p. то4. $t$. $16 . f^{\circ} .35$.

Valeriana mixta; florihus triandris, caule quadrifido, foliis imis bipinnatifidis, seminis pappo plumoso. Sauv. monsp. 275. Lin. syst. veg. 82, Habitat Moaspelii. 
sibirica. 11. FFDIA foliis suhcarnosis, caulinis pinnatifidis, laciniis integerrimis obtusis subuniformibus, caule bifariam piloso.

Valeriana lutea humilis. Amm, ruth, 18. n. 25 . f. 3 .

Valeriana sibirica; floribus tetrandris aequalihus, foliis pinnatifidis, seminibus paleae ovali adnatis. Lin. syst. veg. 82 .

Valeriana ruthenica; floribus tetrandris, foliis ovatis carnosis pinnatifido-dentatis, seminihus paleae ovali adnatis. Wild. spec. pl. I. p. $18 \mathrm{I}$.

Habitat in Sibiriae campis. Specimina miserunt Com. Muschin Puschin et D. Meyer, qui ea a Pallasio habuerunt. 4

Caulis erectus, teres. Folia radicalia oblonga, dentata: caulina bi-tripollicaria, glabra, basi

1 ciliata; laciniae lineares, oppositae, intus versus minores, terminalis tripartita: floralia lacinia terminali longissima. Pedunculi primum trichotomi, dein dichotomi, bifariam pilosi. Paleae ovales, membranaceae, venoso-reticulatae.

supestris. 12. FEDIA foliis pinnatifidis, lacinils lanceolatis acutis terminali maxino, caule glabro.

Valerianella procera, folio varie secto semine galericulato. Anm. ruth. rn. n. $2^{h}$.

Valerianella tetrasternon, semine foliolo innato. Comm. Gött. r. p. 20\%. t. 9. Gmel. sib. 3. p. I $23 . t$. 24.

Valeriana rupestris; floribus pentapetalis, saepius pentandris, foliis crebris pinnatifidis, seminibus folliculo paleaceo innatis. Pall. it. 3 . p. 2 r 5 .

Valeriana sibirica. Trild. spec. pl. r. p. $18 \mathrm{r}$. Habitat in Sibiria. Meyer. 24

Caulis erectus, pedalis vel uttra, teres, purpurascens, simplicissimus, oculo armato leviter pulverulentus. Folia membranacea, glabra, nervosa: radicalia petiolata, oblonga, pollicaria, serrato-incisa, basi attenuata: caulina bipollicaria; laciniae oppositae vel aliernae, terminalis major, serrato-incisa: floralia infima caulinis simillima, corymbo longiora, reliqua 
indivisa. Corymbi prinum trichotomi, dein dichotomi. Flores flavi. Stamina quatuor, quinque vel sex.

Planta distincta a sibirica: foliis frequentioribus, membranaceis et diverso modo divisis.

Aliam habui diversam: laciniis ornnibus subuniformibus, frequentioribus, utrinque dente unico, duobus vel tribus, interdum tantum $a b$ altero latere, rarissime integerrimis. Forte modo varietas.

Habitus. Caulis herbaceus, plerumque dichoto me-ramosus. Folia sessilia, opposita.

76. Polycnemum. Cal. 5-phyllus. Cor. 0. Sem. I.

1. POI YCNEMUM foliis alternis subulatis trique- arvense. tris pungentibus.

Antly llis altera italorum. Lobel. hist. $22 \mathrm{I}$. iG. 404.

Polycnemum arvense. Lin. syst. veg. 84. Jacqu. fl. austr. 4. t. 355. Roth. tent. fl. ger. r. p. 45. Mabitat in Germaniae, Galliae, Italiae arvis. ( Caulis erectus, angulattes, ramosis, superne parum villosus: ramuli alterni, simplicissimi, sursum sensim breviores Folia pollicaria, spinula termirata: rudimenta ramulorum in axillis fuliorum.

2. POLYCNEMUM foliis alternis filiformibus car- salsum. nosis villosis.

Polycnemum triandrum. Palk, it, s. appa n. 95 t. G. f. 2, et $H . f$. . .

Habitat in locis arenosis subsalsis humidis Sibiriae. 4

Caulis teres, basi lignosus, subflexuosus: Rami sparsi, patentes, uti cuulis albidi. Folia pollicaria, basi dilatato-vaginantia, acuta, glauca.

Planta saepe cubitalis, diffusior, ram sissima, sed rarius sparsa; in siccis vix spithamalis, pumila, hispidior, foliisque magis congestis. Pall. . c .

3. POLYCNEMUM folis alternis linearibus villo- monandrui. sis inermibus, floribus monandris.

Polycnemum monandrum. Pall. it. ז. app. $\pi$. 94. t. G. f. I. 
Fabitat in Sibiriae locis aridis subsalsis. 2

Caulis semipedalis, erectus, a basi ramosus: Rami elongati, ramulosi; ramuli frequente:, alierni, zeretes, simpïicissimi, floriferi viliosi. Folid semiunguicutaria, frequentia, patula, viridicanescentia. Flores ex omnibus axillis foliorum ramulorum, inferiores folio breviores, superiores aequantes.

selerosper- 9. POLYCNEMUM foliis teretibus carnosis mumum. cronatis, infimis oppositis, floribus diandris. Polycnemum sclerospermum. Pall. it. 3. app. $n$. 8+. t. M. f. =. Ee.

Habitat in limasis saisis Sibiriae ad Jaikum et circa lacum Alton. (-)

Planta digitalis vel dodranialis, ramosa, succulenta, glauca: Rami infimi oppositi, reliqui alterni, teretes, patentes. Folia aiterna, praeter infima, pollicaria, patentia, spinula terminata.

oppositifo- 5. POLYCNEMUM foliis semicylindricis carnosis, รiuminferioribus oppositis superioribus alternis.

Polycnemum oppositifolium. Pall, it. 1. app. n. 9 s. $t$. H. f. 2 .

Habitat in paludosis versus Mare Caspium. ()

Caulis spithamaeus, erectus, simplicissimus vel ramosus, glaber: Pami inferiores oppositi, superiores alterni, patentes, simplices. Folia pollicaria, patentissima, acuta, basi latiora; inferiora opposita, subconnata, attenuata, villosa, glaucescentia: midimenta ramulorum foiiosa, axillaria. Hlores intra vaginam folii.

Stamina constanier quinque. Pallas.

Habitus. Caulis herbaceus. Folia sessilia, indivisa, integerrima. Tlores axillares, solitarï, sessiles, basi bractcis sieffulti.

77. Loefringia. Cal. 5-phyllus foliolis utrinque 1-dentatis. Cor. 5-petala. Caps. I-locularis 3-valvis, polysperma.

hispanica, I. LOEFLINGIA floribus triandris monogynis. Act. holm. I-5s. p. I6. t. I. f. г. Loefl. it. I13. t. :. f. 2. Lin. spec. pl. 50 .

Habitat in Hispaniae collibus apricis inque Tin. gide. (-) 
Caules digitales vel veltra, viscosi, remrissime prebescentes: Rami brezes. Folia semiunnucularia; inferiora linearia, basi parunt latiora. utrinque denticulo aicuto brevissimo, mucrone brezi terminata; superiora subulata, tridentata, denticulis lateralitits in medin folii, erecris. Flores axillares, conferii, sessiles in spicis lateralibus unguicularibus imbricatis. Calyces apice et laterilus utrinque spinula flavescente, subinermi.

a. LOEFLINGIA floribus pentandris trigynis. Loeflingia pentandra; fuliis oppositis subulatis connatis utrinque unidentais, floribus trigynis. Cavan ic. 2. p. 32. t. $14.8 . f_{0} 2$.

Habitat in arenosis maris mediterranei.

Caules prostrati, bi-tripollicares, teretes, vitlosit. Folia brevia. Flores axiliares, sessites, $f a-$ sciculati. Calycis foliola ovała, tria exteriora utrinque biáentaic. Corolla alba.

Habitus. Caules herbacei: Rami alterni, floriferi. Folia all articulos opposita.

Loeflingia indica vix hujus generis.

78. Ortagia. Cal. 5-phyHlus. Cor. o. Caps. r-locularis, 3-valvis. Sent. plurima.

x. ORTEGIA caule ramoso, ramis ramulisque op- hicpanica. positis, pedunculis multifloris.

Juncaria salmantica. Clus. hist. I. po. r7a.

Ortegia hispanica; floribus subverticillatis caule simplici. Lin. syst. veg. 83. Loef. it. i т2.

Oriegia hispanica; caule tetragono, ramis oppositis: floribus axillaribus solitnriis. Cavan. ic. T. p. 35.t. 4. ?.

Habitat in Castilia, Baetica, Salmanca. 24

Caulis erectus, spithamaeus iel pedalis, articu. latus, geniculis incrassatis, quadirangularis, striatus, scabriuscultes: Rami a basi caulis us. que at apicem, ramutosi. Folia semuncialia, erecta, scabriuscula. Flores conferti in corymbis dichotomis. Bracteae minimae, oppositae ad singulam divisionem dichotomiae. Loeff. l. c.

2. ORTEGIA ramis floriferis dichotomis, floribus dichotona. solitariis. 
Ortegia dichotoma, axillis foliorum subhispidis. Allion. spec. $176 . t$. 4. f. 1 .

Ortegia dichotoma; floribus solitariis axillaribus, caule dichotomo. Lin. mant. 175 .

Habitat in Italia. 4

- Caules tenues, striati, angulati, glabri: Rami patentes. Folia unguicularia, remota, glabra. Flores in dichotomiis et in ramis ultimis sessiles, alterni, solitarii.

Polycarpo maxime affinis. Lin.

Habitus. Caules herbacei, striati: Pami oppositi Folia sessilia, opposita, linearia.

79. Rotala. Cal. 3-dentatus. Cor. o. Caps. 3 -locularis, polysperma.

verticillaris. $x$ : ROTALA. Lin. mant. I 75.

Ene-pael. Rheed. mal. 9. p. 159. t. 8 г.

Habitat in India orientali. König. ()

Planta digitalis vel palmaris, tota glabra, facie Ammanniae. Caulis simplicissimus, interdum ramo uno val altero, filiformis, tetragonus. Folia sessilia, frequentia, patentia, verticillato-sena, semiunguicularia, inferiora, internodia aequantia, superiora parum longiora, linearia, integerrima. Flores axillares, verticillati, sessiles, parvi.

So, Hippocratea, Cal. 5-phyllus. Petala 5. Nectar. carnosum staminiferum. Caps. 3. compressae, 2-valves, medio dehiscentes.

obcordata. 1. HIPPOCRATEA foliis ovato-lanceolatis serratis, capsulis obcordatis. Lamarck. illustr. I. $p$. roo. t. $28 . f$. r.

Hippoçratea scandens. Jacqu, hist. 9. t. 9.

Habitat in America meridionali. v. Rohr. 5

Rami purpurascentes. Folia uni-ad tripollicaria, poliicem vel parum ultra lata, basi rotundata, parum acuminata, inferne integerrima. Stipula minuta, setacea, in axillis foliorum. Paniculae rami et flores, ut in ovata.

vata. 2. HIPPOCRATEA foliis oblongo-ovatis lanceolato-ellipticisve serratis, capsulis ovalibus. 
Coa scandens, fructu trigemino, subrotundo. Pl:tm. gen. 8. Ic. 76. t. 88 .

Bejuco pendulus, floribus paniculatis. Loefl. it. $3+\div$ ?

Hippocratea volubilis. Jin. syst. veg. 84 .

Hippocratea ovata; foliis ovalibus laeviter dentatis, capsulis ovatis integerrimis. Lamarck. illustr. r. p. 100. t. $29 . f$. 2 .

Habitat in America meridionali, von Rohr, in Puertorico. West. $\hbar$

Folia bi-tripollicaria, utrinque obtusa, supra nitida. Petioli purpurascentes, supra canaliculati. Paniculae rami divaricati, uti flores leviter ferrugineo-tomentosi. Capsulae subbipollicares, pollicem fere latae, obtusissimae, $r a$ ro emarginatae.

Capsulae in figura Plumierii breviores ac rotundiores et folia minora magisque oblonga, serraturis obsoletioribus, uitrnque obtusioribus quam in speciminibus a Westio missis. Rohrii autem planta optime convenit quoad folia cum Plumierii, ambas vero non nisi varietates ejusdem speciei esse credo.

3. HIPPOCRATEA foliis ovato-oblongis obsolete laevigata. crenatis,

Habitat in Cajenna. Richard.

Rami leviter ferruginea-tomentosi. Folia tripollicaria, ob̉tusiuscula, nitida, subtus rufescentia, tenuissime venosa. Petioli purpurascentes, laeves. Pedicelli duo uniflori in divisuris paniculae. Inflorescentia, pedunculi et flores, ut in ovata.

Fructum non vidi, at habitze a reliquis speciebus mihi notis recedit. Ex auctoritate Richardi huc retuli.

4. HIPPOCPATEA foliis ovatis obtuse acuminatis viritis. serratis integerrimisque, pedunculis folio brevioribus, capsulis ovalibus emarginatis. $\dagger$

Hippocratea viridis; corymbis dichotomis, foliis ovatis obtuse acuminatis. Fl. per. 1. p. 44. t. $74 . f . a$.

Habitat in nemoribus Andium. $\hbar$

Tota glabra: Rami brachiati. Folia patentia, interdum oblonga, subcoriacea, supra nitida. 
Petioli contorti, breves. Pedunculi folio dimiaio breviores. Bracteae ovatae, acutae, con * cavae. Flores lutei. Stamina in urceolum germen involventem coalita, superne libera: Antherae superne dehiscentes. Germen ob̆ovatum, trigonum. Stylus apice trisuicus. Stigma trigonum. Capsulae pollicares.

disperma. 5. HIPPOCRATEA folis ellipticis acuminatis serrulatis, capsulis lanceolatis dispermis uixinque ohtusis.

Hipjocratea indica; foliis ellipticis obtusiusculis crenulatis, corymbis axillaribus. ivid. spec. p?.' '. p. ig? ?

Euonymoides. f. foliis oblongis obovatisve apice integris emarginatisve.

Iiabitat in India orientali, Cingha?ensibus Sardena dicta. Pöttler. ந

Tota glabra. : Rami teretes. Folia Eipollicaria, cxtrorsum obsolete serrata, acuta vel obtusiuscula, meinbranacea, pallite viridia, supra obsolcie nervosa. Paniculae folio breviores. Flores glaúri. Capsulae pollicares, striatae, mędio dehisentes.

6. differt: Ramis remotissimis: foliis triplo ve? quadruplo minoribus: paniculis floribus pau cioribus.

paniculata. 6. HIPPOCFATEA foliis oblongis utrinque acutis obtuse serratis.

Iabitat ad Sierram Lecnam. Ex herbario Jussiaci.

Rami nitidi, patentissimi, ad articulos dilatati, apice compressi. Folia tri-quadripallicaria, membranacea, pallide viridia. Pedunculi folio dimidio breviores.

Fruectum non vidi.

macrophyila. 7. HYPPOCRATEA foliis oblongis acuminatis? integerrimis nitidis hasi obtusis.

Habitat aç Sierram Leonam. Ex herbaario Jus. siaci. 占

Folia quinque-sexpollicaria, parum acuminata. nembranacea, pallide viridia, supra nitia'a.

Fructum non vicit. Distincta ab antecedente. 
8. HIPPOCRATEA foliis subcordato-ovatis acumi- comose.

nitis integerrimis, pedunculis multifidis capillaribus, capsulis oblongis obovatisve.

Hippocratea comosa; paniculis comosis, pedunculis multifidis capillaribus, foliis ovatis acuminatis integris. Swartz prodr. 17. Fl. ind. occid. i. p. it.

Habitat in sylvis Hispaniolae interioris. 5

Caulis altissime scandens: Rami divaricati, reflexi, penduli. Folia tri-quadripollicaria, lata. Paniculae ramis erectis, in infinitum divisis, pedicellis terminatis, copiosissimis, unifloris. Flores polygami, paucissimi fructiferi. Petala oblonga, obtusa, apice reflexa, alba, persistentia. Nectarium fermen cingens illique atb natum, carnosum, depressum, integrum. Filamenta margini interiori nectarii inserta. Stioma trifidim. Capsulae bi-triunciales, leviter striatae, bivalves, medio longitudinaliter dehiscentes. Nuces quatuor, oblongae, angu-. latae, initio moilliores, dein induratae, apice ct latere alatae. Sivartz. l. c.

Habitus. Arbores scandentes: Rami patentissimi, laeves, inferne teretes, glabri, superne subtetragoni. Folia petiolata, opposita, utringue glabra. Paniculae axillares et terminales, oppositae, dichotomae. Flores minuti. Capsulae glabrae.

81. Tonselra. Cal. 5 -fidus. Petala. 5. Necto suburceolatum. Bacca i-locularis, polysperma.

3. TONSELLA foliis ovato-oblongis integerrimis scabra. scabriusculis, paniculis dich tomis.

Tontelea scandens. Aubl. fl. guian. 31. t. ro. fig. haud optima.

Hippocratea aspera; foliis ovatis subintegerrimis glabris: subtus venosis et asperis. Inamarck. illustr. т. $p$. гол.

Tonsella scandens. Symb. bot. 2.p. 17 .

Halitat in Cajenna et insula Trinitatis.

Arbor: Ramis teretibus, cortice purpurascerte, superne pilosis. Folia sesquipollicaria et ultra, distantia, acumine brevi terminata, rigida, venosa, utrinque scabriuscula, subtus venis vit- 
losa: juniora punctis minutissimis adspersa. Pedunculi folio duplo breviores, oppositi, tomentosi, minime scabri, apice dichotome-ramosi: ramis ramulisque brevibus. Bracteae ad basin ramorum et ramulortem paniculae, parvae, oppositae, lanceolatae. Calycis laciniae ovatae, acutae, margine denticulatae. Petala uti calyces canescentia, nectarii margini ungue brevi inserta, denticulato-ciliata, duo parum minora. Nectarium intus villoso-subsericeum. Filamenta disco nectarii inserta, stylo approximata, lanceolata, compressa, brevia. Stylus conicus, longitudine filamentorum. Stigma obtusum.

Quantum mihi notum, fructus bacca est, ideoque non Hippocrateae species.

decussata. 2. TONSELLA foliis oblongo-ovatis obtuse serratis nitidis, paniculis dichotomis. +

Anthodon decussatum; corymbis dichotomis, foliis oblongis leviter serratis. $F l$. per. 1. p. 45 . t. 7 . f. $b$.

Habitat in nemoribus Andium. $\hbar$

Caulis ramosissimus: Rami brachiati, cinerei; teneri purpurascentes. Folia patentia, acuminata, utrinque glabra. Petioli contorti. Pedunculi oppositi, tetragoni, folio breviores: pedicelli breves. Bracteae oppositae, ovatae, concavae, apice ciliatae. Fiores parvi, lutei. Calyx pentaphyllus: foliola subrotunda, decidua, concava, marginibus invicem incumbentia, dentato-ciliata. Petala quinque, inaequalia, ovato-oblonga, patentia, calyce triplo longiora, dentato-ciliata. Nectarium discus minimus, cyathiformis inter petala et stamina. Stamina longitudine nectarii. Germen ovatum. Stylus brevis. Stigma obtusum. Fl. per. l. c.

Fructus equidem ignotus, e descriptione autem apparet, quod antecedenti maxime affinis et vel hujus generis vel Hippocrateae species sit.

africana. 3. TONSELLA foliis ovalibus nitidis extrorsum denticulatis, pedunculis congestis unifloris.

Tonsella africana; foliis obtusis glanduloso-dentatis. Wild. spec. pl. г. p. 194.

Habitat in Guinea. Isert, Thonning. $\frac{\hbar}{3}$ 
Frutex ramosissimus: Rami horizontales, teretes, flexuosi, bifidi, glabri. Folia pollicaria et ultra, interdum unicum vel alterum alternum, parum acuminata, dentibus subglandulosis, submembranacea, glabra, laevia, subtus tenuissime venosa. Pedunculi plurimi, folio multo breviores.

Radix longissima, repens. Caulis fruticosus, debilis. Folia subdisticha, tenella margine denticulis setaceis, vix nisi oculo armato videndis, marcescentibus. Pedunculi sex ad duodecim, longitudine petioli. Bracteae squamula ad basin pedunculorum. Calyx minimus, quinquepartitus, depressus: lacinice subrotundae, obtusissimae, concavae. Corolla rotata, quinquepartita, calyce quadruplo longior: laciniae ovatae, ad lentem denticulatae, sordide luteae, post anthesin rellexae. Nectarium urceolatum, carnosum, germini adnatum. Filamenta tria, latiuscula, longitudine corollae, margini nectarii inserta, pistillo adpressa, post anthesin reflexa: Antherae subrotundae, didymae. Stylus subulatus, longitudine filamentorum: Stigma acutiusculum. Bacca sphaerica, magnitudine mali armeniaci, coriacea, glabra, rugosiuscula, minime nitida, aurantia, suturis tribus elevatis spuriis subangulata, unilocularis. Semina nidulantia, sex ad decem, difformia, muitua compressione angulata, ob pulpam mucosam-adinatam baccata, a cortice baccae discreta. Thonning.

4. TONSELLA foliis oblongis acuminatis laevibus senegalensis. nitidis extrorsum serratis, pedunculis congestis unifluris, ramis scabris.

Hippocratea senegalensis; foliis ovatis laeviter dentatis, ramulis punctatis, floribus verticillatis. Lamarck. illustrir. I. $p$. го г.

Habitat in Senegal. Ex herbario Lamarckii, specimen dedit Dupuis.

Rami alterni, glabri. Folia pollicaria vel parum ultra, acumine semiunguiculari obtusiusculo terminata, obscure serrata, ope lentis margine crassiore flavescente cincta, glaberrima, supra avenia, niiida; subtus venosa, pallida. Tubercutum axillare brevissimum, floriferum. 
Pedunculi copiosi, capillares, vix unguiculares, laxi. Flores glabri. Petala linearia.

madagasca- 5. TONSELLA foliis lanceolato-oblongis subinteriensis. gerrimis acuminatis laevibus nitidis, pedunculis congestis unilloris, ramis scabris.

- Hippocratea madagascarensis; foliis ovatis acutis nitidis subintegerimis, ramulis leprosis, floribus verticillatis. Lamarck. illustr. r. p. I॰r.

Habitat in Madagascar. Ex herbario Lamarckii. \$ Rami glabri, oppositi, interium laeviores. Folia sesquipollicaria vel parum ultra, lanceolatooblonga vel lanceolata, apice acuminata, acumine saepe obtuso emarginato, interdum extrorsum denticulis nonnullis obscure serrata, glaberrima, subcoriacea, supra avenia; subtus venosa, palliaiora. Tuberculum axillare loco pedunculi communis, nultiflorum: Pedunculi capillares, unguicuiares, plurimi. Flores nutantes, glabri. Petala linearia.

mitifora. 6. TONSELIA foliis obovatis integerrimis nitidis, pedunculis congestis subtrifloris.

Hippocratea multiflora; foliis lato-ovalibus laevibus integerrimis; cymis crebris multifloris. Lamarck. illustr. ז. p. iо т.

Iippocraiea obovata; foliis obovatis integerrimis rigidis, paniculis confertiuscule multiloris. Act. soc. liist. n. par. r. p. 106.

Habitat in Cajenna. Ex herbario Lamarchii et Richardi. $\overline{5}$

Rami oppositi, glabri. Folia tri-quadripollicaria, interdum oblungo-ovata, glaberrima, avenia. Pedunculi plturimi, vix semipollicares, bi-triflori: pedicelli unguiculares, uniflori. Bracteae minutae, ad basin pedunculorum' et pedicellorim. Flores glabir. Petala oblonga.

Quamvis fructum hujus nec duarum antecedentium non vidi, ad Tonsellam tamen retuli prop. ter summam affinitatem cum Tons. africana.

Habitus. Rami scandentes, teretes, punctis elevatis minutis scabri. Folia petiolata, opposita. Pedunculi axillares et terminales.

Generi Salaciae Linnaei maxime affinis, et forte cum ea conjungenda. Primam speciem sub nomine Salaciae misit acutissimus von Rohr. Lou- 
reiri Salacia cochinchinensis non elifferre videtur nisi defectu filamentorum et stylo, praesertim si supponitur quod nectarium, germini accretum, pro parte ipsius germinis assumserit; Linnaei Sal. chinensis foliis alternis discrepat, at in africana folia opposita, subalterna et alterna saepe in eodem ramulo occurrunt.

82. Olax. Cal. margo integer. Cor. 5-petala, singula duo mediantibus filamentis connata, quintum liberum. Nect. foliola 5 -linearia. Drupa. 1-sperma (nux Jussieu.)

3. OLAX foliis ovatis aveniis, ramis angulatis. zeylanica. Malla holla. Herm. zeyl. 13.

Arbor stercuraria zeylanica glandifera. Burm. zeyl. 26.

Olax. Lin. fl. zeyl. 34.

Olax zeylanica. Syinb. bot. 3. p. 7 .

Habitat in Zeylona. $\hbar$

Rami flaccidi, glabri, cortice viriäi-flavescenti, ut in Visco, transversim tenuissime rugosi. Folia $b i$-tripollicaria, tenuissime nervosa, vix venosa. Racemi simplicissimi, plerumque solitarii quinqueflori. Flores minores quam in sequente.

A Fissilia genere non differt, quod enim Linnaeo Nectarium dicitur Jussiaeo stamina sterilia sunt..

2. OLAX foliis ovato-oblongis lanceolatisque sub- Psittacorum. - venosis, ramis teretibus.

Fissilia. Juss. gen. 260.

Fissilia psittacorum. Lamarck. illustr. 1. p. 102, t. 28 .

Habitat in insula Mauritiana Commerson, in Zeylona König. 占

Rami rigidi, glabri, punctis griseis adspersi. Folia sesquipollicaria, ovato-oionga vel lanceolata, interdum ovalia, subcoriacea, enervia, obsslete venosa, pallide viridia. Facemi simplicissimi, rarissime superne ramulo aucti, interdum biflori, interdum usque ad vigintiflori: pedicelli interdum pedunculo longiores. Calyx margo brevis, persistens, integerrimus. Petala quinque, duum parium mediantilins filamentis con-

Tom. II. 
nata, quintum liberum. Nectaria quinque, filiformia, medio petali inserta ejusque longitudinis, basi macula nigra notata. Stamina tria, corolla breviora. Drupa piso duplo major, calyce ad nedium tecta.

Aliam habeo, foliis tenerioribus, magis venosis; ramis pubescentibus, forie modo varietas.

Habitus. Arbores semperitentes: Rami alterni, flexuosi. Folia petiolata, alterna, integerriria, obtusiuscula, glaberrima, laevia. Racemi axillares, brevissini, simplicissimi: pedicelli uniflori.

83. Cneorum. Cat.3-4. dentatus. Petala 3-4. aequalia. Drupac 3-\%. aggregatae, siccae.

tricoccs. I. CNEORUM glabrum, floribus axillaribus.

Chamaelea tricoccos. Clus. hist. I. p. 87. Camer. epit. 973 .

Cneorum; tricoccon. Lin. syst, veg. 83.

Habitat in Hispaniac, Narbonac glareosis. 5

Rami flexuosi. Folia alterna, vix pollicuria, mucrone minuto terminata, interdum parum emarginati, firma, avenia. Flores solitarii.

Drupas quatuor et in hac specie observavi, at ut plurimum tres.

pulverulen: lenrum.

2. CNEORUM incanum, foliis floriferis.

Cneorum pulverulentum; foliis cinereo-pulverulentis floriferis, petalis staminibusque quaternis. Venten. hort. cels $77 . t .77 \cdot$

Habilat in Teneriffa Le Dru. \$

Totum pulverulento-incanum. Ranii crassitie pennae anserinae et ultra; ramuli $e$ basi folii partum deeurente subangulati. Folia sparsa, saepe fasciculata; sesquipollicaria. Pedunculi versus basin foliorum, plerumque solitarii, rarius gemini, tuberculo insidentes, tetragoni. Calyx quadrifidus. Drupae quatzor, triplo vel quadruplo majores, quam antecedentis.

Petala quatuor, basi calycis inseria, lineari-lanceolata, obtusa, glabra, flcva. Stamina quatuor. Stylus tetragonus: Stigmata quatuor. Ventenat $l$. $c$.

Habitus. Caulis fruticosus: Rami teretes. Folia subsessilia; lineari-lanceolata, basin versus angustata, integervima, obtısa. Pedunculi unifleri. 
84. Comocladia. Cal. 3-partitus. Cor. 3-partita. Drupa oblonga: nuce 2-loba.

x. COMOCLADIA foliolis ovato-lanceolatis inte- integrifolia, gerrimis.

Prunus racemosa, caudice non ramoso, alato fraxini folio non crenato, fructu rubro subdulci. Sloan. hist. 2. p. 13 г. t. 222., f. b. Rai. dendir. $4 \div$.

Comorladia caudice simplici, floribus confertis sessilibus, racemis alaribus. Brown jam. i 24.

Comoclądia integrifolia; foliolis integris. Jacqu. amer. i2. Lin. syst. veg. 83. Lainarch. illustr. 1. p. 99. t. 27.f. r.

Habitat in America calidiore. Ex kerbario Jussiaei. 方

Rami apice canescentes. Folia saepe bipedalia: foliola tri-octojuga, opposita vel alterna, petiolata, bi-quadripollicaria, intus versus sersim minora, attenuata, tenera, venosa, utrinque glaberrina, nitiala. Baçemi axillures, elongati, intéräum sesquipedales, paniculati: pedunculi canescentes. Flores numerosissimi, exigzii. Fructus oblongus, nitidus, Finba coffeae parum major.

Stamina et petaln saepe quatuor Jacquin.

2. COMOCLADIA foliolis ovato-lanceolatis spino- dentate. so-dentatis.

Comocladia dentata; foliolis spinoso dentatis. Jacqu. amer. 13. t. 173. $f$. 4 .

Habitat in America meridionali. Ex herbario Jussiaei et Ventenatii. 方

Folia pedalia et ultra: foliola tri-undecimjuca, subpetiolata, inferiora et exteriora opposita, intermedia alierna; extima tri-quadripollicaria, basi ovata, interiora sensim minora basi subcorlata, intima vix pollicariu: omnia acuta, margine e nervis immersis ultra foliolum excurrentibus remote spinosa, supra glabra, laevia, nitida, subtus nervis venisque exsiantibus villosis sordide-canescentibus. Petioli teretes, tomentosi. Panicula pedalis et ultra, patens, glabra: pedunculi purpurascentes. Flores minuti, saepe glomerati, sparsi. 
Tariat foliis subtus glabris.

Odor siercoris. Succus niger vix elıendus. Jacqu. l. $c$.

iiicifolia. 3. COMOCLADLA foliolis angulato-spinosis. Swartz. prodr. 1 $7 . f l$. ind. occid. 1. p. 75.

Dodonaea aquifolii folio tricuspidato. Plum. gen. ac. ic. $1 \odot 8$. t. I $18 . f$. т.

Ilex Dodonaea; foliis pinnatis. Lin. spec. pl. is 2 . Comocladia tricuspidata; foliis pinnatis: foliolis ovatis tricuspidatis, racemis subsimplicibus. Lamarck. in act. par. 17\$4. p. 347.

Comocladia ilicifolia; foliolis subrotundis angulato-spinosis utrinque glabris. Lamarck. illustr. x. p. $99 \cdot t \cdot 2 ? \cdot f .2$.

inermis. $\beta$. Dodonaea aquifolii folio anguloso non aculeato. Plum. gen. 20.

Habitat in insula St. Crucis Dr. Pflug, in Domingo herbarium Lamarchici. 方.

Rami crassitie pennae anserinae, cicatricati, punctati, superne villoso-tomentosi. Foliola circiter octojuga; opposita, semipollicaria vel minora, basi cordata, ovato-vel subrotundo-triangularia; angulis apiceque spina pungente flavescente terminatis, glaberrima, avenia. Petioli pubescentes. Racemi folio longiores, subcompositi. Flores minuti, in pedunculis partialious confertissimi, subsessiles.

Num Dodonaea aquifolii folio anguloso et aculectto Plum. gen. 20. hujus varietas vel species distincta est, milii non constat, certe vero Lamarckii $C$. tricuspidate ad plantam descriptam pertinet.

Habitus. Arbores mediocres. Folia versus apices ramorum conferta, alterna, petiolata, pinnaia cum impari. Pedunculi axillares, elongati. Pseudobrasititum Lamarchii congener est cum $P i$ cramnia Swartzii ni fallor.

85. Rumphra. Cal. 3-fidus, Petala 3. Drupa 3 - locularis.

ambuinensis, 1. RUMPHIA. Lin. syst. veg. 83. †

Tsiem-tani. Pheed. mal. 4. p. 25. t. Iт.

Myxa pyriformis ossiculo trispermo. Rai. hist. I $55^{6}$.

Habitat-in India orientali. $\frac{\hbar}{5}$ 
Arhor vastae magnitudinis: Rami non raro hirsuti. Folia alterna, petiolata, cordato ovata, firsuta, aspera. Raceni axillares, spitlsamaei. Rheed. l. $c$.

85. Henycrea. Cal. 5-dentatus. Cor. o. Druna I-sperma, mollis. Nü x I-sperma, fibris tecta.

3. HODYCRFA.

Licania incana. Aubl. fl. gritan. I19. t. 45.

Habitut in Guiana Riclard. 方

Rami teretes, fusci, e punctis griseis scabriusculi.

Folia petiolata, alterna, bipollicaria vel parum ultra, oblonga, integerrima, acuininata, supra nitidiuscula, subtus incand; costis glabris. Petioli breves. Pedunculi axillares et terminales, folio duplo breviores, solitarii rigidi, interdum basi ramulo unó alterove aucli, miltiflori. Flores sparsi, sessiles. Bracteae ducle ad basin calycis.

Arbor quiatuor-quinquepedalis. Stipulae oblongae. Corolla alba. Drupa candida, punctis rubris notata, edulis. Lignum olei rancidi odorem exlualat. Aubl. l. $c$.

'Triandra est ex observatione Richardi, cui majorem fidem adhibeo quam Aubletio.

87. Macrolobium. Cal. 4-dentatus, Cor petalum r-cum, planum. Legum. peäicellatum, coriaceum, I-sperinum.

1. MACROLOPIUM foliolis oblongis basi inae- Hymenasoiqualibis, leguminibus oblongis altero max- des. gine bialatis.

Vouapa bifolia. Aubl. fl. guian. 25. t. 7. fig. mala. Halitiat in sylvis Cajennae et Guianae. Ex herbario Lamarckii. b

Rami teretes. Foliola quadri-quinquepollicaria, altero latere angustiora, subfaicata, mombranacea. Pracemi infrafoliacei, simplices, recti, uti pedicelli et calyces tomentosi. Germen villosum.

2. MiCROLOBIUM foliolis subovato-lanceolatis sphnerocarhasi aequalibus, leguminibus ovalibus mar- pum. gine undique lacvibus. 
Vouapa Simira. Aull. fl. E̊zinn. 27. t. s. Habitat in Guiana. Exherbario Richardi et Desfontainii. 5

Folisla bi-scxpollicaria, niticia. Legumina tripollicaria, pollices dhos latı, margine undique aequalia.

Hiabitus. Árbores excelsne: Rami glabri. Folia petiolata, alterna, binata: foliota petiolata, integerrima, acuminata, glabra, venosa. Stipulae binae, deciducie. Bracteae cluae ad basin calycis, concavae. Racemi axillares et terminales. Legumen bivalve.

An verius pentapetala, decančra, petalis et staminibus quibusdam citius caducis? Juss. gen. pl. 380 .

Parivoa grandiflora. Aubt. affinis.

88. Outea. Cal. turbinątus, 5-dentatus. Pet. 5. superius maximum. Stam. 4: I-cum sterile. Germen pedicellatum.

shianensis, 1. OUTEA, Aubl.fl. guian. 28. t. 9. + Habitat in sy-lvis Guianae. to

Arbor alta. Folia petiolata, alterna, abrupte pinnata: foliola bijuga, elliptica', integerrima, glabra. Stipulae duae, deciduae, Racemi axillares et terminales. Bracteae duae, con. cavae, ad basin calycis. Corolla violacea. Stamina fertilia longissima, sterile breve, villosum sub petalo superiore. Aub. l. c.

Genus a Macrolobio diversum secundum Richarc?. ideoque retinui.

89. Axra. Cal. 3 -fidus, Cor. I-petala, ro-fida. Sen. unicum.

eachinchi- 1. AXIA. Lour. fl. cochinch. 36. +

zensis.

Fiabitat in Cochinchina. 5

Frutex bipedalis, rannosissimus, procumbens. Folia opposita, parva, inaequalia, ovato-lanceolata, subcrencta, iomeniosa. Piacemi subterminales. Calycis laciniae inaequales, deciduae, acutae. Corollac limbius planus: laciniae rotundatae, breves. Antherae didymae. Germen ovatum, sulcatum. Stylus filiformis: Stigma crassiusculum. Semen ovatum, suleatum, hirsutum. Lour. $l$. c. 
90. Wrllichia. Cal. 4-fidus. Cor. 4-fida. Caps. 2-locularis, polysperma.

I, WILLICHIA. Lin. mant. 558. +

repens.

Habitat in Mexico. $\odot$

Radix fibrosa. Canlis repens, filiformis, ramosus, herbaceus, hirsutus, subbipedalis. Folia alterne, petiolata, remotiuscula, orbiculata, subpeltaia, crcitata, pollicaria, hirsuta, subtus rubescentic. Petioli longissimi, hirsuti, caule crassiores. Pedunculi axillares, gemini, uniflori, filiformes, hirsuti, longitudine petio lorim. Flores parvi, rosei, calyce hirsuto. Lin. l. c.

9r. Oxrbaphus. Cal. 5-fidus, campanulatus. Cor. infundibuliformis. Nux -sperma, calyce grandefacto explanato circumdata.

3. OXYBAPHUS villoso-viscosus, foliis cordatis, floribus racemosis, staminibus corolla longioribus.

Oxybapphus viscosus. l'Heret. monngr. c. icone.

Mirabilis viscosa; floribus racemosis; foliis cordatis, orbiculato-açutis, tomentosis. Cavan. ic. I. p. 13 . t. 19.

Calyxhymenia viscosa; floribus paniculatis, foliis cordatis, staminibus corolla duplo lon. gioribus. Fl. per. 1. p. $4^{6}$.

Habitat in Peruvia. 4

Caulis orgyalis, erectus, uii tola planta villąszss; villis ariculatis, glanduliferis: Pami patenies, oppositi. Folia acuta vel obtusiuscula, interdum subrepanda, sibbtus villoșiora. Racemi axillares simplices; oppositi; terminales compositi: pedicelli alterni, uniflori, solitarii. Bracteae parvae, ab̉ongae, obtusae. Calyx fructi. ferus magnus, expansies, quinquenervis, pentagonus, membranaceus, verioso-reticulatus, quinquelobus: lobis rotundatis, acutis. $\mathrm{Co}$ rolla purpureo-rosea, calyce florifero tripls major.

Stamina interdum quatuor. Nux ovata, pentagona, longitudinaliter sulcata; sulcis verruco. şis. Cavan. i. c. 


\section{TRIANDRIA. MONOGYNIA.}

Differt $a b$ insequente: caule superne non dichotomo sed ramis undique oppositis: foliis uti caulis villoso-viscosis, non attenuatis, nec margine scabris: floribus racemosis.

glabrifolius. 2. OXYBAPHUS foliis cordato-ovatis glabris, pedunculis terminalibus congestis, staminibus corolla brevioribus. +

Calyxhymenia glabrifolia; caule inferne brachiato, superne dichotomo, foliis cordatis acutis glabris, genitalibus inclusis. Ort. decad. 5. t. $\mathrm{r}$.

Mirabilis corymbosa; caule tetragono dichotomo: foliis cordatis: floribus corymbosis. $\mathrm{Ca}$ van. ic. 4. p. 55 . t. 379 .

Ilabiat in Peruvia et nova Hispania. 4

Planta glauca, acritzdine Sedi, adulta villos maxima ex parte exuens. Caulis tripedalis et ultra, inferne brachiatus, superne dichotomus, hispidiusculus, vilits glunduliferis. Folia patentia, acuta, integerrima, margine retrorsum scabra: floralia subrotundo-ovaia, acuminata, reflexa, villosa. Petioli canaliculati, folio breviores. Pedunculi breves, inaequales. $\mathrm{Ca}$ lyx apice subrubens, corolla ditplo brevior. Corolla purpurea. Semina fusca, granulosa. Ort. $l$. $c$.

ovatus. 3. OXYBAPHUS hirsutus, viscosus, foliis ovatis, pedunculis terminalihus dichotomis, staminibus corollan subaequantibus, caule erecto: $\dagger$ Calyxhymenia ovaía; floribus dichotomo-corymbosis, foliis oratis viscosis hirsutis, staminibus longitudine fere corollae. Fl. per. I. p. 45 . t. $\div 5 . f . b$.

Flabitat in collibus et montibus Peruviae. 4 Villi articulai, glanduliferi. Caulis tripedalis. Folia acuta, integerrima, margine scabra, crassa, venosa. Pedicelli unifiori. Calyces excrescentes in membranam venoso-reticulatam, patentissimam. Corolla rubra, calyce duplo major: Limbus plicatilis. Semen obovatum, laeve. Fl. per. $l$. $c$.

prostratus. 4. OXYBAPHUS foliis ovatis cordatisque pubescentibus, floribus axillaribus terminalibusque subcorymbosis, caule prostrato. $\dagger$ 
Calyxhymenia prostrata; floribus suhcorymhosis. foliis cordalis ovatisque, staminibus corolla breviorihus, th. per. r. p. 4c.t. 75. f.c.

Huhitat in collibus Peruviale. $\boldsymbol{Z}$

Caulis tripedalis, leviter pubescens, striatus: Rami alterni, superne dichotomi. Folia patentia, obsnlete crenulata, repundo-zundulata, venosa. Pedunculi axitlares, terninalss et e dichotomiis, breves, quinque-ocioflori, giunciulosi. Flores breviter pedicellati. Calycis laciniae otatae. Corolla purpurea, calyce triplo longior, plicatilis. F1. per. . c.

5. OXXBAPHUS folis ovatis glahris, pedunculis expansus. rerminalibus dichotomis, staminibus longitudine corollae, caule erecto. +

Calyxhymenia expansa; floribus dichotonio-corymbosis, foliis ovatis subrepandis glabris, staninibns corollae longitudine. Fil. per. 1. p. +5.t. $75 \cdot f \cdot a$.

Habitat in collibus aridis Limae. 24

Caulis sexpedalis, striains. Folia distantia, obsolete cremelata, subrcpanda, actita, venosa: floralia subsessilia. Pedunculi terminales, di. chotomo-corymbosi, sex-tundecimflori. Flores pedicellati: pedicelli inuequales, parum viscosi. Calyx mubescens, glutinosus. Corolla purpurea, subcampaniulaia. Semen olviongum, obovatum, scabrum. Fl. per. l. c.

6. OIYBAPITS foliis lanceolatis, pedunculis ax-aggtegatus illaribus solitariis,

Calyxhymenia aggregata ; raule herbaceo hispicio, foiiis lanceolatis undulatis, floribus aggregatis. Ort. decad. 81. t. i i.

Mirabilis aggregata, calycibus trifloris. Cavan. ic. $5 . p$. 22, t. 43 ?

Iirlitat in nova Hispania. 4

Caulis pedalis et ultra, statim a basi ramosus, striatus, glaber (hispidus Ortega): Rami dichotomi. Folia sesquipollicarin, crassizsscula, ope lentis remote denticulata, acutiuscula, glabra. Petioli breves. Pedunculi ex axillis et dichotomiis; fructiferi nutantes, breves. Flores tres, rarizs duo vel quatuor, sessiles intra caljcem communem canivantilatum quinquefi- 
dum; laciniis ovatis, inaequalibus: fructiferus grandefactus. Calyx proprius nuilus. Corolla rubescens. Stamina longitudine corollae. \$. Ivuces tres, saepius duac, reliqune aboriteztes, nagrice, villosae, decussatim positae in sinu calycis ampliati, primum conniventes, deinde paituli. Oit. l. c.

Habitus. Caulis herbaceus, ramosus, teres. Folia petiolata, opposita, parum undulata, opposito minore.

92. Tripterelia. Cor. 6 -fida: lacinitis alternis minutis: tubo angulato, basi ventricoso.

tapisata. I. TRIPTERELLA. Michaux fl. bor. am. I. p. Ic. $t .3$.

Anonymos capitatus. Walt. fl. car. 68.

Vogelia capitata. Gmel. ed. syst. Lin. 2. p. 107. Habitat in udis Carolinae Bosc, in Cajenna Richard.

Caulis filiformis, spithamaens vel semipedalis, erectus, simplisissimus, glaber. Folia sparsa, remotissima, pauca, vaginanlia, parva, subulata. Flores albi, capitati: capitulum magnitudine pisi. Spatio univalvis.

Corolla morzopetala, basi ventricosa, medio courctata, superne angulata; angulis subexstantibus: Limbus sexfidus; laciniis aliernis, mirutits. Antherae subsessiles infra lacinias. Germen inferum: Stylus longitudine staminum: Sitgma trifidum. Capsula triquetra, triloculais, polysperma. Affinis Burmanniae. Richard.

93. Fieterantiera. Cor, 6-partita: laciniis subaequalibus. Stigma simplex.

azmta. r. HETERANTHERA foliis subrotundo-reniformibus acutis, spathis subtrifloris glabris.

Heteranthera. Beauvois in act. soc. amer. 4. p. I73. cum icone.

Ileteranthera acuta; caule procumbente sarmentoso, foliis reniformibus acutis. Wild. in nzov. act. soc. am. h. nat. 3. p. 438 .

Leptanthus reniformis; foliis orbiculato-reniformibus: staminibus duobus tertio inulto minoribus. Mickaux fl. Bor. amer. 1, p. 25. 
Habitat in Pensylvania et Virginia. Bosc.

Caulis repens, an geniculos radicans, teres; articulis'sesquipollicaribus: Rumi radicales oppositi, brevissimi, monodipliylli. Folia petio!ata, primardialier nełantia, poilliaria et weltra, longitudine et latitudine acqualia, basi sinu parvo cordata, glabra, uit reliqua plenta. Spica versus is ain petioii. Spatha oblonga, pozicoris.

Corolla bipartita: laciniis rrifidis; intermedia superioris majore, infegrioris angustiore. Stamina duso breviora, antheris rotundis; tertizm longius, anthera oblonga. Capsula oblonga, trigona. Semina oblonga utrinque obtusa. Beaurois. $l$. c.

2. HETERANTHERA foliis subroundo-reniformi- renifurmis. bus, spathis oblongis acuminatis multifloris. +

Heteranthera reniformis; foliis reniformibus, caule repente. Prodr. fl. per. 9. $t$. 2. flor per. 1. p. $43 . t \cdot 7, \cdot, a$.

Habitat in Limae paluclosis et stagnnosise

Caulịs ramosus, articulatus, teres, striatus. Spathas communzes ex caulis articulationibus, $a b$ longae, convolutae, membranaceae, siriatae, tenucissimae, pellucidae, folia et fructificationes teneras involventes. Folia subuis lineata. Petioli longissimi, semiamplexicaliles, margine membranacei, teretes, leviter striati. l'edunculi recurvati. Spatha primum convoluta, demun reflexa, acumine lineari terminata. Flores tres vel quiatuor, breziter pedicellati, alterni. Corolla albo-viridis. Filamentum tertium, uti illius anthera sagittata reliquis major. Fl. per. l. $c$.

3. HETERANTHERA foliis cordatis acutis, spa- pubescess. this linearibus multifloris. $t$

Pontederia. Loefl. it 178 .

Ifabitat in palzidosis Barcellonae Americae meridionalis. 4

Caulis spitlamaezs. Folia glabra, raciecalios pusbescentia. Sfpatha tandem digitalis. Flures alterni. Corolla purpureo-coerzlea, marcescens; tretous filifuimis: Fimbus, sexparitius; 
laciniae subaeruales, Antherae subrotundae. Germen lineare: stylus filiformis: stigma capitatum. Capsula teres, lineqris. Loefl. l. c.

cordata. 4. IIFTERANTIERA foliis cordato-ovalibus obtusissimis, spathis subtrifloris oblongis obtusiscimis.

Habitat in America meridionali. von Rohr.

Caulis spithamaeus. Folia coule aliora, semipoliticaria vel parum ziltra, latitudine et longitudine subaequalia, inierdum cordato-subrotunde. Petioli striati. Spatha brevis, angusta, triflora.

limosa. 5. IEETERANTYITRA foliis ovato-oblongis, spathis lanceolatis unifloris.

Nymphaeae affinis: planta palistris aquatica, floxe hexapetalo, stellato, coeruleo. Sloan. cat. $12 \mathrm{I}$. hist. ז. $t$. $149 . f$. .

Pontederia limusa; foliis cordato-ovatis; scapis lateralibus unifloris, floribus triandris. Swartz. prodr. 37. Fl. ind. occid. 1. p. 6ri.

Leptanthus ovalis: ramulis subracicalibus, unifoliis, unifloris: folio longe peicolato, ovali: floқe ex imo petiolo erumpente. Michaux fl. bor. am. I. p. $=$. t. $5 . f$. r,

Habitat ad ripas limosas flutiorum Jimaicae, Hispaniolae, in paludosis Illionensibus. 26

Caules brevissimi, monophylli vel diphylli. Folia pollicaria vel minora, obtura. Petiolus teres, fistulosus. Spatha fere pollicaris, acumine setaceo terminata. Radices geniculatae, longae, ad genicula fibrae capillares. Corolla coerulea, sexpartita. Antherae sagitutae. Germen cyindricum. Stigmata sex. Swartz. l. c.

Specimen a Sicartzio missum, exacte in onnibus cum illo a Richardio mecum communicato convenit.

diversifolia, 6. HETERANTHERA foliis cordato-ovatis petiolatis linearibusque sessilibus.

Habitat in Guiana. Richard.

Facies Potamog. heterophyllae. Caulis temis, inferne radicans, ramosus, glaber, uti tota planta. Folia sparsa; inferiora linearia, sursum magis approximata, sesquipollicaria, acita, subundulata, enervia, avenia; suprema petio- 
lata, an natantia? ramo altiora, unguicularia et parum ulira, obtusissima, integerrima, inferioribus crassioribus. Petiolus teretiusculus. Fructificationem non vidi.

Spatha bivalvis, linearis Richard, cujus autoritate huc retuli.

7. HETERANTHEPA foliis omnibus linearibus. graminea. Leptantlius gramineus; caule gracili, fluitante, dichotomo: foliis impetiolatis, angusto-linearibus. Michaux fl. bor. amer. ז. p. 25. t. 5. f. 2 .

Habitat in flumine Ohio. Ex herbario Richardi. Facies Potumogetonis graminei. Caulis subnullus, wel dichotomus, filiformis. Folia bipolitcaria, basi vaginantia. Flores axillares, solitarii. Spatha oblonga, hinc dehiscens, uniflora.

Corolla monopetala, regularis: tubus gracilis longitudine fere folii, spatha longior. Corollae limbus sexpartitus; laciniae oblongae, tres parum minores, minus patentes. Stamina interdum quatuor, limbo calycis breviora, juxta faucem inserta. Germen intra corollae tubum: stylus setaceus, longitudine tubi. Capsula spatha involuta, oblonga, subtrigona, triloctilaris, trivalvis, polysperma, trifariam dehiscens; septis angustissimis, contrariis. Pontederiae affinis. Kichard.

Habitus. Caulis repens. Folia alterna, longissime petiolata, integerrima, glabra, tenuissime nervoso-striata, absque costa. Petioli basin versus bifido-vaginaeformes. Pedunculi e vagina folii, solitarii.

94. Crocus. Cor. 6-partita, aequalis. Stigmata convoluta.

I. CROCUS stigmate exserto tripartito, segmen- sativus. tis linearibus. Snith. fl. angl. 30 .

Crocus. Erunsf. herb. 3. p. 150. Fuchs. hish. 44. Crocum. Math. 62.63.

Crocus autumnalis. Besl. hort. eyst. autumt. ord.

3. t. 5. f. 3. Smith. english. bot. t. 343 .

Crocus sativus autumnalis; foliis angustioribus margine revolutis. Lin. syst. veg. S4.

Habitat in Oriente. 4 
Folia spithamaea et veltra, margine parum revotuta, subtus medio albidla. Stamina corolla breviorr. Stylus longitudine coroliue, profiunde trifidus: Stirmata inter lacinicis corollate exsertia.

E Tauria misit Dn. IIacquet Crocum bulbo comico reticulato, flore quadruplo minore, crocei coloris, laciniis tribus extus clorso fuscis; Stig. mate ui in sativo, forte vix specie diversus.

vernus. 2. OROCIS stigmate incluso trifido: lobis cuneiformibus incisis. Smith. fl. angl. 40.

Crocus. Cube n. 12r.

Crocus vernus. Clus. hist. 203. Besl. hort. eyst. aest. ord. 3. t. 10. f. 3. Jacqu. austr. app. 47. t. 36. Curtis mag. t. 45. Smith. engl. bot. $t$. $332 \%$

Crocus sativus vernalis, foliis latioribus margine patulo. Lin. syst. veg. 84.

Habitat in alpibus Helveticis, Pyrenaeis, Lusitanicis, Thracicis, Carniolicis. 4

Folia latiora minusque revoluta quam in praece. dente, praccipice vero differt: Stigmate incluso, erecto, minus profunde trifido, pallido, inodoro: laciniis cumeatis margine involutis, apice inaequaliter incisis et crosis. Smith. l. c.

$\checkmark$ ariat colore florum. \&:-

nuสiiforus. 3. CROCUS stigmate incluso trifido, lobis multifido-laciniatis penicilliformibus, flore aphyllo. Sinith. fl. angl. 41 .

Crocume pyrenaeum autumnale. Clus. cur. post. 23. et app. alt.

Crocus nudiflorus. Smith. engl. bot. $t .49 \mathrm{I}$.

Crocus multifidus; flore aphyllo, stigmatibus capillaceo multifiais. Ramiond in diar. soc. philom. vol. 2. n. 41. p. 129. t. 8.

IXabitat in Pyrenaeis, Anglia. 4

Flores omnino aphylli, purpureo-violacei. Stigma satiuate fulvum. Folia erectiora, pallidiora, vix revoluta, nec apice emarcida. Smith. i. $c$.

Specimen mecum a Dn. Ramond communicatum gaudet corollae tubo fere pedali, inferne vaginis tribus tecto, limbo majors quam in reliquis. 
Forte luc spectat CROCUS speciosus; spatina radicali uniflora, foliis tardissimis, strminibus stigmate tripartito ramoso hreviozibus. Marsch. in Diar. Schrad. 1. vot. I. P. 455.

Hatituls. Radix bulbosa. Flos in ipso radice sessilis fere cebsque ullo pedunculo. Folia linearia, revoluta: vaginae memuranaceae flores et folia includentes.

95. Witsfnia. Cor. i-petala: limbo erecto 6-10bo. Stigma sub 3-fidum.

I. WITSENIA caule subsimplici, floribus spicatis maura. extus tomeniosis.

Antholyza maura; corollis regularibus cxtus toimentosis. Firm. Mant. I 65 .

Mitsenia mauid. 'Thunb. nov. gen. 2. p. 34. cum icone. Lumarcí. illustr. т. p. Iоs. t. RC.

Habitai ad lätera montum Cap. b. spei. 4

Caulis bipedalis, simplex, intercium superne ramo auctzes, basí fritescens. Folia apuroximala, sitbspithamaea, sieperiora caule altiora, basí intus forruginea. Spica terminalis, composita $\boldsymbol{e}$ spiculis alternis, imbricatis. Spathulae subbiflorae. Corolla infundibuliformis: tubo siperne atro: Limbus intzis luteus.

2. WITSENIA caule ramoso fruticoso, floribus ramcsa. terminalibus subsolitariis glabris.

Ixia fruticosa; caule fruticoso rarnoso. Lin. suppl. 93.

Ixia fruticesa; caule iamoso foliis imbricatis tecio. Thunb. Ixia. n. I. t. I.

Ixia fruticosa; caule fruticoso ramoso, foliis linearibus distiche imbricatis. Lamarck. illıstr. r. p. 108 . t. $3 \mathrm{I} \cdot f \cdot 4$.

Habitat in Cap. b. spei. \$

Caulis semipedalis, ramosus: Rami sparsi, fusci, inferne post casum foliorum oblique annilatocicatricati et alternation denticulati. Folia ver. sus apices ramorum, pollicaria, sursum mino. ra, confertissima. Flores solitarii vel gemini. Spathae membranaceae, ferrugineae. Corollac tubus semipollicaris, filiformis, flavus: Limbus coeruleus. 
pumila. 5. WITSENIA caule simplici unifloro.

Ixia pumila; caule simplici unifforo, foliis subulatis compressis distichis. Forst. in comment. götting. 9. p. 20. $t$. 2.

Tapeinia. Juss. gen. 59.

Ixia magellanica caulibus fasciculato-caespitosis brevissimis subramosis, foliis distiche imbricatis, floribus solitariis subsessilibus. Lamarck. illustr. r. p. rog.

Moraea magellanica; caule ancipiti folioso, foliis distichis falcatis, flore terminali solitario. ivild. spec. pl. ז. $p .=+1$.

Habitat al fretum Marellanicum.

Caules plures, cacspitosi, interdum sesquipollicares. Folia coriferissima, pollicaria. Flores parvi, subsessiles inter folia ultima spathaeformia.

Galaxia obscura Cavan. diss. alia planta est et vix hujus generis.

Habitus. Caulis anceps, vaginis foliorum tectus. Folia equitantia, disticha, lineari-ensiformia, acuta, striata, glabra.

96. MARICA. Cor. r-petala: laciniís tribus exterioribus majoribus. Stigma petaloideum, 3-fidum: laciniis indivisis. Caps. 3-locularis.

paludasa. I. MARICA. Schreb. gen. n. 8r.

Cipura paludosa. Aubl. fl. guian. 38. t. г 3.

Habitat in pratis humidis Cajennae. von Rohr, Richard. 4

Bulbus conoideo-globosus, tunicatus. Folia radicalia, plura, petiolata, tri-quinquepollicaria, et ultra, lineari-lanceolata, glabra, striata. Scapus erectus, foliis brevior, apice monophyllus: folium erectum, basi vaginans, structura radicalium. Spica simplex, ad basin folii, terminalis, sessilis, distiche imbricata. Bracteae pollicares, conduplicatae, ovato.lanceolatae, amplectentes: flos unicus intra singulam.

Corolla per latus bracieae exserta, coerulescens, sexpartita: laciniae tres exteriores majores, subovatae, recurvato-patentissimae; tres inte- 
riores multo minores, concavae, quasi in $\mathrm{ur}$ ceolo genitalia obtegentes, conniventes: Tubus brevis, deorsum acutus. Stamina tria, brevissima. Richard.

97. IxIA. Spatha I. 2-valvis. Cor. 6-partita; laciniis aequalibus, patentibus; tubo recto.

* Scapo foliis breviore.

3. IXIA foliis lineari-setaceis subaequantibus sca- minusa. pum uniflorum.

Ixia minuta; scapis unifloris. Lin. suppl. 92.

Ixia minuta; scapis unifloris, foliis laevibus. Thunb. ix. n. 2. t. 1.

Habitat in Cap. b. spei locis arenosis inundaits. 24 Planta vix pollicaris. Bulbus globosus, vix magnitudine pisi, reticulatus. Folia vagina inclusa, angustissima, subtus convexa, supra concava, erecta, unicum pro singulo scapo, uti tota planta glabra. Scapi plerumque duo ad quinque, capillares, erecti, teretes. Spatha valvulis linearibus, angustissimis, acutis. Corollae tubus capillaris.

Corollae tubus albus, striis purpureis: Limbi laciniae supra concavae nivecae, subtus albae, stria duplici purpurea, longitudine tubi, lineam dimidiam longae. Capsula virescens, striis purpureis. Thunb. $l$. c.

2. IXIA foliis filiformibus, scapis unifloris corolla roser. campanulata brevioribus.

Bulbocodium pedunculis nudis unifloris, foliis subulatis linearibus longissimis. Mill. ic. I60. t. 240.

Crocus capensis; floribus violaceis. Burm. prodr. 2. Ixia rosea; scapo unifloro brevissimo aphyllo. Lin. syst. veg. ed. Murr. 75 .

Ixia Bulbocodium; flore amplo violaceo. Lamarck. dict. bot. 3. p. 3.35 .

Ixia Bulbocodium; corollis roseis fundo luteo. Thunb. ix. n. 3. var. ?.

Ixia campanulata; scapo brevissimo paucifloro, corollis amplis campanulatis scapo longioribus, foliis filiformihus striatis. Iamarck. illustr. I. p. $1 \circ 9$.

Habitat in Cap. b. spei. 4

Tom. II. 
Valde affinis Ix. Bulbocodio, an modo varietas? differre vicietur folïs angustioribus. Culta: scapus parum longior eveulit.

ochroleuca, 3. IXIA foliis linearibus unico longissimo reflexosubfalcatu, scapo unifloro.

Ixia ochroleuca; scapo unifloro; foliis linearibus, subulato-conniventibus, prostratis, longissimis, subgeminis. Jacqu. collect. 4. p. 180. Ic. rar. 2. t. 232 .

Habitat in Cap. b. spei. 4

Bulbus piso diuplo major, ovatus, fuscus, nitidus. Folia tria-quatuor cum totidem scapis vagina membranacea inclusa, angusia, inierdum parum latiora, rigida, attcnucta, bisulcan, duo-tria erecta, altitudine scapi, unicum duplo vel triplo longius. Scapi superne subcompressi. Spatha tubo corollae longior: valuulae unguiculares, aequales, lanceolatas, concavae, strictae, interior margine membranacea. Corolla sub. campanulata.

Variat corollis albis, laciniis tribus exterioribus extus virentibus. Ixia Pulbocodium varietas ta. Thunbergii: corollis flavis, lacinits tribus exterioribus exius viridibus, tribus interioribus fla. vis. Ixia Bulbocodium varietas Ina: corollis cyancis, laciniis exterioribus extus virentibus.

Buboco- 4. IXIA foliis filiformibus sulcatis flexuosis, scapo dium. ramoso, ramis unifloris, spathis tubo corollae longioribus.

Ixia Bulbocodium; scapo unifloro brevissimo, foliis angulatis caulinis, stigmatibus sextuplicihus. Lin. syst. veg. ed. murr. 75. mant. 320 .

narviflora. $\alpha$. Crocus vernus minor. 1. Clus. hisp. 260.

Crocus vernus angustifolius 2. Clus, hist. r. $p$. 207. quoad figuram.

Crocus vernus angustifolius 3 . Clus. hist. I. $p$. 208. quoad descriptionem.

Sisyrinchium Theophrasti. Colum. ecphr. $23 \pi^{\circ}$

media. fo. Crocus vernus minor. 1. Clus. hisp. 259.

Crocus vernus angustifolius 1 . Clzıs. hist. I. p. 2. grandiflora.

$\gamma$. Crocus vernus angustifolius, violaceo flore. Clus. hist. I. p. 208 . 
Sisyrinchium alterum angustifolium. Col. ecphr. z. $p$. $t$. ?. f. r.

Sisyrinchium majus angustifolium, radice prostrata, flore majore variegato. "Moris hist. 2. p. 345 . sect. 4. t. - f. $\mathrm{f}$.

Bulbocodium crocifolium, flore magno albo, furdu luteo. Tournef. cor. 50 .

Romulea. Marat.

Ixia Bulbocodium; caule unifloro; foliis linearibus, canaliculatis, conniventibus; floribus sulcatis, patentissimis. Jacqu. cullect. 3. p. 265 . Ic. rar. $=. t .27 \mathrm{r}$.

Ixia Bulbocodium. Curti. magaz. 8.t. 265 .

Habitat in arenosis maritimis maris mediterranei. 4

Bulbus interdum magnitudine nucis coryli, interclum minor, glaber, laevis. Folia tria-quirque, saepe spithamaea, unicum reliquis longius, laxum, angustissima, sulco utrinque ad costam, varie flexa; omnia cum scapo vagina inclusa. Scapus superne lateribus convexis, marginibus oppositis acutiusculis, pauciflorus. Flores sensim florentes, unicus tantum exsertus, reliqui inter spatham reconditi: styli trifidi: stigmata bifida. Fo gaudet scapo saepe digitali, et spathis lanceolatis concavis ininterdum longitudine totius floris. $\%$. Corolla plerumque scapo longior. Omnes varietates quoad colorem variant.

5. IXIA foliis filiformibus recurvis, scapo uniflo- elongata. ro, spathis aridis corollae tubo brevioribus.

Habitat in littoribus arenosis Sardiniae. 4

Similis praecedenti, an modo varietas? differre videtur spathis pollicaribus et ulira, praesertim vero tubi corollae longitudine unguiculari spatha longiore.

6. IXIA foliis linearibus basi attenuatis quadricari- cruciata. natis, scapo unifloro. Willd. spec. pl. 1. $p$. 197. +

Ixia cruciata; foliis clavato-subulatis, quadricanaliculatis; scapo unifloro. Jacqu. suppl. 16. Ic. rar. 2. t. 290.

Habitat in Cap. b. spei. 4 
Bulbus obovatus, tunicatus, magnitudine avellanae. Folia duo reliquis longiora, utrinque attemeata, una cum scupo vagina inclusa. Scapi duo vel tres, uniciales. Spatha semiuncialis, viridis: valvuiae lato-lanceolatae, acutae, concavue, striatae, aequales. Corollae intus rubrae, basi flavo et coeruleo stivatae: laciniae elongatae, lanceolatae, acutae, rarius quaeclam incisae; tres interiores extus coeruleae cum striis saturatioribus; exteriores exius flavae violaceo striatae; unguibus erectis, flavis, longitudine spathae. Jacqu. l. $c$.

quadrangula. $z$. IXIA foliis canaliculato-quadrangulis, scapo paucifloro, corollarum tubo brevissimo. +

Ixia quadrangula; bulbo squamato squamis exterioribus maximis, caule simplicissimo foliis canaliculato-quadrangulis breviore. De la Roche diss. $n .2$.

Habitat in Cap. b. spei. 24

Bulbi quadruplo ordine squamarum; squama margine lacerae. Folia pauca, stricta. Scapus simplicissimus. Flores laxe spicati, coerulei. Corolla infundibuliformis : tubus vix longitudine tertiae partis spathae: Limbi laciniae ovaiae. De la Roche. $l$. $c$.

A Thumbergio conjungitur cum Ix. Bulbocodio, at differre videtur bulbo squamis imbricato, nec tunicato. Affinior est Ix. cruciatae quoad folia at ab hac quoque bulbo diversa.

fragrans. 8. IXIA foliis linearibus jeclinatis, scäpo suhcompresso subbifloro, spathis membranaceis aristatis tubum aequantibus. +

Ixia fragrans; scapo subbifloro, foliis sublinearibus reclinatis. Jacqu. suppl. 9. Ic. rar. 2. t. 290.

Habitat in Cap. b. spei. 4

Bulbus pusillus. Folia inferiora longiora pedalia, inteitora scapum fere totum vaginantia, graminea, acuta, angusta, tenuissime striata. Scapus semipedalis, foliis brevior. Flores plerumque gemini, inferior sessilis, suaveolentissimi. Spatha scariosa, albida, purpúreo-striata: valvulae latae. Corolla tota lutea: Limbi laciniae tubo triplo longiores, oblongae, obtusae, 
patentissimae, subaequales. Capsula subrotundo-ovata. Јacqu. l. c.

An huc pertinet Ixia sublutea; foliis convolutis setaceis scapo unifloro longioribus, spatha 'ongitudine tubi. Lamarck, dict. bot. 3. p. 335 . illustr. 1. p. 109. ?

9. IXIA foliis linearibus multisulcatis erectis, flori- humilis. hus secundis.

Ixia bulbocodioides; caule foliis breviore, ramis unifloris. De la Roche diss. n. 6 .

Ixia humilis; scapo ramoso, floribus secundis, foliis sulcatis erectis. Thunb. ix. $n, 4$.

Habitat in Cap. b. spei. 24

Folia spithamaea et ultra, angustissima, unicum superne. Scapus simplex vel ramosus, filiformis, erectus. Rachis quatri-ostoflorus; flores distantes. Spathae vix unguictulares, oblongae, truncatae, striatae, virides, tubo corollae parum breviores.

$V$ ariat floribus luteis vel albido-rufescentibus sive incarnatis. Thuṇb. $l$. c.

An huc spectat Ixia flava; scapo folioso subbifloro, foliis linearibus canaliculatis striatis longissimis, stylo brevi. Lamarck. illustr. I. p. 109. ?

Ix. bulbocodioideam cum Ix. Bulbocodio conjungit Cel. Thunbergius, at mihi videtur quadrare in ejusdem Ix. humilem.

10. IXIA foliis inferioribus ensiformibus, florali- pytanidaiis, + bus ovatis attenuatis.

Ixia pyramidalis; caule subramoso, foliis lineazibus striatis distichis patentissimis : superioribus latioribus sensim breviorihus spathaceis. Lamarck. dict. bot. 3. p. 334. illustr. 1. p. 109. 6. humilior.

Habitat in insula Franciae Commerson. Ex herbario Jussiaei et Thoztinii. $\beta$. in Cap. b. spei. 4 Bulbus ozovatus. Caulis spithamaeus vel semipedalis, erecins, apics divisus in quatuor-quinque ramos simplices, interdum simplex, $e$ dorso foliorum decurrente anceps. Folia disticina: inferiora caule aliora; superiora sensim mi. nora, ensiformia, basi vaginantia, strinta; suprema semipollicaria, spatacer, ante florescen: 
tiam bifariam inbricata, ovata, atienuata, recurva, margine membranacea, glauca. Spatha brevis, conduplicata, lanceolata. Flores ex axillis foliorum fioralium. Corollae tubus, longitudine foliorum floralium, filiformis, sursum sensim ampliatus: Limbi laciniae oblongae, quinquenerves, purpureo-violaceae.

$V$ arietatem f. non vidi.

$$
\begin{gathered}
\text { * } \text { Scapo foliis longiore. } \\
\text { - pilosae. }
\end{gathered}
$$

pilosa. II. IXIA foliis linearibus pilosis, scapo glabro.

Ixia pilosa; scapo simplici, foliis linearibus pilosis. Lin. suppl. 92.

Ixia pilosa; folïs linearibus pilosis, floribus alternis. Thunb. ix $n .5$.

Habitat in Cap. b. spei. If

Bulbus globosus, vix magnitudine pisi. Folia subterna, erecta, attenuata, pilis adspersa. Scapus palmaris et ulira, foliis duplo altior, simplex, apice flexuosus, teres, striatus. Flores tres vel plures, subnutantes. Spathae concavae, lanceolatae, acutae, virides, striatae. Corollae tubus capitlaris: Linebi laciniae lanceolatae, concavae, tres exteriores intus albae, extus purpureo-virescenies, margine albo, ires interiores albae.

Antherae basi bifidie. Stigmata hirta. Capsula sexsulcata. Vesperi ab hora quarta flores aperit. Thunb. l. c.

114. I2. IXIA foliis ensiformibus hirtis, scapo glabro, floribus secundis.

Ixia inflexa; caule ad angulum flexo, floribus erectis secundis, spatha exteriore calycina corollae fere longitudine. De la Roclee diss. $n$. I. Ixia hirta; foliis ensiformibus hirtis, floribus secundis. Thunb. ix. n. 6.

Habitat in arenosis humidis. Cap. b. spei.

Talde sinilis $\mathrm{Ix}$. secundae, differt: ioliis valde villosis, pilis althidis.

Folia striata, scapo breviora. Scapus simplex, inflexo-erectus. Flnres saturate cocrulei. Spathae integrac. Thunb. $l$. $c$.

An Ixia foliis gladinlatis nervosis, hirsutis, floribus spicatis terminalibus, Mill. ic. I03. $t$. I 55 . f. 1. huc pertinet? 
13. IXIA foliis lineari-ensiformibus glabris, caule secunda. villoso scabriusculo, floribus secuncis.

Ixia secunda; caule ramoso erecto, floribns secundis, stigmatibus latis membranaceis. Dela Roche diss. 7 . 1 .

Ixia secunda; polystachya, spicis cernuis sẹcunndis. Berg. cap. 6.

Ixia secunda; folitis elliptico-enșiformilus, scapo villoso scabro. Thunb. ix. n. $z$. Jacqu, collect. 4. p. 180. Ic. rar. 2. t. 277.

Iabitat in Cap. b. spei. 4

Bulbus magnitudine nucis coryli, ovatus, basi truncatus, deorsum squamoso-imbricatus. Caulis spitamaeus vel pedaits, raro simplex, plerumque ramosus, flexuosus. Folia duo in caule, reliqua radicalia, suoffalcata, utringue attenuata, nervo medio cressiuscula, striata. Pachis quadri-sexflora. Flores distantes, saturate coerulei. Spathae lanceolatae', virides, apice brumneae. Corollae tu= bus brevissimus.

\section{- glabrae, foliis crispis.}

4. IXIA foliis linearibus, spathae valvulis exterio- crispa. ribus tridentatis.

Iria undulata; foliị lanceolato-linearibus undulatis, scapo tiifloro. Burm. prodr. 1.

Ixia crispa; fuliis subulatis crispis, scapo setaceo. Iin suppt. 9 :

Ixia crispa; foliis linearibus crispis, floribus a!ternis. Thunb. ix. n. 8. t. 2 .

Habitat in Cap. b. spei. 4

Fulia circiter quinque, scapo duplo-quadruplo breviora, unicum interdum inferne in scapo, angusta, attenuata, medio nervo flavescerate, Scapus pedalis, simplex vel inferne ramo scapo breviore, multiflorus, superne flexuosus, laevis. Flores parvi, inferiores remotiores, superiores confertiores. Spatha bivalvis, brevis, memỏranacea; valvula exterior tricientatc, dentibus aequalibus, trinervis; interior bi-dentata, binervis. Corollae tubus subviridis: Limbi laciniue coeruleae. Stigmata apice clavata.

Variat floribus albis. Thunb.l. c. 
cinnamonea. 15. IXIA foliis subfalcato-reflexis, spathae valvulis exterioribus obtusis acuminatis.

Ixia cinnamomea; foliis lanceolatis undulatis, spica secunda. Lin. suppl. 02.

Ixia cinnamomea; foliis lanceolatis crispis, floribus alternis. Thunb. ix. n. g. t. 2 .

Ixia cinnamomea; foliis falcatis crispis; floribus alternis, noctiflorens, cinnamomi odore. Andr. repos. $t$. +4 .

Habitat in Cap. b. spei. 4

Tota glabra. Bulbus magnitudine pisi, conicus, truncaitus, deorsum imbricatus. Folia radicalia duo, scapo triplo breviora, nervo medio elevato; cotyledonis unguiculare, amplexicaule, ovatum, obtusum, apice reflexum: caulina duo, remota, spathaeformia; inferius pollicare-tripollicare, saepe crispum, convoluto-vaginans vagina longa, apice compressum: superius unguiculare. Flores tres-novem, erecti. Rachis subflexuosa. Spathae valuula exterior conca$v a$, obtusa cum acumine, apice purpurascens; interior apice bifida. Corollae tubus spatha parum longior, purpurascens. Limbi laciniae albac, tres exteriores extus purpurascentes. Thunb. $l$. $c$.

Flores nactu suave olent instar Cinnamomi.

+ corymuosa. 6. IXIA foliis ensiformibus falcatis nervosis, callle ancipiti.

Caryophyllus monomotapensis nervosis bupleurifoliis, intus cavis, flore coeruleo, cauliculis secundum longitudinem alatis. Plukn. alm. 8. t. $275 \cdot$ f. 1 .

Ixia corymbosa : floribus corymbosis pedunculatis, caule ancipiti. Lin. am. ac. 4. p. 300. spec. pi. $5 \mathrm{r}$.

Ixia corymbosa; foliis lanceolatis crispis, scapo ancipiti. Thunb. ix. n. 10. Jacqu. collect. 4. p. 179. Ic. rar. 2. 1.89 .

B. floribus albis.

$\%$. Inumilior.

Ixia fastigiata ; foliis ensiformi-lingulatis nerrosis crispis, caule ancipiti, floribus glomeratis fastigiatis. Lamarck. dict. bot. 3. p. 33\%. illustr. I. p. 110. 
Habitat in sabulosis et ipsis viis Swartlandiae ad Cap. b. spei. 4

Bulbus ovatus, truncatus, reticulatus. Caulis spithamacus, flexuosus, superne in ranos floriferos fastigiatos divisus, mono-diphylius, $e$ margine extcriore foliorum decurrente interdum crispo interdum plano anceps, striatus. Folium unicum radicale interdum cuule altius, interdum brevius, erectum, quinquenerve, crispum: caulina similia, modo brevicra et saepe margine plana. Pedunculi plerumque dichotomi, raro indivisi, compressi. Bractea parva ad basin singuli pedunculi. Flos unicus vel duo in singulo pedicello, alter inferior, saepe sessilis. Spathae oblongae, apice rotundato rubicundo. Corolla coerulea: tubus spatha parum longior: Limbi laciniae lanceolatae.

Varietatem vidi scapo semipedali, folio radicali morgine plano.

17. IXIA foliis radicalibus lineari-ensiformibus pla- heterophyila nis, floralibus linearibus obtasis unculatis floribus longioribus, spathis univalvibus. $\dagger$

Galaxia plicata; foliis plicatis. Jacqu. suppl. 30. Ic. rar. 2. $t .29 \mathrm{I}$.

Habitat in Cap. b. spei. 4.

Bulbus conicus, striato-rugasus, fuscus, avellana minor. Caulis sesuncialis, adscendens vel erectus, infra terram foliolo radicali spathaeformi acuto vaginato, teres, superne incrassatus, albidus, apice solutus in fasciculum densum foliorum striato-plicatorum. Folium infimum circiter quinque uncias longum, lineare, inferne versus sensin latius, erectum, actium; alized huic oppositum, sesunciale, oblongum, obtusum, amplexicaule, superne patentissinum: reliqua sublinearia, obtusa, undulata, patula. Flores axillares, albi. Spatha albida, pellitcicke, apice incrassata et viridis, uncicalis. Corollae tubus filiformis, uncialis, parzim incurvatus, superne triangularis: Limbi lacinine lanceolatae, parum concavae, patentissimae, subacquales, tubo triplo brevores. Jacqu. l. c. 


$$
\text { - - giabrae, foliis planis. }
$$

anemonae- Is. IXIA foliis lineari-ensiformibus erectis scapum flora.

uniflorum aequantibus. $\div$

Ixia anemonaeflora; scapo unifforo; foliis lineari-cnsiformibus, superne obliquis, longitudine scapi, erectis. Jacqu. suppl. Iо. Ic. rar. 2. $t .273$.

Habilat in Cap. b. spei. 4

Bulbus magritudine fere avellanae, subrotundus, tunica striata fusca tectus. Folia radicalia, pluta, decempollicaria, disticha, striata, nervo medio protuberante. Scapus circa medium inflexus, gracilis, nitidus, viridis. Spatha brevis, scariosa: valvula altera bidentata, altera tridentata. Corolla alba flavedine levissime tincta; tubus longitudine spathac: Limbus diametro biunciali; laciniae ob̉ovatae, parum concavae, obtusissimae, subaequales. Stigmata apice latescentia. Jacqu. l. c.

coelestina. I9. IXIA foliis lineari subulatis scapo unifforo multoties brevioribus. Wild.spec. pl. 1. p. 200. + Ixia coelestina; radice bulbosa suhrotunda, caule tereti vaginato, foliis lineari-lanceolatis, fioribus expansis magnis coeruleis. Bartr. it. r.52. t. 3 .

Fiabitat in Carolina. 4

recurva. 20. IXIA foliis linearibus, scapo simplícissimo, spicis secundis, floribus recurvis.

Ixia linearis; scapo simplici flexuoso glabro, foliis linearibus, bulbo conico. Jacqu. collect.

4. p. 183. Ic. rar. 2. t. 270.

Ixia fistulosa; foliis linearibus fistulosis; floribus sccundis noctu fragrantibus, bulbus campanulatus, margine acuto fibroso. Andr, repos. 59.

Hrabitat in Can. b. spei. 2

Folia angusta, nervo intermedio et marginali crassioribus, duo scapum longe vaginantia, brevissima; vaginae striatae. Scapus pedaiis, gracilis. Flores octo-decem, distantes. Spathae unguiculares, lineares, acutae, striatae, viridi-flavescentes, apice parum purpurascentes, interrac; valuula exterior longitudine tubi. Corollae laciniae lanceolatae, subaequa- 
les; tres exteriores extus flavescentes intus pallide purpurascentes, interiores albae.

21. IP.IA foliis linearibus, scapo simplici flexuoso, angusta. floribus secundis.

Ixia linearis; scapo simplici flexuoso glabro, folis linearibus; bulbo conico. Jacqli. collect. 4. p. 1\&3. Ic. rar. 2. ta 279.

Habitat in Cap. b. spei. 4

Affinis luabitu et structura florum Ix. falcatae. Folia disticha, erecta, angusta, striatula. Scapus octopollicaris, foliis altior. Flores tresquatuor: Differt $a b$ Ix. falcata petalis utrinque albis. Jacqu. $l$. c.

22. IXIA foliis setaceis, scapo ramoso virgato flex- virgata. uoso. Will. spec. pl. 1. p. 202.

Moraca virgata; caule tereti ramisque virgatis; fuliis linearihus, longissimis; floribus solitariis ex spathis. Jacqu. collect. 3. p. 194. Ic. rar. 2. t. 228 .

Habitat in Cap. b. spei. 26

Caulis sesquipedalis, inferne flexuosus, gracilis: Rami virgati. Folia bipedalia, pau$c a$, linearia, basi vaginantia, angustissima, flaccida, striatula. Spathae saepe quadrivalves, convolutae, acuminatae, palliclae, extima scariosa, amplexicaulis. Flores brevissime pedunculati, solitarii, ex spathis successive prodeuntes. Corollae infundibuliformes; tubus pallidus; iaciniae lanceolato-oblongae, obtisae, planae, patentissimae, tubo triplo longiores, luteae cum fascia media virescente. Filamenta flava. Stigma sexfidum. Jacqu. l. c.

23. IXIA foliis linearibus, floribus secundis, spa- scillaris. thae valvula exteriori membranacea intc sra, tubo corollae brevissimo.

Ixia scillaris; foliis linearibus, floribus secundis, rachide flextosa. Thunb. $i x, n$. 14.

Hallitat ad Cap. b. spei. 4

Bulbus magnitudine pisi, ovatus, truncatus, deorsum squamatzis. Folia longe vaginamia, spithamaca, scapo breviora, circiter tria, lineam dimiriam vix lata, crassiuscrcia, stria diuplici profundie: Thami filiformes, nudi, flexuosi, laxi. 
Flores remoti, saepe decem. Spathae valvula exterior parum longior, membranacea, striata, basi virilis, apice cinerea, integra, interior basi viridis, apice membranacea, bifida, cinerea. Corollae tubus brevissimus, fiazo-virescens: Limbi, laciniae concavae, flavae, tribus exteriorilus dorso purpurascentibus. Thunb. l. c.

Scapus interdum simplex. Flores parvi.

capillaris. 24. IXIA foliis linearibus cartilagineo marginatis, scapi ramis pedicelliformibus unifloris, snathis membranaceis dentatis. +

Ixia capillaris; caule multifloro, floribus pedunculatis erectis, foliis linearibus erectis. Lin. suppl. 92.

Ixia capillaris; foliis linearibus, scapo polystachyo, spathis scariosis. Thunb. ix. n. 12. $t .2$. $f .=$

Ixia lancea; scapo simplici, erecto; foliis cnsiformibus, ad oras revolutis; floribus secundis, racemosis. Jacqu. suppl. I3 Ic, rar. 2. t. $28 \mathrm{I}$.

gracillima. B. foliis linearibus angustissimis non marginatis, spatha tubum superante. Curt. mag. t. 570 .

aulica. $\quad \%$ robustior ramis multifloris, spathā tulum subaequante. Curt. $l$. c.

Ixia aulica; foliis ensiformibus nervosis, floribus racemosis, bracteis integris, Hort. kew. I. p. 57 .

Habitat in Cap. b. spei. 24

Bulbus reticulatus, fibrosus, magnitudine Avellanae. Folia scapo dimidio breviora, angusta, nervosa. Scapus bipedalis, capillaris, apice divisus. Flores in ramis solitarii, in apice scapi alterni, erecti, albidi, venoso-reticulati. Spathae venis fuscis. Thunb. $l$. $c$.

incarnata. 25. IXIA foliis ensiformibus margine reflexis, floribus sessilibus secundis, spathae valvula exteriore tridentata, +

Ixia incarnata; caule simplici, erecto; foliis ensiformibus, ad oras revolutis; floribus secun. dis, spicatis. Jacqu. suppl. I3. Ic. rar. 2. t. $28 \mathrm{I}$.

Habitat in Cap. b. spei. 4 
Bulbus magnitudine aveilanae, subrotundus, reticalatus. Folia semipedalia, longe vaginantia, erecta, firmula, margine parum incrussata, striatula, nervo medio protuberante. Scapus fere sesquipedalis, simpiex, gracilis. Flores quini vel plures, erectiusculi, unciales, inodori.. Spatha membranacea: valvulis dentais, stria pallida purpurea pro singulo dente, altera bidentata. Corollae tubus incurvatus, allidus: Limbi iacinice subuequales, longitudine tubi, pallide roseae, oblongae, apice rotundatae, planae, patenitissimae. Jacqu. $l$. $c$.

26. IXIA foliis linearibus angustissimis convexis, linearis. scapo simplici, floribus secundis, spathis ovatis acutis.

Ixia linearis; caule simplici erecto, foliis linearibus convexis striatis. Lin. suppl. 92.

Ixia linearis; foliis linearibus, scapo simplici erecto. Thunh. ix. n. I 2 .

Habitat in Cap. b. spei arenosis. 2

Bulbus ovatus, magnitudine Avellanae. Caulis palmaris et ultra. Folia circiter tria; infimum longe vaginans, erectum, angustissimum, attenuatum, utrinque convexum, linea media elevata, scapo paulo brevius: superiora duo, spathacea, pollicaria, sursum versus parum minora. Flores raro solitarii, plerumque duo vel tres, secundi. Spatha convoluta, acuta, striata: valvula exterior ovata. Corollae tubus albidus: Limbi laciniae unguiculares, obtusae cum acumine. Stigmata rewoluto-patentia, purpurascentia. Capsula vix angulata, sexstriata. Thunb. $l$. $c$.

27. IXIA foliis linearibus, scapo polystachyo, flo- imbricata. ribus secundis, spathis longitudine tubi ovatis acutis.

Ixia imbricata; bulbo squamis imbricatis tecto, caule erecto ramoso, spatha exteriore calycina tubi corollae longitudine. De la Roche diss. $n .3$.

Habitat in Cap. b. spei. 4

Bulbus squamis imbricatus. Caulis dodrantalis: Ramil graciles. Folia caule dimidio breviora. Flores laxe spicati. Spathae ovatae: valvula 
exteriore majore, margine colorata, apice acuia. Corollae laciniae lanceolatae, tres exius rubrae, omnia intcrne luteo-alba. De la Roche. l. $c$.

I arieiatem esse Ix. corymbosae suspicatur Thunbergius, at bulbus reticulatus, nec scapus anccps, nec folia crispa, saltem secunáum descriptionem de la Rochei. An potius varietas Ixiae linearis?

inncea, 28. IXIA foliis ensiformibus margine revolutis, scapo simplici flexuoso, floribus secundis, spathis obtusis. If

Ixia lancea; foliis ensiformibus, floribus secundis, scapo simplici flexuoso. Thunb. ix. n. 2 r. Habitat in Cap. b. spei. 4

Bulbus avellana major, rudimentis foliorum dense involutus. Folia tria vel quatuor, digitalia, marginibus et nervo medio crassioribus, tenuissime striata, erecta, uricum vel alterum spathaeforme in scapo. Scapus foliis duplo longior, hinc inde compressus. Flores circiter sex, aibo purpurascentes. Spathae obtusae, integrae, cinereae, apice ferrugineae. Thumb. $l$. c.

pectinata. 29. IXIA foliis revoluto-subulatis, floribus secundis, spathis membranaceis obtusissimis tubo elongato brevioribus.

Habitat in Cap. b. spei. 4

Caulis pedalis, simplex, inferne teres, superne compressus, flexuosus. Folia lduo vel tria in caule, sesquipollicaria vel minora. Flores septem, sesquipollicares, parum distantes. Syathae vix semipollicares, oblongae, nervosostriatae, griseae, apice fusco marginatae, subdenticulatae, interior parum brevior. Corollae albido-incarnatae, tubus spatha duplo longior: Limbi laciniae oblongae, obtusae.

An eadem cum Ix. lancea Thunbergii?

tenuifolia. 30. IXIA foliis subulatis quadrisulcatis, scapo filiformi, spathis membranaceis dentatis tubo corollae brevioribus.

Habitat in Cap. b. spei. Ex herbario Royenii. 2': Folia tria, semipedalia vel parum ultra, unicum scapum parum excedens, reliqua breviora, an- 
gustissina, medio nervi duo approximati, et unicus ad singulum marginem, uti scapres vagina superne lineari-lanceolata ferruginea involutu. Scapus foliis parum gracilior, lwevis, nitidus. Flores sex-septem. Pachis paruin flexuosa. Spathae apice fusco-purpirascentes, tubo triplo breviores; exterior tridentata, interior iidentata. Corollae tubus filiformis, purpurezıs, sersim dilatatus versus faucem: Limbi laciniac pallide purpureae, lineari-oblongae, obtusae.

31. IXIA foliis ensiformibus, scapo simplici, spi- fliformis." cis subnutantihus, spathis membranaceis dentatis tubo brevioribus.

Ixia aristata. Schnev. ic. I. t. 32 .

Ixia filiformis; foliis ensiformibus, acuminatis, scapo filiformi, erecto; spica nutante; laciniis calycinis tubo longioribus. Venten. hort. cels. 4.. t. + र. Redouté pl. lill. t. 30.

Halitat in Cap. b. spei.

Bulbus tunicatus, magnitudine avellanae. Folia disticha, nervosa. Scapus gracilis, foliis duplo altior, mitidus. Flores purpurei, plitres, inodori. Spathae valvula exterior trisiriata, triaristata; interior bistriata, biaristata. Corollae tubus gracibis, albido-virescens.

32. IXIA foliis lineari-ensiformibus, floribus se-leucantin, cundis, spathis dentatis tubo brevioribus.

Ixia leucantha; scapo polystachyo, erecto; foliis lineari-ensiformibus, obliquis, erectis; striatulis; floribus secundis, nutantibus. Jacqu. suppl. 10. Ic. rar. 2. t. 278.

Habitat in Cap. b. spei. 4

Bulbus magnitudine avellanae, subrotundus, depressies, tunica striata tectus. Folia longitudine scapivel breviora, firma, bina-terna, obliqua, acuta, subtilissime striata. Scapus pedalis vel sesquipedalis, penna columbina gracilior, duplici ramo auctus, inferiore plerimque abortiente. Flores secundi, quatuor-septem, expansi, nutantes, inodori. Spatha albida, viridi-paucistriata: valvulne late ovatae, exierior 
tridentata altera bidentata. Corollae tubus gracilis, incurvus, viridi pallens, spatha paulo longior: Limbus albilius, extus basi leviter flavo-viridulus; laciniae ovales, obtusae, patentissimae, alternae parum angustiores, immaculatae. Stigmata apice villosa. Jacqu. l. c.

Spathae valvulae apice coerulescentes. \&

An huc pertinet Ixia foliis linearibus, floribus spicatis sessilibus. Mill. ic. 10\%. t. I56. $f$. 2 ? vix enim ad flexuosam spectat.

+ macura. 33. IXIA foliis lineari-ensiformibus marginatis, scapo polystachyo, corollis basi maculatis, tubo spathis longiore.

Ixia maculata; foliis ensiformibus floribus altersis, corollis basi maculatis. Thunb. ix. $n$. I 9 . «. albida.

ß. flava.

Sisyriachium majus africanum, flore luteo macula notato. Oid. afr. 32.

Ixia foliis gladiolatis glabris, floribus corymbosis terminalibus. Mill. ic. 104. t. 156. f. I.

Ixia maculata, foliis ensiformíbus, floribus alternis: petalis basi obscuris. Lin. spec. pl. Ififo.

$\gamma$. flava apicibus purpureis.

d. viridis.

Ixia viridiflora; foliis linearibus angustis striatis, caule simplicissimo spicato, spathis exterioribus indivisis. Lamarck. dict. bot. 340. illustr. 1. p. 112 .

Ixia maculata viridis; foliis linearibus, scapo saepius simplici, floribus alternis, corollis viridibus in centro apice purpureis. Schneev. ic. r. t. J. Jacqu. ic. rar. t. 23.

s. albo-coerulescens.

5. coerulea. Jacqu. ic. rar. t. Ig.

\%. purpurea macula pallida.

9. rubra. Schneev. ic. I. t. 25. Jacqu. ic. rar. t. 20.

Violacea. Jacqu. ic. rar. t. 23.

Habitat in Cap. b. spei. 4.

Ab Ix. polystachya vix nisi macula basi corollae diver'sa. Scapus plerumque simplex, rarius polystachyus. Folia angusta, interdum parum latiora. Viridis spica clongata gaudet, et brac- 
teae apice integrae, quod tamen quoque occurrit interdum in reliquis varietatibus. Plures adhuc varietates vide apud Jacqu. ic. rar. $t$. $2 \mathrm{I}, 22$.

34. IXIA foliis lineari-ensiformibus marginatis, ereck $\leftarrow$ scapo polystachyo, floribus immaculatis, spathis tubo corollae brevioribus.

Ornithogalum spicatum minus album, foliis ner vosis a fricanum. Plukn. alm. 272.t. $310 . f_{0}{ }^{4} \mathrm{I}$. Ixia foliis lineari-lanceolatis, floribus alaribus et terminalibus. Mill. ic. ro . $t$. I55. f. 2.

Ixia polystachya; foliis linearibus, scapo spicis pluribus. Lin. spec. pl. $5 \mathrm{I}$.

Ixia thyrsiflora; caule polystachyo, spicis aiternis, cauli approximatis, germinibus inter spathas pedunculatis. De la Proche diss. $n$. ${ }^{\circ}$

Ixia erecta; polystachya, tubis corollarum capillaribus erectis spathis duplo longioribus. Berg. cap. 5.

Ixia erecta; foliis ensiformibus, scapo polystachyo, floribus alternis immaculatis. Thumb. ix. n. 18 .

ค. floribus flavis. Jacqu. hort. schoenbr. I. p. 9, t. 18.

Habitat ad Cap. b. spei. 24

Folia tria-quatuor, pedalia, longe vaginantia, erecta; nervi marginales et costae protuberantes. Scapus interdum bipedalis, gracilis. Pedunculi alterni, remoti, digitales vel breviores, capillares, erecti. Rachis longitudine digiti minimi, novemflora, pauciores in lateralibus. Spathae breves, membranaceae, punctis minutis adspersae: valvula exterior tridentata, tristriata; interior bidentata, bistriata. Corollae tubus capillaris.

$V$ ariat corollis albis, luteis et violaceis unicoloribus.

35. IXIA foliis lineari-ensiformibus marginatis, string. spathis membranaceis, valvula exteriore tridentata longitudine tubi.

Habitat in Cap. b. spei. Ex herbario Royenii. 4 Bulbus reticulatus. Folia radicalia plura; alter. natim disticha, tri-quadripollicaria, inferiora

Tom. II

E 
minora, intimum longius totum vaginans, attenuata, subtilissime striata, nervo medio et marginalibus crassioribus. Scapus pedalis, laevis, inter flores flexuosus. Flores quatuor vel sex, remoti. Spathae unguiculares, striatae, nervosae, fusco-purpurascentes; valvula exterior obtusa, leviter tridentata, interior apice bidentata. Corolla pollicaris, alba, venis fuscescentibus picta; tubus gracilis: Limbus campantilatus; basi tinctura flavescente; laciniae oblongae, obtusae, apice interclun macula livearis fusca.

tenuiflo:a. 36. IXIA foliis ensiformibus, floribus distichis, spathis membranaceis tubo brevioribus, laciniis corollae linearibus.

Habitat in Cap. b. spei. Exherbario Royenii. 4 Folia semiunguem lata, attenuata, nervo costali crassiore. Scapus infcrne teres, superne parum angulatus, in pedunculos duos vel tres divisus. Bractea duplex ad basin pedunculorum, lanceolata, ferruginea; exterior pollicaris, in aristam attenuata, interior triplo brevior, bifida. Pedunculi rigidiusculi, remioti, subcompressi. Flores quindecim, in lateralibus pauciores, remoti. Spatha semiuiguicularis, apice ferruginea; valvula exterior integra, nervis coloratis striata; interior bidentata, bistriata. Corolla sordide albescens; tubus pollicaris: Limbi laciniae angustae, obtusae.

pendula. 37. IXIA foliis lineari-ensiformibus, scapo polystachyo, spicis pendulis. Thunb. ix. $n$. I 6 .

Ixia pendula; foliis lineari-ensiformibus, caule paniculato, racemis pluribus pendulis. Lin. suppl. 9 r.

Habitat in Cap. b. spei locis udis prope Krumrivier. 4

Bulbi moniliformi-articulati: articuli approximati, orbiculati, depressi, carnosi, rufescentes. Folia pedalia et ultra, longe vaginantia, apice in acumen ferruginetun membranaceum desinentia: vaginae margine tenui membranaceo. Scapus orgyalis, laevissimus, superne divisus in pedunculos: pedunculi qua- 
tuor vel quinque, remoti, capillares, nutantes, biflori; flos alter sessilis, alter pedicellatus: plures in terminali, omnes sessiles. Spathae membranaceae, lacerae, lanceolatae, hyalinae, nervasae, purpureo-lineato-maculatae. Corollae incarnatae, magnae, campanulatae.

39. IXIA foliis ensiformibus reflexo-falcatis, scapo flabellularis. simplici flexuoso, spathis membranaceis aristatis tubo brevioribus.

Habitat in Cap. b. spei. Ex herbario Royeni. 4 Folia digitalia, acuta. Scapus spithamaeus, superne parum compressus. Flores quatuor, remoti, pollicares. Spatha vix unguicuiaris, purpurea: valvula exterior aristis tribus, interior duabus. Corolla flava; tubus filiformis: Limbus campanulatus, venosus; laciniae oblongae, obtusae.

39. IXIA foliis ensiformibus nervosis, spathae ex-pentandra. terioris valvula carinata tridentata tubum subaequante.

Ixia scillaris; foliis ensiformibus striata, spica elongata. Lin. spec. pl. 5 =.?

Ixia. Houtt. syst. pl. I r. p. 33. t. 77. f. 2 .

Ixia pentandra; floribus pentandris, staminibus curvis, foliis ensiformibus. Lin. suppl. $9=$.

Ixia pentandra; foliis ensiformibus, floribus pentandris. Thunb. ix. n. 22.

Ixia polystachya. Jacqu. coll. 3. p. 269.

Habitat in Cap. b. spei. 4

Folia inferne in scapo, distiche alternantia, inferiora sesquipollicaria, parum latiora, acuta, insequentia sesqui-bipollicaria, attenuata, acttiora, omnia tri-quinquenervia, subtilissime striata. Scapus semipedalis vel longior, simplex vel ramosus, iaevis. Rachis multiflora. Flores parvi inferiores remotiores, superiores magis approximati. Spatha brevis, membranacea, basi fusca, apice coeruleo leviter tincta; valvula exterior tridentata, dentibus subaequalibus, subulatis; interior bifida. Corollae tubus capillaris, spatha vix longior, virescens: Limbi laciniae purpureae. Stamina limbo duplo breviora, saepius tria, rarius quatuor-quinque: Antherae didymae 
ovatae, incumbentes. Stigmata tria saepius, rarius quatuor-quinque, filamentis parum breviora, plumosa. Thunb. $l$. c.

setacea. 40. IXIA foliis linearibus, scapo uni-multifloro, spathis herbaceis longitudine tubi.

Ixia setacea; foliis linearibus, scapo flexuoso glabro. Thunb. ix. n. 13 .

Habitat in Cap. b. spei. 4

Bulbus semine coriandri partum major. Folia radicalia duo-tria, vix pollicaria, angustissima, acuia, uti reliqua planta glabra, medio nervo elevato, unicum in scapo inferne. Scapus capillaris, saepe vix longitudine digiti minimi, parum flexuosus, simplicissimus, uniflorus, vel multiflorus, interdurn bificlus bi-multiflorus. Spatha subinflata: valvulae semiunguiculares, aequales, concavae, oblongae, acutiusculae, striatae. Corollae laciniae tres exteriores intus albae, extus rubro striatae; tres interiores totae albae, basi macula fusca.

$V$ ariat flore virescente limbi apice albo, flore luteo. Thunb. l. c.

geminata, 4I. IXIA foliis linearibus, scapo ramoso, floribus secundis, spathis lanceolatis longitudine tubi, valvula exteriori bifida.

Habitat in Cap. b. spei. 4

Folia tria vel quatuor, scapo triplo wel quadruplo breviora, angusta. Scapus pedalis, superne angulatus, parum supra basin geniculatus, geniculo folio vaginato instructo, e cujus axilla ramus scapiformis, scapo ipso parum breviore,' hinc quasi scapi gemini. Flores quinque, duo in ramo, distantes, fere pollicares. Spathae virides, herbaceae, fere unguiculares. Corolla flavescens: Limbi laciniae lanceolatae, acutae, tres exteriores extus rubicundae.

adiata. 42. IXIA foliis ensiformibus, scapo flexuoso geniculato simplici, floribus secundis, limbo corollae patenti.

Ixia radiata; scapo simplici, geniculato; foliis linearibus, glabris, bulbi conici basi plana 
excurrente in orbiculum dentato-radiatum. Jacqu. suppl. 15. Ic. rar. 2. t. 280.

Habitat in Cap. b. spei. 4

Bulbus avellana minor, conicus. Caulis fere sesquipedalis, crassitie pennae columbinae, sim. plex, debilis. Folia caulina circiter quatuor, caule multo breviora. Flores circiter septem, distantes, inodori. Spathae valuula exterior. oblonga, acuminata, convoluta, striata, virescens; interior angusta, brevior, bidentata, hy. alina. Corollae tubus longitudine spathae, erectiusculus, pallidus: Limbus nutans; laciniae lanceolatae, sordide albentes, obscure striatae, patentissimae; tres exteriores sordide rubentes, paulo latiores et longiores. Stigmata interdum quatuor. Jacqu. $l$. $c$.

Scapus interdum spithamaeus, triflorus.

43. IXIA foliis ensiformibus reflexo-falcatis, spa-falcata. this corollarum tubum aequantibus acutis.

Ixia falcata; caule simplici, foliis falcatis. Lin. suppl. 92.

Ixia falcata; foliis ensiformibus reflexo-falcatis. Thunb. ix. n. 23 .

Ixia falcata; scapo polystachyo flexuoso, foliis ensiformibus striatis, scapo brevioribus, rachi erecta. Jacqu. collect. 4. p. I\$3. Ic. rar. 2. t. 276 .

Habitat in Cap. b. spei. 4

Bulbus basi truncatus, deorsum squamis imbricatus, magnitudine pisi. Folia disticha, interdum recta. Scapus pedalis, simplex vel ramosus, saepe valde flexuosus, interdum minus, superne purpurascens, bi-tri-multiflorus. Spathae valvulae lineari-lanceolatae, striatae. Corollae tubus purpurascens: Limbi laciniae acutae; exteriores parum longiores, intus albae extus rubrae; interiores albae.

Germen triquetrum. Jacqu. l. c.

44. IXIA foliis oblongis margine interiori inferne excisa. excisis, scapo flexuoso, floribus secundis.

Ixia excisa; caule simplici, foliis ovato-oblongis, latere interiori excisis. Lin. suppl. 92. 
Ixia excisa; foliis ovatis, floribus secundis, scapo flexuoso. Thunb. ix. n. 24. t. 1 .

Habitat in Cap. b. spei. 4

Bulbus globosus, fibrilloso-tunicatus. Folia radicalia duo, scmipollicaria, obtusa, margine interiori inferne amplectentia, exciso-angustiora; unicuin spathaeforme infra medium scapi. Scapus digitalis vel palmaris, uniflorus vel multiflorus. Spatha orevissima: valvulae obtusae, subcrenatae. Corollae tubus filiformis.

Scapus rarissime e medio cauliculum edit, uniflorum. Corollae tubus ruber: Limbi laciniae obtusissimae, patentes, extus rufescentes, intus albae, utrinque rubro striatae. Thunb. $l$. c.

Trariat glumis lanceolatis, longitudine dimidii tubi; floribus uno-duobus. l. c.

An huc spectat Ixia ovata foliis radicalibus binis ovalibus connatis, scapo in summitate inflexo. Burm. prodr. 1. ?

enarginats. 45. IXIA foliis ensiformibus, inferne margine interiore exciso angustatis, bracteis tridentatis tubo corollae brevioribus.

Ixia emarginata; foliis linearibus uno flatere exciso emarginatis, caule ramoso, tubo spathis multoties longiore. Lamarck. dict. bot. 3 . p. $3 \div 2$. illustr. 1. p. I 12.

Habitat in Gap. b. spei. 4

Folia radicalia quinque-septem, disticha, bi-stripollicaria, inferiora minora, lanceolata, acuta, a medio versus basin angustiora, striata, nervo medio protuberante. Scapus spithamaeus vel semipedalis. Pedunculi solitarii vel bini scapo breviores, folium ad basin singuli lineare. Rachis quinque vel septemflora. Flores distantes. Spathae valarula exterior oblonga, truncata, dentibus lateralibus brevibus, intermedius subulatus, patens, viridis. Corolla infundibuliformis; tubus quinquangularis, semipollicaris, spatha triplo longior, gracilis, cinerascens, angulis purpureis: Limbi laciniae concavae oblongae, obtusae, basin versus parum angustatae, pallide roseae, exteriores extus fere totae purpureae, interiores linea dorsali purpurea, tres inferiores versus basin macula purpurca, dicae 
laterales cum macula lanata alba et linea purpurea versus faucem decurrente, intermedia cum macula cuneata bipartita lutea et inferne versus tubum lunula alba.

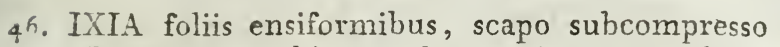
aristata. + flexuoso, spathis membranaceis setaceo-laceris, corollae tubus brevissimus.

Ixia foliis gladiolatis nervosis, spatha lacera. Mill. ic. $158 \cdot$ t. $237 \cdot f$. 1 .

Ixia aristata; foliis linearibus, spathis aristatodentatis. Thunb. ix. n. 15 .

Ixia fimbriata; foliis ensiformibus, cavle angulato flexuoso, simplici, spathis fimbriato-laceris. Lamarck. dict. bot. 3, p. 339. illustr. I. p. $4 \mathrm{IT}$.

B. corollis purpureis.

Ixia foliis gladiolatis glabris, caule unifloro. Mill. ic. $158 . t$. $237 \cdot f$. 3 .

Ixia uniflora; scapo unifloro, foliis ensiformihus, spatha lacera. Lin. mant. 27. Jacqu. collect. 4. p. 18. I. Ic. rar. $257 \cdot$ f. 3 .

$\%$ corollis violaceis.

Ixia foliis gladiolatis glabris, spatha breviore quinquefida. Mill. ic. 158. t. $237 . f$. 2.

Ixia grandiflora, caule simplicissimo, foliis lanceolato-linearibus, floribus distichis. De la Roche diss. 7n. I 1 .

Habitat in Cap. b. spei. Ex herbario Royenii et Lamarckii. 4

Bulbus truncatus, nuce avellanae parum minor 2 fibrosus. Folia radicalia, circiter quinqueseptem, disticha, bi-tripollicaria, attenuata. Bulbi nulli in axillis. Scapus quadripollicaris vel parum ultra. Flos rarissime unicus, plerumque tres-novem, distantes, magnitudine fere Ix. crocatae. Spathae unguiculares, nervoso-striatae, apice multifidae; laciniis setaceis, longitudine spathae, inaequalibus, fuscoputpurascentibus. Corollae laciniae oblongae, obtusae.

47. IXIA foliis subensiformibus, corollis campan patens. nulatis patulis, laciniis alternis angustioribus. + 
Ixia paiens; foliis ensiformibus glabris, racemo terminali, corollis campanulatis patulis, laciniis alternis angustioribus, filamentis crectis. Hort. kew. . p. 5 s,

I Iabitat in Cap. b. spei. 4

bicolos. 48. IXIA foliis ensiformibus nervosis reflexis, scapo ramoso floyuoso. $\div$

Ixia bicolur; foliis ensiformibus multinerviis reflexis, scapo ramoso, corollis luteis basi coeruleis. Thunb. in Web. et Mohr. arcliv. 1. $P$. r. p. 23.

Habitat in dzmis sabutosis Cap. b. spei. 4

Scapus palmaris vel spithamaeus, filiformis, flexuoso-erectus, foliis paulo longior. Flos unus ad quatuor. Corollae limbus totus luteus; tubus apice coeruleus, basi lutescens. Thunb. b. c.

bulbifera. 49. IXIA foliis lineari-ensiformibus, caule subcompresso-flexuoso, spathis membranaceis setaceo laceris tubum aequantibus.

Ixia foliis linearibus glabris, caule folioso bulbifero. Mill. ic. 152. t. $236 . f$. $=$.

Ixia bulbifera; foliis lineari-ensiformibus, axillis bulbiferis, floribus alternis, staminibus lateralibus. Lin. am. ac. 4.p. 300. spec. pl. $5 \mathrm{I}$.

Ixia bulbifera; foliis ensiformibus, spathis membranaceis setaceo-laceris. Thunb. ix. $\pi$. r 7 .

noloserises. B. Ixia holosericea; scapo simplici; foliis lineariensiformibus, glabris; spathis aristato laceris. Jacqu. hort. schoenbr. x. p. 9. t. 1 ?

monorssha. $\gamma$. Ixia monanthos; caule ! unifloro folis Ianceolato - linearibus longiore. De la Roche diss. n. 8.

d. Axillis absque bulbis.

Habitat in Cap. b. spei. 2f:

Caulis palmaris, pedalis vel ultra, simplex vel ramosus, striatus, foliis vaginatus. Folia tria ziel quatioor in scapo, spithamaea, sursum minora, erecta, attenuata, striata: vaginae margine angusto membranaceo. Bulbi saepe axiliares, solitarii-termi, ovati. Flores tres vel plures, distantes. Spathae nervosae, laciniis fusco-purpicrascentibus. Corollae tubis temuis: Limbi laciniae obiongae, obtusae. 
Variat floribus purpureis, rebro albogue varie. gatis, flavis. Thunb.

Gaudet foliis latioribus quam reliquae.

50. IXIA foliis lineari-lanceolatis, laciniis limbi squalida. ovato-oblongis, spathis membranaceis fissis tubo brevioribus. $t$

Ixia squalida; foliis lineari-lanceolatis, floribus alternis sessitibus, tuho bracteis longiore, laminis ovato-oblongis. Hort. kew. 1. p. $6 \mathrm{I}$.

*. Laminis cuneiformi-oblongis obtusis emargi- patulta. natis basi subhyalinis. Hort. kew. l. $c$.

f. foliis strictis, laminis ovato-oblongis integer-stricta. rimis basi concoloribus. Hort. kew. l. c.

Gladiolus lineaius. Curt. mag. t. 487 .

Habitat in Cap. h. spei. $₹$

$\nabla$ arietas $\alpha$. Ixiae crocatae valde affinis, sed difffert: Limbi laciniis angustioribus, magis pellucidis ideoque venis exstantioribus, leviter emarginatis, pallide rufescentibus seu sordide carneis, cum parva flavedine.

$\checkmark$ arietas $\beta$. Folia vix spithamaea, acuminata, stricta, pland. Scapus foliis duplo longior. Spatha vix semunciatis. Corolla paltide lutea: Limb̈i laciniae ovato-oblongae, obtusizesculae; exteriores prope apicem ribicundae; into teriortum una coeteris paulo latior. Hort. $\mathrm{kew}$. l. c.

5r. IXIA foliis ensiformibus, corollae tulo longi- crocats. tudine bractearum, laciniis obovatis basi hyaIino - fenestratis.

Ixia planifolia eanlo multifloro, spatha brevissima. Mill. ic. 16e. t. $23 \%$. f. 2 .

Ixia crocata; foliis ensiformibus, fioribus alıernis, petalis basi hyalino-fenestratis. Lin. $p z_{0}$ rar. 1. p. . .5. t. 7 .

Ixia Milleri; folìis lineari angustis: vaginis ancipitibus, spica terminali, spathis griseis. Lerg. cap. s.

Ixia crocata; foliis ensiformibus, floribus securzdis, corollis basi hyalino-fenestratis. Thunb. ix. n. 20. Curt. mag. 6. t. 18 f.

B. floribus lacte rubris.

Habitat in Cap. b. spei. 2 


\section{TRIANDRIA. MOÑOGYNIA.}

Folia circiter quinque, digilalia vel palmaria, subfalcata, nervoso-striata. Scapus foliis dimidio vel duplo altior, interdum semipedalis, simplex vel ramosus, subcompressus, superre flexuosis, laevis. Flores duo-septem, secundil vel distichi, 'distantes; speciosi. Spathae oblongo-subrotundae, membranaceae, griseae, purpureo-striatae et punctatae, apice coloratiores. Jacqu. coll. 3 .

tricolos. 52. IXIA foliis ensiformibus erectis, scapo flexuoso subtrifloro, spathis fusco maculatis tenuissime sulcato-plicatis. Curt. mag. t. $38 \mathrm{I} . \dagger$

Habitat in Cap. b. spei, 4

Scapus pedalis, plerumque simplex, flexuosus, bitriflorus. Corolla magna: laciniae subcuneatae, basi flavae, media macula fusco-purpurascente sursum et deorsum emittens lineam ejusdem coloris, extus croceae. Cuit. l. c.

deusta. 53. IXIA foliis ensiformibus, tubo spathis breviore, laciniis exterioribus extus gibbis intus basi carinatis.

Ixia crocata; scapo simplici brevi paucifloro et macula atra supra fenestratam. Thunb. $i x$. n. 15, var. $a$.

a. laciniis limbi exterioribus inferne macula atro-purpurea, interioribus immaculatis.

Ixia deusta; foliis lanceolatis nervosis; floribus alternis sessilibus, tubo bracteis breviore, laminis obtusis; exterioribus basi maculatis carinatisque. Hort. kew. I. p. 60.

f. corollis fauce lineatis.

Ixia miniata; foliis ensiformibus, scapo polystachyo, corollis fauce lineatis nec hyalinis. Iucqu. hort. scicoenbr. r. p. 10. t. i 4 .

$\gamma$. laciniis quinque macula lineari flava, infima immaculata. Zucc. hort. flor. 32.

d. laciniis tribus exterioribus macula Kermesina. Zuccc. hort. flor. 32.

8. laciniis tribus exterioribus maculis ohcordatis kermesinis merlio linea flava saepe bifurcata et intcrupta, duo linea flava kermesino marginata, sexta immaculata. Zucc. hort. flor. 32 . 
2. rubella, laciniis fundo subhyalinis sexmaculatis; maculis tribus cordatis totidemque alternis flavis. Zucc. hort. flor. 32.

Habitat in Cap. b. spei. 4

Folia palnuria vel spithamaea, acuta. Scapus simplex, foliis interdum vix altior. Spathae wix seminnguiculares, secundae, circiter sex, ablongae, exterior concava, carinata, basi herbacea, viridis, superne membranacea, flore explicato fissa. Corolla plerumque fulva: tisbus angustus: Limbi laciniae ovatae, leviter emarginatae; tribus exterioribus versus basin linea elevata, brevis. के

54. IXIA foliis scapoque simplici ramoso-filifor- radians. mibus, floribus solitariis.

Ixia radians; foliis filiformibus scapo erecto unifloro, corolla bicolori. Thunb. in $W e b$ a et Molvr, arch. r. P. I, p. 23 .

Habitat in Cap. b. snei arenosis. 24

Folia bisulca, scapo breviora: vaginae inflatae. Scapus flexuoso-erectus, palmaris usque spithamaeus, simplex et ramosus. Flos grandis. Corollae limbus apice coeruleus, medio arcu albido, basi purpureus cum macula satziratiore. Spathae longitudine tubi. Thunb. l. c.

55. IXIA foliis ensiformibus, floribus secundis, la- hyalina. ciniis corollae obovatis inferne margine hyalinis. $t$

Ixia hyalina; floribus fulvis, petalis latere hyalinis in medio baseos linea flava. Lin. suppl. 91.

Ixia fenestrata; foliis ensiformibus; floribus secundis; corollae laciniis ad utramque oram a basi ad medietatem usque hyalino-fenestratae. Jacqu. collect. 3. p. 270 . Ic. rar. 2. t. 289 .

Habitat in Cap. b. spei. 24

Caulis sesquipedalis, simplicissimus, interdum ramo auctus, inferne erectus, supra folia horizontaliter reflexus. Folia semipedalia, disticha, erectiuscula, acuta, summa breviora. Flores circiter septem, distantes, bipollicares, saturate miniati. Spathae margine scariosac. Corollae tubus pallidus, macula linearis flava ad basin laciniarum. Germen ovatum, triquetrum, Jacqu. et Lin. l. $c$. 
purpurea. 56. IXIA foliis ensiformibus subfalcatis nervosis. Ixia crocata varietas. Thunb. diss. n. 20. var. c. Ixia purpurea; foliis lineari-ensiformibus brevibus nervosis, caule simplici superne nudo. Lamarck. dict. bot. 3. p. 34 I. illustr. I. p. 112. Habitat in Cap. b. spei. Ex herbario Lamarckï. 24 $V$ alde affinis Ix. crocatae. Folia radicalia plur a, sesquipollicaria, semiunguem lata, acuta. Scapus semipedalis et ultra. Flores circiter sex, distantes. Spathae semiunguiculares, membranaceae, nervosce, superne purpureo-punctatae: valvula exterior apice trifida; interior bifida. Corolla magnitudine fere Ix. crocatae, laciniae nec basi nec margine hyalinae.

\section{Dubiae.}

triticea. IXIA foliis vaginantihus subulatis, spathis imbricatis triticeis, floribus approximatis. Burnso prodr. I. +

Habitat in Cap. b. spei. 4

Habitu et colore ferrugineo ut Ixia africana. Sca. pus bipedalis. Spathre duodecim. Flores tubulosi. Burm. l. c.

Forte eadem cum Antholyza lucidor.

piguaea. IXIA foliis ovalihus planis nervosis, petiolis 'vaginantibus, spatha bivalvi pyramidata. Burm. prodr. r. +

B. Plukn. phyt. t. $424, f .8$.

Habitat in Cap. b. spei. 4

Folia sex, alterna, gleberrima, oblongo-ovalia,

nervis quinque ad petiolum contractis. Petioli membranacei, vaginantes, glabri, margine pilis albicantibus. Scapus palmaris, simplex, triflorus. Corolla maxima, lutea, zinguibus purpurascentibns. Burm. $l . c^{\circ}$

Potius Gladioli species.

kbuloss. IXIA spathis appressis lanceolatis, tubis florum filiformibus. Burm. prodr. I. $\dagger$

Habitat in Cap. b. spei. 24

Binae in hac specie varietates, altera foliis instar junci, floribus albidis tenerioribus; altera fo- 
liis latioribus, petiolis foliorum longitudine contractis, floribus rufescentibus maculis rubris. Flores distichi, post evolutionem secundi. Burm. l. $c$.

Forte a. Gladiolo tubato non diversa.

IXIA foliis ensiformibus, spica simplici secun, spicatz.

da. Burm. prodr. I. $\dagger$

Habitat in Cap. b. spei. 24

Spicae nudae. Flores parvi, septem. Spathae. breves, bivalves, muticae; valvulis ovatis, nervosis. Corollae tubus spatha duplo longior: Limbus irregulariter divisus, violaceus. Burm. l. $c$.

Verosimile species Gladioli.

IXIA foliis ensiformibus planis, floribus tubu- caryophyllalosis. Burm, prodr. I. + Habitat in Cap. b. spei. 4

Caulis brevissimus, foliosus, declinatus. Flores albescentes, maculis flavis. Burm. l. c.

IXIA scapo foliaceo, foliis planis inflexis acu- arcuata.

minatis, floribus tubulosis. Burm. prodr.2. i

Habitat in Cap. b. spei. 4

Singularis foliorum inferiorum decursus, quae sesquipalmaria longitudine scapi sic inflectuntur, ut apicibus summos flơ⿱⺈ saepius attingant, quorum corolla tubulosa, purpurascens, calycibus magnis tubulosis. Burm. l. c.

Habitus. Bulbi solitarii vel plures, alter supra. alterum. Folia radicalia disticha, margine vaginantia, acuta, tenuiter striata. Scapus erectus, simplex vel in pedunculos divisus, plerumque teres. Pachis flexuosa. Flores in plurimis sessiles, alterni. Spathae uniflorae.

98. Gladrolus. Cor. 6-fida, laciniis limbi inaequalibus, tubo subcurvato. Stam. adscendentia.

*. Scapo monostáchiygri:

s. GLADIOLUS corollae ringentis tubo spathis montanus. obtusis aequali, laciniis spathulatis, foliis ensiformibus nervosis. 
Gladiolus parviflorus; foliis lineari-ensiformibus; caule simplicissimo; floribus spicatis. Jacqu. obs. 4. p. 2. t. 78 .

Gladiolus montanus; foliis ensiformibus nervosis glabris, floribus spicatis, corolla ringeute. Lin. suppl. 95.

Gladiolus montanus; corollae ringentis tubo spathae obtusae aequali, foliis ellipticis nervosis. Thunb. Glad. n. I. $t$. I.

Habitat in planitie montis tabularis Cap. b. spei. 4 Folia radicalia, subpedalia, vix semiunguem lata vel angustiora, inferne sensim attenuata, trinervia. Scapus foliis parum longior, subflexuosius. Flores distantes. Spathae oblongae, obtusissimab, purpurascentes. Corolla unguicularis et parum ultra, tubo spathis brevior: lacinia superior fornicata, canaliculata, macula purpurea; laterales patentes, divaricatae; inferiores tres aequales, purpureae.

spicatus. 2. GLADIOLUS spica imbricata disticha, scapo glabro, foliis linearibus. +

Gladiolus caule simplissimo, foliis linearibus, floribus spicatis. Royen. lugdb. I 9 .

Gladiolus spicatus; foliis linearibus, caule simplicissimo, floribus spicatis. Syst. ves. 57.

Ixia alopecuroidea; caule simplici, foliis linearibus, floribus imbricatis. Lin. suppl. 92.

Gladiolus spicatus; corollis erectis, spica imbricata disticha, foliis linearibus. Thunb. Glad. n. $\times 3$.

Habitat in Cap. b. spei. 4

Scapus spithamaeus. Folia quatuor, longe vaginantia, inferiora sensim breviora, angustissima, glabra. Flores circiter duodecim parium, coerulei, in spica pollicari. Thunb. l. $c$.

Differt a Gl. alopecuroide: floribus majoribus, spica breviori, scapo simplici. Thunb. l. c.

+ fiśtulosıs. 3. GLADIOLUS spica imbricata disticha, foliis teretibus fistulosis. Jacqu. hort. schoenb. r. p. 8.

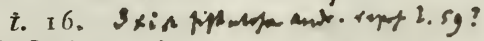

Gladiolus tubulosus, foliis cylindraceis nervosis glaberrimis, florum spica disticha. Burm. prodr. 2.

Habitat ad Cap. b. spei. Ex herbario Burmanni. 4 
Folia crassitie pennae cygneae et ultra, bi-tripollicaria, basi fissa, intus cava, nervosa, apice fusca, obtusa, mucronate: vaginae integrae, arctae. Scapus vaginis foliorum tectus. Spica palmaris et ultra, pyramidata, apice ante expïicationein flortum teretiuscuia. Flores copiosi, conferti, parvi. Spathae ovaiae, compressae, denticulatae, dorso fuscae, latere membranaceo-kyalinae, mucronatae. Corolla spatha parum longior.

Spica exacte G1. alopecuroidis, at tam ab illo quam $a b$ omnibus reliquis distinctissimus foliis fistulosis, adultiorum apex modo opercueli deciduo.

4. GLADIOLUS spica imbricata secunda, scapo inbricatus. glabro, foliis ensiformibus. $†$

Gladiolus imhricatus; foliis ensiformibus, floribus imbricatis. Lin. spec. pl. j.. Georg. iter. .. p. $19^{\text {h. }}$

Hubitat in Russia citeriore. 4

Flores parvi, versus unum latus imbricati. Lin l.c. An species Antholyzae? Thunberg.

5. Gladiolus spica imbricata, scapo villoso.

Gladiolus spicatus; caule simplici villoso, floriparviforts. bus imbricato - spicatis. Lamarck. illustr. ז. $p$. I 20.

Habitat in Cap. b. spei. Ex. herbario Lamarkii. Differt a Gl. spicato Lin. caule villoso: spica undique imbricata: floribus minoribus.

6. GLADIOLUS corollae ringentis tubo filiformi flexuosus. spathis longiore, laciniis acutis, scapo flexuoso, foliis linearibus.

Gladiolus flexuosus; foliis linearibus, caule simplici flexuoso, floribus spicatis ringentibus, tubo longo. Lin. suppl. $9^{6}$.

Glarliolus flexuosus; corollae ringentis tubo spatha acuta longiore, scapo flexuoso. Thunb. glad. n. 2. $t$. 1.

Habitat in Cap. b. spei. 4

Scapus pedalis, versus bulbum valde attenuatus. Folia duo vel tria, brevia, canaliculata, vagginantia. Spica triflora, ovata. Flores primum approximati, demum remotiores. Spathae lanceolato-oblongae, attenuatae, fusco- 


\section{So TRIANDRIA. MONOGYNIA.}

ferrugineae, tubo corollae parum breviores. Corollae laciniae lanceolatac.

Differt ab insequente: scapo rigidiore; foliis angustioribus: spathis brevioribus, ferrugineis.

exscapus. 7. GLADIOIUS corollae ringentis tubo filiformi, spathis laciniis lanceolatis obtusis, scapo flexuoso, foliis lineari-ensiformibus.

Gladiolus exscapus; foliis ensiformibus trinerviis, tubo corollae filiformi spathis longiori. Thunb. prodr. 184. Act. soc. h. n. hafir. vol. 6. cum icone.

Habitat in Cap. h. spei. 4

Scapus spithamaeus, usque pedalis, basi arcuatim adscendens, dein flexuosus. Folia duo radicalia, scapo breviora, duo caulina, margine et costa flavescentia. Flores duo-sex, erecti, albi. Spathae bi-tripollicares et ultra, lineari-lanceolatae, acutiores vel obtusiores, convolutae, subtilissime striatae. Corollae tubus tri-quinquepollicaris, erectus, filiformis.

Dignoscitur a reliquis mihi notis Inngitudine spatharum et tubi, a praecedente differt foliis longioribus: spathis viridibus, nec fuscis.

brevifolius. 8. GI,ADIOLUS corollae ringentis tubo spathis ovato-lanceolatis aequali, laciniis lanceolatis, scapo aphyllo.

Gladiolus tristis. 'Thamb. glad. n. 8. $i$ et $k$.

Gladiolus brevifolius; corolla subringente; foliis ultra vaginas omnium brevissimis; spica secunda erecta. Jacqu. collect. 4. p. I56. liIc. rar. 2. t. 249.

Gladiolus brevifolius; monostachyus, aphyllus, corolla curva incarnata, spathis cuspidatis laevibus longitudine tubi. Thunb. prodr. 185 . Act. soc. h. n. hafn. vol. 6.

Habitat in Cap. b. spei. 4

Folia nulia sub florescentia, eorum loco vaginae duae-quatuor, inferiores breviores, superiores longiores, scapum arcte vestientes, suprema in folium unguiculare, attenuatum desinens, striatae, ore oblique truncatae, apice fuscae. Scapus pedalis, bipedalis, apice cernuus et flexuosus. Spica palmaris, tri-decemflora. Flo- 
res plerumque secundi, inierdum distichi, incarnati, cernui. Spathae bivalves, unguiculares vel parum ultra, subaequales, ovato-lanceolatae, attenuatae, longitudine tubi. Corollae tubus curvatus: Limbi laciniae inferiores angustiores.

9. GLADIOLUS corollae ringentis tubo longitu- elongatus. dine spathae laevi, laciniis lanceolatis obtusiusculis. +

Gladiolus tristis; corollis parvis, viriscenti-albidis, plurimis. Thunb. glad. n. 8. e.

Gladiolus tistis. Jacqu. collect. 4. p. 158. Ic. rar. 2. tab. 244 .

Gladiolus elongatus; foliis quatuor linearibus bisulcis, corolla viresconte, spathis laevibus longitudine tubi. Thunb. prodir. 185. Act. sos. h. n. havn. vol. 6.

Habitat in Cap. b. spei. 4

Folia radicalia quatuor, scopum aequantia, superne bisulca, inferne sex-sulca; duo spathaeformia, subpollicaria, supra medium scapi, lancea, acuminata. Scapus bipedalis vel paulo ultra, superne flexuosus. Flores septem vel octo, erecti. Spathae tubo corollae vix longiores, lanceolatae. Corolla semipollicaris, virescens. Thunb. l. c.

10. GLADIOLUS corollae ringentis tubo spathis tenellus, striatis aequante, laciniis lanceolatis obtusis, folio radicali sulitario. $\leftarrow$

Gladiolus tristis, humilis et luteus. Thunb. glad. n. ९. f. $h$.

Gladiolus tenellus; corolla subringente; foliis linearibus, convolutis, glabris; caule flexuoso, bifloro. Jacqu. collect. 3. p. 255. Ic. rar. 2. t. 248. Schneev. ic. t. 40.

Gladiolus tenellus; monostachyus folio lineari bisulco longiori, corolla curva lutea, spathis striatis tubum aequantibus. Thunb. prod. 185. Act. soc. h. n. hafn. vol. 6.

B. Jacqu. collect. 4. p. i60.t. 3.f. г.

Habitat in Cap. b. spei. 4

Folium radicale unicum, longitudine scapi, diso caulina, sensim breviora: omnia erectiuscula, linearia, acuta. Scapus semipedalis, biflorus, subflexuosus, ad folia geniculatus, supra foTom. II. 
lium summum declinatus, gracilis, debilis. Flos sesuncialis. Spatha bivalvis; valvulis swbarqualibus, lineari-lanceolatis erectis, concavis. Corolla ochroleuca, subringens, linea longitudinali sordide violacea: Limbi laciniae duae patulae, ad faucem punctatae. Jacqu. l. c.

B. Scapus semipedalis. Folia longitudine scrpi, infima brevia, sequentia lanceolato-linearia, striatula. Spatha flore dimidio brevior. Corolla laciniae lanceolatae, saturate luteae. Jacqu. 1. $c$.

gracilis. Ir. GLADIOLUS corollae subringentis tabo spatham aequante, laciniis lanceolatis.

Gladiolus tristis, punctatus. Thunb. glad. n. $8 . g$. Gladiolus gracilis; corolla subringente; foliis linearihus, glabris; caule superne geniculato, foliis alternis vestito, subbifloro, foliis altiore. Jacqu. collect. 4. p. I59. Ic. rar. 2. t. 246.

Gladiolus gracilis; monostachyus, foliis linearibus multistriatis, corolla ovata coerulea, spathis longitudine tubi. Thunb. prodr. 185. Act. soc. h. n. hafn. vol. 6.

Habitat ad Cap. b. spei. 4

Scanus pecialis vel bipedalis, inferne foliosus, gracilis, debilis, superne geniculatus. Folia longe vaginantia, supra vaginam brevia, canaliculata, striata. Flores pleruntque duo, raro unicus, biunciales, parum cernui. Spatha bivalvis; valvulis longitudine faucis corollae, lanceolatis, acutis, concavis. Corollae tubus cylindricus, albus; faux incurva: Limbus infundibutiformis, pallide violaceus; laciniae acutae, tria superiora duplo latiora, linea saturatiore in dorso; duae inferiores striis punctisque variegatis; intermedia linea unica picta. Jacqu. i. $c$.

An Gladiolus punctatus; foliis linearibus, spathis acutis, petalis punctatis inferioribus longioribus et acutioribus. Lamarck. illustr. I. p. I I7. huc pertinet?

- carinatus. 52. GLADIOLUS corollae subringentis tubo spathis limboque breviore, stigmatibus indivisis complicatis, foliis utrinque carinatis. 
Gladiolus carinatus; foliis linearibus utrinque carinatis glabris, tubo spathis limbisque breviore, stigmatibus indivisis complicatis. Hort. kew. : p. 64.

Gladiolus punctatus; corolla ringente ; foliis linearibus; scapo subquinquefloro; floribus erectis, distantibus; folio infimo vaginanti punctato. Jacqu. collect. 4. p. 160. Ic. rar. 2. t. $247^{\circ}$ Gladiolıs ringens; foliis linearibus, costatis; floribus ringentibus, odoratissimis. Andr. re* pos. $t$. 27 .

Habitat ad Cap. b. spei. 24

Scapus sesquipedalis, superne foliosus. Folia infima spathacea, scapum vaginantia; superiora scapo altiora, uti vaginae striata, angusta. Flores subquini, birinciales. Spatha bivalvis: valvulis lanceolatis, subaequalibus, virentibus. Corollae tubus semipollicaris, cylindricus: Limbi laciniae tres superiores obovato-oblongae; inferiores lanceoiatae, patentissimae.

Corollae tubus albidus: limbi laciniae superiores pallide violaceae; intermedia inferiorum longitudine superiorum, infra medium flavicans; laterales breviores, medio flavae. Hort. kew. $l$. $c$.

Folium in bulbo non florente sesquipedale, lineare, angustissimum. Vagina infima punctis badiis variegata. Jacqu. $l$. $c$.

13. GLADIOLUS corollis secundis cermuis, spa-laevis. this tubo longioribus, foliis bisulcis. +

Gladiolus tristis inodorus. Thunb. glad. n. \&. d.

Gladiolus laevis; folio lineari bisulco longiori, corolla curva lutescente, spathis laevibus tubo longioribus. Thunb. prodr. 184. Act. soc. h. n. havn. vol. 6 .

Habitat in Cap. b. spei. 4

Folia radicalia duo, infimum scapo longius, alterum brevius, apice attenuata, niticla; unicum in scapo supra medium, apice valde attenuatum. Scapus pedalis, simplex, apice flexuosus. Flores bini-tres, secundi, lutescenti-albidi. Spathae bivalves: valvulae inaequales; exterior corollam fere aequans, interior longitu. dine fere tubi, convolutae, obverse lanceolatae, 
nervosae. Corollae carina extus stria duplici purpurea: Limbi laciniis intus purpureo striatis. Thunb. $l$. $c$.

+ tristis. 14. GLADIOIUS corollae subringentis tubo spathis longiore, laciniis ovato-lanceolatis planis, foliis linearibus bisulcatis.

unicolor. \%. Gladiolus foliis sulcatis linearibus, floribus alternis, petalis acuioribus. Mill. ic. 15?. $t$. $235 . f$. 1 .

Gladiolus tristis; foliis lineari-cruciatis, corollis campanulatis. Lin. spec. pl. 53. Jacqu collect. - . p. 15 ? Ic. rar. 2. t. 243 . Redouté pl. liliac. $t .35$.

versicolor. क. Gladiolus, floribus e spadiceo et flavo variegatis, suprema lacinia brevissima. Breyn. ic. rar. 20. $t .7 \cdot f$..

Gladiolus bifolius et biflorus, foliis quadrangulis. Trew. Ehret. t. 39.

Gladiolus tristis. Jacqu, suppl. 20. ic. rar. t. 245. Gladiolus tristis. Curt. mag. \&. t. 272 .

Habitat in Cap. b. spei. 4

Folia longe vaginantia, zonicum scapo altius, subulutum, tortum, angulis quatuor exstanfibus planis cruciaia, reliqua breviora: vaginae striatae. Scapus superne flexuosus. Flos interdum unicus, saepe plures, parum-nutuns, odoratissimus. Spatha trivalvis: valvulae lanceolatae, concavue, margine tenui membranaceo; exterior longitudine fere tubi. Corollae laciniae lanceolatae, suprema latior erecta, reliquae angustiores, parum reflexae.

In multiflora folia rite ensiformia evadunt. Lin. l. c.

albidus. 15. GLADIOLUS corollae subringentis laciniae lanceolatae, tribus superioribus undulatis, tribus inferioribus apice conniventibus bimaculatis. +

Gladiolus albidus; corolla subringente; laciniis acutis, tribus superioribus unâulatis, tribus inferioribus apice conniventibus; foliis ensiformibus, subobliquis. Jacqu. suppl. $2 \mathrm{I}$. Ic. rar. 2. $t .256$.

Habitat ad Cap. b. spei. 4.

Bulbus subrotundus, magnitudine avellanae. Scapus vix pedalis, crassitie pennae columbinae, 
flexunsus. Folia plura, infimum semipedale, superiora sensim breviora, crecta, firma, striatula. Flores tres.quatuor, inodori, triunciales. Spatha bivalvis, sesuncialis: valvulae lanceolatae, acuminatae, convolutae; interior brevior. Corolla alba; tubus longitudine fere spathae, subcylindricus, incurvus: Limbi laciniae acutae; superiores duplo longiores, inferiores apice purpurascentes, supra medium maculae duae roseae. Jacqu. l. c.

16. GLADIOLUS corollis subringentibus secundis cuspidatus. cernuis, laciniis-lanceolatis undulatis cuspidatis, tribus inferioribus macula ocellata.

Gladiolus cuspidatus; corolla subringente; laciniis lanceolato - cuspidatis, undulatis; foliis lineari-ensiformibus, glabris; floribus secundis, cernuis. Jacqu, suppl, 17. Ic. rar. $t, 257$. Redouté liliac. t. $3^{\text {th. }}$

Habitat ad Cap. b. spei. $2 t$

Bulbus subrotundis, avellana multo major. Scapus sesquipe'alis, crassitie pennae columbinae, flexuosus. Folia striatula; radicalia tria, longitudine fere scapi, longe vaginantia, duo caulina brevia. Plores secundi, plerumque qualuor, distantes, quadriunciales, patuli. Spatha bivalvis, biuncialis et ultra, convoluta; exterior integerrima, interior brevior, bidentata. Corollae tubus sensim ampliatus, incurvulus, extıs sordidissime pallens: Limbi lacinice cuspidatae, magis vel minus undulatae, saepe obliquar, patentissimae; tres superiores duplo latiores, parum longiores, utrinque sordidissime et pallide carneae, in medio dorsi purpurascentes; inferiorcs stramineae, basi macula purpurso-rubra ocellata. Jacqu. l. c.

77. GLADIOLIS corollae cernuae tuba spathis trimaculatus. longiore, laciniis tribus inferioribus macula cordata purpurea.

Gladiolus trimaculatus; foliis lineari-lanceolatis, tubo curvo limho vix longiore, petalls trihus macula cordiformi inscriptis, Lamarck. dict. bot. 2. p. 727 . illustr. I. p. $116 . t .32 .0^{\circ} f$. 3. 
Glaciolus cordatus; monostachyus, foliis ensiformibus rervosis, corolla curra incarnata: macula cordata, spathis laevibus tubo brevioribus. Tiluinb. prodr. 18 . Act. soc. h. n. haf. vol. 6.

Habitat in Cap. b. spei. 2

Folia plura, zesque ad quaiuor, infimum scapo longius, reliqua sensim breviora, apice atienuata, marginata costic tribus, quarum media major, flavescentibus. Scapus pedatis, apice flexuosus. Flores duo-quinque, bipollicares, campanulati, cernui. Spathae subpollicares, obiongae, acutae, nervosae, tubo paulo breviores. Corolla albido-incarnata; tubus sesquipollicaris, curvatus: Limbi laciniae infimae tres macula cordata purpurea. Thunb. $l$. c.

hastatus. 38. GLADIOLUS corollae campanulatae tubo spathis breviore, laciniis ovatis obtusis tribus inferioribus macula hastata. +

Gladiolus tristis hastatus, corollis albo-incarnatis macula hastata. Thunb. glad. n. S. o.

Gladiolus angustus. Jacqu. collect. 4. p. I54. Ic. rar. 2. t. 252 .

Gladiolus hastatus; monostachyus, foliis linearibisulcis, corolla campanulata: macula hastata, spathis laevibus tubo longioribus. Thunb. prodr. 185. Act. soc. hist. n. hafin. vol. 6.

Fabitat in Cap. b. spei. 4

Folia radicalia duo, scapo paulo breviora, basi latiora, striis pluribus, apice linearia bisulca; scapi versus apicem simile, bipollicare. Scapus pedalis, apice flexuosus. Flores circiter \&res. Spathae convolutae, longitudine dimidia corollae, ovatae, obtusae, nervosae. Corolla albo-incarnata: Limbi laciniae inferiores macula hastata. Thunb. $l$. c.

reeurvus. 19. GLADIOLUS corollae laciniae lanceolatae planae recurvatae. +

Gladiolus foliis linearibus sulcatis, floribus uno versus dispositis, tubo floris longiore. Mill. ic. $157 \cdot t .235 \cdot f$. 2 .

Gladiolus recurvus; foliis ensiformibus, petalis subaequalibus lanceolatis recurvatis, Lin. mant. 28 . 
Habitat in Cap. b. spei. 24

Differt a Gl. undulato petalis non unctulatis minus. gue acuminatis: tubo corollae non filiformi, laxo aut perdulo; cocterum valde affinis. Lin. i. $c$.

An Gladiolus recurvus Thunbergii idem ac Linnaei? secundum Thunbergium nimis affinis est Gl. falcato, secundum Linné vero affinis Gl. undulato, qui multum distat a falcațo.

9. GLADIOLUS corollis campanulatis, bracteịs grandis. limbum aequantibus, laciniis ovatis. $\dot{T}$

Gladiolus tristis, grandis. Thumb. glad. n. 8. c.

Gladiolus versicolor; foliis lineari cruciatis; floribus maximis, versicoloribus. Andr. repos. t. 192 .

- Gladiolus grandis; folio ensiformi-attenuato multistriaio, corolla curva purpureo-striata, tubo simplici ampliato. Thunb. prodr. $185^{\circ}$ Act. soc. h. n. havn. v. 6 .

Habitat in Cap, b. spei. 4

Folium radicale unicum, longitudine scapi, apico valde attenututum, erectum, multinervosum; scapi sub, floribus brasiciformia, corollam sub. aequantia, circiter duo, cluversa, convoluta, ensiformia. Scapus pecdalis vel ultra, flexuosus. Florẹs biní, cernui, magni Spatha intra brasteam, similis, sed brevior. Corollae tubus curvatus, sensim ampliatus in Limbum campanulatum, albido-fiavescentem: Limbi laciniae tres superiores intus linea duplici purpurea, extus purpureo-intiltistriatae; inferiores inius sulco medio flavescente, apice purputa. scente. Thunb. $l$. c.

Glad. versicolor Andr. videtur esse varieiatem hujus.

2. GLADIOLUS corollạe inflato-campanulatae infatms. tubo spathis ovatis nervosis aequante, foliis bisulcis. †

Gladiolus tristis violaceus. Thunb. glad. $n$. 8. $n$,

Gladiolus inflatus; folio ineari bisulco, corolla campanulata violacea; spathis ovatis nervosis tubum aequantibus. Thunb. prodr. 13 3 . $A c \hat{t}_{\text {s }}$ soc. i. n. havia. vol. 6.

Habitat in Gap. b. spei. 24 
Folia radicalia duo, infimum scapo longius, alterum brevius, basi latiora, parum attenuata, apice linearia, multistriata; scapi sesquipollicare. Flores bini-quatuor, sesquipollicares, subsecundi, curvi, inflato-campanulati, incarnati vel purpurei : tubus brevis. Spathae valde latae, convolutae, acutae. Thunb. l. c.

hyalinus. 22. GLADIOLUS corollae subringentis laciniae lanceolatae, foliis vaginisque glabris. $f$

Gladiolus strictus. Jacqu. collect. 4. p. r 70.

Gladiolus hyalinus; corolla subringente; foliis caulinis alternis, ensiformi-linearibus, glabris, caule multo-brevioribus; caule et floribus erectis. Jacqu. ic. rar. 2. t. 242.

Habitat in Cap. b. spei. 4

- Scapus pedalis, debilis. Folia tria, infimum radicale, stricta, subtrinervia. Flores circiter tres. Spathae lineari-lanceolatae, obtusiusculae, virides : valvula exterior semuncialis; interior brevior, apice bifida. Corolla biunciaTis: tubus cylindricus, uncialis, coerulescens, pallida cum maculis sordide purpurascentìbus: Limbi laciniae acutae, sulpellucidae; stuprema triplo latiore, albida, superne flavescente cum striis punctisque purpurascentibus; reliquae concolores et sordide flavescentes, cum linea perpendiculari media, striis punctisque purpureis. Jacqu. l. $c$.

hirsutus, 23. GLADIOLUS corollae subringentis laciniae obovatae subundulatae, foliis ensiformibus villosulis, vaginis pilosis. $f$

Gladiolus hirsutus; corolla campanulata; foliis ensiformibus, villosulis; vaginis pilosis; caule bifloro spathisque glabris. Jacqu. collect. 4. $p$. 161. Ic. rar. 2. t. $=50$.

Gladiolus roseus; foliis lanceolatis, tortis, rubro-marginatis, pubescentibus; floribus roseis odoratissimis. Andr. repos t. Ii.

Halitat ad Cap. b. spei. 4

Scapus sesquipedalis, debilis, superne flexuosus, glaber, vaginis foliorum tectus; inferne vagina sine folio, glabra. Folia disticha, triun- 
cialia, ensiformia, striatula, ad lentem hir. sutula, margine sacpe purpurascentia, rigidula: vaginae longae, striatae. Flores duo, alterni, odoratissimi. Spaiha livalvis, longitudine tubi corollae, lanceolata, acuminata, giabra, viridis. Corollae tubus virili-fiavens; faux purpurascens: Limbus campanzilatus, roseus; laciniis acutis, tribus superiorious âplo latioribus, summa immacillata, rcliquae linea media utrinque saturatiori. Stigmatis laciniae spathulatae. Jacqu. l. c.

24. GLADIOLUS corollis ringentibus secundis, la- striatus. ciniis alternis crispis, foliis lanceolato-ensiformibus undulatis ciliatis. +

Gladiolus striatus; corolia divaricata, ringente; laciniis tribus alternis crispis; foliis lanceo. lato-ensiformibus, crispis, glabris, ciliatis. Jacqu. suppl. 28. Ic. rar, 2. t. 260.

Habitat in Cap. b. spei. 2

Bulbus subrotundus, avellanae magnitudine. Scapus foliosus, pedalis, inferne aphyllus, atroviolaceus. Folia semipedalia vel minora, g'auca. Spica subsexjlora, interdum horizonalis. Corolla sesquipollicaris. Spatha dipltylla, superne scariosa, germine duplo longior: valvulae subovatae; exterior acuminata; interior bifida. Corollae tubus angustus, spatha duplo longior, pallide et sordide virens: Limbus profunde fissus; laciniis tribus acutiusculis flavescentibus, tribus mucronatis, pallide violaceis cum fascia longitudinali media rubra, plana. Jacqu. l. $c$.

25. GLADIOLUS corollae ringentis laciniae tres galeatus. inferiores subspathulatae, foliis ensiformibus obtusis.

Sisyrinchium viperatum. Plukn. alm. 34 s. t. 224 . $f$. .

Gladiolus flore singulari miniato, inferioribus laciniis luteo-viridibus. Ereyn. ic. rar. 25. $t$. 12. f. 2. Seb. thes. .. t. . . f. 3 .

Gladiolus alatus; foliis ensiforrnibus, petalis lateralibus latissimis. Lin. amoen. ac. 6. p. 83.

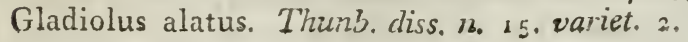


Gladiolus: galeatus; corolla divaricate ringente. lacinia summa erecta; foliis ensiformibus, glabris. Jacqu. coll. 4 p. 167. Ic. rar. 2. i. 258.

Fabitat in Cap. b. spei. 4

Scapus semipedalis, flexuostis. Folia radicalia plura, caule breviora. Flores plures, distantes, parum nutantes, inodori. Spathae scariosae, bivaives, longitudine faucis corollae: valvulae acuminatac, ut plurinum bifidae. Corolla ex violaceo sordide pallens: Limbi lacinia superior magis violacea, saepe ad latera flavens; tres inferiores interne circa medium aut ex integro aut tantum ad latus extimum saiurate fuiventes. Jacqu. l. c.

+ commis. 26. GLADIOLUS corollis subringentibus, laniniis spathulatis; spathis tubolongicribus, foliis ensifarmibus nervosis.

Xiphion, spatha seu gladiolus segetalis. Ruell. de nat. stirp. $78 \mathrm{I}$.

Gladiolus Dod. pempt. 20c. Riv. monop.

Gladiolus narbonensis flore incarnato et flore purpureo. Besl. hort. eyst. aest. ord. 4. fol. ro.

Gladiolus communis, foliis exsiformibus distantibus. Lin. syst. veg. 87. Roth. fl. germ. =. P. I. p. 44 .

6. Gladiolus italicus binis florum ordinibus cine tum. Lob. ic. 99.

Gladiolus utrinque floriferus. Dod. pempt. $=09$.

Gladiolus italicus fiore rubro. Resl. hort. eyst. aest. ord. 4 . fol. 12 ,

Fiabitat in Europa Australi et Africa boreali. 26 Folia scapo multo breviora, pollicem fere lata. Scapus bipedalis; ultra medium foliis vaginatus. Spathae bivalves: valvulae lanconlatar; exterior pollicaris et ultra, tubo longior, attenuata, interior brevior, longitudine tubi.

sarnezs. 27. GLADIOLUS corollis subringentibus distichis cornuis, laciniis oblongis, folïs ensiformibus marginatis.

Gladiolus carneus; caule simplicissimo, petalis superioribus divergentibus, foliis ensiformibus. Ea fioche diss. n. 3. t. 4. 
Gladiolus carneus: corolla subringente; foliis ensiformibus, striatis, glabris; scano flexuuso erecto; floribus cemuis. Jacqu, collect. =. p. 3-c. Ic. rar. 2. $\therefore$. $=55$.

Gladiolus reniricosts; folits ensiformilus zorvosis glubris, limbo ventricuso lifformi, styli lacinits dilatato membranaceis spathulatis. $I a$.

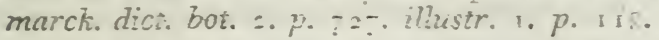

Mabitat al Cap. b. spei Ex herbario Lamarchì et Iioyeni. 21

Scapus perialis, flextosus, quadiri-ostoflorus. Fo. lia radicatia semipectalia, diso vel tria in scapo, erecta, rigidula, acula, striata, nervo crassiore marginata. Flores sessiles, distichi, distantes, incarnati. tripcllicares, vel parum ultra. Spatha bivalvis, exterior saepe bipolizcaris, interioni longior, lanscolata, astenuata, ziridis. Corollae tubus spatins rix longior, curvatzs: Limbi lacinia superior latior. Stigmata extrorsum dilatata.

28. GLADIOLUS corollae campanulatae iubo. bre- squiran. vissimo, laciniis oratis, scapo compresso, foliis ensiformibus multin̨riis marginatis.

Gladiolus equitans; foliis ensiformibus marginatis multinerviis, scapo compresso, corolla campanulata tubo brevissimo. Thutzb. prodr. Act. soc. h. n. hafn. vol. 6. cum figura.

Habitat in Cap. b. spei, $2 /$

Folia circiter quatisor, scapo breviora; infimuns plusqram pollicem Latim, subfalcatum, patens, equitantia, multinervia; nervis et mar gine crasso flavescentious. Scapus pedalis. flexiosis. Ilores piapurci. Spathae corclla longiores, cbiongae, acutae, convolutae, falidae, margine et carina purpurece.

Simitis Glad. alato, sed longe major et simplex, Thunb. l. c.

Dignoscitur a religuis foliis latissimis.

29. GLADIOiUS corollae campanulatae tuho spav iridifoins. this longine, laciniis subcuneiformi-oblon is, scapo tereit, foliis ensiformibus.

Gladiolus pyramidalis; spica pyramidali longissime, basi laxa snbrämosa, flurious amplis 
liliaceis nutantibus, stylis tripartito-bifidis. Lamarck. dict. bot. 2. p. 72k. illusir. r. p. 1.

Gladiolus iridifolius; corollis infundibuliformibus, limbi laciniis aequalibus; foliisensiformibus, distichis, rectis. Jacqu. cullect. $\uparrow$. ${ } .51$. Ic rar. 2. $t .23+$.

ค. Gladiolus maximus promont. b. spei flore rubro incarnato. Suert. flor. t. 66. Jacqu. ic. rar. 2. t. $23 \%$.

Hubitat in Cap. b. spei. Exherbario Lamarchii. 4 Folia radicalia, circiter septem, bipedalia, vel minora, inaequalia, pollicem vix lata, utrinque attenuata. Scapus tripedulis, crussitie permue cygneae, vaginis nonnullis lanceolatis vesilius. laevis. Spica sesquipeialis, muliflora, parum flexuosa, disticha. Spathae bivalves: vaivulae semipollicares, aequales, lanceolatae, attenua. tae, superne flavescentes cum rubedine. Corolla fere tripollicaris, pallide carnea; tichus longitudine spathae, fauce flavescente: Limbi laciniae alternae mucronatae.

Differt ab antecedente: scapo altiore: foliis multo longioribus, angustioribus, nervoso-siriatis: spathis brevibus, multo angustioribus: floribus plutimis.

+ Cardinalis, 30. GLADIOIUS corollis campanulatis secundis, tuho spathis breviore, laciniis lanceolatis, foliis ensiformibus narginatis.

Gladiolus cardinalis; corollae erectae limbo campanulato, floribus secundis, scapo multifloro; foliis ensiformibus multinerviis. Curt. mag. 4 . t. $\$ 3.5$.

Gladiolus cardinalis; foliis ensiformibus, caule multifloro, floribus secundis, corollae laciniis inferioribus macula alba rhomboidea distinstis. Scheev. ic, t. $2 \%$.

Iabitat in Cap. b. spci. 4

Folia unguen vel ulira laia, scapo breviora, patentia, laxa, margine parum incrassata, nervoso-striata; scapi superne, vaginantia, brevia, tri-quadripollicaria. Scapus bi-tripedalis, rore glauco adspersus. Spicae solitariae vel geminae, parum recurvatae, sex-septemflorae. Flores remoti, erecto-patentes. Spatha bivalvis: valvula exterior sesquipollicaris, lan- 
cenlata, attenuata, concava, extus convexa, rore glaucescchie adspersa; interior ab exieriore inclusa, brivior, angrustior, apice bifida. Corollae tubus spatha longior, coccineus: Limbi lacinia superior major et longior quam reliquas, erecta, apice reflexo-patens, oblongoovaia, obiusa; duae laterales, lato-lanceolatae, reflexae, coscineae, uti superior immaculatae; tres inferiores lateralibus angustiores, planio. res, lunceolatae, obtusae, coccineue, a medio ad basin macula albida in lineam albidan - tenuissimam densinens. Filamenta coccinea. Stigmata compresso-clavata, coccinea, albidovillosa.

Planta divcrsissima a Gl. iridifolio.

31. GLADIOLUS corollae infundibuliformis la- roseo-albus. ciniae ellipticae aequales, foliis lineari-ensiformibus.

Gladiolu' rosco-alhus; corollis infundibulifornishus; limhi laciniis aequalibus: fauce tereti ; folis anguste ensiformibus, obliquis; spathae valvula interiori bifida. Jacqu. hort. schoenbr. x. p. -. t. 13 .

Habitat ad Cap. b. spei. 4

Radix tunicata. Folia anguste ensiformia, pedalia. Scapus foliis brevibus vestitus, longitudine foliorum. Flores distichi, circiter seni. Spathae lanceolatae, acuminatae, fuscae: valvula interior bifida. Corollae tubus spatha parum longior: Limbus patentissimus.

32. GLADIOLUS corollis subcampanulatis cernuis, Warsonius. laciniis lanceolatis acutis, spathis acuminatis, foliis lineari-ensiformihus marginatis.

Antholyza revoluta; staminibus adscendentibus, corollis revolutis, foliis lanceolatis nervosis. Burm. prodr. flor. cap.

Gladiolus IVatsonius; corollis cernuis, tubo duplici, limbi laciniis oblongis, foliis linearibus glabris. Thunb. glad. n. io. Curt. magaz. 450 .

Glarliolus Watsonius; corollis infundibuliformibus; limbi laciniis subaequalibus, linearibus, margine revolutis. Jacqu. collect. 2. p. $25 \pi^{\circ}$. IG. rar. 2. t. 233 . 
Gladiolus praecox; foliis ensiformibus, apicibus tortis, lineari-cruciacis; corollis subcampanulatis, rubris; petalis acuminatis. Andr. repos. t. $3 \hat{n}$.

f. corollis majoribus luteo-variegatis. Curt. mag. t. 569 .

Habitat ad latera montium Cap. 7. spei. 2\%.

Folia tria, scapo breviera, longe vaginantia, angustissima, attenuata, trinervia cum nervis marginalious, utrinque bisulcata. Scapus pedalis et uitra. Flores tres-quinque, subsecundi, purpierci. Corollae tubtes sesquipollicaris,, geniculatus, curvatus. Thunb. $i$. c.

$\checkmark$ ariat spathis brevioribus et longioribus convolutis ionge acuminatis.

accatus. 33. GLADIOLUS corollis infundibuliformibus cernuis fauce teretibus, laciniis oblongis obtusis, spathis lanceolatis attenuatis. $t$

Gladiolus laccatus; corollis infundibuliformibus, limbi laciniis aeqnalibus, fauce tereti; foliis anguste ensiformibus obliquis. Jacqu. collect. 4. p. r 7 I. Ic. rar. t. 2. t. 232.

Habitat ad Cap. b. spei. 4

Folia plura, pedalia, angusta, erectiuscula, nervo medio utrinque protulerante. Scapus foliis parzm altior, foliortu vaginis vestitus. Flores circiter gtiatuor, distuntes. Spatha bivalvis: valuulis anguste lanceoiatis, basi virentibus, superne sphaceiaitis et fuscescentibus. Corollae colore laccae florentinae: tubus longitudine fere spathae; faux supra tubum incurvata: Limbus campanulatus; laciniis inmaculatis. Stigmatis laciniae bifidae. Jacqu. l. $c$.

Merianus. 34. GLADIOLUS corollis infundibuliformibus cernuis fauce compressiusculis, spathis oblongis, foliis lineari-ensiformibus vaginis glabris. Meriana flore rubello. Trew. Ehret. t. 40. Antholyza Meriana; corollis infundibuliformibus, foliis ensiformibus. Lin. syst. veg. 88 .

Watsonia Meriana. Mill. dict. ic. t. 276 .

Gladiolus Merianus; corollis cernuis subcylindricis, tubo duplici, limbi laciniis ovatis, 
follis ensiformibus glabris. Thunb.giad. $n . \mathrm{x} \approx$ Pedouté pl. litiac. $t$, I $x$.

Gladiolus Merianus; corollis infundibuliformibus, limbi laciniis aequalibus, fauce compressiuscula; foliis anguste ensiformibus, obJiquis. Jacque. collect. †. p. 150. Ic. rar. 2. t. 230 .

6. Gladioli Meriani varietas. Jacqu. suppl. 17. parvisora. Tc. rar. 2, t. $23 \mathrm{r}$.

Hahitat ad Cap. b. spei. 4

Folia radicalia saepè quatuor, scapo breviora, parum striata, marginata. Scapus sesquipedalis, inferne foliis vaginatus, flexuosus, striatus. Flores quatuor-octo, purpurei, inodori. Spathae bivalves, vix pollicares: valvulis oblongis, acutis, margine ruhentibus; exterior parum longior interioribus, subtilissime striata. Corollae tubus sesquipollicaris, spatha parum longiar, angulatus, geniculo reflexus: Limbi laciniae alternae, mucronatae.

An ß. distincta species? flores angustiores et minores. Alium vidi corollis fere tripollicaribus; laciniis obtusiusculis; spathis brevibus minime acuminatis, obtusitisculis; vaginis superioribus scapi in folium subulatum desinentibus.

35. GLADIOLUS corollis infundibuliformibus cer- Merianellis. nuis secundis, laciniis limbi oblongis, foliis linearibus, vaginis pilosis.

Waisonia humilis; foliis lineari-filiformibus, tubo floris longissimo. Mill. ic. 198. t. 207.

Antholyza Merianella; corollis infundibuliformibus, foliis linearibus. Lin. syst. veg. 89.

Gladiolus Merianellus; corollis cernuis, tubo duplici, limbi laciniis ovatis, foliis ensiformilsus pilosis. Thunb. glad. $n$. I .

Habitat in Cap. b. spei. 4

Eolia scapo breviora, tria-quatuor, angusta, nervoso-striata, longe vaginantia, interdum pilosa, interdum glabra: vaginae sulcatae, semper pilosae. Scapus sesquipedalis, superne flexuosus. Flores tres-quatuor, flavo incarnati. Spathae bivalves, semipollicares, lanceolatae, acutae, striatae. Corollae tubus inferne tenuis, supra spatilas ampliatus. 
aietroides. 36. GLADIOLUS corollis tubulosis refractis, laciniis ovatis erectis, foliis ensiformibus marginatis.

Antholyza aletroides; corollis declinatis monopetalis vix dentatis genitalia includentibus; foliis ensiformibus. Burm. prodr. fl. cap.

Gladiolus tubulosus. Jacqu. collect. 4. p. 15. Ic. rar. 2. t. 220 .

Habitat ad Cap. b. spei. Ex herbario Burmanni et Royeni.

Facie Aloes vel Aletri. Folia radicalia tria-quatuor, sesquipelatia, unguem lata, striata, marfine incrassata. Scapus fere bipedalis, vaginatus. Spica spithamaea, quinque duodecimflora. Spathae alternae, subimbricatae, distichae, trivalves: valvula exterior vix semipollicaris, complicata, obovata, striata, sordide purpurascens; interiores lineari-lanceolatae. Corolla sesquipollicaris, diametro pennae anserinae, saturate coccinea: laciniae breves, aequales. Stigmatis laciniae bifidae.

viridis. 37. GLADIOLUS corollae limbo patenti-reflexo, foliis ensiformibus glabris, scapo triquetro, angulis membranaceis. Hort. kew. 3.p. $48 \mathrm{~s}$ † Habilat in Cap. b. spei. 4

Singularis corollis viridibus, externe striis obsolete purpureis. Hort kew. $l$. c.

crispus. 38. GIADIOLUS corollis infundibuliformibus secundis, laciniis lineari-oblongis, foliis lanceolato-ensiformibus undulato-crispis.

Gladiolus crispus; foliis lanceolatis crenatis undulatis, floribus secundis, spicis duabus, tuho filiformi longo. Lin. suppl. 94 .

Gladiolus crispus; corollae erectae limbo campanulato, floribus secundis, foliis crispis. Thunb. glad. n. . . t. ז.

Gladiolus crispus; corollae tubo gracili longissimo, laciniis rotundatis; foliis ensiformibus striatis, glabris, ad oras crispis et barbatis. Jacqu. collect. suppl. 27. Ic. rar. 2. t. 267.

Habitat ad Cap. b. spei. 4

Scapus spithamaeus, flexuosus, glaber. Folia quatuor-quinque, tripollicaria, striata. Flo- 
res quatuor-quinque. Spathae brevissimae, obtusae, denticulatae, rubrae. Corollae tubus sesquipollicaris, allido-incarnatus.

39. GLADIOLUS corollae erectae limbo campa-biflorus. culato, scapo bifloro, foliis linearibus. Thunb. glad. 2 . 5. +

Habitat ad fretum Magellanicum?

Folia circiter tria, supremo longitudine scapi, infino brevissimo, longe vaginantia. Scapus peclulis, erectus, totus tectus vaginis folioruin. Flores terminales, coloris tristis. Thunb. l. c.

40. GLADIOLUS corollae limbo patenti, folio falcatus. lanceolato falcato. Thunb. glad. n. t. t. т.

Gladiolus falcatus; caule simplici, foliis falcatis, floribus alternis, stylo trifido. Lin. suppl. 96.

Habitat ad Cap. b. spei. 4

Folium unicum vel duo, pollicare, ovato-lanceolatum, obtusiusculum; spathaceum in medio scapi. Scapus palmaris, compressus, flexuosus, striatus. Spathae virides, obtusae, tubo mulio breviores. Corolla coerulea. Thunb. l. c.

4r. GLADIOLUS corollae tubo spathis obtusis subulatus. nervosis longiore, laciniis oblongis subaequalibus, foliis subulatis teretiusculis.

Gladiolus bracteolatus; foliis convolutisfiliform:subulatis, floribus spicatis, bracteis alternis ovalibus multinerviis spathas includentibus. Lamarck. dict. bot. 2. p. 725. illustr. 1. p. 117.

Habitat in Cap. b. spei. Bulore. 24

Scapus seinipedalis, teres, tri-teirayiny-llus, vagirits foliorum tectus. Folia altitudine scapi, sul.filiformia, acrutissima, enervia, subtilissirize striata: vaginae arctae. Spica sesquipoilicaris, distiche subimbricate, circiter duo. decimflora. Spathae vix unguiculares, multinerviae, ferrugineae, margine minime meri:branaceae. Corolla semipollicaris, vivlacea, tubus superne curvatıs, albidus, purpureo, lineatus: laciniae acutae.

An Gladiolus spicatus Lin.? qui vero similis est Glad. alopecuroideo secundum Thunbergium, 
cum quo planta descripta nequidem minimam affinitatem habet.

subens. 42. GLADIOLUS corollae tubo spathis acutis nervosis longiore, laciniis oblongis subaequalibus, foliis linearibus nervosis.

Habitat in Cap. b. spei. 2

Folia scapo fere altiora, angusta, quinquenervia.

Scapus superne, rachis et spatinae fusco-purpurascentes.

Similis antecedenti, diversus: foliis planis nervosis, nec subulatis enervïs: scapo altiore: spathis acutis nec obtusissimis.

rubro - cya- 43. GLADIOLUS villosus corollae limbo patentisned. simo, laciniis oblongis, foliis oblongo-lanceolatis scapo longioribus ensiformibus plicatis. $\div$ Ixia africana foliis palmatis flore coeruleo macula coccinea insignito. Has. cat. p. 68. cum figura.

Ixia rubro-cyanen; foliis oblongo-lanceolazis villosis plicatis distichis, spatia trivalvi, corollae limbo patentissimo. Jacqu. colleet. $3 . p$. 268 . Ic. rar. 2. t. 285 . Curt. mag. t. 4 io.

Ixia villosa. Schneev. ic. I. t. I 6 .

Habitat in Cap. b. spei. 4

Totus, exceptis corollis, villosus. Folia spithamaea vel semipedalia, interdum parum latiora, interdum angustiora, basi attenuata, trinervia. Scapus foliis saepe duplo brevior, superne interdum folio setaceo brevi, quadri-quinquefiorus, apice partem flexuosus. Spathae trivalves: valvulae lineares, acutae; exterior reliquis longior. Corollae tuobus pallicle rubens: Limbi laciniae subaequales, alternae mucronatae, saturate cyaneae, basi rubrae. Jacqn. l. c.

Tanta est hujus affinitas aeque ac Ixiae puniceae, purpureae et villosae Horti Kewensis cum Gladiolo plicato, sambucino et reliquis iis proximis, ut potius varietates ejusdem speciei esse appareant, quam species distincti generis, nam in dictis Gladiolis corollae laciniae non magis inaequales, nec tubus magis curvatus quam in nominatis Ixiis; si itaque hae erunt Ixiae generis, Gladiolus plicatus, uti et reliqui illuc transfe. rendi sint. 
44. GLADIOLUS villosus, corollis campanulatis sulphureus, secundis, laciniis lanceolatis undulatis, foliis nervoso-plicatis, scapo declinato. $t$

Gladiolus sulphureus; corolla campanulata; foliis ensiformihus, plicatis, hirsutis; spatha trivalvi; valvulis omnibus acutis, integerrimis, Jacqu. collect. 2. p. 258. Ic. rar.2. t. 239. Habitat in Cap. b. spei.

Totus villosus. Folia quadri-quinquepollicaria, erecta, ensiformia acuta, plicatula, nervosa, mollia: vaginae ancipites, infinlae purpurascentes. Scapus pedalis, declinatus. Flores circiter septem, bipollicares, secundi, sessiles. Spathae trivalves, lanceolatae, acutae: valvula extima reliquis duplo longior. Corollae tubus spathis brevior, incurvus, violacens: Limbus campanulatus; laciniis subaequalibus, obtusis, pallide sulphureis, alternis, saepius undulatis. Jacqu. l. c.

\section{* Scapo polystachyo.}

\section{- Glabri.}

45. GLADIOLUS spica imbricata disticha, foliis alopecuroilineari-ensiformibus.

Gladiolo affinis, floribus minimis coeruleis dense spicatis. Raii. hist. 2. p. sto.

Gladiolus alopecuroides; foliis linearibus, spica disticha imbricata. Lin. am. acad. i. p. $30 \mathrm{r}$. syst. veg. 87.

Gladiolus alopecuroides; polystachyus, spica im bricata disticha, foliis ensiformibus nervosis. Thunb. glad. $n$. I 4 .

Ixia plantaginea; foliis linearibus strictis, spica aisticha imbricata, Hort. kew. I. p. 59.

Gladiolus alopecuroides; foliis linearibus ner. vosis, spica subsolitaria imbricata disticha, spathis margine scariosis. Lamarck. illustr. I. p. 1 I8. t. 32 . f. 4.

Habitat in Cap. b. spei. 4

Bulbilli plurimi. Scapus spithamaeus vel peclalis, flexuosus. Folia duo vel tria in scapo eoque breviora, latitudine unguis, longe vaginantia. Spicae solitariae, interdum duae vel tres, digitales, erectae. Flores copiosi, paivi. Spa- 
thae ovatae, compressae: valvula exterior parumi longior, dorso fusco, marginibus membranaceis hyalinis.

$V$ ariat floribus albis et coeruleis.

setifolius. 46. GLADIOLUS corollis ringentibus, foliis lineari-setaceis. †

Glarlinlus sctifolius; caule ramoso, coroka ringente, folio infimo filiformi-setaceo. Lin. suppl. $9^{\prime}$.

Glartiolus setifolius; polystachyus, foliis linearisetaceis. Thunb. glad. n. 19.

Habilat in Cap. b. spei. 4

Folia circiter tria, sensim breviora, infimo longissimo, scapum aequante. Scapus palmaris, rarissime simplex, flexiosus: Rami teretes, erecti. Corollae albidae: tubres spathis vix longioz. Thunb. $7 . c$.

alatus. 47. GLADIOLUS corollae ringentis laciniae spathulatze, duabus lateralibus majoribus, scapo subalato.

Gladiolus alatus; corolla divaricate ringente, 7acinia summa falcata, foliis ensiformi-linearibus glahris, scapo ramoso. Jacqu. coll. +. $p$. 165. Ic. rat. 2. t. 259 .

3. Gladiolus alatus; foliis ensiformibus costatis; petalis lateralibus latissimis. Andr. repos. $t .8$.

Habitat in Cap. b. spei. 4

Scapus spithamaeus vel subpedalis, simplex vel ramo auctus, flextosus, striatus, superne $e$ carina spatharum decurrente subalatıs, inferne teres. Folia plurima inferne, unicum vel duo in scapo, infima scapo saepe altiora, superiora breviora, angusta, tri-quinquestivata. Flores secundi, distantes, odoratissimi. Spathae valvula exterior tubo corollae duplo longior, lanceolata, compressa, obtusa, carina et margine purpurea. Corollae tubus pailidus: Limbus cinerascens; laciniae laterales, superiores satu. ratius coloratae et subtilissime lineatae; inferiores basin versus flavae.

B. Videtur differre colore laciniarum superiorum coccineo. 
48. GLADIOLUS corollae ringentis, laciniae spa- permeabilis. thulatae longe unguiculatae; duabus lateralibus latioribus, scapo tereti.

Gladiolus permeabilis; caule ramoso, floribus imhricatis secundis, foliis subulato-quadrangulis. De la Roche diss. n. 1. t. 2.

Habitat in Cap. b. spei. Ex herbario Royeni. 4

Scapus bi-tripedalis, simplex vel ramosus. Folia radicalia diıo vel tria, longitudine fere scapi, angustissima; scapi sensim breviora, vaginaeformia, attenuata, nervo utrinque marginata. Flores plures, secundi, pollicares. Spathae bivalves: valvulae lanceolatae, membranacea, obtusiusculae, tubo breviores: Limbi faux inflata, ventricosa, inter laciniarum unguibus hians, patulo-permsabilis.

Gladiolus permeabilis Tizunbergï prodr. 185. an idem? discriptio in Act. soc. hist. n. hav. vol. $\therefore$ haud satis convenit.

49. GLADIOLUS spicis subtrifloris, corollae laciniis ovatis suhrequalibus aristatis, scapo paniculato, ramis flexuosis.

Gladiolus gramineus; petalis lanceolatis setaceoacuminais. Lin. suppl. i) .

Gladiolus gramineus; polystachyus, scapo laxo, spicis capillaribus flexuosis, foliis ensiformibus glabris. Thunt. glad. n. 26 .

Gladiolus gramineus; corollae tubo hrevissimo, lacimiis subaequalibus aristatis, scapo paniculato. Jacqu. collect. :- p. 303. Ic. rar. 2. t. 236.

Habitat in Cap. b. spei. 7

Folia tria-sex, unicum in scapo eoque breviora, ungliem lata, tenuiter nervosa. Scapus pedaTis et ultra, vix crassitie pennae columbinae, superne jlexuosus. Pedunculi divaricati, filiformes; pedicelli capillares, bi-triflori. Bracteae duae setaceue ad basin pedicellorum. Flores distantes. Spathae ovatae, acuminatae, virescentes, margine albo-membranaceae. Corolla virescens: tuvo vix ullo: Limbi lacinine ovatae, concavae, subaequales, extus carina virescenie, intus linea purpurea, arista coerulescente. 


\section{IO2 TRIANDRIA. MONOGYNIA.}

involutus. 50. GLADIOLUS corollis ringentibus remotis distichis, tubo spathis breviore, laciniis lanceolatis lateralibus margine involutis.

Gladiolus caule ramoso foliis linearibus planis, spatha glabra acutiore. Mill. ic. 2. p. 15s. $t$. $23 \%$. f.r.

Gladiolus involutus; caule ramoso, foliis linearibus, spicis distichis. De la Roch. diss. $n .2$. t. 3 .

Gladiolus bimaculatus; foliis linearibus perangustis, petalis superioribus brevicribus patentireflexis; trium inferiorum lateralibus maculatis angustioribus. Lamarck. dict. bot. 2. $p$. 727. illustr. 1. p. I 16.

Mabitat in Cap. b. spei. 4

Scapus sesquipedalis, parum flexuosus, in ramos duos-tres floriferos divisus. Folia angusta; caulina sub ramificationibus. Flo. res quinque-octo, distantes. Spathae bivalves: valvulae pollicares, lanceolatae, attenuatae, tenerae, laeves, margine membranaceae. Corollae ultra pollicem longae, roseae: Limbi laciniae tres superiores majores; inferiores tres patentes, intermedia latior lanceolata, laterales lineares, inferne macula purpurea.

muduatus. 51. GLADIOLUS corollis secundis subringentibus, tubo spathis longiore, laciniis subaequalibus undulatis. $t$

Gladiolus undulatus; foliis ensiformibus, petalis subaequalibus lanceolatis undulatis. 'Lin. Mant. 27.

Gladiolus undulatus; corolla subringente; foliis ensiformibus; caule flexuoso, ramoso; laciniis petali undulatis. Jacqu. coll. 3. p. 256. Ic. rar: =. t. $25 \mathrm{I}$.

Gladiolus undulatus; polystachyus, foliis ensiformibus, laciniis limbi undulatis; tuho spathis longiore. Thunb. prodr. 166. Act. soc. h. $n$. hafn. vol. 6.

Habitat in Cap. b. spei. 4

Folia circiter duo, scapo breviora, longe vaginantia, apice attenuata, multinervia, glabra. Scapus pedalis-bipedalis, rarius simplex, sao 
pius superne ramosus, flexuosus. Flores biniocto, secundi. Spathae convolutae, pollicares, ollongae, acutae, glabrae. Corollae tubus filiformis, bi-tripollicaris, rectus: Limbi laciniae lineari-caudatae. Thunb. $l$. $c$.

52. GLADIOLUS corollis subringentibus secundis, laciniis lanceolatis tribus inferioribus inferne macula rhombea sanguinea, scapo ancipiti.

Gladiolus africanus, folio gramineo, floribus carneis, macula rhomboidea inscriptis. Boerk. Lugdb. 2. p. 127 .

Gladiolus foliis linearibus. Lin. hort. cliff. $p_{0}=0$. t. $\ell$.

Gladiolus floribus patentibus externe carneis' interne candidis, stella maculisque purpureis insignitis, suprema lacinia maxima. Breyn. ic. rar. 2 I. t. $7 . f$. 2 .

Gladiolus angustus; foliis linearibus, floribus distantihus, corollarum tubo limbis longiore. Lin. syst. veg. 8?. Mill. ic. r. p. 95. t. 142.f.2.

Haúltat in Cap. b. spei. 4

Scapus pedalis vel sesquipedalis, anceps. Folia caule vix latiora. Flores tres-quatuor. Corollae fiavescentes: iubus bi-tripollicaris: Limbi laciniae acutae, macula sangrinea superne in laciniis inferioribus lineaque ejusdem coloris ad fauceri decurrens.

53. GLADIOLUS corollae laciniis inaequalibus blandus. suprema reflexa, tribus infimis lineari-lanlanceolatis, stigmatibus subbilobis. +

Gladiolus blandus; foliis lineari-lanceolatis nervosis glabris, floribus spicatis; lacinia suprema reflexa, stigmatibus subbilobis. Hort. kew. r. p. $6 \div$.

Habitat ad Cap. b. spei. 4

Corollae tubus sesquiuncialis, angustus, compressus, parum incurvus, pallide rubens: Limbi lacinia suprema, longitudine tubi, oblonga, acuta, medio concava, ibique dilatata, supra medium reflexa, ex albo incarnata; duae laterales supremo paulo breviores, oblongo-lanceolatae, patentes, apice reflexae, incarnatue; tres inferiores superioribus paulo breviores, ereclo-patentes, supra medium parum reflexae. 


\section{IOf TRIANDRIA. MONOGYNIA.}

ex albido - incarnatac, in medio macula rubra iransversa notatae; intermedia coeteris acutior. Stigmata dilatata, biloba, margine viliosa. Hort. kew. l. c.

junceus. 54. GLADIOLUS spicis secundis, foliis lato-lanceolatis subundulatis, stigmatibus hifidis $\dagger$

Gladiolus junceus; foliis latu-larıceolatis, culnıo ramoso, floribus secundis, stylo sexpartito. Lin. suppl. 94.

Gladiolus junceus; polystachyus, floribus secundis, foliis lanceolatis. Thunb. glad. n. 18.

Gladiolus marmoratus; foliis ensiformibus nervosis glabris maculosis, floribus distichis, stylo sexpartito. Lamarck. dict. bot. 2. p. 1. illustr. 1. p. i i 8 .

Habitat in Cap. b. spei. 4

Folia quatuor-sex, scapo breviora, subundulata, Scapus palmaris, interdum simplex, filiformis, flexuosus. Flores quatuor-septem, erecti, coerulescentes. Bracteae brevissimae. Thunb. l. $c$.

marginatus. 55. GLADIOLUS spicis adpressis pluribus, floribus cernuis, foliis ensiformibus nervosis marginatis, stigmatibus bificlis.

Gladiolus maximus ramosus floribus argentcis. Plukn. mant. 9 . fide herb. Plukn.

Gladiolus marginatus; foliis cartilagineo-marginatis glabris multinerviis, spica elongata, floribus alternis nutantibus. Lin. suppl. 95.

Gladiolus marginatus; polystachyus, spica longissima, floribus alternis cernuis, foliis ensiformibus multinerviis marginatis. Thunb. glad. $n .20$.

Ixia marginata; polystachya, foliis ensiformibus nervosis marcine incrassatis, spicis pluribus adpressis, tubo incurvo, stigmatibus bifidis. Hort. kew. 1. p. 59 .

Ixia cartilaginea; foliis ensiformibus nervosis marginato cartilagineis, caule polystachio, tubo spathis longiore. Lamarcli. dict. bot. 3 . p. 340. illustr. 1. p. 112.

Habitat ad Cap. b. spei. 4

Folia pedaliu, semipollicem vel ultra lata, erccta, nervi in medio et ad margines incrassati, fia- 
vescentes, disci tenuiores. Scapus bipedalis,
inferne foliis vagunatus. Spica semipedalis
et ultra. Flores cermui, magni.

56. GLADIOLUS spicis pluribus erectis, corollae glumacens. tubn filiformi spathis breviore, foliis ensiformibus margine incrassato.

Gladiolus maroinatus purpureus. Thunb. glad. n. 2 . :

Gladiolus glumaceus; polystachyus foliis ensiformibus multinerviis marginatis, tubo filifurmi spathis breviore. Thunb. prodr. 186. Act. soc. h. n. hafn. vol.

Habitat in Cap. b. spei. 4

Folia duo vel tria, scapo breviora, attenuata, marginata et multinervosa; nervis crassis, flavescentibus. Scapus bipedalis, foliis vaginatus, apice ramosius. Spica spitizamaea et ultra; spicae laterales, breves. Spathre unguiculares, membranaceae, convolutae, lanceae, acuminatae. Corolla campanulata, purpurascenticoerulea: tubus filiformis, spatha brevior. Thunb. l. $c$.

Spathae in setam attenuatae, striatae.

57. GLADIOLUS spicis subsolitariis, corollis cam- testaceus. panulatis, tubo filiformi longitudine spathae, foliis lanceolato-ensiformibus subfalcatis. † Antholyza spicata; floribus infundibuliformibus, spicatis, incarnato-pallidis; foliis falcatis, brevissimis. Andr. reprs. $t$. 56 .

Habitat in Cap. b. spei. 4

Secundum figuram affinis videtur. Glad. iridifolio, at diversus: foliis brevibus: spicis geminis: corollis minoribus.

58. GLADIOTLS corollis campanulatis, scapo bis dichotomtis. bifido, ramis bifloris, foliis linearibus. +

Gladiolus dichotomus; corollae erectae limbo campanulato, scapo bis dichotomo quadrifloro; foliis linearihus. Thunb. glad. n. 6 .

Habitat in Cap. b. spei. 4

Folium basi vaginans, scapo longius, glabrain; folium spathaceum sub dicliotomiis, lineare, acutum. Scapus pedalis, apice bifidus, brachio singulo bifloro. Flores secundi, erecti. Thunb. l. c. 
+ bicolor. 59. GLADIOLUS corolla ringente, spathis laceroaristatis, foliis ensiformibus. Thunb. glad. n. I6. t. 2. Jacqu. collect. suppl. 25. Ic. rar. 2. t. 240.

Habitat in collibus ad Cap. b. spei. 4

Bulbus ovatus, reticulatus. Folia scapo duplo breviora, alternatim vaginantia, obtusa cim acumine. Scapus spithamaeus, basi foliis vaginatus, flexuosus, angulatus, striatus, sulco utrinque profundo exaratus. Spicae duae; altera uniflora, tenuior: altera triflora crassior, longitudine dimidii scapi. Rachis angulata. Spatha membranacea, apice lacerato-partita, venosa, basi grisea, apice ferruginea. Corollae tubus ampliatus, spatha duplo longior, filiformis, sensim ampliatus: Limbi laciniae flavae; suprema major ovata, concava, apice coerulea; laterales inferiores lanceolatae, convolutae, ultima apice coeruleo; infima brevior, parum a reliquis separata, extra laterales collocata: omnes basi linea duplici purpurea in ore tubi. Thunb. $l$. $c$.

silenoides. 60 . GLADIOLUS corollae tubo filiformi elongato, genitalibus exsertis, foliis lineari-ensiformibus. +

Gladiolus silenoides; corollae tubo filiformi longissimo, floribus sessilibus axillaribus, foliis ensiformi - linearibus glabris, genitalibus longitudine corollae. Jacqu. collect. 4. p. I68. Ic. rar. 2. $t$. 270 .

Habitat ad Cap. b. spei. 4

Bulbus obovatus. Scapus gracilis, inferne ramosiss, debilis, flexuosus, multifloris. Folium radicale unicum; caulina inferiora cluo, interdum opposita, bi-tripollicaria, breviter vaginantia, glauco-viridia. Flores aiterni, secundi. Spathae trivalves: valvulae sublineares, acutae, conniventes; longiori biunciali, intima bificla. Corollae tubus biuncialis, albis, inferne incurvatus: Limbus eleganter purpureus; laciniis lanceolatis, tribus inferioribus parum minoribus, basi macula flavescente, et macula praeterea sanguinea in duabus lateralibus. Jacqu. l. c. 
6r. GLADIOLU'S corollis tuino filiformi, laciniis- fissifolins. lanceolatis, scapo ancipiti, foliis ovatis undulatis subtus subhirtis. $t$

Gladiolus fissifolius; corollae tubo filiformi tongissimo, floribus sessilibus axillaribus, foliis hirtulis, in superiore margine fissis, superioribus quidem ad oppositum marginem usque, inferioribus autem ad apicem indivisis. Jacqu. coll. 4. p. 164. ic. rar. t. 268 .

Habitat ad Cap. b. spei. 4

Gladiolo ancipiti affinis, singularis foliis fissis. Scapus spithamaeus, flexuosus. Folia semuncialia, amplexicaulia, ovata, inferiora acuta, superiora obtusa, nervosa, subtus hirtula, margine crispa, lateribus reflexa. Vel verius folia ensiformia, margine altero interiori fisso amplexicaulia; quae fissura in foliis superioribis ad marginem folii oppositum sive exteriorem pertingit, unde hic margo tunc evadit nervus folii medius, dum orae divisae horizontaliter expanduntur non tantum, sed etiam reflectuintur. Flores solitarii, erecti, unciales. Spatha. bivalvis, brevissima, membranacea, albida: valvula exterior ovata, dorso medio viridi. Corollae tubus parum incurvatus, albus, superne violaceus: Limbi laciniae lanceolatae, subtus pallide violaceae, supra purpureo-rubrae, basi albidae, linea media atro-purpurea. Jacqu. l.c.

62. GLADIOLUS floribus imbricatis, corollae la- bracteatus, ciniis ovatis, spathis rhombeis, scapo compresso, foliis ensiformibus obtusis. †

Gladiolus bracteatus; polystachyus scapo ancipiti, corollac laciniis ovatis, spathis ovatis imbricatis. Thunb. prodr. 186. Act. soc. h. $n$. hafin. vol. 6. cum figura.

Habitat in Cap. b. spei. $2 \%$

Scapus spithamaeus, ramosus. Folia sub ramis sessilia, digitalia, ensiformia, obtusa, patentia vel subrecurvato-falcata, multinervosa. Flores plurimi, ante anthesin spathis tectio Spathae unguiculares, ovatae, acutue, convolutue, integrae. Corolla alba: tubus filiformis, erectus, apice geniculatus, dein ampliatus in limbum nutantem. Thunb. l. c. 
Fabricii. 63. GLADIOLUS corollae tubo laciniisque filiformibus, scapo ancipiti, foliis spathisque carina integerrimis. †

Gladiolus Fabricii; polystachyus scapo ancipiti; laciniis corollae filiformihus. Thunb. prodr. iś. Act. soc. h. n. hafn. vol. 6.

Habitat in Cap. b. spei. 4

Scapus spithamaeus vel ultra, inferne teres, superne anceps, ramosus: Rami compressi, divaricati, erecti, virgati. Folia radicalia circiter tria, scapo breviora, ensiformia, acuta, multinervia; scapi sub ramis similia, unguicularia, angustiora. Flores plures, erecti, albi. Spathae lineam longae, ovatae, obtusiusculae. Corollae tubus pollicaris, filiformis. Thunb. l. $c$.

Thunbergius huc revocat Gladiolum Fabricii de la Roche, sed in illo anguli caulis dentati sient, quod non in Thunbergii, quantum e descriptione conjicere licet, laciniae quoque in corolla Gl. ancipitis non filiformes.

anceps, 64. GLADIOLUS corollae tubo filiformi, scapo ancipiti flexuoso, foliis ensiformilus spathaeque carina extrorsum denticulatis.

Ixia Fabricii; caule dichotomo ancipiti. De la Roche diss. $n$. 5 .

Gladiolus anceps; foliis ensiformibus undulatis, caule ramoso ancipiti divaricato. Lin. suppl. 94. Jacqu. collect. 4. p. 163. Ic. rar. 2. t. 269.

Gladiolus anceps; scapo ancipiti, spathis crispis. Thunb. glad. n. 17 .

Gladiolus denticulatus; foliis ensiformibus obtusis carina denticulata decurrentibus, caule paniculato ancipiti. Lamarck. illustr. 1. p. is.

Lapeyrousa compressa. Pourret in act. tolos. 3 . p. 79. t. 6.

Habitat ad Cap. b. spei. 4

Scapus palmaris et ultra, angulis denticulatis: Rami simpliccs, scapo similes. Folia sescuipollicaria, amplexicaulia, conferta, acuta. Flores solitarii, alterni. Spathae bivalves, stsbpol. licares, sensim minores: valvula exterior similis foliis caulinis, obtusa, uti folia caulina carina decurrente, margine exteriore superne crispodenticulata, apice purpurea. Corollae tubus 
sensim ampliatus, spathis longior, pallide coerulescens: Limbi laciniae subaequales, lanceolato-subcuneatae.

65. GLADIOLUS spicis refractis secundis, corollis refractus infuntihuliformibus, spathis brevissimis, foliis lineari-ensiformibus.

Gladiolus refractus; corolla subringente; foliis lineari-ensiformibus, glabris; scapo ranoso; floribus secundis, erectis, resupinatis. Jacqu. suppl. 2r. Ic. rar. 2, t. 24 r.

Habitat in Cap. b. spei. Ex herbario Royeni. 4 Scapus pedalis, crassitie fili emporetici tenuioris, teres, diphyllus, mono-distachyus, laevis. Folia spithamaea vel minora, caulina breviora, angusta, leviter striata. Spicae remotae, triseptemflorae. Spathae bivalves, tubo fere quadruplo breviores: valvulae aequales, subrotundac, membranaceae, albescentes; exterior apice macula una; interior duabus fusco-purpurascentibus, purpureo striatis. Corollae tubus croceus.

66. GLADIOLUS spicis subsecundis, corollae luteus. limbo campanulato, tubo spathis breviore, foliis lineari-ensiformibus.

Gladiolus luteus; foliis linearibus angustis longissimis, floribus spicatis subsecundis luteis, tubo curvo spatha breviore. Lamarck. dict. bot. 2. p. 725 . illustr. 1. $p$. I1 ?.

Habitat in Madagascar Commerson. Ex herbario Jussiaei. 4

Scapus pedalis, adscendens, simplex, interdum ramo unico divisus. Folia scapo altiora. Flo. res plurimi, approximati, lutei. Spathae oblongae, acutae. Corolla curvata: Limbus unguicularis vel parum ultra.

67. GLADIOI.US corollae fauce labii superioris securigex, trilaminata, laminis unguiformibus, spathis obtusis, foliis lineari-ensiformibus. †

Gladiolus securiger; foliis lineari-ensiformibus planis, fauce labii superioris trilaminato: laminis unguiformibus perpendicularibus, bracteis obtusis. ITort. kew. r. p. 65. Curt. mag. 383.

Habitat in Cap. b. sp̣ei. 4 
Folia spitamaea vel longiora. Scapus foliis parum brevior, interdium ramosus, teretiusculus. Spathae breves, ovatae, obtusae; interdum apise incisae, membranaceae. Corolla pallide fulva: tubus uncia brevior: Limbi laciniae oblongae, ovatas, obtuisae, interdum obsolete emarginatae, tubo breviores; superiores tres in fauce macula flava, margine rubicundo, ubique auctae laminis tribus compressis, obtusis, perpendicularibus, flavis, diametro sesquilineari. Hort. kew. $l . c$.

Aavus. 68. GLADIOLUS corollae fauce labii superioris trilaminata, laminis unguiformibus, spathis acuminatis, foliis lanceolato-ensiformibus.

Gladiolus flavus; foliis lanceolato-ensiformibus planis, fauce labii superioris trilaminato: laminis unguiformibus perpendicularibus, bracteis acuminatis. Hort. kew. I. p. 65.

Ixia gladiolaris; foliis linearibus, floribus subaequalibus spicatis, petalis tribus, squamula erecta medio carinatis. Lamarck. dict. bot. 3 . p. $3+$ r. illustr. I. p. II 2 .

Habitat in Cap. b. spei. 2!

Differt a Glad. securigere: bracteis acuminatis. corolla tota intense flava et foliis paulo latioribus. Hort. kew. l. c.

Folia saepe longitudine scapi, interdum breviora. Scapus septem-decempollicaris, interdum simplex, saepe ramosus. Flores quatuor vel quinque, campanulati. Spathae membranaceae, bivalves: laminae faucis truncatae. Lamarck. $l$. $c$.

ז0sens. 69. GLADIOLUS corollae tubus longissimus, lacinia superiore ovata, foliis lineari-ensiformibus. $\dagger$

Gladiolus roseus; corollae muticae; tubo gracili longissimo; foliis ensiformi-linearibus, glabris; caule ramoso; spathae valvula exteriore integerrima, interiore apice bifida. Jacqu. suppl. 22. Ic. rar. 2. t. 261.

Habitat in Cap. b. spei. 4

Bulbus subrotundus, magnitudine avellanae. Folia longe vaginantia, radicalia plura, pedalia. Scapus foliis parum longior, erectiuscullus vel 
supra ramos declinatus, flexuosus, gracilis: Rami basi folio brevi suffulit. Flores secundi, bini vel terni, biunciales, inodori. Spatha bivalvis, scariosa, concava, acuminata, straminea. Corollae tubus gracilis, incurvulus, pallide roseus: Limbi laciniaerotundatae, patentissimae, intus pallide roseae; suprema ovata, duplo latior, medio dorsi rosea; la.erales subtus roseae, medio coloratiores; inferiores basi macula subcuneiformi, rubra cum area longitudinali flava, alia ad singulum marginem. Jacqu. l. c.

Affinis videtur longifloro foliis parum latioribus lacinia superiore oblonga tantum diversus.

70. GLADIOLUS corollae tubo longissimo, laci- longiflorus niae limbi alternae angustiores, foliis lineariensiformibus.

Ixia paniculata; caule paniculato, tubo floris longissimo, arcuato. De la Roche diss. n. 14. Ixia longiflora; polystachya, tubis corollarum filifornibus longissimis nutantibus. Berg. cap. 7 .

Gladiolus longiflorus; caule tereti, tubo longissimo, spathis foliisque linearibus glabris. Lin. suppl. 96.

Gladiolus longiflorus; polystachyus, tubo corollae longissimo, spathis obtusis foliisque ensiformibus glabris. Thunb. glad. n. 22. Redouté pl. lil. t. 34 .

Gladiolus longiflorus. Jacqu. suppl. 24. Ic. rar. 2. $t .263$.

f. Gladiolus longiflorus; corollae muticae; tubo gracili, longissimo; foliis angustis, ensiformibus, glabris; caule ramoso; spatha valvula exteriore tridentata, interiore bidentata. Jacqu. suppl. 23. Ic. rar. 2. t. 262.

Habitat in Caq. b. spei. 4

Folia tria vel quatuor, scapo breviora, angusta, linearia, longe vaginantia, trinervia praeter nervos marginales. Scapus pedalis et ultra, interdum simplex, saepius superne in pedunculos remotos patentes divisus. Flores nutantes. Spathae brevissimae, membranaceae; valvula exterior integra, altera bidentata. Corollae 


\section{TRIANDRIA. MONOGYNIA.}

tubus bipollicaris, superne parum curvatis: Limbi laciniae lineares, alternae angustiores obiusiores.

Sub nomine Ixiae longiflorae frequenter occurrit Gladiolus longiflorus. Jacqu. $t$. 2 ?3. et vix dubito, quin eadem sit ac auctorum; sic synonyma ad illum pertinent minime vero ad Gladiolum longiflorum. Jacqu. tab. $2 h=$. qui differre videtur spathae valvulis exterioribus tridentatis, interioribus bidentatis: corollae tubo magis curvato: Limbi lacinia superiore oblonga latiore, reliquis aequalibus.

An facqu. $t$. «in 2 specie diversus? species dantur quae minus inter se diversae quam hae duae.

Aoribundus, 7 1. GLADIOLUS corollae subringentis tuho longitudine spathae, laciniis limbi lanceolatis, foliis lanceolato-ensiformibus. †

Gladiolus floribundus; corolla subringente, foliis ensiformibus striatis, glabris, scapo spicato toto florigero. Jacqu. collect. 4. p. $1 \mathrm{\delta}_{2}$. Ic. rar. =. t. 254 .

Habitat ad Cap. b. spei. 4

Folia plura, semipedalia, erecta, disticha, acuta. Scapus longitudine fere foliorren, flexunsus, superne sriepe geniculatus- Flores triunciales, sessiles, distantes, erecti. Spatha bivalvis, convoluta: valuula exterior bipollicaris, interimi longior, viridis. Corollae tubus subcylindricus, albidus: Limbi laciniae lanceolatae, pailide ocliroleucae, linea utrinque media purpurea. Stigmatis laciniae apice latescentes. Jacqu. $l$. c.

\section{- viliosi.}

rubiforus. 72. GLADIOLUS spicis secundis, corollae tubo lonissimo, laciniis lineari lanceolatis subaequalions inmaculatis, foliis nervoso-plicatis.

Gladiolus tubiflorus; caule tereti, tubo lungis. simo, spathis foliisque hirsutis. Lin. suppl. $9^{5}$.

Gladiolus tubiflorus; polystachyus tubo corollae longissimo, spathis foliisque ellipticis plicatis hirsutis. Thunb. glad. n. 23. t. 2.f. 2.

Gladiolus tubiflorus; foliis lineari-lanceolatis villosis subplicatis scapo longioribus, tubo longissimo, spathis hirsutis. Hort. kew. I. p. 62. 
Gladiolus tubiflorus; foliis linearibus plicatis villosis, floribus aiternis secundis, tubo filiformi spathis multolies longiore. Lamarck. dict. 2. p. $7=4$.

Gladiolus angustifolius; hirsutus, foliis angustissimis nervo is caule longioribus, spathis alternis secundis, tubo filiformi longissimo. Lamarck. illustr. 1. p. 119.

Habitat in Cap. b. spei. 4

Folia radicalia, circiter sex, scapo longiora. anguista, utrinque attemutu basi in petiolum, erecta, villosa. nervosa, vix plicata. Scapus pollicaris vel palmaris, basi foliis involutus, superne villoso-canescens. Flores circiter quatuor, secundi vel distichi, distantes. Spathae sesquipollicares, sursum sensim parum minores, villoso-canescentes, trivalves: valvulae lanceolatae, attenuatae, apice glabrae; exterior longior. Corollae tubus spatha duplo longior: Limbi laciniae alternae mucronatae.

73. GLADIOLUS spicis secundis, corollae tubo tubatus. longissimo, laciniis oblongis inaequalibus tribus inferioribus macula rubra, foliis nervoso. plicatis. $\dot{\dagger}$

Gladiolus tubatus; corollae tubo gracili, longissimo; laciniis alternis mucronatis; foliis ensiformibus, plicatis, hirsutis; spatha bivalvi. Jacqu. suppl. 18. Ic. rar. 2. t. 264.

f. Jacqu. suppl. 19. Ic. rar. 2. t. $=65$.

Gladiolus longiflorus; foliis ensiformibus, plicatis, villosis, corollis tubiformibus, longissimis; petalis undulatis, reflexis. Andr. repos. t. 5 .

Habitat in Cap. b. spei. 4

Bulbus subrotundus, magnitudine avellanae. Folia quinque-decem urecias longa. Scapus foliis brevior, crassitie pernae columbinae, villosulus, mollis. Flores plures, erecti. Spatha bivalvis, villosa, vividis, apice ferruginea, acuta, concuva, striatula: valvula exterior integra, interdum tridentata; interior multo brevior, bilentata. Corollae tubus cylindricus, fere tripollicaris, incurvuins, albus: Limbi la- 


\section{I4 TRIANDRIA. MONOGYNIA.}

cinice unciales, acutae, ochroieuco-albidae, dorso medio purpurascentes; suprema concava, erecta, tres alternae mucronatae; inferiores basin versus macula rubra, superioribus minoribus. Jacqu. l. c.

P. Differt: foliis longioribus: coroliarum tubo violaceo: Limbi laciniae superiores pallide carneae.

puniceus. 74. GLADIOLUS corollis campanulatis, spathis irivalvibus, valvula exteriori acuminata; foliis oblongo-lanceolatis vaginis glabris. +

Ixia punicea; foliis oblongo-lanceolatis, villosis, plicatis, distichis; vaginis glabris; spatha trivalvi; scapo polystachyo; corollae limho campanulato. Jacqu. suppl. !2. Ic. rar. 2. t. 287.

Habitat in Cap. b. spei. 24

Bulbus fibroso-tunicatus. Folia plura, disticha, in vaginam longissimam desinentia, molliter villosa. Scapus saepe polysiachyus, longitudine foliorum, teretiusculus, inferne erectus, superne parum declinatus, villosies. Flores erecti, circiter quini, inodori, spcciosi. Spatha villosa: valvula exterior major, fere sesuncialis, lanceolata, acuminata, Corolla saturatissime punicea, sesquipollicaris : tubus filiformis, erectus: Limbus campanulatus; laciniae lanceolatae, subaequales, patentissimae, tribus alternis mucrone innocuo terminatae. Jacqu. $l$. c.

$V$ ariat floribus magis rubris, minoribus.

purpureus. 75. GLADIOLUS corollis patentissimis, laciniis oblongis acutis, spathis trivalvibus acutis, foliis lanceolato-ensiformibus, vaginis glabris. $t$

Ixia purpurea; foliis ensiformihus, villosulis, plicatis, distichis; vaginis glabris; spatha trivalvi; scapo polystachyo; corollat limbo patentissimo. Jacqu. collect. 3. p. 268 . Ic. rar. 2. t. 286 .

Habitat in Cap. h. spei. 4

Folia plura, erecta, basi longe vaginantia, acuta. Scapus longitudine foliorum, pauciflorus, villosiss. Spathae concavae: valvula exterior linzgior. Flores distichi, saepe terni. Corollae butus pallide purpurascens: Limbi lacinice 
su'sequales, patentissimae, longitudine tubi, saturute purpureae. Jacqu. $l$. c.

An modo varietas praecedentis? parum differre videtur.

76. GLADIOLUS corollis subringentibus; spathis mucronatus trivalvibus integerrimis, vaginis scapoque angulato-glabris. +

Gladiolus mucronatus; corolla subringente, mucronata; foliis ensî̂ormibus, plicatis, hirsutis; spatha trivalvi, villosa; scapo ralisoso. Jacriu. collect. 4. p. inz. Ic. rar. 2. t. 253.

Gladiolus ringens; polystachyus, foliis plicatis hirsutis, corolla ringente, spathis hirsutis. I'hunb. prodr. 186. Act. soc. h. n. hafn. vol. 6.

Habitut in Cap. b. spei. 4

Folia radicalia plura, disticha, tri-quadripollicaria, nervosa, margine hirsuta: vaginac longae, petioliformes. Scapus foliis altior, ruro simplex, parum flexuosus. Flores plures. Spathae virides: valvulae lanceolatae, concavae, hirsutae, ciliatae, striatae. Corolla biuncialis; tubus longitudine spathae, subcylindricus, pallidus; faux flavescens: Limbi laciniae tres superiores cuneiformes, obtusae, mucronatae, dilute purpureo-violaceae; inferiores patulae, magisque flavae. Stigmata apice latescentia. Jacqu. l. c.

Scapus superne villosus, compressus. Folia digitalia-spithamaea, altitudine scapi. Corollae plus minusve albidae, vel saturatiores, vel flavescentes. Spathae ovatae, convolutae, apice (membranaceae, obtusae, longitudine tubi. Thunb. $l$. $c$.

Conjungitur a Thunbergio cun Ixia villosa Jacquini.

77. GLADIOLUS corollis suhcampanulatis disti- villous. + chis, spathis triphyllis integerrimis, laciniis lineari-subcuneatis, foliis oblongo-lariceolatis.

Ixia villosa; foliis oblongo-linceolatis acutis villosis subplicatis, tuho spathae aequali. Hort. Kew. I. p. 5 s.

Habitat in Cap. b. spei. Ex herbario Royenii. 4 Totus villosus. Bulbus praeteriti anni lateralis, tunicatus, subovatus, magnitudine avellanoe. 


\section{II6 TRIANDRIA. MONOGYNIA.}

Folia in petiolum vaginantem desinentia, bi-tripollicaria, semipollicem lata, acutiuscula, tenuiter nervosa, suinplicaia; unicum sessile lineare inforne in scapo. Scapus spitizamaeus, canc. scens. Spica interdum simplex, interrium inferne ramo aucta. Flores quinque ad septem, parum distantes, auplo vel triplo minores quam in Glad. pícato, violacei. Spatha longitudize tubi; vaivulis linearibus, acuits, integerrimis, apice glabitis.

Ixia villosa Jaquini mihi videiur diversa. A Glad. plicato differt: spathae valvulis integerrimis; corollis minoribus; lacinuis limbi angustis.

plicatus. 78. GLADIOLUS corollis campanulatis secundis, spathis trivalvibus, valvula exteriore tridentata, foliis oblongo-lanceolatis.

Sisyrinchium latifolium, floribus patentibus vix difformibus. Breyn. ic. rar. 22. t. 9.f. 2.

Ixia plicata; foliis ensiformibus plicatis villosis. Lin. amoen. acad. 4. p. 300 .

Ixia flabellifolia; foliis flabellifornibus, corcllae tubo spathis duplo longiore. De la Roche diss. $n$. 12 .

Gladivius plicatus; foliis ensiformibus plicatis villosis, scapo laterali, corollis regularibus. Lin. spec. pl. 53 .

Gladiolus plicatus; foliis oblongo-lanceolatis villosis plicatis, tubo spathis longiore. Hort. kew. I. p. 63.

Gladiolus plicatus; corollis subcampanulatis, secundis ; foliis ensiformibus, plicatis, hirsutis; spatha trivalvi, valvula exteriore tridentata. Jacqu. collect. 4. p. I55. Ic, rar. 2. t. 237 .

angustifolius.

B. Jacqu. collect. 4. p. I5 5 . Icon. rar. =. t. 238.

Habitat in Cap. b. spei. 4

Folia circiler sena, scapo paulo longiora, subpetiolatr, digitalia, erecta, obtusı vel acuta, apice obliqua, villosa, mollia, plicata, nervosa; nervi a basi interiori orti. Scapus pedalis, simplex vel ramosus, flexuosus, villosus, subcaicscens: Rami brevissimi: inferiores longiores. Flores primum distichi, dein secundi. Spathae villosae. Corollae laciniae subaecua- 
les, margine undulatae, praesertim inferne, $o b$ longae, obtusae, violaceae; tres mucrone terminatae.

Folia flabelliformia, saepe finduntur in apice ut in Areca. Thunb.

79. GLADIOLUS corollis subcampanulatis secun-fragrans. dis, spathis trivalvibus integerrimis, foliis ensiformibus. +

Gladiolus fragrans; corollis subcampanulatis, secundis; foliis ensiformibus plicatis, hirsutis; spathae tribus valvulis integerrimis omnibus. Jacqu. hort. schoenbr. 1. p. 7. t. 14.

Habitat in Cap. b. spei. 4

Spathae valvulae apice scariosae. Odor fragrantissimus. Jacqu. l. $c$.

so. GL.IDIOLUS corollis campanulatis, laciniis sambucinus. alternis subplicatis, spathis bivalvibus, foliis ensiformibus, scapo subcompresșo. †

Gladiolus sambucinus; corollis campanulatis; foliis ensiformibus, subplicatis, villosis; scapo ramoso glabro; spatha bivalvi; laciniis corollae alternis undulatis. Jacqu. hort. schoen.

I. p. 7. t. 15 .

Habitat ad Cap. b. spei. 4

Folia raciicalia circiter quatuor, plerumque scapo longiora, sexpollicaria, oblonga. Flores quini. Corolla coerulea, basi macula lutea: laciniae oblongae, obtusae, subaequales. Jacqu. $l . c$.

8r. GLADIOLUS corollae tubo spathis breviore, latifolius. foliis lato-lanceolatis scapo longioribus. $f$

Gladiolus hatifolius; hirsutus, foliis lato-lanceolatis plicatis nervosis raceno longioribus, tubo spathis breviore. Lamarck, illustr. $1 . p$. I 9 .

Habitat in insula Franciae. Commerson. 4

82. GILADIOLUS spicis secundis multifloris, spa-secundus. this glabris membranaceis apice laceris corollae ringentis tubo brevioribus. $f$

Gladiolus secundus; polystacliyus foliis plicatis hirsutis, corolla ringente, spathis gląbris. Thunb. prodr. 186. Act. soc. h. n. hafn. vol. 6. cum fig.

Habitat in Cap. b. spei. 4 
Folia scapo multo breviora, subpetiolata, plura usque sex, plicata, nililtinervia, hirsuta. Scapus spithamaeus, profunde descendens, flexuosus, glaber. Flores in ramis flexwosis, plurimi, interdum quindecim, secundi, coerulei. Spathae vix semiunguiculares, membranaceae, apice lacerae, striatae, brunneae. Corollae tubus spathis vix longior, filiformis. Thunb. l. c.

Flores distantes.

palerecus. 83. GLADIOLUS spicis imbricatis, corollae tubo filiformi spathis membranaceis hyalinis longiore, foliis linearibus.

Habitat in Cap. b. spei. Ex herbario Royenii. 4 Folia scapo breviora, nervosa. Scapus inferne vaginatus, pilis raris adspersus. Spica tripollicaris. Spathae paleaceae, lanceolatae, ferrugineo-maculatae et striatae. Corollae tubus bracteis duplo longior, filiformis.

spathaceus. 84. GLADIOLUS spicis imbricatis, corollae tubo spathis membranaceis glabris longiore.

Gladiolus spathaceus, caule ramoso, floribus spicato-imbricatis, spathis membranaceis aristatis, foliis plicatis. Lin. suppl. 96.

Gladiolus spathaceus; polystachyus, spathis membranaceis aristatis glabris, foliis ensiformibus plicatis hirsutis. Thunb. glad. n. 25 .

Habitat in Cap. b. spei. 4

Folia longitudine scapi.

Scapus spithamaeus. Spicae digitales, plurimae. Flores spathis multo longiores, albidi. Spathae saepe lacerae. Similis Gl. tubifloro et plicato. Thunb. i. c.

strictus. 85. GLADIOLUS spicis racemosis secmudis imbricatis, corollae tubo spathis breviore, foliis plicatis, scapo anguloso.

Gladiolus strictus; foliis lineari-lanceolatis villosis plicatis, tubo spathae aequali. Hort. keve. r. $p .63$.

Gladiolus nervosus; foliis ensiformibus plicatonervosis villosis, racemulis pluribus alternis, tubo spathis breviore. Lamarck. dict. bot. 2. p. 724 . illustr. 1. p. I 10.

Habitat in Cap. b. spei. 4 
Scapus pedalis, flexuosus, griseo-villosus. Folia caule breviora vel fere aequantia, pollicem $f e$ re lata, basi attenuata, acuta. Spicae plerumque ternae, remotae, patentes, quadriseptemflori. Flores saturate coerulei. Spathre trivalves, acutae: valunia exterior lineari-oblongu, obtusa, mucronata, villosa, duo interiores partum breviores, angustiores, acutae. Corollas laciniae alternae mucronatae.

36. GLADIOLUS spicis alternis secundis sessilibus mollis. imbricatis, spathis villosis apice membranaceis longitudine tubi.

Antholyza hirsuta; foliis ensiformibus, angustis nervosis; caule striato hirsuto; floribus adscendentibus, in spicas unilaterales dispositis. Lamarck. Dict. bot. 2. p. $20 \mathrm{r}$.

Gladiolus sulcatus; hirsutus, foliis lineari-ensiformibus, floribus ringentibus adscendentibus in spicas secundas dispositis, staminibus exsertis. Lamarck. illustr. I. $p$. 119.

Habitat in Cap. b. spei. 4

Scapus sesquipedalis, striato-angulatus, superne flexilosus, villoso-canescens, inferne aetate glaber. Folia spithamaea et zeltra, vix un. guem lata, sursum breviora et angustiora, molliter villosa. Spicae sessiles, circiter quatuor, remotae, octo-decemflorae, adscendentes. Spathae trivalves, villoso-canescentes: valizula exterior semipollicaris et parum ultra, linearilanceolaia, obtusa cum mucrone, interdum parum bifida; apice membranacea, fusca, glabra; interiores breviores, lanceolatae, attenuatae, acutae. Corolla fere bipollicaris: tubus spatha vix longior: Limbi laciniae angustae. Stamina limbo perum longiorn.

Differt a Glari. stricto: foliis modo siriatis nec nervosis: valvis exterioribus spatharum duplo longioribus: corollae tubo crassiore, sensinn in limTum desinente, spatha longiore, nec filiformi spatha breviore. A Glad. spathaceo, foliis minime plicatis: spathis non membranaceis, nec glabris. Ab Antholyza plicata: foliis non plicatis, nervis exstantibus: spathis lineari-lanceulatis, nec ovatis. 


\section{I20 TRIANDRIA. MONOGYNIA.}

\section{Minzes cogniti.}

pyramidalis, GLADIOLUS foliis lanceolatis nervosis, floribus sessilibus imbricatis, tubo lineari longitudine spathae. Burm. prodr. 2.

laceratus. GLADIOLUS foliis ensiformibus laceris, floribus tubo filiformi longissimo. Burm. prodr. 2.

punicens. GLADIOLUS foliis linearibus, floribus horizontalibus secundis immaculatis, petalis inferioribus paulo longioribus. Lamarck. dict. bot. 2. p. 727 .

Gladiolus flore ferme regulari miniato, angustifolius. Breyn. ic. rar. 24. $t$. 12. $f$. 1.

Varietas Glad. angusti secundum Burm. prodr. 2. an potius varietas Glad. brevifolii?

liliaceus. GLADIOLUS. Houtt, syst. pl. 11. p. 65. t. 79. f. 3 .

mucronatus. GLADIOLUS hirsutus, foliis lincaribus nerrosis, spathis tubo longioribus, petalis apice emarginatis mucronatis. Lamarcli. illustr. I. p. 139 .

Habitat in Cap. b. spei. 4

Flores magni. Racemus simplex.

Plures adhuc species tam hujus generis quam praecedentis in Andr. repositorio inveniri vidi ex Ephemeridibus variis; sed cum non nisi tabulae sexaginta tres hujus operis ad me perventernent, et sic species reliquae tantummodo ex solo nomine triviali notae, has enumerare nequeo.

Habitus. Scapus plerisque teres. Folia margine altero vaginantia, striata. Rachis flexuosa. Flores sessiles.

Genus, uti praecedens, quoaá diffeientias specificas difficillimum. Tereor quin pluerés non nisi rarietates sint et suepe vix nisi colore diversae, cum vero $a b$ auctoribus uti species distinctae habeniur a plurinorum opinione recedere noini. Semina Gladioli secunalum Jussiaeum arillati sunt, vix vero in omnibus.

99. Antholyza. Cor. tuhulosa, ringens, recur. va; laciniae laterales labii superioris breviores. 
1. ANTHOLYZA foliis ensiformihus utrinque at- aethiopica. tenuatis, spathis oblongis mucronatis, spica disticha.

Gladiolus aethiopicus, flore coccineo. Corn. ca-

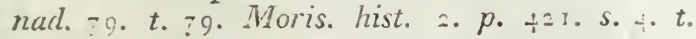
23. f. $T$.

Hyacinthus africanus; foliis colchici floribus coccineis. Plukn. tab. 1०5. f. 2.

Antholyza aethiopica; corollis incurvatis: labii quinquepartiti lobis duobus alternis petalis majoribus lanceolatis. Lin. spec. pl. 54.

Antholyza aethiopica; foliis ensiformihus utrinque attenuatis nervosis, spica oblonga disticha. Thunb. prodr. 7. anthol. n. 2.

Habitat in Cap. b. spei. 4

Folia longitudine fere scapi, fere policen lata, inferne latere aliero subito angustata, striata. Scapus interdum bipedalis. Spathae distantes, unguiculares, aequales. Cornllae tubo parte tenuiore spatha longiore: lobi duo laterales ovati, acuti.

2. ANTHOLYZA foliis ensiformibus plicatis, sca-ringers. po dichotomo villoso, spathis lanceolatis, snicis secundis.

Gladiolus floridus rictum referens coccineus : suprema lacinia erecta et fistulosa. Breyn. ic. rar. 2 i. t. s.f. .

Antholyza ringens; corollae lahiis divaricatis, fauce compressa, Lin. syst. veg. $8 \delta$.

Antholyza ringens; foliis ensiformibus plicatis, spica secunda, spathis lanceolatis glabris. Thunb. prodr. ?. anthol. n. 5.

Habitat in dunis Cap. b. spei. 2l

Folia plura, usque ad decem, plicata, sulcis interjectis proficndis, lineis elevatis flavescentibus pluribus nervosa, lor:gitudine scapi. Scapus profunace sub arcna, supra brevissimus, saepe vix pollicaris, totues foliis vestitus. Flores plurimi, approximati, purpurei, magni, specicsi. Spathae basi villosae, sesquipollicares. Corolla incarnata; rictus amplus. Thunb. l. c.

3. ANTHOIYYZA foliis ensiformibus utrinque atte- Cunonia, nuatis, scapo simplici glabro, spica disticha, spathis lanceolatis, 
Cunonia floribus sessilibus, spathis maximis. Bütr. cunt. $2 \mathrm{I}$. $f$. I.

Antholyza Cunonia ; corollis subpapilionaceis : labii lobis duobus externis latioribus adscendentibus. Lin. spec. pl. 5t. Mill. ic. I13.

Antholyza Cunonia; foliis ensiformibus glabris striatis, spica oblonga disticha. Thunb. prodr. 7. anthol. n. 4. Redouté plant. liliac. t. I2.

Habitat in Gap. b. spei. 4

Folia semiunguem vel parum ultra lata. Spica interdum secunda. Corollae labium superius obtusum, cuneatum, quinquepartitum: laciniis tribus intermediis minutis; lateralibus latis, quinta superiore dimidio breviore obtusa.

plicata. 4. ANTHOLYZA foliis ensiformibus plicatis, spicis secundis, spatinis ovatis villosis. Thunb. prodr. 7. Anthol. n. 6. †

Antiolyza plicata; foliis plicatis, caule ramoso hirsuto, corolla ringente staminibus breviore. Lin. suppl 96.

Habitat in Cap. b. spei. 4

Differt $a b$ Anth. ringente habitu et in eo guod organa genercitionis non adeo e?ongata ut in illa. Lin. l. c.

Folia temuissime villosa, scapo breviora. Spicae plurimae, sex-septem, alternae, multiflorae imbricatae; rachide villosa. Sprathate ovatae, apice ferrugineae, sublacerae, tubo paulo breviores, unguiculares. Thunb. $l$. $c$.

nervosa. 5. ANTHOLYZA foliis ensiformibus quadrinervosis, spica oblonga disticha. Thunt. prodr. 7 . anth. n. 3.

Habitat in Cap. b. spei. 4

Folia radicalia, circiter tria vel quatuor, iongitudine fere scapi. Scapus flexuosus, pedalis ct ultra. Flores approximati in spica ovata, subfastigiata, cernui, incarnati. Spathae ovatae, brunneae, tubo multo breviores. Thunb. l. c.

fuciton c. ANTHOLYZA foliis radicalibus basi filiformi apice linearibus nervosis, caule simplici folioso.

Antholyza lucidur; foliis radicalibus basi filiformi apice cilatato-subulatis, caule simplicissino folioso. Lin. suppl. 96. 
Antholyza lucidor; foliis basi filiformibus apice lincaribus nervosis, spica obionga disticha. Thunb. predr. 7. antit. n. I.

Habitat in Cap. b. spei. 2f

Folia radicalia basi angustata, longitudine scapi: convoluro-subulata, basi dilatatu. Scapus sesqui-bipedalis. Spathae valuulae inaequales, lanceclatae, purpurascentes. Flores perum incurvati. Stylus longitudine corollae: Stigma trifidum.

\section{Minus cognitae.}

ANTHOLYZA staminibus leclinetis, alis revolu- quadrangutis, foliis linearibus tetragonis. Eurm. prodr. laris.

Foliis longissimis. Scapo bicubitali. Spathis bivalvibus, oblongis. Burm. l. c.

ANTHOLYZA foliis ensiformibus, floribus tu. caryophyllabulosis aequalibus, laminis duobus superiori- cea. bus adscendentibus. Burm. prodr.

Convenit meltum cum Anth. Cunonia, nisi quod spathae et flores tenuiores, non adeo rubicundi, caryophyllacei. Scapus tripedalis. Folia rariora. Burm. $l$. $c$.

ANTHOLYZA. Houtt. syst. II. p. 77. t. 79.f.3. caryophyllea.

Potius Gladioli species et Meriano affinis ab Ant. caryophyllacea Burmanni diversa videtur. Tix tainen hujus generis.

Halitus. Folia disticha, striata. Scapus simplex, erectus, teres. Flores spicati.

Genus a Gladiolo cliaractcre difficile distinguitur, magis habitu a Gaertnero conjungitur.

100. Aristea. Petala $\kappa$. Styl. declinatus. Stigma infundibuliforme, hians. Caps. poly" sperma.

x. ARISTEA capitulo terminali, spathis laceris, cyanea. scapo ancipiti.

Perfiliato angustifolio montano Columnae similis planta umbellifera nova, fructu triplici nembranaceo, C. b. spei. Breyn. fasc. in cent. pl. 25. 


\section{I24 TRIANDRIA. MONOGYNIA.}

Gramen tomentosum pumilum promontorii bonae spei. Plukn. alm. 179. t. 299. f. 5 .

Ixia. Hort. cliff. 490.

Ixia foliis ad radicem nervosis, gramineis, flori-

I bus ic fructu pappo convolutis. Burm. afr. г $\rightarrow$ r. $t . \rightarrow$. $f$. $=$.

Moraea africana; floribus capitatis, spathis laceris. Lin. syst. veg. 95

Moraea africana; scapo ancipiti, foliis distichis, floribus capitatis, spathis membranaceis laceris. Thunb. mor. n. 3 .

Aristea cyanea. Hort. kew. T. p. 67.

Aristea cyanea; foliis ensiformibus, radicalibus; floribus capitatis cyaneis. Andr. repos. $t$. Io.

Habitat in Cap. b. spei. 4

Planta digitalis. Scapi plures. Folia radicalia scapo parum breviora, unicum vel duo in scapo. Spathae duce, oppositae, longitudine florum, lanceolatae, fuscae, apice et margine membranaceae, paliidae, lacero-multipartitae. Flores coerulei, interdum capitulum praeter terminale ex axilla vaginae supromae.

spiralis, 2. ARISTEA floribus alternis subsecundis, scapo ancipiti.

Moraea spiralis; caule compresso articulato multifloro, foliis ensiformibus erectis, floribus axillaribus. Lin. suppl. 99.

Moraea spiralis; scapo compresso articulato, foliis erectis, floribus alternis subsecundis. Thunb. mor. n. 2.

Habitat ad Cap. b. spei. 4

Scapus anceps, pedalis. Folia radica?ia scapo vix breviora, erecta, acuta: scapi spathaeformes. Flores laterales. Spathae longitudine corollae, subbiflorae, concavae, acuminatae, brunneae. Corolla albido-coerulea: laciniae aequales, pollicares, ovatae, oltusae, extus albo-virescentes, intus albae, inferne crassae, basi intus macula cordata, purpurea. Stigma simplex, truncatum, villosum, violacezm.

coerulea. 3. ARISTEA floribus capitatis racemosis, spathis integerrimis, scapo tereti.

Gladiolus capitatus; caule ramoso, capitulis pedunculatis, radice tuberosa. Lin. spec. pl. 53. 
Moraea coerulea; scapo tereti, foliis distichis, florum calvitulis alternis, spathis membranaceis integris. Thunb. mor. n. +5. t.2.

Habitat in Cap. b. spei. 4

Scapus bipedalis. simplex, erectus. Folia radicalia plurima, scapo breviora: scapi similia, vaginantia, internodiis longiora. Florurn capitula superne, pedunculata: pedunculi alterni, unguiculares, teretes. Spathae universales longitudine capituli, lanceolatae, attenuatae, concavae: partiales ovatae, margine membranaceae. Corolla subhexapetala, coerulea: laciniae ovatae, obtusne, concavae, erecto-patentes, venosae, alternae paulo angustiores. Stigma simplex, obtusum, trigonum.

Habitus. Folia radicalia disticha, erecta, lineariensiformia, striata, uti reliqua planta glabra. Scapus erectus, in pedunculos divisus, articulaius, subtilissime striatus, fusco-purpurascens.

10I. IRIs. Cor. 6-partita: laciniis alternis reflexis. Stigmata petaliformia.

* Corollis barbatis.

- Foliis ensiformibus.

r. InIS caule unifloro foliis longiore, laciniis co-susiana. rollae deflexis minoribus.

Iris calcedonica variegata. Lobel. ic. 67 .

Iris susiana. Cliıs. pann. 243.

Iris latifolia major. Clus. hist. r. p. 2 r 7 .

Iris chalcedonica latifolia. Besl. hort. eyst. vern. ord. s. fol. 4 .

Iris susiana; corolla barbata, caule foliis longiore unifloro. Lin. spec. pl. 55. Curt. mag. 3. t. 91. Redonté plant. lil. t. I8.

Habitat in Oriente. $V$ enit Constantinopoli in Belgium $1572 . \psi$

Caulis pedalis, simplex, uniflorus, sulcatus. Folia semiunguem vel parum ultra lata, sursum minora, ereclu, tenuissime striata. Corulla omnitsm cogenerum maxima, albo subnigroque variegata: Laciniae erectce subrotundae, undulatae, apice inflexo: minores deflexre, ovatae, obtusae, margine sacpe retroflexus, pa- 
rum dilutius coloratae, involutae. Stigmata Bifida: laciniae ovatae, crenatae. Capsula obsolete trigona, acuminata. - के

Aorentina. 2. IPIS caule foliis altiore subbifloro, floribus sessilibus.

Iris florentina. Bes?. hort. eyst. vern. ord. 8. fol. A.

Iris alba florentina. Bauh. theatr. 577. pin. 3 r.

Iris florentina; corollis barbatis, caule foliis altiore subbifloro, floribus sessilibus. Lin. spec. pl. 55. Redouté liliac. t. 23.

e. Iris nostras vulgaris candidis floribus. Lob. ic. 59.

Iris alba germanica. Bauh. tineatr. 576. pin. $3 \mathrm{r}$.

Habitat in Europa australiori, Carniolia. 4

Caulis sesquipedalis, crassitie digiti minimi et ultra, striatus. Folia sesquipollicem fere lata, nervosa, glaucescentia. Corolla alla, interne tinctura laevi coerulea: laciniae exteriores dependenies, obtusae, apice subdentato-repandae, basi extus viridi-venosae: interiores oblongae, basi plicato-unduiatae. Stigmata corolla concolora, bificia; lacinine acutae, crenulatae. Capsula pollicaris, acuminata. \&્

Flores et radix odorati.

germanica. 3. IRIS caule multifloro foliis altiore, floribus inferioribus pedunculatis, spathis adultioribus coloratis. Lin. spec. pl. 55. Pollich. pal. n. 34. Yreos. Cube ed. alt. n. 538 .

Iris germanica. Fuchs. 317 .

Iris latifolia vulgaris coerulea. Besl. hort. eyst. vern. ord. s. fol. 5 .

Iris vulgaris violacea. Bauh. hist. 2. p. ?09.

Habitat in Germuniae, Helvetiae, Galliae et Italiae incultis et muris. 4

Caulis inferne divisus, subbipedalis. Folia sesquipollicem lata, reflexo-falcata, nervosa. Spathae virides, margine et apice membranaceae. Corolla magna, violaceo-purpurea: laciniae exteriores planae, obovatae; interiores integerrimae, spathulatae; lamina oblonga nec marginata, dilutius colorata, magnitudine 
fere exteriorum; onnes extrorsum inaequaliter dentatae. Stigmata violacea; laciniis serratis. Parum odora. 广s

Varietas plures habet Clusius.

4. IRIS foliis caule multifloro brevioribus, floribus pallide sessilibus, spathis albis.

Iris dilute coerulea, involucro albo. Tabern. ic. 6 . 7 .

Iris hortensis, pallide coerulea. Bauh. 3 r. Tournef. inst. r. herb. 358 .

Iris pallida; corollis barbatis, caule foliis altiore multifloro, spathis albis. Lamarck. dict. bot. 3. p. 294. illustr. r. p. ז2 г.

Iris odoratissima; barbata; foliis ensiformibus, glabris, brevioribus scapo multifloro; petalis magnitudine omnibus aequalibus. Jacqu. hort. Schoenbr. ז. p. 5. t. o.

f. Iris hortensis, palide coerulea, involucro albo, minor. Thournef. inst. $r$. kerb. 358 .

Habitat in Oriente? 4

Caulis altior quam in reliquis, tripedalis. Folia sesquipollicem lata. Flores remoti, gemini ad quinque in singula spatha. Spathae lanceolatae, aridae ante quam flores erumpunt. Coxollae laciniae exteriores obovatae, extus inferne carina viridi, supra dilute coeruleae, basi violaceo-fuscescente-venosae, integerrimae, vix emarginatae; barba alba, apice flava: interiores convexe conniventes, superne margine sub. dentatae, spathulatae, inferne integerrimae, urgue albido canaliculato, venis fuscescentibus picto, coeterum majoribus concolores. Stigmata colore petalorum, margine dilutiora, bifida, lacinits serratis, acutis. - 6

5. InIS caule subbifloro longitudine foliorum, orientalis. germinibus trigonis. +

Koli Tsubatta. Kaemph. amoen. 5. p. 872.

Iris germanica. Thunb. fl. jap. 33.

Iris orientalis; imberbis, foliis linearibus, scapo subbifloro tereti-articulato, germinibus trigonis, corollis reticulatis. Thunb. in act. soc. Lin. 2. p. 328 .

Habitat in Japonia. 4 
Caulis pedatis et ultra, articulatus, striatus. Folia linearia, apice attenuata, nervosa, glabra. Spathae foliis similes, sensim breviores. Flores subterminales. Corolla fusco-reticulata. Thunb. l. c.

sambucina. 6. IPIS caule multifloro foliis altiore, laciniis corollae emarginatis exterioribus planis.

Iris major latifolia. 8. Clus. hist. I. p. 210.

Iris latifolia belgica odore sambuci. Bauh. theatr. 589.

Tris latifolia, cui in flore crassae venae purpureae. Bauh. hist. 2. $p .7 \times 7$.

Iris sambucina; corollis barbatis, caule foliis altiore multifloro, petalis deflexis planis: erectis emarginatis. Lin. spec. pl. 55. Jacqu. hort. Find. 1. p. 1. t. 2. Curt. mag. 6. t. 187.

Habitat in - - -

Caulis bipedalis, superne divisus. Folia sesquipollicem la:a, sensim minora, apice inflexo-falcata, nervosa. Spathae uniflorae, bivalves, valvulis ovatis, margine vioiaceis, apice membranaceis. Flores inferiores pedunculati. Corollae laciniae exteriores oblongae, integerrimae, basin versits venis saturatioribus violaceis pictae, cum interstitiis dilutioribus: intcriores cbovutac, incurvato-arcuutae, vix denticuiatae, ciiinte coeruleae, hasi violaceo-subvenosae. Stigmatis latera albido-coerulescentia, carina coeru'ea; lacinuis acutis serratis. \&.

lurida. $\%$. IfIS caule foliis altiore multifloro, petalis exterioribus revolutis, interioribus erecto - inflexis subundulatis subemarginatis. Hort. kew. I. $p$. is. $\div$

Habitat in Europa austraii. 4

Petala exteriora retroflexa, atro-purpurea, infra medium lituris flavicantibus ornata: barba luiea: interiora obovaio-oblonga, exterioribus paulo breviora; lamina purpurascente, ungue squalido lutescente. Stigmata squalide lutescentia, superne pallide purpurascentia. Hort. kew. l. c.

An varietas Ireos sambucinae? sed omnino inodora. Hort. kew. l. c. 
8. IrIS caule multifloro foliis altiore, corollae la-squniens. ciniis deflexis replicatis, erectis emarginatis. Iris folio lato rugoso, petalis repandis ex purpu. reo sordido pallido et luteo variis, erectis vero squaide lutescentibus. Boerh. Lugdb. 2. p. $\quad I=+$.

Iris squalens; corollis harbatis, caule foliis altio. re multifloro, petalis deflexis replicatis, erec. tis emarginatis. Lin. spec. pl. 56.

Fiubitat in Europa australi. 4

Caulis bipedalis, superne in pedunculos divisus. Folia nervosa, acuta; caulina in medio ultra pollicem lata. Spathae vix bipollicares, obtusae, ventricosae, unijlorae, lanceolatae, margine purpurascentes. Floies remoti, superiores brevius pedunculati. Corollae laciniae exteriores oblongae, integerrinae, minime enarginatae; extus basi viridi-flavescentes, venis obsolete sulpurpurascentiós, extrorsum saturate purpureis; supra a basi ad medium albae, simpliciter violaceo-venosae, margine flavae, venis et punctis paucis violaceis ornatae; a medio ad apicem intense purpureo-violaceae; barba flava, apice violacea: interiores spatiulatae; laminae oblongae, stigmatibus duplo longiores, superne serratae, inferne integerrimae sordide flavescentes, cum tinctura violacea, basi extus viridi-flavescentes, supra violaceae, margine violaceo-venosae. Germen oblongum, subtrigonum, sexsulcatum. Stigmata sordide flavescentia, carina lutea laciniis acutis, serrulatis. मे०

9. IRIS foliis falcatis glabris caule compresso mul- japonisa. tifloro brevioribus. Thunb. in act. soc. lin. 2 . p. $327 .+$

Saga et Siaga. Kaempf. Amoen. 5. p. 872 .

Iris squalens. Thunb. jap. 33.

Habitat in Japonia.

Caulis pedalis, articulatus, striatus, glaber. Folia nervosa. Spathae sub floribus foliis similes, obversae, sensim breviores. Corollae albae. Tluunb. $l$. $c$.

vo. IRIS caule multifloro, foliis aequantibus, laci- variegata. niis corollae deflexis emarginatis. 


\section{TRIANDRIA. MONOGYNIA.}

Iris lutea variegata. Lob. hist. 34. Ehr, pict. $t$. io. f. 3-

Iris major latifolia. Clus. hist. r. p. $22 \mathrm{r}$.

Iris pannonica variegata. Besl. hort. eyst. pern. ord. Q. fol. 6.

Iris latifolia pannonica colore multiplici. Bauh. theatr. $58 \%$

Iris lutea, foliis repandis variegatis, Eauh. hist. 2. p. 720 .

Iris variegata; corollis barbatis, caule subfolioso Iongitudine foliorum multifioro. Lin. syst. veg. 90. Cuit. mag. 1. t. 16.

Habitat in Austria. 4

Caulis fere bipodalis, foliis parum longicr. Fo. lia policem lata, erecta, acuta; superiora sensim breviora. Flores superne, circiter quatuor, remoit, pedunculati, flavi, speciosi, superior primun florens. Sputhae iniflorae, ovato. ianceolaiae. Corollae laciniae exteriores deflexae, cunciformes, cxtus viridi-fiavescentes, supra albidae, pictae lineis purpureo-violaceis, ranosis, versus marginem abruptis, integerrimae, emarginatae, basi flavescentes: interiores oblongar, basi attenuatae, canaliculatae, integerrimae, flavae, lituris angusits purpurecviolaceis. Germen oblongum, sexsulcatum, angulis obtusis. Stigmata flava, bifida; laciniis acutis, serratis. $\because$

Swertii. $1 x$. IRIS foliis caule trifloro brevioribus, laciniis corollae majoribus undulatis reflexis, minoribus emarginatis.

Iris alba oris coeruleis. Swert. floril. $t .4 \mathbf{r}, f$. $\mathbf{r}_{\text {? }}$ Iris latifolia minor alba, oris coeruleis. Tournef. inst. $r . h . p .35 \%$.

Iris latifolia minor alba, oris dilute purpureis. Tournef. inst. r. h. p. 358 .

Iris Swertii; corollis barbatis, caule trifloro foliis altiore, petalis undulatis replicatis subemarginatis. Lamarck. dict. bot. 3. p. 296. illusir. $\mathrm{r}, p .12 \mathrm{I}$.

Habitat in - - -4

Radix odora. Caulis sesquipedalis, inferre foliis nonnullis ziestitus. Folia vix pollicem lata. Flo. res superne, tres, breviter pedunculati. Spa- 
thae aridae. Petala alba: majora extus dorso viriclia, margine violaceo punctaia, versus medium utringue zenis ronzullis violaceis picta; minora apice conniventia, spathulata; ungue violaceo convexo; lamina oblonga, integerrima, carina picta linea violacea, inferne integerrima, sursum venas emittens, margine parum violacea; supra linea violacea ab apice al medium áucta. Barba apice lutea, pili superiores violaceo tincti. Germen oblongum, obsczere triquetrum, laeve. Stigmata violacea, utinque versus marginem albidla, petalis interioribus dimidio breviora, lifida; lacinius acutis, extrorsum serratis, inferne integerrimis. sp $^{\circ}$

12. IPIS caule subtrifloro fistuloso, foliis lineari- Alexusa. ensiformibus altiore. +

Iris candidis floribus angustifolia. Lob. adv. 2. p. 4.79 . ?

Iris flexuosa; corollis barbatis, caule crasso, fistuloso, subfolioso, trifloro, altiori folis angustis flexuosis. Murr. in nov. comm. Tom. 7. p. 30. t. 4 .

Habitat in Germania? $\%$

Caulis crassus. Folia tertiam pollicis partem la$t a$, caulina pauca. Spatha ferruginea, bivel multivalvis. Corolla alba: Limbi lacinia reflexae denticulatae, ungue luteo venis violaceis picto; erectae dimidio fere breviores, undulatae. Germen trigonum. Stigmatum laciniae crenatae. Murr. l. c.

Toto habitu similis Ir. sibiricae, at corollae barbatae.

An Lobel. synonymum huc pertinet? varietatem etenim Ir. silbiricae vidi floribus albis.

13. IRIS caule multifloro tereti foliis altiore, la- plica:n. ciniis corollae plicatis, erectis latioribus. $\mathbf{L} a$ marck dict. bot. 3. p. 297. illustr. 1. p. 121. +

Habitat - - 4

Caulis tripedalis. Folia pedalia, viridi-glaucescentia. Spathae membranaceae, interdum biflorae. Flores Ir. germanicae duplo minores, odore Aurantii, albido et dilute coeruleo variegati. Corollae laciniae superne basi intense purpureo-venosae, medio albidae et concavae: 


\section{\$32 TRIANDRIA. MONOGYNIA.}

reflexae margine inflexae: erectae rotundatas. Stigmata pallide violacea; laciniis vix dentatis. Germen cylindricum, sexsulcatum. Lamarck. l. $c$.

bifora. 4. InIS scapo tereti subirifloro foliis longiore, laciniis corollae deflexis erectis angustioribus. Chanaeiris latifolia bifiora. Eesl. hort. eyst. vern. ord. c. fol. 1 .

Chamaeiris major saturate purpurea bifiora. Barti. pin. 3.3 .

Iris biflora; corollis barbatis, caule foliis breviorihus trifioro. Lin. sy.st. veg. 90.

Hnbitat in Iusitaniae rupibus. 26

Folia sterilia tria-quinque, spithamaea et ulira, inasqualia, pollicem lata, falcata, acuta. Scapi ad latera foliorum steriium, plerumque duo, foliis sierilibus parum alioribus, basi foiiis duobus vel tribus brevissimis steritibus angustioribis vaginati, alter inier duas vaginas spathaseas ortus, alter nudius, laeves. Flores superne, plerumque gemini, sulsessiles. Spathae ovatae, oblongae, tubo corollae ampliores, curinatae, attenuatae, viridi-violaceae. Coroila intense purpuren-violacea: laciniae obsolete denticulatae, minime emarginatae; tres deflexae, erectis parum angustioribus; tres erectae, arcuatim superne conniventes, spathulatae; lamina ob́longa. Germen tubo triplo brevius, tereitusculum, subsexlineatum. Stigmata longitudine harbae, laciniis corollae concolora, bifida; laciniis ovatis acutis extror. sum dentata.

cristata. 15. IRIS caule compresso subunifloro longitudine foliorum, laciniis corollarum aequalibus, barba cristata, germinibus trigonis. $t$

Iris cristata; corollis barbatis: barba cristata, caule subunifloro longitudine foliorum, germinibus trigonis, petalis subaequalibus. Hort. kew. x. p. 70. Smith. spicil. bot. 1. p. 12, t. 13. Curt. marg. I2. t. 412 .

Iris cristata; pumila, uni-biflora: calycis tubo setaceo; Incinis 3 fascia subtrifariam undulato-crenatis. Mich. fl. bor anier. I. p. $2 \approx 0$

Habitat in America boreali. 24 
Radir repens. Caules plurimi, vix digitales. Folia vix semipedalia, apice subfalcata, margine pallido membranaceo. Flos subsolitarius, fulis parum humilior, erectus, purpureo-cyanetis. Curollae laciniae exterivies dependentes, ol.longae, obtusae, coeruleae, maculis su uraitonibus, in medio lineis tribu: longitudinali'nus elevaits, indulatis, luteo fulvogue variegatis loco tarbae: interiores parum angustiores, acutce, totne coerulecue. Stirmata liciniis corollae dimidio breviora et concolora. Hort. kew. et Smith. l. c.

*6. IRIS scapo compresso, multifloro, stigmati- chinensis. bus laciniatis.

Iris chinensis; radice repente, caule paniculato multifloro, floribus cristatis, sigmatibus laciniatis. Curt. mag. 1 I. $t .373$.

Iris fimbriata; foliis scapo compresso multifforo vix brevioribus; stigmatibus fimbriatis. Vent. hort. cels. ${ }^{-}$. $t$. 9.

Hubitat in China. 4

Folia scapo parum breviora, pollicem fere lata, sensim attenuata. Scapus vix semipedalis, cras. sitie pennae anserinae, superne in pedunculos divisus, inter flores flexuosus. Pedunculi bitriflori. Spathae bivalves, oblongae, acutae. Flores pedunçulati, pallide coerulescentes. Corollae laciniae inaequaliter dentatae: exteriores subcuneatae, flavo maculatae: interiores immaculatae. Stigmata bifida.

Affinis praecedenti.

37. IRIS foliis, glabris scapum teretem multiflorum aphylia. nudum aequantibus.

Iris major lutifulia : 5. Clus. hist. I. p. $=23$.

Iris latifolia, caule aphyllo. Bauh. pin. 52

Iris flore violaceo, folio virente. Bauh. hist. 2. p. 723 .

Ixis aphylla; corollis tarbatis; scapo nudo longitudine foliorum. Lin. syst. veg. 90.

Iris nudicaulis; corollis harbatis, scapis subternis nudis suhmultifloris, spathis ventricosis viridibus, Lamarck, dict, 3. p. 296. illustr. ‥ p. $12 \mathrm{t}$.

Fiabitat in ---4 


\section{I34 TRPANDRIA. MONOGYNIA:}

Folia radicalia, pedalia, pollicem lata, glabra, nervosa. Scapi ad latcra foliorum, frequenter tres, laterales uniflori, intermedius bi-triflorus. Spathae ventricosae, virides, acuminatac. Corolla magna, purpureo-violacea: petala exteriora ovalia, basi albida venis picta: inteteriora magnitudine exteriorum. Stigmata petalis concolora: laciniis serratis. Germen trigonum. Iamarck. l. $c$.

arenaria. 18. IRIS foliis scapo brevissimo bifloro longioribus, flore superiore ahortiente. Kitaib. plant. rar. Hungr. i. p. 57. t. 57. +

Habitat in Hungariae arenosis. 4

Scapus sesquipollicaris, erectus, rarissime unifloris, nitidus. Folia pauca, glabra, subnervosa. Flores brevissime pedunculati: alter qui primus floret abortiens; alter inferior, uno alterove die serius evolvendus, fertilis Spatha trivalvis, submembranacea, pallida, nitida: valvulae duae exteriores, subinflatae, carinatae, acutae vel acuminatae; interior minor, si flores duo adsunt, apice bifida, dorso canaliculata, si unicus, apice integra, dorso. laevi. Corolla pallide flava: petala abtusa, superne subcrenata, emarginata, basi rubroviolaceo-venosa: interiora versus basin subundulata: tubus pallide virens: Barba croceo flava. Antherae cinereo-purpurascentes. Germen $o b$ tuse subtriangulatum, sexsulcatum, nitidum. Stigmatum labium exterius albidum cum sulco. lutescente; interius pallide flavum, bifidum; laciniis undulatis, versus apicem denticulatis.

Affinis Ir.lutescenti, differt: scapo foliis breviore, bifloro, flore altero abortiente: spata inflata.

tutcscens. 9 . IRIS scapo brevissimo subunifloro, spatha erecta longitudine tubi.

Chamaeiris latifolia minor 9. Clus. hist. 227.

Chamaeiris minor ochroleucos. Bauh. theatr. 612.

Chamaeiris flore pallide luteo 8. Chamaeiris minor ochroleuca. Bauh. pin. 34.

Iris lutcscens; corollis barbatis, caule unifloro, foliis longiore, tubo in spatham incluso. Lamarcli, dict. bot. 3. p. 297 . illustr. 1. p. 122.

Fabitat in Germaniae et Galliae locis montosis. 2f 
Similis praecsdenti, differre videtur: Foliis glaucis, scupo brevioribus: Scapo uri.bifloro: Corolla albido-flavescente, laciniis exterioribus basi violaceo - reticulatis undulatis: Spathis tuZum arcte involventibus. Wilden.

20. IRIS scapo bifloro foliis longiore, spathis lon. Pavissina. gitudine tubi.

Iris humilis angustifolia lutea, testa seminali rostrata alba. Amm. ruth. $p$. ror.

Iris foliis ensiformibus, caule bifloro. Gmel. sio. 1. p. 31. t. $5 . f .2$.

Iris flavissima. Pall. it. 3. app. n. $6 \pi$.

Iris flavissima barbata, foliis ensiformibus glabris, caule bifloro. Jacqu. coll. 4. p. qs. ic. rar. 3. t. 200.

Habitat in regionibus Transbai Kalensibus Sibiriae, locis humidis. 4

Affinis Ir: pumilae, differt Foliis angustioribus, magis linearibus: Scapo proceriore, tenuiore, longius inter duo folia exserto, nec undique $e$ spadice vaginato: Spatha brevior quam in reliquis: valvulis subaequalibus; gluma exili, tenuiore inter flores. Corollae tubus, longitudine spathae: laciniae intense flavae, vonis fuscescentibus striatae; barba flava: interiores angustiores. Pall. $l$. 6 .

ax. IRIS scapo brevissimo unifloro, spatae corollae punila. tubo breviores, laciniis reflexis erectis angustioribus.

Chamaeiris latifolia mino:. Clus hist. r. p. 225 . Chamaeiris minor, flore purpureo. Bauh. pin. 33. f. Chamaeiris latifolia minor.

Chamaeiris flore purpureo-coeruleo. Bauh. pin. 3.3 .

\%. Chamaeiris minor flore rubello. Eauh. pin. 33.

o. Chamaeiris latifolia minor pallina et alba. Clus. pair. 225. Bauk. pin. 33 .

Chanaeiris latifolia minor 4. Clus. hist. 2. p. 225. Besl. hart. eyst. vern ord. 8. fol. r.

\&. Chamaeiris latifolia minor varia Clus. par. 225.

Chamaeiris latifolia minor 5. Clus. hist. 225., Chamaeiris minor flore variegato. Bauh. pin. 34. 5. Iris angustifolia maritima minor, Eazeh. pir. 33. 


\section{I36 TRIANDRIA. MONOGYNIA.}

भ. Chamaeiris lutea altera. Loh. ic. 66.

Chamaeiris flore luteo et pallide luteo. Bauh. pin. 34 .

2. Perpusilla saxatilis $I$ is latifolia acaulis ferme. Lob. ic. 5 .

Chamaeiris saxatilis gallica. Bath. pin. 34.

Iris pumila; corollis harhatis, caule foliis bre. viore unifloro. Lin. syst. veg. 9. Jacqu. austr. . p. .t. . Curt. mag. I. $t$. o.

Ilabilat in Galliae, Austriae, Pannoniae collibus sterilihus. 4

Folia circiter quinque, quadri-quinquepollicaria, pollicem interdum lata. Scapus vix sesynipollicaris, simplex, inferne subcompressus, spathis vaginatus. Spathae tres, prope germen ortae, scapo parum ampliores, lineari-lanceolatae, uniangulatae, acuminatae, pallide virescentes, exterior interioribus longior. Corollae tubus tri-quadripollicaris, spathis longior: laciniae emarginatae; exteriores primum patentis, dein superne reflexae, oblongae, basin versus sensim angustiores, ferne margine reflexae: interiores latiores, longitudine exteriorum, sursum arcuatin conniventes; lamina ovato-oblonga. Germen vix trigonum, tubo corollae parum crassius, obsolete sexstriatum. Stigmata corollae concolora, bificia; laciniis ovatis, attemuatis, serratis. \&्.

Tarietates plures praeter enumeratas dantur, illa flore flavescente gaudet laciniis corollae exterioribus a medio ad basin sordido virescentibus.

fichotoma 22. IRIS subacaulis, scapo paniculato tereti, ramis bi-quadrifloris. $\frac{1}{-}$

Iris dichotoma latifolia, variegata procerior. Amm. ruth. 103 .

Iris dichotoma, Pall. it. 3. app.n. 6r, t. A. f. 2.

Iris dichotoma; corolla tenuissime barbata, cau- Ie tereti elongato paniculato, ramis alternis. divaricatis bi-s-quadrifloris. Lin. szppl. 97.

Habitat in rupestribus apricis totius. Dauriae. 4

Caulis inferne tectus foliis sex-septem, subradicatis, foliis altior, subflexuosus: Rami simplices, elongati, patentissimi, suffulti folio brevissimo, terminati spatha diphylla, bi-tri-quadriflora. 


\section{TRIANDRIA. MONOGYNIA.}

Flores omnium congererum minimi, longe pedunculati. Corollae laciniae exteriores parum majwes, villis vix conspicuis barbatae, violascentes, alho punctatae: interiores saturatiores, bilohae. Stimata angusta, acuminata, bifida. Causula mrjus ula, obsoiete trigona, acuminata. Pall. et Lin. l. c.

23. IPIS filiis glabris, caule paniculato compres- compressa. s:). Thu b. diss. n. Tर. +

Iris compressa; corallis barbatis, foliis ensiformihus planis, caule ramoso compresso. Lin. suppl. 98.

Habitat in Cap. b. spei. 4

Caulis frutescens, pedalis, decumbens, apice erec. tiusculus, dichotome ramosus, articulatus, bracteatus, striatus, giaber: Rami elongati, uniflori. Folia caule breviora, acuta, nervosa, glabra. Bracteae seu spathae ir caule et ramis alternae, lanceolatae, policares, interno. diis breviores, apice membranaceae, carina acutae, glabrae, fusco-jerrugineae, striatae. Corollae laminae obtusae. Stigmata albo-coerule. scentia: labium exterius crenulatum: interius bifidum; laciniae lanceolatae, erectae. Thunb. l. $c$.

24. IRIS foliis ciliatis, petalis minoribus obova-cilis?2. tis. $t$

Iris ciliata; corollis barbatis, foliis lanceolatis undulatis ciliatis, petalis alternis obovatis. Lin. suppl. 98 .

Iris ciliata; barhata, foliis ensiformibus ciliatis, Thunb. Ir. n. I.

Habitat in collibus ad Cap. b. spei. 2/,

Caules plures, plurimi in vaginis fuliorum reconditi, unicus florens, lotus vaginatus, simplex, palmaris, debilis, uniflorus, compressus, glaber, albies. Folia radicalia çirciter sena, sçapo subaequalia, interiora sensim breviora, basi convoluta, scapum ad summum alternation vaginantia, erecto-patentia vel recurva, acuminata, nervosa, glabra. Curolla intea. Stigmatis labium interius bifidiem; laciniae setaceae. Capsulae trigonae, sulcatac. Thumb, \& $c$. 
ainuta. 25. IlIS glabra, scapis unifloris, petalis minoribus lanceolatis. $f$

Iris minuta; corollis barbatis, foliis lanceolatis clabris, petalis alternis trifidis. Lin. suppl. ng.

Iris minuta; barbata, foliis ensiformibus glabris, scapo unifioro, petalis oblongis acutis. Thunb. diss. n. 2.

Hchitat in monte Leuwestart ad Cap. b. spei. 4 Caulis simplex, palmaris, foliis vaginatus. Folia circiter quatuor, alternatim vaginantia, scapum aequanita, siperiora sensim breviora, subfalcato-reflexa. Corolla lutea. Thunb. $l . c$.

- Foliis lineariuzes.

rripetala. 26. IRIS folio scapo unifloro longiore, petalis alternis subulatis. Thunb. diss. $n$. id.

Iris tripetala; corollis barbatis, folio radicali unico lineari-ensiformi canaliculato, petalis alternis subulatis. Lin. suppl. 97. Jacqu. collect. 3. p. 272 . Ic. rar. 2. t. 24.

Habitat in Cap. b. spei. 4

Folium unicum, vaginans, scapo duplo longizs, laxum, dependens, canaliculatum, glabrum, nervosum. Scapus simplex, pedalis, subuniflorus, geniculatus, glaber: genicula bracteis spathis similibus amplexata. Flos terminalis, solitarius. Spatha bivalvis, pedunculum amplectens, inferior brevior, acuta, glabra, unguicularis vel ultra. Corolla cocrilea; laminae ovatae, acutae: petalorum minorum line ari-subulatae. Germen sexsulcatum. Stigmata linearia: labium exterius obtisum; interius longissimum, longitudine fere laminarum. Thunb. $l$. c.

* Corollis imberbibus.

- Foliis ensiformibus.

seud-Aco- 27. IRIS foliis planis, laciniis corollae interiorirus. bus stigmate minoribus.

Gladiolus. Cube ed. alt. n. 2 1. Acorus. Brunsf. herb. 2. p. 27. Acorus officinarum. Fuch. 13. Acorus adulterinus, Bauh. theatr. 634. 
Ixis Pseur-Acorus; corollis imberbihus, petalis interioribus stigrnate ninoribus Lin. spec. pl. 5.. Fl. dan. t. +94. Pollich pal. n. 35 ,

Eabitat in Europa as ripus paludum et fossa. rum. 4

Caulis tripedalis, tri-qualififorus, superne pa. rum flexuosus. Folia caulem aequantia, pol. licem laia, minus rigida quam Ir. germanicae. Spathae lanceolatae, tripollicares, pollicem ratae. Corolla flava.

28. IRIS caule uniangulato mulifforo foliis lon-foetidissima giore.

Spathula foetida. Cub. edit. 2. n. 49. Fuch. 797. Besl. hort. eyst. vern. ord. 8. fo?. \&.

Xyris et Iris agria Theophrasti. Lobel. ic.

Gladiolus foetidus. Bauls. theatr. 564 .

Spathula foetida, xyris. Bauh. hist. 2. p. 73 .

Iris foetidissima; corollis imberbibus, petalis inferioribus patentissimis, caule uniangulato, foliis ensiformibus. Lir. spec. pl. 57 .

Habitat in Gallia, Anglia, Hetruria. 4

Caulis bipcdalis, simplex, semiteres, articulatus, foliis spathaceis vaginatus. Folia acuta, ner. vosa, foetida. Corolla coerulescenti-tristis; ungues laciniarum exteriarum subtus plicis rugosis: Petala interiora patula, stigmatibus majora. भ-

9. IRIS caule tereti flexuaso folia aequante, ger- versicolor. minibus subtrigonis.

Iris americana versicolor, stylo non crenato. Dili. Elth. 187. t. 1 $55 \cdot f$. 187 .

Iris americana versicolor, stylo crenato. Dill. Elth. $188 . t$. $155 \cdot f$. 188 .

Iris latifolia virginiana, florum petalis repandis purpureis. Ehret. pict. t. t. $f .=$.

Iris versicolor; corollis imberbibus, germinibus subtrigonis, caule tereti flexuoso, follis ensiformibus. Lin. spec. pl. 57. Curt. mag. I. t. $2 \mathrm{r}$.

Habitat in Virginia, Pensylvania, Marilandia. 2\%

Caulis bipedalis, simplex 2e? superne bificius, bi-triflorus, crticuslatus. Folia semipoilicem lata, vaginantia, sursum sensim breviora. Pedunculi alterni, breves. Spathae lan. ceolatae, longitudine tubi corollae Flores 
magnituäine $I r$. sibiricae. Corollae lacinias exteriores semipollicem latae, iniegerrimae, emarginuiae, exius a basi ad medium virescentes, carina alba, extrorsum purpureo-violaceae; suyra extrorsum purureo-violaceae, inferne albidae venis et punctis violaceis pictae, medio lu. teae: interiores patentes cuneatae, longitudine stigmatum, integerrimae, coeruleo-violaceae. Germen trigonum, absque sulcis. Stiomata violacea, margine albida, bifida, laciniis obtusis.

virginica. 30. IRIS caule ancipiti multifloro foliis altiore. +

Iris virginica; corollis imherbibus, garminibus trigonis, caule ancipiti. Gron. virg. - Lin. syst. veg. 91. Jacqu. collect. 2. p. 32 =. ic. rar. 2. $t .222$.

Iris hexagona; nectariis tomentosis; caule tereti; foliis ensifurmihus; corollis inferne riridescentihus, superne purpureis; stigmate petalis interioribus breviori; capsula trigona, angulis profunde sulco bifidis ut fere hexagona. Walt. fl. car. ht.

Iris virginica; caule anguste folioso, hinc acuto subtrifloro: calycis laciniae trifasciae mucilo tomentosae: capsula oblonga, angulis sulcatis. Mich, fl. bor. am. ' p. 22 .

Habitat in Virginia, Carolina. 4

Caulis pedalis vel altior, articulatus, foliis vaginatus. Folia angustiora, apice incurva, sieperiora sensim breviora. Spathae margine tenuissime membranaceae. Thunb.

Elatior. Spathae lineari-lanceolatae Corolla coerulescens, purpureo-venosa. Capsula trigona, angulis suica exaratis. Mich. l. c.

spuria.

3 I. IRIS caule subtrifloro foliis longiore, laciniis exterioribus corollae spathulatis, germinibus hexagonis.

Iris sylvestris maritima narbonensis. Lob. ic. 68 .

Iris angustifolia pannonica. Clus pan. 252 ,

Iris angustifolia . Clus. hist. r. p. 228.

Iris foliis angustis prima Clusii. Besl. hort. eyst. aest. ord. fol. 1 .

Iris angustifolia maritima major. Bauk, theatr. 6Q0. 
Iris spuria; corollis imberhibus, germinibus sexancularibus, caule tereti, foliis sublinearibus. Lin. sysi. veg. 93. Fil. dan. t. 734. Jacqu. austr. I. p. 1. t. 4. Curt. mag. 2. t. 5 s.

Iris spathulata; imherbis, foliis ensiformibus angustis erectis, caule subbrevioribus, spathis viridıbus, petalis majoribus spathulatis. Lamarch. dict. bot. x. p. 300. illustr. I. p. 123.

Habitat in Europae pratis.

Radix crassitie pollicis, squamis latis, fusco-ferrugineis tecta. Caulis sesquipedalis, simplex, tri-quadrijorus, vaginis foliorum iectus. Folia semiunguem lata, niargine parum crassiorn. Spathae lanceolatae. Flores coerulei. Corollae laciniae exteriores basin versus dilatatae, canaliculatae, extrorsum violaceae, intus flavae violaceo striatae: interiores erectae, lanceolatae, totae violaceae.

Ir. spathulatam Lamarchii a spuria non differre, docuit specimen ab ipso mecum communicatum.

32. IRIS caule subtereti flexuoso, germinibus ochroleuca. hexagonis.

Iris ochroleuca; corollis imberbibus, germinibus sexangularihus, caule subtereti, foliis ensiformibus striatis. Lin. mant. 175. Curt. mag. 2. t. 5 r.

Iris Gyldenstaedtii. Lepech. in act. peirop. I78 t. r. p. 292 . t. . .

Habitat in Oriente.

Caulis sesquipedalis, vaginis foliorum tectus, multiflorus, vix compressus. Folia alititudine caulis, quinque ad sex in caule, dimiolio angustiora quam Ir. germanicae, nervosa, stricta. Spathae alternae, triflorae, lanceolatae, acuminatae, apice'membranaceae. Corollae laciniae exteriores reflexae, spathulatae; lamina ovata, vix \$semipollicaris, flava, margine albiáa; unguis lamina duplo longior, medio parum dilatasus, uti laminu venis obscurioribus pictus: interiores:longitudine exteriorum, lanceolatae, niveae, flavescenti-venosae.

33. IPIS folis radicalibus 'lon rissimis, caule foliis halophila. alticre, germinibus hexagonis. $t$ 


\section{TRIANDRIA. MONOGYNIA:}

Iris halophila. Pall. it. 2. n. 99. vol. 3. n. 63. t. 13. f. 2 .

Iris halophila; corollis imberbibus, germinibus sexangularibus, caule tereti, foliis radicalibus longissimis. Hort. Kew. 1. p. 72 .

Habitat in Sibiria. 4

Caulis sesquipedalis, triflorıs. Folia Ir. Pseudacori, glaucescentia, Spathae magnae, inflatae, margine membranaceae. Flores minores, palliai, superiore praecociore. Corullae laciniae interiores angustae, stigmate parum latiores, inedio nervo, venisque flavidioribus. Pall. l. c.

Famosa. 34. IRIS caule paniculato muliffloro. Thunb. ir. i2. $24 . \div$

Iris ramosissima; corollis imberbibus, foliis ensiformibus planis, caule paniculato ramosissimo obsolete tetragono. Lin. suppl. 99.

Habitat in arenosis Cap. b. spei. 2/

Caulis inferne teres, aigitum crassus, superne ranosissimus, multifloris: Rami subtrichotomi, compresso-angulati, flexuosi, giabri. Folia rrdicalia longitudine fere caulis, longe vaginantia, apice attenucita, glaöra; caulina sensim bre. viora et in spatias abeuntia. Bracteae ad ramificaitones ovatae, acutae, membranaceae, ramis et pedunculis breviores. Flores lutei. Thunb. $l$. $c$.

spathacea. 35. IRIS foliis rigidis, caule tereti bifloro, spathis longissimis. Thunb. ir. n. 2?.

Iris spathulata; coroliis imberbibus, foliis ensiformibus glabris striatis rigidis, spathis subu. latis longissimis. Lin. suppl. 99.

Habitat in Cap. b. spei. 24

Caulis simplex pedalis, multiflorus. Folia duo vel unicum, a medio ad apicem sensinz valde attenuata, marginata, nervoso-striata, glabia. Spathae foliis similes sed latiores, apice membranaceae, spithamaeae. Thunb. l. c.

nirroptera. $3 €$. IRIS acaulis, corollae tubus longissimus; laciniis erectis minimis patulis.

Iris bulbosa latifolia I. Clus. rar. hisp..374.

Iris bulbosa latifolia flore coeruleo et candido. Bauk. pin. 38. 
Iris alata; imberbis, foliis ensiformibus, tubo longo filiformi, petalis interioribus minimis patenti reflexis. Poir. it. 2. p. 86. Lamarck. dict. bot. 3. p. 302. iliustr. 1. p. 124 .

Iris scorpioides; acaulis, foliis canaliculatis; $c 0$. rollae laciniis tribus erectis minimis; tubo longissimo. Desfont. fl. atl. s. p. 4c. t. 6.

Habitat in Barbaria. 4

Bulbus nuce juglandis major, basi emittens tubera plura, fusiformia, fasciculata, crassitie digiti minimi, sensim angustati. Folia racicalice, piura, flore breviora, semiunguem lata, sensim attenuata, glabra Scapus brevissimus, plerumque uniflorus. Spatha tubo brevior. Corolla coeruiea magnitudine fere Iridis germanicae: tzilus tenuis: laminae exteriores ovato-oblongae, crenilatae: erectae minimae, lanceolatae. Stiomata maxima, longitudine fere Zaminarum exteriarum, profunde bifida; laciniis denticulatis.

37. IRIS acaulis, corollae tubo longissimo, làci-nnguicularis. niis omnibus subaequalibus.

Iris unguicularis; imberbis: tubo filiformi lon. gissimo, petalis omnibus erectis subaequalibus. Poir. it. 2. p. 86. Lamarck. dict. bot. 3. p. 302. illustr. 1. j. 124.

Iris stylosa; acaulis; foliis exsiformibus; co. rollae laciniis subaequalibus; tubo longissimo. Desfont. fl. at?. 1. p. 40.t. 5 .

Habitat in Barbaria. 4

Folia erecta, lineari-ensiformia, flore altiora, semiunguem lata. Scapus sesquipolicaris, uniflorus. Spatha diphylla foliis similis, interior longitudine tubi. Corolla coerriea: tubus seiapolicicaris, tenuis: laminae oblongae, inferno sensim angustiores, integerrimae. Germer ob. longun, teres: stylus longitudine tubi: Stigmata linearia, angusta, profunde bifida; icciniis acutis.

38. IRIS foliis canaliculato-subulatis, caule biflo- Xiphiura; ro, laciniis corollae stigmate fere angustioribus, germine tereti trigono. Ehrh. beitr. 7. p. 1390 


\section{TRIANDRIA. MONOGYNIA.}

Iris bulbosa flore luteo, violaceo mixto, variegato. B. Besl. hort. eyst. aest. ord. 4. fol. 2. '. II. Iris bulbosa coeruleo-violacea. Bauh. pin. 'r. Iris Xiphium; corollis imberbihus, fluribus binis, foliis subulato canaliculatis caule breviorihus. Lin. hort. up. $\mathrm{T}^{-}$.

Xiphium vulgare. Mill. dict.

Iris variabilis. Jacqu. collect. 2, p. 32 I.

Habitat in Hispania et Lusitania. 4

Bulbus ovatus. Caulis sesquipedalis. Folia coule parum longiora, convoluta, subulata. Spathae longitudine tuỏi. Corollae iuciniae exteriores oblongae.

Bulhus minor quam in sequente. Folia angustiora. Corollae lactniae exteriores vix emarginatae. Jaqu. l. c.

xiphoides 39. IRIS foliis canaliculato-subulatis, caule hifloro, coroilae laciniis stigmate multo latioribus, gormine acute angulato. Ehrh. beitr.? p. 140

Iris bulbosa anolicana major, flore candidó, vio. laceo, coeruleo; dilute cueruleo. Besl. hort. eyst. aest. ord. 4. fol. 7. 9. 9. 10.

Iris bulhosa latifolia caule donata. Bauh. pin. 38. Xiphium latifolium. Mill. diut.

Iris Xiphium ק. Lin. spec. pl. 58 .

Iris Xiphium. Jacqu. collect. $=$. p. 320 .

Habitat in Hispania. If

Corollae laciniae emarginatae. Jacqu. l. c.

Sisyrinchium. 40. IPIS foliis canaliculatis scapo subtrifloro longioribus.

Sisyrinchium Cordi et Clusii. Lobel ic. 9?.

Sisyrinchium majus. Clus. hisp. 279. hist. x. p. $2: \kappa$.

6. Parva noselha; Sisyrinchium Theophrasti. Clus. Lob. ic. 97.

Sisyrinchium minus. Clus. hisp. 280. hist. I. p. $21^{\mathrm{f}}$. Besl. hort. eyst. aest. ord. ? fol. $\%$.

Iris Sisyrinchium; corollis imberbibus, foliis canaliculatis, bulbis geminis super impositis. Lin. spec. pl. 59. Cavan. ic. 2. p. 74. t. 193.

Habitat in Hispania, Lusitania, Barbaria. 4 Bulbi saepe gemini, alter supra alterum, subrctuncii, exius reticulato-tunicait. Folia scapo 
duplo altiora, laxa, attenuata, arcuata, interdum contorta. Scapus spithamaeus, simplex, superne tectus spathis laxis, attenuatis, membranaceis, basifoliis vaginatus. Spathae tres, $\boldsymbol{e}$ singula flos unicus. Corolla parva, pallide coerulea: laciniae exteriores macula lutea ornatae: interiora parum breviora.

4I. IRIS foliis convolutis subulatis caule subbifloro juscea. altioribus, corollae tubo elongato.

Iris mauritanica. Clus. cur. post. 24.

Iris bulbosa angustifolia flore flavo medio albo. Grisl. virid. lus.

Xiphion minus, flore luteo. Tournef. inst. $r . r_{0}$ 364.

Iris juncea ; imherbis, foliis junceis filiformibus, scapo unifloro, spathis mucronatis. Poir. it. 2. $p$. 135 .

Iris juncea; bulbo tunicato; caule subbifloro; foliis subulatis canaliculatis, spatha diphylla, acuta; tubo corollae elongato. Desfont. $f l$. Atl. т. p. 39. t. I.

Habitat in montosis circa Hamamelif Tuneti, in Atlante. Desfontaines. 4

Bulbus subrotundus. Caulis pedalis, crassitie pennae columbinae, simplex, striatus, articulatus, glaber, vaginis foliorum tectus. Folia caule duplo angustiora, basi vaginantia, tenuissima. Spatha diphylla; foliolis lanceolatis, laxis, subventricosis, acuminatis, margine superne ct acumine membranaceis. Corolla lustea: Petala exteriora magnitudine Ir. PseudAcori, patentissima: lamina ovata, emarginata; interiora angusta. Stigmata bifida; laciniis denticulatis. Capsula triangularis.

42. IRIS folio filiformi erecto cauleque submono- setifolit. phyllo subunifloro glabro, spathis acutis.

Iris setifolia; corollis imberbibus, folio filiformi glabro, caule simplici, spathis mem. branaceis. Lin. suppl. 99.

Iris setacea; folio filiformi-lineari erecto glabro, scapo glabro unifloro, spathis acutis membranaceis. Thumb. diss. n. 29. t. I.

Habitat ad Cap. b. spei. 4 


\section{I46 TRIANDRIA. MONOGYNIA.}

Caulis palmaris vel spithamaeus, erectus, saepius simplex, uniflorus, raro civisus, triflorus. Folium saepius unicum, raro duo in caule, erectum, scapo duplo longius; apice cernuum. Flores minuti, coerulei. Thunb. l. c.

2ngusta. 43. IPIS folio filiformi erecto scapoque subunifloro glabro, spathis obtusis. +

Iris angusta; imberbis, folio filiformi lineari erecto glabro, scapo glabro subunifloro, spathis obtusis. Thunb. diss. n. 28 .

Habitat ad Cap. b. spei. 4

Scapus spithamaeus vel ultra, subsimplex, vaginatus, articulatus. Folium scapurn inferne longe vaginans eoque longius, acuminaium, glabrum. Flores terminales, unicus vel duo, erecti, simul florentes. Spatha exterior glabra, viridis, apice rubro, pollicaris; interiores tenuissimae, albas. Petalorum laminae pollicares, ovatae, obtusae, extus purpureo-nervosae, intus flavae: minorum lanceolatae, obtusae, flavae, extus fusco-purpureo striatae. Stigmatum labium interius bifidum; laciniae oblongae, latere exteriori productae. Capsula trigona, obtusa. Thunb. l. c.

tenuifolia. 44. IRIS acanlis, foliis filiformibus longissimis, scapo brevissimo bifloro, corollarum tubo filiformi elongato.

Iris tenuifolia. Pall. it. 3. app. n. 27. t. C. f. 2 .

Iris tenuifolia; corolla imberbi, spatha biflora, folio longissimo filiformi, tubo filiformi elongato. Lin. suppl. 97 .

Habitat in arenosis Diuuriae et al WVo?gam. 46

Caespitosa. Folia subsolituria, scapo multolies longiora. Spathae terminales biflorae, trivalves: valvulis subaequalibus, lanceolatis, acuminatis. Flores pallide coerulei, odore caryophylleo fragrantes. Corvilae tubus albidus: laciniae longae, lanceolatae, inferne versus sensirn attenuatae; exteriores disco albidae, coeruleo-venosae; interiores apice vix conniventes, laete coeruleae. Stigmaia profunde bifida; laciniis apice crenatis. Pall. l. c. 
45. IRIS foliis lineari-subulatis canaliculatis scapo persics, brevissimo unifloro altioribus, corollae laciniis interioribus brevissimis patentissimis.

Iris persica variegata praecox, Ferr. fl. cult. I 52. Iris bulbosa praecox minus odora persica variegata. Moris. hist. 2. p. 357 .

Xiphium persicum praecox, flore variegato. Tournef. inst. r. h. 363.

Iris persica; corolla imberbi: petalis interioribus patentissimis serratis, foliis subulato-canaliculatis, caule longioribus. Lin. spec. plo 59. Curt. mag. I. t. I.

Habitat in Persia. 26

Radix bulbosa. Folia radicalia, tripollicaria, nervosa, glaucescentia. Scapus brevissimus. Carollae tubus elongatus: laciniae tres majores erecto-patentes, oblongae, medio dilatatae, undulatae, subemarginatae, albae, medio linea flava, punctis violaceis adspersae, apice violaceae: interiores unguiculares, lineari-oblongae, convolutae. Stigmata longitudine laciniarum exteriorum, albida, medio linea dilute coerulea, bifida; laciniiis semiunguicularibus, lanceolatis, serratis.

46. IRIS foliis planis, scapo unifloro foliis bre- verna. viore, petalis subaequalibus. '

Iris virginiana pumila s. chamaeiris verna angustifolia, flore purpurea-coeruleo odorato. Plukn. alm. 19?. t. : $0^{4}$. f. "

Iris verna; corollis imberbibus, caule unifloro foliis breviore, radice fibrosa. Lin. syst. veg. 92.

Habitat in Virginia. 4

Scapus simplex, inferne spathis alternis tectus.

47. IRIS subcaulescens, caule subbifloro foliis ventricosa. breviore, spathis ventricosis, germinibus trigonis. +

Iris ventricosa. Pall. it. 3. app. n. 62. t. B. f. I.

Habitat in montosis Dauuriae. 4

Caespitosa. Caulis dodrantalis, simplex, folio vaginante, lanceolato-ensiformi instructus. Folia pauca, angustissima. Spatha ventricosa, biflora, bivalvis; valvulis tribus, latis. Corollae pallide coeruleae: tubus elongatus: laciniae exteriores 


\section{I48 TRIANDRIA. MONOGYNIA.}

erecto-patulae, oblongae: interiores erectae, oblongo-lineares. Stigmat? lacinias corollae aequantia, bifida; laciniis sublinearibus. Germen trigonum, lateribus sulco bipartitis. Pall. l. c.

eipitica. 48. IRIS caule fistuloso subtrifloro foliis altiore, germinibus trigonis.

Xiphion sive gladiolus coeruleus minor. Trag. 557.

Iris sylvestris byzantina peramocna. Lob. ic. 69. Iris angustifolia media sive varia. Clus, pan. 252.

fyis angustifólia 2. Clus. hist. I. p. 229 .

Iris pratensis major. Besl. hort. eyst. vern. ord.s. Iris pratensis angustifolia, non foetida altior. Bauh. pin. 32. theatr. 97.

Iris sibirica; corollis imberbibus, germinibus trigonis, caule tereti, foliis linearibus. Lin. spec. pl. 5i. Pollich. pal. n. 36. Jacqu. austr. I. p. 6. t. 3. Curt. mag. 2. t. 50.

Iris pratensis; imberbis, foliis linearibus planis suberectis, caule fistuloso brevioribus, gers minibus trigonis. Lamarck. dict. bot. 3. p. 300. illustr. I. $p$. 123 .

Habitat in Sibiriae, Austriae, Helvetiae pratis. 26 Gaulis suobipecialis, tri-vel multiflorus, superne divisus. Folia semiunguem lata, suberecta. Spathae scariosae, brunneae. Flores coerulei. Corollae laciniae exteriores oblongae, sensin inferne versus angustatae, emarginatae, integerrimae, basi reflexae, cxtus inferne lateribus jiavescenibus, violaceo-venosis, dorso virides: supra violaceo-venosae, in medio albidae, reticulatae: interiores erectae, cuneaio-lanceolatae, integerrimae, "parum coloratiores, violaceorenosae, basi e marginibus conniventibus canalicula:ae. Stigmata violacea, bificla, extrorsum serrata. \%:

Tariat corollis albis, laciniis reflexis violaceo. venosis.

ensata. 49. Ilis caule subbifloro tereti, germinibus hexagonis. +

Iris graminea. Thunb. jap. 34. 


\section{TRIANDRIA, MONOGYNIA.}

Iris ensata; imberbis, foliis linearibus, scapo subbifloro tereti, germinibus hexagonis. Thunb. in act. soc. Lin. 2. p. 328.

Habitat in Japonia. 4

50. IRIS caule subbifloro ancipiti foliis breviore, graminex: germinitus hexagonis.

Chamaexyris angustifolia. Lob. ic. 69 .

Iris graminea; corollis imberbibus, germinibus sexangularibus, caule ancipiti, foliis linearibus, Lin. syst. veg. 92. Jacqu. austr. t. 2 .

Habilat in Austria ad radices montium. 4

Caulis pedalis, subdiphyllus, uni-biflorus. Folia angusta. Flores coerulei. Capsula hexagona, verutricosa. क्ष.

51. IRIS acaulis; scapo subunifloro foliis breviore, biglumis. spathis diphyllis glumaceis, capsulis triquetro-sexangulatis.

Iris an spuria. Pall. it. 3. append. p. 26. t. C. $f$. '.

Habitat in Sibiria. 4

Radix repens, setis sordidis tecta. Folia radica. lia, plura, palnaria, semiunguem lata, tempore florendi scapo breviora, autumno saepe tripedalia, lineari-ensiformia, attenuata, acuta. Scapi basi duobus foliis brevioribius vaginati, coeterum nudi, longitudine digiti intermedii. Spatha in apice scapi, diphylla: foliolis ungzicularibus, flumasformibus, oblongis, obtusis . aridis, subitlissime striatis, stramincis. Flores solitarii vel gemini, terminales, sessiles, dilute cyanci: laciniae lanceolatae; exteriores reflexae, dilutiores, medio albidae, venis coernleis saturatioribus pictae; interiores parum angustiores, uti stigmata intertsius coloratae. Germen siriatum, sulcis allernis profundioribus.

Capsulae magnae, fuscae, iriquetro-sexangule. tae; angulis carinatis. Semina testacea, subglobosa. Pall. l. c.

An Iris lactea Pall. it. 3. app. 64. varietas? differre videtur, partiuin magnitudinc.

52. IRIS folio lineari canaliculato Iungissimo, sca- longifolia po tereti multifloro. $\dot{-}$ 
Iris longifolia; foliis linearibus, canaliculatis, longissimis, glaucis; scapus teres, multiflorus; radix bulbosa. Andr. repos. $t .45$.

Habitat in Cap. b. spei. 4

bituminosa. 53. IRIS foliis spiralibus, caule viscoso. Thunb. ir. n. 42. t. 2 .

Iris bituminosa; corollis imberbibus, foliis ensiformibus spiralibus, petalis reflexis, caule viscoso. Lin. suppl. 98.

Habitat ad Cap. b. spei. 4

Caulis pedalis, flexuosus, articulatus, superne divisus, multiflorus, glutinosus. Folium unicum, caule brevius, apice attenuatum, glabrum. Flores in pedunculis solitariis. Pedunculi e vaginis cum scapo duo, poillicares et ultra, patentes, flexuosi, filiformes, viscosi. Corolla flava: petala majora obtusa. Stigmata lutea: labium exterius minimum, interius bifidum; laciniae lanceolatae, acutae, longitudine petalorum minorum. Thunb. $l$. c.

viscaria. 54. IRIS foliis planis, caule viscoso. Thunb. ir. $\boldsymbol{n}$. $41 .+$

Iris viscaria; corollis imberbibus, foliis linearibus planis, petalis patentibus, caule viscoso. Lin. suppl. 9 s.

Habitat ad Cap. b. spei. 4

Caulis pedalis, flexuosus, superne divisus, glaber, purpurascens, glutinosus. Folia pauca, scapo longiora, erecta. Pedunculi alterni, flexuosi, uniflori, glutinosi. Petalorum majorum laminae unguiculares, ovatae, obtusiusculae: minorum angustiores et breviores. Stigmatis labium interius bifiaum; laciniis lanceolatis petalorum majorum laminis duplo brevioribus; exterius bifidum duplo brevius. Thunb. l. c.

polystachya. 55. IRIS foliis planis, caule ramoso glabro, spathis apice laceris. $t$

Iris lacera; imberbis, foliis linearibus, scapo ramoso multifloro, spathis laceris. Lamarck. dict. bot. 3. p. 304. illustr. 1. p. 125.

Iris polystachya; imberbis, foliis linearibus planis, scapo glabro ramoso. Thunb. ir. n. 40.

Habitat in Cap. b. spei. 4 


\section{TRIANDRIA. MONOGYNIA. IjI}

Caulis pedalis, vel ultra, teres, superne divisus, articulatus, multiflorus. Folia scapum aequuntia, erecta, apice setaceo-attenuata, nervosa. Flores magni, speciosi, coerulei. Spathae apice scariosae. Thunb. $l$. c.

56. IRIS foliis glabris, caule ramoso hirto. Thunb. tristis. ir. 22. 39. $\div$

Iris tristis; corollis imberbibus, caule ramoso hirsuto, foliis longioribus ensiformibus glabris. Lin. suppl. 97.

Habitat in Cap. b. spei. 4

Caulis spithamaeus, erectinsculus, multiflorus: Rami seu pedunculi flexuosi, patentissimi, hirsuti, uniflori usque triflori. Folia scapo longiora, ensiformi-linearia, apice dependentia, undulata, nervosa. Petalorum laminae ommes tristes seu triste rufescentes. Stigmatis labium interius bifidum; laciniae lanceolatae, carina intus coeruiea. Thunb. $l$. $c$.

57. IRIS hirta, foliis reflexis cauleque diviso vil- papilionacea, losis.

Iris papilionacea; hirta, corollis imberbibus, foliis revolutis. Lim. suppl. 93. Jacqus. suppl. I 59 . t. 3. f. 2 .

Iris papilionacea; imberbis, foliis linearibus reflexis hirtis. Thunb. ir. n. 37. $t .2$.

Habitat ad Cap. b. spei. 4

Bulbus magnitudine nucis coryli, ovatus, tunicatus. Caulis palmaris, divisus, uti folia pilosus, subcanescens. Folia longitudine scapi, superiora breviora, semiznguem lata, convo7uta, flexuosa, recurvata, extus nervosa, suprema spathaeformia. Spathae binae, vaginantes, foliis similes, pilosac. Pedunculi trigoni, ex eodem centro bini, tres vel quinque, incrassati, inaequales, sensim florentes, glabri. Petala majora laminis ovatis, acutis; minorum ovaio-oblongis. Stigmatis labium interius bifidum; laciniae oủlongae. Thunb. l. c.

Variat I) corolla tota flava, genu circulo viridi: 2) petalis et pistiultis intus ruhris, genu macula fluza, circu'o fusco: 3) petalis tribus majo- 
ribus totis flavis, genu circulo viridi, petalo. rum trium minorum laminis pistillorumque labiis internis sanguineis. Thunb.

crispd, 58. IRIS glabra, foliis reflexis crispis.

Iris crispa; corollis imberbibus, foliis ensiformibus revolutis crispis, petalis patentibus. Lin. suppl. o,

Iris crispa; imberbis, foliis linearibus crispis. Thunb. ir. n. 36. t. r.

Habitat ad Cap. b. spei. 4

Caulis palmaris vel ultra, superne divisus, flexuosus. Folia inferne in caule, eique aequalia vel longiora, attenuata. Flores alterni, pedunculati, tres vel quatuor. Spathae unguiculares, lanceolatae, acutae, striatae. Petala alterna majora unguicularia, obtusa, alterna minora angustiora. Stigmatis labium luteum, exterius brevissimum: interius bifidum; laciniis lanceolatis, acutis. Thunb. l. c.

$V$ ariat corollis luteis, coeruleis, incarnatis. Thunb.

Euberosa. 59. IRIS foliis tetragonis.

Iris tuberosa belgarum. Lob. ic, 98. Bauh. hist. 2. $p .73 c$.

Iris tuberosa, folio anguloso, flore obscure viridi colore. Moris. hist. 2. p. 348. s. 4. t. 5. f. I.

Hermodactylus folio quadrangulo. Tourn. cor, 50.

Iris tuberosa; corollis imberbibus, foliis tetragonis. Lin. syst. veg. 93.

Habitat in Arabia, Oriente. 4

Radix tubera duo-tria, oblonga, fasciculata. Caulis pedalis, simplex, uniflorus, foliis vaginatus. Folia scapo altiora: vaginae longae. Spathae diphyllae, longitudine floris, lanceolatae. Flos pedunculatus inter latera spatharum subpropendens. Petalorum laminae fuscoviolaceae. Germen oblongo-globosum, utrinque acutum. ฉุ. 


\section{Minus cognitae.}

IRIS corolla imberbi; germinibus subtrigonis; tripetalas caule tereti foliis longiore; foiis ensiformihus; rudimentis petalorum interiorum tridentatis, denticulo medio acuminato. Walt. fl. car. 67 .

Habitat in Carolina.

Flos inferne luteus; petala et stigmata coertilea; tubus intus lineis purpureis. Walt. $l$. $c$.

IRIS corollis imberbibus, foliis linearibus longis- capensis. simis. Burm. prodr. 2.

Habitat in Cap. b. spei.

Habitus. Folia vaginantia, striata. Scapi erecti, striatio

102. MoraeA. Cor. 6-petala: petalis patentibus, tribus minoribus.

* Scapo ancipiti.

. MORAEA caule subbifloro, foliis subfalcatis. Melalerica.

Moraea lugens; caule ancipiti uni-s-bifloro; foliis ensiformibus: infimis subfalcatis, floribus terminalibus. Lin. suppi. 9 9.

Moraea melaleuca; scapo ancipiti, foliis subfalcatis, flore subsolitario. Thunb. mor. n. I. $t$. I.

Habitut ad Cap. b. spei. 4

Caulis di-vel triphyllas, pedalis, simplex. Folia radicalia plura, bi-tripollicaria, disticha, lineari-ensiformia; caulina alterna, remota, vaginantia; supremum pollicare; inferiora parum longiora. Flores terminales, solitarii, interdum duo, raro tres, pedunculati, erecti. Spatha bivalvis ad basin pedunculorum; valvuiis lanceolatis, unguicularibus, pedunculo brevioribus, concavis, menbbranaceis. Petala tria cxteriora pollicaria, obovata, emarginata basi alba, versus apicem cocrulea: interiore angustiora, ovata, obtusa, basi alba, a medio ad apicem atra. Stigma multipartitum. Dignoscitur facile a reliquis colore florum. 


\section{TRIANDRIA. MONOGYNIA.}

pusilla. 2. MORAEA scapo subunifloro, foliis lineari-laneceolatis subfalcatis. $\frac{1}{1}$

Moraea pusilla; scapo ancipiti; foliis disticlis, flore subsolitario. Thunỏ. mor. n. 4.

Habitat in Cap. b. spei. 4

Folia rarlicalia, disticha, scano breviora, glabra. Scapus simplex, uniflorus vel biflorus, palmaris. Spathae naviculares, integrae, longitudine floris. Corolla coerulea: laciniae alternae aingustiores. Thunb. $l$. $c$.

điandra 3. MORAEA scapo simplici, spathis multifioris, floribus diandris.

Diplarrena moraea. Labillard. it. I. p. I57. t. I5. Habitat in nova Hollandia.

Germen trigonum.

Differre tanium videtur a Moraea filamentis duobus.

slata. 4. MORAEA scapo alato, foliis ensiformibus nervosis, pedunculis umbellatis dichotomis.

Sisyrinchium palmifolium; foliis ensiformibus nervosis. Lin. mant. 122.

Habitat in Brasilia. Commerson, Thouin. 4

Folia radicalia, pedalia et ultra, disticha, utrinque altenuata, sexnervia, glabra uti tota planta. Scapus bipedalis, simplicissimus, teres, utrinque $\boldsymbol{e}$ membrana nervosa decurrente anceps, enodis, desinens in involucrum attenuatum, acutum, bi-vel tripollicare, longitudine umbellae. Pedunculi tres quatuor, tecti spathis alternis lanceolatis, attenuatis, carinatis: partialibus bivalvibus, oppositis, navicularibus, margine membranaseis. Hedicelli duo-tres e spathis partialibus, capillares, compressi, laxi. Corolla hexajelaia. Filamenta distincta.

Northiana. 5. MORAEA spathis universalibus diphyllis, partialibus bifloris, pedunculis simplicibus. †

Moraea Northiana; scapo ancipiti alato, foliis distichis ensiformibus subfalcatis, spathis bivalvibus hifloris. Sclneev. ic. 4 I et 42 .

Habitat in Peruvia? potius forte in Brasilia. 
Radices fibrosae Folia lata. Scapus quadri-quinquepedalis, erectus, desinens in spatham diphyllam, multifloram: spathae partiales biflorae. Flores breviter pedunculati, majores quam in reliquis specielus, spectabiles. Petala tria majorce reflexa, plana, alba: interiora minora pulchre variegata. Schneev. l.c.

6. MORAEA pedunculis lateralibus involucrum mo- gladiata: nophyllum subaequantibus.

Ixia gladiata; stylis tribus, culmo nudo compresso, glumarum squamis muticis. Lin. suppl. 93.

Moraea gladiata ; scapo foliisque compressis, spica laterali solitaria involucro daplo breviore. Thunb. mor. n. 8 .

Habitat in Cap. b. spei. 4

Folia radicalia longitudine scapi, pauca, erecta, rigiclula, linearia, uti scapus glabra. Scapus bi-tripedalis, simplex. Pedunculi superne, la- erales, duo vel tres, uniflori, e scapo ulterius excrescente involucrati, teretes, villoso-canescentes. Spathae plures, imbricatae, inaequales, concavae, acutae, striatae, glabrae. Corolla flava.' 'Stigmata tria. Thunb. $l . c$.

7. MORAEA capitulis lateralibus involucro mul- aphylla. toties brevioribus.

Moraea aphylla; scrpo compresso nudo glaberrimo, spatha longissima subulata, floribus capitatis. Lin. suppl. 99.

Moraea aphylla; scapo foliisque compressis, spica laterali solitaria involucro multoties breviore. Thunb. mor. n. q. t. 2 .

Habitat ad Cap. b. spei. 4

Scapus enodis, pectalis et ziltra, glaber. Capitulum supra medium, laterale. Involucrum $e$ scapo continuatum, capitulo decies longius, curvatum. Flores lutei. Thunb. l. $c$.

8. MORAEA scapo foliisque filiformibus, floribus filiformis. terminalibus solitariis. Lin. suppl. roc.

Moraea filiformis; scapo foliisque compressis subfiliformibus, flore solitario terminali. Thunb. mor. n. го. t. т.

Habitat in Cap. b. spei. 4 


\section{I56 TRIANDRIA. MONOGYNIA;}

Folia duo vel tria, compressa, flexuoso-erecta, scapo breviora. Scapus enodis, simplex, pedaits, glaber. Involucrum extimum flore ditp. lo brevitus. Spathae alternae, glabrae. Corolla lutea: lacinice alternae angustiores. Stigmata tria, filiformia. Thunb. l. c.

$$
\text { * * Scapo tereti. }
$$

spathacea. 9. MORAEA foliis teretibus dependentibus, floribus terminalibus aggregato-capitatis.

Bobartia indica; spicis capitatis, involucro folioso. Lin. fl. Zeyl. n. 41. Am. acad. 1. p.338. Moraea spathacea; scapo tereti, foliis teretibus dependentibus longis, floribus aggregatis capitatis. Lin. suppl. 99.

Moraea spathacea; scapo foliisque teręibus dependentibus, spicis lateralibus aggregatis. Thunb. mor. $n$. I т. $t$. I.

Moraea spathacea; foliis teretibus subfiliformibus praelongis, spicis aggregato-umbellatis terminalibus, involucro diphyllo. L'amarck. illustr. 1. p. Ix4. t. 31. f. 2.

Habitat in Cap. b. sjei. 4.

Folia radicalia, teretia, scapo longiora, parum erecta, dein dependeintia, striata. Scapus semiorgyalis, enodis. Capitulum terminale $e$ spicis plurimis, aggregatis, pollicaribus. Involucrum diphyllum, patentissimum, foliolo unico longiore, tri-quadripollicari, altero longitudine spicurum. Spathae glumaceae, acutae. Corollae laciniae flavae, unguiculares, obtusae; alternae duplo angustiores.

(lextrosa. 10. MORAEA caule articulato subramoso, foliis reflexis subundulatis, spica flexuosa. +

Ixia longifolia. Jacqu hort. 3. p. 47.t. 9c.

Moraea flexuosa; caule tereti articulato ramoso, foliis planis laxis revolutis, spica flexuosa. Lin. suppl. гос.

Moraea flexuosa; scapo tereti articulato, folio reflexo subundulato nervoso. Tinunb. mor. n. I 2 .

Habitat ad Cap. b. spei. 4

Caulis simplex vel ramocus, pedalis et ultra glaber. Fulium radicale unicum, raro duo, lineare, scapo brevius, reflexum, striatum: 
ramea similia. Flores alterni. Spathae oblongae, apice acutae, lacerae. Corollae lacinine vix connatae, subaequales, obtusae cum cocumine, concavae, . unguiculares, linea longitudinali elevata, supra flavae, subtus tres alternae virescentes. Stigmata subcana, filiformia. Thunb. l. c.

21. MORAEA caule ramosissimo, foliis subulatis, poiyanthos. laciniis corollae alternis.

Moraea polyanthos; caule ramosissimo, foliis subulatis glabris, petalis alternis minoribus, stigmatibus bifidis. Lin. suppl. 99 .

Moraea polyanthos; foliis flexuoso-erectis, laciniis corollae alternis minoribus. Thunb. mor. 7n. 14 .

Hazitat in Cap. b. spei. 24

Folium radicale scapo longius, lineare, erectum, curvatum: ramea simillima, vaginantia. Caulis articulatus, paniculatus, pedalis. Flores ex apice ramulorum, plerzmque gemini, interdum solitarii vel tres. Corolla coerulea: petala obtusa; tria alterna angustiora et breviora. Stigmata tria. Thunb. $l$. c.

12. MORAEA snicis terminalibus umbellatis, in- unbellata. volucris longissimis.

Moraea umbellata scapo tereti striato, florum spicis umbellato paniculatis, involucris diphyllis longissimis. Thunb. mor. $n$. I'.

Moraea corniculata; scapo tereti nudo, foliis subteretibus longissimis, spicis corniculatis subpaniculatis lateralibus. Lamarck. illustr. I. p.: 115.

Habitat ad Cap. b. spei. 4

Scapus simplex, perlalis, glaber. Spicae plertumque quatuor, pedunculatae, uni-bi:triflorae. Pedunculi compressi, pollicares. Involucrum diphyllum, folium alterum e scapo continuato, elongatum, longitudine scapi; alterum interdum umbella parum longius, interdum ejus longitudine. Spathae lanceolatae, striatae, inferiores breviores in aristam attenuatae, ope lentis purpureo punctatae. Corolla coerulea.

Mor. corniculata Lamarckii differt involucri folio altero vix longitudine umbellas. 


\section{TRIANDRIA. MONOGYNIA.}

6rispa. 13. MORAEA scapo articulato, folio convoluto crispo reflexo. Thunb. mor. $n$. 17. +

Habitat in Africa australi. 4

Folium radicale solitarium, lineare, longitudine scapi. Scapus simplex, spithamaeus. Flores terminales, pauci, coerulei. Thunb. $l$. c.

pilosa. 14. MORAEA scapo foliisque pilosis, floribus terminalibus solitariis pedunculatis. †

Moraea pilosa; scapo tereti, erecto, piloso; foliis quaternis, gramineis, "pilosis; floribus terminalibus solitariis; pedicellis glabris. Wendl. obs. bot." 42.

Habitat in Cap. b. spei. 24

Folia quatuor, erecta. Pedunculi glabri. Petala ribra, striata: tria latiora basi macula flava, margine fusco cincta, medio viridi punctata. Wendl. $l$. $c$.

iridioides. 15. MORAEA foliis lineari-ensiformibus striatis scapo squamis vaginato altioribus, flore terminali subsolitario.

Iris orientalis pumila sémpervirens, gramineo acuto rigido folio, flore luteo et coeruleo mixto inodora. Till. pis. "n. t. ??.

Moraea spatha uniflora foliis gladiatis, radice fibrosa. Mill. ic. 150. t. 239.f. .

Moraea iridioides; foliis gladiatis. Lin. mant. 28.

Habitat in Oriente. 4

Folia radicalia, disticha, pedalia vel ultra, uti tota planta glabra. Scapus tectus vaginis pollicaribus, oblongis, basin versus angustatis, apice vix membranaceis, obtusis. Petala tria cuneiformia; tria lanceolata, angustiora.

iriopetala. 16. MORAEA caule subramoso, foliis lineari-ensiformibus striatis, petalis tribus majoribus barbatis, stigmatibus multifidis.

Moraea iriopetala; foliis gramineis, petalis tribus majoribus barbatis. Lin. suppl. ' oc.

Iris plumaria; barbata, foliis linearibus, scapo multifloro, stigmatibns setaceo - multifidis. Thunb. ir. n. It.

juncea. a. squamis bulbi basi distinctis.

Moraea juncea spathis bifloris, foliis subulatis. Lin. spec. pl. 59. Mill. dict.

vegeta. fo. squamis bulbi basi comnexis. 


\section{TRIANDRIA. MONOGYNIA.}

Moraea vegeta foliis canaliculatis. Lin. spec. pl. 39 .

Moraea spatha biflora, caule planifolio; floribus minoribus et majoribus. Mill. ic. 159. t. 138. f. r. 2 .

Habitat in Cap. b. spei. 4

Caulis spithamaeus vel pedalis, flexuosus, glaber, uti folia. Folia sparsa, pauca, caule altiora, utnguem lata, multinervia, laxa. Pedunculi axillares, solitarii, vel gemini, longi, uni-bitriflori. Flores pedicellati. Spatha bivalvis, sib pedicellis: valurelis lanceolatis, striatis, acutis, margine parum membranuceis, altera paulum breviore. Petala violaces. Capsulae piso duplo majores.

ж. Culmus ramosus: Ramis tribus-quatuor: spathae biflorae: fiores albi. B. Flores in scapo vix plures quam bini, cocrulei.

37. MOPAEA scapo simplici, foliis ensiformibus, chinensis. pedunculis umbellatis subdichotomis.

Belam canda Schularmani. Rheed. mal. I. $p$. 73. $t$. 37 .

Bermudiana radice carnosa, floribus maculatis, seminibus pulpa obductis. Amm. in act. petr. I I. p. $300, t . \cdots$.

Ixia chinensis; foliis ensiformibus, floribus remotis, panicula dichotoma, floribus pedunculatis. Lin. spec. $p l .52$. Trew. Ehret. 23. t. 52. Curt. mag. vol. 5. t. 17 1.

Moraea chinensis; scapo tereti, foliis distichis ensiformibus, floribus umbellatis. Thunb. mor. n. I 9 .

Heditat in arenosis Indiae, Chinae, Japoniae. 4

Caulis bi-quinquepedalis glaber, uti tota planta. Folia radicalia disticha, caulina remota, altitudine rscapi, pollicem lata. Pedunculi superni et terminales, duo vel tres, teretes, divisi. Petala lanceolata, subaequalia, crocea, maculata.

38 MORAEA foliis ensiformibus petiolatis nervosis plicata. plicatis, pedunculis geminis, pedicellis subumbellatis.

Bermudiana palmaefolio, radice bulbosa. Tournef. inst. r. herb. 389. Plum. ic. 35. t. 46. f. 2. 
Sisyriachium palmifolium; radice bulbosa, foliis radicalibus petiolatis nervosis ensiformibus. Cavan. diss. p. 3+3. t. 4 i. f. $\mathrm{r}$.

Sisyrinchium palmifolium; foliis ensiformibus nervosis plicatis. Swartz. prodr. :-.

Moraea palmifolia; scapo teretiusculo nudo, floribus racenosis secundis, foliis ensiformibus nervosis plicatis. Jacqu. ic. rar. 2. t. 227. Collect. 3. p. 192.

Moraea plicata; scapo ancipiti, foliis ensiformibus nerrosis plicatis.; floribus capitatis, pedunculo bifido. Swartz. fl. ind. occid. 1. p. 82.

Habitat in Caribaeis.

Folia radicalia, bi-tripedalia, pollicem et ultra lata, basi in petiolum brevem attenuata, sexduodecimnervia, glaberrima. Scapi folio longiores, tereti-ancipites, apice terminati folio pedali, lanceolato, pollicem lato, basi attenuato, spathaceo. Pedunculi tres e vagina folii terminalis, patentes, ancipites, inferior longior multifiorus, apice spatha lanceolata longitudine umbellae terminatus: intermerius brevissimus; superior bi-triflorus. Spathae partiales bivalves, ovatae, obtusae, subtilissime striatae. Petala aequalia, alba.

unguicularis, 39. MORAEA foliis linearibus nervosis, floribus spicatis, spathis obtusis, corollae laciniis spathulatis.

Moraea unguicularis foliis linearibus nervosis, floribus spicatis sessilibus, spathis obtusis, petalis longe unguiculatis. Lamarck. dict. bot. 4. p. 275 . illustr. I. p. I I 4 .

Habilat in Cap. b. spei. Ex herbario Lamarch. 4 Bulbus superne setosus. Folia radicalia, semipedalia, angusta, basi valde attenuata, binervia. Scapus foliis altior. Spathae ovales, margine parum membranaceae, subcoloratae. Petalo. rum lamina ovalis.

An potius Ixiae species?

Fabitus. Folia margine vaginantia, striata. Scapi erecti, striati, apice floriferi. 
103. Diratris. Cor. 6-petala, hirsuta. Filamentum tertium reliquis minus; Anthera majore. Stigma simplex. Caps. globosa, infera, 3 -locularis.

3. DILATRIS petalis oblongis, corymbo fastigiato umbellata. liirsuto.

Dilatris corymbosa. Berg. cap. 9. t. ?. f. 5 .

Ixia hirsuta; hirsutissima, umbella bifida racemosa. Lin. mant. 27.

Wachendorfia umbellata. Mant. 320.

Dilatris umbellata; petalis ovatis, corymbo fastigiato hirsuto. Lin. suppl. гог. Thunb. in act. soc. am. list. nat. berol. 4. p. 46.

Dilatris ixioides; panicula ovata villosa, petalis ovalibus externe barbatis, staminibus corolla longioribus. Lamarck. illustr. 1. p. 127. t. 34 . Habitat ad Cap. b. spei. 4

Caulis inferne teres glaber, superne triangularis cinereo-tomentosus. Folia plurima radicalia, iria circiter in caule, remotissima, tripollicaria, lineari-lanceolata, inferiora glabra, superiora viliosa. Corymbus terminalis, densus; pedunculis, bracteis, petalis extus germinibusque hirsutis: pedunculi canescentes; pedicelli alterni, breves, secundi, uniflori. Bracteae lanceolatae. Petala purpurea, apice puncto fusco, trinervia.

2. DILATRIS petalis linearibus, corymbo fasti- viscosa. giato villoso viscido. Lin. suppl. 1 ог. Thunb. in act. soc. an. hist. nat. berol. 4. p. 48. †

Habitat in summitate montis tabularis Eap. b. spei. 24

Caulis teretizlsculus, uti tota planta, foliis radicalibus exceptis, hirsutissimus; pilis rufescentibus apice glandulosis, glutinosis. Folia radicalia plura, vaginantia, caule breviora, striata: caulina tiria wel quatuor, pollicaria. Corymbus densus. Pedunculi pollicares. Bracteae lineares. Petala unguicularia, viscida. Filamenta longitudine corollae.

3. DILATRIS petalis lanceolatis, panicula oblon- paniculata. ga villoso-viscosa. Lin. suppl. 1о1. Thunb. in act. soc. am. hist. n. ber. p. p. 5 x. †

Habitat in cirenosis Cap. b. spei. 4

Tom. II. 
Caulis striatus, uti tota planta hirsutissimus, pilis densis patentibus rufescentibus glandulosoviscosis. Folia caulina pauca, pollicaria vel ultra, lanceolata. Flores a medio caulis ad apicem, paniculati. Bracteae lanceolatae. Pedunculi pollicares : pedicelli subquadriflori. Corolla purpureo-flavescens: Petala unguicularia. Filamenta corolla breviora. Thunb. l. $c$.

Habitus. Radix carnosa, succo rubro farcta. Caulis suffruticosus, erectus, pedalis, simplicissimus, hirsutissimus. Folia caulina alterna, amplexicaulia. Pedunculi bifidi. Petala extus hirsuta.

Dilatris carolinia. Lamarck. illustr. г. $p$. I2?. Quae l'Heretieria Michaux fl. bor. Amer. т. $p$. 20. ad Lanariam Hort. kew. pertinere videtur.

104. Xiphidiun. Cor. 6-petala aequalis. Caps. supera 3 -locularis polysperma.

Aloribundun. 1. XIPHIDIUM. Swartz. prodr. 1 . Fl. ind occid. I. $p$. ९०. $t .2$.

Ixia Xiphidium. Loefl. it. $1 \geq 9$.

Xiphidium albidum; foliis ensiformibus glahris subintegerrimis, flore albido. Lamarck. illustr.

ז. p. 13r.

coerulenin. $\beta$. Xiphidium coeruleum floribus paniculatis, flore et foliis pilosis. Aubl. fl. guian. p.3. t. 11. Xiphidium floribundum. Ecl. amer. I. $p$. 5 . Swartz. prodr. 17. Fl. ind. occid. 1. p. 806.

Habitat in America meridionali, 4

Radix fibrosa, stolonifera: stolones pedales et ultra, articulati, vaginati: vaginac ovatae, acuminatae. Caulis erectus, interium fere bipedalis, simplicissimus, inferne tecrus, striatus, superne pubescens. Folia disticha, pedalia et ultra, sesquipollicem lata, extrorsum utrinque aculeis minutis serrulata; inferiora a basi ad medium conduplicata latereque interiore angustiora; supremum sessile, a reliquis remotum, lineari-lanceolatum, margine exieriore a basi ad apicem, interiore tantum versus apicem serrulatum. Vaginae approximatae, caule ampliores, integrae. Racemus palmaris et ultra, compositus; pedunculi partiales patentes, apice 
ante florescentiam reflexi; pedicelli e latere superiore alterni, uti pedunculus communis villosi. Bracteae subulatae. Petala persistentia, ovato-lanceolata, tria interiora parum breviora. Antherae oblongae erectae. Germen globosum: stylus persistens. Capsula mollis, gloZosa, magnitudine pisi, lineis tribus exarata, trilocularis, superne in valvulis tribus dehiscens. Dissepimenta centralia. Receptaculum seminum carnosum, globoso-triquetrum, subturbinatum.

Xiph. albidum gaudet pedunculis villosis, uti coeruleum, secundum specimen herbarii Lamarckii; differt modo denticulis minoribus, et petalis intus albis: specimina enim $X$. coerulei a. $v$. Rohrio Cajennae lecta possideo foliis floribusque omnino glabris.

I05. WACHENDOREIA. Cor. 6-petala, inaequalis, infera. Caps. 3 -locularis.

I. WACHENDOREIA scapo sutsimplici, panicula thyrsiflora. coarctata, foliis ensiformibus quinquenerviis plicatis glabris. Thunb. prodr. I2.

Tachendorfia foliis lanceolatis quinquenerviis canaliculato plicatis, florihus in thyrsum collectis. Burm. monogr. 2. f. 2. Nov. act. n. c. т. obs. . t. 2. $f$. '

Wachendorfia thyrsiflora; scapo simplici. Lin. syst. veg. 97 .

Hahitat ad Cap. b. spei. 4

Scapus villoso-subtomentosus. Folia nonnulla in scapo. Flores in spica terminali, alterni: rachis angulata, inferne ramulo uno alterove trivel quadrifloro, flexuosa, villoso-tomentosa. Bracteae lanceolatae, villosae, attenuatae, longitudine florum. Petala cuneato-lanceolata.

2. WACHENDOPEIA scapo polystachyo, panicu- paniculata. la patente, foliis ensiformibus trinerviis plicatis glabris. Thunb. prodr. i 2.

Erythrobulbus hellebori albi plicatis foliis. Plukn. mant. 70.

Asphodelus latifolius, floribus patulis, flavescentibus, rubicundis, intus maculis notatis. Breyn. prodr. 3. p. 22, t..$\cdot f$. . . 


\section{I64 TRIANDRIA. MONOGYNIA.}

Wachendorfia foliis ensiformibus trinerviis; flo. ribus paniculatis, Eurm. monogr. 4. $f$. I. Nov. act. n. c. 1. obs. 5 1. t. =. f. 10.

Wachendorfia paniculata; scapo polystachyo. Lin. sp. pl. 59 .

Wachendorfia paniculata; scapo polystachyo, foliis plicatis. Smith. ic. pict. ז. p. 5.t. 5.

Habitat ad Cap. b. spei. 4

Folia radicalia bifaria, equitantia, verticalia. triplo minora quam in thyrsiflora, pauca in scapo, parva. Pedunculi patentes, tri-quinqueflori: pedicelli racenosi, secundi, puhescentes. Bracteae oblongae, acutae. Petàla obovata, flava, extus pubescentia, rubicunda. Smith. l. c.

hirsuta. 3. WACHENDORFIA scapo polystachyo, panicula patente, foliis ensiformibus trinerviis plicatis villosis. Thunb. prodr. $\mathbf{2} 2$.

Sisyrinchium ramosum aethiopicum. Breyn. cent. $85 . f .3 \%$

Habitat ad Cap. b. spei. 4

Scapus sesquipedalis, villosus, superne inter flores triangulatus. Folia attenuata, nervi tres reli. quis majores, basi, glabra. Pedunculi quadriquinqueflori, secundi, alterni. Bracteae lanceolatae, villosae. Flores purpureo-violacei. Germen villosum.

senella, 4. WACHENDORFIA scapo subpolystachyo, panicula patente, foliis linearibus trinerviis glabris. Thunb. prodr. 1. p. 12. $\frac{1}{1}$

Habitat ad Cap. b. spei. 26

maninea. 5. WACHENDORFIA scapo polystachyo, panicula patente, foliis ensiformibus glanris. Thunb. prodr. 1. p. 12. $\frac{1}{1}$

Wachendorfia graminifolia caule polystachyo hirsuto, foliis ensiformibus glabris. Lin. suppl. Ior.

Habitat in Cap. b. spei. 4

Rarissima inter Liliaceas capenses. Lin.

Habitus. Scapus simplex, inferne teres, erectus.

Folia radicalia equitantia, nervosa, scapi vaginantia, acuta. Pedunculi alterni. 
306. Commelina. Cal. 3 -phyllus. Cor. 3 -petala. Filam. 2-3." sterilia, glandulis cruciatis instructa. Caps. $2-3$ locularis.

* Floribus involucratis.

. COMMELINA foliis lineari-lanceolatis glabris, angustifolie. vaginis subciliatis, involucris cordatis conduplicatis.

Coinmelina angustifolia; assurgens, debilis, glabriuscula, dipetaloidea: foliis lineari-lanceolatis, acuțissimis, planis: bracteis pedunculatis, solitariis, extensione brevi cordatis. Mich. fl. bor. am. x. p. 24 .

Habitat in campestribus Carolinae. Richard.

Similis sequenti, at folia angustiora. Vaginae minus amplae: involucrum longius pedunculatum, conduplicatum. Corollae subaequales. Sylvestris plerumque erecta, caulibus simpliciusculis, vel ab imo simpliciter ramosis: culta vero solito procumbens. Flores coerulescentes. Semina cylindracea. Mich. $l$. c.

Accedit ad Plukneti synonymum a Linnaeo ad Com. virginicam relatum.

2. COMMELINA foliis lineari-lanceolatis sessili- iongifolia. bus glabris, vaginis subciliatis, involucris cucullatis turbinatis.

Commelina longifolia; corollis subaequalibus, foliis lanceolato-linearibus, pedunculis longiusculis. Lasnarck. illust. : p. 220.

Habitat in Java. Commersor. Ex herbario Lamarckii.

Canlis gracitis, glaber. Folia bi-tripollicaria, angusta. Vagina semipollicaris Pedunculus ierminalis, solicarines, brevissimus. Involacrum rare villosum, ope lentis margine membranaceum. Corollae subaequales.

3. COMMELINA foliis lineari-lanceolatis sessili- longicaulis. bus subpilosis, involucris ovatis conduplicatis, cauie repente. $\div$

Commelina lon icaulis corollis subaequalibus, foliis lanceolatis sessilibus glabriusculis, curule repente, pedicellis geminis filiformibus geniculatis. Jacqu. colect. 3. p. $23 \%$. Ic. rer. 2.

t. $=94$. 
Habitat ad rivulos et in humidis ad Carracas. 4

Caules longissimi, ramosissimi, crassitie pennae columbinae, teretes, geniculati, glabri. Folia tripollicaria, angustissima, margine laevia, utrinque rariter hirtula. Vagina ore ciliata. Pedunculi solitarii, semipollicares, filiformes, erecti. Pedicelli graciles, erecti, geniculati. Flores parvi. Calycis foliola ovata, pallida. Petala coerulea, subrotunda, subaequalia. Jacqu. l. $c$.

hirtella. 4. COMMELINA foliis lanceolatis petiolatis cauleque erecto pilosis conduplicatis, involucris lateralibus terminalibusque sessilibus.

Commelina longifolia; stricte elatior, tota conspicue pubescens: foliis longissime lanceolatis; vaginis ad faucem rufo-barbatissimis: bractcis subsessiliter aggregato-terminalibus: calyce subaequaliter tripetaluideo. Mich. flor. bor. am. I. p. 2.3 .

Habitat in umbrosis sylvarum Virginiae et Carolinae. Richard.

Caulis bipedaiis et ultra, crassus, striatus, scabriusculus, ramosus. Folia quadripollicaria vel suhsemipedalia, remota, attenucata, margine scabra, utrinque pilosa, minime vero ciliata. Vaginae ferrugine-ciliatae. Involucrum cordato-falcatum, vix semipollicare, coloratum, glabrum. Corollae coeruleae. Semina subelliptica, compressa. Michaux.

Nomen longifoliae huic potius competit quam ullae ex aliis, sed hoc nomen plantae specie diversae jamdudtem imposuit Lamarck.

nervosa. 5. COMMELINA foliis lanceolatis subpetiolatis glabris basi hirsutis, involucris cordatis, caule erecto. +

Commelina nervosa; corollis subaequalibus, foliis lanceolatis sedecimnervibus, vaginis hircutis, caule erecto. Fl. per. г. p. 44.

Habitat in umbrosis Peruviae.

Caulis tripedalis. Folia erecta, acuta, supra nitida, utrinque glabra, basi hirsuta, decidua. Vaginae ore hirsufae. Pedunculi laterales. Involucrum multiflorum. Corolla purpureoviolacea, subaequalis. Fl. per. l. c. 
6. COMMELINA foliis lanceolatis subpetiolatis virginica. supra scabris, vaginae subpubescentes, caule erecto simplici.

Ephemerum phalangioides virginianum majus erectum. Plukn. alm. 135.t. 174. f. 1.

Commelina virginica; corollis subaequalibus, foliis lanceolatis subpetiolatis ore barbatis, caulibus erectis, Lin. spec. pl. 6 เ.

Habitat in Virginia.

Caules bipedales, laeves. Folia supra retrorsum scabra. Vaginae ore pilis ferrugineis ciliatae. Involucrum terminale, subcordatum. Flores coerulei, petalis cordatis, integerrimis: inferiore brevius pedicellato. Corolla subaequalis. Lin. l. $c$.

7. COMMELINA foliis lanceolatis sessilibus caule- africana. que decumbente glabris, involucris cordatis conduplicatis.

Commelina procumbens flore luteo. Royen Lugd. 508 .

Commelina africana; corollis inaequalibus, foliis lanceolatis glabris, caulẹ decumbente. Lin. syst. veg. 95. Willich illustr. n. I9. Berg. cap. 9 .

Habitat in Africa. 24

Caulis eiongatus, ramosus, articuli inferiores vaginis tecti, aphylli. Folia bi-s-tripollicaria, acuta. Vaginae semipollicares, superne ciliatae. Pedunculi laterales et terminales, vix semipollicares, fructiferi reflexi. Involucrum interdum pollicare, acuminatum, minime reticulatum. Flures flavi, inaequales.

8. COMMELINA fuliis lanceolatis, involucris cor. fasciculata. datis, caule ardscendente. $\dot{T}$

Commelina fasciculata; foliis lanceolatis acutis, vaginis ciliatis, caule assurgente, radice fasciculata. Fl. per. 1. p. 44. t. $7=f$. $b$.

Habitat in collibus et arvis Limae. 4

Radix tuberosa, fasciculata; tubera oblonga, pendula, lanuginosa. Caulis striatus, pilosus; pili decidui. Folia angusta, carinata, sub. tus magis pubescentia: villis deciduis, novemnervia. Pedicelli duo, villosi, alter ienuis lon- 


\section{I68 TRIANDRIA. MONOGYNIA.}

gus, uni-biflorus, alter crassiusculus, quadriquinqueflorus, brevis. Calyx albidus. Petala coerulea, aequalia. Fl. per. $l$. c.

pilosula. 9. COMMELINA foliis lanceolatis, involucris ciliatis. $t$

Commelina pilosula; pumila, diffusa, foliis lanceolatis, vaginis et involucris ciliatis. Act. soc. h. n. par. 1. p. 106.

Habitat in Cajenna.

attenuata. 10. COMMELINA foliis lineari-lanceolatis glabris, vaginis ciliatis, involucris cordato-lanceolatis attenuatis, caule repente.

Habitat in Irdia orientuli. König.

Caulis pedalis, ramosus, filiformis, striatus, angulatus, glater; geniculis inferioribus radicantibus infractis. Folia sesquipollicaria, sessilia, attenuata, glabra. Vaginae unzuiculares, superne ciliatae. Pedunculi laterales et terminales, solitarii, semipollicares. Involucrum pollicare, valde attenuatum, latere interiore villosum. Corolla subaequalis, coerulta.

obtusifolia r. COMMELINA foliis oblongis semiamplexicaulibus obtusiusculis, vaginis brevissimis, caule procumbente.

Habitat in Moluccis insula Bonra. Commerson. Ex herbario Thouini.

Caulis gracilis: Rami glabri. Folia semipollicaria vel minora, versus apices ramorum apfroximata, avenia, vix nervosa, glabra, interclum ad oculum armatum pitis rarissimis adspersa, basi subciliata. Vaginae vix lineam longae, ore ciliatae.

racifica. 12. COMMELINA foliis ovato-lanceolatis sessilihus, involucris cordatis attenuatis conduplicatis, caule erecto.

Commelina virginica? Forst. prodr. n. $=6$.

Habitat in insula Tongatabu.

Caulis filiformis, glaber. Folia pollicaria vel purum ultra, glabra, acuta: Vaginae tubulosae, superne parum latiores, semipollicares. Involucrum pedunculatum, terminale, cordatum, attenuaium, semipollicare. Pedicelli capillares, spaitua longiores. Flores parvi, subaequales. 
3. COMMELINA foliis ovato-lanceolatis petiolatis cajenensis. glaberrimis, involucris cordatis, caule procumbente.

Commelina cajenensis; procumbens, foliis ovato-lanceolatis, sursum sensin angustatis acutissimis glaberrimis, vaginis ciliatis, Nectariis bilobis. Act. soc. h. n. par. 1. p. 106.

Habitat in Cajenna. Richard.

Pami filiformes; teretes, glabri. Folia pollicaria et ultra, acuta, vix nervosa. Vaginae unguiculares, in petiolum brevem desinentes. I'edunculi axillares folio breviores. Involucrum vix semipollicare, tenuissime undecimnerve, basi ciliatum. Pedicelli capillares, vix ultra involucrum exserti. Flores parvi, coerulei, subaequales.

$A$ praecedente differt: foliis petiolatis; involucro acuto nec attenuato, breviore.

34. COMMELINA foliis ovato-lanceolatis sessili- divaricata. bus, involucris cordato-ovatis conduplicatis ciliatis, ramis divaricatis.

Commelina benghalensis. Forsk. descript. p. I 2. Habitat in Arabia. Forskâl.

Caulis decumbens, dichotome ramosus, glaber. Folia pollicaria, inferne remotiora superne approximata, subtus glaucescentia, margine scabra, glabra, interdum ope lentis rare pilosa. Vaginae unguiculares, pilis longis ciliatae, purpureo-punctatae. Involucrum laterale et terminale, pedunculatum.

$V$ ariat floribus dipetalis flavis et tripetalis coeruleis. Forsk. l. c.

8. COMMELINA foliis ovato-sublanceolatis acu- diffusa. tis, involucris cordatis conduplicatis, caule repente. $\dagger$

Commelina diffusa; corollis aequalibus, pedunculis capillaribus, foliis ovato-oblongis, involucro nullo. Burm. ind. Is. t. 7. f. 2.

Habitat in Coromandel.

Figura ipsa Burmanni monstrat, quod ad involucratas pertinet. Corollae aequales.

-5. COMMELINA foliis ovato-lanceulatis obtusis hispida. hispidulis, involucris cordatis conduplicatis, caule erecto. $t$ 


\section{TRIANDRIA. MONOGYNIA.}

Commelina hispida; corollis aequalibus, foliis ovato-lanceolatis obtusis hispidulis margine scabris, pedunculis subquinquefloris. $F l$. per. I. p. 43.t. $73 \cdot f \cdot a$.

Habitat in Peruviae collibus.

Radix fibrosa. Caulis sesquiulnaris, teres, striatus, pubescens. Folia majora bipalmaria, obtusa, utrinque hispidula, undecim-septendecim nervia. Vaginae ore ciliatae, antice linea villosa, subpurpurascentes. Pedunculi solitarii, foliis paulo breviores, superne incrassati. Involucrum deflexum, nervosum, hispidulum, ciliatum, quadri-sexflorum. Pedicelli recurvati; spatha parva sub singulo flore. Calycis foliola duo exteriora obovata, tertium oblongum, concavum. Petala aequalia, maxima, ovalia, emarginata, concava, breviter unguiculata. Nectarium filamenta tria. Stigma obsolete tridentatum. Semina compressa. Fl. per. l. $c$.

communis, 17. COMVELINA foliis ovato-lanceolatis subsessilibus acutis cauleque repente glabris, involucris cordatis conduplicatis.

Caapotiragoa. Marcgr. bras. p. 8 .

Ephemerum africanum annuum flore bipetalo. Herm. Lugdb. 231. Moris. hist. 3. p. 606. sect. $1 ; . t .=f .3$.

Commelina foliis ovato-lanceolatis, caule procumbente glabro, petalis duobus majoribus. Lin. hort. cliff. $2 \mathrm{r}$.

Commelina procumbens annua, saponariaefolio. Dill. elth. 9.3. t. 7 \%. $f .89$.

Commelina communis; corollis inaequalibus, follis ovato-lanceolatis, caule repente glabro. Lin. syst. veget. 95 .

polygama. $\quad \beta$. Commelina polygama; corollis inaequalibus diandris hermaphroditis et masculis, ramis prostratis radicantibus. Roth. catalect. I. p. I.

Habitat in America inque Cap. ib. spei.

Rami elongati. Folia bipollicaria, attenuata. Vaginae semipollicares, caule parum ampliores. Pedunculi laterales et terminales, semipollicares. Involucrum longitudine pedunculi. Corolla inaequalis. 
Valde dubito num Commelina caroliniana; corollis inaequalibus, floribus binis oppositifoliis, spathis ciliatis acuminatis, foliis ovatolanceolatis vix ciliatis, caule ramoso repente. Walt. fl. car. 68. specie differat, plantam enim Parisiis habui e Carolina optime cum Walt. quadrantem et a Linnaei C. communi non diversam nisi foliis parum angustioribus.

38. COMMELINA foliis ovato-lanceolatis sessilibus tukeros\$. ciliatis, involucris cordatis conduplicatis, caule erecto.

Matlalytztic Tetzocana s. triorchis Mexicana. Hern. mex. 253.

Commelina foliis ovato-lanceolatis, petalis tribus majoribus aequalibus. Lin. hort. cliff. 21 .

Commelina radice anacampseroides. Dill. elth. 94. t. $70 . f \cdot 00$.

Commelina tuberosa; corollis aequalibus, foliis

- sessilibus ovato-lanceolatis subciliatis. Lin. syst. veg. 96. Willich. illustr. $n$. 18.

Habitat in Mexico. 4

Caules plures, pedales, parum ramosi, glabri. Folia bi-tri-pollicaria, semipollicem lata vel ultra, ovato-lanceolata vel lanceolata, juniora villis aliquot adspersa, coeterum excepto margine glabra. Vaginae interdum pollicares. Pedunculi terminales, gemini, alier brevior. Involucrum pollicare et ultra, acutum, pilosum. Pedicelli longitudine vaginae. Corolla aequalis, coerulea.

39. COMMLLINA pubescens, foliis ovato-oblon- turbinata. gis petiolatis, involucris cucullatis turbinatis, caule repente.

Commelina mollis; corollis subaequalibus, foliis ovatis petiolatis villosulis mollibus, caule repente. Jacqu. collect. 3. p. 235. Ic. rar. 235.

Habitat in insula St. Crucis. Dr. Pflug, West. 4 Caules pedales et ultra, graciles, ramosi: articuli tri-quadripollicares. Folia bipollicaria, altero latere baseos interdum obliqua, acuta, utrinque adspersa pilis haud frequentibus, subtus canescentia, tenuiter septenmervia: Vaginae unguiculares, basi partm anpliores, nervosae, vix ciliatae, in petiolum brevem cilia- 


\section{TRIANDRIA, MONOGYNIA.}

tum desinentes. Pedunculi terminales, gemini breves. Involucrum utriculatum, vix semipollicare. Pedicelli exserti, capillares. Flores coerulei, aequales.

Affinis Com. mollis, sed folia non exacte ovata, et involucrum margine laterali omnino coalitum. $V$ ariat foliis longioribus et latioribus, brevioribus et angusioribus.

Forskålaei. 20. COMMELINA foliis ovato-oblongis sessilibus glabris, involucris lateralibus terminalibusque pedunculatis cordatis conduplicatis.

Habitat in Arabia. Forsikàl.

Caulis ramosus, teres, erectus (?) striatus, uti tota planta glaber. Folia tripolicaria et parum ultra, attenuata, subundulata, ope lentis margine membranaceo scabro cincta, supra scabriuscula, obscure multinervia. Vaginae semipollicares, ore subnudae. Involucrum cordato-falcatum, margine membranaceum. Flores exserti, coerulei, subaequales.

obliqua. 21. COMMELINA foliis ovato-lanceolatis petiolatis basi obliquis cauleque glabro, involucris reniformibus conduplicatis.

\section{Habitat - - Ex horto Celsii.}

Caulis crassitie pennae columbinae. Folia triquinquepollicaria, pollicem et ultra lata, attenuata, basi altero latere breviora et obliqua, acuta. Vaginae vix pollicares, supremae articulorum longitudine, pilis setaceis rufis ciliatae. Pedunculi terminales, solitarii, gemini. involucrum semipollicare, coloratum, glabrum. Pedicelli involucro duplo longiores, biflori, ope lentis villosi, declinati. Corolla subaequalis.

An varietas $\mathrm{C}$. erectae?

erecta. 22. COMMELINA foliis ovato-lanceolatis scabris, involucris cucullatis turbinatis, caule erecto. Ephemerum phalangoides, lilii convallii foliis scabris. Plukn. mant. 67.

Ephemerum erectum Noveboracense Cardamomi foliis. Herm. parad. bat. i 1 .

Commelina foliis ovato-lanceolatis, caule erectiuscizlo scabro, petalis duobus majoribus. Lin. hort. cliff. 495 . 
Commelina erecta, ampliore subcoeruleo flore. Dill. elth. 9r. t. $77 \cdot f$. 88 .

Commelina erecta; corollis inaequalibus, foliis ovato-lanceolatis, caule erecto subhirsuto simplicissimo. Lin. syst. veg. 96.

Habitat in Virginia. 4

Caulis simplicissimus, crassitie fere pennae anserinae, villis adspersus, inferne glaber. Folia quadri-quinquepollicaria, pollicem lata et ultra, attenuata, supra scabra, praesertim margine, subtus laevia. Vaginae pollicares, superiores longitudine internodiorum, pilosae, margine hirsuto-cilintae, praesertim superiores. Petiolus brevissimus. Involucra terminalia, geminata, sessilia, diametro semipollicari. Pedicelli involucro longiores. Corollae inaequales. \&-

23. COMMELINA villosa foliis ovatis petiolatis, mollis. involucris semiorbiculatis margine conduplicatis, caule repente. +

Commelina mollis; corollis subaequalibus, foliis ovatis petiolatis villosulis mollibus, caule repente. Jacqu. collect. 3. p. 2. t. 235. Ic. rar. 2. $t .293$.

Habitat ad Caracas. 4

Caules bipedales, crassitie calami, teretes, ramosissimi, geniculati. Folia tri-quadripollicaria, acuta, mollia, subtus pallidiora. Petiolus ciliatus. Involucrum brevissime pedunculatum, subbiflorum. Flos ut in C. longicauli. Jacqu. l.c.

24. COMMELINA foliis ovatis sessilibus, vaginis barbata. barbatis, caule repente. Lamarck illustr. I. p. $12^{n}$.

Habitat in insula Mauritiana.

Corollae subaequales. Lamarck. l. c.

25. COMMELINA foliis ovatis petiolatis acutis vil- canescens. liso canescentibus, involucris cucullatis turrinatis, caule repente.

Hahitat in Arabia. Forskâl.

Caulis ramosus, crassitie fere pennae columbinae, striatus, pilis rarissimis adspersus. Folia sesquipollicaria, utrinque e villis frequentibus canescentia, praesertim subtus. Petioli unguiculares pilosi. Vaginae semipollicares, pilosac, ore albo ciliuiae. Pedunculi terminales, vix extra 


\section{TRIANDRIA. MONOGYNIA.}

vaginam porrecti, gemini. Involucrum ut in Com. cucullata. Pedicelli fere pollicares. Flores parvi, coerulei.

An modo varietas Com. benghalensis?

benghalensis. 26. COMMELINA foliis ovatis petiolatis obtusis, involucris cucullatis turbinatis, caule repente. Eplemerum benghalense, serpens, folio subrotundo brevi, phalangioides. Plukn. alm. 130. t. $27 \cdot f \cdot 3$.

Commelina benghalensis; corollis inaequalibus, foliis ovatis obtusis, caule repente. Lin. syst. veg. 97. murr. in comment. gött. 1779. p. 18. t. 5 .

Commelina nervosa; corollis aequalibus, foliis ovatis, nervosis. Burm. ind 12.t. ᄀ. f. 3 .

Comnelina cucullata; corollis aequalibus, foliis oratis, involucris cucullatis turbinatis. Lin. mant. i 7 h.

Habitat in India orientali.

Caules ramosi, teretes, pilosi. Folia pollicaria vel minora, remota, subundulata, villis raris adspersa. Vaginae unguiculares, uti petioli pilis setaceis distantibus rufescentibus ciliatae. Involucrum terminale, breviter pedunculatum, pilosum. Pedicelli involucro longiores.

gracilis. 27. COMMELINA foliis ovatis subpetiolatis glaberrimis, involucris cordatis ciliatis, caule repente. +

Commelina gracilis; corollis aequalibus, foliis ovatis acutis margine scabris, vaginis longis ciliatis, caule repente. Fl. per. 1. p. 44. t. 72 . f. a.

Habitat in cultis et humidis locis Limae.

Rarix fibrosa. Caulis bipedalis, gracilis, ramosus, teres, geniculatus, striatus, glaber, sneje purpurascens. Folia margine retrorsum scabra, utrinque glaberrima. Vaginae longae, ciliatae. Pedicelli longitudine fere involucri, solitarii, quinqueflori, saepe gemini, alter uni-biflorus, alter tri-quadriflorus. Calycis foliola ovata, parva, concava, albida, duo latiora. Petala subcoerulea, subundulata, subrotunda, duo majora patentia, unguiculata. 
Nectarii filamenta duo. Capsula ovata, trian. gularis, trisulca. Semina bina in singulo loculo, angulata. Fl. per. l. c.

** Floribus nudis.

28. COMMELINA foliis radicalibus subulatis, scapo medica. multifloro subnudo. +

Commelina medica; floribus aequalibus, foliis sessilibus subulatis glabris. Lour. fl. cochinch. 40.

Habitat in China et Cochinchina.

Planta acaulis, repens, tuberibus plurimis, $f a$ sciculatis, parvis. Folia congesta, reflexa, glabra, crassa. Scapus sexpollicaris, tenuis, teres. Spica interdum simplex, interdum ramosa. Corolla coerulea. Filamenta duo, villosa. 'Lour. l. c.

29. COMMELINA foliis lanceolatis, scapo bifloro nudicaulis. medio bracteato. $\dagger$

Commelina nudicaulis; corollis aequalibus scapo indiviso, foliis lanceolatis radicalibus, Burm. ind. $17 . t$. s.f. I.

Habitat in Java.

Radix fibrosa, repens. Caules procumbentes. Folia basi vaginantia. Scapus erectus, filiformis, indivisus. Bracteae revolutae. Flores coerulei. Burm. l. c.

An modo varietas Com. nudiflorae vel Tradescantiae malabaricae?

30. COMMELINA foliis linearibus, pedunculis la- vaginta. teralibus terminalibusque vagina involucratis unifloris.

Commelina vaginata, corollis aequalibus, foliis linearibus, floribus diandris involucro vaginatis. Lin. mant. 17.7 .

Habitat in India orientali. König. (2)

Caules plures, adscendentes, spithamaei, filifor. mes, teretes, glabri. Folia bi quadripollicaria, sessilia, angusta, acuta, striata, glabra: Vaginae breves. Pedunculi solitarii vel gemini, raro tantum terminales, plerumque unicus vel duo laterales, remoti, unguiculares, uniflori; vagina cylindrica, pedunculo brevior, striata, obtusa, involucrata. Calycis foliola lanceolata, 
apice co?orata. Petala ovata. Nectarii filamenta quatuor; corpuscula linearia. Stamina duo barbata, longitudine corollae. König.

sudiflor, 3 г. COMMELINA foliis linearibus, pedunculis lateralibus terminalibusque submultifloris nudis.

Ephemerum phalangioides maderaspatense minimum foliis perangustis, perfoliatum. Plzkn. alm. $13 \%$. t. $27, f .4$.

Commelina corollis aequalibus, pedunculis capillaribus, foliis lineari-lanceolatis, involucro nullo. Lin. fl. Zeyl. 31 .

Commelina nudiflora; corollis aequalibus, pedunculis capillaribus, foliis linearibus, involucro nullo, floribus diandris. Lin. mant. r7?• Habitat in Indiae orientalis aridis graminosis. König. -

Caules basi repentes dein erecti, palmares vel spithamaei, parum ramosi; debiles. Folia bitripollicaria, sessilia, remota, angusta, acuta, glabra. Vagina brevis. Pedunculi folio, longiores, capillares, tri-sexflori, rarissime uniflori; pedicelli racemosi, conferti. Involucrum nullum. Calycis foliola ovato-lanceoluta, corolla breviora.

Petala tria, ovata. Nectarii filamenta tria, nuda: Corpuscula deltoidea. Stamina duo, in medio barbata. König.

spirata. 32. COMMELINA foliis subcordato lanceolatis undulatis, floribus racemosis paniculatisque, caule repente.

Commelina spirata; corollis aequalibus, foliis lanceolatis undulatis, floribus paniculatis. Lin. mant. $1 ? 6$.

Commelina bracteolata; corollis aequalibus, foliis lanceolato-linearibus undulatis subcrispis, pedunculis paniculatis, bracteolis semivaginalibus. Lamarck. dict. bot. 2. p. 69. illustr. I. p. I 20 .

Habitat in India orientali ad rivulos locis humen tibus. König.

Caules spithamaei, parum ramosi, glabri. Folia amplexicaulia, pollicaria vel minora, angusta. acuta, striata, glabra. Vaginae breves, subeiliatae. Pedunculus terminalis, capillaris, 
flexuosus, saepe purpurascens, teres, laevis. Racemus simplex vel compositus, tri-quinqueflorus: pedicelli unguiculares, uniflori. Bracteae minutae, ad basin singuli pedicelli, semivaginantes. Nectarii filamenta tria, subciliata; corpuscula cruciformia apicibus globosis albicantibus. König.

33. COMMELINA foliis lineari-lanceolatis basi ci-simplex, liatis; racemo terminali subcomposito, caule erecto simplicissimo.

Habitat in Guinea. Isert, Thonning. $\hbar$

Caulis spithamaezs, bi-s-trinodis, striatus, glaber. Folia 2 vel 3 in caule, remotissima, striata, glabra, basi coarctata, uti fissura obliqua vaginae ciliata, attenuata. Pedunculi terminales solitarii, terni: pedicelli breves, pauci, spithanaei. Spatha vix unguicularis, lanceolata. Flores nutantes.

Similis sequenti, at omnibus partibus duplo minor: Racemi simplices, gemini vel terni, alterni, tri-vel quadriflori: pedunculi et pedicelli capillares.

34. COMMELINA foliis linearibus, vaginis ore gigantea. nudis, caule erecto simplicissimo, racemis terminalibus bipartitis, floribus secundis.

Habitat in India orientali. Röttler.

Radices longae, crassitie pennae columbinae, teretes, carnosae. Caulis bipedalis et ultra, striatus, ad geniculos incrassatus, glaber, uti tota planta. Folia pedialia et ultra, sursum sensim minora, condluplicata, remota; duo suprema spathacea: Vaginae pollicares, ore et nargine glabrae. Pedunculi partiales gemini, breves, erecti, post casum pedicellorum denticulait; circiter trigintaflori; pedicelli alterni, approxinzati. Capsula magnitudine pisi, nitida. Flores non vidi.

35. COMMELINA foliis ovato-lanceolatis subpe-serrulata. tiolatis margine scaberrimis, pedunculis lateralibus terminalibusque multifloris,' caule erecto.

Torr. II. 


\section{I.78 TRIANDRIA. MONOGYNIA.}

Commelina serrulata; pedunculis axillaribus subsolitariis multifloris, foliis lanceolatis margine serrulato-scaberrimis, vaginis ciliatis. Ecl. am. 2. p. 4 .

Habitat in Cajenna. v. Rohr.

Caulis striatzs, glaber, purpurascens. Folia quadri-quinquepollicaria, latitudine fere pollicis, attenuata, ope lentis serrulata. Vaginae pollicares. Pedunculi superne, solitarii vel gemini, breves: partiales longiores, unguiculares, quinque-sexflori: pedicelli breves. Bracteae duae, oblongae, aridae, pilosae, ad basin pedunculorum communium, brevissimae. Calycis foliola oblonga, acutiuscula, oculo armato pilis rarioribus adspersa.

japonica. 36. COMMELINA foliis ovato-lanceolatis undulatis glabris, caule erecto angulato piloso, floribus paniculatis. Thunb. in act. soc. Lin. 2. p. $332 .+$

Habitat in Japonia.

Caulis pedalis, sulcatus, apice paniculatus. Folia inferiora digitalia, superiora pollicaria, oblonga, acuta, glabra. Flores racemosi. Thunb. l. c.

elata. 37 , COMMELINA foliis ovato-lanceolatis ciliatis; floribus paniculatis, caule erecto.

Habitat in India orientali? Ex herbario Jussiaei. Caulis altus, crassitie pennae cygneae, striatus, oculo armato villosus. Folia spithamaea et ultra. Vagina vix pollicaris. Panicula patens. Bracteae minutae, ovatae, membranaceae. Calycis foliola tria, linearia. Petala venosa. Stamina tria, barbata. Corpuscula cruciata.

micrantha. $3 \mathrm{~S}$. COMMELINA foliis ovato-lanceolatis petiolatis glabris, floribus racemosis, caule procumbente.

Habitat in India orientali. Ex herbario Jussiaei.

Caulis oculo armato villosulus. Folia bipollicaria, valde attenuata, obsolete nervosa. Vaginae internodiis breviores, villosulae. Pedunculiterminales, tenues: pedicelli distantes, subuniflori. Bracteae minutae, cucullatae. Involucrum nullum. 


\section{TRIANDRIA. MONOGYNIA.}

39. COMMELINA foliis ovatis nervosis petiolatis, umbrosa. petiolis ciliatis, racemis compositis, caule erecto.

Habitat in umbrosis Assjamae Guinea. Isert.

Caulis sulcatus, angulatus. Folia bipollicaria, ovata, vel ovato-lanceolata, acuta, septemnervia, glabra, integerrima, basi in petiolum acuminata. Petiolus unguicularis. Vagina unguicularis basi pilis rufis barbata. Pedunculus terminalis, interdum gemini, folio duplo breviores: pedicelli alterni, distantes, squamis minutis ovatis persistentibus tecti.

40. COMMELINA foliis ovatis subpetiolatis acu- paniculata. tis basi ciliatis, floribus paniculatis.

Commelina tuberosa. Forsk. descr. p. 12.

Habitat in Arabia. Forskâl.

Caulis ramosus. Folia breviter petiolata, sesquipollicaria, margine e denticulis minutissimis scabra, obscure undecimnervia, oculo armato pilis rarissimis adspersa, ceterum glabra. Vaginae unguiculares, tenuiter nervosae, ad lentem villosulae, ore subciliatae. Pedunculi laterales et terminales, gemini, alter longior et magis divisus, subdichotomi; partiales patentes; vagina unguicularis, ciliata ad basin singuli : pedicelli racemosi, interdun octo, interdum pauciores, unguiculares, nutantes, uniflori; spatha minuta, glabra, ad basin singuli.

Caulis in aquosis repens. Forsk. l. c.

Habitus. Caulis herbaceus, articulatus. Rami alterni. Folia alterna, integerrima, margine saepius scabra, tenuissime nervosa. Vaginae tubulosae, membranaceae, caule plus minusve ampliores, nervosae, plus minusve ciliatae. Pedunculi oppositifolii et laterales. Involucra compressa.

107. Haemodorum. Pet. 6. tria interiora supra. medium staminifera. Stigma obtusum. Caps. 3-locularis. Smith.

I. HAEMODORUM. Smith. in act. soc. Lin. 4. corymbop. 2 2.3. +

Habitat in Australasia. 


\section{TRIANDRIA. MONOGYNIA:}

Herba facie Corymbii, glabra, inflorescentia co. rymbosa, tota punicea, et siccatione nigra.

A. Wachendorfia differt germine infero; petalis apicem versus staminiferis; staminibus abortivis nullis. Smith. $l$. $c$.

108. Callisia. Cal. 3 phyllus. Pet. 3. Anth. geminae. Caps. 2 locularis.

«epens. I. CALIISIA foliis ovato-lanceolatis sessilibus, caule procumbente, floribus axillaribus sessilibus. Commelina? Wachendorfia loefl. it. $176^{\circ}$

Callisia. Loefl. it. 305.

Iapalanthus repens. Jacqu. hist. p. I r. t. Ir.

Habitat in Americae meridionalis udis depressis umbrosis. 24

Caules repentes, filiformes, ramosi, glabri. Fo. lia sessilia, remota, ovata, corciata, acuta, glabra: Vaginae breves, caule ampliores, margine subciliatae. Flores dico-sex, axillares, bracteis lanceolatis, membranaceis interstincti.

nmbellulata. 2. CALLISIA umbellis pedunculatis lateralibus er terminalibus, caule superne pedunculisque villosis. Lamarck. illust. I. p. 13c. t. 35. f. z.

Habitat in America meridionali.

Flores diandri.

Habitus. Commelinae.

109. SyenA. Cal. 3-phyllus. Petala 3. Caps. I-locularis, 3 -valvis.

Ruviatilis. I. SYENA.

Mayaca fluviatilis. Aubl. fl. gu. 4 =. t. 15.

Biaslia. Vand. fl. lusit. et brasil. spec. in Römer script. de pl. hisp. lus. et bras. 7. t. $6 . f$. 2.

Habitat in rivulis Guianae. Richard, in Brasilia. Vellozo.

Facies musci frondosi. Caules filiformes, inferne radicantes, teretes, ramosi. Folia copiosissima, confertissima, sparsa, patentissima, vix semiunguicularia, subulata, glabra. Pedunculi axillares, solitarii, uniflori, longitudine foliorum. Calycis foliola lineari-lanceolata.

Antherae apice perforatae. Capsula unilocularis. Semina plurima, rugosa. Vand, l.c. 
An capsula potius trilocularis, septo valvularum medio post maturitatem retracto? Juss. gen. pl. 45 .

110. FICUS. Recept. commune turbinatum vel, globosum, carrosum; squamis conniventibus clausum, occultans flosculos apetalos vel in eodem vel in distincto individua. $\delta^{\lambda}$ Cal. 3 -partit. $ᄋ$ Cal. 5 -partit, Ovarium semiinferum. Utriculus pulposus.

* Foliis indivisis.

_-_ Integerrimis.

x. FICUS foliis ovato cordatis acuminatissimis, religiosa. fructu sessili.

Arealii. IRheed. mal. I. p. 47. t. 27.

Ficus malabariensis, folio cuspidato, fructu rotundo parvo gemino. Plekn. alm. 144. t. 178 . fig. 2.

Ficus religiosa, foliis cordatis oblongis integerrimis acuminatissimis. Lin. mant. $504 . S_{0} V .921$. Habitat in India. \$

Rami superne angulati. Folia petiolata basi pollices quatuor lata, venosa, subtus pallidiora, utrinque glcebra, supra nitida, obscure subrepanda, acumine bipollicari. Petiolus longitudine folï. Fructus axillaris, geminatus, sessilis, calyculatus, globosus, magnitudine pisi, glaber, laevis.

2. FICUS foliis exquisite cortatis acutis, fructibus populifolia. geminis pedicellatis. Symb. bot. x. p. 8z.t. 22 . Ficus religiosa. Forst. descr. p. 182.

Habitat in Arabia. $b$

Rani teretes, glabri, cortice rugosa. Folia petiolata, corciata, acuta, integerrima, utrinque glaberrima, venosa, bipollicaria, basi ejusdem Zatitudinis. Petiolus longitudine folii, glaber. Pedunculi gemini, axillares, giabri, basi apiceque crassiores, semipollicares. Squamae binae vel ternae sub fructu, subrotundae, breves. Fructus globosus, glaber, magnitudine pisi.

Distinguitur a F. religiosa foliis acutis nec longo acumine terminatis, fructibus peciunculatis. 


\section{I82 TRIANDRIA. MONOGYNIA.}

a F. nymphaeifolia, foliis exquisite cordatis, utrinque concoloribus, minime obtusis, mucronatis.

a F. sycomoro et cordifolia Thumbergii fructu pedunculato.

umbellata. 3. FICUS foliis exacte cordiformibus acuminatis glabris, pedunculis tri-quinque umbellatis.

Habitat in Guinea. Thonning. ち

Arbor alta, patentissima, ramis sparsis $v$. verticillatim subadproximatis, ramulis teretibus, glabris. Folia sparsa, paulo longiora quam lata, albido-costata, tenuissime reticulata, subtus laete viridia, quadri-septempollicaria- $\mathrm{Pe}$ tiolus dimidia folii longitudine. Pedunculi in ramis adultioribus pollicares. Calyx bifidus. Fructus globosus, tuberculo umbilicatus, glaber, viridis, magnitudine pruni. Thonning.

nymphaeifo-1. FICUS foliis cordatis subrotundis mucronatis glalis. bris subtus glaucis. Lin. mant. $305 . S . V . p .921$ 。 Ficus foliis ovato-cordatis integerrimis glabris. Mill. dict. 9. Hort. cliff. 47 .

Habitat in India. $\hbar$

Folia in hoc genere maxima, Nympheae luteae paria, subundata, obtusa cum mucrone, pendula, quasi peltata, glabra, subtus albida. Lin.

cordata. 5. FICUS foliis subcordatis ovatis acutis glabris coriaceis, caule fruticoso erecto. Thunb. fic. p. 8. cum tabula. +

Habitat in Cap. b. spei. Ђ

Frutex mediocris, totus glaber. Rami teretes, subrugosi, cinerei. Folia versus apices ramorum et ramulorum approximata, obsolete corlata, ovata, acuta, integra, venosa; venis reticulatis, patentia, sesquipollicaria. Fructus sessiles, versus apices ramorum, axillares, approximati, globosi, magnitudine pisi. Thunb.

polita. 6. FICUS foliis cordato-ovatis acuminatis glabris laevibus integefrimis.

Habitat in Guinea. Isert. †

Tota glabra. Folia bipollicaria et ultra, venosa. Fructus pedunculatus, glaber, laevis, globosus, magnitudine nucis Coryli. 
7. FICUS foliis cordatis scabris. Forsk. desc. p. 2 19. $†$ Chanas. Malitat in Montosis Arabiae. $\hbar$ Sycomoro similis. Fructus edulis. Forsk.

8. FICUS foliis ovatis cordatis: sinu profundo an- costata. gusto glabris acutis utrinque viridibus. Hort.

kew. 3. p. 452 . $t$

Ilabitat in India orientali. $\hbar$.

9. FICUS foliis cordatis ovatis acuminatis venosis laevigata. laevissimis, fructibus pedunculatis globosis glabris.

Habitat in India occidentali. Dn. West. $\hbar$

Rami teretes, glabri, cortice cinereo. Folia petiolata, sparsa, tri-vel quadripollicaria, utrinque glabra, integerrima, acumine obtusiusculo, tenuissime venosa. Petiolus pollicaris. Fructus magnitudine cerasi, glaber, laevis, ore trilobo.

10. FICUS foliis ovato-oblongis subcordatis acumi- lentiginosa. natis, fructibus lateralibus axillaribusque geminis pedunculatis.

An Ficus foliis ovatis. Plum, ic. tab. 131. fig. =.? Sed folia obtusa nec acuminata.

Habitat in Montserat. Dr. Ryar. $\hbar$ Rami glabri. Folia petiolata, palmaria et ultra, utrinque glabra, membranacea, venosa, integerriina, acumine obtuso terminata. Fructus magnitudine pisi, globosus, glaber. Pedunculi gemini, fusci, fructu breviores. Calyculo minuto sub flore.

11. FICUS foliis cordato ovatis obliquis subtus scabre: scabris, fructibus turbinatis ecalyculatis.

Ficus scabra. Forster fl. austr. $p .76$.

Habitat in insula Tanna, Namola. Herbar. mus. $\hbar$ Rani glabri, apice subiomentosi. Folia semipedalia, ovata, basi cordata, inaequalia, attenuata, remote dentata, supra scabriuscula, subtus scabra, pallidiora, villosula.

12. FICUS foliis cordato-ovalibus acutiusculis citrifolia. nervosis utrinque glabris, fructibus globosis solitariis pedunculatis. Lamarch. Enc. =. p. 494. Amacoztic s. sycomorus saxatilis mexicana. Ilern. mex. p. 81.82 .

Ficus folio citri acutiore fructu viridi. Plum. Ic.

t. 13 1. f. 2 . 


\section{I84 TRIANDRIA. MONOGYNIA.}

\section{Habitat in India occidentali. $\hbar$}

Folia basi cordata, subtus inter venas concava, hinc quasi bullata, $5-7$ pollicaria. Fructus magnitudine nucis Coryli. Lamarck.

Rami uti petioli et folia subtus villosi. Folia basi subcordata, oblonga, obtusiuscula, tenuissime venosa, 6-7 pollicaria.

iacida, r3. FICUS foliis ovatis corclatis glabris obtusis basi trinerviis, ramis erectis. Hort. kew. 3.p.451. $\dagger$ Habitat in India orientali. $\hbar$

scandens. $\mathbf{4}$. FICUS foliis cordatis basi inaequalibus subtus venoso-reticulatis, stipulis lanceolatis oppositis, caulibus scandentibus. Lamarck. Eic. =. p. 498 .

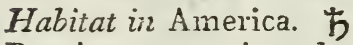

Rami versus apicem leviter villosi.

stipulata, 15. FICUS foliis oblique cordatis obtusis glabris, caule decumbente squamoso. Thunb. fic, n. $7 \cdot \dagger$

Habitat in China Japonia. $\hbar$

Caulis lignosus, filiformis, decumbens, rufescens, glaber. Ranifilifornies, decumbentes, stipulati. Stipulae sparsae, subulatae, patentes, rufescentes. Folia brevissime petiolata, ovata, obtusa, supra laete viridia subtus pallicliora, reticulata, unguicularia vel serizipollicaria. Thunb.

sagittata. I6. FICUS foliis cordatis oblongis acutis utrinque scabris, caule repente.

Habitat in India orientali. 5

Caulis repens, radiculis oppositifoliis, glaber, su. perne pubescens Folia petiolata, cordato-ob. longa, auriculis rectis rotundata, integerrima, utrinque scabra, subtus punctis sparsis, acuta, sesquipollicaria. Petiolus brevissimus vix bilinearis. Stipulae utrinque, lunceolatae.

Fructum noi vidi, ex autoritate Förigii et summa convenientia cum caeteris luc retuli.

fedunculata. 17. FICUS foliis ovato-oblongis cordatis acutis glabris, fructibus globosis, pedunculis geminis elongatis. Hort. kew. 3. p. 450. 


\section{TRIANDRIA. MONOGYNIA. I8S}

Ficus arbor americana, arbuti foliis non serrata, fructu pisi magnitudine, funiculis e ramis ad terram demissis prolifera. Plukn, alm. 144. t. 17 . fig. 4 .

Habitat in America. $\hbar$

Rami teretes, cortice cinereo, glabri. Folia petiolata, sparsa, tri-quatuorpollicaria, pollicem vel parum ultra lata, acuminata, integerrima, utrinque gla'jra, nervosa, subvenosa, basi siniu parvo subcordata. Petiolus pollicaris. Periunculi unguiculares. Fructus magnitudine pisi.

8. FICUS foliis ovatis subcordatis acutis laevibus venosa. supra punctato impressis. Hort. liere. 3. p. $45 \mathrm{I} \cdot \frac{1}{!}$

Ficus Tsjakela. Rheed. mal. 3.p. 87.t. 64.

Habitat in India orientali. $\frac{5}{b}$

3. FICUS foliis ovali-oblongis acuminatis basi lutea. subemarginatis glabris, fructibus geminatis globosis sessilibus, calyce quadrifido.

Habitat in Guinea. Thomning. \$)

Arbor subalta, patens. Ramis sparsis v. verticillatin subapproximatis. Ranulis teretiusculis glabris. Folia sparsa, coriacea, albido-costata, tenuissime reticulata, subtus pallido-viridie, quadri-octopollicaria. Petiolus folio triplo brevior. Fructus axillares, vix cerasi magnituaine, tuberculo bifido zembilicati, lutei, maturescendo badii absque tuberculo poro umbilicati. Thonning.

2c. FICUS foliis ovato-oblongis, fructibus gemi-ovata. nis sessilibus, calyce comnuni calyptriformi caduco, fructuum lacerato-bifido.

Habitat in Guinea. Thonning. 5

Arbor alta ramis subverticillatis, erecto-patentibus, saepe radiculiferis. Folia sparsa acumina!a, basi subemarginata, glabra, subcoriacea, albido-costuta, subtus palrivia et minime niticla, quinque-octopollicaria. l'etiolus folio triplo brevior. Fructus ante anthesin calyptra carnoso-coriacea basi circumscissa tecti, tulbercu'o zunbilicati; maturi ovato-sutrommdi, magnitudine prini, absque iu’e'tculo perforati. Thonning. 
calyptratu. 2r. FICUS foliis oblongiusculo-ovatis, fructibus geminis, calyce communi et fructuum calyptriformibus caducis.

Habitat in Guinea. Thonning. $\hbar$

Arbor alta, expansa. Folia sparsa, subacuminata, glabra, subcoriacea, albido-costata, tenuissime venosa; subtus laete viridia, quinquepollicaria. Petiolus folio triplo brevior. Calyx communis calyptriformis, coriaceo-carnosus, basi circumscissus, anthe anthesin caducus. Calyx proprius item calyptriformis, caducus. Pructus globosi, sessiles, vix cerasi magnitudine aurantii. Thonning.

granatum. 22. FICUS foliis ovatis, pedunculis terminalibus geminis horizontaliter divergentibus, fructibus calyculatis globosis. Forst. pl. escul. austr. pag. $37 \cdot+$

Habitat in insula Tanna. 4

septica, 23. FICUS foliis ovatis acuminatis, caule erecto, fructu solitario. Burm. fl. ind. p. 226.

Handur-alii. Rheed. mal. 3. p. 77. t. 59.

Ficus septica. Rumph. amb. 3. p. I 53. t. 96.

Habitat in India orientali. Ex herb. Jussiaei.

Rami teretes, glabri. Folia petiolata, sex-septempollicaria, lato-oblonga, membranacea, acumine pollicari acuto, glaberrima, subtus glauca, venosa. Stipulae lanceolatae. Petioli teretes, bipollicares, basi apiceqve colorati.

Acumen foliorum in fig. Hheed. desideratur.

Taab. 24. FICUS foliis ovatis petiolatis conjugatis. Forst. descr. p. $2190^{\circ}+$

Habitat in Arabia. $\hbar$

Ampelos. 25. FICUS foliis ovatis acutis scabris, fructihus pedicellatis umbilico squamoso hiante. Lamarch. Enc. 2. p. 496. †

Teregam. Rheed. mal. 3. p. 79. t. 60.

Ficus ampelos. Burman. ind. p. 22 h.

Ficus politoria foliis oblongo-ovatis integerrimis scabris: fructu subrotundo spicato caule erecto. Lour. fl. Coch. :. p. 667 .

Habitat in Incia orientali. b

Ramuli peticli et pedunculi hispidi. Fructus axillaris, magnitudine grossulariae. Lamarcl. 
26. FICUS foliis ovatis acuminatis ciliatis. Burm. pyrifolia. fl. Ind. p. 226 . Rherd. mal. т. p. 45. t. 26. Habitat in India orientáli. Ex herb. Juss. 古 Rami obscure articulati, uti reliqua planta glabri, cortice purpurascente. Folia petiolata, bipollicaria, oblonga, remote nervosa, subvenosa, glaberrima, parum acuminata. Petiolus pollicaris. Pedunculi brevissimi. Fructus globosus, piso parum major, punctis elevatis submuricatus.

27. FICUS foliis ovatis acuminatis transverse stria- bcnjamina. tis margine laevi. Lin. mant. I 29.

Ficus arbor densioribus foliis parvis integris. Plukn. Phyt. t. 243. t. 4 .

Itty-alu. Rheed. mal. т. p. 45. t. $=6$.

Varinga parviflora. Rumph. amb. 3. p. 1 39: t. g0.

Habitat in India. $\hbar$

Pami tenues. Folia petiolata, exacte ovata, acuminata, subtransverse tenerrime striata, margine distincto laevi, perennia, facie pyri. Lin.

Rami dichotomi. Folia i - 2 pollicaria, stupra nitida: transversin nervosa, subtus pallidiora. Fructus breviter pedunculatus, axillaris, oblongo-subrotundus, magnitudine pisi. Herb. Jussiaei.

28. FICUS foliis ovato-oblongis glabris, fructibus benghalensis. globosis sessilibus geminatis.

Peralu. Pheed. mal. 1. p. 49. t. 2 9.

Ficus benghalensis, folio subrotundo, fructu orbiculato. Com. hort. I. p. ing. t. 62 .

Ficus americana, latiore folio venoso. Plukn. phyt.t. 17 \&. f. г.?

Ficus vasta foliis cordato-ovalibus. Forsk. descr. p. $\mathbf{1} 79$.

Ficus benghalensis, foliis ovatis integerrimis obtusis, caule inferne radicato. Lin. syst. veg. $94^{\circ}$ Habitat in India. 5

Rami cicatricati, glabri. Folia petiolata, oblonga, spithamaea, utrinque glabra, basi apiceque obtusa, venosa. Fructus gemini, globosi, sessiles, magnitudine pruni, ockío armato villosuli. 


\section{TRIANDRIA. MONOGYNIA.}

callosa. 29. FICUS foliis oblongis obtusis basi angustatis calloso-bipunctatis subtus scabris. $\dagger$

Ficus callosa foliis oblongis obtusis basi angustatis integerrimis subtus scabris, receptaculis umbilicatis. Wild. diss. fic. p. 25, t. 4.

Habitat in India orientali. $\hbar$

Folia superne nitida, glabra, basi punctis binis callosis, inferne paliidiora. Reseptacula globosa, umbilicata, magnitudine cerasi. Wilden.

microcarga. 30. FlCUS foliis oblongiusculo-ovatis obtusis glabris, ramulis subvirgatis, fructibus geminatis globosis sessilibus.

Habitat in Guinea. Thonning. $\$$

Arbor subalta, patentissima. Ramis sparsis vel subverticillatis, radiculiferis. Folia sparsa, subattenuata, basi rotundata v. subacuta, tenuissime reticulata, subtus pallida, tri-quinquepollicaria. Petiolus folio triplo brevior. Calyx communis rumpens, parvus. Calyx proprius bi-trifidus. Fructus parvus. Thonning.,

parasitica. 31. FICUS foliis elipticis obtusiusculis subtus reticulatis scabriusculis, pedunculis geminatis, fructibus globosis umbilicatis, Wilden. dissert. fic. $p .=5 . t .3 . \div$

Habitat in India orientali. $\hbar$

Rami teretes, laeves. Folia basi et apice parum attenuata obtusiuscula, coriacea, reticulatovenosa praesertim subtus, superne nitida glabra, inferne scabriuscula. Pedunculi axillares. Fructus magnitudine pisi. Wilden.

amcricana. 32. FICUS foliis ovatis oblongis renosis, baccis axillaribus pedunculatis confertis. Sucartz. prodr. p. I $2=$. $\dagger$

Ficus alia, foliis lauri fructu minore. Plum. spec. $124: t .132 . f .2$.

Ficus americana. Aubl. glitan. $2 . p$. 952 .

Habitat in Jamaica. b

racemosa. 33. FICUS foliis elliptico-ovatis acutis supra punctatis; fructibus sessilibus turbinatis villosis.

Alty-alu. Rheed, malab. т. p. 4.3. t. 25.

Ficus racemosa foliis ovatis integerrimis acutis impresso punciatis caule arboreo. Lin. syst. veg. 922 . 
Habitat in India. 5

Rami superne pubescentes. Folia petiolata, remota, bi-s-tripollicaria, utrinque angustata, praesertim extus, acuta, nervoso-substriata, subvenosa, utrinque glabra, supra oculo armato punctata. Petioli subvillosi. Fructus sessiles, pyriformes, villosi. 34. FICUS foliis ovato-lanceolatis coriaceis subtus cotonenefosubpubescentibus, fructibus sessilibus. $\dagger$

Ficus indica theophrasti. Tabern. hist. $1370 . \mathrm{Am}$. acad. T. p. 27 .

Ficus indica foliis mali cotoneae similibus, fructu ficubus simili. Bauh. pin. 457 .

Katou-alou. Rheed. mal. 3. p. 73. t. 57 .

Saringa latifolia. Rumph. amb. 3. p. 127.t.84.

Ficus indica. Lamarck. Enc. 2. p. 494.

Habitat in Indiis.

35. FICUS foliis distichis scabris ovato. lanceolatis Toka. petiolatis. Forsk. desc. p. 2 I $9 . \div$

Habitat in Arabia. 4

36. FICUS foliis oblongis emarginatis glabris punctata. subtus punctatis, caule flexuoso radicante. Thunb. fic. p. .9. +

Halitat in India orientali.

Caulis parasiticus, longe scandens, flexuosus, teres, rugosus; brunneus, crassitie vix calami scriptorii. Rami flexuosi, laeves. Folia oblonga, obtusa, obsolete emarginata, integra, margine parum reflexo, glabra, supra laevia, subtus impresso punctata, patentia et reflexa, unguicularia et pollicaria. Petioli brevissimi. Fructus obovati, magnitudine fere caricae. Thunb.

37. FICUS foliis ovatis oblongis acuminatis glabris, pertusa. fructibus globosis pedunculatis umbilicatis, calycibus bifidis.

Ficus alia lauri foliis, fructu minori. Plum. ic. p. 12 . t. $132 . f_{:} 2$.

Ficus pertusa foliis ovatis glabris, calycibus bifidis, baccis globosis foramine umbilicatis. Lin. suppl. p. $4 \%$. syst. veg. p. 922 .

Habitat in Surinamo. $\hbar$ 
Rami glabri. Folia petiolata, bipollicaria et ultra, glabra, membranacea, tenuissime venosa, acuta. Racemi axillares, pollicares. Fructus magnitudine ribesii, pedicellati, foramine umbilicali tereti.

pumila. 38. FICUS foliis oblongo-ovatis obtusis glabris subtus seticulatis, caule articulato-repente, fructibus pedunculatis. Thunb. fic. 10.

Ficus sylvestris procumbens, folio simplici. Kaempf. am. ex. 803 . t. 804 .

Ficus foliis oblongo-ovatis acutis integerrimis subtus reticulatis, caule articulato repente. Lin. syst. veg. p. $92=$.

Habitat in China, Japonia. \$

Caulis decumbens, repens, ramosus, cinereus, glaber. Folia ovata, obtusiuscula, integra, coriacea, supra laevia, viridia, subtus pallidiora, reticulata, glabra, pollicaria vel bipollicaria. Fructus petiolati, ovati, glabri, magnitudine pruni. Pedunculi reflexi, unguiculares. Thunb.

reflexa. 39. FICUS foliis ellipticis obtusis glabris, ramis recurvis, fructibus globosis sessilibus. Thunb. ficus. $p .11 .+$.

Habitat in India orientali. $\hbar$

Rami striati, rugosi, refiexi, cinerei, giabri. Folia illiptico obovata, obtusa, integerrima; parallelo nervosa, glabra, digitalia. Petioli cinerai, folio dimidio breziores. Fructus in ramis sparsi, aggregatique, sessiles, globosi, glabri, magnitudine pisi. Thunb.

rrigona. 40. FICUS foliis elipticis obtusis glabris, caule erecto, fructibus umbilico triangulari, calycibus bifidis. $\frac{1}{1}$

Ficus folio citri obtuso, fructu sanguineo. Plum. ic. p. 123. t. 1 $32 . f$. 1 .

Ficus trigona foliis ellipticis, calycibus bifidis, baccis umbilico triangulari. Lin. suppl. $p .+4 r$. syst. veg. p. 922 .

Habitat in Surinamo. $\hbar$

Folia alterna, petiolata, ovalia, vix cordata, subtus megis costata, glabra. Fructus axillares, 
plures, magnitudine baccae Pibis grossulariae, globosi. Umbilicus triangularis, singulo angulo lacuna oblonga fisso. Yedunculi brevissimi, uniflori. Lin.

4I. FICUS foliis ellipticis acutis glabris, fructibus nitidn. retuso-umbilicatis sessilibus. Thunb. fic.

p. 10.

Ittsi-are alou. Rheed. mal. 3.t. 55.

Habitat in India orientali. $\hbar$

Caulis totus glaber. Rami striato-rugosi, erectopatentes. Folia parallelo-nervosa, patentia, pollicaria usque palmaria. Petioli semiteretes, vix unguiculares. Fructus in apicibus ramulorum, globosi, magnitudine pisi. Thunb. l. c.

Pami glabri, inferne teretes, superne angulati. Folia petiolata, sparsa, utrinque glabra, nervosa, striato-subvenosa, parum acuminata, basi acuta, integerrima, sesquipollicaria. Fructus glaber, laevis.

42. FICUS foliis ovalibus glabris subtus minutis- rubra. sime reticulatis, fructibus globosis sessilibus.

Lamarck. Enc. 2. p. 497. †

An varinga rubra. Rumph. amb. 3. ¿. 85 ?

Ficus pyrifolia. Lamarck. l. c.

Habitat in insula Franciae. $\hbar$

Folia petiolata, tripollicaria.

43. FICUS foliis ovalibus obtusis glabris superne aggregata.

punctatis, fructibus globosis aggregatis sessi-

libus. Lamarck. Enc. 2. p. 495. $\dagger$

Ficus punctata. Lamarck.

Habitat in India orientali. $\hbar$

Rami radicantes. Folia petiolata, basi parum angustata, albo punctata, tripollicaria, in ramulis conferta. Lamarck.

44. FICUS foliis oblongis obtuse mucronatis sca-politoria. bris, fructibus globosis pedunculatis axillaribus. Lamarck. Enc. 2. p. 500.

An Ficus pyrifolia. Burmanni?

Habitat in India orientali, Madagascar. Ex herb. Thouini. $\hbar$

Tota scaberrima. Pami superne pilis rigidis pungentibus. Folia subopposita, superne $2 \frac{\mathrm{T}}{2}$ 


\section{I92 TRIANDRIA. MONOGYNIA.}

pollices longa, margine et nervis pilis rigidis.

Fructus magnitudine Ribesii iligri. Lamarck.

Rami terctes, laeves, apice scabri. Folia tripollicaria, oblonga, acumine brevi obtuso, utrinque uti petiolus scaberrima, basi acuia. 'etiolus unguicularis. Fructus subsolitarii, laeves.

Aliud Specimen vidi e Madagascar, foliis lanceolatis, spithameis, salicinis, denticulatis, utrinque liti ramis scaberrimis.

smollis. 45. FICUS foliis oblongis subtus villosis, fructibus axillaribus sessilibus tomentosis. Symb. bot. r. p. $8=$.

Ficus mollis foliis oblongis integerrimis, supra scabriusculis, subtus villoso-mollibus, receptaculis lateralibus glohosis umbilicatis sessilibus pubescentibus. IVilden. fic. p. 26.t. 5 .

Habitat in India orientali. 5

Rami teretes, villosi, versus apicem tomentosi. Folia petiolata, obtusa, basi parum angustiora, ad petiolum sinu angusto, supra laevia, subtus venosa, submollia, bipollicaria. Petiolus villosus, folio brevior. Fructus solitarius, mi-. nutus.

verrucosa. 46. FICUS foliis ohlongo-ovatis obliquis acuminatis, pedunculis apice calyculatis, fructibus verrucosis. Forst. fl. austr. p. $z^{6} . \dagger$

Ficus septica. Forster.

Habitat in insuia Tanna. Ђ

coriaces. 47. FICUS foliis obiongis laevibus basi attenuatis corlatis coriaceis : venis imimersis. Hort. kew.

3. P. $4 \div 3 . \div$

Iabitat in India orientali. 5

crecta, 48. FICUS foliis oblongis acutis glabris subius reticulais, caule decumbente, ramis erectis, fructibus pedunculatis. Thunb. fic. $p$. c. $\div$

Habitat in Japonia. $\hbar$

Caulis debilis, pamun decumbens, teres, ranososiriatus, cinereo-ferrugineus, glaber. Rami alterni vel subumbellato-aggregati, erecti. Folia obovala, utrinque partim attenuata, glabra, subius cinerea, pollicaria vel digitalia. Fructus in rammils sprrsi, erecti, subglobosi magrindine avellanae. Thumb. 
49. FICUS foliis oblongis falcatis glabris, caule falcata; filiformi radicante. Thunb. Fic. p. 5.

Habitat in Java. Thouin. $\frac{\hbar}{2}$

Caulis decumbens, flexuosus, brunneus. Folia oblique inserta, latere altero angustiora, ob. tusa, tenuissime nervosa, subtus pallida, unguicularia. Petiolus brevissimus. Thunb.

Caules tenues, glabri, repentes. Folia alterna, utrinque glabra, venulosa, supra avenia. Stipulae lanceolatae, ferrugineae, parvae.

50. FICUS foliis obovatis cuspidatis glabris, fruc- drupacea. tibus ovatis rugosis sessilibus. Thunb. fic.

p. I1. $t$

Habitat in India orientali. $\hbar$

Rami teretes, sulcati, glabri. Folia sparsa, acu. minata, coriacea, nervosa, subtus cinerea, palmaria. Petioli crassi, semiteretes. Fructus versus apicem ramorum sessiles, glabri, magnitudine jruni. Thunb.

51. FICUS foliis obovatis oblongis obtusissimis; retust. ramis angulatis, fructibus sessilibus. Lin. mant. 129 .

Habitat in India. $\hbar$

Rami teretes, cinereo-punctati, glabri. Folia petiolata, alterna, glabra, subcoriacea, unibipollicaria, subtus venosiora, basi subacuta, apice retusa. Fructus gemini, globosi, magnitudine pisi, glabri, laeves, sessiles, basi calyculati.

52. FICUS foliis lanceolato-oblongis acuminatis prolixa, subtus punctatis, pedunculis undulatis glabris, fructibus globosis axillaribus subgeminis.

Ficus prolixa foliis lanceolato-oblongis acuminatis subtus punctatis, pedunculis geminis, apice calyculatis. Forst. fl. austr. p. 77.

Habitat in societatis Insulis. $\hbar$

Rami glabri. Folia petiolata, tri-quadripollica. ria, pollicem et ultra lata, tenuissime subnervosa, vix venosa, membranacea. Fructus axillaris, magnitudine pisi, brevissime pedun. culatus, glaber, apice acumine brevissimo. 
Iaurifolia. 53. FICUS foliis oblongo-lanceolatis glabris supra punctis raris impressis, fructibus sessilibus solitariis. Lamarck. Enc. 2. p. 495.

Ficus virens foliis oblongis acuminatis laevibus basi angustato-rotundatis. Hort. kew. 3. p. $45 \mathrm{I}$. Ficus indica maxima. Sloan. hist. 2. p. 140. t. 223. Habitat in America. \$

Rami radicantes. Folia ovato-oblonga, glaberrima, subtus pallidiora, tenuissime venoso-reticulata, Petiolo et costis coloratis, quinqueseptempollicaria, parum acuminata.

Aliud specimen e China specie forte diversum in herb. Jussiaei vidi.

Rami teretes, frequentissime tuberculato-cicatricati. Folia superne approximata, oblonga; triquadripollicaria, glaberrima, subtus pallidiora, costis et nervis basi tantum coloratis. Petioli bipollicares. Pedunculi e cicatricibus, brevissimi, uniflori. Fructus globosi, glabri, magnitudine pisi.

grisea. 54. FICUS glabra, foliis oblongis obtusis basi angustatis, fructibus sessilibus subsolitariis.

Habitat - - herb. Juss. $\hbar$

Rami teretes, glabri, superne grisei. Folia pe. tiolata, tri-quadripollicaria, basin versus sensim parum angustata, glaberrima, subtus pallidiora, integerrima, utrinque obtusa. Petiolus pollicaris. Fructus globosus, piso duplo major, griseus. Stipulae lanceolatae, attenuatae, glabrae, unguiculares.

pallida. 55. FICUS foliis subcuneato-oblongis' glabris laevibus obtusis, fructibus geminis axillaribus subpedunculatis.

Habitat ad St. Martham. Dn. v. Rolır. $\hbar$

Rami teretes, glabri, cortice subcinerascente. Folia petiolata, alterna, bi-s-tripollicaria, membranacea, pollicem circiter lata, basin versus angustata, uti apice obtusa, utrinque glabra, laete viridia, subtilissime venosa. Costa subtus flavescens. Petioli subtus convexi, tenues, glabri, pollicares. Pedunculi axillares, brevissimi, gemini. Fructus glaber, globosus, magnitudine piperis nigri. 
56. FICUS foliis lanceolato-ellipticis altero latere excelsa. basi angustioribus acutis, fructibus pedunculatis globosis.

Atti-meer-alou. Rheed. mal. 3. p. 75.t. 58.

Habitat in India orientali. König. $\hbar$

Rami teretes, glabri. Folia subcoriacea, subtus venosa, supra subavenia, utrinque glabra, basi apiceque acuta, tri-quadripollicaria, brevi petiolata. Fructus gemini, axillares, magnitudine pisi, laeves, glabri. Pedunculus petiolo longior.

57. FICUS foliis lato-lanceolatis acuminatissimis indica. glabris, fructibus aggregatis pedunculatis globosis glabris.

Tsjela. Rheed mal. 3. p. 85.t. 63.

Varinga latifolia. Rumph. amb. 3. p. ז27. t. 84.

Ficus indica fo. Lin. sp. plant. 2. p. 1514.

Habitat in India orientali. $\hbar$

Rami glabri, teretes. Folia brevi-petiolata, alterna, bi-s-tripollicaria, reticulato-venosa, supra laete viridia, subito acuminata, acumine pollicari, lineari, obtuso, basi acuta. Fructus axillares, pedunculis brevissimis.

58. FICUS foliis lanceolatis acuminatis, fructibus salicifolin. geminis axillaribus pedunculatis. Symb. bot.

I. p. 82. t. 23.

Ficus indica. Forsk. descr. p. 179 .

Habitat in Arabia. 5

Tota glaberrima, laevis. Folia petiolata, glabra, reticulato-venosa, pallida, attenuato-acuminata, acula, basi rotundata, supra laevia, subtus punctis elevatis minutis dense conspersa. Petiolus sesqui-bipollicaris. Stipulae lanceolatae, deciduae. Fructus gemini, axillares, pedunculati, globosi, laeves, magnitudine pisi.

59. FICUS foliis lanceolatis glaberrimis margine obliqua. cartilagineis, pedunculis geminis brevissimis, 


\section{I96 TRIANDRIA. MONOGYNIA.}

calycibus caducis longitudine fructus. Forst. fl. austr. p. $77 .+$

Habitat in insulis Namoka et Tanna Oceani pacifici. $\hbar$

\section{- Foliis serratis.}

auriculata. 60. FICUS foliis cordatis acuminatis subserratis, fructibus auriculatis racemosis terminalibus. Loureiro fl. Cochinch. 2. p. 666. †

Habitat in Cochinchina. $\hbar$

Arbor magna. Folia tomentosa, magna, petiolata. Fructus turbinatus, bi-pollicaris, laevis, ruber. Racemi congesti, terminales, erecti. Calyx tri-phyllus. Ad humeros Fructus patent foramina quatuor-cartilagine prominente circumvallata, auriculas representantia. Lour. l. c.

Forslsilaei. 6 r. FICUS foliis cordato-ovatis utrinque scabris petiolo longioribus. Forsk. descr. p. 179. †

Ficus morifolia. Forsk. $l$. $c$.

Habitat in Arabia. 方

Folia semispithamaea, acuta, alterna. Stipulas lineari-lanceolatae. Forsk.

murritian. 6z. FICUS foliis cordato-ovatis subtus tomentosis asperis, ramis fructigeris nudis dependentibus, fructibus turbinato-globosis. Lamarck. Enc. p. 2. p. 499.

An Hort. mal. 3.f. 6.1? haud male convenit.

Habitat in insula Borboniae. Commers. herb. Juss. $\frac{b}{5}$

Folia sex-septempollicaria. Fructus magnitudine nucis juglandis, basi calyce triphyllo. Pedunculi gemini. Lamarck.

Rami apice villoso-tomeintosi, sordide flavescentes. Folia spithamaea, ovata, basi cordata, gross. serrata, acuminata, supra laevia, subtuis flavescenti villoso - subtomentosa, utrinque venosa. Petioli tripollicares, villoso-subtomentosi.

Aliam e philippinis vidi foliis basi non cordatis multoque latioribus, crenato-subrepandis, obscure lobatis altero latere, supremis tomento rufo in rervis et venis majoribus. 
63. FICUS foliis cordato-ovatis acutis glabris, fruc- lateriflora tibus globosis pedunculatis. Lamarck. Enc. 2. p. 499. +

Ficus morifolia. Lamarck.

Habitat in insula Borboniae.

Folia obtuse serrata, vix scabra, tripollicaria, facie foliorum mori. Fructus in ramorum parte nuda, sparsi. Lamarck.

64. FICUS foliis ovatis rariter dentatis acuminatis ulmifolia, basi apiceque inaequalibus utrinque scabris. Lamarck. Enc. 2. p. +99 .

Habitat in Java. Commerson. herb. Juss, in Philippinis Lamarck. ந

Rami teretes, scabri. Folia bi-tripollicaria, ovato-oblonga, utrinque e punctis scaberrima, in acumen fere pollicare subulatum desinentia, pollicem lata, dentato-subrepanda, interdum subtrifida, interdum dentato-subpinnatifida, interdum trifida, laciniis angustis pinnatifidis. Petioli unguiculares, uti fructus. Fructus pedunculatus, globosus, scaberrimus, piso parum major. Pedunculus petiolo dimidio brevior.

65. FICUS foliis oratis acutis glabris, fructibus capensis. pedunculatis turbinatis glabris. Thunb. fic. p. 1.3. †

Habitat in Cap. h. spei. $\hbar$

Arbor excelsa, vasta. Folia ovato-oblonga, sinuato-dentata, subtus pallidiora, nervosa, digitalia. Fructus sparsi, turbinati, magnitudine avellanae et ultra. Thunb. $l$. $c$.

66. FICUS foliis ovatis apice serratis subtus luteoalbicantibus. Burm. fl. ind. p. 227. †

Habitat in India orientali. $b$

67. FICUS foliis oblongo-ovatis scaberrimis extror- axasperata.

sum dentatis acuminatis, fructibus pedunculatis globosis.

Ficus scabra, foliis subrotundo-ellipticis dentatis acuminatis scaberrimis. Wilden. fic. t. 2.

Habitat in Guinea Isert. Ђ

Rami teretes, glabri, laeves, juniores scabri. Folia petiolata, tripollicaria, basin versus integerrima, acuta, trinervia, subtus pubescentia. Petioli scabri. Pedunculi gemini, unguiculares. Fructus magnitudine pisi, scaber. 
symphytifo- 68. FICUS foliis ovato-oblongis acutis denticulatis utrinque scabris, fructibus hirsutis pedunculatis subverticillatis racemosis. Lamarck. Enc. 2. p. $49 \%$.

An Perim Teregam. Hort. mal. 3. p. 8r.t.61? Habitat in Java. $\$$

Folia petiolata, 9- го pollicaria, nervis villosa. Fructus globosi, in ramis racemosi. Lamarck. Rami teretes, tuberculati. Folia spithamaea, basi ovata, e punctis minutis utringue scaberrima. Petiolus uni-bipollicaris. Fructus sessilis, globosus, magnitudine cerasi.

maculata. 69. FICUS foliis oblongis acuminatis. Lin. spec. pl. I 5 I 5 . +

Ficus castaneae folio, fructu globoso macúlato. Plum. spec. $=\mathrm{r}$. ic. 1.31.f. I.

Habitat in America.

hispida. 7o. FICUS foliis oblongis cuspidatis utrinque scabris pilosis, fructibus pedunculatis strigosohispidis. +

Ficus hispida foliis ohlongis petiolatis acutis, fructibus strigoso hispidis. Lin. suppl. p. $4+2$. syst. veg. p. 922 . Thunb. Fic. n. 24.

Habitat in Java. 5

Rami glaủri, teretes, striati. Folia petiolata, cuspidata, supra viridia, silitus virentia, utrinque scabra, nervis pilosis, subspithamaea. Fructus axillares, racemosi, turbinati, villosohispidi, magnitudine pruni. Pedunculi hispidi. Thunb.

Daemonum. $z^{1}$. FICUS foliis oppositis oblongis subtus mollissimis supra scaberrimis.

Habitat in India orientali. König. $\hbar$

Rami teretes, dense villosi. Folia petiolata, palmaria, acuta, venosa, opposita. Fructus villosus magnitudine cerasi.

montana. 72. FICUS foliis oblongis repando-serratis, fructu - minimo. Burm. fl. ind. p. $=26$. + Habitat in India orientali.

- Foliis angulatis sinuatisque.

Sycomorus. 73 . FICUS foliis cordatis ovalibus obtuse angulosis repandis utrinque glabris. Lamarck. Enc. 2. p. 492. 
Ficus Cypria. Rauw. it. t. 57.

Syco morus, Ficus pharaonis. Camm. in matth. 103. $f .3$.

Ficus folio mori, fructum in caudice ferens. Bauh. pin. 459.

Syco morus. Bauh. hist. r. p. r24.f. r. 2.

Iicus Sycomorus foliis cordatis subrotundis integerrimis subtus tomentosis. Lin. S. $V . p .9=1$.

Habitat in Aegypto. $\hbar$

Folia petiolata, basi sinu parvo, medio latiora, obtusa, nervosa, obsolete simpliciter venosa. Fructificatio in ramis majoribus in ramulis vel pedunculis propriis tortuosis, aggregatis. Fructus figura Caricae, pollicaris, umbilico stellato.

74. FICUS foliis oblongis subrhomboidalibusque rhomboidavenosis, fructibus pedunculatis globosis vil- lis. losulis.

Habitat in India orientali. Dn. Röttler. \$

Rami teretes, crassi, ramulosi, glabri, cortice cinereo. Folia petiolata, sparsa, pallide viridia, integerrima, utrinque glabrata, apice interdum acuta, interdum obtusa, basi acuta, medio saepe utrinque angulo exstante. Fructus axillares, solitarii, magnitudine pisi, umbilicati.

75. FICUS foliis ellipticis subangulatis cuspidatis reticulata. glabris subtus reticulatis, fructibus globosis solitariis petiolatis. Thunb. fic. p. г2. $\div$

Habitat in India orientali.

Rami teretes, rigosi, purpurei, glabri. Folia obovata, inferne attenuata, cuspidata, subangulata, dentata, nargine refleio, glabra, nervoso-reticulata, subtus pallida, palmaria. Petioli semiteretes, vix unguiculares. Fructus axillares, pedunculati, globosi, glabri, piso majores. Thunb.

76. FICUS foliis lanceolatis repandis glaberrimis Sur. basi subcordatis. Forsk. descr. p. 180.

Iabitat in Arabia. $\hbar$

Rami apice villosi. Folia latiusculo-lanceolata, dentato-repanda, subcoriacea, laevia; subtus reticulata, pallida. Petiolus subtus villosus. Stipulae villosae.

Arbor Sycomoro similis. Fructus prope truncrem conferii, ovi columbini magnitudinc. Fors's. l. $c$. 
\$spera. 77. FICUS foliis oblique cordato-oblongis glabris acuminatis subtus asperis, fructibus turbinatis, calycis margine obsoleto adnato.

Ficus aspera. Forst. pl. escul. austr. p. 37.

Habitat in insula Tanna.

Rami flexuosi, teretes, apice villosi, angulati.

Folia petiolata, spithainaea, supra minus sca-

bra, subtus pallidiora, integerrima.

Fructus villosus. Petioli villosi, gemini, axillares, sessiles, magnitudine Caricae. Forst.

sinuata. 78. FICUS foliis ellipticis sinuato-dentatis cuspidatis glabris, fructibus globosis aggregatis pedunculatis. Thunb. fic. p. 12. +

Habitat in India orientali.

Rami teretes, glabri. Folia obovata, superne dentato angulata, margine reflexo, subtus pallida, nervosa, reticulata, glabra, palmaria. Fructus in ramulis sparsi et aggregati, sessiles, globosi, nodulosi, pipere vix majores, glabri. Thunb.

rostrata. 79. FICUS foliis ovato-oblongis difformiter repandis rostrato-acuminatis glabris, fructibus sessilibus. Lamarck. Enc. 2. p. 498.

Habitat in Java. Commerson. herb. Juss. $\hbar$

Rami tenues, teretes, glabri. Folia tri-quatuorpollicaria, oblonga. in acumen pollicare angustum desinentia, basi acuta, versus apicem pollicem lata, altero latere subito breviora, cum margine angusto ad costam in acumen excurrentia, interdum versus medium utrinque sinu repanda, interdum tantum ab altero latere; supra nitida, venosa. Fructus sessiles, aggregati, magnitudini Piperis, glabri. Petiolus semiunguicularis.

difformis, 80. FICUS foliis oblongis acutis scabris difformibus subangulatis sinuosis profundeque laciniatis. Lamarck. Enc. 2. p. 500 . $\dagger$

Ficus indica sylvestris. Rai hist. pl. 3. App. p. 50. $\pi$. 12.

Habitat in Philippinis. \$

$$
\text { * * Foliis divisis. }
$$

palmata. 8I. FICUS foliis cordaio - ovatis lobatisque serratis, fructibus pyriformibus pedunculatis glabris. Symb. bot. 1. p. 84. t. 24. 
Ficus palmata; foliis cordato-acutis, palmatisque, serrato-crenatis, scabris, flexilibus. Forsh. descr. p. 179 .

Habitat in Arabia. $\hbar$

Rami teretes, glabri. Folia petiolata, cordatoovata, integra, bi-s. triloba, ad basin usque ferme acute scrrata, utrinque scalbra, venosa, subtus pallidiora, venis purpurascentibus, bipollicaria: Lobi ovaii, acuti. Petiolus folio duplo brevior. Fructus pedunculatus, solitarius, pyriformis, glaber, piso parum major. Pedunculus longitudine fructus, medio, Bracteae binae, oprositae, minutae.

32. FICUS foliis cordato-oblongis indivisis trilo- hirta. bisve serrulatis supra laevibus, fructibus sessilibus hispidis.

Habitat in China. Incarville. $\hbar$

Rami teretes, lineis elevatis remotis, ad folia subarticulati, superne scabri. Folia distantia, basi subcordata, extrorsum trifida: laciniis lanceolatis, rectis, lateralibus brevioribus et dimidio angustioribus intermedio, acuminatis, tenuiter serratis; subtus venosa, pallidiora, nervis hirsuta, coeterum glabra. Petioli sesquipollicares hirti. Fructus axillaris, sessilis, solitarius, hi.piảus, magnitudine pisi.

Aliud specimen e java. Foliis divisis et indivisis: Lobo intermedio ovato, supra villosulis. Fructus duplo majores, duo vel tres in axillis.

83. FICUS foliis oblongis indivisis lobatisque inte- truncata. gerrimis scabris, fructibus peanculatis oblongo-truncatis. Symb. bot. i. p. 83 .

Habitat in India orientali. 方

Rami angulati, glabri, laeves. Folia petiolata, oblonga, integra vel triloba, interclum quinqueloba, integerrima, acuta, utrinque scabra, venosa, reticulata, supra nitida, subtus pallidiora, bipollicaria et ultra. Lobi oblongi, laterales obtusi. Petiolus brevis, rugosus, supra canaliculatus. Fructus pedunculatus, longus, e punctis minutis scabriusculus, apice eminentia truncata. 


\section{TRIANDRIA. MONOGYNIA.}

serrata. 84. FICUS foliis oblongis indivisis palmatisque repando-dentatis scabris, fructibus pedunculatis globosis villosis scaberrimis. Symb. bot. I. p. 83.

Ficus serrata; foliis ovali-acutis palmatisque, scabris, crenato repandis. Forsk. descr. p. 179. Habitat in Arahia. $\hbar$

Rami superne, uti folia juniora, ex punctis minutissimis numerosis scaberrimi. Folia petiolata, nervosa, opaca, basi integerrima, acuta. Fructus brevissime pedunculatus, magnitudine fere nucis avellanae.

denticulata. 85. FICUS foliis oblongis indivisis trilobis sinuatisque denticulatis scabris, fructibus pedunculatis globosis muricatis. Symb. bot. i. p. 83 .

Habitat in India orientali. König. 5

Rami superne angulati, pilosi. Folia petiolata, superne bi-triloba, utrinque scaberrima, venosa, acuta, remote inaequaliter denticulata, versus basin integerrima, saepe altero latere vix ad medium folii dentata, bipollicaria et ultra. Petiolus brevissimis, villosus. Fructus glaber, piso parum major, verruca truncuia terminatus, tuberculis inaequalibus sparsis exasperatus.

toxicaria. 86. FICUS foliis cordatis inciso-lobatis denticulatis subtus albis, fructibus pedunculatis tomentosis. +

Ficus Padana. Burm. ind. 226 .

Ficus toxicaria foliis cordato-ovatis subdenticulatis subtus tomentosis. Lin. mant. p. 305. syst. veg. p. 922 .

Ficus toxicaria foliis cordatis sinuatis subtus albo-tornentosis, fructibus tomentosis. Thunb. fic. $n .27$.

Habitat in Sumatrae pago Pandano. $\frac{\hbar}{b}$

Rami teretes, glabri, ferruginei. Folia ovata, acuta, sinuata, angulaia, supra villosa, viridia, subtus alba, spithamaea et ultra. Petioli tomentosi. Fructus pedunculati, ovati, magnitudine pruni. Thunb.

hete:ophylla. 87. FICUS foliis oblongis indivisis incisisque acutis scabris, caule hispido, fructu pedunculato glabro. 
Ficus heterophylla foliis oblongis, indivisis trilobis sinuatisque scabris, caule hispido, fructu pedunculato glabro. Lin. suppl. p. $4+2$. syst. veg. 022 .

Habitat in India orientali prope rivulos. $\frac{\hbar}{5}$

Rami tenues, scabri, apice pilosi, incani. Folia petiolata, alterna, oblongo-lanceolața, basi subovata, acuminitta, acuta, tenuia, integerrima, interdum apice obscure serrata, vix venosa, subtus pallidiora, e punctis minutis elevatis scaberima. Fructus pedunculatus, subrotundus, piso parum major, laezis, glaber.

88. FICUS foliis caulinis hastatis incisis, rameis cannabina. ovato- Janceolatis subserratis, caule suberecto. Lour. fl. Coch. 2. p. 669. †

Habitat in Cochinchina. 市

Frutex sexpedalis, ramosus. Rami glabri. Folia scaberrima, petiolata. Fructus ovali-turbinatus. Pedunculi longi, solitarii, laterales. Calyx trifidus. Lour.

8. FICUS foliis ovato-oblongis subdenticulatis in-rufescens. divisis lobatisque scabris, ramis petiolis fructibusque subpedunculatis hispidis. Lamarck. Enc. 2. p. 499. †

Walii teregam. Hort. mal. 3. p. 83. t. 62 .

Ficus heterophylla. Lamarck.

Habitat in India orientali. 古

Folia quinquepollicaria, pollices duos lata, alia integra, alia tri-quadriloba, oblonga vel lanceolata. Petioli hispidissimi. Fructus axillares, brevissime pedunculati, villis rufescentibus. Lamarck.

90. FICUS foliis tripartitis scaberrimis, laciniis morifolia. lanceolatis subpinnatifido-angulatis.

Habitat in India orientali. 5

Rami tenues, vix scabri, superne villosuli. Folia petiolata, alterna, basi obtusa, trinervia, supra avenia, subtus obsolete venosa, utringue glabra, punctis minutis scaberrima, supra oculo armato albo-membranaceo-squamulosa; laciniis angustis attenuatis.

9r. FICUS foliis palmatis, caule simplicissimo, simplicissifructu compresso. Lour. fi. Coch. =. p. 667. $\div$ ma. 
Habitat in sylvis Cochinchinae. $\mathbf{5}$

Frutex quinquepedalis, erectus. Rami nulli. Folia aspera, magna, petiolata. Fructus sphaeroideus, sessilis, axillaris, solitarius, parvus, croceus. Lour.

Carica. 92. FICUS foliis trilobis scabris, fructibus turbinatis umbilicatis laevibus. Thunb. fic. $n .26$.

Ficus. Dod. permpt. $\$ 12$.

Ficus communis. Bauh. pin. 457.

§ Caprificus. Bauhin. hist. x. p. 134.

f. Ficus humilis. Bauh. pin. p. $45 \%$.

Ficus carica foliis palmatis. Lin. syst. veg. p. $92 \mathbf{2}$.

Habitat in Europa australi, Asia. $\hbar$

Rami glabri, erecti, flexuosi et retroflexi. Folia cordata, indivisa vel tri-quinque loba, sinubus rotundatis, serrato-dentata, subtus pallida, utrinque scabra. Fructus axillares, solitarii, pedunculati, magnitudine pyri. Thunb.

Habitus. Arbores v. frutices polygami lactescentes. Folia petiolata, simplicia. Stipulae intra foliaceae, caducae.

II I. XYris. Cor. 3-petala, aequalis. Glum. 3valves cartilagineae in capitulum. Caps. supera, I-locularis.

indica. r. XYRIS scapo sulcato multangulo, capitulo ovạto. Ranmotha. Herm. zeyl. 41 .

Kotsjilet ti-pullu. Hort. mal. 9. p. r39. t. 7 r.

Gladiolo lacustri accedens malabarica e capitulo botryoideo florifero. Pluk. alm. I70. t. 4 I6. $f: 4$.

Xyris indica. Lir. fl. zeyl. p. I 4 .

Habitat in India orientali. 4

Folia interdum pedalia vel longitudine scapi, laxa, acuta, unguem fere lata. Scapi plures, penna columbina parum tenuiores, sex-vel octosulcati, inferne torti. Capitulum nuce Coryli parum minus: squamae subrotundae. Antherae lineares, emarginatae; corpusculum penicilliforme ad basin singulae, uti jarndudum observavit Rheede. $l$. c.

Folia nunquam tam lata vidi, ut habet figura Rheedii.

macroce-

2. XYRIS scapo uniangulato, phàia. que ovatis dorso cinereis. Habitat in Cajenna. Ex herbario Desfontainii. 


\section{TRIANDRIA. MONOGYNIA.}

Folia sesquipedalia, unguem et ultra lata. Scapi folio altiores, inferne teretes, superne subaneipites, altero latere convexiusculi, altero acuti. Capitulum fructiferum nuce Coryli duplo majus, ovatum. Squamae obtusae.

Differt a reliquis latitudine foliorum, magnitudine capituli. Xyr. ancipitis varietas $\beta$. Lamarckii huc pertinet, ni fallor, differt tantumodo capitulis parum minoribus, uti floriferis nec fructiferis.

3. XYRIS scapo ancipiti laevi, capitulo subglo- anceps. boso.

$\mathrm{Xyris}$ indica altera. Symb. bot. 3. p. 7 .

$\mathrm{Xyris}$ anceps; culmo compresso biangulari, capitulo subgloboso. Lamarck. illustr. 1. p. 132. Habitat in Malabaria. 4

Folia rigidiuscula, scapo triplo vel quadruplo breviora, angusta. Scapi plures, pedales et ultra, torti, laeves, minime striati. Capitulum vix magnitudine pisi : squamae subrotundae, parum cmarginatae, convexae. Calyx squamae tres, duae exteriores, naviculares, inferne attenuatae; tertia subrotunda, marginibus latis, tenuioribus, florem nondum evolutum fovens, $a b$ exterioribus inclusa, compressiuscula, brevior. Corolla tripetala: ungues hyalinae, longitudine calycis: laminae obovatae, luteae, patentes, denticulatae. Antherae in fauce corollae, apice tridentatae, basi stipatae corpusculis binis penicilliformibus, longitudine antherarum, ope lentis hyalinis. Stylus profunde trifidus: laciniis superne dilatatis, compressis, apice oculo armato margine denticulatis.

4. XYRIS scapo superne ancipiti, capitulo ovato- americana. oblongo.

Jupicai. Pis. bras. 23s. fide herb. Marcgrawii.

Xyris americana; flore coeruleo, foliis setaceis. Aubl. fl. guian. 40. t. I4. Capitulum, minime vero folia.

Xyris jupicai; foliis gramineis linearibus lateribus subparallelis obtusulis, scapo ad apicem dilatato squamis rotundato-obtusis. Act, soc. h. n. par. 1. p. 106.

Habitat in Cajenna. 4 


\section{TRIANDRIA. MONOGYNIA.}

Folia scapo dimidio vel duplo breviora, graminea, angusta, acuta. Scapus pedalis, vel ultra, inferne teres, e lineis duabus decurrentibus subbiangulatus, superne compressus, sub capitulo parum dilatatus. Capitulum obtusum, piso partem majus: squamae oblongae, concavae, apice emarginatae, clim mucrone subcalloso fuscescente in emarginatura, nitidae.

Folia in Xyride americana Aubletii ad speciem Eriocauli pertinent, capitulum vero Xyridis est, at pessime depictum tan quoad squamas capituli, tam quoad flores.

caroliniara. 5. XYRIS scapo ancipiti, capitulo ovato acuto.

Xyris caroliniana; culmo compresso, capitulo oblongo subacuto. Lamarck. illustr. r. p. I 32.

Xyris caroliniana; foliis gladiatis, scapo longo, floribus luteis, filamentis latis. Stylo trifido patulo, longitudine staminum. Stigmatibus capitatis. Walt. fl. car. 60.

Xyris jupicai. Michaux fl. bor, amer. 1. p. 23 .

Habitat in Carolina. Specimina mecum communicarunt Lamarck, Richard et Bosc. 4

Differre milhi videtur a $X$. americana: foliis rigidioribus: capitulis majoribus, acutis nec obtusissimis: floribus luteis minime vero coeruleis. Specimen Lamarckii gaudet capitulis oblongis, longioribus quam Richardii; in specimine Boscii foliolum basi fusco-magricans. $V$ ariat foliis longioribus et brevioribus.

capensis. 6. XYRIS capitulo ovato, foliis linearibus brevissimis. Thumb. prodr. fl. cap. 12. †

Habitat in Cap. b. spei.

brevifolia. 7. XYRIS scapo tereti, capitulo globoso.

Xyris brevifolia; foliis subbiuncialibus, fere subulato-gladiatis: scapo gracili, teretiusculo, subasquali: capitulo parvo, globoso. Michaux fl. bor. am. I. p. 23 .

Habitat in pratensibus udis Georgiae inferioris. Bosc.

Folia sesquipollicaria, angusta. Scapus spithamaeus, filiformis. Capitulum magnitudine Pip. nigri. Squamae lato-oblongae; exteriores angustiores, carinatae. 
8. XYRIS scapo tetragono, capitulo ovato.

$\mathrm{Xyris}$ pauciflora; foliis lineari-subulatis scapum vaginantibus, capitulo oblongo, squamis ovatis obtusis. Wilden. phytog. 1. p. 2. t. г.f. 1. Habitat in India orientali. König, Röttler. 4 Folia angustissima, bi-tripollicaria, duo vel tria inferne in scapo. Scapus filiformis, spithamaeus vel parum ultra.

9. XYRIS scapo filifurmi ancipiti, capitulo squa- filiformis. misque oblongis.

$\mathrm{X}$ yris filiformis; culmo filiformi compresso, capitulo ovato minimo. Lamarck. illustr.. p. 133.

Habitat ad Sierram Leonam. Ex herbario Lamarkii.

Folia vix semipollicaria, angustissima, linearia. Scapi spithamaei. Capitula magnitudine seminis sorghi.

хо. XYRIS scapo filiformi, foliis subulatis, capi- subulatz. tulo subtrifloro. $t$

Xyris subulata; spica bi-triflora, scapo unifloro, foliis subulatis. Fl. per. г. p. 4\%.t. ? г. f. $b$.

Habitat in altis Peruviae locis humidis et stagnatibus.

Si descriptio et icon fl. per. vera, discrepat a reliquis Antheris absque appendiculis eorumque loco setis tribus e fundo corollae, apice penicillatis. Planta caespitosa. Folia subpollicaria, basi villosa. Scapus gracilis, fere bipalmaris. Capitulum bi-triflorum. Corolla lutea. Fl. per. l. c.

Habitus. Folia radicalia, basi vaginantia, ensiformia, scapo breviora, glaberrima, striata. Scapi erecti, simplicissimi, glabri. Capitulum terminale, solitarium, imbricatum squamis ferrugineis, margine dilutioribus.

I 2. Schoenus. Squamae paleaceae, inferiores vacuae. Styl. deciduus. Sem. 1, inter squamas superiores.

* Culmo nudo.

๘. SCHOENUS spicis subgeminatis, involucri val- ferrugineus. vula altera longitudinem spicae aequante, culmo tereti, 
Schoenus ferrugineus: culmo tereti nudo, spica duplici, involucri valvula majore spicam aequante. Lin. fl. suec. ed. 1. n. 37. ed. 2. n2. 39. syst. veg. 97.

Habitat in Europae paludosis. 4

Sinilis Sch. nigricanti, diversus: culmo spithamaeo vel parum ultra: foliis pollicaribus vel minoribus, vix longitudine vaginarum, tenuioribus: spicis duabus: squama infima in foliolum acuminata, spicis parum longiore.

nigricans. 2. SCHOENUS spicis capitatis, involucri valvula altera capitulo longiore, culmo tereti, foliis vaginisque glabris.

Gramen sparteum nigro capitulo. Merret. pin. p. 58 .

Juncus lithospermi semine. Moris. hort. reg. bles. го6. Magn. mons. $p$. 1 45. cum fig.

Juncus laevis minor, panicula glomerata nigricante. Moris. hist. 3. p. 233. s. 8. t. 10. f. 28. Junco affinis capitulo glomerato nigricante. Scheuchz. gram. $349 . t$. 7. f. 13. 14. 15.

Schoenus nigricans; culmo tereti nudo, capitulo ovato, involucri diphylli valvula altera subulata longa. Lin. fl. suec. 39. Pollich. pal. n. 37 .

Habitat in Europae paludibus aestate exsiccatis, in Cap. b. spei. Thunberg. 4

Culmi plures, sesquipedales. Folia culmo breviora ex apice vaginarum, semiteretia, rigida : vaginae-pollicares, inferne fusco-nigricantes, superne dilutiores. Involucrum diphyllum, alterum foliaceum inferius e basi ovato-attenuatum, capitulo duplo longius, alterum squama ovata cum acumine, interdum absque. Spicae decem-viginti, semiunguiculares, lanceolatae, actitae, compressiusculae, fusco-nigricantes, nitidae: squamae lanceolatae. Semen trigonum, albidum. Setae nullae.

Interdum involucrum omnino deest.

pilosus. 3. SCHOENUS spicis capitatis involucro diphyllo brevioribus, culmo tereti, foliis vaginisque pilosis.

Schoenus pilosus; culmo tereti, vaginis foliorum pilosis, floribus fasciculatis. Wilden. phyt. т. p. 3. t. i. $f$. 3 .

Habitat in Guinea Isert, in Senegal Richard. 4 
Culmi plures, sesquipedales, glabri. Folia culmo triplo breviora, linearia, angusta, subtus uti vaginae pilosa: vaginae parum fissae, ore ad folium pilis longis albidis barbatae, interior tri-quadripollicaris. Involucrum spicis parum longius, villosum, basi dilatatum utrinque pilis barbatum. Spicae terminales, circiter duodecim, unguiculares, lanceolatae, complanatae, aculae, distiche imbricatae: squamae lanceolatae, mucronatae, compressae, duae vel tres infimae steriles, fusco-purpurascentes, carina et mucrone viridi. Stylus trifidus. Semen globosum, transversim undulatum. Setae nullae.

4. SCHOENUS subaphyllus, spicis capitatis invo- aphyllus. lucro diphyllo breviopibus, culmo tereti, vaginis glabris.

Habitat in insula Franciae. Commerson. Ex herbario Jussiaei.

Culmi plures, pedales. Folia nulla nisi vaginae tri-quinquepollicares, apice desinentes in ligulam lanceolatam, unguicularem. Involucrum diphyllum, erecto-patulum; foliolum unicum saepe quadripollicare, alteruri pollicare, caulino simillimum. Spicae quinque-sex, lanceolatae.

5. SCHOENUS spicis subternis, involucro mono- pusillus. phyllo spicas aequante, culmo capillari trigono, foliis ciliatis.

Schoenus pusillus; culmo triquetro nudo filifor$\mathrm{mi}$; spiculis terminalibus subfasciculatis sessilibus, foliolo subjecto spicam aequante. Swartz. prodr. 20. Fl. ind. occid. 1. p. I1 2. Ic. t. 6.

Habitat in graminosis saxosis nemorosis montium Jamaicae australis. Swartz. in Domingo. Thouin.

Radices capillares, simplices. Culmi pollicaresbipollicares, ad lentem trigoni. Folia altitudine culmi, ejusque latitudinis; basi carinata, ope lentis ciliata. Bractea foliacea sub spica infima. Spicae tres-quatuor, minutissimae, subfasciculatae, una supra alteram, sessiles, ovatae, acuminatae: squamae ovatae, carinatae, muticae. Germen subrotundum: Stylus basi trigonus, trifidus. Semen subrotun- 


\section{IO TRIANDRIA. MONOGYNIA.}

dum, obtuse trigonum, scabrum, oculo armato quasi echinatum. Swartz. $l$. c.

scariosus. 6. SCHOENUS spica cylindrica acuta, involucro monophyllo spicam aequante, squamis margine scariosis.

Scirpus trigynus; culmo tereti nudo, spica cylindrica squamis lanceolatis basi laterali mem. branaceis. Lin. mant. 180.

Schoenus deustus; culmo tereti nudo folia aequante, capitulo oblongo, glumis calycinis subaequalibus mucronatis spicam involventibus. Berg. cap. I0.

Scirpus bulbosus; radice bulbosa; scapis teretibus, canaliculatis, foliis setaceis, spica cylindrica, terminali. Rottb. gram. 46, t. $\mathbf{1} 6 . f .2$. Scirpus scariosus; culmo tereti, capitulo oblongo, involucro monophyllo, glumis margine scariosis. Thunb. prodr. i6.

Habitat in Cap. b. spei. König. 4

Facies Scirpi lacustris. Culmi plurimi, pedales, teretes, basi e reliquiis vaginarum copiosis fuscis bulbosi. Folia culmo parum breviora, ca. naliculata, margine laevia, rigida: vaginae superne lacerae, albidae. Spica pollicaris, utrinque angustata, frusca: squamae lanceolatae, mucronatae, infima in folium subulatum longitudine spicae desinens. Stylus trifidus. Semen oblongum. Setae nullae.

In unico vidi membranam squamae involucrantis latitudine dimidiae fere spicae et ejus longiludi$n e$, in aliis vero speciminibus angustiorem et breviorem.

spadicetıs. 7. SCHOENUS spica ovato-oblonga obtusissima, involucro monophyllo spica breviore, squamis margine nudis.

Eriocaulon spadiceum; culmo tenuissimo longissimo substriato, foliis setaceis, capitulo ovato spadiceo laevi. Lamarck. illustr. I. p. 214.

Habitat in St. Domingo. Ex herbario Lamarck.

Culmi setacei. Spica vix unguicularis, crassitie fere pennae anserinae, obtusissima, spadicea, basi bractea subulata, spica triplo brevior: squamae infimae subrotundae, superiores obovatae, basi albidae. Stamina tria. Semina subrotunda, nigra, nitida. 
Stylum non vidi. Species Eriocauli certe non est, rectius ad Schoenos numeratur.

8. SCHOENUS spicis capitatis, involucro diphyllo lateralis. foliolo aitero capitulo longiore, culmo foliisque filiformibus.

Habitat in Cap. b. spei arenosis. 4

Radices filiformes, longi. Culmi copiosi, longitudine digiti minimi, teretes, filiformes, pallide virides. Folia ex eadem vagina ac culmi, ejusque fere longitudinis et crassitiei, plana, rigida. Involucrum diphyllum; unicum capitulo brevius, alterum e culmo continuato longius. Spicae tres-quinque, spatio unguiculari infra apicem culmi in capitulo sessiles, fusco-nigricantes, ovatae, acutae, parvae: squamae ovatae, obtusae, concavae, vix carinatae.

An folia potius cuimi steriles?

9. SCHOENUS spicis capitatis subternis, involu- filiformis. cro diphyllo foliolo altero capitulo longiore, culmo foliisque capillaribus. .

Schoenus filiformis; culmo tereti filiformi nudo, foliis setaceis, spiculis subternis fasciculatis; involucro diphyllo inaequali. Lamarck. illustr. I. $p$. 135 .

Schoenus filiformis ; culmo tereti capillari, capitulo oblongo, involucro triphyllo. Thunb. prodr. in.

Habitat in Cap. b. spei. Ex herbario Thouini. 4 Culmi plures, spithamaei, teretes, basi e congerie vaginarum bulbosi. Folia culmo similia, ejusque longitudinis: vaginae fuscae. Involucrum mono-diphyllum; foliolum unicum unguiculare, alterum longitudine capituli. Spicae tres-quatuor, parvae, oblongae, obtusae, fuscae: squamae oblongae.

г. SCHOENUS spicis capitatis subternis, involu- juncoides. cro triphyllo spicis longiore basi dilatato scarioso, foliis setaceis.

Habitat in monte video Commerson.

Culmi plures, spithamaei, teretes, filiformes. Folia culmo triplo breviora, canaliculata: vaginae latae, membranaceae, in folium acuminatae. Involucrum basi ovatum, acuminatum. 


\section{TRIANDRIA. MONOGYNIA.}

Spicae tres-quatuor, oblongae. Squamae ovatae, fuscae, striatae, carina virides, infimae acuminatae, reliquae mucronatae.

Differt $a b$ antecedente: culmo foliisque rigidioribus, latioribus: foliis brevioribus; spicis majoribus.

indicus. I1. SCHOENUS capitulo ovato involucro subdiphyllo breviore, culmo filiformi, foliis setaceis.

Schoenus indicus; culmo nudo tereti tenuissimo, capitulo parvo nigricante, involucro brevi subulato subtriphyllo. Lamarck. dict. bot. 1. 740. illustr. ז. p. r 35 .

Schoenus Capitellum; culmo tereti, capitulo ovato, involucro diphyllo.- Thunb. prodr. If.

Habitat in India orientali et Cap. Һ. spei. Ex herbario Lamarckii.

Culmi plures, peảales, teretes. Folia culmo breviora. Involucrum diphyllum-triphyllum, setaceum, capitulo longius; foliolum unicum interdum subbipollicare, interdum vix unguiculare. Capitulum magnitudine pisi. Spica quinque-sex: squamae ovatae, latae, acuminatae, fuscae, striatae: carina viridi. Stamina tria. Stylus trifidus. Semen obovatum, apice muticum, nigrum, oculo ormato transversim undulatum. Setae plures.

striatus. 12. SCHOENUS capitulo ovato involucro triphyllo breviore, culmo foliisque filiformibus.

Schoenus striatus; culmo tereti, capitulo ovato, involucro triphyllo. Thunb. prodr. I6.

Habitat in Cap. b. spei.

Radix stolonifera. Culmi duo-tres semipedales, bulbosi. Folia culmo breviora, canaliculata: vaginae latae, membranaceae, fusco-ferrugineae. Involucrum foliolis basi dilatatis, filiformibus, praeterea duo vel tria alia inter spicas, breviora, at capitulo longiora, omnia margine fusca, carina viridia. Capitulum piso parım majus, ovato-subglobosum. Spicae oblongae: squamae ovatae, acuminatae, striatae, fusconigricantes, dorso virides. Stamina tria: antherae lineares, flavae. Stylus profunde trifidus. Stigmata villosa. Semen oblongum. Setae longae, articulatae. 
13. SCHOENUS capitulo involucro pentaphyllo Bobartias. breviore, culmo compresso, foliis linearibus. $f$ Schoenus Bobartiae; culmo compresso, capitulo terminali, involucro pentaphyllo. Retz, obs. $4 . p$. 9 .

Habitat in Zeylona.

Radices plures, congesti e tunicis fuscis inflatis, bulbosae. Folia linearia, saepe altitudine culmi. Involucrum foliolis decrescentibus: longiore novempollicari, brevissimo sesquipollicari. Capitulum spiratum, breve, terminale. Spicae plures: squamae scariosae, ovatae, cavae, subquinae. Retz. $l$. $c$.

4. SCHOENUS capitulo subrotundo, involucro ruber. monophyllo lanuginoso, culmo tcreti. †

Schoenus ruber; culmo tereti nudio, capitulo subrutundo, involucro monophyllo. Lour. flo cochinch. $4 \mathrm{I}$.

Habitat in Cochinchina.

Culmus bipedalis, erectus. Folia graminea. Capitulum rubrum, compactur. Involucrum bre. ve. Lour. l. $c$.

15. SCHOENUS capitulo subgloposo, involucra inucronatus. longissimo reflexo, culmo tereti.

Kalli 3. Alp. aegrpt.

Gramen cyperoides maritimum. Bauh. theatr. $9 \mathrm{r}$.

Scirpus maritimus; capitc glomerato. Tournef. inst. r. herb. 46. Scheuchz. gram. 367. t. 8.f. I. Juncus maritimus, panicula subrotunda glumosa. Barrel. ic. $203 . f .1$.

Schoonus mucronatus; culmo tereti nudo, spiculis ovatis fasciculatis involucro subhexaphyllo, foliis canaliculatis. Lin. spec. pl. 63. syst. veg. 97 .

Cyperus capitatus; culmo tereti nuda, capitulo glomerato, folioso, terminali. Tand. fasc. 5.

Scirpus Kalli; culmo tereti, folioso, spiculis terminalibus, confertis, sessilibus; involucris longitudine foliorum. Forst. desc. p. I 5 .

Cyperus aegyptiacus; culmo tereti nudo, apice spiculis multis compactis, involucro maximo foliisque recurvis. Gloxin obs. bot. 20.t. 3 .

Habilat in maritimis arenosis Europae azstralis, Africae borealis, Smyrnae. 24. 


\section{TRIANDRIA. MONOGYNIA.}

Radix bulbosa, crassitie digiti intermedii, stolonifera; Stolones pedales, squamis lanceolatis ferrugineis tecti. Culmi solitarii, spithamaei, in. terdum vix longitudine digiti minimi, crassitie pennae columbinae, basi membranis plurimis aridis fuscis tecti, uti folia pallide virentes. Folia plura, culmo longiora, canaliculata, margine scabra, rigida, exteriore parte saepe versus medium decidua, remanente annulo fusco. Involucrum triphyllum, praeter nonnulla foliola breviora inter spicas exteriores, culmo longiora, arcuata vel recurva, structura foliorum. Capitulum ovato-globosum, magnitudine cerasi, sessile. Spicae plurimae, ovatooblongae, complanatae: squamae subdistichae, ovatae, mucronatae, basi purpureae, margine albido-membranaceae. Stylu's trifidus. Semen obovatum, trigonum, nigricans. Setae nullae.

tristachyos. 16. SCHOENUS capitulis tribus, culmo articulato tereti. $f$

Schoenus tristachyos; culmo tereti articulato laevi, capitulis tribus terminalibus. Thunb. prodr. 16.

Habitat in Cap. b. spei.

compressus, 1\%. SCHOENUS spica disticha, spiculis multifloris, involucro monophyllo, culmo teretiusculo.

Gramen cyperoides, spica simplici compressa disticha, Raii synops. 425. Scheuchz. gram. 490.t. ri. f. 6 .

Carex uliginosa; spica composita, spiculis androgynis: inferioribus remotioribus folio longiore instructis, culmo tereti. Lin. fl. suec. p. 325. syst. veg. 843 .

Schoenus compressus; culmo subtriquetro nudo, spica disticha, involucro monophyllo. Lin. syst. veg. 97. Pollich. pal. n. 38. t. 1. f. 3. Leers herb. 32. $t$. г. $f$. т.

Scirpus caricis; culmo subtriquetro nudo, spica disticha compressa, involucro monophyllo. Retz. prodr. n. 64.

Habitat in Europae paludibus turfnsis.

Radix stolonifera. Culmi palmures-pedales, superne hinc parum complanati, basi vaginis fuscis foliorum tecti. Folia culmo longiora vel 
breviora, linearia, carinata, margine scabriuscula. Spica ovato-oblonga, interdum pollicaris: spiculae quinque-sedecim, oblongae, fuscae, nitentes: squamae ovatae, acutae. Stylus bifidus. Semen oblongum, trigonum. Setae plures, semine longiores, ope lentis retrorsum pilosae. Folium sub spica plerumque ea longius, specimina vero vidi ubi brevius erat; variat quoque spicis angustioribus vel latioribus.

1s. SCHOENUS spica disticha, spiculis paucifloris, rufus. involucro monophyllo, culmo tereti.

Schoeni compressi, varietas. Ligft. $f l$. scot. 1 I 38 . t. $24 . f .2$.

Schoenus rufus; culmo tereti nudo, spica disticha involucro monophyllo obtuso longiore, spicis paucifloris, foliis canaliculatis. Smith. fl. angl. 1. p. 45 .

Habitat in paludosis Schotiae, Helvetiae. 4 Similis praecedenti, diversus: foliis canaliculatis, angustioribus: spicis tenuioribus: spiculis plerumque tifloris: squamae infimae longitudine spiculae: stylo trifido.

19. SCHOENUS aphyllus, spicis aggregatis, squa- sristatus, mis cuspidatis, involucro monophyllo, culmo tereti. +

Schoenus aristatus; culmo tereti aphyllo, spicis aggregatis, involucro monopyllo, glumis cuspidatis. Thunb. prodr. 16.

Habitat in Cap. b. spei.

20. SCHOENUS spica secunda, spiculis ovato- secundus. subglobosis approximatis subinvolucratis, culmo tereti filiformi, foliis setaceis.

Schoenus bulbosus. Lamarck. illustr. I. p. I36. \& fide herbarii ejus.

Schoenus bulbosus; culmo tereti filiformi, spicis racemosis secundis, involucris solitariis. Thunb. prodr. 16.

Habitat in Cap. b. spei. Lamarck.

Culmi plures, pedales vel ininores, bulbosi. Folia culmo breviora: vaginae membranaceae, purpurascentes. Involicrum foliolum ad basin spicae urrius vet alterius. Spicae tres-viginti, semine coriundiri paruin mojores, nitidae: 
squamae ovatae, apice carinatae, concavae, basi flavescente:, superne fuscae, mucrone flavo terminatae, margine albido-membranaceae. Flosculi plures. Stylus tripartitus. Semen obovatum, altero latere parum carinatum, basi acuminatum, oculo armato transversim undulatum. Setae nullae.

Distinctissimus a Scirpo capensi Rottböllii vel Schoeno bulboso Linnaei. Schoenus bulbosus Thumbergii vero huc pertinere videtur, quamvis secundum differentiam spicae essent racemosae.

spicatus. 21. SCHOENUS capitulis spicatis involucratis, culmo tereti capillari. Thunb. prodr. I6. $t$ Habitat in Cap. b. spei.

bulbosus. 22. SCHOENUS spicis glomeratis, glomerulis alternis, bracteis solitariis, culmo foliisque setaceis.

Schoenus bulbosus, culmis triquetris nudis, florum glomerulis alternis, foliis lineari-filiformibus. Lin. mant. 178 .

Scirpus capensis; scapis foliisque setaceis, basi alatis; capitulis glomeratis, per bracteas setaceas interstinctis. Pottb. gram. 53. t. I6. f. 3 . Habitat in Cap. b. spei. König. 4

Radix bulbosa, vestita rudinentis foliorum praeteritorum. Culmi spithamaei vel parum ultra, teretiusculi, fillformes. Folia culmo parum breviora, canaliculata: vagina diluta, membranacea. Involucrum folium setaceum ad singulum glomerulum eoque longius. Spicae glomeratae, ovatae, parvae: glomeruli alterni, circiter quatuor, inferior saepe remotus, reliqui approximati: squamae ovatae, concavae, infima acuta, reliquae obtusae, purpureo striatae. Antherae cuspidatae. Stylus trifidus. Setae nullae.

compar. 23. SCHOENUS aphyllus, spicis alternis subgeminatis sessilibus pedicellatisque, involucro solitario, culmo tereti.

Schoenus compar; culmo tereti nudo, spica composita, spiculis geminatis. Lin. mant. 117.

Schoenus scapo strictissimo tereti; spicis glomeratis; bracteis subulatis. Rottb. gram. 65. $t$. 18, $f$. 4 . 
Schoenus compar; culmo tereti aphyllo, spicis aggregatis, involucris monophyllis brevioribus, glumis acutis. Thunb. prodr. 16.

Habitat in Cap. b. spei.

Culmi bipedales, superne subsulcati. Involucrum monophyllum sub singulo glomerulo, erectum, subulatum, subtus carinatum, nitidum, fuscum, rigidum, serruluto-scabrum, inferius longius. Spicae duae vel tres, oblongo-lanceolatae, teretes, unica sessilis, reliquae breviter pedicellatae, oblongae, magnitudine fere grani tritici, bitriflorae; squamae infinae ovatae, superiores lanceolatae, omnes acutae, basi flavescentes, apice fuscas. Antherae ferrugineae, cuspide flava terminatae. Germen obovatum. Stylus trifidus. Stamina tria in flosculo terminali, quatuor in reliquis numeravit Rottb. qui quoque credit flosculum terminalem tantum fertilem esse, reliquos steriles.

24. SCHOENUS spicis paniculatis involucro soli-cuspidatus. tario brevioribus, culmo tereti.

Schoenus cuspidatus; culmis teretibus, subnudis; panicula tenuissima, lineari; bracteis annularibus, obliquis, brevissimis, mucrone longissimo terminatis. Rottb. gram. 66. $t$. I8. f. 3 .

Schoenus cuspidatus; culmo tereti, spicis paniculatis involucris baevioribus. Thunb. prodr. 16.

Habitat in Cap. b. spei. König. 4

Culmi plures, sesquipedales, viridi-flavescentes. Folia filiformia, culmo breviora, canaliculata, rigida: vaginae fusco-purpurascentes. Involucrum bractea fusca, annularis, in folium setaceum altero latere productum, spica longius. Spicae inferiores quatuor, duae pedunculatae, duae subsessiles, quinque in unico pedicello et tres in altero, subulatae, tenuissimae.

25. SCHOENUS aphyllus, paniculis lateralibus, punctorius. culmo tereti apice subulato rigido pungente.

Habitat in Cap. b. spei.

Culmus penna columbina fere crassior, desinens in involucrum panicula longius, basi vaginans, supeine subulatum, rectum, rigidum jungens, 


\section{TRIANDRIA. MONOGYNIA.}

fusco-flavescens; simile sub pedunculis partialibus et spicis, at pedunculis spicisque brevius. Panicula contracta: pedunculi tres-quatuor $e$ singula vagina involucri, altero latere plani, altero convexi; pedicelli brevissimi monostachyi. Spicae subsemipollicares, lanceolato-oblongae, fuscae: Squamae lanceolatae, mucronatae, ca. rinatae, laeves: flosculus unicus inter squamas terminales. Stamina tria." Germen minutum: Stylus tenuissimus, quinquefidus. Setae paucae. Singularis stylo quinquefido.

inanis, 26. SCHOENUS aphyllus, panicula terminali spicis squamisque oblongis acutis, culmo tereti.

Schoenus inanis; culmo tereti aphyllo, spicis paniculatis, glumis acutis. Thunb. prodr. I6.

Habitat in Cap. b. spei.

Culmus crassitie pennae anserinae, superne punc. tis fuscis irroratus. Involucrum bracteae spataeformes, fusco-flavesentes; duae inferiores approximatae, insequentes remotiores, infima brevis, ovato-oblonga, mucrone subulato terminata, reliquae lanceolatae, longiores et longius mucronatae. Panicula terminalis; pedunculi duo-quatuor e singula bractea, compressi, laxi, inaequales, longior ex inferioribus tri-quadripollicaris; pedicelli breves, mono-distachyi. Spicae pallide fuscae, parvae: squamae fere onnes fertiles, oblongae, mucronatae. Germen obovatum: stylus trifidus. Setae nullae.

$$
\text { * Culmo folioso. }
$$

laevis. 27. SCHOENUS capitulis lateralibus, spicis ovatis, squamis mucronatis, culmo trigono. $f$

Schoenus laevis; culmo trigono folioso, capitulis lateralibus, glumis mucronatis, spicis ovatis. Thunb. prodr, I 7 .

Habitat in Cap. b, spei.

apillaceus. 28. SCHOENUS spicis subracemosis, squamis mucronatis, culma tereti, foliis capillaceis. +

Schoenus capillaceus; culmo tereti folioso, spicis subracemosis, glumis mucronatis, foliis capillaceis. Thuno. prodr, 16 ,

Habitat in Cap. b. spei, 
29. SCHOENUS pedunculis axillaribus terminali- fasciatus.

busque, spicis subsolitariis, squamis aristatis, culmo filiformi tereti, foliis setaceis.

Schoenus fasciatus; culmis foliisque setaceis lon. gissimis, floribus tenuissimis aristatis. Rottb. gram. 67.t. 16. f. 5 .

Habitat in Cap. b. spei. 4

Culmi plures, pedales et ultra, geniculis remotis, basi involuti vaginis fuscis altero latere cancellatis. Folia longa, canaliculata, margine scabra: vaginae caulinae vix pollicares, fusconigricantes, nitidae. Pedunculi axillares, saepe terni, folio breviores, capillares, margine scabri, subtristachyi. Spicae remotae, pedicillatae, subulatae, tenues. Bractea linearis ad basin singuli pedicelli in aristam desinens, fusca: squamae lineares.

An Sch. capillaceus Thunb.?

30. SCHOENUS pedunculis axillaribus terminali- setaceus, busque subtrifloris, culmo trigono foliisque setaceis.

Schoenus setaceus; culmo tereti striato, foliis setaceis, floribus lateralibus. Berg. in act. helv. $7 \cdot p$. г 30. t. 9 .

Schoenus setaceus; culmo triquetro, foliisque setaceis, spicis aggregatis, floribus diandris. Rottb. gram. 62. t. $2 \mathrm{r}$.

Schoenus setaceus; culmo triquetro subnudo, foliis setaceis, spiculis aggregatis, flosculis diandris. Swartz. fl. ind, occid. 1. p. 1०7.

Habitat in Surinamo, Caribaeis, Carolina.

Culmi pedales vel minores, uni-binodosi. Folia duo-tria, culmo breviora, remotissima. Pedunculus ex axilla superiore solitarius, terminales plerumque gemini, cum folio setaceo ad basin pedunculos aequante. Spicae duae-sex, subulatae, acutissimae, pallide fuscae: squamae infimae ovatae, mucronatae; superiores lanceolatae. Stamina duo. Stylus bifidus. Semina subrotunda, margine compressa, rugosa, bidentata.

3r. SCHOENUS pedunculis axillaribus terminali- hispidulus. bus tristachyis, spicis subglobosis pedicellatis, foliis filiformibus hispidulis. 
Habitat in Carolina? Ex herbario Lamarckii.

Hispidulus. Radix fibrosa. Culmi palmares-spithamaei, angulati. Folia distantia, duo ad quatuor in culmo, superiora culmo longiora, linearia, inferne carinata: vaginae breves. Pedunculi axillares solitarii, terminales interdum gemini: pedicelli versus apicem, plerumque gemini, interdum unicus, pollicares vel minores, alterni, monostachyi, laxi. Spicae globosae, magnitudine seminis coriandri, glabrae: squamae subrotundae, concavae, fuscae. Flosculi tres. Stamina tria. Stylus bifidus, purpureus, glaber. Semen globosum undulato - rugosum.

microstachys. 32. SCHOENUS pedunculis subgeminatis, spicis subgeminatis sessilibus oblongis, culmo foliisque filiformibus glabris.

Habitat in Cap. b. spei. 4

Culmi plures, semipedales, teretes, squamis interstincti. Folia remota, altitudine culmi, canaliculata, extrorsum serrulata, rigida: vaginae pollicares, sensim minores demum bracteae. Pedunculi axillares, gemini, terni, interdum semel divisi, unicus reliquis longior, inter inferiores, saepe bi-tripollicaris, margine serrulati. Spicae duae tres sessiles, oblongae, acutae, parvae, fuscae: squama infima in mu. cronem longitudine spicae desinens; reliquae ovatae, acutae, carinatae.

arundinaceus.33. SCHOENUS paniculis diffusis axillaribus terminalibusque, spicis subsolitariis, foliis longissimis.

Schoenus radiatus. Forst. prodr. n. $49 \mathrm{I}$.

Habitat in nova Caledonia. Fabricius Professor Kilonensis. 4

Culmi superne laeves. Folia margine aculeato scabra. Panicula pedalis: pedunculi partiales gemini e singula vagina, filiformes, compressi; pedicelli margine scabri; vaginae pollicares, sensim minores, remstae, aristatae, ferrugineae. Spicae solitariae vel geminae in apice pedicellorum, parvae, oblongae, teretiusculae, acutae, arcte subdistiche imbricatae, fuscae: squamae ovatae, acutae. 
34. SCHOENUS paniculis contractis, spicis oblon-Mariscus. gis, culmo tereti.

Cyperus longus inodorus vulgaris. Park. theatr. I 263 .

Cyperus longus inodorus germanicus. Bauk. theatr. $22 \mathrm{I}$.

Pseudocyperus palustris, foliis et carina serratis, Scheuchz. gram. 375.t. 8. f. 7 - I .

Schoenus Mariscus; culmo tereti, foliis margine dorsoque aculeạtis. Lin. it. gottl. = c. syst. veg. 96. Roth. fl. germ. 2. p. t5. Jacqu. collect. 3. p. $\tau^{2}$.

Habitat in Europae paludibus. 4

Culmi tripedales et ulira. Folia elongata, margine carinaque serrata. Pedunculi axillares et terminales solitarii, bis vel ter áivisi. Spicae quatuor-sex, sessiles, oblongae, obtusiuscuiae, flavescenti-fuscae, nitidae.

Alium e Puertorico misit IVest incic similem: panicula magis diffusa spiculis floriferis simiiibus: fructiferis ovato-globosis, fusco-ferrugineis: seminibus globosis; fusco-albidoque variegatis. An potius sequens adultior? culmus vero teres nisi ad vaginas.

35. SCHOENUS paniculis diffusis, spicis oblongis, Cladiun. culmo obtuse trigono.

Cladium, culmo nodoso, floribus quasi umbellatis, umbellis gradatim assurgentibus. Brown jam. I I 4 .

Schoenus Cladium; culmo obtuse triquetro folioso laevi, foliis antrorsum aculeatis, paniculis diffusis, spiculis unifloris sessilibus diandris. Sulartz. prodr. 19. Fl. ind. occid. 1. p. 97.

Habitat in Jamaicae paludosis maritimis.

Folia sesquipedalia et ultra, semipollicem lata, carinata, margine carinaque cartilagineoserrata: vaginae sesquipollicares, basi fuscae. Paniculae solitariae. Pedunculi partiales sin.. guli e vagina lanceolata attenuata conferti, compressi, margine laeves, laxi, supradecomposite divisi. Spicae tres-quatuor, sessiles, parvae, uniflorae, acutae, fusco-ferrugineas: squamae oblongae, acutae. 


\section{TRIANDRIA. MONOGYNIA.}

Culmus octo-decem pedails. Filamenta duo brevissima. Germen lineare, oblongum: Stylus trifidus.' Semen ovatum, acutum, nitidum, fuscum.

Differt a Sch. marisco, culmo altiore; panicula maxima, diffusa; pedunculis pedicellisque longioribus, filiformibus: spiculis minoribus. Swartz. l. $c$.

lanceus. 36. SCHOENUS spicis paniculatis, squamisque lanceolatis, culmo trigono. +

Schoenus lanceus; culmo trigono folioso, spicis paniculatis lateralibus, glumis spiculisque lanceolatis. Thunb. prodr. 17 .

Habitat in Cap. b. spei.

ustulatus. 37. SCHOENUS spicis racemosis lanceolato-oblongis, squamis aristatis, culmo tereti.

Schoenus ustulatus; culmo tereti folioso, spicis pedunculatis pendulis oblongis aristatis. Lin. mant. 178 .

Schoenus culmo tereti; vaginis lucidis; spicis distichis aristatis, singulis simplicibus, spatha unica cinctis. Rottb. gram. 63. t. 19. $f$. 1.

Schoenus ustulatus; culmo tereti, folioso, spicis racemosis, glumis aristatis. Thunb. prodr. r 6 .

Habitat in Cap. b. spei.

Culmus bipedalis. Folia pauca, remotissima, superius culmo longius, filiformia, margine scabra, laxa: vaginae bipollicares, fusconigricantes, altero latere cancellatae; florales latiores, uti culmi in folium acuminatae. Pedunculi solitarii, vel gemini, inferiores remotiores, supremi approximati, laxi, apice trigoni, crassiores, margine scabri. Spicae plerumque geminae, altera sessilis altera pedunculata, biflorae, compressiusculae, fere pollicares, fusco-ferrugineae: squamae lanceolatae, compressae, carinatae, in aristam desinentes. Flosculus terminalis fertilis, inferior sterilis. Antherae cuspidatae. Stylus trifidus. Semen oblongum, trigonum.

Rottböllius non nisi partem superiorem culmi vidit, ideoque eum enoden dixit. 
38. SCHOENUS paniculis nutantibus, spicis con- involucratus. gestis, squamis inferioribus lineari-lanceolatis aristatis supremis ovatis mucronatis.

Schoenus involucratus; panicula foliosa, nutante; spicis congestis, aristatis, subdistichis; flosculis gemellis nectariferis. Rottb. gram.64. t. 19. f. 1 .

Habitat in Cap. b. spei.

Araxime affinis sequenti, at culmus tenuior. Folia et vaginae angustiores: Spicae minores, oblongae, magis distinctae: squamae ovatae. Flosculum terminalem hermapliroditum invenio, alterum inferiorem vero semper masculum, quod quonue sic esse apparet ex ipsa icone Rottböllii, modo quod ambo oppositi yicti sunt. Antherae apice mucronatae, mucrone hamoso. Setae ut in sequente.

$A$ Sch. flexuoso valde differet.

39. SCHOENUS paniculis nutantibus, spicis con- thermalis. gestis, squamis lanceolatis inferioribus aristatis interioribus acutis, culmo tereti.

Schoenus thermalis; culmo triquetro folioso, capitulis lateralibus compositis subsessilibus, foliis ensiformibus carinatis. Lin. mant. 179.0

Schoenus culmo tereti; spicis alternis aristatis; singula composita spiculis plurimis, per totidem bracteas interstinctis. Rottb. gram. 63. t. $18 . f .2$.

Schoenus bromoides; culmo tereti folioso, spiculis pedunculatis solitariis crassis aristatis. Lamarck. illustr. ז. p. 137. fide herbarii ejus.

Habitat in Cap. b. spei.

Culmus altus, penna anserina paululum tenuior, ad articulos obscure trigonns, pallide viridis. Folia pedalia, remota, sensim minora et magis approximata, demum spathaeformia, linearilanceolata, sensim attenuata, margine carinaque serrulato-scabra: vaginae bipollicares et ultra, integrae, attate superne fissae, fissura filis cancellata, basi fusco-flavescentes. Panicula magna, bipedalis et ultra. Bractea spathaeformis, foliacea, in aristam longam sensim breviorem desinens, fusca, apice scabriuscula. Pedunculi quatuor e singula spatha, inferiores 


\section{TRIANDRIA. MONOGYNIA.}

longiores, sensim breviores; supremi brevissimi, longior inferiorum fere semipedalis, iterum divisus; reliqui sensim decrescentes et simplices; omnes, uti pedicelli, laxi, penduli, laeves, nitentes. Spicae tres-quatuor in singulo capitulo, sessiles vel breviter pedicellati, teretes: squamae lanceolatap, fusco-ferrugineae; infimae interioribus longiores, aristatue; superiores acutae. Stamina tria, squama distincta a pistillo: Anterae nigrae, apice mucrone recto terminatae. Pistillum inter duas squamas ulitimas: germen minutum: stylus superne parum crassior, bifidus. Setae sex, tam in flosculo masculino quam foemineo, albidae, superne pilosae.

Rottböllius Sc. thermalem descripsit et delineavit secundum specimen junius et vix dubito quin Linnaeus, simili insiructus tantum modo secundum habitum ad Schoenum amandaverit, alias certe descriptionem partium fructificationis oculatus non omisisset.

Quod uti spicam delineavit non est spica ipsa sed solummodo vaginae capitulorum, nondum visibilium; in quotquot enim ex illis spicis, quae Rottböllio compositae dicuntur, dissectis, semper non nisi unam squamam intra alteram sensim decrescentem vidi, nunquam vero stamina vel pistilla. Specimina plura tam istius ut supra Rescripsi, quam Rottböllii consimilia possideo. Cel. Wildenowius primus est qui hujus descriptionem partium fructificationis tradidit, sed quantum ex ipsius descriptione apparet, specimen haud $a b$ omni parte perfectum habuit.

aactyloides. 40. SCHOENUS capitulis paniculatis, spicis Ianceolatis acutis, squamis acutis: infimae ciliatae, culmo superne trigono.

Schoenus glomeratus; culmo trigono folioso, canitulis paniculatis, glumis ciliatis. Thunb. prodr. 77.

Habitat in Cap. b. spei.

Facies Dactylidis glomeratae. Vaginae superne, alternae, longitudine capituli, in folium ciliatum desinentes, infimo sesquipollicari. Pedunculi gemini $e$ singula vagina, breves. Capitula semipollicaria, ovato-oblonga. Spicae confertissimae: squamae lanceolatae, 
attenuatae, infima longitudine spicae ciliata, reliquae subciliatae, viridi-flavescentes. Stamina tria. Stylus trifidus. Semen oblongum, trigonum. Setae nonnullae.

41. SCHOENUS paniculis erectis, spicis congestis flexuosus. oblongo-subcylindricis squamis ovato-lanceolatis mucronatis, culmo tereti.

Schoenus flexuosus; culmo tereti folioso, spicis paniculatis, glumis mucronatis. Thunb. prodr. i 6.

Habitat in Cap. b. spei.

Culmus pedalis vel ultra, rigidus. Folia remota, bi-tripollicaria, linearia, attenuata, planiuscula, rigida, apice nigra: Vaginae pollicares, nitentes. Pedunculi e vaginis superioribus, gemini, inferne remotiores, vagina longiores, inaequales, partiales brevissimi; pedicelli tristachyi. Spicae grano tritici minores, uniflorae: squamae in aristam sensim minorem acuminatae, infima longitudine spicae, striata, reliquae laeves. Stamina tria. Stylus trifidus: Stigmata pubescentia. Germen obovatum, obtusum. Setae nullae.

42. SCHOENUS paniculis elongatis, spicis conge-angustifolius. stis teretibus subulatis, culmo tereti.

Gramen fluviatile geniculatum, panicula foliacea virginiana. Moris. hist. 3. p. 183. sect. 8. t. 3 . $f$. . $^{-}$

Gramen junceum elatius, caule articulato, virginianum, cyperi paniculis inter folia prope summitatem prodeuntibus. Pluk. alm. 179. $t$. 30 . $f$. 1 .

Cyperus racemis simplicibus lateralibus solitariis distichis, spicis alternis patentibus. Gron. virg. I 5 I. ed.

Cyperus ferrugineus. Spec. pl. ed. т. p. 44.

Schoenus spathaceus; culmo tereti, spathis alternis mucronatis paniculas obvolventibus, spicis alternis patentibus. Lin. spec. pl. 63 .

Cyperus spathaceus; culmo vaginis foliorum vestito, pedunculis pinnatis lateralibus. Lin. syst. veg. Ion.

Habitat in Virginia. 


\section{TRIANDRIA. MONOGYNIA.}

Culmi altitudine Sacchari, erecti, stricti vaginis foliorum toti tecti. Folia frequentia, bipollicaria et ultra, sursum sensim minora, linearia, laevia: Vaginae semipollicares, ore fusco marginatae, striatae. Pedunculi superne e vaginis foliorum, eaque parum longiores, solitarii, filiformes, compressi, ope lentis margine denticulati. Spiculae circiter sex, sessiles, alternae, semipollicares, parum distantes, teretiusculae, subulatae: flosculi sex; valvulis lineari-lanceolatis, striatis, margine ferrugineomembranaceis, infima sterili. Filamenta tria, albida. Germen cinctum setis sex-decem, ferrugineis, ope lentis retrorsum denticulatis. Stylus squama longior: stigmata duo, ad lentem villosa. Semen lineare, compressiusculum.

Habitus. Primae sectionis. Culmi erecti enodes. Folia radicalia basi culmum vaginantia. Spicae in plerisque terminales. Secundae sectionis. Culmi erecti, nodosi, foliosi, rigidi, ad nodos crassiores. Folia remota: vaginae integrae, plus minusve fuscae. Pedunculi axillares minus divisi, terminales magis, altero latere convexi, altero plani vel canaliculati.

-- Dubii generis.

Hytrix. 43. SCHOENUS spica terminali solitaria, valvulis acuminatissimis squarrosis, culmo aphyllo.

Habitat in Cap. b. spei. 4

Culmus teres, nodosus, fusco-virescens. . Folia nulla: vaginae pollicares, arctae, apice flavescentes, mucrone brevi flavo terminatae. Involucrum nullum nisi squama infima, longitu. dine dimidia spicae, ovato-lanceolata, margine flava. Spica obovata, magnitudine fere nucis coryli, imbricata, fusco-nigrescens: squamae ovatae, rigidae, planiusculae, laeves, margine albida membranaceae, in aristam acuminatae; arista squamis longior, patula, rigida, oculo armato subserrata. Flosculi nulli inter squamas inferiores.

Fructificationem non vidi, at Restio non est, quamvis habitu convenit, forte proprii generis.

tatifolius. 44. SCHOENUS pedunculis axillaribus, spicis alternis spicatis subquaternis, culmo triquetro folioso.

Habitat in Puertorice Ventenat. 4 
Culmus altus, crassitie pennae anserinae, erectus, articulatus, acute trigonus, angulis serrulatoscabris. Folia pedalia, interdum ultra, pollicem lata, ensiformia, utrinque per vaginam decurrentia, margine serrulato - scabra, utrinque trinervia et sulco in utraque pagina nervis opposito; nervi in pagina superiore scabri: Vaginae. internodiis breviores, acumine folio opposito ovato terminatae. Pedunculi solitarii bi-tripollicares, compressi, ancipites, margine scabri. Spicae compositae, approximatae, brevissimae. Bractea oblonga, carinata, arista acuminata, ciliata. Spiculae tres-quatuor in singulo pedunculo, confertissimae, semiunguiculares, teretiusculae, bifariam laxe imbricatae: valvulae circiter quatuordecim, ovato-lanceclatae, attenuatae, concavae, carinatae.

Fructificationem ecuidem non vidi, Preoque tantummodo secundum habitum ad Schjenos retuli.

45. SCHOENUS culmo tereti, folis setaceis va- Burmanni. ginantibus, florun panicula stricta.

Schoenus spicatus. Eurme prodr. 3.

Habitat in Cap. b. spei.

46. SCHOENUS umbella terminali, spiculis glo- cyperoides. meratis, culmo triquetro folioso. Swartz. prod. I 9. Fl. ind. occidl. 1. p. I 10

Habitat in montibus Jamaicae australis.

Culmus bipedalis, trigonus. Folia semipedatia, linearia, carinata, striata, glabra; carina serrata. Pedunculi ex vaginis foliorum terminalium, plures, inaequales, trigoni. Spicae in glomerulis terminalibus, interdum compositae, confertissimae, sessiles, acuminatae, patentes: squamae inaequales, subimbricatae, interiores teneriores, angustiores, minores, uniflorae. Stylus trifidus. Semen obovatum, fere obcordatum, obtuse trigonum, ferrugineum. Setae duae longitudine valvularum. Swartz. l. c.

47. SCHOENUS culmo triquetro folioso, corym- nemorum. bo terminali composito folioso. Symb. bot. 3 . p. ?.

Eeera-Kaida. Rheed. mal. 12. p. rog. t. 58 . 
Habitat in India orientali.

Culmus erectus, pedalis et ultra, triqueter, glaber, vaginatus Folia culmo duplo longiora, pollicem lata, glabra, carinata, trinervia, margine et carina retrorsum scabra. Corymbus terminalis, compositus. Folia ad basin pedunculorum partialium et pedicellorum; infima corymbo longiora; insequentia sensim breviora. Ochreae ferrugineae, bifidae, acutae. Spiculae subternae in singulo pedicello, undique imbricatae, multiflonae; tenellae lineari-oblongae, obtusae, fructiferae globosae, vix magnitudine piperis nigri. Squamae infimae steriles, flosculo unico sub singuIis reliquis, oblongo-subrotundae, subcarinatae, glabrae. Calyx oblongus, squama brevior, bivalvis; valvulae lineares, concavae, tenues, acuminatae, ope lentis villosulae. Filamenta duo squama longiora. Antherae erectae. Germen sublenticulare; setae ad basin nullae. Stylus bipartitus, -squama longior. SeInen globoso-compressiusculum, basi styli breviter et obtuse acuminatum, rugosum, nigrum.

A Schoenis differt calyce bivalvi intra squamam; a Machaerina setarum defectu et habitu; a Hypaelyptis paleis persistentilus et habitu diversissimo; forte rectius proprii generis.

cyinosus. 48. SCHOENUS culmo triquetro folioso, umbella terminali composita, spiculis ovatis striatis. Wilden. spec. pl. 1, p. 265 , t.

Habitat in America boreali. 24

Culmus pedalis, erectus, foliosus. Folia linearia, cyperina, glabra, carinata, numerosa in culvio, superiora umbella longiora. Umbella terminalis, uncialis, ramis umbellatis inaequalibus. Spiculae ovatae, acuminatae, magnitudine seminis sinapis, tres semper glo'meratae, sessiles. Squamae ovatae, acuminatae, nervosae, brunneae. Involucrum universale polyphyllum; foliolum unicum umbella longius, reliqua multo minora: partiale nullum. Wild. $l$. $c$.

Ex autoritate Wildenowii huc locavi, quamvis inflorescentia aliena a Schoenorum, an Scirpus polyphyllus? 
Schoenus incanus. Forsk. descr. 12. + Minime hujus generis et nequidem ordinis, forte errore editoris, qui minus recte nomen Forskálianum ex ejus schedulis tradidit.

Schoenus Fabri. Rottb. est varietas monstrosa milii villosi.

I13. Ry vacuae. Cor. o. Sem. r. coronatum stylo persistente indurato, basi latitudine seminis.

I. RYNCHOSPORA ccrymbis diffusis lateralibus aurea. subdecompositis terminalibus supradecompositis, pedunculis glabris, rostello longitudine seminis.

Gramen quinta species. Marcg. hist. bras. I. fide herbarii ejus.

Gramen cyperoides indicum foliis varie adumbratis, paniculis graminis pratensis minoris nostratium, ex alis foliorum prodeuntibus. Plukn. amalth. $\mathbf{1} 2$.

Scirpus corymbosus; culmo triquetro folioso, corymbis lateralibus simplicibus: terminali prolifero, spicis subulatis. Lin amoen. ac. 4. p. 303. syst. veg. 102.

Schoenus surinamensis, culmo folioso triquetro, pedunculis corymbosis, inferioribus alternis, superioribus in umbellam aggregatis. Rottb. gram. 68. t. 2 I. f. r.

Schoenus surinamensis; culmo folioso triquetro, pedunculis corymbosis; inferioribus alternis distantibus, superioribus confertis. Swartz. fl. Ind. occid. 1. p. 99 .

Habitat in Surinamo, Jamaica, India orientali, China. 4

Culmi saepe quadripedales, acutanguli, interdum prope vaginas angulis scabri, interdum laeves. Folia margine carinaque serrulata, unguem lata. Vaginae pollicares et ultra. Pedunculi partiales inaequales, laxi:. Pedicelli approximati, plerumque triflori. Stylus indivisus. Semen obovatum, puncticulatum; Rostellum teretiusculum medio sulco exaratum. 
polyphylla 2. RYNCHOSPORA corymbis contractis axillaribus compositis terminalibus decompositis, pedunculis villosis, rostello longitudine seminis.

Schoenus polyphyllus; culmo triquetro folioso, foliis carinatis dorso marginibusque scabris, spicis decompositis axillaribus, ${ }^{2}$ cl. amer. 2.

p. 5 .

Habitat in Montserrat. Ryan. 4

Culmus bipedalis vel ultra, angulis acutis, saepe totus vaginis foliorum tectus, apicem versus parum pilosus. Folia frequentia, approximata, sesquipedalia, superiora culmo altiora, sentiunguem lata, erecto-patentia, margine carinaque scabra, pallide viridia: vaginae bipollicares vel minores. Corymbi compositi vel decompositi, solitarii vel gemini, bipollicares, multiflari: pedunculi partiales patentes. Spicae solitariae, approximatae, triflorae, testaceae: squamae lanceolatae. Semen fuscum: rostellum ovatum, longitudine seminis, Setae semine longiores, glabrae. -

spars. 3. RYNCHOSPORA corymbis diffusis axillaribus compositis terminalibus decompositis, pedunculis capillaribus, seminibus rostro longioribus.

Schoenus miliaceus; culmo triquetro folioso, paniculis lateralibus et terminalibus, flosculis distinctis pedicellatis. Lamarck. illustr. $\mathrm{r}$. p. 137.

Schoenus sparsus; culmo triquetro folioso: paniculis axillaribus terminalique, laxe multifloris; spiculis pusillis, ovoideis, omnibus distinctis et pedicellatis: semine globuloso, transverse subrugoso - striato; tuberculo terminali brevissimo. Mich. fl. bor, amer, I. p. 35.

Habitat in umbrosis sylvarum Carolinae, Georgiae, Richard.

Glauca. Culmi acutanguli, pallide virides. Folia distantia, spithamaea, culmo breviora, duastres lineas lata, laxa, extrorsum margine carinaque scabra, glauco-viridia: vaginae integrae. Corymbi axillares, pedunculati, solitarii : pedunculi setacei, remoti; pedicelli uniflori, capillares. Ochreae truncatae, flavoferrugineae. Spicae vix magnitudine seminis 
milii, uniflorae, ovatae, fuscae: squamae ovatae, concavae, mucronatae. Semen globosum, rostello minuto obtuso terminatum. Setae nonnullae.

4. RYNCHOSPORA hirsuta, corymbis axillaribus hirsuta. patentibus simplicibus terminalibus composi' tis, culmo foliisque filiformibus.

Schoenus hirsutus; hirsutus, pedunculis lateralibus terminalibusque: pedicellis racemosis trifloris. Ecl. amer. 1. p. 6 .

Habitat in America. v. Rohr.

Tota piloso-hirsuta. Culmi plures, spithamaei. Folia culma breviora. Pedicelli, capillares, vix unguiculares, mono-tristachyi. Spicae parvae, sessiles: squamáe oblongae, ferrugineae, margine albidae, infima rare pilosa. Stylus profunde bifidus. Setae plurimae.

3. RYNCHOSPORA corymbis diffusis axillaribus micrantha. simplicibus terminalibus compositis, pedunculis capillaribus, culmo foliisque filiformibus glabris.

Schoenus rariflorus; foliis culmoque folioso se. taceis: panicillis laxe rarifloris; spiculis ovatis: semine obovato, rugoso; tuberculo apicilari abbreviato; setulis multo brevioribus. Mich. fl. bor. amer. 1. p. 35 .

Habitat in Georgia. Richard, in Puertorico. West.

Culmi spithamaei vel pedales, obsolete angulati, laxi. Folia culmo breviora, pauca, remotissima, linearia, angustissima, laxa, margine scabriuscula: vaginae vix pollicares. Corymbi pauciflori, solitarii: pediçelli submonostachyi. Spicae minutae, flavesçentes: squamae ovatae. Semen obovatum, transverse rugosum: rostellum ovatum, vix longitudine seminis. Setae semine longiores.

6. RYNCHOSPORA corymbis terminalibus com- laxa. positis, spicis solitariis, rostello seminum longisssimo, culmo acutangulo, scabro.

Schoenus corniculatus; culno triquetro folioso, corymbis alternis compositis laxissimis, spiculis corniculatis aristatis. Lamarck. illustr.

1. p. 132 . 
Schoenus longirostris, latifolius: umbellis foliosis; spiculis fasciculatis: semine compressoobovato, longissime mucronato; setulis sex, ipso brevioribus. Mich. fl. bor. amer. 1. p. 35 . Habitat in Virginia, Carolina. Ex herbario Lamarkii.

Culmi margine scabriusculi. Pedunculi approximati, inferiores tri-quadripollicares, quinquesexflori, unus vel alter iterum divisus; superiores vix pollicares bi-triflori; omnes laxi, margine scabri Bractea infima pollicaris. Ochrea truncata, fusca. Spicae subulatae, maturae fere pollicares. Stylus indivisus. Semina obovata, compressa, magnitudine seminis cannabis, oculo armato puncticulata: rosiellum squamis dimidio longius, e tuberculis minutissimis scabrum. Setae rigidulae.

triflora. 7. RYNCHOSPORA corymbis axillaribus simplicibus terminalibus subcompositis, rostello longitudine seminis, culmo acutangulo scabro, spicis subgeminis.

Habitat in India orientali.

Folia remota, culmo breviora, margine scabriuscula. Pedunculi remoti, axillares solitarii, partiales trispicati, margine scabri, basi folio corymbo longiore suffulti. Ochreae parvae, truncatae. Spicae sessiles, semiunguiculares, oblongae, teretes, attenuatae- Semen obovatum, transverse rugosum; rostello subulato. Setae semine longiores, retrorsum pilosae.

filiformis. 8. RYNCHOSPORA corymbis axillariblis simplicibus, terminalibus subcompositis, culmo obtusangulo laevi foliisque filiformibus.

Habitat in Puertorico Le Dru.

Culmi pedales et ultra. Folia remota, culmo breviora, stricta, extrorsum margine scabra. Corymbi solitarii: pedunculi partiales inferiores semipollicares. Spicae angustae, vix unguiculares. Semen laeve; rostello ovato, seminis longitudine.

inexpansa 9. RYNCHOSPORA corymbis coarctatis axillaribus simplicibus compositisque terminalibus decompositis, culmo filiformi. 
Schoenus inexpansus; anguste foliosus: paniculis remotis; ramulis approximato-erectis; spiculis fusiformibus: semine oblongiusculo, subrugoso, mucrone brevi ; setulis sex, duplo longioribus. Mich. fl. bor. amer. x. p. 35.

Habitat in Carolina. Bosc.

Culmi bipedales, inferne crassitie pennae columbinae, obtusanguli, laeves. Folia remotissima, longitudine internodiorum, lineari-filiformia, superne margine scabra, glauco-viridia. Pedunculi solitarii, capillares, superiores folio longiores. Spicae parvae, subulatae, fuscoferrugineae: squamae lanceolatae, exteriores carinatae. Semen transversim undulato-rugosum; rostellum ovatum, acutum, semine dimidio brevius. Setae denticulatae.

10. RYNCHOSPORA corymbis axillaribus termi- setacea. nalibusque simplicibus paucifloris, culmo foliisque setaceis.

Habitat in America meridionali? Ex herbario Jussiaei.

Glauca. Folia in adultioribus remota, culmo breviora. Pedunculi axillares et terminales, solitarii, capillares, laxi, folio breviores. Corymbus axillaris pedicellis tribus-quatuor, terminalis sex-septem. Spicarum squamae ovatae. Seminis rostellum ovatum, acutum, longitudine seminis. Setae semine breviores.

11. RYNCHOSPORA spicis corymboso-fásciculatis glauca. approximatis solitariis, culmo acutangulo, foliis linearibus.

Schoenus rugosus; culmo triquetro folioso, pedunculis corymbosis distantibus, spiculis ovatis acutis, seminibus undulato-rugosis. Ecl. amer. 2. p. 5 .

Habitat in America meridionali. von Rohr.

Glauca. Culmi plures, sesquipeddales. Folia culmo breviora, extrorsum margine scabriuscula. Pedunculi superne ex duabus axillis ultimis solitarii, pollicares, folio breviores. Corymbi parvi, contracti. Spicae parvae, ovatae, actitae, ferrugineae, triflorae: squamae ovatae. Semina lenticularia, margine obsoleto cincta, transversim undulato-rugosa; rostello ovato, longitudine seminis. Setae semine longiores. 


\section{TRIANDRIA. MONOGMNIA.}

fascicularis. 12. RYNCHOSPORA spicis corymboso-fasciculatis, foliis linearibus latitudine culmi.

Schoenus fascicularis angustiuscule planifolius: fasciculis lateralibus terminalique; spiculis planiusculis, oblongis glabris; squamis mucronatis: setulis semine laevi duplo longioribus, sursum hispidulis. Mich. fl. bor. amer. 1. p. 37 .

Habitat in Carolina. Bosc.

Glaucus. Culmi pedales, acutanguli. Folia tria in culmo, remota, caule breviora. Corymbi axillares et terminales, solitarii vel gemini, parvi, compositi vel decompositi; pedunculis pedicellisque brevibus, basi folium setaceum, corymbo parum longius. Spicae fasciculatae, juniores subulatae, fuscae. Semen laeve. Setae hispidulae.

gracilis. -13. RYNCHOSPORA spicis corymboso-fasciculatis, foliis linearibus culmo filiformi latioribus.

Schoenus gracilis; culmo triquetro folicso longissimo filiformi, spicis lateralibus pedunculatis. Swartz. prodr. I9. Fl. ind. occid. I. p. 109 .

Habitat in sylvis montium altissimorum Jamaicae. Maxime affinis praecedenti, diversa culmo multo teneriore; foliis angutioribus, remotioribus: pedunculis remotioribus.

Culmi tri-sexpedales, laxi, Folia longissima. Pedunculi axillares solitarï, terminales interdum gemini; alter brevissimus, alter vix semipollicaris.

Stylus trifidus secundum cel. Swartz. at in specimine ab ipso misso Stigmata tantum duo vidi.

glomerata. 14. RYNCHOSPORA spicis corymboso-fasciculatis remotissimis geminatis, culmo obtusangulo, foliis linearibus.

Schoenus culmo triquetro, pedunculis geminis lateralibus, floribus conglomeratis. Gron. virg. 9.

Schoenus glomeratus; culmo triquetro folioso, floribus fasciculatis, pedunculis lateralibus ge minis. Lin. syst. veg. 97.

Habitat in America boreali. 


\section{TRIANDRIA. MONOGYNIA.}

Affinis R. distanti, differt: culmo altiori, crassiore: foliis triplo latioribus: pedunculis geminis nec solitariis: semen obovatum, setis brevius.

Culmus bipedalis et ultra. Semina lacvia niti$d a$; rostellum longitudine seminis. Setae retrorsum muricatae.

15. PYNCHOSPORA spicis corymboso-fasciculatis distans.

- remotissimis solitariis, culmo obtusangulo, foliis filiformibus.

Schoenus axillaris; culmo triquetro folioso, corymbis minimis alternis axillaribus, spiculis confertis. Lamarck, illustr. 1. p. 137.

Schoenus distans; anguste foliosus: fasciculis subcapitatis, dissite lateralibus et terminali : spiculis ovatis, glabris: semine lenticulari; mucrone brevi; setulis illius longitudine. Mich. fl. bor. amer. 1. $p, 360^{\circ}$

Habitat in Carolina. Pichard.

Culmi pedales, viridi-glaucescentes. Folia remotissima, internodiis breviora. Pedunculi axillares, solitarii, setacei. Spicae confertae in corymbo subcapitato, parvae, ovatae, acutae, ferrugineae: squamae ovatae, acutae. Semen lenticulare, nigrum, nitidum, laevissimum.

16. RYNCHOSPORA spicis corymboso - fasciculatis capitellata. approximatis subgeminatis, bracteis glabris, culmo filiformi acutangulo.

Schoenus capitellatus; anguste foliosus: capitulis proxime alternis, erectis; spiculis oblongis: semine stipitato, breviuscule mucronato; setulis longioribus obmuricatis. Mich. fl. bor, amer. 1. p. 36 .

Habitat in Carolina.

Culmus acutangulus. Capitula' breviter pedunculata, interdum geminata. Rostellum semine parum longius. Setae retrorsum muricatae. Michaux l. $c$.

7. RYNCHOSPORA spicis corymboso-fasciculatis ciliata. terminalibus, bracteis foliisque obtusiusculis ciliatis. 


\section{TRIANDRIA. MONOGYNIA.}

Schoenus ciliaris; foliis linearibus, obtusiasculis: fasciculo terminali; bracteis brevissimis bracteolisque ciliatis: spiculis ovatis: semine lenticulari, laevi: setulis brevissimis, sursum hispidulis. Mich. fl. bor. amer. 1. p. 36 .

Habitat in Florida. Richard.

Glaucus. Culmi pedales, filiformes, superne ad folia pubescentes. Folia ad basin frequentia, tria-quatuor in culmo, pollicaria, remota, angusta. Capitula tria, terminalia, breviter pedunculata, fastigiata, interdum tria ex ala superiore. Spicae vix pedicellatae, oblongae, acutae, parvae, fuscae: squamae ovatae, mucronatae. Semen lenticulare, laeve, rostello brevi ovato terminatum. Setae semine breviores.

Differt a reliquis foliis culmi brevibus.

siba. 18. RYNCHOSPORA spicis corymboso fasciculatis, culmo foliisque setaceis.

Gramen junceum leucanthemum. Ger. emac. 30. Cyperus minor palustris hirsutus paniculis albis paleaceis. Moris. hist 3. p. 239. sect. 8. t. 9. $f .39$.

Gramen cyperoides palustre leucanthemum. Scheuchz. gram. 502. t. I1. f. 2.

Schoenus albus; culmo triquetro folioso, floribus fasciculatis, foliis setaceis. Lin. syst. veg. 98. Fl. dan. t. 320. Pollich. pal. n. $3 \%$.

fuscus. $\quad \beta$. Cyperus minor angustifolius palustris, capitulis fuscis paleaceis. Moris. hist. 3. p. 239. sect. 8. t. is.f. 40 .

Schoenus fuscus; culmo tereti folioso, spiculis subfasciculatis, foliis filiformibus canaliculatis. Lin. spec. pl. I6h4.

Schoenus setaceus; culmis numerose aggregatis longisque, foliis setaceis, stricte erectis : spiculis rufis, tereti-ovatis, pauciter in capitulum terminale collectis: involucro diphyllo, altero floribus longiore. Thuill. fl. par. I9.

Habitat in Europae paludibus turfosis. 4

Radix repens. Culmi palmares-semipedales, filiformes, adscendentes, uninodosi. Folia duotria in culmo, remota, inferius sacpe longitudine culmi, superiora breviora, filiformia, ca- 
naliculata. Pedunculus ex axilla folii superioris et apice, interdum ex apice solummodo, salitaria. Spicae oblongae, acutae, aetate fuscae; foliolum unicum vel duo sub fasciculo terminali, fasciculo longiore: squamae ovato-lanceolatae, acutae. Semen obovatum, rostello longitudine seminis terminatum. Setae plures, semine longiores.

Hallerus jam suspicavit, Schoenum non esse.

19. RYNCHOSPORA spicis glomeratis globoso- cephalotes, capitatis.

Schoenus cephalotes; culmo folioso, triquetro; involucro tetraphyllo, deflexo; capitulo oblongo, terminali. Rottb. gram. 6 г. t. 20.

Habitat in Surinamo. Rolander, von Rohr. 4

Culmus altus, acutangulus, crassitie pennae columbinae. Folia sesquipedalia et ultra, semipollicem fere lata, margine carinaque scabra. Involucrum tetraphyllum, longissimum, dependens. Capitulum magnitudine nucis juglandis, ovato-subglobosum. Spicae floriferae subulatae, acutae; fructiferae oblongae obtusae, crassae, subtriflorae: squamae ovatae, acutae, extimae minores, concavae, griseae. Semen sublenticulare, transversim undulato-striatum, fuscum, margine flavo cinctum; rostello semiunguiculari terminatum.

Habitus. Culmi erecti, trigoni, nodosi, simplicissimi, foliosi. Folia carinata: vaginae integrae. Corymbi pedunculati; axillares simpliciores; terminales magis compositi. Pedunculus communis inter partiales angulatus, flexuosus: partiales inferiores superioribus altiores, compressi, ochreati: foliolum ad basin pedunculorum partialium et pedicellorum, plerumque setaceum. Spicae fuscae, plurimae monoicae. Rostellum seminis albidum. Cephalotes sola ost quae ad modum florendi a reliquis recedit, coeterum in omnibus similis:

Hallerus jam dudum monuit, Schoenum fuscum a plurimis aliis Schoenis differre ideoque eum ad Scirpos retulit, indicans aristas vel ad basin seminis vel apicem coronantes, uti notam characteristicam generis. Quod squamae infe- 


\section{TRIANDRIA. MONOGYNIA.}

riores vacuae sunt, character haud certe magni momenti est, dantur enim Schoeni squamis paucioribus vel pluribus fertilibus, et Scirpi varii squamis inferioribus sterilibus. Fructificatio vero longe praestantiorem praebet, igitur cum tot species tam quoad fructificationem tam quoad habitum inter se conveniunt et in hoc a reliquis Schoenis Scirpisque differunt, nescio cur non licitum esset eas uti proprium genus tradere, praesertim suadente Cel. Richardo qui in perscrutandis generibus vestigia Jussiaei insistit.

Character naturalis.

CAL. Glumae paleaceae, infimae vacuae, superiores flosculiferae, univalves, inferiores bre. viores, mucronatae.

COR. nulla.

STAM. Filamentum unicum, duo vel tria.

PIS. Germen minutum. Stylus indivisus vel bifidus, inferne persistens, basi latitudine apicis geminis. Stigmata longa.

SEM. obovatum vel lenticulare, convexiusculum, basi acutum, apice obtusum, ut plurimum transversim undulato - rugosum, apice coronatum rostro parte styli inferiore persistente et cum semine decidente, conico vel subulato, compresso.

I14. Machafrina. Paleae laxe imbricatae. Cal. bivalvis. Corolla o. Setae basi seminis.

restioides. 1. MACHAERINA spicis oblongis, stylo tripartito, culmo ancipiti.

Schoenus restioides; culmo foliisque inferne compresso-ancipitibus glaberrimis, floribus paniculatis, vaginis apice lanceolatis. Swartz. prodr. :9.' fl. ind. occ. ז. p. 104.

Habitat in Montserrat. Dn. Ryan.

Culmus erectus, simplicissimus, compressus, anceps; apice triqueter, articulatus. Folia radicalia plura, culmo dimidio altiora, pollicem lata, enervia, glabra, margine ferrugineo, facie foliorum Iridis germanicae, basi equitantia; unicum praeter floralia superne in culmo. Pedunculi corymboso-paniculati, plures e vagina spathacea, alterni, ancipites, semel vel bis 
ramosi, vaginulis undique ad divisuras. Spiculae apice ramulorum, oblongae, pauciflorae. Squamae ovato-lanceolatae. Semen triquetrum. Flores polygami. Setae pistillo adsidentes. Filament. 2. 3. Swartz. l. c.

II5. Melancranis. Squamae paleaceae, undique imbricatae. Spicula sub singula squama multiflora disticha. Stylus 2 - fidus.

3. MELANCRANIS capitulo oblongo, involucro scariosa. subtriphyllo.

Schoenus scariosus; culmo tereti, capitulo oblongo, involucro monophyllo, glumis margine scariosis. Thunb. prodr. í

Habitat in Cap. b. spei. Stadtmann. 4

Culmi saespitosi, pedales vel minores, sub capitulo angulati, filiformes. Folia culmo breviora, setacea, canaliculata, basi in vaginam dilatata. Capitulum terminale, semipollicare, oblongum, imbricatum squamis ovatis, latis, in aristam attenuatis, membranaceis, rigidiusculis, laevibus, nitidis, apice patulis: tres inferiores steriles, acuminatae in foliolum setaceum infimae tripollicare. Spicula sub singula squama, quinqueflora; reliqua ut in sequente.

2. MELANCRANIS capitulo subgloboso, involucris radiata. polyphyllis.

Habitat in Cap. b. spei. 4

Culmus pedalis et ultra. Involucri foliola sexocto, unicum semipollicare, reliqua sensim minora, patentissima, subulata, rigida, subpungentia. Capitulum magnitudine cerasi. Spicae numerosissimae, glomeratae, ovatae: squamae purpureo striatae et punctatae. Folia non vidi.

Habitus. Culmi enodes, rigidi, apice trigoni, subtilissime striati. Capitulum terminale.

Character naturalis.

SPICAE undique imbricatae. Squamis ovatis, mucronatis. Spicula sub singula squama ejusque longitudinis, septemflora, oblonga, compressa, disticha.

CAL. bivalvis: valvulae glumis corollinis brevio. res et angustiores. 


\section{TRIANDRIA. MONOGYNIA.}

COR. uniglumis: Glumae lanceolatae, confertim purpureo-punctatae.

STAM. Filamenta tria, linearia, longitudine squamarum, albida, purpureo-punctata. Antherae lineares.

PIST. Germen oblongum. Stylus unicus, glaber, bifidus. Stigmata simplicia.

SEM. unicum. Setae mullae.

16. Dichromena. Squamae undique imbricatae. Cor. c. Styl. 2 -fidus. Sem. sublenticu. lare, transversim undulato-rugulosum obtuse acuminatum. Setae nullae.

leucocephala. I. DICHROMENA glabra, involucris basi utrinque coloratis.

Gramen cyperoides spica compacta alba, foliis ad spicam partim albis, partim viridibus. Sloan. cat. 36 . hist. г. p. I I 9. t. 7 \%. f. г.

Schoenus stellatus; culmo triquetro basi folioso, capitulo glomerato parvo, involucro stellato colorato pentaphyllo. Lamarck. dict. I. p. 74 I. Illustr. 1. p. I 36 .

Schoenus stellatus; culmo subtriquetro; spiculis conglomeratis, involucro foliaceo, basi colorato. Swartz. prodr. 19. fl. ind. occid. I. p. 102 .

Dichromena leucocephala ; erecta, glabella: in = volucro inferne capituloque candidis. Mich. fl. bor amer. r. p. 37.

Habitat in Caribaeis. von Rohr, in Carolina. Bosc.

Tota glabra. Culmus saepe pedalis vel parum ultra, apice obtuse vel acute angulatus. Folia culmo interdum longiora, interdum brevio$\dot{r} a$, superne margine scabriuscula. Involucri foliola quinque-sex; longius quadri-quinque pollicare, lineare, attenuatum. Spiculae niveae. Semen subrotundum, compressiusculum, magnum. Swartz. $l$. c.

ciliata. 2. DICHROMENA pilosa, involucris supra basin coloratis.

Gramen quarta species. Margr. hist. I. fide her. barii Marcgravii.

Habitat in America meridionali. Richard. Puertorico. West. 
Culmi pedales vel ultra, filiformes, apice acuts vel obtuse angulati, pilosi, interdum glabri excepto apice. Folia culmo breviora, carinata, margine hirsutissima, aetate glabriora: vaginae hirsutissimae. Involucra basi extus mar. gineque pilosa, hexaphylla, supra basin versus albido-flavescentia; foliolum longius tripollicare. Spiculae quinque-sex glabrae albidae. Semen transversim tenuiter undulatum, basi purpurascens, acumine nigro.

3. DICHROMENA glabra, involucris undique con- nervosa. coloribus multinerviis.

Habitat in America meridionali. v. Rohr.

Culmi semipedales, filiformes, obtuse angulati. Folia culmo longiora, angusta. Involucrum pentaphyllum; longius quinque-sexpollicare. Spiculae tres-quinque: squamae e punctis numerosissimis purpureis albido-purpurascentes.

Dignoscitur involucris decem duodecimnerviis, quae in reliquis tantum striata sunt.

4. DICHROMENA foliis involucrisque undique pubera conculorihus ciliatis, spiculis pubescentibus.

Habitat in America meridionali. Richard, in insula Trinitatis. v. Rohr.

Culmi spithamaei vel semipedales, setacei, interdum parum crassiores, obtuse angulati. Folia altitudine culmi vel breviora, plana: vaginae glabrae. Involucrum tri-tetraphyllum; longius bipoliicare. Spiculae tres-quinque in singulo capitulo: squamae pubescentes, ciliatae, albidae, purpureo punctatae. Semen transversim profunde undulato-striatum.

5. DICHROMENA glabra, involucris undique repens concoloribus, culmo repente.

Scirpus reptans; humilis, reptans, stoloniferus: foliis serrulatis glabris: involucro subtriphyllo, breviusculo: capitulo terminali e pluribus spicis sessilibus. Act. soc. h. n. par. 1. p. 126.

Habitat in Guiana. Richard, 2

Radices trigoni, filiformes, articulati, ad genicula radicantes; articulis bipollicaribus. Culmi erecti, tripollicares, solitarii, filiformes. Folia ad genicula, duo quatuor in culmo, bipollicaria vel minora, laxa, serrulata. Involu.

Tom. II. 


\section{TRIANDRIA. MONOGYNIA.}

crum triphyllum: longius pollicare vel bre. vius. Spicae duae-tres in capitulo, oblongie, niveae: squamae lanceolatae. Semina lenticulari-subglobosa, margine parum crassiore cincta, flavescentia. Stamen unicum. Richard. . Haec sola culmo repente gaudet, reliquae erecto.

Habitus. Facies Kyllingae. Culmi plures, enodes, apice trigoni, striati, inferne vaginis foliorum tecti. Folia plura, linearia: vaginae integrae, uti folia subtilissime striatae. Involucrum patentissimum: foliola structura foliorum, unicum capitulo brevius, reliqua sensim longiora. Spiculae in capitulo sessiles, oblongae: squamae membranaceae, hyalinae, subcarinatae, acutae, albidae.

Character naturalis.

CAL. Spica undique imbricata: Squamis ovato. lanceolatis, concavis, flores distinguentibus.

COR. nulla.

STAM. Filamenta tria, rarissime unicum, de. mum elongata. Antherae lineares.

PIST. Germen minutum. Stylus capillaris, elongatus, basi dilatatus, compressus. Stigmata dus, capillaria, longitudine styli.

PER. nullum.

SEM. unicum, sublenticulare, transversim undulato-rugulosum, apice basi styli persistente acu. minatum; acumine obtuso. Setae nullae.

II7. Scirpus. Squamae paleaceae, undique imbricatae. Cor. o. Sem. imberbe, triquetrum.

* Culmo monostachyo.

pygmaeus. I. SCIRPUS spica oblonga subbiflora, culmis subangulatis setiformibus.

Scirpus pygmaeus; culmo setiformi nudo subangulato, spica terminali nuda subuniflora. Lamarck. illustr. 1. $p$. 139 .

Habitat in India orientali. Ex herbario Lamarck. Culmi vix longitudine digiti minimi. Vaginae purpureae. Spicae squamae calycinae lanceolatae, purpureae, margine scariosae.

crespitosus. 2. SCIRPUS squamis infimis spicam aequantibus, culmis teretibus, vaginis aristatis, radicibus squamula interstinctis. 
Gramen junceum cum foliis et spica junci minus. Bauh. theatr. 79 .

Juncus parvus montanus cum parvis capitulis luteis. Bauh. hist. 2. p. 52.3 .

Scirpus montanus, capitulo breviore. Scheuchz. gram. $363 \cdot t .7 \cdot f$. 18 .

Scirpus caespitosus; culmo striato nudo, spica bivalvi terminali longitudine calycis, radicibus squamula interstinctis. Lin. syst. veg. 100. Pollich. pal. n. 44 .

Habitat in Europae paludibus caespitosis sylvaticis. 4

Culmi copiosissimi, digitales vel altiores. Vaginae oblique truncatae; interstinctae squamis plurimis, ovato-lanceolatis, membranaceis, nervosis, pallide fuscis. Spica parva, pauciflora, rufa. Squamae duae infimae longitudine spicae. Semen et Setae minutae.

3. SCIRPUS squamis duabus infimis subaequalibus pumilus. spica brevioribus, culmis tetragonis setaceis, vaginis aristatis.

Habitat in Helvetia. Colsmann. 4

Radix fibrosa. Culmi bipollicares. Vaginae in aristam semiunguicularem subfoliaceam desinentes, squamis non interstinctae. Spica tri-quadriflora obtusa: squamae ovatae, acutae, nitidae. Stylus basi aequalis. Semen obovatum, obtuse trigonum, laeve. Setae nullae.

4. SCIRPUS spica lineari, squamis subaequalibus campestrif. spicam subaequantibus, culmis teretibus setaceis, vaginis muticis.

Scirpus minimus spica breviore spadicea. Scheuchz. gram. $364 . t$. 7 . f. 19.

Scirpus campestris; culmo striato nudo, spica terminali calycem bivalvem vix superante, glumis calycinis oblongis apice membranaceis obtusis subaequalibus. Roth. catalect. 1. p. 5 .

Habitat in Ducatu Oldenburgensi et Bremensi. 4 Radix subbulbosa, stolonifera. Culmi duo ad quatuor, saepe solitarii, unciales-biunciales, nonnunquam incurvi. Vagina infima rubicunda, sequens viridis, obtusa, fere truncata. Spica plerumque tres lineas longa, subquadriflora; florifera linearis; fructifera oblonga. Squa- 


\section{TRIANDRIA. MONOGYNIA.}

mae ovato-oblongae, concavae, atropurpureae, margine apiceque albo-flavescentes. Stylus trifidus. Setae ad basin germinis. Roth. $l$. c.

A Scirpo caespitoso differt: fibris radicum rufis, nec albis: culmis tenuioribus, paucioribus, absque squamis inter vaginas; nec densissimis, caespitosis: vaginis apice truncatis, muticis; nec folii rudimento terminatis: spica duplo fere angustiore et longiore: squamis plerumque aequalibus, duplo longioribus, atropurpureis, flavo marginatis, apice nudis; nec semper inaequalibus, unicoloribus, dilute brunneis, rudimento folii viridi apice acutis.

A Scirpo Baeothryon dignoscitur: culmis brevioribus: spica florifera lineari, fructifera oblonga; nec florifera oblonga, fructifera ovata et quasi bifida: squamis calycinis plerumque aequalibus, duplo vel triplo longioribus, spicam adaequantibus; nec inaequalibus, altera longiore, spica tamen duplo breviore: floscu-. lis paucioribus, tribus-quatuor; nec plerumque sex aut pluribus. Roth. l. c.

Bacothryon. 5. SCIRPUS spica bivalvi, squamis inaequalibus ovatis obtusiusculis altera majore spica duplo breviore, culmis teretibus.

Scirpus minimus, capitulo squamoso breviore et crassiore fusco. Scheuchz. gram. 360. $t$ ' $^{\circ} 7$. f. 2 I.

Scirpus caule tereti, spica nuda pauciflora, glumis calycinis longiore. Hall. hist. n. 1335 .

Scirpus pauciflorus; culmo striato nudo, spica terminali pauciflora valvis calycinis longiore. Lightf. fl. scot. Iо78.

Scirpus Baeothryon; culmo tereti striato nudo basi vaginato, vagina truncata, spica terminali pauciflora bivalvi, valvulis ovatis spica brevioribus margine scariosis, exteriori breviori. Lin. suppl. 1о3. Roth. germ. 1, p. 21. 2. p. 54 .

Scirpus Halleri; foliis teretibus, culmi vagina truncata, spica terminali triflora, seminibus villis paucis circumvallatis. Villars. Delph. 2. p. Is8. 


\section{TRIANDRIA. MONOGYNIA.}

Scirpus Bacothryon; culmo striato nudo, spica bivalvi, glumis calycinis inaequalihus ovatis obtusiusculis membranaceis; altera majore spica dupio breviore. Roth. catalect. 2. p. .

Habitat in turfosis Sueciae, Daniae, Germaniae, Galliae, Angliae. 4

Culmi plures digitales vel parum ultra. Squamae nullae ad vaginas. Spica parva, subsexflora, fusca: squamae margine membranaceae. Stylus basi incrassatus. Semen oblongum, acute trigonum, apice e basi styli persistente acumine nigro terminatum. Setae paucae, longitudine seminis.

Nomen triviale Baeothryon retinui, cum magis adoptatum est quam pauciflorus.

6. SCIRPUS spica ovata, squamis duabus infimis acicularis majoribus, culmis tetragonis setaceis, vaginis muticis.

Juncus inutilis sive chamaeschoenus. Bauh. theatr. 133.

Juncellus minimus, capitulis equiseti. Plukn. alm. 20 r. t. $40 . f .7$.

Scirpus acicularis; culmo tereti nudo setiformi, spica uvata bivalvi, seminibus nudis. Lin. syst. veg. 100. Fl. dan. 287. Pollich. pul. n. 45.

Habitat in Europa sub aquis purioribus 4

Culmi bi-tripollicares, arcte vaginati. Spica lineam longa, interdum minor, quinque-sexflora, acuta, fusca. Squamae duae irfimae saepe longitudine spicae, interdum rimidio-breviores, ovatae, acutae. Semen obovatum, apice tuberculatum. Setae nullae.

7. SCIRPUS spica ovato-oblonga, culmis angula- cernuus. tis capillaribus, vaginis mucronatis.

Habitat in Lusitania. Rathke. 4

Radix fibrosa. Culmi copiosissimi, caespitosi, pollicares-sesquipollicares, Vaginae culmo triplo breviores, in mucronem desinentes, squarnis non interstinctae. Spica parum ultra lineam longa, multiflora, obtusa, imbricata. Squamae ovatae, duae infimae coeteris parum majores, acutae; reliquae obtusae, atropurpureae, dorso linea viridi, substriatae. Semen obovatum. Setae nullae. 


\section{TRIANDRIA. MONOGYNIA.}

fluitans. 8. SCIRPUS spica oblonga squamas duas infimas aequante, culmis teretibus ramosis foliosis flaccidis.

Juncellus capitulis equiseti fluitans. Bauh. theatr. 187.

Gramen junceum clavatum minimum. Plukn. alm. r80. t. $35 . f$. r.

Scirpus equiseti capitulo minori. Scheuchz. gram. $3^{4} 5 \cdot t$. ? $\cdot f \cdot 20$.

Scirpus fluitans; culmis teretibus nudis alternis, caule folioso flaccido. Lin. syst. veg. 100. Fl. dan. t. 1082. Roth. germ. I. p. 22. 2. p. 55 .

- tolonifor. f. Scirpus stolonifer; culmo canaliculato basi folioso, spica terminali bivalvi subbiflora. Roth. in Ust. ann. nov. 4. p. 36.

Habitat in Daniae, Germaniae, Angliae, Galliae udis. 4

Culmi longissimi, fluitantes, ad genicula radicantes. Folia pollicaria vel bipollicaria, in fasciculos alternos collecta, ad genicula solitaria. Pedunculi superne versus, solitarii, bi-tripollicares. Spica parva. Squamae oblongae, obtusae. Stylus bifidus. Semen obovatum. Setae nullae.

pusillus 9. SCIPiPUS spica oblonga acuta, squamís linearioblongis obtusis, culmis angulatis capillaribus.

Scirpus capillaris; perpusillus: cuImis foliisque omnium tenuissime capillaceis, flaccidis: spica oblongo-ovoidea, acuta, imbricata; squamis paucis, oblongis, castaneis. Mish. fl. bor. amer. p. 30 .

Habitat in nova Anglia. Richard.

Omnium tenuissimus. Culmi palmares, angulati. Folia radicalia culmis parum breviora vel longiora, teretia. Spica minima. Squamae fuscae, margine tenui membranaceo, ovatae, acutae. Semen acute trigonum. Setae plures, albidae.

multicaulis. ro. SCIRPUS spica oblongo-ovata, culmis teretibus, vaginis muticis, radice fibrosa.

Scirpus equiseti capitulis crassioribus et habitioribus pumilus et multicaulis. Rupp. jen. 3 I go

Scirpus palustris. Lin. fl. lapp. n. 19. f.

Scirpus acicularis. Flor. dan. 167 . 
Scirpus multicaulis; culmo tereti basi vaginato, spica ovata terminali, glumis obtusis aequalibus, radice fibrosa. Smith. fl, angl. I. p. 48. Habitat in paludibus turfosis Daniae et Angliae. 4

Radix fibrosa. Culmi numerosi, palmares vel spithamaei. Vaginae arctae, rufae, saepius duplicatae, squamis non interstinctae. Spica fusco-ferruginea, multiflora. Squamae ovatae, obtusae, apice membranaceae. Smith. $l$. $c$. Flosculorum unus vel alter ad basin spicae, saepe viriparus et divaricatus evadit. Smith. $l . c$.

Scirpus intermedius. Thuill. fl. par. p. 21. huc forte spectat.

11. SCIRPUS spica ovali, squamis lanceolatis acu- palustris. tis, culmis teretibus, vaginis muticis lanceolatis acutis, radice repente.

Juncus palustris, capitulo equiseti major. Lobel. ic. 86 .

Juncus equiseti capitulis. Bauh. theatr. 186. Scirpus equiseti capitulo majore. Scheuchz. gram. 360. Lin. fl. lapp. 19.

Scirpus palustris culmo tereti nudo, spica subovata terminali. Lin. syst. veg. 100. Fl. dan. $t$. 273. Pollich. pal. n. 43. Leers fl. herb. n. 34. t. . . $f$. 3 .

6. Juncus capitulis equiseti longior. Moris. hist. 3. p. 233 . s. 8. t. 10. f. 33 .

Scirpus equiseti capitulo majori alter. Sckeuchz. gram. $3^{6} \mathrm{r} . t .7 \cdot f_{\text {. }}{ }_{7}$.

Scirpus reptans; radice reptante: culmis cespitosis, plurimis sterilibus, recurvatis, spica oblonga : squamis lanceolatis acutissimis. Thuill. fl. par. 22 .

Habitat in Europae fossis et inundatis. 4

Culmi copiosi, pedales - bipedales, arcte vaginati. Spica unguicularis, multiflora. "Squamae duae, infimae subrotundae, reliquae lanceolatae, $f u$ scae, margine albido-membranaceae.

Scirpus reptans Thuillieri vix nisi culmis recurvatis a palustri differt.

Setae quatuor ad basin germinis. Leers.

12. SCIRPUS spica oblonga acuta, seminibus or- maculosus. biculo coronatis, culmis filiformibus angulatis ferrugineo maculatis, vaginis muticis. 
Habitat in Guadeloupe. Richard.

Culmi pedales et ultra, trisulcati. Vagina loco foliorum singulum culmum arcte vestiens, sesquipollicaris, sulcata, purpurascens, apice membranacea. Spica vix semiunguicularis. Squamae oblongae, convexae, obtusae, vix carinatae, castaneae, margine tuberculo orbiculato plano membranaceae. Semen obovatum, compressiusculum, apice e basi styli persistente coronatum latitudine apicis, laeve, nigrum. Sétae plures, albidae.

mberculosus.13. SCIPPUS spica ovata acuta, squamis subrotundis, seminibus tuberculo ovato coronatis, culmis teretibus.

Scirpus tuberculosus; aphyllus, erectus: spica - turgide ovata, subacuta: squamis subrotundis, obtusis: semine setis ipso longioribus stipato et tuberculo crassiore terminato. Mich. fl. bor. amer. 1. p. 30.

Habitat in Carolina inferiore Richard. 4

Culmi pedales, graciles. Vaginae oblique truncatae, acumine brevissimo ovato acuto terminatae. Spica magnitudine pisi: squamae latae, apice carinatae, sordide flavescentes, margine parum rufescentes. 'Setae sex ad basin seminis eoque parum longiores. Semen subglobosum, oculo armato striatum, strïs transversim lineatis, flavescens, terminatum tuberculo semine ipso parum latiore et longiore, compresso.

fliformis. 14. SCIRPUS spica cylindrica oblonga obtusa, squamis subrotundis seminibus vertice nudis, culmis filiformibus teretibus.

Scirpus filiformis; culmo filiformi subangulato nudo, spica terminali ovata, squamis obtusis. Lamarck. illustr. s. p. 138 .

Habitat in Carolina inferiore. Lamarck.

Culmi pedales. Folia nulla. Spica semiunguicularis, dense imbricata. Squamae fuscae, margine membranaceae. Semen flavum, obovatum, trigonum, ope lentis rugosum apice obtusum. Setae nullae.

polythrichio- I5. SCIRPUS spica oblonga subnutante, squamis ides. ovatis carinatis mucronatis, culmis subcompressis. 
Gramen polytrichum. Rumph. amb. 6. p. I . $t$. ?. $f$ i.

Scirpus polytrichioides; culmis compressis setaceis, spicis terminalibus solitariis subnutantibus monandris. Retz. obs. 4. p. Ir.

Habitat in pascuis depressis subudis Zeylonae. König.

Facics Sc. cespitosi. Culmi digitales vel palmares, basi vaginis oblique truncatis vestiti. Folia potius culmi steriles. Squamae duăe infimae majores, spicula dimidio breviores. Stylus bifidus. Semen obovatum, subtrigonum. Setae mullae.

6. SCIRPUS aphyllus, spica ovato-oblonga erecta, squamis ovatis laevibus, floribus monanatropurpiito rells. dris, culmis setaceis teretiusculis.

Scirpus atropurpureus; culmis setaceis teretibus fasciculatis, spicis terminalibus oratis solitariis, floribus monandris. Retz. obs. 5. $p$. I 4 .

Habitat in uliginosis Indiae orientalis. König.

Culmi numerosi, aggregati, longitudine digiti minimi, stricti, basi vaginis fusco-purpureis vestiti. Spica parva, obtusa, tempore pluvioso praesertim atropurpurea. Squamae acutiusculae, minime striatae, dorso virides. Semen obovatum, nigrum, nitidum. Setae nullae.

37. SCIRPUS spica ovata, squamis oblongis, flo- ovatus.

ribus subdiandris, culmis subcompressis, vaginis muticis.

Juncus clavatus (medius) minor capitulis rotundiuribus. Moris. hist. 3. p. 233. s. 8. t. 10. f. 34 .

Scirpus capitatus. Screb. spec. p. 60.

Scirpus compressus; radice fibrosa non repente, culmo nudo caespitoso subcompresso erecto setiforni, spiculis terminalibus solitariis su\}globosis nudis, staminibus duobus tribusve, stylo bifido. Moench. meth. 394 .

Scirpus ovatus; culmo subcompresso nudo filiformi, spica ovata terminali, floribus diandris. Poth. catalect r. p. 5 .

Scirpus annuus; confertissime multicaulis, erec. tus, aphyllus: spica turgida orata, obtusa, compacta, fusco-feruginea; squamis parvulis ovalibus obtusis. Tfuill. ft. par. $=2$. 


\section{TRIANDRIA. MONOGYNIA.}

Habitat in Germaniae et Galliae humidis. 4

Radix fibrosa. Culmi palmares et ultra. Spica magnitudine seminis coriandri vel parum major: squamae fuscae, dorso virescentes, apice margine membranaceae. Stylus bifidus. Semen pyriforme, compressiusculum, apice tuberculo ovato nigro terminatum, flavum, nitidum. Setae nonnullae, semine longiores.

Scirpus annuus Thuillierii vix differt. - Specimina a Cel. Richardio mecum communicata non diversa sunt $a b$ illis ex germania missis, nisi quod omnibus partibus robustiora sunt. An Thuillierii revera annua?

sapitatus. 18. SCIRPUS spica subglobosa, culmis sulcatoangulatis setaceis, vaginis muticis, spica sub- . globosa.

Juncus aquaticus capitulis equiseti minimis. Sloan. hist. 1. p. 122.

Scirpus culmo setaceo nudo, spica subglobosa. Gron. virg. I 2.

Scirpus capitatus culmo tereti nudo setiformi, spica subglobosa terminali. Lin. syst. veg. 1०॰.

Scirpus minimus nudus, capitulo stricto ovato, radice fibrosa. Brown. jam. 1 26. n. 3.

Scirpus caribaeus; culmis fasciculatis, setaceis, sulcatis, triquetris; spica minima, ovata, terminali. Rottb. granz. 46. t. I 5. $f$. 3 .

Habitat in Virginia, Caribaeis inque India orientali.

Culmi basi vaginati, pallide virides; vagina truncata, in aristam desinens. Folia nulla, nisi Culmi steriles. Spica parva, vix magnitudine seminis coriandri. Sqamae oblongae, obtusae, concavae, apice carinatae, testaceae vel ferrugineae, dorso pallidae. Semen pyriforme compressiusculum, nigrum, nitidum, apice tuberculo albido. Setae purpureae.

Rottböllii vix a Linnaei diversus, nisi quod junior, tenellus, squamae duae inferiores longitudine capituli oblongi, aetate breviores.

geniculutus. Ig. SCIRPUS spica ovato-oblonga, squamis ovatosubrotundis, culmis teretibus approximate interstinctis. 
Juncus aquaticus geniculatus, capitulis equiseti major. Sloan. catal. 37. hist. 1. p. 121. t. 83. f. 3 .

Scirpus culmo rotundo nudo, spica stricta oblonga terminali. Brown. jam. 126. n. 5 .

Scirpus geniculatus; culmo tereti nudo, spica oblonga terminali. Lin. syst.veg. 100. Rottb. gram. $4^{\text {s. }}$

ค. Spica subglobosa.

Juncus aquaticus geniculatus, capitulis equiseti, minor. Sloan. cat. 37. hist. 1., p. 122 . t. 7 ? f. :.

Scirpus culmo nudo, spica terminali subrotunda. Lin. hort. cliff. $2 \mathrm{r}$.

Habitat in Jamaica.

Culmi sesquipedales, vix crassitie pennae anserinae. Spica semipollicaris, penna anserina parum crassior, obtusa. Squamae numerosissimae, parvae, dorso linea exaratae, fuscae, margine albidae. Stylus bifidus. Semen pyriforme, compressiusculum, apice tuberculo plano albido coronatum, nigrum, nitidum. Setae plures, purpureae, semine longiores.

An $\beta$ distincta species? mihi non visus.

2c. SCIRPUS squamis subrotundis laevibus, cul-inerstinctus. mis teretibus superne approximate interstincţis.

Habitat in Caribaeis. Martfelt.

Similis praecedenti, at: istlmi superne approximati, nec remotissimi: squamae non carinatae.

Culmus flavescens. Spica bipollicaris, obtusa. Squamae prope marginem linea fusca cinctae cum macula in apice; margo ipse membranaceus. Stylus trifidus, ut in antecedente basi incrassatus.

21. SCIRPUS spica cylindrica, squamis subrotun-plantagineus. dis carinatis, culmis teretibus remote interstinctis.

Scirpus plantaginoides; culmis ventricosis, sulcatis, nudis: spica cylindrico-subulata, terminali; flosculis carinatis. Rottb. gram. 45. $t$. I 5., $f$. 2 .

Scirpus plantagineus; culmis teretibus geniculatis nudis, spica terminali cylindrica nuda. Retz. ols. 5. p. it.

Habitat in India orientalt. König. 


\section{TRIANDRIA. MONOGYNIA.}

Gulmi bi-tripedales, crassitie pennae cygnieae, siccitate coilabentes; basi vaginis longis, membranaceis, vestiti. Spica sesquipollicaris, acutiuscula. Squamae margine fuscae. Stylus trifidus. Germen setis purpureis cinctum.

Junioris culmi superne uti squamae versus apicem pilis rarioribus adspersi.

An huc pertinet Cyperus dulcis. Rumph. amb. 6. p. 7. t. 3. f. 1. uti et Hippuris indica, Lour. fl. Cochinch.?

spiralis. 22. SCIPPUS spica cylindrica, squamis spiralibus cunciformibus truncatis, culmis triquetris.

Scirpus spiralis; culmis aggregatis subnudis triquetris, spica cylindrica terminali, flosculis cuneiformibus truncatis spiraliter dispositis. Pottb. gram. 45.t. I5. f. I.

Habitat in India orientali König.

Radix fibrosa. Culmi plures, sesquipedales, triquetri, inferne vaginis membranaceis vestiti. Spica pollicaris, obtusa: squamae flavescentes, prope marginem linea subfusca cinctae, minime carinatae.

mutatus. 23. SCIRPUS squamis obovatis, culmis triquetris. Scirpus culmo triquetro nudo, spica oblonga stricta terminali. Brown. jam. I26. n. 4.

Scirpus mutatus; culmo triquetro nudo, spica cylindrica terminali. Lin. amoen. acad. 5. $p$. 39 I. syst. veg. 100.

Habitat in Jamaica.

Parum differt a S. spirali: Culmus crassior; spica longior, bipollicaris.

quadrangu- 24. SCIRPUS spica cylindrica, squamis oblongolatus. subrotundis, culmis tetragonis.

Scirpus quadrangulatus; aphyllus; culmis stricte erectis, acute quadrangulatis : spica longo-cylindrica; squamis rotundato-obtusis. Mich. fl. bor amer. ז. p. 30.

Habitat in Carolina. Richard.

Facies antecedentium. Culmi basi vaginati. Spica sesquipoliicaris, acutiuscuia: squamae flavescentes, prope marginem linea subfusca cinctae. Stamina, pistilla, semina, setae ut in quatuor antecedentibus. 
** Culmo polystachyo.

† Spicis lateralibus.

25. SCIRPUS spicis ovatis acutis subsolitariis, cul-minimu. mis foliisquc capillaribus curvatis.

Gramen junceum perpusillum, capillaceis foliis, aethiopicum. Plukn. alm. 179. t. 300. f. 5 .

Juncellus perpusillus, aethiopicus, capillaceus, capitulis, ut plurimum ternis, sessilibus. Moris. hist. 3. s. 8. p. 233 .

Cyperus culmo tereti spicas infra apicem ferente. Lin. hort. cliff. 2 I.?

Cyperus minimus; culmo tereti nudo, spicis sub apice. Lin. syst. veg. 98.?

Scirpus setaceus. Rottb. gram. 47.t. 15.f. 4 .

Habitat in America, Africa. Specimen meum a Dn. von Rohr ex America boreali habui.

Facies Sc. acicularis, at spicula infra apicem. Culmi bipollicares vel minores, omnium tenuissinil, trigoni, monophylli. Folia culmo parum breviora et angustiora, plerumque recurva. Spicae solitariae vel geminae, minutae, pauciflorae: squamae ovatae, carinatae, fuscae, carina virides, infima attenuata, longitudine fere spicae.

Quos vidi exacte conveniunt cum figura Pluknetii et descriptione Morisonii. Spicas nunquam pedicellatas vidi, sed semper sessiles.

26. SCIRPUS spicis subgeminis ovatis obtusis, cul- setaceus. mo foliisque setaceis strictis, seminibus longitudinaliter striatis.

Juncellus omnium minimus. Lob. adv. 44. Moris. hist. 3. p. 232 . s. 8. t. 10. f. 23.

Gramen junceum minimum, capite squamoso. Bauh. prodr: 13.

Scirpus omnium minimus, capitulo breviori. Scheuchz. gram. 359.

Scirpus culmo nudo setaceo, spicis lateralibus subsolitariis sessilibus. Lin. it. scan. $22 \%$.

Scirpus setaceus; culmo nudo setaceo, spica terminali sessili. Lin. syst. veg. 101 . Fl. dan. t. 3r. Rottb. gram. 47.t. 15.f. 5. 6. Leers fl. herb. n. 35. t. 1. f. 6 .

Mariscus setaceus, capitulis lateralibus perpaucis. Hall. hist. $n .13+5$. 


\section{TRIANDRIA. MONOGYNIA.}

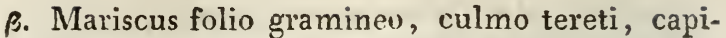
tulis lateralibus ternis. Hall. hist. n. 1344.

Habitat passim in Europa, praesertim in arenosis maritimis. 4

Culmi caespitosi pollicares-quadripollicares, teretes. Folium unicum breve, ex apice vaginae, supra planiusculum, stria longitudinaliter exaratum: Vagina basi purpurascens. Involucrum nullum nisi apex culmi. Spicae plerumque duae interdum tres - quatuor, interdum solitariae: squamae subrotundo-ovatae sensim deciduae, fuscae, carina viridi brevissima terminatae. Stylus trifidus. Setae nullae.

ß. Non videtur differre nisi magnitudine. Culmos in siccis speciminibus saepe trigonos inveni.

numidianus. 27. SCIRPUS spicis subglobosis subsolitariis, squamis subrotundis, culmis setaceis, vaginis aristatis, seminibus laevibus.

Habitat in Numidia. Lamarck.

Similis antecedenti: squamae fere ut in illo, at rotundiores. Culmi fere pedales, teretes, vaginarum arista unguicularis. Spicae solitariae vel geminae. Semen subglobosum, albidum. Setae mullae.

natars. 28. SCIRPUS spicis duabus, culmo compresso folioso flexuoso erecto. Thunb. prodr. 17 .

Habitat in Cap. b. spei.

micranthus. 29. SCIRPUS spicis ovatis acutis ternis aphyllis, squamis oblongis, culmo foliisque setaceis.

Habitat in America meridionali? Richard.

Culmi digitales, teretes, monophylli. Folium unicum, culmo brevius. Involucrum nullum praeter apicem culmi. Spicae parvae, spatio semipollicari infra apicem, fuscae: squamae oblongae, acutae, sensim deciduae. Semen oblongum, compressiusculum, laeve. Setae nullae.

Squamu infima spicae unius setaceo-acuminata, at decidua uti reliquae, sic involucrum nullum, in reliquis vero acumen deest.

rristachyos, 30. SCIRPUS spicis oblongis subternis, squamis integris ovatis, involucro diphyllo, culmo setaceo. 
Gramen pusillum junci capitulis minimis, ad basin foliolis binis acutis. Burm. zeyl. 109. $t$. 47. f. 2 .

Scirpus culmo teretiusculo seminudo; spicis capitatis sessilibus; involucro diphyllo setaceo. Lin. fl. zeyl. 2.39.

Scirpus tristachyos; culmo nudo setaceo; spicis ternis, sessilibus, involucro diphyllo. Rottb. gram. 48. t. I $3 . f .4$.

Scirpus tristachyos, culmo capillari, capitulo tristachyo, glumis integris, involucro diphyllo. Thunb. prodr. 17.

Habitat in Cap. b. spei.

Culmi plures, palmares et ultra, basi vaginati. Folia plura, culmo breviora, capillaria, planiuscula: vaginae membranaceae, albidae. Involucri foliolum alterum unguiculare, erectum, e culmo continuato; alterum patens longitudine spicularum. Spicae tres-quatıor vel plures, obtusae: squamae obtusae, carinatae, striatae, fusco-ferrugineae. Semen obovatum. Setae nullae.

Non dubito quin Burmanni idem sit, cum sutum verosimile descripsit secundum specimen herbarii Hermanni, quod apud filium Laur. Burmann vidi. Hermannus enim plura herbaria paravit, nam Lugduni Batavorum aliud vidi.

3r. SCIRPUS capitulo tristachyo, glumis integris inarginatus. glabris, involucro monophyllo, culmo capillari. Thunb. prodr. I?. $f$

Habitat in Cap. b. spei.

32. SCIRPUS spicis oblongis, squamis ciliato-la- pungens. ceris emarginatis aristatis, culmo subdiphyllo trigono.

Juncus acutus maritimus, caule triangulo. Bauh. prodr. 22. Moris. hist. 3. p. 232 . s. 8. t. 10. f. 20 .

Juncus acutus maritimus, caule triquetro rigido, mucrone pungente. Plukn. alm. 200. $t$. 4०. $f$. $r$.

Scirpo-Cyperus maritimus, humilis, caule pallide virens, panicula glomerata. Mich. gen. 47 . 
Scirpus mucronatus; culmo triangulo nudo, spiculis lateralibus oblongis conglomeratis sessilibus, mucrone erecto. Roth. fl. germ. 1. $p$. 23. 2. p. 50.

Scirpus triqueter; culmo triquetro nudo, spicis ovali-oblongis subacuminatis sessilibus conglomeratis lateralibus, mucrone erecto. Roth. neue beytr. ז. p. 91.

Habitat in Europa, in insula Borboniae. Commerson. 4

Affinis certe sequenti, at in variis videtur diversus: culmi humiliores, teneriores, rigidi: folia longiora, multo angustiora, carinata, extrorsum margine scabra: vagina magis membranacea: spicae ex autoritate Rothii constanter sessiles.

Variat spicis solitariis, geminis vel ternis, interlum squama infima in acumen longitudine spicae desinente. Squamae et fructificatio ut in sequente.

mucronatus, 33. SCIPPUS aphyllus spicis oЂlongis, squamis integerrimis mucronato-acuminatis, culmo triquetro.

Juncus acutus maritimus, caule triquetro molli, spica glomerata in stylo sessili. Plukn. alm. 200.t. 40. f. 3 .

Scirpo-Cyperus panicula glomerata e spicis inbricatis composita. Scheuchz. gram. 404. t. 9. f. If.

Scirpo-Gyperus palustris, caule molli, panicula nitida, glomerata, semine nigro. Mich. gen. 4 .

Scirpus mucronatus; culmo triangulo nudo acuminato, spicis conglomeratis sessilibus. Lin. syst. veg. $10 \mathrm{I}$.

Habitat in Italia, Virginia, in Indiae orientalis paludosis. König. 4

Culmi sesquipedales, penna columbina crassiores, spongiosi, inferne lateribus planis, superne excavatis, arcte vaginati, saepe glauci. Folia nulla. Vaginae duae-tres, inferiores breviores, fuscae, interiores quinque-sexpollicares, oblique hianies, obtusae, ore membranaceae. Involucrum nullum. Spiculae spatio sesquipollicari infra apicem glomeratae, sessiles, duae- 
viginti, fere unguiculares, obtusiusculae: squamae ovatae, latae, mucronatae, mucrone brevi, minime emarginatae, substriatae, juniores virides margine ferugineo, adultiores fuscae. Fructificatio ut in S. triquetro.

Apex quandoque reflectitur, uti jam dudum monuit Scheuchzerus l. c., saepe erectus.

34. SCIRPUS spicis oblongis, culmo aequali mo. supinus. nophyllo.

Juncus maderaspatensis minor. Pet. in act. soc. lond. 282. p. 1253 . fide herbarii Vaillantii.

Scirpus supinus minimus, capitulis conglobatis, foliis rotundo teretibus. Tournef. inst. r. herb. 528 .

Scirpus supinus; culmo tereti nudo, spicis sessilibus in medio culmo glomeratis. Lin. syst. veg. Iо т. Roth. fl. germ. 2. p. 58.

Scirpus lateralis; culmis triquetris nudis, spicis subternis lateralibus, involucro monophyllo. Retz. ob. 4. p, х2. et 5. p. I6.

Schoenus junceus; culmo tereti subnudo, umbella sessili laterali. Wilden. phyt. r. p. 2. $n$ 。 o. t. i. f. 4 .

Habitat in Europa, in India orientali. König, in Guinea. Isert, in Aegypt. Desfontaines 4

Culmi plures, palmares vel pedales. Folia brevia, linearia, basi vaginantia. Involucrum monophyllum, longitudine spicularum. Spicae versus medium culmi vel altius, tres-novem, semiunguiculares, acutiusculae: squamae ovatae, acutae, carinatae, lateribus confertim purpureo punctatae, carina virides. Stamina tria. Stylus trifidus. Semina transversim undulato-rugosa, nigra. Setae nullae.

Scirpus lateralis Retzii vix specie differt, observo enim in speciminibus Sc. supini robustioribus exsiccatis culmum superne parum angulatum apparere; sed forte culinus exsiccatione collabitur et faciem angulatam acquirit; minora specimina vero, tam ex India quam e Guinea, culno tereti gaudent. Involucrum, quod vix nisi squama inferior est in aristam filiformem longitudine spicae elongata, adest quoque in Sc. supino et deest interdum in Sc. laterali. 


\section{TRIANDRIA. MONOGYNIA.}

Stylus in Sc. laterali semper trifidus et omnia reliqua ut in Sc. supino. Wildenowii Sch. junceus certe idem est ac Sc. lateralis Retzii.

articulatus. 35. SCIRPUS aphyllus spicis ovatis globoso-capitatis, culmo interstincto.

Tsieli. Rheed. mal. 1 2. p. 135. t. 7 r.

Scirpus articulatus; culmo tereti semigeniculato, capitulo glomerato laterali. Lin. spec. pl. 70. Rottb. gram. 53.

Scirpus fistulosus; culmo subulato nudo, basi vaginato, capitulo laterali. Forsk. descr. p. I4.

Habitat in Aegypti aquosis arenosis, in India orientali et occidentali. 4

Radix fibrosa. Culmi sesqui-tripedales, inter. dum crassitie pennae cygneae, fistulosi, istlımis intercepti, apicem versus sensim attenuati: vaginae laxae, oblique truncatae. Involucrum nullum. Capitulum in Indicis infra medium, in Americanis versus summitatem culmi, magnitudine nucis coryli. Spicae plúrimae: squamae lato-ovatae, acutae, striatae, ferrugineae, carina virides. Stylus bifidus., Semen trigonum, nigrum, laeve, nitidum. Setae versus apicem vix denticulatae.

Specimina ex America robustiora sunt.

nodosus. 36. SCIRPUS spicis oblongis glomeratis globosocapitatis squamis integris, involucro nullo, culmo compresso.

Scirpus nodosus; culmo-compresso, nodoso; in capitulo glomerato mucronato. Rottb. gram. 52. t. 8. f. 3 .

Habitat ad Cap. b. spei. 4

Culmus tortus, in mucronem rigidum pungentem desinens. Involucrumn nullum. Capitulum magnitudine nucis Coryli, semipollicis vel pollicis distantia infra apicem. Spicae copiosissimae, fuscae: squamae oblongae, obtusae. Stylus trifidus. Semen obovatum, compressum. Setae nullae.

vaginatus. 37. SCIRPUS capitulis alternis involucro brevioribus, culmo filiformi. Thunb. prodr. fl. cap. 17. $t$

Habitat in Cap. b. spei. 


\section{** Spicis terminalibus.}

38. SCIRPUS pilosus capitulis axillaribus termina- uncinatus, libusque pedunculatis, culmo folioso.

Gramen hirsutum indicum, glomeratis capitulis lagopi coeruleis, gluma e squamis plurimis purpurascentibus, arista unica donatis, compactili Plukn. alm. I78. t. 100. f. ?.

Scirpus uncinatus; pilosus, culmo tereti folioso, spicis in capitulum conglomeratis terminalibus axillaribusque. IVild. spec. pl. I. p. 300.

Habitat in India orientali. König.

Culmi plures, paimares, spithamaei vel parum ultra, diffusi, inferne glabri, superne pilosi. Folium unum vel alterum ex infimis altitudine culmi, reliqua sensim minora, duo tria superne in culmo, utrinque pilosa. Involucrum diphyllum, folio altero vix pollicari, capitulo longiore, aliero aequante. Capitula axillaria solitaria, pedunculata; terminalia gemina, altero sessili absque involucro, globosa, octoduodecimflora. Spicae parvae, quinque-septemflorae: squamae lancenlatae, compressae, nervosae, nervis rufescentibus, interstitizs viridibus. Stamina tria. Stylus trifidus. Semen trigonum. Setae nullae.

An Scirpus capitatus Burmanni fl. ind. 2t, huc pertinet?

39. SCIRPUS capitulo subdistachyo, glumis acu- Hystrix。 minatis squarrosis, involucro monophyllo, culmo capillari. Thunb. prodr. $17 .+$

Habitat in Cap. b. spei.

40. SCIRPUS spicis oblongis subternis, squamis squarrosus, ovatis aristatis, aristis recurvatis involucro diphyllo, culmo trigono.

Gramen'cyperoides orientale perpusillum, capi tulis subrotundis, hispidis, plerumque gemel. lis. Vanamalleecoddee malabarorum. Plukn. mant. 98.t. 3.50 . f. 6.

Gramen cyperoides Cheusanense tricephalon, globulis echinatis. Plukn. amalth. $\mathrm{i} 2$.

Motta-Pullu. Rheed. mal. г 2. p. $72 . t 0^{\circ} 3^{\circ}$.

Scirpus chinensis; culmo triquetro subnudo, spicis ternis sessilibus terminalibus, involucro diphyllo reflexo. Osbeck. it. 220. 


\section{TRIANDRIA, MONOGYNIA:}

Scirpus squarrosus; culmo triquetro nudo setaceo, spicis ternis sessilibus ovatis squarrosis. Lin. mant. 181 .

Scirpus culmo setaceo, triquetro; capitulis subternis, sessilibus, squarrosis; involucro diphyllo, stricto. Rottb. gram. 49. t. I . $f: 5$.

Habitat in India orientali.

Glaucus. Culmi plures, bipollicares-semipedales, setacei. Folia culmo breviora, setacea: vaginae fuscae. Involucri foliolum unicum bipollicare, erectius; alterum patentissimum, semipollicare. Spicae solitariae, duae-tres, interdum quatuor, sessiles, obtussissimae: squamae sensim deciduae, ferrugineae; arista longitudino ipsius squainae. Styli duo, breves. Setae nullae. Stamen uricum, rarius duo. Rottböll. $l$. c.

Facies omnino Hypaelypti, tantummodo defectu corollae et tuberculorum receptaculi distinctus.

erispicatus. 4r. SCIRPUS spicis oblongis ternis, culmo angulato aphyllo.

Scirpus trispicatus; culmo angulato nudo, spicis terminalibus ternis sessilibus nudis. Lin. suppl. ro3.

Scirpus Sparmanni. Lamarck. illustr. 1. p. 140.

Scirpus trispicatus, culmo angulato aphyllo, spicis tribus terminalibus. Thunb. prodr. 17.

Habitat in Cap. b. spei.

Culmi plures, pedales-bipedales, sulcati. Folia vix ulla nisi squamae ferrugineae radicales. Involucrum polyphyllum: foliolis subulatis brevissimis. Spicae parvae, oblongce, aequales, erectae. Lin. $l$. c.

fastigiatus. 42. SCIRPUS capitulo convexo compresso, glumis extimis mucronatis, involucro nullo, culmo filiformi. Thunb. prodr. 18. †

Habitat in Cap. b. spei.

truncatus. 43. SCIRPUS capitulo glomerato globoso, involucro diphyllo, foliis linearibus, culmo tereti. Thunb. prodr. fl. cap. 17. †

Habitat in Cap. b. spei.

daciniatus. 44. SCIRPUS capitulo triangulari, glumis ovatis ciliatis, involucro diphyllo. Thunb. prodr. 17. $t$

Habitat in Cap. b. spei. 
45. SCIRPUS capitulo angulato, glumis ovatis membranamembranaceis, involucro triphyllo. Thunb. ceus. prodr. $17 .+$

Habitat in Cap. b. spei.

46. SCIRPUS capitulo globoșo, squamis mucrona- antarcticns. tis, involucro brevi, foliis capillaribus, vaginis ore barbatis.

Juncus maderaspatensis capitatus major. Petiv. in act. Lond. n. 282, p. 1261. fide herbarii Vaillantii.

Gramen junceum parvum supinum s. holosteum strictissimis et hirsutis foliis maderaspatanum. Plukn. alm. 179. t. 299. f. 3 .

Scirpus parvus maderaspatanus, capitulo glomerato fusco. Scheuchz. gram. 3:0.

Scirpus antarcticus; culmo triquetro nudo, capitulo globoso, involucro monophyllo. Lin. mant. I 81 .

Scirpus barbatus; culmo triquetro; vaginis suboppositis; ora superiori barbatis; capitulo ter. minali, subrotundo, polystachyo. Rottb. gram. 52.t. I ?. f. 4 .

Scirpus antarcticus; culmo capillari, capitulo fasciculato rotundato, glumis glabris, involucro monophyllo. Thuinb. prodr. $1 \%$.

Habitat in Cap. b. spei, in India orientali. König, in Guinea. Isert et Thonning. 4.

Culmi copiosissimi, digitales, spithamaei vel pedales, setacei, trigoni, glabri. Folia culmo longiora vel breviora, capillaria, inferne canaliculata, exius teretia: vaginae flavae vel fusco-ferruginene, ore utringue barbatae. Involucrum mono-tetraphyllum, capitulo longius. Capitulum piso parum majus, strbrotundum. Spicae plurimae, tri-quadrifariam imbricatae, angulatae: squamae lineares, compréssae, carinatae, mucronatae, mucrone patulo, purpureae, carina viridi, margine albae, saepe ad lentem villosae. Stylus trifidus. Semen griseum, trigonum, laeve. Setąe nullac.

47. SCIRPUS capitulo globoso squamis acutis, in- coronaris. volucra tetraphyllo elongato, foliis setaceis, vaginis ore nudis.

Habitat in nemorosis prope Ischandrancona $e_{a}^{:}$ nillibi aliter observatus. König. 
Facies Kyllingae monocephalae. Culmi plures, spithamaei, filiformes, triquetri, basi bulbosi. Folia culmo multo breviora, filiformia, carinata, apice laevia. 'Involucrum subtetraphyllum, patentissimum, capitulo longius. Capitulum piso majus. Spicae plures, laxe imbricatae. Squamae lineari-lanceolatae, striatae. Stylus bifidus. Semen oblongum, trigonum, fuscum. Setae nullae.

Gramen Benghalense pulcherrimum. Spicae obovatae, niveae: squamae retusae. Stamen unicum. König.

Rarissime spica parum infra capitulum sessilis. Squamae non mucronatae ut in antecedente, nec apice patulae.

flamentosus, 48. SCIRPUS capitulo globoso, squamis ovatis, involucro diphyllo, foliis setaceis, vaginis ore nudis.

Habitat in Guinea. Thonning.

Affinis Sc, antarctico. Culmi sesquipedales vel minores, setacei, trigoni. Folia setacea, culmo breviora, canaliculata, superne margine scabra: vaginae aetate margine filamentosolacerae, minime ore barbatae, fuscae. Involucri foliolum alterum semipollicare capitulo longius, alterum brevius. Capitulum piso duplo majus. Spicae plures, trifariam imbricatae, trigonae, parvae, fusço-nigricantes, glaberrimae: squamae compressae, carinatae. Stylus trifidus. Setae nullae.

radiatus. 49. SCIRPUS capitulo hemisphaerico, involucro polyphyllo. Thunb. prodr. is. $t$

Schoenus radiatus; culmo teretiusculo, capitulo subrotundo, involucro octophyllo longissimo. Lin. suppl. 1о г.

Habitat ad Cap. b. spei. 4

Culmus palmaris, teretiusculus. Folia plura, spithamaea, radicalia, linearia, canaliculata, rigidiuscula, laevia. Capitulum magnitudine pruni. Involucrum longitudine culmi; foliola lanceolata, foliis triplo latiora, flava: foliola alia inter acervos florum, involucri similia, sed minora. Flores ex squamis parvis, lanceolatis, unifloris, omnibus e basi acervorum nec imbricatis. Stamina tria. Stylus unicus. Setae nullae. Lin. l. $c$. 
30. SCIRPUS capitulo ovato, glumis lanceolatis pilosus. ciliatis, involucro tetraphyllo. culmo compresso. Thunb. prodr. 18. +

Habitat in Cap. b. spei.

5r. SCIRPUS capitulo ovato squarroso, involucro cephalotes. triphyllo longo. Lin. spec. $p l .7_{6}$. $†$

Habitat in India.

Culmus altus, trigonus, laevis. Involucrum longissimum, tri-tetraphyllum, reflexum, margine scabrum. Lin. $l$. $c$.

52. SCIRPUS spicis cylindricis congestis, squamis Vahlii. subulatis apice patulis, involucro subpentaphyllo longissimo.

Scirpus Vahlii; culmo triquetro subnudo, spiculis oblongis fasciculato-capitatis, involucro setaceo praelongo. Lamarck. illustr. I. p. 139.

Habitat in America meridionali, nec in Hispania. Ex herbario antiquo, verosimile Loeflingii Matriti habui.

Culmi copiosi, bipollicares vel minores, capillares, compressi. Folia culmo altiora, convolutocapillaria, subtus, uti involucra e spinulis minutissimis ocilo armato videndis scaberrima. Involucrum umbella longius, erectum. Capitulum e spicis quindecim congestis compositum, interdum spica unica in culmo. Spicae semiunguiculares, acutae: squamae parvae, carinatae, virescenti-fuscae. Stamina tria. Stylus trifidus. Semina subglobosa, laevia. Setae nullae.

53. SCIRPUS spicis oblongis glomeratis globoso- inichelianu capitatis, involucro polyphyllo longo, culmo trigono.

Juncus foliatus minimus. Bauh. hist. 2, p. $5=3$. submaturo fructu Gouan.

Cyperus italicus omnium minimus. Till. pis. $5 \mathrm{r}$. t. 2 . $f .5$.

Scirpus michelianus, culmo triquetro, capitulo globoso, involucro polyphyllo longo. Lin.syst. veg. 103. Schkuhr in U/st. an, 1. p. 2c. t. 2.

Scirpus michelianus; culmo triquetro, capitulo globoso, involucro subdiphyllo, Gourn. illustr. p. 3 .

Habitat in Italia, Monspelii, Germania. $\odot$ 
Culmi plures, bipollicares vel minores. Folia culmo altiora, linearia. Involucrum subhexaphyllum, culmo longius. Gapitulum magnitudine pisi. Spicae numerosae, minutae, oblongae; foliolum basi ovatum, in aristam attenuatum ad singulam spicam, eaque interdum longius: squamae lanceolatae. Stylus trifidus, bifidus. Schkuhr.

Holoschoe- 54. SCIRPUS spicis globosis capitato-glomeratis, nus. capitulis globosis pedunculatis sessilibusve, foliis canaliculatis.

Juncus. Holoschoenus Ruell. 602.

Juncus acutus maritimus, capitulis rotundis.

Bauh. theatr. 174 .

Juncus maritimus capitulis rotundis. Plukn. alm. t. $40 . f$. 4 .

Scirpoides inaritimum, capitulis sparsis glomeratis. Scheuchz. gram. 37 r. t. $8 . f$. 2 .

Scirpus Holoschoenus; culmo tereti nudo, spicis subglobosis glomeratis pedunculatis, involucro diphyllo inaequali mucronato. Lin. syst. veg. 101. Fl. dan. t. 454. Roth. germ. I. p. 22. 2. p. $5 \mathrm{~s}$.

Scirpus Holoschoenus; culmo tereti nudo, capitulis glomeratis pedunculatis sessilibusve, involucro diphyllo inaequali, foliis canaliculatis. Snith. fl. angl. r. p. 53 .

mastraks. $\beta$. Juncus minor acutus maritimus prolifer. Plukn. almi. t. 40. f. 5 .

Scirpus australis; culno tereti nudo, capitulo laterali, bractea reflexa, 'foliis canaliculatis. Lin. syst. veg. гог.

romanus. $\gamma$. Juncus laevis, floccis orbiculatis, nigris. Caesalp. plant. 188.

Scirpoides acutum maritimum, capitulo glomerato solitario. Scheuchz. gram. 373. t. 8. f. 6 .

Scirpoides maritimum, capitulis non omnibus in pediculis insidentibus, foliis, et scapo supra paniculam, carinam ferentibus viridem. Mich. gen. 52 .

Scirpus romanus; culmo tereti nudo, capitulo laterali conglobato, bractea reflexa. Lin. spec. pl. z2. Jacqu. austr. t. 448. 
Habitat in paludosis maritimis Daniae, Germaniae, Angliae et Europae australis. 4

Radiculae descandentes, villosae. Culmi basi bulbosi, squamis lanceolatis, ferrugineis, vaginati, trigoni, medio teretes. Folia cluo-tria, culmo breviora, inaequalia, subtus convexa, supra canaliculata, albida, margine scabra, apice saepe teretia: vaginae membranaceae, aetate fuscae, margine filamentoso-lacerae. Involucrum diphyllum, alterum vix longitudine capituli, patens, alterum e culmo continuaio, variae magnitudinis, supra canaliculatum, albidum, margine scabrum, subtus convexum. Capitula piso parum majora, umbellata vel solitaria, sessilia: radii quatuor-sex, compressi. Spicae numerosae, compactae, subglobosae; squamae duae exteriores longitudine fere spiculae, fuscae, obliquae aetate; onnes oblongae, obtusissimae, concarae. Stamina tria. Stylus trifidus. Semen altero latere planiusculum. Setae nullae.

Sc. Holoschoenum, australem et romanum jure conjunxit Smith; in Sc. Holoschaeno capitulum interdum solitarium, uti in romano saepe plura, in australi vero, quem in arenosis insulae Lido legi, solitarium tantum vidi. Involucrum longius etiam ut in romano interdum erectum. Radix caespitosa et culmi fasciculati in Holoschoeno et romano, in australi radix horizontaliter refens, tecta squamis ovatis, latis, acutis, fusco-nigricantibus: culmi, serie longitudinali positi, approximati, rigicliores: capituio duplo vel triplo majore, coeterum vero tam similis romano, excepto culmo crassiore et humiliore, ut separari nequit. S. romanus gaudet culmo graciliore et longiore quam reliqui. $V$ ariant omnes culmo superne laevi, compresso, tereti vel trigono, interdum infra capitulum serrulato-scabro.

55. SCIRPUS aphyllus, spicis oblongis capitato-prolifer. glomeratis, capitulis proliferis globosis, in. volucro nullo, culmo tereti.

Scirpus prolifer; culmo tereti, compresso, nudo; capitulis glomeratis, nudis, tandem proliferis. Rottb. gram. 55. t. 17.f. 2. fide herbarii ejus. 
Cyperus punctatus; culmo tereti nudo basi vaginato, spiculis sessilibus proliferis, squamis punctato-variegatis. Lamarck. illustr. I.

p. 144 . fide herbarii ejus.

Habitat in Cap. b. spei. 24

Culmi plures, sesquipedales, siccitate collabentes. Vaginae bi-tripollicares, culmo parum ampliores, oblique truncatae, purpurascentes. Capitula magnitudine nucis coryli, multiflora, enittentia radios tres-quinque, capituliferos: capitella interdum iterum prolifera, pauciflora: radii compressi, inaequales. Ochreae unguiculares, oblique truncatae, coccineae. Squamae oblongae, purpureo punctatae. Setae nullae.

Junior htemilior, capitulo terminali solitario non prolifero. Squamae undique imbricatae, nec ut in Cyp. prolifero Thunbergii distiche tantum.

globiferus 56. SCIRPUS spicis capitato-glomeratis, capitulis umbellatis globosis proliferis, involucro diphyllo, culmo tereti. $†$

Scirpus globiferus; culmo teréti nudo, umbella terminali composita; capitulis globosis ex spiculis pluribus arcte congestis. Lin. suppl. 104. Habitat in Teneriffa.

Culmus aphyllus, glaberrimus, terminatus spatha. Spathą brevissima diphylia: foliola aequalia, subulata, mucronata. Pedunculi e sprtha exeuntes, plures, ancipites, terminati globulis ex spicis brevissimis, congesiis. Hi globuli circa basin emittunt novos radios globiferos, iterum similiter dividenios, unele inflorescentia refert umbellam compositam umbellis basi proliferis. Lin. $l$. c.

Luzulac. 57. SCIRPUS spicis subrotundis capitato-glomeratis, capitulis umbellatis globosis proliferis, involucro polyphyllo, culmo trigono. $\dagger$

Scirpus lazulae culmo triquetro nudo, umbella foliosa prolifera, spiculis subrotundis. Lin. spec. pl. $7 \div$.

Hatitat in Inaiia orienta $i$.

Culmus plusquam pedalis, nudus. Involucrum universale foliis ensiformibus, umbella longioribus: partiale nullum nisi setae brevissimae. Umbellae pedunculi intermedii brevissimi; om- 
nes terminati capitello, iterum prolifero. $\mathrm{Ca}$ pitella subrotunda, glomerata ex spiculis sub. rotundis. Lin. $l$. c.

Gramen cyperoides orientale. Plukn. mant. t. $+17 . f$. 3. huc. revocat Burmannis in $f l$. ind. figura vero non bene quadrat cum descriptione Linnaei.

58. SCIRPUS aphyllus, spicis oblongis, squamis lacustris. glabris, stylis trifidis, umbella decomposita.

Juncus. Cube ed. alt. 261 .

Juncus aquaticus maximus. Lob. ic. \$5.

Juncus maximus s. Scirpus major. Bauh. theatr.

$17 \%$.

Scirpus palustris altissimus. Scheuchz. 35.

Scirpus lacustris; culmo tereti nudo, spicis ovatis pluribus pedunculatis terminalibus. Lin. syst. ver. 100. Fl. dan. t. I 7 2. Pollich. pal. $n$. $4^{h}$.

ค. Juncus sylvaticus. Tabern. ic.

Juncus sive Scirpus medius. Bauh. theatr. Is 1 . Juncus palusiris humilior. Scheuchz. gram. ₹ f $^{\circ}$ $\gamma$. Ann. aquaticus major carinatus. Pet. gazo.

Juncus aquaticus medius, caule carinato. Raii synop. $+2 \pi$.

Habitat in Europae aquis puris stagnantibus et fluviatilibus. 2!

Radix repens. Culmi quadiri-quinque pedales, crassitic pennae anserinae, sursum atleniliati, basi alternatim vaginati. Involucrum spathaeforme, foliolum longizus e culmo continuato. basi nodosum, umbella parum longius vel úr vius, lineari-subulatum, inferne versus sensim dilatatun, margine membranaceum, alterum bre. vius umlella decomposita; radii compressi, mar. gine denticulati, scabri. Spicae congestae tresquinque, vel solituriae, fuscae: squamae sub. rotunice, concavae, mucronatae, margine la. cero, ciliatae. Semen altero latere convexum, altero planum. Setae retrorsum ciliaise.

Varietaicm hujus in Hispania legi; culmo triplo teneriore et mulio humiliore involucri folio mu. jore vix semiunguiculari: spicis plurimis in capitulo congestis absque radiis lateralibus; vix tamen diversam et forte e solo sicciore ortam. 


\section{TRIANDRIA. MONOGYNIA.}

validus 59. SCIRPUS aphyllus, spicis ovato-oblongis, squamis dorso villosis, stylis bifidis, umbella decomposita, involucro brevissimo apice tereti.

Habitat in Caribąeis. 24

Culmus altus, inferne crassitie fere pollicis, sursum sensim attenuatus subtilissime striatus, glaucus. Involucri foliola duo basi dilatata, concava, in acumen subulatum, teres, rigidum attenuata, margine membranacea; longius vix semipollicare; squamae praeterea inter radios, lanceolato-cvatae, concavae, pallide ferrugineae. Ochreae radios universales et partiales vaginantes, submembranaceae, pallide ferrugineae. Umbellae radii universales longiores bipollicares; partiales ultimi monostachyi, raro distachyi, spiculc altera inferiore sessili; omnes suhcanaliculati, margine retrorsum $e$ denticulis minutis scaberrimi. Spicae semiunguiculares, obtusae: squamae ovato-oblongae, concavae, emarginatae cum mucrone e carina viridi excurrente, margine subciliatae, purpureo punctatae, Semen obovatum, altero latere planum, altero convexum, flavescens. Setae retrorsum denticulatae.

$\checkmark$ alde similis antecedenti at in paucis distinctus nempe: crassitie culmi, involucro brevissino: squamis pallidis, dorso pubescentibus: stylo bifido. Est forte Juncus Sloan. hist. I. p. I22. n. 55 .

sabulatus. 6o. SCIRPUS aphyllus, spicis oblongis, squamis carina pubescentibus, stylo trifido, involucri foliolum longius rigidum laeve.

Habitat in instelis Nicobaricis. 4

Culmi penna columbina parum crassiores, glauci. Involucri foliolum longius e culmo continuato, trigono-subulatum, rigidissimum; involucri foliolum alterum umbella brevius vel parum longius, alterum vix nisi squama: partiale nullum. Umbella subcomposita: radii capillares, semiteretes, margine scabri, mono-distachyi. Spicae vix unguiculares, solitariae vel duae-tres congestae: squamae oblongae, emarginatae cum mucrone, margine vix lacerae, hyalinae, laeves, dorso ferrugineae, superne et versus late- 


\section{TRIANDRIA. MONOGYNIA.}

ra ferrugineae. Stylus glaber. Semen obovatum, altero latere planum, ope lentis elevatopunctatum, altero convexum. Setae apice plumosae.

Affinis Sc. lacustri, differt in primis: estis non longitudinaliter retrorsum ciliatis, ciliis distantibus, sed ciliis superne, confertis, longioribus.

6 s. SCIRPUS spicis oblongis cylindricisve, corym- maritinus. bo folioso composito, culmo trigono.

Gramen aquaticum cyperoides vulgaris. $\mathbf{G e r}$. em. 22.

Scirpus maritimus; culmo triquetro, panicula conglobata foliacea, spicularum squamis trifidis, intermedia subulata. Fl. svec. 39.

B. Cyperus rotundus littoreus. Ger. emac $3 \mathbf{r}$.

Cyperus rotundus littoreus inodorus. Lob. ic. 7 ? Moris. hist. 3. p. 234. s: 8. t. г1: f. 8 .

\%. Cyperus panicula compacta, e spicis teretibus, crassioribus composita. Scheuchz. gram. 400 .

j. Cyperus aquaticus septentrionalis. Lob. ic. 77 .

Cyperus rotundus inodorus. Moris hist. 3. p. 237 . s. s. $t$. ir. $f$. o.

ع. Gramen cyperoides aquaticum vulgatius. Ger. 22. Lob. ic. 20 .

Cyperus panicula sparsa, e spicis longioribus, tenuioribus, teretibus composita. Scheuchz. gram. $398 . t$. 9.f. $7 \cdot 8$.

Scirpus corymbosus; culmo triquetro folioso; panicula terminali foliacea, spiculis sessilibus confertis. Forsk. descr. p. I 4 .

?. Scirpo-Cyperus palustris, raàice repente nodosa inodora panicula sparsa, capitulis majoribus. Mich. gen. 48 .

भ. Spiculis cylindricis sesquipollicaribus, radiis umbellae brevissimis, involucro umbella dimidio longiore.

9. cirpus glaucus; culmo triquetro folioso, umbella composita subpaniculato, spiculis pedicellatis. Lamarck. illustr. I. p. 142 .

6. Spicis ovatis magnis.

Habitat in Europae et Arabiae maritimis, $\xi$. in Arragonia, 9. ad Senegal, _. Carolina. Bosc.

Radix repens, nodosa vel tuberosa. Culmi pedales-tripedales, acutanguli, inferne foliosi, 


\section{TRIANDRIA. MONOGYNIA.}

angulis superne scabri. Folia carinata, mar. gine scabra: vaginae ore membranaceo, ferrugineo. Involucrum subpentaphyllum, longitudine et latitudine varians. Umbella subcomposita, interdum spiculae confertae in capitulum absque radiis lateralibus; radii alterni, basi bractea lanceolato-subulata, longitudine radii. Spicae duae-septem sessiles in apice radii, primum ovatae, dein longiores cylindricae: squamae ovatae, margine lacerae, apice bifidae cum mucrone, carinatae, fusco-ferrugineae. Semen obovatum. Setae ad basin germinis.

Sc. Glaucus Lamarckii non differt nisi colore glauco foliorum et culmi, spicis flavescentibus, interdum unica in singulo radio partiali, sed interdum quoque duae-tres. Varietas ı. differt spicis crassitie fere digiti minimi.

triqueter 62. SCIRPUS spicis ovatis sessilibus pedunculatisque, squamis lacero-ciliatis, culmo triquetro submonophyllo.

Juncus acutus maritimus, caule triquetro molli, procerior. Plukn. alm. 200. t. 4c. f.".2.

Scirpo-Crperus palustris, caule molli; panicula sparsa minore, capitulis subrotundis plurimis simul junctis subfuscis. Mich. gen. $+\cdots$.

Scirpus triqueter; culmo triquetro nudo, spicis subsessilibus pedunculatisque, mucronem aequantibus. Lin. mant. 29 . Sinith. fl. angl. 1. p. 5 .

Habitat in Anglia et Europa australi. 24

Culmi tripedales, spongiosi. Folium inicum-duo $e$ vaginis longis, lanceolatzm, tripollicare, margine laeve: vagina interior saepe spithamaea. Involucrum nullum. Unbella interdum mucrone longior, sex-septem radiata: radii longiores sesquipollicares, conaliculati. Spicae duae-octo, glomeratae, semininguiculares, ovatae: squamae oblongo-ovatae, emarginatae, obtusissimae, aristatue, fuscae, carina virides. Stylus trifidus. Semen altero latere planiusculum, laeve, nitidım. Setae retrorsum pilis denticulatae.

grossus. 63. SCIRPUS spicis ovatis pedicellatis, corymbo, supradecomposito folioso, involucro suhdiphyllo longissimo lanceolato, culmo triquetro. 
Scirpus grossus; culmo triquetro nudo, umbella supradecomposita spicis pediceliatis, involucro subdiphyllo lanceolato subulato longissimo. Lin. suppl. 1@4. Retz. obs. 5. p. 15.

Habitat in Indiae orientalis lacubus frequens. König. 24

Culni novem-pedales, crassitie digiti, basi foliosi. Involucrum triphyllum, foliola duo majora, longius bipedale et ultra, basi semipollicem lata, sensim attenuato-subulata, carinata, margine scabra; partiale nullum, nisi squamae subulatae ad basin. Ochreae semipollicares, truncatae. Panicula corymbosa, supradecomposita, magna; pedunculis canaliculatis, margine scabris. Spicae solitariae, Pipere nigro parum minores, fusco-ferrugineae: squamne ovatae, mucronatac, virescentes. Stamina tria. Stylus trifidus. Semen subrotundum, altero latere planiusculum. Setae purpureae, retrorsum denticulatae, semine parum longiores.

64. SCIRPUS spicis ovatis squarroso-echinatis, co-aristatus. rymbo terminali diphyllo subfastigiato, culmo tereti folioso. $t$

Scirpus pilosus; culmo tereti striato folioso, panicula terminali diphylla subfastigiata, spiculis ovatis squarroso-echinatis. Retz. obs. 6. p. I9.

Habitat in India orientali.

Culmus spithamaeus, tenuis, superne pilosies. Folium in medio culmi unicum eoque parum longius, nervosum, supra et margine pilosum. Involucri foliolum inferius panicula gizinquies longius, superius sesqui longius, figura folii, utrinque pilosum. Pedunculi mono-distachyi. Spicarum squamae obovatae, tenues, pellucidae, striatae, terminatae filo albido longitudine ipsius squamae, facie aristae, reflexae, utrinque pilis albis quasi pinnatae. Stamina tria, fusca. Germen trigonum, fuscum. Stylus longitudine staminum, trifidus. Retz. l. c.

65. SCIRPUS spicis oblongis congestis, corymbo sulviticus. supradecomposito folioso, culmo folioso trigono.

Cyperus gramineus miliaceus. Ger. em. 30. 


\section{TRIANDRIA. MONOGYNIA.}

Gramen cyperoides miliaceum. Bauh. theatr. 90. Gramen arundinaceum, foliis acutissimis, panicula multiplici; cyperi facie. Loes. prus. I 19. t. 3.3 .

Scirpus sylvaticus ; culmo triquetro folioso, umbella foliacea, pedunculis nudis supradecompositis, spicis confertis. Lin. syst. veg. 102. Fl. dan. t. 307. Leers $f l$ herb. n. 36. t. т. f. 4.

radisans. B. Scirpus radicans; culmo triquetro folioso, umbelia foliacea, culmis sterilibus deflexis apice radicantibus. Schkuhr, in Ust. an. 4. p. 48. t. I.

Habitat in Europae sylvis humentibus. 4

Culmi solitarii. Folia radicalia plura, culmi vaginantia eoque longiora, unguem vel ultra lata, margine scabra. Involucri foliola alterna, duo vel tria, corymbo longiora, reliqua sensim minora, structiora foliorum. Pedunculi universales et partiales scabri. Spicae parvae, congestae, saepe solitariae: squamae oblongae, obtusae, fusco-virescentes. Semina setis cincta.

junciformis. 66. SCIRPUS spicis trigonis paucifloris sessilibus pedunculatisque, panicula diphylla, culmo filiformi subtrigono. $\leftarrow$

Scirpus junciformis; culmo nudo filiformi subtrigono, paniculae spiculis sessilibus pedunculatisque, involucro àiphyllo. Retz. obs. 6. p. I 9 .

Habitat in China.

Culmus pedalis, angulo tertio obliterato ut fere siıbuadrangularis. Folia radicalia, culmo breviora, linearia. Involucrum panicula brevius. Panicula junci bufonii sed brevior. Spicarum squamae exteriores magis carinatae, inter quas Stamen unicum vel duo, vel etiam pistillum tantum; interiores minus carinatae, hermaphroditae, staminibus tribus. Stylo trifido. Stigmatibus villosis. Retz. l. c.

aitens. 67. SCIRPUS spicis ovatis pedicellatis, corymbis subcompositis axillaribus terminalibusque, culmo tereti.

Habitat in Carolina. Bosc.

Culmus sesquipedalis, articulatus, tectus vaginis fuliorum. Folia radicalia culmo breviora, 
laxa, culmi breviora, remota, linearia, angusta. Involucri foliola alterna, subulata, inferiora vix unguicularia, sensim minora. Ochreae breves, oblique truncatae. Corym. bus terminalis compositus, pedunculis senis; axillares simplices, pedunculis quatuor-quinque, unguicularibus: pedicelli quatuor-quinque, mono-distachyi. Spicae ovatae, obtusiusculae, magnitudine serninis coriandri, totae fusco-ferrugineae, nitidae: squamae ovatae, acutae, subcarinatae. Stamina tria. Stylus bifidus, basi dilatatus, compressus, bifidus. Semen subrotundum, transversim rugulosum, acumine ovato e basi styli persistente coronatum. Setae nullae.

69. SCIRPUS spicis oblongo-ovatis pedicellatis, lineatus: corymbis axillaribus terminalibusque supradecompositis, pedunculis elongatis, culmo trigono.

Scirpus lineatus; culmo latiuscule folioso: paniculis lateralibus et terminali: spiculis parvulis, oblongiuscule ovatis: squamis lanceolatis, subcarinatis; linea carinali viridula, promi. nula. Mich. fl. bor. amr. t. p. 32 .

Habitat in Carolina. Bosc.

Culmi bipedales et ultra, inferne penna columbina parum crassiores, sensim attenuati, articulati, superne acute trigoni, vaginis foliorum tecti. Folia remota, culmo breviora, sesquilineam lata, apice margine scabra. Involucri foliola alterna, inferius pollicare, interiora sensim minora, in squamas demum ferrugineas mutata. Ochreae unguiculares, sensim minores, oblique truncatae, obtusae, pallide ferrugineae. Corymbus elongatus, laxissimus; pedunculi circiter novem, praeter nonnullos mono. stachyos in centro, approximati, filiformes, sensim tenuiores, longior semipedalis, magis divisus; ultimi gemini-quatuor ex eodem puncto monostachyi, scabriusculi. Spicae minutae, ovatae: squamae oblongae, acutae, concavae, sensim deciduae, dorso virides, margine membranaceae. Rachis sensim elongata. Stamina tria. Stylus trifidus. Semen trigonum, laeve. Setae nullae. 


\section{TRIANDRIA. MONOGYNIA.}

Differt $a b$ antecedente: culmo altiore: foliis la. tioribus: pedunculis patentissimis: pedicellis capillaribus: spicis triplo minoribus.

pubescens. 69. SCIRPUS spicis oblongis villosis, pedunculis axillaribus terminalibusque submonostachyis, culmo folioso.

Carex pubescens. Poiret itin. =. p. 254 .

Scirpus pubescens; culmo triquetro folioso, spiculis ovatis congestis sessilibus pubescentibus. Lamarck. illustr. 1. p. 139 .

Scirpus pubescens; culmo folioso, triquetro, superne pubescente; spiculis paucis, secundis, terminalibus, ovatis; glumis mucronatis. Desfont. fl. Atl. 1. p. 5 2. $t$. 10.

Habitat ad lacuum ripas Africae septentrionalis.

Glaucus. Culmi pedales vel partum ultra, triguetri, pubescentes vel glabri. Folia remota, tri-quadripollicaria, infima breviora, linearilanceolata, carinata. Pedunculi ex axillis supremis, mono-distachyi. Squamae oblongae, obtusissimae, aristatae, dorso trinerviae, mar. gine versus basin ferrugineae. Stylus trifidus. Setae mullae.

polyphyllus. ?o. SCIRPUS spicis capitulisque subglobosis glo. meratis, corrmbo terminali. culno folioso.

Habitat in America boreali? Ex Anglia attulit Hortulanus Holböll.

Culmus penna columbina parum crassior. vaginis foliorum tectus, apice trigonus. Folia frequenttissima, sex-septempollicaria, superiora culmum superantia, graminea, carinata, margine scabriuscula. Involucrum subpentaphyllum, umbella duplo longius; nullum sub capitulis. Pedunculi circiter decem, longiores, sesquipoliicares, teretes. Capitula piso duplo majora, composita quatior-quinque minoribus. Spicae plures, parrae, orato-subglobosae, fitsco-ferrugineae: squamae oratae, corinatae, mucronatae, carina viridi. Stamina tria. Stylus trifidus. Setae nonnullae ad basin seminis.

glomeratus. 7 I. SCIRPUS spicis ohlongis, involucro diphyllo umbella glomerata breviore, foliis linearibus obtusis rigidis. 
Scirpus glomeratus; culmo nudo teretiusculo, umbella glomerata, involucro diphyllo brevi, floribus diandris. Retz. obs. 4. p. I 1.

Scirpus cymosus; culmo nudo tenui, umbella cymosa congesta composita nuda, glumis obtusis. Lamarck. illustr. 1. p. 14 I. fide herbarii ejus.

Habitat ad margines agrorum Zeylona König, in Java Commerson.

Omnino similis sequenti, ut facile pro varietate haberetur, sed in decem speciminibus mihi visis umbella semper contracta fere in capitulum: Styli bifidi, nec trificli. Spicae sensim elongantur, uti squamae decidunt: squamae obtusae. Semen subrotundum, nigrum.

Variat culno breviore, palmari, foliisque bipollicaribus, vel culmo sesquipedali foliisque quinque-pollicaribus.

72. SCIRPUS spicis oblongis glomeratis, involu- obtusifoliu. cro subtriphyllo umbella composita breviore, foliis linearibus obtusis rigidis.

Scirpus obtusifolius; culmo nudo, umbella parva subcomposita, foliis brevibus angustis glaucis obtusis. Lamarck. illustr. 1. p. 141.

Habitat in India orientali, in Guinea Thon. ning. 4

Radix fibrosa. Culmi plures, pedales, apice trigoni, sulcati, basi e foliorum rudimentis copiosissimis fuscis bulbosi. Folia radicalia, copiosa, tripollicaria vel minora, canaliculata, margine vix scabra, apice saepe sphacelata, glauca. Involucri foliola subulata, rigida, unicum unguiculare: partiale diphyllum. Umbellae radii tres-quinque, vix pollicares, rigidi: partiales tres-quatuor. Spicae tres-sex, sessiles in apice radiorum, parvae: squamae oblongae, obtusae, carinatae, margine albidae, menbranaceae. Stylus trifidus, basi incrassatus. Setae nullae.

73. SCIRPUS spicis oblongis subternis, involucro falcatus, subdiphyllo umbella composita breviore, fo. liis linearibus falcatis.

Habitat in India orientali. König. 4 


\section{TRIANDRIA. MONOGYNIA.}

Glaucus.' Radix crassitie pennae cygneae, obliqua, curvata, longitudinaliter emittens radieulos filiformes, simplices. Culmus semipedalis, filiformis, apice trigonus, basi foliosus. Folia copiosissima, confertissima, basi dilatata, im. bricata, sesquipollicaria, lineam lata, undique ejusdem latitudinis, rigida, obtusa, vix canaliculata, margine serrulato-scabra. Involucrum brevissimum: partiale monophyllum, setaceum. Umbella subquinqueradiata; radii capillares, longior bi-tripollicaris : partiales triradiati: Spicae tres-quatuor in apice singuli radii. Reliqua ut in obtusifolio cui affinis sed diversus foliis et radice.

eapillaris. 74. SCIRPUS spicis ovatis, umbella biradiata, culmo capillari. + .

Scirpus capillaris; culmo nudo capillari, spicis ternis pedunculatis intermedio sessili. Lin. mant. $32 \mathrm{I}$.

Habitat in Virginia, Aethiopia.

Culmi foliis vix longiores vel crassiores. Folia capillaria, vix longitudine digiti. Involucrum monophyllum, setaceum, spicis longius. Spicae terminales: squamae obtusae, ferrugineae, carina viridi. Lin. l. c.

hispidulus. 75. SCIRPUS pilosus, spicis oblongis acutis, umbella subuniradiata, culmo angulato, foliis setaceis.

Habitat in Guinea. Thonning.

Radix fibrosa. Culmi plures, pedales vel minores, setacei, uti folia et involucra, vestiti pilis longis albidis patentibus. Folia culmo breviora, basi vaginantia, capillaria. Involucrum diphyllum, capillare, foliolum unicum umbella longius, semipollicare, margine scabrum. Umbella simplex, interdum uni-biradiata, interdum spicula solitaria absque radio laterali. Spicae semine tritici duplo minores: squamae ovatae, acutae, fusco-nigricantes, ca. rinatae, carina viridi, striatar. Stamina tria. Stylus trifidus. Semen trigonum, transversim undulato-rugosum.

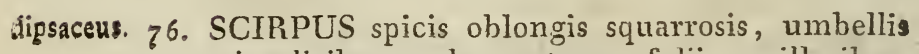
simplicibus, culmo setaceo, foliis capillaribus. 
Scirpus dipsaceus; culmis setaceis; umbella simplici; capitulis squarrosis; flosculis subulatis, recurvis, diandris; germine echinato. Rottb. gram. 56. t. I 2. $f$. r.

Habitat in India orientali. König.

Culmi copiosi, unguiculares, digitales vel parum ultra, trigoni. Vaginae purpurascentes, terminatae folio brevi, capillari. Involucrum tripentaphyllum: foliola capillaria, umbella breviora vel longiora. Umbella bi-sexradiata; interdum culmi monostachyi: radii capillares, semipollicares. Spicae solitariae, duas lineas longaz, obtusissimae: squamae lanceolato subulatae, apice recurvae, carinatae, virescenti-albidae. Stamina tria. Stylus bifidus. Semen lineari-oblongum, utrinque margine spinuloso ciliatum. Setae nullae.

Stamina duo König.

77. SCIRPUS aphyllus, spicis globosis, umbellis globulosuz. simplicibus compositisque, involucro subnullo. Scirpus globulosus; culmo compresso nudo; panicula terminali, spicula unica sessili; pedun. culatis pluribus globosis. Retz. obs. 6. p. Ig.

Habitat in Zeylonae uliginosis. König.

Radix fibrosa. Culmi plures, pedales, teretes, siccitate collabentes, laxe vaginati. Vaginae duae-tres, interior bipollicaris, oblique truncatce, ore ferrugineo, membranaceae. Involucrum nullum, nisi squamulae nonnullae parvae, lanceolatae. Umbella subcomposita, bi-rieininqueradiata: radii breves, monostachyri. Spicae vix magnitudine seminis coriandri; squamae ovatae, ferrugineae, margine scarioso albido lacero, deciduae. Stylus tzifidus. Semen laeve. Setae nullae.

Variat ümbellis simplicibius et compositis, umbellulis uni-biradiatis.

Culmus teres. König.

78. SCIRPUS spicis ovatis, umbella suhsimplici, frigrans. involucris polyphyllis, foliolis setaceis culmoque filiformi pubescentibus. †

Scirpus fragrans culmo tereti striato nudo, spicis ovatis pedunculatis inaequalibus; termina. libus umbellatis. Fl.'peruv. r. p. 47.

Habitat in Peruviae nemorum runcationibus. 
Radix fibrosa, odoratissima. Culmus solitarius, erectus, bipalmaris, foliis fere duplo longior, nudus. Folia semiteretia. Involucri foliola setacea, exteriora spicis duplo longiora. Spicae umbellatae, intermediae breviores, rarius divisae: squamae ovatae, carinatae. Stamina tria. Stigmata tria. Semen triquetrum, superne crassius, acuminatum, glabrum. Fl. per. $l . c$.

mucronula- ? 9. SCIRPUS spicis oblongis acutis, involucro dicus. phyllo umbella composita breviore, culmo filiformi, foliis linearibus.

Scirpus mucronulatus; foliis radicalibus planis: culmo nudo, subancipiti: umbella composita, laxa: spiculis minusculis, oblongo-ovatis, glabris; squamis lanceolatis; carina prominula, discolore, in minutum mucronem desinente: setulis sub genitalibus seu semine nullis, stylo glabro trifido. Mich. fl. bor. amer. 1. p. 32 .

Habitat in montibus Carolinae. Richard.

Facies Fimbristylis dichotomi. Glaucus. Culmus semipedalis, filiformis, debilis. Folia angusta, culmo dimidio breviora. Involucella diphylla, setacea Umbella subquinqueradiata: radii capillares, longiores vix pollicares; partiales biradiatae; radiis monostachyis, sae. pe iterum divisis radio unico. Spicae parvae: squamae lanceolatae, acutissimae, carinatae, ferrugineae, carina viridi.

bivalvis. 80. SCIRPUS spicis oblongis, squamis ovatis mucronatis, involucro diphyllo umbella composita breviore, culmo semitereti.

Scirpus bivalvis; culmo nudo subcompresso, umbella terminali composita, involucro bivalvi brevissimo. Lamarck. illustr. I. p. I4I.

Habitat in Madagascar. Ex herbario Lamai"ckii. Involucrum radiis quintuplo brevius, erectum.

Umbella septemradiata: radii mono-tristachyi. Squamae apice ferrugineae.

cinnamome- 81. SCIRPUS spicis oblongis acutis, involucro ditorum. phyllo umbella decomposita breviore, culmo trigono, foliis setaceis.

Habitat in cinnamometis Zeylonae. König. 
Radix fibrosa. Culmi plures, pedales et ultra. filiformes, rigidiusculi. Folia culmo dimidio breviora, canaliculata, apice margine scabriuscula, basi vaginantia. Involucrum vix unguiculare. Umbella subquinqueradiata: partialis tri-quadriradiata: radii canaliculati, capillares. Spicae solitariae, parvae, tri-quinqueflorae, subulatae: squamae lanceolatae, carinatae, fusco-ferrugineae, marginem versus fusco punctatae, deciduae. Rachis sensim elongata, post casum flosculorum alternatim excavata. Stamina tria. Stylus trifidus. Setae nullae.

82. SCIRPUS spicis ovato-oblongis, involucro subtriphyllo umbella supradecomposita breviore, culmo quinquangulato, foliịs brevissimis.

Habitat in India orientali. König. 4

Culmi bipedales, inferne vaginati. Folium unicum ex apice vaginae longioris, sesquipollicare: vaginae tres-quatuor, longior spithamaea. Involucrum tri-tetraphyllum; foliola duo-bipollicaria, praeterea nonnulla capiliaria inter radios: partiale squamae duae-tres, lanceolatae, attenuatae. Ochreae oblique truncatae, attemeatae, acutae. Umbella expansa, laxa, sub. ruodecimradiata, praeter plurimos brevissimos monostachyos: partialis octo-novemradiata, ultima biradiata, radii capillares, longiores; universales subtripollicares. Spicae semine milii dupln majores, acutiusculae, fusco-flavescentes: squamae ovatae, acutae, carinatae, margine albido, membranaceae, sensim deciduae. Stylus trifidus, basin versus sensim crassior. Semen trigonum, tuberculatum, album.

83. SCIRPUS spicis lineari-oblongis, involucro di-complanatus. phyllo umbellam supradecompositam aequante, culmo compresso ancipiti.

Scirpus complanatus; culmo compresso-ancipiti, umbella supradecomposita, involucro diphyllo longiore. Retz. obs. 5. p. I4.

Habitat in India orientali. König.

Culmus bipedalis, membrana foliacea, utrinque decurrente, inferne versus sensim decrescente alatus, superne margine scaber, inferne folio:

givinquangu-

Laris. 
sus. Folia pauca, graminea, culmo parum breviora et latiora. Involucri foliolum longius, culmo parum latius, longitudine umbellae, alterum brevius: partiale setaceum. Umbella quinque septemradiata: partialis quatuor -quinqueradiata; radii filiformes, laxi. Spicae solitariae, parvae, circiter novemflorae, acutae: squamae lanceolatae, carinatae, fuscoferrugineae, carina albidae. Stylus trifidus. Semen trigonum, niveum. Setae nullae.

Similem vidi in herbario Vaillantii nominatum: Cyperus miliaceus minor virginianus Petiver, solummodo diversum culmo spithamaeo, angustiore: involucro triphyllo, quod in Scirpis aeque ac in Cyperis variat: umbella minus ramosa, omnia vero reliqua ut in S. complanato.

* Obscuri vel dubii generis.

ixteralis. 84. SCIRPUS spicis ovatis lateralibus sessilibus pedunculatisque. Forsk. descr. I5. +

Habitat in Arabia.

Culmus triqueter? pedalis et saepe cubitalis, basi foliosus. Pedunculi laterales, fasciculati, filiformes, inaequales, pollicares. Squaniae ovatae, ferrugineae, margine membranaceae.

In herbario Forskâlaei non aderat.

eapsularis. 85. SCIRPUS culmo tereti nudo, panicula coarctata laterali, fructu capsulari. Lour. fl. cachinch +4 . $†$

Juncus indicus porosus. Clus. cur. post. 64.

Habitat in Cochinchinae et Chinae paludosis.

Culmus quadripedalis, caespitosus. Folia brevia, arcte convoluta. Stigmata tria. Capsula triloba, polysperma. Lour. $l$. $c$.

An Junci species?

ellychniarius. 86. SCIRPUS culmo tereti nudo, spicis globosis quaternis. Molina hist. Chil. 129. +

Habitat in Chili.

capensis. 87. SCIRPUS culmo triquetro folioso, spicis capitatis, involucro diphyllo. Burm. prodr. 3. $t$ Habitat in Cap. b. spei.

88. SCIRPUS. Willem. herb. maur. 9. + Habitat in insula Mauritii. 


\section{TRIANDRIA. MONOGYNIA. $28 \mathrm{I}$}

Culmus basi foliosus. Folia eulmo dimidio breviora. Involucrum polypinyllum, zumbella longitus. Umbella composita. Spicae ovatae. Willem. l. c.

89. SCIRPUS. Willem. herb. maur. g. $\div$

Habitat in insula Mauritii.

Radix fibrosa. Culmi inferne foliosi. Folia graminea, culmo dimidio breviora. Involucrum polyphyllum, corymbo longius. Spicae ovatce, exiguae, in corymbo conglomerato. Pedicelli flexuosi. Willem. l. c.

90. SCIRPUS? culmo triquetro: foliis involucris- longifolius. que longissimis nervosis, corymbo sessili com-

Habitat Cajennae.

9x. SCIRPUS culmo gladiato nudo aspero, um- reticulatus. bella composita foliacea, involucri foliis superficie reticulatis. Lamarck. illustr. x. p.142. + Habitat in Carolina.

92. SCIRPUS culmo teretiusculo filiforrei nudo, junceus.

spica ovata terminali involucrum aequante. Forst. prodr. p. 6. †

Habitat in insulis societatis.

Speciem Schoeni credit Wildenow.

9. SCIRPUS culmo triquetro folioso, spiculis annmalus. ovatis, floribus corollatis infimis diandris superioribus triandris. Retz. obs. 5. p. 15. $†$

Habitat in India orientali.

Culmus subbipedalis, trigonus. Fulia ad basin multa, longitudine culmi, pollicem dimidium lata, plana, trinervia, inermia; in culmo tria hisce similia, sed breviora. Involucri folium sub infimo pedunculo panicula quadruplo longius, huic simile sub secundo pedunculo, sed panicula vix longius, reliqua folia sensim bre. viora, omnia ciliato-scabra. Panicula sesquipollicaris; pedunculis brevibus, semiteretibus, tri-quinquefloris, ciliato-scabris; pedicelli brevissimi, squamis duabus tribusve lanceolatis. spicae imbricatae, squamisobtusis. Corolla dipetala: glumae aéquales, compressae, carina ciliatae. Stylus simplex: Stigmata duo. Retz. l. c. Proprii generis esse videtur. 
eriophortis. 94. SCIRPUS spicis ovatis obtusis setis exsertis, involucro pentaphyllo umbella supradecomposita longiore, culmo folioso.

Cyperus miliaceus ex provincia mariana, panicula villosa aurea. Plukn. mant. 62. t. 419. f. 3 .

Cyperus miliaceus marilandicus; spicis seminiferis magis confertis rubentibus lanuginosis. Raii suppl. 620 .

Scirpus paniculatus, foliis floralibus paniculam superantibus, Gron. virg. I 2.

Eriophorum cyperinum; culmis teretibus foliosis, panicula supradecomposita prolifera, spiculis subternis. Lin. spec. pl. 77 .

Scirpus eriophorus; altissimus; culmo folioso, triquetro: panicula amplissima, decomposita; spiculis copiosissimis, rufidulis; ovatis, omnibus distincte pedicellatis; setulis pistillinis exsertis. Mich. fl. bor. amer. r. p. 33 .

Habitat a Virginia ad Georgiam. 21

Culmus obtuse trigonus, crassitie pennae anserinae. Folia longissima, carinata, margine carinaque scabra. Involucrum pentaphyllum umbella longius, basi ferrugineum: partiale squamae nonnullae, lanceolatae, ferrugineae. Ochreae pollicares, ferrugineae. Umbella supradecomposita, spithamaea: radii capillares, rultimi gemini, monostachyi cum spica sessili in centro. Spicae fructiferae semine cannabis parum majores: squamae oblongae, carinatae, mucronatae, ferrugineae. Semina trigona, albida. Setae squamis longiores, gilvae.

Facies omnino recedit $a \dot{b}$ Eriophoris et Scirpis propinquior, setae praeterea, ut monet $\mathrm{Mi}$ chaux, numero determinato adsunt et solummodo diversae a Scirporum quicod longiores et laxiores sunt.

Habitus. Primae sectionis Culmi caespitosi. Folia nuila nisi culmi steriles, excepto Sc. fluitante et capillari. Spica terminalis. Involucrum nullum.

Secundae sectionis, primae subdivisionis: Culmi basi foliosi, apice elongati. Spicae plures, laterales, sessiles. Involucrum subnullum. Secundae subdivisionis: Culmi in plurimis eno- 
des, basi foliosi, in paucis omnino aplyylli; in ceteris articulati, foliosi: Foliis vaginantibus; vaginis integris. Spicae plures, terminales, aggregatae vel in paucioribus distinctae. Involucrum foliosum, in paucissimis nullum.

II8. Hypalyptum. Paleae arcte imbricatae. Cal. bivalvis. Cor. o. Setae o.

1. HYPAELYPTUM spicis ovato-oblongis, squa-pungens. mis obtusis, involucro pungente.

Habitat in Americá meridionali? Richard.

Culmi bipedales. Folia pedalia. Involucrum sesquipollicare. Capitulum magnitudine coryli. Spicae circiter duodecim, vix semiungıiculares, squamae margine membranaceae, juniores lutescentes, adultiores purpurascentes. Calycis valvulae longitudine fere squamae, purpurascentes, carina ope lentis subciliatae. Stamina corolla multo longiora. Stylus unicus, indivisus? Semina flavescentia, punctis purpurascentibus adspersa ope lentis videndis.

3. HYPAELYPTUM spicis ovatis, squamis acutis, argenteum. stylo trifido, foliis linearibus.

Scirpus senegalensis; culmo angulato subnudo, spiculis terminalibus sessilibus glomerais inrolucratis, Lamarck. illıstr. I. p. 140.

Habitat in India orientali ad margines agrorum et in scaturiginosis König, in Senegal Dupuis. 24

Culmi perlales. Involucri foliolum longius bi-tripollicare. Spicae plerumque quinque-sex, interdum tres, magnitudine piperis migri: Squamae acutae, niveae, nitidae, inferiores punctis purpureis acispersae.

Ornnibus partibus robustius, rigidius quan sequens, coeterum tam simile, ut vix differentiam nisi in stigmate invenio.

3. HYPAELYPTUM spicis ovatis, stylis bifidis, sphacelatun. folins linearibus.

Habitat prope Tranquebar. König, Röttler.

Culmi pedales. Folia glauco-viridia, apice saepe sphacelata. Involucrum rarius monophyllum; foliolum longius tripollicare. Spicae tres-qua- 
tuor, pipere nigro dimidio minores, juniores albidae, aetate fuscae: squamae acutae.

Calyx amentum, squama obovata, concava, colorata. Corolla univalvis, membranacea, excavata. Stamina duo, linearia. Antherae erectae, lineares, flavae. Germen ovato-ob. longum, diaphanum. Styli duo. Stigmata simplicia. Semen ovatum, striatum, altero la. tere planum, altero convexum. Röttler.

Stamina tria et Stylum unicum numeravit König, uti et ego.

nliforme. 4. HYPAELYPTUM spicis oblongis, culma filiformi, foliis setaceis.

Hahitat in Guinea. Thonning.

Glaucum. Culmi semipedales et ultra. Folia culmo triplo breviora. Involucri foliolum longius bipollicare. Spicae plerumque tres, interdum quatuor, duae vel rarius solitariae, semine oryzae duplo minores, aetate fusco-nigricantes: squamae acutae.

Habitus. Radix fibrosa, purpurea. Culmi plures, erecti, acute trigoni, enodes, striati, uti reliquae partes graminis flavescentes, glabri, inferne foliosi. Folia duo-tria, culmo breviora, uti culni.rigida, canaliculata, extrorsum margine scabra, striata, vaginantia; vaginae purpurascentes laxae, basi dilatatae. Involucrum diphyllum, raro monophyllum vel tetraphyllum, patentissimum; foliola structura foliorum, basi dilatata, spiculis longiora, unicum reliquis longius. Spicae terminales, sessiles, glomeratae, obtusissimae, arcte imbricatae, laterales patentes, intermedia erecta. Flosculi sensim decidui.

Character naturalis.

SPICA undique confertissime imbricata squamis obovatis, concavis, flores distinguentibus, flos unicus sub singula squama.

CAL. bivalvis: valvulis linearibus, compressis, acutis, diaphanis; altera angustiore.

COR. nulla.

STAM. Filamenta tria. Antherae lineares.

PIST. Germen oblongo-ovatum. Stylus; unicus vel bifidus. Stigmata indivisa. 
SEM. oblongo-ovatum, obsolete trigonum. Setae nullae.

RACHIS filiformis, confertissime spiraliter tuberculata; tuberculis scrobiculatis.

I19. Fimbristyus. Squamae paleaceae undique imbricatae. Cor. o. Styl. 2 -fidus, basi bulbostis, compressus, margine ciliatus. Set. 0 .

2. FIMBRISTYLIS spica ovata attenuata acuta so- acuminatun. litaria; foliis nullis, culmo filiformi.

Habiłat in India orientali. König.

Affine maxime schoenoidi, differt: vaginis oblique truncatis, acutis; nec in folium desinentibus, spicis ovato-oblongis, attenuatis, acutissimis; nec ovatis, obtusis: seminibus transversim sulcatis, plumbei coloris; nec flavis, laevibus.

2. FIMBRISTYLIS spica ovato-oblonga nutante, nutans. squamis ovatis striatis, culmo subcompresso.

Scirpus nutans; culmo compresso subtetragona nudo, spica ovata solitaria terminali nutanie. Retz. obs. 4. p. I 2.

Habitat in uliginosis Malaccae. König. 4

Culmi aggregati, pedales, filiformes. Folia nulla. Vaginae pollicares, obtusae, ferrugineae. Spica seminnguicularis. Squamae latae, mucronatae, dorso convexae, virides, margin fuscae.

3. FIMBRISTYLIS spica ovata obtusa, involucro pygmaem. submonophyllo, culmo filiformi subaphyllo.

Habitat in Bonaria. Commerson.

Simile omnino S. setaceo: diverssum squamis et seminibus. Culmis tripollicaris in exsiccatis trigonus. Vaginae rarius in folium culmo bre. vius desinentes. Involucri foliolum alterum longitudine spicae, alterum squama. Squamae ovatae acutae, pallidae, nargine membranaceae, prope carinam striatae. Semen transversim undulatum. In quam. plurimis spiciminibus spiculam tantum unicam vidi.

4. FIMBRISTYLIS culmo angulato filiformi di- serruhtum, phyllo, spica ovata, involucro diphyllo foliisque linearibus extrorsum serrulatis. 


\section{TRIANDRIA. MONOGYNIA.}

Habitat in America meridionali. von Rohr.

Culmi digitales, plures, vaginati. Folia culmo duplo breviora, obtusiuscula, extrorsum e serraturis oculo armato videndis scabra, canaliculata. Vaginae duae, ferrugineae, folio breviores. Involucri foliolum alterum spica parum longius, alterum aequale. Spica semine milii parum major, primum ovata, oltusa, sensim maturitate elongata: Squamae ovatae, acuminatae, sensim striatae, desiduae, sordide flavescentes.

schoenoides, 5. FIMBRISTYLIS spicis ovatis obtusis solitariis subternisquè lateralibus pedunculatis, culmo foliisque filiformibus glabris.

Scirpus schaenoides; culmo setaceo compresso, spica ovata, involucro monophyllo brevi membraniceo, seminibus turbinatis compressis. Retz. obs. 5. p. 14.

Habitat in India orientali. Röttler.

Glaucum. Culmi teretes, semipedales vel breviores, monophylli. Folia culmo breviora, linearia, angustissima, vel setacea, margine convoluta: Vaginae saepe bipollicares, colore foliorum vel fuscae. Involucrum nullum nisi squama ovata, acuminata, spica brevior. Umbella uni-biradiata; interdum spica solitaria absque radio laterali. Spica magnitudine piperis nigri: squamae ovatae, latae, mucronatae, albidae. Semen obovatum, compressiusculum.

histelim.6. FIMBRISTYLIS spicis ovatis geminatis altera pedunculata, foliis pilosis culmóque setaceis.

Habitat in America meridionali. von Rohr. $\odot$

Culmi palmares, apice trigoni, glabri. Folia duo, unicum culmo longius, capillaria, canaliculata: vaginae ferrugineae. Involucrum diphyllum, pilosum; foliolum unicum, umbella mulioties longius, alterum brevius. Umbella tantum distachya, spicula altera sessili, altera pedunculata. Spica major et obtusior quam in dichotomo: Squamae ovatae, mucrone brevissimo terminatae, substriatae, glabrae, ferrugineae. Semen longitudinaliter striatum, niveum. 
7. FIMBRISTYLIS spicis globosis, involucris sub- miliaccu:r. diphyllis umbella decomposita brevioribus, culmo basi folioso.

Scirpus miliaceus; culmo triquetro nudo, umbella supradecomposita, spicis intermediis sessilibus; involucro setaceo. Lin. spec. pl. 75. Burm. ind. t. 9. f. 2.

Scirpus culmo triquetro, nudo; involucro setaceo; panicula verticillata, supradecomposita; spicis centralibus, sessilibus. Rottb. gram. $57 \cdot$ t. 5. f. 2.

Habitat in India orientali. 4

Culmi plures, pedales, triquetri, laxi. Folia culmo altiora et inferne multo latiora, laxa, margine laevia, basi vaginantia: Vaginae amplae, margine membranaceae, ferrugineae. Involucra et involucellu di-triphylla, setacea; squamae duae, ovatae, attenuatae, membranaceae, sub ultimis radiis. Umbella quadri-quinqueradiata; radii laxi, longior sesquipollicaris: partialis bi-triradiata. Spicae magnitudine seminis Sinapis, fusco-ferrugineae: Squamae subrotundae, concavae. Stamina tria. Semen ope lentis tuberculatum.

8. FIMBRISTYLIS spicis ovato-oblongis, involu-dichoromum cro subtriphyllo umbella decomposita longiore.

Gramen cyperoides maderaspatanum, juncelli gesneri capitulis sparsis. Plukn. alm. 179. t. 119. $f .3$.

Cyperus maderaspatanus, calamo compresso, spicis minoribus fuscis. Scheuchz. gram. 395. t.9.

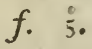

Cyperus supinus minimus, sparsa panicula e ra. rioribus locustis conferta. Monti prodr. 13.

Scirpus dichotomus; culmo triquetro nudo, umbella decomposita, spicis dichotomiae sessilibus. Lin. fl. zeyl. 40. Rottb. gram. 57. t. 13. f. T.

Scirpus annuus; culmo triquetro nudo, involucro diphyllo, pedunculis nudis, spicis solita-. riis. All. fl. pedem, $n .2, \cdots$.

ß. Scirpus bisumbellatus, culmo basi vagina- villosum. to; spicis pedunculatis terminalibus bis umbellatis. Forsk. descr. $p$. х 
Fabitat in India orientali, in Italia forte cum Oryza allatum.

Glaucum. Culmi digitales pedales, trigoni. Folia culmo altiora vel breviora, linearia, angzsta: vaginae ferrugineae. Involucrum partiale diphyllum, umbella brevius. Umbella suboctoradiata; radii longiores, sesquipollicares: 1 partialis quinque-septemradiata. Spicae ferrugineae: squamae ovatae, acutae. Stamina tria. Semen fiscum, longitudinaliter striatum.

Tariat plurimis modis: culnis altioribus brevioribus: foliis glabris vel villosis: umbella simplici, bi-triradiata, composita vel decomposita.

giaucum. 9. FIMBRISTYLIS spicis oblongis obtusis, involucro subdiphyllo umbella decomposita breviore.

Habitat in India orientali König.

Culmi sesquipedales, apice compressi, uti folia glauci. Folia culmi longitudine vel breviora, Iinearia, plana. Involucrum partiale nullum. Umbella quinque - sexradiata; radii longiores sesquipollicares, interdum divaricato-patentissimi: partiales tres-quatuor, ultimi uni-biradiati. Spiculae magnitudine seminis coriandri, pallide fuscae: squamae obtusissimae, absque mucrone. Stamina tria. Semen longitudinaliter striatum, niveum.

Affine Fimbr. dichotomo, diversum: spiculis squamisque eblongis, obtusis: involucro universali umbella duplo breviore, interdum sub. nullo.

restivale. ro. FIMBRISTYLIS spicis teretibus subsquarrosis, involucro subhexaphyllo umbella com. posita longiore, flosculis monandris.

Scirpus aestivalis; culmis depressis triquetris nudis, umbellis compositis involucratis, floribus monandris. Retz. obs. 4. p. 12.

Habitat in fluviis fundo limosis sub Sirio exsiccatis Zeylonae.

Glaucum. Culmi bipollicares, palmares vel spithamaci, filiformes, trigoni, glabri. Folia culmo longiora vel breviorn, filiformia, basi vaginantia: vaginae, uti folia hirtae. Invo- 
Jucrum hexa-octophyllum, setaceum, hirtum: involucella brevia. Umbella quinque-octoradiata; radii longiores semipollicares, capillares: partialis quadri-sexradiata. Spicae parvae: squecmae lanceolatae, in aristam patulam attenuatae, villosae, pallide fuscae, curina viridi. Culmi depressi. König.

I. FIMBPISTYLIS spicis teretibus squarrosis, sqquarrosum. involucro subtetrapliyllo umbellam decompositam subaequante, culmo filiformi, foliis setaceis.

Habitat in America meridionali. Ex herbario antiquo, forte Loeflingii, matriti habui.

Culmi digitales vel palmares, setacei, laxi, subcompressi, basi monophylli. Folia radicalia, culmo parum breviora, convoluto-capillacea: vaginae fusco-ferrugineae, saepe uti-folia et involucra villosae. Involucrum foliolo, unico umbellam aequante: partiale diphyllim, brevissimum. Umbella ratione plantae magna, patens, laxa, subdecemradiata : partialis quinque-sexradiata. Spicae semiunguiculares, cylindricae, acutiusculae: squamae lanceolatae, in aristam apice patulam attenuatae, ferrugineae; carina striata, villosa. Stamina tria. Semen subgloboso-compressiusculum.

2. FIMBPISTYLIS spicis ovatis pubescentibus, puberulum. involucro involucellisque diphyllis umbella composita umbellulisque longioribus.

Scirpus puberulus; foliis radicalibus angustissimis longis: umbella terminali sparsa; ramulis mono-tetrastachyis: spiculis crassiuscule ovatis; squamis minutim pubentibus, lato ovalibus: stylo fimbriato bifido. Mich. fl. bor. amer. I. p. $3 \mathrm{I}$.

Habitat in Carolina et Georgia.

Culıni pédales et ultra, superne striato-angulati, inferne foliosi. Folia culmo altiora, angusta. Spicae parvae: squamae mucronatae.

Planta junior tota pilosa, incana etiam spiculae, aetate fere glabra.

3. FIMBRISTYLIS spicis ovato-oblongis, involu- diphyluma cro diphyllo umbella composita breviore, flosculis 'monandris. 


\section{TRIANDRIA. MONOGYNIA.}

Scirpus diphyllus; culmis semicylindricis striatis diphyllis, umbella composita involucro diphyllo longiore. Retz. obs. 5. p.. .

Habitat in India orientali. König.

Glabrum, glaucum. Culmi bipedales et ultra, di-triphylli, apice angulato-subcompressi. Folia extima minora, intima culmo breviora. Involucri foliolum unicum vix longitudine umbellae vel brevius; partiale diphyllum, brevissimum. Umbella composita, sex-septemradiata, radius longior bipollicaris: partialis tri-quadriradiata. Squamae ovatae, mucronatae, pallide fuscae, nitidae. Stamen unicum. Semen subrotundum, cruciatim undulato-striatum.

$\boldsymbol{U} t$ in nonmullis aliis culmus parum infra umbetlam scaber.

tomenrosum. i4. FIMBRISTYLIS spicis ovatis acutis, involucro subpentaphyllo umbella composita longiore basi foliisque pilosissimis.

Habitat in India orientali, habui inter plantas ex regno Avae missas. 4

Totum piloso-incanum. Culmi bipedales vel ultra, tenues, compressi, apice subtrigoni ditriphylli. Folia culmo breviora, linearia, angusta. Involucri foliola duo umbella longiora, basi pilosissima. Umbella septemradiata: radii longiores tripollicares, plurimi; partialis bitriradiata. Spicae semine cannabis duplo majores, acuminatae: squamae ovatae, acutae, fuscae, tenellae pilosae, aetate glabrae, nitidae. Stamen unicum. Semen longitudinaliter striatum, transversim subunclulatum.

pilosun. 15. FIMBRISTYLIS spicis ovatis obtusis glabris, involucro diphyllo umbella subdecomposita breviore.

Mabitat in Insula Franciae, in Guinea Thonning. 4

Glaucum. Culmi saepe bipedales, tenues, apice subtrigoni, di-triphylli, glabri. Folia culmo breviora, angusta, inferne rare piloso-ciliata, vaginae pilosae, margine membranaceae, ferrugineae. Involucrum ciliatum: partiale diphyllum, brevissimum. Umbella circiter sexradiata: radius longior vix tripollicaris: parti- 
alis tri-quadripollicaris. Spiculae piso parum minores, obtusiusculae: squamae ovatae, latae, mucrone brevi terminatae, fuscae. Stamen unicum. Semen longitudinaliter undulato-striatum, substipitatum.

16. FIMBRISTYLIS spicis oblongis tortis, squa- arvense.

mis medio subtomentoso - canescentibus, involucro submonophyllo umbellam simplicem subaequante.

Scirpus arvensis; culmis compressis striatis, umbellis simplicibus, involucro submonophyllo brevi. Retz.obs. 4. p. I I.

Habitat in India orientali. König, Röttler. 4

Glaucum. Culmi spithamaei-pedales; inferne compressi, apice obsolete trigoni, basi squamis lanceolatis, semivaginantibus vestiti. Folium zinicum una cum culmo e vagina longiore, bitripollicare, lineare, erectum, acutum, rigidiusculum: vaginae membranaceae, ferrugineae. Involucrum mono-diphyllum, longius semipollicare. Umbella bi-quinqueradiata. Spicae acutae, plerumgue tortae: squamae oblongae, mucronatae, latere ferrugineae.

E septem speciminibus sex spicas omnes tortas habebant, septimum spicam tantummodo unicam.

17. FIMBRISTYLIS spicis oblongis, involucro unbellare. brevissimo, umbella simplici.

Scirpus umbellaris'; culmo nudo, umbella terminali simplici, involucro bivaivi brevissimo. Lamarck. illitstr.' $1 . " p .14 \mathrm{I}$.

Habitat - - Ex herbario Lamarckii.

Culmi subcompressi. Umbellae radii sex.

Forte varietas tantummodo sequentis.

18. FIMBRISTYLIS spicis orato-oblongis, squa- ferrugineum mis medio subtomentoso-incanis, involucro subdiphyllo umbellam simplicem aequante.

Gramen cyperoides majus, spicis ex oblongo rotundis compactis ferrugineis. Sloan. cat. 36 . hist. $\mathrm{x} . p .3^{\circ} \cdot t .77 \cdot f$. 1 .

Scirpus ferrugineus; culmo triquetro subnudo, involucris longitudine paniculae. Lin. syst. veg. 102. 


\section{TRIANDRIA. MONOGYNIA.}

Scirpus debilis; culmo filiformi nudo, umbella simplici depauperata, involucro bivalvi subciliato. Lamarck. illustr. I. p. I4I.

Habitat in Caribaeis. 4

Glaucum. Culmi sesquipedales, apice angulatosubcompressi, di-triphylli. Folia culmo breviora, filiformia, apice interdum sphacelata: vaginae margine membranaceae, ferrugineae. Involucrum di-triphyllum: foliolum unicum zumbella parum longius, rigidiusculum. Umbella tri-sexradiata; radius longior, pollicaris, interdum distachyus. Spicae magnitudine seminis tritici: squamae latae, ovatae, mucronatae, ferrugineae, dorso e villis minutissimis cinereae. Stamina tria. Semen flavum, laeve.

Uti in plurimis affinibus involucra basi subciliata. De synonymo Lamarckii non dubito, specimen enim Sc. debilis ab ipso habui.

kaxum. 19. FIMBRISTYLIS spicis ovatis glabris, involucro subdiphyllo umbella decomposita breviore, culmo foliisque filiformibus.

Habitat in America meridionali.: Richard. 4

Spiculae triplo minores quam in antecedente. Stamen unicum. Semen flavum subrotundum, longitudinaliter striatum, transversim undulatum.

Aliud specimen sub nomine Fimbr. hybridi mećum communicavit Dn. Richard, solummodo diversum culmo duplo crassiore, involucro zimbella breviore, piloso; ideoque separare non audeo.

Eastaneum. 20. FIMBRISTYLIS spicis ovato-oblongis obtusis, involucro diphyllo rigido umbellan subcompositam aequante.

Schoenus umbellatus; culmo subtriquetro folioso, floribus in umbellis compositis. Walt. $f l$. car. 70. secunclum Bosc.

Scirpus carolinianus; culmo nudo suhtriquetro filiformi, umbella composita, involucro diphyllo.longiusculo. Lamarck. illustr, $1, p .1420$

Scirpus castaneus; foliis radicalibus, angustissimis, longis, stricte erectis, rigidulis: culmo subtereti, striato: umbella terminali, brac- 
teis pluribus erectis involucrata, ramulis mono-tetrastachyis: spiculis subrotundo-ovatis, lucide nigricanti-castaneis; squamis suborhiculatis, pauciusculis: stylo fimbriato, bifido. Mich. fl. bor. amer. I. p. 3 I.

Halitat in Florida.

Glaucum. Culmi sesquipedales, rigidi, inferne foliosi, graciles. Folia angusta, rigida. Involucri foliola linearia, recta. Umbellae radii quinque -sex, longior pollicaris:- partialis unicus-quatuor, mono-distachyi, spisula altera inferior sessilis. Spicae piperis nigri magnitudine: squamae ovato-subrotundae, juniores dilute ferrugineae; substriatae, aetate castaneae.

Specimen quod a Lamarckio habui gaudet spiculis parum majoribus et villosioribus quam illud, quod in herbario Richardi vidi; quod Boscius mecum benevole communicavit parum tenerius et spiculis glabris, coeterum in omnibus simile.

21. FIMBRISTYLIS spicis oblongis, involucro mucronatur. submonophyllo brevi rigido, umbella simplici.

Habitat in insula Mahon. Richard. 24

Culmi trigoni, spongiosi. Involucrum e culmo continuato et e squama:opposita, ovata, acuta, fusco-. ferruginea, striata, dorso virescente. Umhella bi-quadriradiata: radii compressi, margine scabri. Spicae vix semiunguiculares, badiae, nitentes: Squarnae oblongae, obtusissimae, mucronatae, margine albido-membranaceae. Stamina tria.

Facies Scirpi lacustris.

22. FIMBRISTYLIS spicis cylindricis obtusissimis, cylindricum, involucro submonophyllo rigido umbellam simplicem aequante.

Scirpus palustris altissimus: capitulis fuscis cylindraceis paniculatis, culmum terminantibus. Gron. virg. II.

Habitat in America septentrionali. Bosc. 4

Culmi bipedales et ultra, tenues, apice triquetri. Folia culmo breviora, convoluto-filiformia, glaucescentia: vaginae fusco-nigricantes. Involucrum umbella parum brevius, lineare, pla- . num. Umbella quinqueradiata; rudü setacei, 
compressi, longior bipollicaris. Spicae fere unguiculares, penna columbina parum crassiores, arcte imbricatae, obtusae, spadiceae: squamae subrotundae, striatae; foliola duo setacea sub spicula, longius pedunculata. Stamina tria. Semen subrotundum, subcompressum, laeve.

spadiceum. 23. FIMBRISTYLIS spicis oblongis teretibus acutis, involucro diphyllo rigido umbellam decompositam aequante.

Gramen cyperoides majus aquaticum, paniculis plarimis junceis sparsis, spicis ex oblongosubrotundis spadiceis. Sloan-cat. 36. hist. 1. p. $118 . t$. $76 . f .2$.

Scirpus spadiceus; culmo triquetro nudo umbella subnuda, spicis oblongis sessilibus. Lin. syst. veg. 102 .

Scirpus spadiceus; culmo semitereti nudo retrorsum scabro, umbella composita, spicis dichotomiae sessilibus. Ecl. am. I. p. 7 .

Habitat in Caribaeis. 4

Culmi bi-tripedales, rigidi, marginibus retrorsum scabri. Folia angusta, culmo breviora. Involucri foliola erecta, linearia, partiale nullum nisi squamae duae subulatae, basi dilatatae, uti universale basi fusco-nigricantes. Umbella octo-novemradiata, radii langiores triquadripollicares: partialis octoradiata; radii omnes canciliculati, margine scabri. Spicae unguiculares arcte imbricatae, fusco-nitidae: squamae oblongae, obtusae, mucronatae. Stamina duo. Semen obovato-oblongum, ope lentis punctatum.

argentcum. 24. FIMBRISTYLIS spicis cylindricis obtusis glomerato-capitatis sessilibus.

Mullen-Pulla. Rheed. nial. 12. p. sor. t. 54. secundum liottböll.

Scirpus argenteus; culmis setaceis, triquetris; involucro tetraphyllo longissimo; spicis cylindricis plurimis in capitulo glomeratis. Rottb. gram. 5 เ. $t .17 \cdot f .6$.

Scirpus monander; culmo setaceo; involucro triphyllo, longo; capitulo sessili, glomerato; flosculis nonandris. Rottb. gram. 50. t. 14. f. 3 . 
Habitat in Indiae orientalis sylvis et graminosis humidiusculis. König.

Giauco-virescens. Culmi copiosi, digitales vel minores, setacei. Folia altitudine culmi vel breviora, setacea, patentia. Involucrum subtetraphyllum, capitulo multo longius. Capitulum hemisphaericum, piso duplo vel triplo majus. Spicae interdum viginti quinque, semiunguiculares: squamae ovatae, acutae, subargenteae, ferrugineo - striatae.

Scirpus monander Rotthöllii $a b$ èjusdem argentea non differt nisi numero staminum et culmo parum longiore, at Königius in argenteo stamen unicum dua-tria observavit.

Habitus. Culmi plures, erecti, enodes, inferne foliosi. Folia canaliculata, extrorsum margine scabra: : Involucrum structura foliorum. Umbellae radii monostachyi cum spica in centro sessili, interdum distachyi spica altera sessi$l i$, altera pedunculata, sensim, uti maturescunt semina, elongatae. Squamae carina virides.

Ingens Scirporum multitudo tantas difficultates in characteribus specierum constituendis parit, $u t$, licet omni cura adlizita, vix satis distincti possint obtineri, Culmi, fotia et reliqua notas tam paucas praebent, ut saepe differentia duarum specierum exprimi nequeat, quamuis manifeste appareat, illas non unam eandemque constituere speciem, ut taceam quod in nonmullis e nominatis partibus haud raro varient. Hiaec incommoda fortassis ex parte tollentur, dividendo genus. Consultius igitur duxi sub uns distincto genere has Scirporum species combinare, quia fructificatione aeque distant a Cirpis ac Pelargonium et Erodium $a$ Geranio. Eas Scirpis esse maxime affines et forte nonnisi sectionem ejusdern generis naturalis efficere

- palam est. Si itaque tanquam genus artificiale considerantur, hoc genus locum Scirpis proximum obtinet; si vero placet illas tantum ut sectionem Scirpi distinctam retinere, fundamentum primarium divisionis Scirporum crelmis polystachyis e fructificatione desumendum erit, qreod, nullis quippe variationibus olmoxium, illi e culmo paniculis foliaceis vel nudis petito curte f.̈revalebit. Individua enim haud raro 


\section{TRIANDRIA. MONOGYNIA.}

inveniuntur in una eademque radice, alia involucro folioso, alia nullo aut saltem tam brevi instructa, ut foliola squamarum potius quam foliorum nomen mereantur; unde rursus sequitur, ut, si exemplar speciei, involucro alias. gaudentis, ad manus est, inter paniculatas nudas frustra quaeratur, et tum forte vel tanquam species distincta falso proponatur, vel cum alia plane diversa combinetur. Habitum denique proprium et suum a quam plurimis Scirpis diversum hae species habent.

Character naturalis.

CAL. Spica undique imbricata: Squamis concavis, carinatis, flores clistinguentibus, sensim deciduis.

COR. nulla.

STAM. Filamenta plerumque tria, raro unicum vel duo. Antherae lineares.

PIST. Germen minimum. Stylus basi semigloboso-bulbosus, bulbo cum stylo decidente, sursum compressus, sensim dilatatus, margine ciliato-fimbriatus. Stigmata duo, capillaria.

PER. nullum.

SEM. unicum, lenticulare, utrinque convexum, basi acuminatum. Setae nullae.

RACHIS sensim elongata, confertissime foveolata; foveolis margine membranaceis.

120. Agrldgatida. Valvulae paleaceae, subdistiche imbricatae. Cor. o. Semen e basi styli persistente trigono acuminatum. Setae nullae.

sronostachya. x. ABILDGAAPDIA monandra, spica solitaria.

Gramen cypervides linimimum, spica simplici compacta, radice tubcrosa odorata. Sloan. catal. 36. hist. r. p. 120. t. 79.f. 2 .

Cyperus monostachyos; culmo triquetro nudo, spica simplici ovata terminali squanis mucronatis. Lirr. mant. 180. Swartz. obs. 29.

Cyperus culmis setaceis triquetris, subnudis; spica simplici, terminali, ovata; squamis infimis longius mucronatis. Rottb. gram. Is. $t$. I 3 f. 3 .

Mabitat in umbrosis Indiae orientalis Fönig, inque pascuis aridis Jamaicae et Hispaniolae. 
Caespitosa, glauca. Culmi spithamaei vel perixles, foliis longiores vel breviores, apice trigoni. Folia articulatione versus medumn recidua. Spica inguicularis.

2. ABILDGAAPDIA triandra, spicis ternis.

Cyperus triflorus; culmo triquetro nudo, umbella tristachya, intermedia sessili, spiculis laevigatis. Lin. mant. iso.

Schoenus cyperoides; culmo compresso semitereti nudo, spicis sessilibus lanceolatis tortis, infima involucrata. Retz. obs. +. p. s.

Habitat in pascuis aridis Indiae orientalis. König. Culmi pedales-bipedales, erecti, rigidiusculi, basi bulhosi, vaginis aridis sordide fuscis cum foliis involuti, inferne teretes, superne semileretes. Folia culmo breviora, canaliculata, laevia. Spicae tres-quatuor; laterales pectunctuZatae, intermestia sessilis, interdum zurica absque radiis lateralibus, pollicares, attenuatae, tortae; valvulae carinatae, inferiores Freviores, angustiores, mucrone acuminatae. Stamina tria.

Iabitus. Culni basi foliosi. Folia cannlicula$t a$, vaginantia. Spicae ovato-oblongae: compressae, saepe tortae, acutae. Squamae laevissimae, nitidae, allidae, carina virides, punctis purpatreis adspersae; diuae infimae angustiores.

\section{Character neturalis.}

CAL. Spica subdistiche imbricata: squamis ovatis, mucronatis, concavis, compressis, flores. distingleertibus.

COP. nulla.

STAM. Filamentum zenicum vel tria, s1sh germine inserta, sensim aetate longiora. Antiherae filamento longiores.

PiST. Germen acute trigonim, apice suthcoaretatum. Stylus basi pyrminidato-bulbosus; bul. bo trigono, germine ampliore, persistente; sursum setacezis. Stigmata tria, stylo breviora.

SEM. subpyriforme, trigonum, basi angustatım, apice basi styli acuminatum: lateribus convexis; punctato-scabrum, niveum. Sctae muliae.

RACHIS filiformis, sensin elongata, foneolata; foueolae margine membraceae e bnsi valuularum remanente, fertugines punctatae. 


\section{TRIANDRIA. MONOGYNIA.}

Memoriam Petri Chr. Abildgaardii, Dani, olimartis veterinariae Prof., qui ad Rottböllii Graminologiam plurima contribuit, veneraturus, huic seneri nomen ejus imposui.

12I. CYPFRUS. Squamae paleaceae, carinatae, distiche imbricatae. Cor. ○. Sem. 1. nudum.

* Culmo tereti.

pectinatus. I. CYPERUS spiculis terminalibus sessilibus oblongis obtusis laevibus involucrum aequantibus.

Habitat in Guinea. Isert.

Culmi plures, pedales, basi vaginis duabus tecti; interior triplo vel quadruplo, longior: Folia nulla. Involucri foliola duo vel nulla, subulata, rigida, spiculis vix longiora. Spiculae tres-octo, unguiculares, latae, trigintaflorae, complanatae, e valvularum apice patente dentatae, flavescentes: valvulae lanceolatae, acutae. Semen compressum, oblongum, altero latere subcarinatum, medio fuscum, margine flavum.

Menarius. 2. CYPERUS spiculis ovatis subgloboso-capitatis invulucro subdiphyllo brevioribus, culmo teretiusculo basi folioso.

Gramen cyperoides maderaspatanum, capite ex spicis plurimis acuminatis, in cacumine caulis glomerato. Plukn. alm. 17\%. t. 309. f. 7 .

Scirpus maderaspatanus, capitulo squamoso subgloboso. Scheuchz. gram. 369.

Cyperus arenarius; culmo compresso nudo, spicis capituli glomeratis sessilibus, involucro submonuphyllo. Ketz. obs. $4 \cdot$ p. 9.

Habitat in arena mobili Indiae orientalis. König. 2

Radices longae, repentes, squamis lanceolatis ferrugineis striatis vaginatae, ad geniculos surculos simplices, bi-vel trificlos, adscendentes emittentes. Culmus ex singulo apice surculi, palmaris vel parum ultra, gracilis. Folia plura, nonnulla culmo longiora, ejusque latitudinis. Capitulum avcllanae fere magnitudine. Involucrum plerumque diphyllim, interdum tripiryllum, rarius monophyllum: foliolo altero saepe triplo vel quadruplo lon- 
giore, altero capitulo parum longiore vel aequali. Spiculae septem-octo, sessiles, duodecim-quatuordecimflorae: valvulae ovatae, acutae, striatae, griseo-purpurascentes, margine membranaceae.

Tota canescenti-viridis. Caulis teretiusculus. Spiculae albicantes. König.

3. CYPERUS spiculis oblongis obtusis capitatis, tëner. valvulis striatis, culmo nudo.

Habitat in Guzuratc.

Culmus tenuis, aphyllus, perlalis. Capitulum laterale supra mecliurn. Spiculae septem-novem, vix unguiculares. Squamae ovatae, mucronatae, flavae, carinatce, virides. Semina globoso-triquetra, ope lentis transversim undulata.

4. CYPERUS capitulis ovatis glomeratis involucro refexus, triphyllo reflexo brevioribus, spiculis ovatis, culmo semitereti.

Habitat in Monte video Commerson. Ex herbario Jussiaei.

Culmi erecti, stricti, basi foliosi. Folia pauca, linearia, brevia, canaliculata, margine laevia. Capitulum magnitudine cerasi, e plurimis minoribus sessilibus congestum. Involucri foliola linearia, angustissima, margine laevia, planiuscula; longius bi-tripollicare. Spiculae parvae, acutae, quinqueflorae: valvulae ovatae, carinatae, acutae, fuscae, carina virescentes, minime striatae.

5. CYPERUS capitulis glohosis glomeratis prolife- prolifer. ris, spiculis ovatis, válvulis margine membranaceis.

Cyperus glomeratus, culmo tereti, capitulo globoso prolifero. Thunb. prodr. 18.

Habitat in Cap. h. spei.

Culmus sesquipedalis. Capitulum sessile, congestum, piso parum majus, duo vel tria alia breviter pedunculata. Spiculae brevissimae: valvulae lanceolatae.

Rottbüllii Scirpus prolifer est genuina species Scirpi ideoque non hujus loci, Thunbergii vero huc pertinet fide speciminis ab ipso missi.

6. CYPERUS spiculis aggregatis lanceolatis, um- cra:sipes. bella contracta radiis brevissimis. 
Habilat ad Senega1? Ex herbario Jussiaei.

Cuimus pedalis, crassitie pennae cygneae, rectus, basifoliosus. Folia altitudine cumi, carinata, laevia, glauco-viridia. Umbellae radii contracti in capitulum magnitudine pomi minoris. Spiculae plures, semipolticares, compressae, septemulecimflorae: valvulae acutae.

serrulatus. 7. CYPERUS spiculis subcapitatis lanceolato-oblongis obtusis, involucro triphyllo, foliis lineari - lanceolatis.

Habitat in Madagascar. Ex herbario horti parisini.

Culmi spithamaei vel parum ultra, basi foliosi, sulicompressi, uti folia glauci. Folia culmo altiora, attenuata, margine serrulato-scabra, basi fusca. Involucri foliola duo capitulo multo longiora. Umbella simplex, quadriquinqueradiata: radiis brevissimis, fere in caritulum contractis. Spiculae,sessiles, sex-septem, innguiculares, latae, compressae, decemflorae: valvulae ovatae, obtusae, vix striatae.

effus:1s. 8. CY PERUS capitulis subternis intermedio sessili, spiculis oblongis, involucris rigidis unico longiore adunco.

Cyperus effusus; culmo tereti subligneo, umbella rara, spicis conglomeratis, involucro subulato, triphyllo. Rottb. gram. 22. t. i2.f. 3 .

Habitat in Arabia. Forstâl.

Culmi crassitie fere pennae columbinae, duri, vix striati. Capitula solitaria duo vel tria. Involucrum universale di-triphyllum: foliolum mrximum e culmo continuato, sesquipollicare, capitulo vel umbella longius; subulatum, anceps, canaliculatum; reliqua subuiaia, umbella breviora; omnia margine denticulato-scabra. Spiculae circiter septem in singulo capitulo, ungusiculares, oblongo-lanceolatae, acutae, ad lentem subpubescentes; flosculi 2 1-31: valvulae ovatae, carinatae, acumine brevi terminatae, concavae, margine parum membranaccae, sordicie flavescentes, nitidiusculae.

spicigetus. g. CYPERUS spicis cylindricis imbricatis, spiculis subulatis, involucro hexaphyllo umbella simplici multoties breviore. 
Habitat prope Para, ad ripam dextram fluminis Amazonum. Richard. 4

Culmus sesquipedalis et forte ultra. Folia nulla. Involucri foliola unguicularia, aequalia, unicum ovatum, acuminatum, reliqua subulata. Ochreae semiunguiculares, bifidae, fuscae. Umbellae radii novem, pollicares, vel minores. Spiculae numerosae, confertae in spicam fere pollicarem, quadriflorae, parvae: valvulae angustae, margine membranaceae, fusco-virescentes.

10. CYPERUS spiculis umbellatis ovatis, foliis su-collinus. bulatis canaliculatis, culmo retrorsum scabro.

Cyperus striatus; culmo tereti striato nudo, spicis ovatis pedunculatis, inaequalibus; terminalibus umbellatis, Fl. per. 1. pag. 47.

Habitat in collibus aridis Peruviae.

Radix fibrosa. Culmus erectus, filiformis, foliis paulo longior. Folia usque ad medium vaginantia, inferne margine ciliata. Valvulae ovatae, atropurpureae. Semen acuminalum, nitidum. Fl. per. $l$. $c$.

II. CYPERUS spiculis compressis elongatis niti- articulatus. diusculis, involucro subnullo, culmo articulato.

Apoyomatli. Hern. mex. 33.

Juncus cyperoides creberrime geniculatus medulla farctus aquaticus, radice rubra tuberosa. Sloan. cat. 36 . hist. I. p. 121. t. 81,f. I.

Cyperus articulatus; culmo tereti nudo articulato. Lin. syst. veg. 98 .

Habitat in rivulis Caribaearum et Guinea. 24

Culmus inferne crassitie digiti minimi, sensim attenuatus. Folia nulla: vaginae palmares et ultra, purpurascentes. Involucrum squamae dure, lineari-lanceolatae, longior vix unguicularis. Umbella subsimplex, sex-rarliata; radii altero latere, convexi, altero canaliculati, longior bipollicaris. Spiculae pollicares, interdum sesquipollicares, tres-decem, sessiles, alternae, approximatae, lineares, attenuatae, acutae, trigintasexflorae: valvulae lineari-lan. ceolatae, acutae, flavescentes. 


\section{TRIANDRIA. MONOGYNIA:}

Cyp. articulatum americanum $a b$ aegyptiaco et indico separare ausus fui, collatis enim plurimis individuis ex hisce regionibus, vidi quod aegyptiacus et indicus conveniznt, et in nonnullis $a b$ americano differunt.

niloticus. 12. CYPERUS spiculis compressis brevibus, involucris subnullis, culmo articulato.

Cyperus niloticus; culmo tereti, nudo, aequali, non arsiculato; umbella composita; spicis globosis. Forsk. descr. p. 13.

Habitat ad ripam Niil occidentalem limosan Rosette. Forshâl. 4

Involucri squamae ovato-lanceolatae, attenuatae, cinereae, ferrugineo marginatae. Umbellae radii universalis novem, longiores tripollicares; partialis gemini. Stylus trifidus.

Convenit cum praecedente: culmo, longitudine involucri, radiis umbellae filiformibus, figura et colore valvularum flosculorum, differt vero: Involucris foliolis latioribus: Umb̌ellae radiis pluribus, usque ad novem, longioribus: Spiculis pluribus, quatuor ad tredecim, vix unguicularibus: angustioribus, magis approximatis, minime nitidis, acutis, nec attenuatis: Flosculis paucioribus, vix ultra viginti, terminalibus saepe divaricatis.

Culmus sesquicubitalis, basi crassitie digiti minimi, sensim angustatus. Forsk. l. c.

Forte culmus in gramine vivo aequalis est, sed cum spongiosus est et isthmis interceptus ex auctoritate ipsius inventoris, per se patet quod exsiccatione inter isthmos collabi debeat et articulatus evadere. Specimina ex India orientali ab aegyptiacis nullo modo differunt.

Koenigii, 13. CYPERUS spiculis teretiusculis brevibus, involucro triphyllo umbella breviore, culmo aequali.

Habitat in India orientali. König. 4

Habitus omnino duorum praecedentium at Culmus minime articulatus. Involucri foliola tria, sesquipollicaria, graminea. Spiculae teretiusculae, angustiores: valvulae striatae, pallide virides, margine albidae. Umbella composita: 


\section{TRIANDRIA. MONOGYNIA: 303}

universalis novemradiata; radius longior quadripollicaris; partiales bi-quinqueradiatae. Flosculi vix ultra viginti.

14. CYPERUS spiculis lanceolatis, valvulis mu-pusillus. cronatis, involucro tetraphyllo umbella longiore.

Cyperus pygmaeus, culmo tereti, umbella composita involucrata, spicis lanceolatis, glumis mucronatis. Retz. obs. +. p. 9 .

Habitat in arenosis Tranquebariae. König.

Culmus vix sesquipollicaris. Folia radicalia, culmo duplo longiora, filiformia. Umbella composita; radii partiales quinque-sex, quadrisexflori: valvulae pallidae, medio rufo fuscae. Retzius. $l$. c.

35. CYPERUS spiculis oblongis brunneis, umbel- marginatus. la composita. Thunb. prodr. 18. +

Habitat in Cap. b. spei. 4

6. CYPERUS spiculis aggregatis ovatis subsquar- viscosts. rosis, involucro umbella longiore, foliis convoluto-teretibus involucrisque asperis.

Cyperus odoratus viscosus subteres maritimus, spicillis compressis conglobatis et radiatis. Brow. jam. $129 . n$. iा.

Cyperus elegans. Rottb. gram. 34. t. 6. f. 4. fide herb. Rottb.

Cyperus viscosus; culmo compresso basi viscido, foliis asperis apice triquetris. Hort. kew. I. p. 79 .

Cyperus viscosus; culmo triquetro nudo, foliis convoluto - teretibus, umbella foliosa decomposita, spicis confertis, spiculis compressis ovatis. Swartz. fl. ind. occid, 1. p. I 13 . Jacqu. suppl. 32. Ic. rar. 2. t. 295.

Habitat in humidis maritimis Caribaearum. 24

Viscosus. Culmus bi-tripedalis, nudus, striatus, subcompressus, superne semiteres, apice vix trigonus. Folia altitudine culmi, striata: vaginae margine membranaceae, humore viscosoresinoso odorato culmo agglutinatae. Involuc.um tri-tetraphyllum: foliolum unicum umbella brevius, reliqua longiora, unicum inter. dum sesquipedale; omnia convoluta, sursum iriquetra, ex angulis denticulatis asperrima: 


\section{jo4 TRIANDRIA. MONOGYNIA.}

involucella subtriphylla, eapitulo breviora, reflexa. Ochreae breves, bidentatae. Umbella composita, quinque-septemradiata: radiis tri-quadripollicaribus vel minoribus, trigonis; partiales bi-quinqueradiatae: radiis horizontaliter patentibus, inaequalibus. Spiculae septemsedecim, ovatae, novem vel undecimflorae: valvulae ovatae, carinatae, acuminatae, striatae, pallide virides, margine fuscae.' Umbella interdum simplex.

compactus. 17. CYPERUS spiculis subulatis capitatis subspiralibus, involucro pentaphyllo. $t$

Cyperus compactus; umbella decomposita, involucro pentaphyllo, spiculis congestis subspilalibus. Retz. obs. ${ }^{*}$. p. 10.

Habitat in China.

Culmus bipedalis, inferne foliosus. Folia altitudine fere culmi, linearia, margine carinaque inermia: vaginae purpurascentes. Involucri foliolum unicum sesquipedale, Urevissimum tripollicare, margine scabra: involucella pro radiorum numero, capitulo breviora, ciliata. Umbella decomposita, tri-quinqueradiata. Cajitula compacta e spiculis patentissimis, semipollicaribus, sessilibus, lineari-subulatis, ferrugineis, sexfloris: valvulae subulatae, striutae, margine conniventes, purpurascentes, carina viridi. Retz. $l$. $c$.

rextilis. I8. CYPERUS spicis corymbosis, spiculis Jinearilanceolatis terminalibus, involvcro dodecaphyllo umbella longiore.

Cyperus textilis; culmo tereti, umbella decomposita involucro doriecaphyllo laevi breviore, spiculis oblongis. Thunb. prodr. Is.

Habitat in Cap. b. spei. Stadtmann. 4

Culmi penna columbina vix crassiores, vix striati. Involucri universalis foliola semipedalia vel breviora, omnia umbjella longiora, margine serrulato-scabra: partiale nullum. Ochreae breves, membranaceae, oblique truncatae. Umbella subdecomposita. Spiculae ierminales, tres-quinqus, circiter quatuordecimflorae, acutae, sordide flavescentes: valvulae lanceolatae, acutae. 


\section{TRIANDRIA. MONOGYNIA. 305}

I9. CYPERUS spicis corymbosis, spiculis alternis pennatus: confertis, involucro hexaphyllo, culmo semitereti.

Cyperus pennatus; culmo semitereti, umbel. la supradecomposita foliosa, spiculis alternis confertis pennatis, paucifloris. Lamarck. illusir. 1. p. I4\%.

Habitat in Java Commerson. Ex herbario Jussiaei.

Involucri foliola margine scabra. Umbella supradecomposita: radii sex-septem, ramosi: rami alterni. Spiculae alternae, sessiles, actltae, pallide ferrugineae, quinqueflorae: valvulae ovatae, acutae, striatae, margine tenuissimo membranaceo cinctae.

* Culmo triquetro.

- Spiculis solitariis vel aggregatis.

20. CYPERUS spicula solitaria oblonga subtriflora, depauperainvolucro nullo, culmis capillaribus incurvis.

tus.

Habitat in India occidentali. $v$. Rohr.

Culmi vix longitudine digiti minimi, tenuissimi, triquetri, nudi. Spicula magnitudine capituli aciculae, bi-triflora: valvulae lanceolatae, laeves, purpurascentes, margine membranaceae.

2r. CYPERUS spicula solitaria subquinqueflora, setaceus. involucro nullo, culmis setaceis rectis.

Cyperus setaceus; culmis setaceis striato-angulosis nudis, spica terminali subquadriflora nuda. Retz. obs. 5. p. xо.

Habitat in graminosis humidiuscutis Calcutae. Facies Scirpi setacei. Culmi plures, digitales, erecti, basi vaginati. Folia nulla: vagina semipollicaris, purpurascens. Spicula ovata, quadri-quinque-sexflora: valvulae vix striatae, margine membranaceae, dorso albido-virescentes, disco purpurascentes.

22. CYPERUS spiculis solitariis geminisque sessili- tenallws. bus, involucror monophyllo, culmis setaceis.

Gramen.parvum aethiopicum tenuissimis foliis, spica simplici et gemella. Plukn. alm. 176 . $t$. 300. $f .4$. 5 .

Cyperus lateralis; culmo teretiusculo nudo, spica laterali sessili. Lin. suppl. 102. 


\section{TRIANDRIA. MONOGYNIA.}

Cyperus tenellus; culmo nudo setaceo, spicis solitariis geminisque sessilibus. Lin. suppl. го3.

Cyperus minimus; culmo capillari, spica solitaria geminaque, involucro monophyllo. Thunb. prodr. 18.

Cyperus pygmaeus; culmo teretiusculo nudo vix unciali, spica sessili sub apice, squamis striatis. Lamarck. illustr. ז. p. $1+3$.

Habitat ad Cap. b. spei. ()

Culmi plures, digitales vel pollicares. Spicula unica vel geminae, infra apicem culmi, oblongae, decem-duodecimflorae: valvulae ovatae, acutae, striatae, pallide virides, interdum margine pallite ferrugineae.

Scirpi setacei varietates Rottböllii capitulis undique imbricatis, fide herbarii ipsius, omnes gaudent, ergo genuinae Scirpi species sunt, neque huc ut synonyma pertinere possunt.

inucronatus. 23. CYPERUS spiculis lineari-lanceolatis aggregatis, involucro diphyllo, culmis erectis apice trigonis, radice repente.

gumilus. $u$. Cyperus panicula minima radice rubra; inodora, repente. Tournef. cor. 39. Ex herbario Tournefortii.

albidus. $\quad$ s. Cyperus mucronatus; scapo nudo vaginato triquetro, involucro monophyllo stricto, spicis subternis sessilibus. Rottb. gram. 19. t.-8. f. 4 .

Cyperus lateralis; culmo tereti, basi vaginatofolioso, capitulo laterali. Forsk. descr. p. 13.

Cyperus mucronatus; culmo tereti? nudo, spicis lateralibus sessilibus, involucro monophyllo. Retz. obs. 5. p. Iо.

macrostachyos. $\gamma$. spicis pollicaribus.

ster. d. Cyperus distachyos; culmo triquetro nudo, spicis sessilibus lateralibus, radice perenni. Allion. auct. 48 . t. $2 . f .5$.

Cyperus junciformis; culmo mucronato, spiculis lateralibus, nigris, abફque involucro. $\mathrm{Ca}$ van. ic. 3. p. 2. t. $204 . f$. $\mathrm{r}$.

Cyperus junciformis; culmo junciformi, subtereti, basi monophyllo; spiculis aggregatis sessilibus; spatha diphylla; folio altero spiculis breviore. Desfont. fl. atlant. I. p. 42. t. 7 . f. I. 
Cyperus distachyos; culmo triquetro filiformi basi folioso, spicis binis sessilibus involucro brevioribus. Wilden. spec. pl. ז. p. 272.

Habitat $\alpha$. in Oriente, $\beta$. in Arabia et in scaturiginosis ad Wissapatnam, $\gamma$. in Aegypto. Desfontaines, $\delta$. in Italia, Hispania, Barbaria et Aegypto. 4

Radix stolonifera; stolones articulati, saepe nodosi, flexuosi, tecti vaginis ferrugineis, striatis. Culmi ex singulo geniculo solitarii, gemini vel terni, plerumque duo e singula vagina alter floriferus alter sterilis, inferne teretes, sub spiculis trigoni, pallide virides. Folium ex apice vaginae longioris, unguiculare vel brevius, setaceum: vaginae tres, membranaceae, fuscae; extima brevissima, reliquis latior, mucronata, intima pollicaris et ultra. Involucrum praeter culmum continuatum diphyllum vel monophyllum: foliola brevissima, linearia, basi dilatata. Spiculae solitariae, duodecim, saepe vigintiflorae: valvulae ovatae, obtusiusculae, concavae, nitidae.

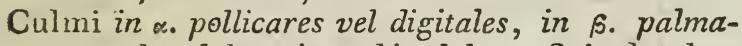
res vel pedales, in $\gamma$. bipedales. Spiculae longiores vel breviores, acutiores vel obtusiores: intermedia saepe pedicellata; in $\alpha$. et $\delta$. nigrae, in $\beta$. et $\%$ albidae. C. Junciformis et distachyos a mucronato non nisi colore spicularum differunt; uti et monuit amicissimus Desfontaines in literis, qui omnes varietates ex Aegypto habuit.

24. CYPLRUS spiculis ovato-oblongis aggregatis, culmis prostratis, radice fibrosa.

Cyperus pannonicus; culmo triquetro, spicis sessilibus, glumis lateralibus sphacelatis. Lin. suppl.' 103. Jacqu. austr. 5. app. 24. t. 6.

Habitat in Austria, Hungaria. (-)

Similis praecedenti, diversus: Radice fibrosa, annua; Culmis plurimis prostratis; Spiculis obtusioribus.

Spiculae juniores totae albidae, interdum solitariae.

25. CYPERUS spiculis aggregatis oblongo-lanceo- margaritalatis, involucrum tetraphyllum subaequantibus, ceus. foliis convoluto - subulatis culmoque rigidis: 
Habitat in Guinea. Isert, Thonning.

Culmi caespitosi, pedales' et ultra, tenues, obtuse angulati, basi e congerie vaginarum ferruginearum subbulbosi. Folia spithamaea, convoluta, canaliculata, subglaucescentia. Involucri foliola patentissima, rigida, acuta, duo spiculis parum longiora, duo breviora. Spiculae quatuor vel quinque, stibpollicares, ungue dimidio latiores, circiter vigintiflorae, nitidae, niveàe: valvulae ovatas, obtusae, striatae, apice fuscescentes.

nivers. zó. CYPERUS spiculis aggregatis valrulisque lanceolatis, involucro diphyllo brevioribus, culmo debili filiformi.

Cyperus niveus; culmo triquetro filiformi nudo, umbella terminali sessili diphylla, spicis compressis lanceolatis. Retz. obs. 5. p. 12.

Habitat in Indiae orientalis nemorosis. König.

Culmus sesquipedalis, nudus, obtuse angulatus. Folia radicalia, pauca, brevia, angusta. Involucri foliola angusta, laevia, unicum spiculis triplo longius. Spiculae circiter duodecim, subpollicares, semiunguem fere latae, interdum triginta sexflorae, valde compressae, obtusiusculae, niveae: valvulae attenuatae, acutae, striatae; infimae steriles.

btusiforus. 27. CYPERUS spiculis aggregatis ovatis obtusis, involucro diphyllo brevioribus, foliis carinatis culmoque rigidis.

Habitat in Madagascar. Ex herbario Lamarckii.

Culmus semipedalis, basi e foliis congestis bulbosus, nudus; angulis acutis. Folia radicalia, plurima, bi-tripollicaria, attenuata, margine laevia, basi fusco-ferruginea. Involucri foliola rigida, subreflexa; unicum capitulo duplo longius, alterum ejus longitudinis. Spiculae circiter undecim in capitulo subgloboso, semiunguiculares, parum angustiores, octodecimflorae, sordide niveae: valvulae lineari-lanceolatae, leviter striatae.

rubicundus. 2૬. CYPERUS spiculis aggregatis oblỏngis obtusis, involucro diphyllo brevioribus, foliis linearihus culmoque filiformi laxis.

Habitat in Puertorico. Ventenat. 
Culmi caespitosi, spithamaei, acute angulati, nu. di, basi vaginis foliorum aridis ferrugineis tecti. Folia plura, angusta, nonnulla altitudine culmi. Involucri foliola patentia : unicum capitulo duplo longitus, alterum parum brevius; filiformia. Spiculae octo, unguiculares, in capitulo subgloboso callectae, circiter octodecimflorae: valvulae teneriores quam in affininibus, ovatae, striatae, attenuatue, apice patulae, purpurascentes, margine membranaceae.

29. CYPERUS spiculis aggregatis obtusis involu- rigidus. cro tetraphyllo brevioribus, foliis culmoque rigidis, radice repente.

Habitat in Madagascar. Ex herbario Lamarckii. Similis praecedenti, diversus: Padice repente; Culma semipollicari obtusangulo; Involucro tetraphyllo; Valvulis latioribus.

Facies Schoeni mucronati. Radix penna anserina crassior, tecta squamis confertis, ovatis, striatis, fusco-ferrugineis. Folia et involucra $e$ rigiditate subpungentia, culmo altiora. Involucri foliola basi dilatata, uti folia intus albida. Valvulae obtusae.

Hic, uti quatuor praecedentes nec non Cyp. pectinatus, ab omnibus reliquis dignoscitur spiculis latis et valde compressis, carinatis. Reliqua differentia patet e descriptionibus.

3o. CYPERUS capitulo globoso, spiculis lineari- giobnsus. lanceolatis, involucro tetraphyllo longissimo dependente.

Cyperus globosus; radice perenni, cespitosus, planifolius, culmo triquetro, foliis breviore, capitulo globoso terminali, involucro tetraphyllo. Allion. Auct. 49.

Habitat in pratis spongiosis ad flumen La Var. Bellardi. 4

Culmus pedalis et ultra, angulis acutis, rigidus. Folia radicalia, altitudine culmi: unicum altius; culmo parum latiora, canaliculato-triquetra, margine vix scabra. Involucri foliola capitulo multoties longiora, foliis simillima. Capitulum magnitudine juglandis. Spiculae numerosissimae, sessiles, unguiculares, circiter 


\section{TRIANDRIA. MONOGYNIA.}

vigintiflorae, nitidiusculae: valvulae linearilanceolatae, obtusae, carina et margine vire. scentes, disco purpureae.

zecurvws. 31. CYPERUS capitulo involucro triphyllo breviore, valvulis obtusis aristatis, aristis recurvatis, culmo foliisque setaceis.

Habitat ad Sierram Leonam. Ex herbario Thouini vel Lamarckii.

Culmi plures, digitales et ultra, basi foliosi. Folia altitudine culmi. Involucri foliola setacea, pollicaria. Capitulum piso parum majus, globosum. Spiculae decem-viginti, vix unguiculares, lineares, angustae, patulae, circiter vigintiflorae: valvulae laxae, lineares, purpureae, dorso virides; arista longitudine valvulae, uncinato-recurvata, viridis.

Distinctissimus a Cypero aristato.

Iaevigatus. 32. CYPERUS capitulo globoso involucro diphyllo breviore, spiculis valvulisque obtusis.

Cyperus laevigatus, culmo triquetro nudo, capitulo diphyllo, floribus laevigatis. Lin. mant. 179. Rottb. gram. 19. t. 16. $f$. เ.

Cyperus laevigatus; culmo trigono, capitulo glomerato-globoso, involucro diphyllo. Thunb. prodr. 18.

Habitat in Cap. b. spei.

Culmi bipedales, crassitie fere pennae anserinae, spongiosi, siccitate collabentes, minime vero articulati. Capitulum nuce coryli parum minus. Involucri foliola subulata, canuliculata: majore erecto, minore patulo. Spiculae quatuordeoim ad triginta, albidae, sedecim-vigintiflorae: valvulae dorso striatae, latere laeves.

sphaeroce- 33. CYPERUS capitulis globosis, spiculis ovatis phalus. obtusis, foliis convoluto subulatis, culmo obtusangulo rigido.

Habitat in Cap. b. spei. 4

Radix repens, crassitie digiti minimi, residuis foliorum nigricantibus tecta. Culmus semipedalis. Folia radicalia, tri-quadripollicaria, viridi-glauca. Involucrum bi-triphyllum: duo foliola capitulo longiora, rigida. Capitulum magnitudine nucis coryli. Spiculae octo-duo- 
decim, fere unguiculares, octoflorae, nitidae: valvulae lanceolatae, obtusae, striatae, totae flavo-ferrugineae.

34. CYPERUS spiculis capitatis ovatis complana- striatulus. tis, valvulis lanceolatis, involucro triphyllo, culmo acutangulo.

Cyperus compactus; culmo triquetro nudo, capitulo terminali subtriphyllo, squamis striatis obtusiusculis. Lamarck. illustr. I. p. 144.

Habitat in Madagascar, Commerson. Ex herbario Jussiaei.

Culmi saepe perlales. Folia radicalia, culmo dimidio breviora, attenuata. Involucri foliolum unicum bipollicare; tertium longitudine capituli. Spiculae plures, multiflorae, pallidae: valvulae striatae.

35. CYPERUS capitulo glohoso involucro triphyllo cephalotes. breviore, spiculis complanatis valvulisque ovatis, culmo obtusangulo.

Habitat in insulis Nicobaricis in aquosis.

Radix longissina, fere sesquiperlalis, sensim attenuata. Culmus semipedalis, crassitie pennae columbinae, erectus. Folia duo, radicalia, altitudine fere culmi, vix duas lineas lata. Cajitulum magnitudine fere nucis juglandis, comjiactum. Spiculae numerosissimae, vis semiunguiculares, quatuordecimflorae, confertissimae. obtusiusculae: valvulae carinatae, acutae, dorso striatae, virides, lateribus laevibus, nitidiusculis, fusco-ferrugineis, margine angustissimo membranaceo.

36. CYPERUS capitulo globoso, spiculis teretibus, scirpoides. involucris foliisque canaliculatis recurvis rigidis.

Habitat in Guinea. Thonning. 4

Rarlix repens, perna cygnea crassior, tecta basi foliorum emarcidorum. Culmi vix pedales, adscendentes, obtuse angulati, rigidi. Folia radicalia, culmo altiora, vix lineam lata, convoluto-canaliculata, extrorsum recurva, margine ar basin serrulata, carina laevia. Involucxi foliola tria exteriora, tria interiora, omnia capitulo longiora, unicum culmo vix brevius, foliis simillima. Capitulum nuce arellana 


\section{I2 TRIANDRIA. MONOGYNIA.}

majus, globosum. Spiculae plurimae, unguiculares, crassiores quam in ulla alia specie, octo-decemflorae, acutae, pallide fuscae: valvulae ovato-lanceolatae, convexae, striatae. Stigmata tria.

Facies scirpi, at valvulae bifariam imbricatae et setae nullae ad basin germinis.

coloratus. 37. CYPERUS capitulo ovato, spiculis oblongis subquinquefloris, involucro pentaphyllo foliisque culmo longioribus laxis.

Habitat in Guinea. Thonning.

Culmus semipedalis, trigonus, foliosus. Folia plura, culmo saepe duplo altiora, linearia, laxa. Vaginae culmo parum ampliores, membranaceae. Involucrum pentaphyllum, dependens: foliola duo culmo longiora; basi niveum. Capitulum ovatum, nuce coryli parum minus. Spiculae copiosae, oblongae: squamae ovatae, mucronatae, concavae, multinerviae, apice saepe flavescentes. Stamina tria. Stylus trifidus. Setae nullac.

Similis Cyp. kyllingaeoidi, at squamae undique imbricatae. Maxime affinis Sc micheliano.

Alium e Guinea attulit Dn. Thonning, foliis plurimis, filiformibus, quadri-quinquepollicaribus, dependentibus inter spiculas inferiores, an diversum?

kyllingaeoi-38. CYPERUS capitulo globoso, spiculis oblongis des. convexis suboctofloris, involucro tetraphyllo foliisque carinatis laxis.

Cyperus dubius; culmo setaceo triquetro, capitulo terminali, involucro tetraphyllo longissimo. Rottb. gram. 20. t. 4. f. 5. fide herb. Rottb.

Habitat in Indiae orientalis umbrosis graminosis. König:

Facies exacte Kyllingae monocephalae. Culmi plures palmares vel spithamaei, filiformes, interdum tenuiores, basi foliosi, e vaginis plurimis congestis bulbosi. Folia pauca, unicum saepe altitudine culmi, reliqua breviora, linearia, angusta, carinata: vaginae aridae, striatae, fusco punctatae. Involucri foliola incegualia, unicum tripollicare patentissimum, re- 
liqua reflexa, facie foliorum. Spiculae numerosissimae, in capitulum piso duplo majus confertissimae, breves, quadri-octoflorae, acutae: valvulae ovatae, concavae, obtusae, striatae, ope lentis purpureo punctatae. Semen oblongum, triquetrum.

Omnino diversus a Cyp. leucocephalo Retzii. Specimina mea exacte converiunt cum Rottböllii. Cum nihil dubï habet, nomen triviale mihi maxime absonum visum es ideoque, hoc loco a regula communi recedi.

39. CYPERUS spiculis lato-ovatis capitatis, val- leucocephravulis ubtusis, involucro subtetraphyllo setaceo, lus. foliis culmo filiformi hrevioribus. $\leftarrow$

Cyperus leucocephalus; culmio setaceo triquetro nudo, capitulo sessili, involucro subietraphyllo patentissimo, floribus monandris. Retz. obs. 5. p. i1.

Habitat in nemorosis Tschandranconae. König.

Radix bulbosa, oblonga, fibris longis capillaceis. Culmi semipedales, basi vaginis emarcidis ve-, stiti. Folia graminea. Involucrum plerumque polyphyllum, foliolo longiore pollicari. Spiculae octo-duodecim: valvulae lineares, compressae, infimae longae, superiores sensim breviores, striatae. Stamen unicum. Retz. l. c.

E. descriptione Retzii satis patet, quod a C. dubio Rottböllii differat.

40. CYPERUS capitulis globosis glomeratis, spicu- pygmaeus. lis ovatis planis, involucro polyphyllo foliisque culmo longioribus.

Cyperus pygmaeus; culmis triquetris, aggregatis; involucro polyphyllo, capitulo terminali subsolitario; flosculis subaequalibus, apice spinulosis. Rottb. gram. 20. t. 14. f. 4. 5 .

Habitat in India orientali.

Padices longae, capillares. Culmi plurimi, digitales vel minores, acute angulati. Folia radicalia, plura, linearia, carinata. Involucri foliola quatuor-septem, patentissima, nonnulla culmo longiora, structura foliorum. ' Capitulum solitarizm, interdum trin-quatuor, conglomeratum, piso duplo majus. Spiculae numierasissimae, parvac, decem-duodecimflorae: val- 


\section{I4 TRIANDRIA. MONOGYNIA.}

vulae lanceolatae, acutae: apice patulo minime reflexo; cinereae, carina virides.

$A$ Gypero squarroso Linnaei omnino differt uti et a Scirpo micheliano. Pluknetii synonymum, utpote dubium, exclusi. Ex India orientali sub nomine Scirpi micheliani mihi saepius missus.

$$
\text { * * - Umbellis contractis. }
$$

minutulus. 41. CYPERUS capitulis globosis, spiculis ovatolanceolatis squarrosis, involucro polyphyllo. $\leftarrow$

Cyperus pygmaeus; culmo triqetro folioso; capitulo globoso, glumis mucronatis : involucro sex-heptaphyllo, foliolis tribus longissimis. Cavan. in an. hist. n. mat. Icones 6. p. 65. $t$. $588 . f .2$.

Habitat in Mauritania juxta flumen Sebu.

Radix fibrosa. Culmi pollicares, basi foliosi. Folia culmo breviora, linearia. Involucri foliola tria culmo longiora. Capitulum vix magnitudine Ciceris. Spiculae numerosissimae, duodecimflorae.

Si figura spicularum vera? ad nullam speciem mihi notam referre queo.

capitatus. 42. CYPERUS spiculis lineari-oblongis capitatis, involucro triphyllo, culmo subangulato compresso medio folioso. $\frac{1}{1}$

Cyperus capitatus; culmo subanguloso striato medio folioso, capitulo terminali triphyllo, spicis sessilibus. 'Retz. obs. 4. p. 9.

Habitat in India?

Culmus quadripollicaris, basi folium unum vel allerum, in medio vern fasciculum habet. Folia hasi multum latiora, culmo parum longiora. Valvulae scariosae, mucrone subaristato recurvo terminatae. Rictz. $i$. $c$.

filiformis. 43. CYPERLiS spiculis tereti-subulatis erectis confertis, valvulis oblongis dorso convexis, foliis culmoque filiformibus.

Cyperus filiformis; culmo triquetro nudo filiformi, foliis setaceis, spicis terminalibus sessilibus confertis tereti-subulatis. Swartz. prod. 20. fl. ind. occid. 1. p. 120. 
Habitat in graminosis nemorosis Jamaicae temperatioris australis. Mecum communicatus a Dn. Swartzio.

Culmi pedales-tripedales, laxi. Folia altitudine cuimi parum latiora, laxa. Involucrum ditriphyllum, foliolum unicum vel duo spiculis duplo longiora, foliis similia. Umbella simplex. Spiculae interdum tantum geminae, interdum plures, subpollicares, filiformes, minime imbricatae: valvulae acutae, laeves, ferrugineo-punctatae; pars rachidis fiosculo opposita nucla.

Filamenta solitaria, plerumque inter glumas terminales. Swartz. l. c.

44. CYPERUS spiculis subulatis 'confertis horizon- tenuis. tali-reflexis, involucro subhexaphyllo lineari, culmo filiformi.

Cyperus tenuis; culmo triquetro nudo, umbella simplici, spiculis subulatis confertis horizontali-reflexis; foliis involucri setaceis. Swartz. prodr. 20. fl. ind. occid. 1. p. 119.

Habitat in graminosis montosis Jamaicae occidentalis. Mecum a Dn. Swartzio communicatus.

Culmus pedalis. Folia radicalia, longitudine culmi, linearia, laxa, laevia: vaginae nigricantes. Involucri foliolum longius quadripollicare, unicum umbella brevius. Umbella simplex: radii brevissimi. Spiculae vix semipollicares: valvulae lanceolatae, acutae, striatae, sordide virescentes.

Filamenta plerimque solitaria. Swartz. l. $c$.

45. CYPERUS spiculis lineari-lanceolatis compla- poiystachyos. natis corymboso-fasciculatis confertissimis, involucro subpentaphyllo brevioribus.

Gramen cyperoides, an potius Cyperus indica, graminis amoris spicis plurimis, in summitate caulis. Plulin. mant. 97.

Cyperus polystachyos; culmo triquetro, involucro polyphyllo, panicula terminali sutsessili ramosissima, spiculis lineari lancenlatis cornplanatis. Rottb. gram. 39. t. i. $f$. .

Cyperus fascicularis; culmo triquetro, umbella composita fasciculato-capitata foliata, spiculis linearihus acutis, Lamarck. iliusir. i. p. 14. t. 38. f. 2 . 


\section{TRIANDRIA. MONOGYNIA.}

Cyperus fascicularis; culmo triquetro, nudo, laevi; spiculis linearibus acutis, corymbosofasciculatis; involucris subpentaphyllis, corymbo longioribus. Desforit. fl. atl. 1. p. 44.

ค. Spiculis sessilibus.

Gramen cyperoides, spica longiore compressa, glumarum marginibus argenteis, mashecorae malabarorum. Plukn. mant. 97. t. $416 . f$. 6 .

Habitat in India orientali, Arabia et Africa bo. reali. 4

Culmi sesquipedales, stricti, obtuse angulati, basi foliosi. Folia plura, palmaria, linearia, carinata, margine laevia, glauco-viridia. Involucrum penta-hexaphyllum: foliolum unicum triquadripollicare. Ochreae bidentatae. Umbellae radii plures, brevissimi, ramosi. Spiculae semipollicares, radiis umbellae quintuplo longiores, confertae, circiter vigintiflorae, acutae: valvulae lineares, mucronatae, carina virides, latere purpureae.

bunneus. 46 . CYPFRLS spiculis lanceolatis complanatis sub: sessilibus, involucro triphyllo. $\dagger$

Cyperus brmnneus; culmo triquetro nudo, foliis lato-linearibus planis; umbella triphylla, spicis subsessilibus, compressis: glumis striatis. Swartz. fl. ind occid. 1. p. 116.

Habitat in India occidentali.

Radices filiformes, fasciculatae. Culmus bi-tripedalis, strictus, acutangulys. Folia radicalia, erecta, rigidiuscula. Umbellae radii numerosi, brevissimi, saepe nulli. Involucri foliolum unicum longius. Spiculae lanceolatae, complanatae, acutae, ferrugineae sive brunneae: valvulae lanceolatae, striatae, glabrae, nitidae. Setae duae latiusculae, ad latera germinis. Swartz. l. c.

brizaeus $4 z^{\circ}$ CYPERUS spiculis linearibus teretiusculis involucro triphyllo brevioribus, foliis retrorsum subscabris.

Gyperus Brizaeus triqueter angustifolius, umbellulis confertis aphyllis, spiculis oblongo-ovatis obtusis brizoideis. Act. soc. h. n. par. 1. p. 106.

Habitat in Cajenna Richard, in Puertorico Dn. Le Dru. 
Culmi sesquipedales, acute angulati, laeves. Folia radicalia, culmo dimidio breviora, vix lineas duas lata, carinata, margine retrorsum superne scabra, basi fusco purpurascentia. Involucri foliola simillima foliis modo angustiora, tri-quadripollicaria. Spiculae copiosae, in capitulo hemisphaerico magnitudine nucis juglandis, semipollicares, circiter vigintiflorae, fuscae: valvulae oblongae, apice patulae, stria. tae, acutiusculae, laxae.

Variat culmo breviore, foliis latioribus, unico culmo longiore.

48. CYPERUS spiculis linearibus complanatis con- polyphyllu fertis divergentibus, involucro triphyllo filiformi, foliis linearibus culmum filiformem aequantibus.

Habitat in Guinea. Thonning.

Culmus pedalis, obsolete angulatus, laevis. Folia radicalia, inaequalia, alia altitudiue culmi, alia breviora, carinata, basi vix lineasn lata, sensim in setam attenuata. Involucrum reflexum, simile foliis, modo angustius; longius bipollicare. Spiculae circiter viginti, semipollicares, sessiles, octodecim-vigintiflorae, acutae: valvulae oblongae, obtusae, striatre, dorso virides, latere purpurascentes.

\section{** _ _ - Umbellae radiis elongatis; \\ spiculis terminalibus, umbellatis.}

49. CYPERUS spiculis linearibus digitatis squar- castaneus. rosis, valvulis aristato recurvatis, culmis foliisque setaceis.

Cyperus castaneus; culmo triquetro, umbella composita, spiculis linearibus multifloris, glumis obtusis recurvato-mucronatis, involucro triphyllo longissimo convoluto-setaceo. Wild. spec. pl. I. p. 278.

Habitat in India oriensali. Röttler.

Radices capillares. Culmi plurimi, digitales, palmares et parum ultra, acute angulati. Folia altitudine culmi, convoluto-setacea. Involucrum pentaphyllum: foliola setacea; tria umbella longiora, duo breviora. Ochreae truntcatae. Umbella simplex: radii tres, capillares; longior bipollicaris. Spiculae circiter qua- 
tuordecim, patentes, unguiculares vel parum longiores, angustae, circiter viginti sexflorae: valvulae lineares, obtusae, aristatae: arista uncinata; purpureo-fuscae, stria unica prope carinan viridem.

Tariat colore dilutiore; culmo pollicari; spiculis omnibus sessilibus absque radiis lateralibus; involucris diphyllis. A Dn. Lamarkio habui, qui eum forte cum C. squarroso conjungit.

amabilis. 50. CYPERUS spiculis-linearibus digitatis, valvulis muticis, foliis convoluto-subulatis culmo filiformi brevioribus, involucro longitudine umbellae.

Habitat in Guinea. Thonning. (

Species pulcherrima. Culmi plures, fasciculati, palmares et ultra, acute angulati, stricti. Folia radicalia, pollicaria vel sesquipollicaria: vaginae purpurascentes. Involucrum tetraphyllum, praeter foliola duo ad spiculas centrales, facie foliorum. Ochreae truncatae. Umbella simplex: radii sex, erecto-patentes, longiores sesquipollicares. Spiculae tres-septem, unguiculares, tenues, viginti duoflorae, acutae, ferrugineo-purpurascentes, nitidissimae: valvulae lineari-oblongae, obtusae, utrinque uninerviae, carina virides.

microsta- 51. CYPERUS spiculis linearibus digitatis subquichyos. nis, valvulis mucronatis, umbellulae involucellis foliisque subulatis.

Habitat in Guinea. Thonning. $\odot$

Culmi palmares, filiformes, acute angulati. Folia altitudine culmi, convoluto-subulata, parum recurva. Involucrum subtriphyllum, umbella longius, foliis simillimum: partiale triphyllum, umbellula longius, setaceum. Ochreae truncatae. Umbella composita: radii sex, longior pollicaris; partiales triradiatae. Spiculae tres-quinque, decem-duodecimflorae: valvulae lineari-lanceolatae, obtusae, mucronatae, complanatae, carina virides, latere membranaceae.

autunnalis. 52. CYPERUS spiculis linearibus digitato-subternis, umbella involucrum diphyllum subaequante. 
Scirpus foliosus pusillus autumnalis, culmo plano utrinque paululum compresso capitulis plurimis, panicula laxa, unciali, ab apice distantia erumpentibus. Clayt. in Gron. fl. virg.

Scirpns culmo ancipiti. Gron. fl. virg. 1o.

Scirpus autumalis; culmo ancipiti nudo, umbella decomposita foliosa, spiculis ovatis. Lin. mant. 180.

Scirpus autumnalis; involucro diphyllo; panicula supradecomposita; spicis terminalibus, solitariis, lanceolatis, subtetraquetris. Rottb. gram. 58. t. 17. f. 3.

Cyperus juncoides; culmo triquetro, umbella decomposita, subnuda, spiculis parvis aggregatis serrato-squarrosis, glumis acutis. $L a-$ marck. illustr. 3. p. I 4 ? ficle herbarii ejus.

Cyperus complanatus; culmo compresso plano nudo, umbella composita, involucro diphyllo, partiali brevissimo polyphyllo, foliolis setaceis basi membranaceis. IVild. spec. pl. 270 .

Habitat in Virginia, in Carolina Bosc, in India orientali König.

Facies Junci. Culmi palmares-pedales, penna columbina tenuiores, triquetri, laxi. Folia culmo breviora: unico saepe altiore; laxa, linearia, margine vix scabra. Involucri foliola interdum umbella parum longiora, interdum unicum semipedale, in minus perfectis speciminibus umbella parum breviora: partialis nulla, nisi squamulae nonnullae subulutae. Ochreae truncatae. Umbella decomposita: radii decemduodecim, longiores tri-quadripollicares: partiales septem-decem; zultimi gemini, patentes. Spiculae raro solitariae vel duae, plerumque tres, sedecimflorae: valvulae lineari-oblongae, obtusiusculae, latere ferrugineae; fructiferae patulae.

$V$ ariat valvulis acutioribus vel obtusioribus, vix tamen mucronatis. C. autumnalem saepe sub nomine C. Haspan misit Koenigius, et singuldre est. Linnaeum, qui C. autumnalem nizultos ante annos a Claytonio vel alio Americae septentrionalis botanico procul dubio habuit, in secunda demum Mantissa ejus mentionem facere; 
forte oblitum graminis, quod olim secundum specimen ex herbario Hermanni hoc sub nomine descripsit, et deinde pro eodem habuit.

Specimen Americanum mecum a Boscio communicatum speciminibus Koenigii et herbarii Rottböllii exacte convenit. Linnaci quoque descriptio ad Indicum specimen in omnibus quadrat, ideoque ea non differre certe credo. Willdenowii cyp. complanatus neque in ullis ab hoc recedit, culmus enim in speciminibus exsiccatis oninino compressus apparet et tantummodo pro. pe umbellam diligenti disquisitione est angnlatus. Forte Sc. carolinianus Lamarck illustr. I. p. 1 12. huc quoque pertinet. Cyperus est, nec Scirpus; nam spiculae tam in Indico quam Amerisano omnino Cyperi sunt structura.

Haspan. 53. CYPERUS spiculis linearihus digitatis, umbella involucrum subdiphyllum subaequante.

Gramen cyperoides maderaspatanum panicula magis sparsa et speciosa. Pluckin. alm. $\mathbf{z} 79 . t$. I92. $f .=$.

Cyperus maderaspatanus, panicula speciosa ramosissima. Petiv. mus. 187. Scheuchz. gram. 389.

Cyperus Haspan; culmo triquetro, umbella supradecomposita, spicis umbellato sessilibus. Lin. fl. zeyl. n. 3т. Rottb. gram. 36. t. 6. f. $=$.

Cyperus aphyllus; culmo triquetro hasi vaginato, umbella subcomposita, involucro diphyllo adaequante, spiculis subternis. Ecl. amer. 2. p. 6.

Habitat in India orientali König, in insula Trinitatis von Rohr, in Cajenna Richard.

Folia nulla nisi vaginae duae-tres: interior quinquepollicaris; in ligulam lanceolatam desinentes. Spiculae tres-duodecim.

Ex ulteriori comparatione video aphyllum Rohrii omnino convenire cum C. Haspan Indiae orientalis, ideoque eos conjunxi.

Praecedenti tam similis, ut non differre videatur, praeterquam habitu robustiore et radiis umbellae spiculisque copiosioribus.

sequails. 54. CVPERUS spiculis subgeminatis linearibus, radiis umbeliae numerosissimis aequalibus, involucro subnullo. 


\section{TRIANDRIA. MONCGYNIA. $\hat{\jmath} \approx t$}

Cyperus prolifer; culno triquetro nudo, umbella involucro longiore, radiis numerosissimis, spiculis minimis proliferis. Lamarck. illustr. I. p. $1+7$.

Habitat in insula Franciae. Ex herbario $L a$ marckii.

Culnus sesquipedalis, crassitie fere pennae columbinae, rigidiusculus, obsolete angulatus. Folia nulla nisi vaginae tripollicares, fuscae, in ligulam pollicarem desinentes. Involucrum squamae tres-quatuor, semiunguiculares, ovatae, acutae, praeter nonnullas interiores, minores, margine scariosae. Umbella composita: radii quinquaginti et ultra, sesquipollicares, capillares: partiales uni-vel biradiati vel uniflori. Spiculae seniunguiculares, vigintiflorae, acutae, ferrugineo-flavescentes: valvulae ob́longae, obtusae, margine parum membranuceae.

55. CIPERUS spiculis subgeminatis lineari-lance- diffusus. olatis, umbella diffusa, foliis culmo altioribus.

Habitat in India orientali. $2 /$

Culmi sesquipedales, triquetri. Folia culmo altiora, unguem fere lata, margine scabra. Involucrum subheptaphyllum, umbella longius: unicum culmo longius; partiale tri-pentaphyilum, brevissimum, setaceum. Ochreae oblique truncatae, obtusae. Umbella diffusa, supradecomposita, decem-duodecinuradiuta: radii longiores spithamaei, filiformes; partialis $r a$ diis octo-decem, capillaribıs, patentissimis; ulitmae radiis tribus-quinque patentissimis. Spiculae solitariae, binae-ternae in singulis radiis ultimis, laterales pedicellatae, intermedia sessilis, lineam longae, decemflorae, parum convexae, acutae: valvulae ovatae, mucronatae, striatae, dorso convexae, virides, margine $f u$ scae, fructiferae patulae.

56. CYPERUS spiculis linearibus, umbellis um- alternifolius bellulisque corymbosis, involucris alternis culmoque substriato laevibus.

Cyperus alternifolius; culmo triquetro nudo apice alternatim folioso, pedunculis lateralibus 


\section{TRIANDRIA. MONOGYNIA.}

proliferis. Lin. mant. 28. Jacqu. collect. 2. $p$. 306. Ic. rar. 2. t. 298.

Habitat in Madagascar. 4

$V$ alde affinis sequenti, differt: culmo teneriore laevi, subtilissime striato : involucri foliolis angustioribus, margine tantum scabris, radiis capillaribus: spiculis linearibus, vigintisexfloris: valvulis lanceolatis.

Culmus basi crassitie fere pennae cygneae, vaginis longis inferne vestitus.

fiabellifor-57. CYPERUS spiculis ovato-lanceolatis, umbellis unis. umbellulisque corymbosis, involucris alternis utrinque culmoque sulcato scabris.

Cyperus flabelliformis; culmo sulcato triquetro, involucris alternis, pedunculis axillaribus solitariis, terminalibus umbellatis corymbiferis. Rottb. gram. 42. t. I2. f. 2.

Cyperus gradatus; culmo tereti, angulato, ad basin foliato; bracteis aci apicem pedunculis duplo longioribus, spiraliter remotis. Forsk. descr. $p$. '1 13.

Habitat in Arabia. 24

Glaucus. Culmus bicubitalis, apice crassitie pennae anserinae, obtuse angulatus, sulcatus, basi foliosus. Involurra alterna, circiter vigin$t i$, pedalia, semipollicem lata, semiamplectentia, triplici serie dispositı, ensiformia, attenuata, margine uti et supra infraque scabra, nervosa involucella nulla, nisi squamae ovatae aridae ad basin pedicellorum. Ochreae in ligulam lanceolatam, acutam desinentes; longior pollicaris. Pedunculi solitarii, involucro duplo breviores, sensim minores, inferiores remotio. res, stricti, obscure triquetri, scabriusculi: partiales circiter decem, approximati, patentes, confertissimi: terminales tres-quatuor. Spiculae tres-sex, duodecim-quatuordecimflorae, valvulae ovatae, acutae, membranaceae.

Eragrostis. 58. CYPERUS spiculis subquaternis lanceolatis obtusiusculis, valvulis ovatis, umbella triradiata, involucro diphyllo.

Cyperus cruentus; culmo triquetro, basi folioso, umbella teruninali diphylla simplicissima. Retzii obs. 5. p. 13.

Habitut in Txanquebaxia. König. 
Culmus pedalis et parum ultra, gracilis, acute trigonus, basi foliosus. Folia culmo breviora, laxa, linearia: vaginae sordide griseae. Involucrum patens: foliola umbolla longiora, carinata. Ochreae breves, obtusae. Umbella simplex: radius longior tripollicaris. Spiculae plerumque quatuor, interdum tres, semipollicares, circiter vigintiflorae: valvulae concavae, obtusiusculae, prope carinam unisulcatae, coeterum laeves, carina sordide virescentes, lateribus sanguineae. Semen ovato-subglobosum, fuscum.

Interdum culmus ex eodem cespite spithamaeus, foliis pollicaribus, spiculis omnibus capitatoconglomeratis.

59. CYPERUS spiculis subternis linearibus, val- elegans. vulis bcordatis mucronatis distinctis patulis, umbella laxa.

Cyperus panicula maxime sparsa ferruginea compressa elegantissima. Sloan. cat. 35. hist. i. p. I $17 . t .75 . f$. I.

Cyperus elegans; culmo triquetro nudo, umbella foliosa, pedunculis nudis proliferis, spicis confertis, mucronibus patulis. Lin. syst. veg. 97 .

Cyperus elegans; umbellis subtriradiatis subtrispicatis, spiculis linearibus, squamis obcordatis subdistantibus mucronatis patulis, involucris planis. Ecl. amer. 2. p. 7 .

Cyperus laxus; culmo triquetro nudo, umbella foliosa laxissima, spiculis subaggregatis raris squarrosis. Lamarck. illustr. 1. p. 146.

Habitat in Cajenna, Brasilia. v. Rohr.

Culmus acute trigonus, penna columbina parum tenuior Folia semiiunguem lata. Involucrum. subheptaphyllum: foliolum unicum umbella longius, reliqua aequalia vel breviora, extrorsum, uti folia, margine scabriuscula; partiále di-triphyllum u:nbellula brevius, setaceum. Ochreae. brevissimae. Umbella composita, octoradiata, patentissima: radii longiores quadripollicares, filiformes; pariialis subtriradiata: radii pollicares vel breviores. Spiculae subternae lineares, tredecim-quatuordecimflorae: valvulae 


\section{TRIANDRIA. MONOGYNIA.}

prope carinam utrinque bistriatae, margine membranaceae. Semina triquetra.

Specimina mea optime cum figura Sloanaei conveniunt, nisi quod spiculae pauciores.

denudatus. 60. CYPERUS spiculis linearibus digitatis subsenis, valvulis lanceolatis apice patulis, involucro submonophyllo brevissimo.

Cyperus denudatus; culmo triquetro, involucro subnullo. Lin. suppl. 9 s.

Habitat in Gap. b. spei. Osbeck. 4

Culmus sesquipedalis, penna columzbina crassior, triqueter. Involucrum submonophyllum, semipollicare: partiale nullum. Ochreae brevissimae. Umbella composita: radii septem-octo, bipollicares; partialis subbiradiata: radii vix unguiculares. Spiculae tres-sex, unguiculares, vigintisexflorae, fuscae: valvulae acutae, margine membranaceae, enerves.

compressus. 6r. CYPERUS spiculis digitatis subquaternis lanceolatis, valvulis mucronatis latioribus membranaceis.

Graminis cyperoidis species major vaudemaulecode malabarorum. Plukn. mant. 97. $t .+17$. f. 2 .

Cyperus rotundus gramineus fere inodorus, panicula sparsa compressa viridi. Sloan. cat. 35 .

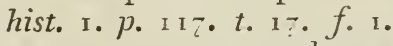

Cyperus compressus culmo triquetro nudo, umbella universali triphylla, glumis mucronatis : lateribus membranaceis. Lin. spcc. pl. 6'8. Rottb. gram. 27.t. o.f. 3. Swartz. obs. 30.

Habitat in pratis graminosis subhumidis Caribaearum, Americae sepientrionalis inque Indiae orientalis.

Culmi semipedales, vel breviores, acute trigoni. Folia radicalia, culno breviora, linearia. Involucrum di-tetraphyillum: omnia umbella longiora. Ochreae truncatae, coccineae, ore pallidae. Unbella simplex: radii plerumque quatuor, bipollicares. Spiculae duae-quinae, unguiculares vel semipollicares, vigintiquatuorflorae: valvulae ovatce, mucrone patulo acıminatae, versus carinam striatae, stria una zel altera interdum purpurea. Spiculae interAlum flavescunt. 
62. CYPERUS spiculis lanccolatis subquaternis, Jeminicus. involucro tetrapliyllo setaceo scabro, culmo foliisque filiformibus incurvis.

Cyperus jeminicus, culno incurvo triquetro, basi bulboso, foliis fasciculatis setaceis, umbella simplicissima, spicis conglomeratis. Rottb. gram. $25 . t .8 \cdot f .1$.

Habitat in Arabia.

Culmi plures, palmares, tenues, obsolete trigoni, uti folia glauco - virescentes, basi vaginis foliorum involucrati. Folia plurima, nonnulla longitudine culni, rigida, canaliculata, ope lentis serrulata: vaginae latae, pallide ferrugineae. Involucri foliola duo umbella longiora, duo breviora, incurva, margine ad lentem serrulata; partiale nullum. Umbella simplex triquadriradiata, duo plerumque longiores, duo brevissimi. Spiculae frequenter quatuor, interdum quinque vel sex, unguiculares, compressae, acutae, duodecim-quatuordecimflorae: valvulae lanceolatae, apice patulai, striatae, viricles, versus carinam clilute fuscae.

Bulbum nunquain vidi, quamvis varia exemplaria examinavi; certe ergo credo cel. Rottböllium congeriem vaginarum bulbum nominasse. Involucrum certe tetraphyllum, sed duo foliola saspe tam brevia, ut facile, si caute non attenditur, pro diphyllo habeatur. Radii omnes interdum brevissimi, hinc spiculae saepe in capitulo globoso magnitudine fere juglandis conglomeratae apparent. Cyperus jeminicus. Retzii obs. 4. p. I . absque dubio est diversus,

63. CYPERUS spiculis lineari-oblongis globoso ca- ochraceus. pitatis patentibus, valvulis oratis, involucro pentaphyllo umbell longiore.

Habitat in insula St. Crucis. West. 2

Culmi plures, fasciculati, pedales et ultra, stricti, rigidi, acute trigoni, basi foliosi. Folia culmo altiora, linearia, carinata, margine laevia, pallide viridia. Involucri foliola quinque umbella longiora: totidem in capitulo centrali, setacea, breviora. Umbella simplex triradiata: radius longior sesquipollicaris. Capitulum nuce avellanae majus. Spiculae copiosae, un- 
dique vergentes, sessiles, unguiculares, obtusiusculce, vigintioctoflorae, nitidae, plus minusve intense flavae: valvulae ovatae, acutiusculae, minime striatae, saepe uninerves.

regetus. 64. CYPERUS spiculis lanceolatis subgloboso-capitatis compactis, valvulis ovatis uninerviis, involucro umbella longiore.

Cyperus compressus. Jacqu. hort. vind. 3. t. 12.

Cyperus glomeratus; culmo triquetro nudo, umbella tetraphylla, pedunculis capitatis glomeratis. Walt. fl. car. 70 .

Cyperus eragrostis; culmo triquetro nudo, umbella composita foliosa, spiculis glomeratis, squamis acutiusculis. Lamarck. illustr. I. p. I 46. fide herb. Lamarckii.

Cyperus declinatus. Moench.

Cyperus monandrus culmo inferne folioso obtuse triangulo, umbella polystachya decomposita, spicis lanceolatis confertis sessilibus, floribus monandris. Roth. cataléct. x. p. 3 .

Habitat in America meridionali, in Carolina Bosc. 4

Giauco-virescens. Culmus sesquipedalis, acute trigonus, inferne foliosus. Folia culmo breviora, lineari-lanceolata, margine serrulato-scabra, carina laevia: vaginae uti folia subtus in exsiccato inter strias punctatae. Involucri foliola quinque, umbella longiora, praeter nonnulla breviora ad capitulum centrale: partiale sub-biphyllum. Ochreae oblique truncatae, pallidae, purpureae, subpunctatae, ore membranaceo. Umbella composita: universalis circiter octoradiata: radius longior pollicaris; partialis tri-quadriradiata, patens. Spiculae plurimae, griseae: valvulae acutae, versus medium subuninerves, margine membranaceae.

Spiculae in hortensi specimine lanceolatae, circiter vigintioctoflorae, in spontaneo verum ovatae, quatuordecimflorae. Umbella interdum simplex, interdum radiis in capitulum magnum contractis, quod etiam in hortensi. Pedicelli ultimi alterni, cunfertissimi, apice spiculis duabus vel tribus sessilibus, quare in hac sectione eum collocavi. 
65. CYPERUS spiculis ovato-lanceolatis capitatis, formosus. involucro subhexaphyllo longissimo margine scabro.

Habitat in Louisiana et Caribaeis. Ex herbario. Jussiaei.

Culnus crassitie pennae anserinae, acute trigonus, basi foliosus. Folia linearia. Involucrum penta-hexaphyllum: partiale di-triphyllum, umbellula brevius. Ochreae breves, truncatae, ore membranaceae. Umbella composita: universalis radii circiter decem, sesquipollicares teretes; partialis pauciores breves. Spiculae circiter octo, unguiculares, viginti-trigintaflorae, flavescentes: valvulae lineari-lanceolatae, acutae, latere laeves, stria unica utrinque ad carinam, deciduae.

66. CYPERUS capitulis subglobosis glomeratis, spiculis ovatis, involucro longissimo.

surinament.

sis.

Graminis tertia species. Marcgr. hist. I. fide herbarii ejus.

Cyperus surinamensis; culmo triquetro nudo, umbella dccomposita, spicis oblongo-ovatis conglomeratis, mucronibus incumbentibus. Rott3. gram. 35.t. 6.f. 5. .

Habitat in Surinamo Rolander, v. Rohr, in Puertorico West. 2

Radix fibrosa. Culmus semi-sesquipedalis, crassitie pennae columbinae, rigidus, obtuse trigonus. Folia radicalia, nonnulla altitudine culmi, "linearia, extrorsum margine carinaque serrulato-scabra, uti culmi viridi-glaucescentia. Involucrum pentaphyllum, omnia umbella longiora, duo fere longitudine culmi: partiale diphyllum, umbella brevius, patentissimum, structura foliorum: folia basi dilatata, in acumen zinguiculare desinentia, margine basi membranacea. Umbella composita; radii quinquetredecim, longior bipollicaris: partialis trisexradiata. Capitula subglobosa, semine Coriandri duplo majora, e tribus-sex minoribus cqnglomerata; squamulis duabus ovatis, atutis involucrata. Spiculae minimae, decem circiter in singulo capitulo, decemflorae, stramineae: valvulae ovatae, acutae, striatae. 


\section{TRIANDRIA. MONOGYNIA.}

Cum Spiculae in capitulis confertissimae sint, Scirpum primo iniuitu facile assimilat.

$V$ ariat umbellis subcompositis, compositis et decompositis.

Luzulae. 67. CYPERUS capitulis simplicibus glomeratisque ovatis, spiculis oblongis, involucro longissimo.

Cyperus umbella simplicissima, polyphylla; capitulis terminalibus, solitariis, oblongo-ovatis, spicis ovatis, concavis, densissime conglomeratis. Rottb. gram. 23. t. r 3.f. 2.

Cyperus polycephalus; culmo triquetro, umbella polyphylla, capitulis ovatis pedunculatis, spiculis densissime congestis. Lamarck. illustr.

1. p. 147 .

Cyperus conoideus; triqueter foliosus, umbella longissime involucrata simplici, capitulis compacte compositis obtuse conoideis. Act. soc. h. n. par. I. p. 106. fide herbarii Lamarckii et Richardii.

Habitat in Surinamo, Cajenna. 24

Culmus bipedalis et altior, crassitie pennae columbinae, superne acute angulatus, basi foliosus. Folia culmo breviora, linearia, pallide viridia. . Involucrum subheptaphyllum: foliola omnia umbella longiora, margine carinaque scabra, duo interdum sesquipedalia. Ochreae oblique truncatae, ferrugineae. Unibella simplex, subsepteniradiata; radii longiores, bipollicares vel ultra. Capitula pisa duplo vel quadruplo majora, interdum e tribus vel quatuor minoribus glomerata. Spiculae mumerosissimae, oblongae, parvae, confertissimae, pallide-virescentes, interdum lateribus ferrugineis: valzulae oblongae, unistriatae. Synonyma a Rottböllio huc allata ninime huc pertinent.

fliculnis. $6 \mathrm{~s} \mid$ CYPERU̇S spiculis linearibus globoso capitatis patentissimis umbella subuniradiata, involucris triphyllis culmisque setaceis.

Habitat in Carolina.

Culmus pedalis, obsolete trigonus, angulis laevibus. Folia spithamaea et ultra, culmo breviora. Involucrum triphyllum, erecto-patens: foliola duo umbella longiora. Ochreae oblique truncatac, obtusae. Radius bipollicaris. Spi- 
culae confertae, in capitulum glnbosum, piso cluplo majus congestae, uniclim in spice ractii, alterum ad ejus basin, copiosae, vix ungzicula. $r e s$, angustae; lineares, terctiusculas, decemflorae: valvulae parum distantes, laxe imbricatae, lineari-oblongae, obtusissimae, striatae, carina virides, latere flavescentes.

* * _ _ _ Umbellae radiis elongatis, spiculis alternis.

69. CYPERUS spiculis oblongis multifloris remo- hyalinus. itusculis squarrosis, valvulis ovatis attenuatis, involucro hexaphyllo longissimo.

Ilabitat in India orientali. Pöttler. ()

Culmus digitalis-semipedalis. Folia uti et involucra culmo saepe longiora. Ochreae truncatae. Unbella tri-quadriradiata. Spiculae sex-octo, sex-actoflorae: valvulae complinatae, carina superne curvata.

Affinis sequenti, differt: foliis et involucris latioribus, copiosioribus : spiculis paucioribus, disfantibus, latioribus, squarrosis: valvulis atternatis, nec mucronatis, lateribus membranaceis, obsolete remote trinerviis, hyalinis.

7c. CYPERUS sniculis oblongis confertis subgin- confertus. boso-capitatis, patentibus, valrulis oblongis stiriatis mucronatis, foliis linearibus.

Cyperus confertus; culmo triquetro nudo, umbella simplici foliosa, spiculis ovatis congiomeratis, glumis apice recurvis acminitis. Swarti. prodr. 20 . fl. ind. occid. 1. p. 115.

Habitat in Caribaeis. "T est.

Culmi palmares, et altiores usque ad bipeclnles, acute angulati, basi foliosi. Folia nltitudine culmi vel parlo longiora. Involucrum triphyllum: foliola longissima; tria uinbeil a breviora, setacea in cripitulo centrali. Ochreae truncatae. Umbella simplex: radii quatuor, triquetri. Spiculae circiter quatiourdecim, breves, octo-decemflorae: valvilae striatae, flavae, dorso virides.

Filamenta duo vel tria. Semina trigona. Swartz. l. c.

Specimina interdum habui absque culnno, radio uno vel altero radicali. 


\section{TRIANDRIA. MONOGYNIA.}

bidentatus. 7 r. CYPERUS spiculis oblongis subtrifloris confertis, valvulis oblongis acuminatis, involucro pentaphyllo longissimo.

Habitat in Senegal? dedit Dupuis. 4

Culmi plures, pedales, acute angulati, basi fo. liosi. Folia interdum culmo altiora, linearia, laxa. Involucrum margine scabrum. Ochreae truncatae. Umbella quadri-quinqueradiata; radius longior vix pollicaris. Spica semiunguicularis, flavescens, foliolum capillare, breve ad basin spicae; spiculae parvae, confertae, compressae, tri-quadriflorae: valvulae oblongae, duae infimae inaequales, steriles: major oblonga, obtusa; reliquae oblongae, striatae, acuminatae, acumine patulo, hinc spiculae apice quasi bidentatae apparent.

membrana- 72 . CYPERUS spiculis oblongis confertissimis subEells. squarrosis, valvulis oblongis obtusis mucronatis laevibus, foliis involucrisque linearibus.

Habitat in India orientali. König. (-

Affinis C. nitenti, differt: spiculis minoribus, alternis, nec ex apice, minime nitidis: valvulae latere griseae, membranaceae.

Involucrum pentaphyllum, umbella longius: unicum culmo dimidio longius; praeter tria foliola ad spiculas centrales, setacer, breviora. Ochreae truncatae. Umbella simplex. Spiculae duplo minores quam in antecedenti, vatvulae latere non striatae; caeteroquin eodem modo variat.

pamilus. 73. CYPERUS spiculis lançeolatis, valvulis mucronatis, involucro diphyllo umbella longiore. + Gramen cyperoides pumilum elegans e maderaspatana. Plukn. alm. 179. t. 19i,f. 8 .

Cyperus pumilus; culmo triquetro nudo, umbella diphylla composita, spiculis alterno-digitatis lanceolatis, glumis mucronatis. Lin. am. acad. 4. p. 302 .

Habitat in India.

Similis C. compresso, sed brevior, distinctus: Glumis minus imbricatis et apice mucronatis. Spiculae vix alternae fere digitatae. Lin. $l$. c.

Quanvis mihi ignotum, a C. pumilo Rottböllii tamen separavi cum descriptio Linnaei et figura 


\section{TRIANDRIA. MONOGYNIA.}

\section{1}

Pluknetii ninime cum Rottböllii specimine convenizunt.

74. CYPEPUS spiculis lanceolatis glomeratis sub- nitens. squarrosis mucronatis, valvulis obtusis, involucro triphyllo umbella longiore.

Cyperus nitens; culmis triquetris hasi foliosis, umbellis subsimplicibus, involucro triphyllo, floribus-monandris. Retz. obs. 5. p. 13.

Habitat in India orientali. König.

Culmi plures, bi-guadripollicares, filiformes, angulis acutiusculis. 'Folia radicalia, unum vel alterum culmo longius, linearia, angusta. Involucri foliola patentia: unicum longitudine culni; tertium umbella brevius. Umbella simplex, bi-quadriradiata: radii vix pollicares. Spiculae circiter decem in apice radiorum, obtusiusculae quatuordecim-vigintiflorae, nitidae: valvulae ovatae, obtusae cum mucrone patulo, hyalinae, interdum griseo virescentes, saepius versus marginem ferrugineae, carinatae, utrinque ad carinam bistriatae.

Culmus interdum mullus spiculis inter folia ad radicem sessilibus.

Accedit ad squarrosum. Saepius sub nomine Cyp. pumili Lin. ex India orientali missus, an diversus?

Differt a C. squarrosu spiculis latioribus, nitidis, disco non flexuosis, minus squarrosis.

75. CYPERUS spiculis linearibus confertissimis, squarrosus.

valvulis aristatis recurvis, foliis involucriscue linearibus.

Gramen cyperoides maderaspatanum minimum ischaemi paniculis cum aristis. Pluk. amallh. I 4 . $t .397 \cdot f .2$.

Cyperus squariosus; culmo triquetro folioso, nnbella foliosa glomerata, spicis striatis squarrosis. Lin. am. acad. 4. p. 303. Rottb. gram. 25. t. 6. f. 3 .

Cyperus maderaspatanus; culmo triquetro, umbella composita, spiculis linearibus, glumis lanceolatis uncinato-muricatis, involucro triphyllo. longissimo lanceolato. Wild. spec. pl. I. p. $27 \%$.

Habitat in India orientali. König, Röttler. 


\section{TRIANDRIA. MONOGYNIA.}

Culmi digitales, foliis saepe breviores, filiformes. Unbella simplex triradiata. Spiculae duodecimflorae, angustae, semiunguiculares, disco flexuosae: valvulae lineares, lateribus menUranaceis, minime striatis.

I ariat eodem modo ac reliquae hujus sectionis.

Jam antea monui C. pygmaeum Rottböllii omnino a C. squarroso Linnaei esse diversum, cum nec ad figuram Pluknetii nec ad descriptionem C. squarrosi in amaenitatibus Lin. conveniat. Cyperus in herbario Rottböllii squarrosus dictus non modo ad figuram citatam Pluknetii et descriptionem Linnaci omnino quadrat, sed etiam ad C. maderaspatensem Wildenowii et specimina a Königio, Kleinio et Rörtlero missa, unde verisimile Cyperum suum cel. Wildenowius obtinuit. Sine dubio specimen radiis destitutum et spiculis terminalibus glomeratis instructum Linnaeus liabuit, ideoque eum umbella carere dixit.

Glicinus. 76. CYPEMUS spiculis lineari lanceolatis remotiusculis, Iaxe imbricatis, involucro triphyllo umbella longiore foliisque laxis.

Habitit in Virginia.

Culmi semipedales, filiformes, acutanguli. Folia racicalia longitudine culmi, linearia, laxa, margine scabra. Involucri foliola folits similia: partiale nullum. Ochreae truncatae. Umbella subcomposita tri-quadriradiata: radius longior pollicaris: partialis trivadiata: raaii brevissimi. Spiculae quatuor-ccto, distantes, vix unguiculares, duodecimflorac, complanatae, patentissimae: laxe imbricatae, flavoferrugineae, nitidae: valvulae oblongae, acutae, prope carinam utrinque unistriatae.

intactus. 77. CIPERUS spiculis linearibus remotis, involucro triphyllo foliisque rigidis.

Habitat Galam. Ex herbario Jussiaei. 4

Similis praecedenti. Spiculae vero breviores et arcitus imbricaiae. Folia rigida.

olivaceus. 78. CYPERUS spicis corymbosis laxis, spiculis lineari-lanceolatis rectis, involucro umbellam aequante.

Habitat in Cap. b. spei? 
Culmus sesquipedalis, gracilis, acute trigonus, nudus. Involucrum triphyllum: foliola dico longitudine umbellae, tertium brevius; partiale nullum. Ochreae brevissimae. Umbella com. posita; radii septem, quinque-bipollicares subaequales, filiformes: partiales cho vel tres, brevissimi, bi-triflori. Spiculae ungticulares, parum distantes, patentissinnae, sordude flavovirentes, vigintiduoflorae, acutae: valvulae lanceolatae, mucronatae, deciduas, ut in sequente.

Differt $a b$ insequente: Involucro brevi; radiis umbellae longioribus, pluribus; spiculis distantibus.

79. CYPERUS spiculis lineari-lanceolatis arcuatis, olidus.

umbellulis corymboso-fasciculatis, involucro triphyllo umbella triradiata longiore.

Habitat in America meridionali. Richard.

Diversus a C. paniculato: involucro triphyllo longiore: umbella universali triradiata: radlis triplo - quadruplo longioribus. Spiculis longioribus, trigintaduafloris, arcuatis, caeterum similis.

80. CYPERUS spiculis lineari-lanceolatis, umbellulis corymboso-fasciculătis, involucro subhexaphyllo. Ecl. am. 2. 7. C. scopellatus.

Cypcrus paniculatus; culmo triquetro, involucro hexaphyllo, subaequali; panicula sessili, terminali, densissima; spicis compressis, lineari-lanceolatis, paucifloris. Rottb. gram. to. Cyperus scopellatus; triqueter, angustifolius: radiis umbellae apice fasciculato-scopaterormibus: spiculis strictis, angusto-linearibus. Act. soc. h. n. par. 1. p. 10 '.

Habitat in Surinamo, Rolander, Cajenna, in Montserrat. Ryan.

Culmus pedalis et ultra, acute trigonus, uti folia pallicle virens, inferne foliosus. Folia culmo breviora, infima disticha, conferta, patentissi$m a$, bi tripollicaria, rigidiuscula, linearia, attenuata, margine carinaque scabra. Involucrum penta-hexaphyllum: foliola tria-quatuor umbella longiora, unicum quinquepollicare. Ochreae breves, fusco-ferrugineae, bidentatae. Umbella composita, subseptemradiata: radii 


\section{TRIANDRIA. MONOGYNIA.}

sesquipollicares, interdum unguiculares: partiales capillares; ramulis alternis. Spiculae semiunguiculares, circiter tredecimflorae, utrinque acutae, albidae vel flavae: valvulae lanceolatae, acutiusculae, lateribus membranaceis, substriatae.

patens. 8r. CYPERUS spiculis linearibus remotiusculis, valvulis oblongis mucronatis patentibus, involucro subtriphyllo, foliisque lineari-subulatis.

Habitat in Guinea Thonning. Similem e Java, ni fallor, vidi (-)

Culni sesquipollicares vel digitales, setacei, triquetri, basifoliosi. Folia altitudine culmi, carinata. Involucri foliolum unicum, umbella longius. Ochreae compressae. Umbella subcomposita, subquadriradiata: radii capillares, longiores sesquipollicares. Spiculae quatuorocto, parurn distantes, interdum geminatae, patentissimae, triginta sexflorae, acutae: valvulae patentissimae, lineari-oblongae, obtusae, mucrone brevi patulo terminatae, enerviae, dorso carinatae, latere albidae vel ferrugineae. Semina oblongo-subrotunda, compressa, nigra.

favidus. 82. CYPERUS spiculis approximatis patentibus valvulis imbricatis lineari-lanceolatis, involucro triphyllo subulato.

Cyperus flavidus; culmo triquetro striato, umbella composita triphylla, spicis lanceolatis, squamulis monandris. Retz. obs. 5. p. 13.

Cyperus divaricatus; culmo tricuetro, umbella composita conferta subtriphylla, spiculis linearibus complanatis divaricatis. Lamarck. illustr. $1 . p .145$.

Habitat in India orientali König. Specimina culta in herbario Lamarchii vidi.

Culmi semiperlales et ultra, obsolete trigoni. Folia radicalia plurima, unicum inferne in culmo eique dimidio brevius, angusta. Involucri foliola erectó-patentia, duo umbella longiora, unico aequante. Ochreae breves, obtusae. Umbella subsimplex: radii plerumque quatuor, longior bi-tripollicaris. Spiculae circiter octo- 
decim, vigintisex-trigintaflorae, in culto saepe quinquagintaflorae, acutiusculae, sordicle fiavescentes, nitidae: valvulae lineari-oblongae, obtusae, margine tenui membranaceo, dorso striato, lateribus laevibus. Rachis inter flores flexuosa. Semen pyriforme, triquetrum, nigrum.

Stamen zonicum, uti Retzius vidi. Ab antecedente differt: valvulis non patentibus apiceque non mucronatis.

83. CYPERUS spiculis ovato-lanceolatis, involu- ater. cro subtriphyllo lineari-lanceolato umbella longiore.

Cyperus culmo folioso, triquetro; involucro tetraphyllo; umbella composita; spicis alternis, oblongo-lanceolatis, nitidis. Rottb. progr. 19. gram. 2n. n. 36. t. 9, f. 4 .

Cjperus nitidus; culmo trigono nudo, umbella composita tetraphylla, spiculis lanceolatis nitidis congesto digitatis. Lamarck. illustr. ז. $p$. 145.

Habitat in India orientali. Ex herbario Lamarck.

Culmus palmaris et ultra, acute angulatus. Folia lineari-lanceolata, margine laevia: vaginae purpurascentes reticulatae. Involucrum tri-tetraphyllum: duo patentia, duo vel tria umbella longiora, brevius umbellam aequans, facie foliorum; partiale nullum. Ochreae obtusae, fuscae. Umbella subcomposita, sex-radiata: radii sesquipollicares, teretes, quatuor subaequales, duo centrales breviores. Spiculae quindecim, quatuor-sex in radiis sentralibus, infimae plerumque geminae, interdum ternae, rarius solitariae, unguiculares, sessiles, approximatae, sedecim-actudecimflorae; acutae, luteae, fuscae vel obscure purpureae: valvulae lineari-oblongae, obtusae, utrinque ad carinam viridem unistriatae, caeterum laeves.

Nec figura Pluknetii., nec descriptio Linnaei ad hunc satis quadrant, ergo haec synonyma omisi. Omnia, quae vidi, specinina umbellam simplicem spiculis in infimo pedicello geminatis ternisve habuerunt.

84. CYPERUS spiculis lineari-lanceolatis, involu- flnve cens cro triphyllo umbella trifida longiore. 


\section{TRIANDRIA. MONOGYNIA.}

Juncus exigutus pratensis. Trag.

Gramen cyperoides, minus, panicula sparsa subflava. Bauh. Theatr. 89.

Cyperus minor pulcher, panicula lata compressa subflavescente. Moris. hist. 3. p. 259. s. 8. t. I I. $f .37$.

Cyperus flavescens; culmo triquetro nudo, umbella triphylla, pedunculis simplicibus inaequalibus, spicis confertis lanceolatis. Lin syst. veg. 97. Pollich. palat. n. $4 \mathrm{r}$.

Habitat in Europae paludosis. (-)

Similis C. fusco. Culmus filiformis. Folia altitudine culmi. Involucrum culmo brevins. Spiculae flavae: valvulae concavae, obtusue. Spiculae interdum duae-sex, involucro diphyllo.

fuscus. 85. CYPFRUS spiculis lineari-lanceolatis confertissimis, involucro subtriphyllo longissimo foliisque linearibus, umbella trifida.

Gramen cyperoides, minus, nigricante panicula. Lob. adv. 463.

Gramen cyperoides, minus, panicula sparsa, obsolete nigricante. Bauh. theatr. $\$ 8$.

Cyperus minor, pulcher, panicula compressa, nigricante. Moris. liist. 3. p. =39. s. 8. t. 9. f. 38 .

Cyperus minimus, panicula sparsa nigricante. Tournef. inst. v. herb. 5\%. Scheucinz. gram. 3 ? Cyperus fuscus; culmo triquetro nudo, umbella trifida, pedunculis simplicibus inaequalibus, spicis confertis linearibus. Lin. spec. pl. 69 . Fl. dan. t. 179. Pollich. palat. n. 42. Leers fl, herb. n. 33. t. r. $f .=$.

Cyperus ferruginens; culmo triquetro, pedali; hasi folioso; umbella foliosa; spiculis fasciculatis, linearibus, compresso-convexis, ferrugineis, margine viriclibus, raro pedicellatis, semper sessilibus, coacervatis ad apicem pedunculorum; bracteis pedicellis longioribus. Forsk. descr. p. r 4 .

virescens. 6. Cyperus compressus noster seu viridis. Krock. siles. $n .69 . t$. 13.

Cyperus virescens; culmo triquetro; umbella universali triphylla, spicis compressis. Hloffm. germ. I 6 .

Habitat in Europae et Aegypti pratis humidis. 
Culmi plurimi, palmares et ultra, acuse trigoni. Folia altitudine culmi, laxa, linearia Involucrum bi-triphyllum, longitudine fere culmi. Umbella subcomposila: radii brevissimi. Spiculae vix sémiunguiculares, infimat binae vel ternae, linearés, duodecimflorae: valvulae oblongae, fuscae, margine carinaque virides, obtusiusculae, raro totae nigricantes.

Cyperus ferrugineus Forsk. vix nisi culmo parum altiore differt.

B. Vix videtur differre specie, valvulae enim in altero saepe patulae et color spicularum vix speciem distinguit in hoc genere.

86. CIPERUS spiculis confertissimis globoso-capi- difformia tatis, valvulis obovatis, umbellulis subbiradiatis, involucro diphyllo umbella longiore.

Gramen cyperoides elegans, panicula spicis valde mollibus composita, maderaspatanum. Plukn. alm. 179. t. 192. $f_{0}=$.

Gramen cyperoides elegans Vassambuo curry Malabarorum. Plukn. t. $41 \% \cdot f \cdot 5$.

Cyperus difformis; culmo triquetro nudo, umbella simplici trifida, spicis cuspidatis intermedia sessili. Lin. am. acad. 4. p. 302. syst. veg. 9\%. Rattb. gram. 24. t. 9.f. $z$.

Habitat in India orientali et Guinea.

Radix fibrosa. Culmus semi-sesquipedalis, trigonus, flaccidus, basi foliosus. Folia culmo breviora, pauca, linearia, laxa, extrorsum margine scabra. Involucrum plerumque diphyllum, interdum tertium interius umbella breuius, reliqua longiora, unicum saepe semipedale: partiale nullum. Ochreae truncatae, mucrone obtuso acuminátae. Umbella compasita; radii quinque-novem, longiores pollicares, setacei, patentes: partiales plerumque duo, interdum unicus, horizontales, breves. Spicu-. lae confertissimae in capitulum laxum piso parum majus, numerosae, vigintisexflorae, semiunguiculares, lineares, convexae, obtusiusculae: valvulae obovato-subrotundae, confertissimae, latere membranaceae, versus dorsum saepe fuscae, deciduae. 
urvatus. 87. CYPERUS spiculis lineari-lanceolatis compla: natis approximatis incurvis, involucro subtriphyllo subulato umbella longiore.

Habitat in India orientali. König. 4

Varietatis C. stoloniferi facie. Radix fibrosa. Culmi pedales, acute trigoni, basi foliosi, superne torti. Folia culmo breviora, linearia, convoluta. Involucri foliola duo, erecta, umbella duplo longiora, tertium brevius, interius. Ochreae oblique truncatae. Umbella simplex bi-triradiata: longior pollicaris. Spiculae circiter undecim, inferiores geminatae, reliquae solitariae, vigintisex-vigintioctoflorae, acutae, plerumque incurvae, rarius rectae: valvulae lanceolatae, obtusiusculae, versus carinam unibinerviae, latere sordide flavescentes.

$\checkmark$ ariat simili modo ac reliqui.

stoloniferus. 88. CYPERUS spiculis confertissimis lineari-lanceolatis convexis, involucro subtriphyllo subulato, culmo acutangulo, radice tuberrosa.

Cyperus stoloniferus; culmo nudo triquetro, umbella composita involucrata, spiculis lanceolatis. Retz. obs. 4. p. Io.

Cyperus spadiceus; culmo triquetro, umbella glomerata, involucro subulato subtriphyllo, spiculis aggregatis, glumis obtusis. Lamarck. illustr. 1. p. I 47.

Habitat in India orientali. König, Lamarck. 4 Radix tuberosa, semipollicaris, oblonga, zonata, tecta setis pollicaribus, rigidiusculis copiosissimis, nigris, stolonifera: stolones horizontales, crassitie fili emporetici, articulati, membranis fuscis vaginati, hinc inde surculos foliosos cum vel absque culmo emittentes. Culmi sernipedales, acute trigoni. Folia culmum basi vaginantia, saepe ejusdem altitudinis, attenuata, margine laevia, basi setis radicis tecta. Involucri foliola saepe duo rarius tria, praeterea duo vel tria ad spiculas centrales, unicum plerumque umbella sesqui vel duplo longius; ornnia basi plana, extrorsum convoluto-subulata. Ochreae obtusae, ore membranaceae. Umbella simplex: radii quinque, longior sesquipollicaris. Spiculae circiter novem, unguiculares: octodecim-vigintiflorae, obtusae: valvulae ova- 
tae, concavae, obtusae, paucistriatae, purpurascentes, margine tenui membranaceo albidae, carina virides.

$V$ ariat culmo pedali: foliis brevioribus, angustiaribus, pallide viridibus: umbellis bi-triradiatis: spiculis quatuor pallide viridibus, apice pirpurascentibus vel totis pallide purpureis; interdum spiculis glomeratis absque radiis ad latera.

89. CYPERUS spiculis ovatis confertissimis, culmo subtrigono, foliis canaliculatis.

Cyperus arundinaceus? caule tereti ad basin folioso, inarticulato, sub panicula in duas partes fisso. Forsl. fl. arab. n. 4 •

Cyperus conglomeratus; culmis subtriquetris; foliis fasciculatis, strictissimis, canaliculatis, sesquipedalibus; capitulo paniculato terminali. Rottb. gram. $21 . t$. 15. f. 7 .

Cyperus strictus culmo subtriquetro, umbella composita subglomerata triphylla, foliis strictis angustis canaliculatis. Lamarcki. illustr. I. p. I $4 \%$

Habitat in Arabia. Forskâl. 2

Culmi pedales et ultra, crassitie digiti minimi, obsolete trigoni, compacti, vaginis aridis uti et vaginae foliorum obvoluti, flavescentes. Folia radicalia plurima, nonnulla culmo al. tiora, subtus convexa, supra canaliculata, tenacia, margine scabra, glauca. Involucrum tetraphyllum, laxum. Ochreae abtusae. Umbella simplex: radii brevissimi, pauci. Spiculae breves, quatuordecim-sedscinflorae, ovatae, griseae cum tinctura purpurascente: valvilae avatae, concavae.

$V$ alde affinis praecedenti.

90. CYPERUS spicis corymbosis patentibus, spicu-torosug, lis teretiusculis, involucro subtriphyllo umbella longiore.

Cyperus culmo triquetro; involucro tetraphyllo; panicula terminali, pedunculata; spicis linearibus torosis, confertissimis, patentibus. Rottb. progr. 22, gram. 4c. t. 11. $f .3$.

Habitat in India orientali. 
Culmus acute angulatus. Involucrum di-tetraphyllum, margine carinaque scabrum: partiale nullum. Ochreae truncatae. Umbella simplex, quinque-sexradiata, radius longior pollicaris: partialis tri-quinqueradiata, radii brevissimi. Spiculae quatuor-octo, unguiculares, circiter vigintiflorae: valvulae ovaine, obtusae, convexae, dorso striatae, totae spadiceae.

A. C. strigoso Linnaei toto coelo diversus.

bicolor. 9r. CYPERUS spiculis linearibus convexiusculis ternis, involucro diphyllo umbella triradiata longiore.

Habitat in Cap. b. spei vel insula Franciae. Stadtmann.

Culmus bipedalis, acute trigonus, basi foliosus. Folia culmo breviora, angusta, carinata, margine laevia. Involucri foliola foliis parum angustiora, ceterum similia, umbella sesqui longiora. Umbella simplex. - Spiculae pollicares, angustae, convexiusculae, trigintisexflorae, acutae, nitidae: valvulae oblongae, obtusae, dorso unistriatae, albido-virescentes, lateribus fuscis laevibus; margine tenui, membranacco, albido.

cubeross. 92. CYPERUS spiculis lineari-lanceolatis convexiusculis, involucro triphyllo umbella quinqueradiata longiore.

Cyperus tulerosus; culmo triquetro, basi folioso; involucro triphyllo; umbella composita; spicis lanceolatis, teretiusculis. Rottb. gram. 28. t. $7 \cdot f$. r.

Habitat in India orientali.

Glaucus. Radix tuberosa, vix magnitudine nucis coryli, stolonifera: stolones, ut in C. stolonifero. Cülmi saepe bipedales, acute trigoni, basi foliosi, plerumque inmaculati, interdum adspersi punctis paucissimis purpureis. Folia altitudine culmi, margine carinaque scabra. Involucri foliola structura foliorum, omnia zumbella longiora, unicum semipedale. Ochreae truncatae, albidae vel purpurascentes. Unbella simplex: radii quinque-sex, longior bipollicaris, semiteretes. Spiculae tres-decem, vix semipollicares, inferiores remotiusculae, $p a$. 
tentes, vigintiquatuorflorae, acutae: valvulae ovatae, acutiusculae, pallide virescentes vel. latere purpureae, sublaeves, margine membranaceae.

93. CYPERUS spiculis lineari-oblongis, confertis- pustulatug. simis convexis obtusis, valvulis margine sphacelatis, involucro umbella longiore.

Habitat in Guinea. Thonning.

Culmus pedalis, acute trigonus. Folia culmo altiora, linearia, angusta, laxa. Involucrum universale triphyllum: foliola margine laevia, duo umbella longiora, unicum semipedale; partiale vel nullum vel foliolum unicum - duo, setaceum, umbellula brevius. Ochreae oblique truncatae, purpurascentes. Unmella composita, patentiuscula, quadri-quinqueradiata; radius longior subtripollicaris: partialis bi-triradiata; raciii breves, patentes. Spiculae quatuor-octo, vix lineas diuas longae, decem-duodecimflorae: convexiusculae, obtusae: valvulae concrvae, striatae, virides, margine macula atro-purpurea.

Affinis serpuenti, differt: spiculis confertissimis, triplo brevioribus, oblongis, nec lineari-lanceolatis: ochreis minime aristatis.

9. CYPERUS spiculis lineari-lanceolatis compla-sphacelatns. natis acutis, valvulis margine sphacelatis, involucro subtetraphyllo.

Cyperus sphacelatus; culmo triquetro; umbella simplicissima; spicis linearibus alternis compressis, flosculis margine sphacelatis. Rottb. gram. $=6$.

Hahitat in Surinamo, Cajenna, Puertorico. in Guinea, Thonning.

Culmus sesquipedalis vel brevior, acute angulatus, inferne bi-trifoliatus, interáum flavescens. Folia culmo breviora, linearia, superne margine scabra, pallide viridia. Involucrum tritetra-hexaphyllum, duo vel tria umóella longiora, structura foliorum: partiale vel nullum, vel duo foliola seiacea umbellula breviora. Ochreae aristatae. Umbella! subcomposita, tri-septemradiata: raciii filiformes, longior interdum quadripollicaris: partiales brevissimi 


\section{TRIANDRIA. MONOGYNIA.}

tri-tetrastachyi, radii indivisi interdum quatuogdecimstachyi. Spiculae vix pollicares, remotiusculae, erectae, circiter vigintiquatuorflorae: valvulae oblongae, obtusiusculae, carinain versus pallide virentes, striatae, marginem versus laeves cum macula atro-rubente in ipso margine.

pallescens. 95. CYPERUS spicis corymbosis, spiculis linearilanceolatis, involucro umbella breviore. $\dagger$

Cyperus pallescens; culmo triquetro, basi folioso; pedunculis supradecompositis; spiculis lineari-subulatis, rectis, distinctis; involucro subtetraphyllo, umbella breviore. Desfont. fl. Altl. i p. 45. t. 9.

Habitat in Barbaria.

Culmi basi crassitie fere digiti minimi, superne acutanguli. Folia pauca, culmo longe breviora, vaginantia, margine tenuissime serrata. Involucrum tri-tetraphyllum. Umbella cornposita, quinque-duodecim ŕadiata. Spiculae quatuor-duodecim, horizontales, primum albae, dein pallide rufae, distantes: valvulae concavae, obtusiusculae, margine membranaceae. Desfont. l. c.

rigidulus. 96. CYPERUS spiculis linearibus confertissimis, involucro diphyllo unbella uniradiata longiore foliisque filiformibus rigidis.

Hubitat in India orientali.

Culmi spithamaei, filiformes, basi foliosi. Folia altitudine culmi ejusque latitudine: vaginae purpurascentes. Involucrum erectum: foliolum unicum, bipollicare. Ochrea oblique truncata, purpurascens. Spiculae sex-duodecim, semiunguiculares, duodecimflorae, purpureae: valvulae oblongae, obtusae, striatae.

bulbosts. 97. CYPERUS spiculis lineari-lanceolatis distantibus, involucro umbella uniradiata longiore foliisque setaceis, radice bulbosa.

Habitat ad Senegal, in Guinea ac in India Orientali. Jussieu, Thonning, König.

Bulbus magnitudine pisi, tectus valvulis ovatis, concavis, striatis, nigris, apice in setas plurimas divisis, cum bulbo alio in axilla alterius valvulae, ovato, acuto, tunica ferruginea lae- 
vi tecto. Radices plurimae sub basi bulbi, pollicares, capillares. Culmi solitarii, spithamaei, obsolete triquetri, filiformes, basi vaginati. Folia ex apice vaginarım, quinque ad septem, plurima altitudine culmi, convo7uto-canaliculata, laxa, laevia: vaginae pollicares et ultra, longitudine aequales, hinc folia quasi fasciculata, fusco-ferrugineae. Involucrum universale et partiale monophyllum, interdum partiale deest, setaceum, patens, spiculis longins; infimum quintuplo longius, squama brevis sub reliquis. Rachis vix pollicaris. Spiculae in rachide flexuosa alternae, quinquedecem, plerumque geminatae, interdum quna vel altera solitaria, saepe semipollicares, compressae, duodecim-quatuordecimflorae, acutae, purpurascentes: valvulae lanceolatae, striatae. Stylus trifidus.

9. CYPERUS spiculis lineari-lanceolatis subqua-tetrastachyos. ternis, involucro subtriphyllo umbella breviore foliisque filiformibus.

Cyperus tetrastachyos; culmo triquetro; involucris subtetraphyllis, corymbo brevioribus; spiculis subquaternis, arcuatis, acutis. Desfont fl. atl. 1. p. 44.t. 8.

Habitat Algiria ad ripas fluminis Taddah. Ex herbario Desfontainii.

$V$ alde affinis C. rotundo, differt: Culmo teneriori, filiformi: Foliis angustioribus fere filiformibus, brevioribus: Involucris filiformiobus, umbella brevioribus: Spiculis duplo longioribus.

Folia margine superne scabriuscula. Involucrum interdum diphyllum. Ochreae albidae, truncatae. Umbella simplex; radii duo-quatuor, capillares. Spiculae solitariae, duae ad quinque, lineares, subpollicares, circiter vigintioctoflorae: interdum parum arcuatce, Valvulae ovatae, acutae; latere laeves purpureae.

9. CYPERUS spiculis lineari-lanceolatis subsenis, rotundus. involucro subtriphyllo umbella longiore foliisque linearibus.

Cyperus urientalis, radice olivarii, spicis longis e spadiceo purpureis. Scheuchz. gram. $39 \mathrm{I}$. 


\section{TRIANDRIA. MONOGYNIA.}

Cyperus culmo triquetro subnudo, umbella decomposita, spicis alternis linearibus. Lin. $f l$. zeyl. $3 \%$ rotundus syst. veg. 98.

Cyperus hexastachyos; foliis gramineis linearibus molliusculis glaucis, umbella simplici flaccida, spicis linearibus alternis subsenis. Rottb. gram. 28 . t. 14. f. 2.

Habitat in Arabia et India orientali. 4

Radix fibrosa, hinc inde tubera emittens. Culmus sesquipedalis, acute trigonus, basi foliosus. Folia interdum altitudine culmi, laxa, margine laevia. Involucrum di-triphyllum. Ochreae truncatae, pallidae, basi purpureae. Umbella

- simplex: radii tres-quatuor, filiformes; longior bi-tripollicaris. Spiculae duae-sex, unguiculares, parum distantes, decem-duodecimflorae, acutae: valvulae latere purpureac, laeves, margine membranaceae.

$V$ ariat involucris umbella longioribus vel aequalibus, frequentius vero longioribus, spiculis magis vel minus purpureis.

Hydra. 100. CYPERUS spicis corymbosis, spiculis linearilanceolatis distantibus, foliis recurvatis, tuberibus oblongo-subrotundis.

Cyperus hydra; radice repente, tuberifera: foliis radicalibus, recurvatis: culmo triquetro laevigato: umbella simplici: spiculis ad summitates proxime alternis, subfasciculatis, patentibus, lanceolato-linearibus, conspicue compressis, saturate castaneis. Mich. fl. bor. am. I. p. 27:

Habitat in Insula St. Crucis, Pryan. in Carolina, Bosc. 24

Maxime affinis varictatibus C. proceri ex India orientali et vix limites inveniuntur. Tubera, ut in affinibus zonata: Culnus plerumque humilior est, spicimina tamen culmo pedali vidi. Folia parum latiora. Involucrum longius vel brevius, diphyllum, foliolis umbella brevioribus; vel triphyllum foliolo unico umbella longiore vel aequali. Umbella saepe simplex, sed et composita, bi-quinqueradiata. Spiculae breviores, interdum latiores, interdum angustiores. Sic vix ullam aliam differentian inve- 
nio quam folic recurva, et figuram tuberum. Spiculae complanatae, nitidae.

Ior. CXPERUS spiculis lineari-lancenlatis distanti- esculentus. bus, umbellulae radijs terminalibus, foliis erectis, tuberibus ovatis.

Trasi. Math. comm. $4 \mathrm{r2}$.

Cyperus rotundus. Lob. ic. 75.

Cyperus rotundus esculentus angustifolius. Bauh. theatr. 22. pin. 14. Scheuchz. gram. 38-2.

Cyperus esculentus; culmo triquetro nudo, umbella foliosa, radicum tuberibus ovatis zonis imbricatis. Lin. syst. veg. $9 \uparrow$.

Habitat Monspelii, inque Italia, Oriente. 4

$A b$ antecedente difficile dignoscitur, et vix nisi tuberilus magis ovatis, foliis erectis, radiis umbellularum saepius ternis, quae ultima note forte constans. Padii umbellae filiformes ut in antecerlente et sequente. Setae duae sub umbella partiali. Variat umbellis compositis et simplicilus.

102. CYPERUS spicis corymbosis, spiculis filifor- Pägoraei. mibus remotiusculis, valvulis linearibus obtusis, involucro triphyllo, culmo triquetro.

Cyperus Pangoraei; culmo triquetro; involucro triphyllo; umbella universali decomposita; partialibus subtrifidis; spicis alternis, filiformibus. Rottb. gram. 3r. t. ?. f. 3 .

Habitat in humidàs Zeylonae. König. 24

Culmi interdum altitudine hominis, crassitic pennae anserinae. Involucri foliola tria, margine scabra: partialia nulla, nisi squamula. Ochrea truncata, ferruginea. Umbella composita; radii septem-octo, capillares, longior quadripollicaris: partiales pollicares vel breviores, alterni. Spiculae quatuor-octo, pollicares et zultra, tenues, vigintisexflorae, ferrugineae: valvulae obtusae, concavae, enerviae, sensim deciduae.

$V$ ereor Cel. Retzii C. Pangomaei diversum esse a Rottböllii, haud raro enim C. proceri varietates aeque ac aliorum sub nomine Pangoraei ex India hảait. Pottböllii $a b$ omnibus affinibus distinctus est, gaudet enim: culmo triquetro nec trigono: spiculis filiformibus nec lineari- 


\section{TRIANDRIA. MONOGYNIA.}

bus: valvulis linearibus obtusis, nec ovato. lanceolatis.

Variat magnitudine; involucro longitudine um. bellae vel subaequante; spiculis remotis vel magis approximatis. Involucrum constanter triphyllum absque foliolis minoribus in centro.

badius. 103. CYPERUS spicis corymboso-fasciculatis, spiculis lineari-lanceolatis, involucro triphyllo.

Cyperus badius; corymbo terminali; foliis margine dorsoque serrulatis; spiculis lineari-subulatis, dense confertis; involucro pedunculis longiore. Desfont. fl. atl. 1. p. 45. t. 7. f. 2 .

Habitat ad ripas rivilorum Algiriae. 4

Culmus sesquipedalis, acutangulus, gracilis. Folia margine et carina scabra. Involucrum triphyllum: foliola duo umbella longiora: partiale nullum. Ochreae truncatae. Umbella composita: radii sex, filiformes, longior tripollicaris; partiales tres vel quatuor, conferti, brevissimi, tri-tetrastachyi. Spiculae unguiculares, octodccimflorae, acutae, fusco-ferrugineae: valvulae oblongae, obtusae, prope carinam uninerviae.

Affinis Cypero tenuifloro.

longus. 104. CYPERUS spicis corymbosis, spiculis linearilanceolatis complanatis, involucris radiisque umbellae longissimis, culmo folioso.

Cyperus. Fuchs, hist. +5 ?

Cyperus longus odoratus. Bauh. theatr. $2 \mathrm{I}^{\mathrm{h}} \mathrm{.}$

Cyperus odoratus radice longa s. Cyperus officinaruin. Bauch. pin. 14. Scheuchz. gram. 378.

Cyperus longus; culmo triquetro folioso, unbella foliosa supradecomposita, pedunculis nudis, spicis alternis. Lin. syst. veg. 98. Jacqu. collect. 3. p. 19 г. Ic. rar. 2. t. 297.

Habitat in Galliae, Italiae, Carnioliae, Egypti et Indiae orientalis paludosis. 4

Culmi alti, crassitie pennae anserinae, acute trigoni, inferne foliosi. Folia pedalia et ultra, margine scabra. Involucrum pentaphyllum: foliola margine scabra; duo sesquipedalia, unguem lata: partiale tri-tetraphyllum, umbella brevius. Ochreae pollicares, oblique truncatae: partiales transversim. Umbella decompo- 
sita; rarlii circiter undecim, inaequales, longiores saepe pedales, graciles, nonnulli filiformes, erecti: partiales filiformes, quini vel plures, bi-tripollicares: ultimi duo-tres, nudi. Spiculae tres-decem, unguiculares, duodecimsedecimflorae, approximatae, distichae, patulae, utrinque acutae, purpureae: valvulae oblongae, obtusae, latere laeves, margine membranaceae.

105. CYPERUS spicis corymbosis, spiculis linea- corymbosus. ribus teretiusculis, involucro umbella longiore, culmo vaginato.

Cyperus corymbosus involucro polyphyllo; umbella supradecomposita, perlunculis filiformi bus corymbosis strictis. Rottb. gram. 42. t. 7 . f. 4 .

Cyperus corymbosus; culmo trigono aphyllo, umbella decomposita involucro breviore, spicis linearibus. Thunb. prodr. Is.

Habitat in Arabia, India orientali et Cap. b. spei. 2

Culmus tripedalis, acute angulatus. Folia nulla, nisi vaginae tres fuscae, apice lanceolatae, interior fere pedalis. Stolones adsendentes vaginati. Involucri foliola tria-quatuor, duo vel tria umbella longiora, ultra linearn lata, margine carinaque scaberrima: partiale nullum, nisi squama; setaeduae ad basin radiorum. Ochreae obliqus truncatae, mucronatae. Umbella decomposita, patens, duodecim-quindecimradiata: radii filiformes, longiores palmares: partiules longiores saepe bipollicares, distantes. Spiculae tres.octo, remotiusculae, tenues, unguiculares, sedecimflorae, acutae: valvulae oblongae, obtusae, vix striatae, pallide purpureae, margine albido membranaceae.

106. CYPERUS spicis corymbosis, spiculis linea-tenuiflorus. ribus convexiusculis, involucro umbella lon. giore, culmo folioso.

Cyperus tenuiflorus, culmo triquetro, foliis linearibus, umbella decomposita, spiculis linearibus acutis angustissimis. Rottb. gram. 30. t. 1 н.f. 1. Jacqu. collect. 3. p. 190. Ic. rar. 2. t. 296.

Habitat - - 4 


\section{TRIANDRIA. MONOGYNIA.}

Viridi-glaucus. Cuimus bipedalis et ultra, acuie angulatus, inferne foliosus. Folia culmo parum breviora, vix duas lineas lata, margine laevia, pallide viridia. Involucrum subtetraphyllum; zınicum umbella duplo longius: partiale diphyllum setaceum. Ochreae oblique truncatae. Umbella composita, subseptemradiata; radii filiformes, longior tripollicaris: partiales quinque-sex, alterni, semipollicares, scrsim breviores, capillares. Spiculae duaeocto, parum distantes, distichae, semipollicares vel parum ultra, angustae, sedecim-vigintiflorae, nitidae, spadiceae: valvulae oblongae, obtilsae, utrinque subuninerviae. ¿े

diphyllus. 10\%. CYPERUS spicis corymbosis, spiculis teretibus, involucro diphyllo brevissimo.

Cyperus diphyllus; culmo subtriquetro diphyllo, umbella supradecomposita, spiculis teretiusculis subpinnazis. Retz. obs. 5. p. I I.

Habitat in fluentis Indiae orientalis König. 4

Culmi bi-sexpedales, spongiosi, inforne teretes, apice acutanguli: stolones adscendentes, vaginati. Folia, in meis speciminibus, nulla, eorum loco vaginae duae, palmares et ultra, apice 7anceolatae, purpureo punctalae. Involucri foliola vix pollicaria, angusta: involucella nuila. C)hreae purpurascentes, uniàentatae. Lmbella composita; radii universales decem, capillares, compressi, longior tri-quadripollicaris: partiales bi-quadriradiati. Sriculae semipollicares, remotiusculae, circiter novem, distichae, graciles, circiter vigintiseptemflorae, acrutue, fiavescentes: valvulae lanceolatae, dorso striatae, margine pallidiores.

In toto habitu Cyp. articulato consimilis. Umbella interdum simplex.

puncticula- 108. CYPERUS spicis corymbosis distichis, spicutus. lis lineari-lanceolatis subpendulis distantibus, involucro triphyllo umbella longiore.

Habitat in Indiae orientaits aquosis. 4

Radices longissimae, fibrosae, ramosissimae. Culmi tripedales et ultra, basi cum vaginis crassitie digiti minimi, inferne foliosi, acute angulati. Folia bipedalia et longinra, duas lineas 
lata, laxa, extrorsum margine carinaque subscabra. Involucrum triphyllum : foliola omnia umbella longiora, structura foliorum: partiale nullum. Ochreae pollicares, truncatae, acumine brevi obtuso terminatae. Umbella composita, ampla, suboctoradiata, longior quinquepollicaris: partialis ractiis tribus vet quinque, brevibus, alternis. Spicae bipollicares. Spiculae vigintiquatuor - vigintisexflorae, vix semipollicares, subpedicellatae, subpendulae, listantes, circiter viginti in singulo radio, lineari-lanceolatae, obtusiusculae: valvulae $o b$ longae, obtusne, minime striatae, latere ferrugineo-purpurascentes, margine membranaceae. liachidis foveola superne puncto fusco notata.

109. CYPERUS spicis corymbosis, spiculis lineari- inaciostalanceolatis remotiusculis longissimis arcuatis, chyos. involucro subdiphyllo, umbellis amplissimis.

Cyperus macrostachyos; culmo triquetro, umbella composita amplissima, spiculis linearibus arcuatis longissimis, glumis obtusiusculis. Lamarck. illustr. 1. p. $147^{\circ}$

Habitat in Africa Larnarck, in India orientali Röttler. 'Lx herbario Lamarchii et proprio.

Viridi-glaucus. Culmus tripedalis et altior, inferne crassitie fere digiti, triqueter, foliosus. Folia bipedalia et ultra, vix unguem lata, ex1rorsum margine et carina serrulato-scabra. Involucrum subtriphyllum, unicum pedale, reliqua umbella breviora, structura foliorum: partiale diphyllum, breve. Ochreae pollicares, truncatae, nigricantes: partiales nullae. Umbella composita, magna: radii quatuor - quinque, longior spithamaeus; partiales patentissimi, duo vel tres breves. Spiculae pollicates vel bipollicares, lineam latae, remotiusculae, frequentes, saepe septuagintaflorae, acutae, juniores rectae, adultiores curvatae, ferrugineopurpurascentes: valvulae oblongae, obtusae, subuninerviae, margine membranaceae, sensim deciduae.

510. CYPERUS spiculis ovatis, involuczo sub-pulcher. hexaphyllo, f 


\section{TRIANDRIA. MONOGYNIA.}

Cyperus pulchef culmo trigono, umbella decomposita, involucro subhexaphyllo, spiculis ovatis. Thunb. prodr. Is.

Habitat in Cap. b. spei.

lanceus. I 1. CYPERUS spiculis lanceolato-oblongis arcte imbricatis confertis, involucro subtriphyllo.

Cyperus lanceus; culmo trigono folioso, umbella composita involucro duplo breviore, spiculis oblongis. Thunb. prodr. 18 .

Habitat in Cap. b, spei. 4

Culmus pedalis et ultra, crassitie pennae columbinae, acute angulatus, basi foliosus. Folia aliitudine fere culni, linearia, margine scabriuscula. Involucrum subtriphyllum, unicum vel duo umbella breviora: partiale nullum. Ochreae oblique truncatae, acuminatae. .Umbella composita, tri-quadriradiata; radii erectopatentes, longior subtripollicaris: partiales bitriradiatae: radiis brevissimis, geminis, ternis. Spiculae geminae-ternae, in radiis partialibus quaternae, semipollicares, linean vel parum ultra latae, obtusiusculae, vigintiquatuorflorae, nitidae, fusco-ferrugineae: valvulae oblongae, obtusae, compressae, margine et carina pallide flavescentes.

serotinus. I z2. CYPERUS spicis corymbosis patentissimis, spiculis lineari-lanceolatis laxe imbricatis distichis remotiusculis, involucro umbella longiore.

Gramen cyperoides, aquaticum, majus, panicula cyperi longi ex crassioribus glumis compacta, at brevibus petiolis donata. Triumf. obs. 64 .

Cyperus serotinus odoratus, radice longa, panicula e locustis latis ferrugineis compactis. Mont. gram. 12. t. 1. f. 2. Scheuchz. gram. 380.

Cyperus serotinus; umbella universali decomposita, foliosa; partialibus nudis subtrifidis; spicis teretiusculis alternatim pinnatis. Rottb. gram. $3 \mathrm{I}$.

Cyperus monti; culmo tereti, umbella supradecomposita, foliis carina laevibus. Lin. suppl. I $0=$.

Habitat in maritimis Italiae et Tergesti, 4 
Glaucus. Culmus bi-tripedalis, acute trigonus. Folia radicalia longissima, margine serrulatoscabra, carina laevia. Involucrum triphyllum, omnia umbella longiora, unicum longissimum, unguem lata, structura foliorum: partiale nullum. Ochreae truncatae. Umbella universalis quinqueradiata; radius longior triquadripollicaris: partiales tres-quinque, subsessiles, horizontaliter patentes, alterni, pollicares, flexuosi. Spiculae quatuordecim-viginti, unguiculares et parum ultra, lineari-lanceolatae, convexiusculae, parum distantes, obtusiusculae: valvulae ovatae, obtusiusculae, concavae, versus carinam parum striatae, margine membranaceae, nitidae, fusca-ferrugineae.

123. CYPERUS spiculis subquinis oblongis approximatis, valvulis margine sanguinolentis, involucro triphyllo.

Cyperus albidus; culmo triquetro, umbella simplici triphylla, spiculis conglomeratis albidis, squamis laevibus. Lamarck. illustr. i. $p, 14^{\text {f. }}$. Habitat in India orientali. Exherbario Lumarckii. Affinis Cyp. cruento. Culmus vix spithamaeus, basifoliosus. Folia culmo breviora. Involucri foliola duo umbella longiora. Umbella simplex, quinqueradiata. Spiculae quatuor vel quinque: valvulae ovatae, albidae, lateribus sanguineis.

114. CYPERUS spiculis subquinis oblongis concruentus. vexis, valvulis punctatis, involucri pentaphylli foliolis omnibus umbella longioribus.

Cyperus cruentus; culmo triquetro, involucro polyphyllo longo, umbella simplici, spicis conglomeratis, flosculis sulcato-punctatis. Rottb. gram. 21.t. 5.f. 1. symb. bot. 1. p. s.

Cyperus globosus; culmo triquetro basi folioso, spicis conglomeratis subglobosis: spiculis convexis, viridibus, nitidis. Forsk. descr. p. 13.

Habitat in Arabia Forskal. 4

Culmi plures, palmares vel spithamaei, graciles, stricti, acute angulati, basi vaginis plurimis aridis ferrugineis tecti. Folia altitudine cul$m i$, angusta, carinata, laxa. Involucri foliola inaequalia, unicum longitudine fere culmi; reliqua breviora, patentia, structura foliorum: 


\section{TRIANDRIA. MONOGYNIA.}

partiale nullım. Umbella simplex, subquadriradiata: radii interdum semipollicares, interdum brevissimi. Spiculae quatuor-sex, parvae, acutaé, duodecim-quatuordecinflorae: valvislae ovatae, striatae, purpureo confertim punctatae, margine membranaceae.

Radii saepe ut in $\mathrm{C}$. jeminico contrahuntur, unde spiculae in capitulo subgioboso conglomeratae apparent.

nonophyllus. I 5. CYPERUS spicis corymbosis, spiculisque teretibus laxe imbricatis, umbella involucrum ciphyllum subaequante.

Habitat in India orientali?

Culmus bipedalis et ultra, crassitie fere pennae anserinae, acute angulatus, inferrie vagina in folium bipollicare desinente vestitus. Involucri foliola linearia, angusta, margine carinaque scabra, rigida, unicum umbella parum longius, bipollicaria; partiale núllum nisi squanae duae brevissimae. Ochreae acuminatae. Umbella conıposita, angustata; radii quinque, sesquipollicares: partiales brevissimi, alterni. Spiculae quatuor-sex, erectae, decemflorae, imguiculares, fusco-virescentes: valvulae oblongae, obtusissimae, convexae, margine membranaceae, albidae, vix striatae.

parvifurus. 116 . CYPERL'S spicis corymbosis linearibus teretiusculis, spiculis oblongis teretibus distantibus, involucro heptaphyllo longissimo.

Habitat in Java Burmann.

Viridi-glarciss. Culmi obtuse angulati. Involucri foliola omnia umbella longiura, nonnulla pedalia et ultra, margine carinaque serrulatoscabra: involucella vix ulla nisi squamae duae, parvae, ovatae, valde attenuatae. Umbella decomposita; radii quatuor, longior pollicaris: partiales tres vel quatuor, uti tres ultimi brevissimi. Spicae pollicares, alternae, erectae. Spiculae sparsae, parvae, quadri-sexflorae, oblongae, acutae, fusco-virentes: valvulae ovatae, acutae, convexae, striatae.

albidus. 117. CYPERUS spicis corymbosis, spiculis latis, seminibus apice capitulatis, involucro pólyphyl. lo longissimo. $t$ 
Cyperus alhidus culmo triquetro nudo, umbella composita, pedunculis corymbosis, inrclucro polyphyllo longissimo. Retz. obs. 6. p. 21 .

Habitat in China.

Culmus tripedalis. Folia ad basin culmi, bipedalia. Involucrum octophyllism, longius sesquipedale, reliqua sensim breviora, brevissinum tripollicare: partiale nullum. Ochrea fissa. Umbella composita, octoradiata; radii Li-tripollicares. Spiculae latiusculae, subsemipollicares, albidae, sedecim-vigintiflorae: valzulac apice divergentes. Semen altero apice acumine elongatum, altero capitulo truncato terminatum stigmati peltato simili. Retz. $l$. c.

II . CYPERUS spicis corymbosis, spiculis ovali-virens. bus, involucro longissimo. +

Cyperus virens; majusculus, nitidus: involucro longึssimo: umbella composita subnuda; ramis summitate divaricato-ramulusis. spiculis fasciculatis, virentibus, ovalibus, plano-conpressis. Hichaux fl. bor. amer. I. $p$. $=9$.

Habitat in Carolina.

Culmus aczete angulatus. Involucrum polyphyllum. Lmbella composita. Spiculae copiosae, undique versae, breviuscule ovatae, Mich. l. c.

19. CYPERUS spicis corymbosis, spiculis lineari-malaccensis bus teretibus curvatis, valvalis fructiferis basi hiantibus, involucro triphyllo.

Cyperus malaccensis, culmo triquetro, umbella paniculata, involucro longissimo, spiculis linearibus subteretibus, squamis obtusis. Iamarch. illustr. I. p. I $q^{6}$.

Habitat in Malacca König, Sonnerat ad littora maris. 4

Culm.1s bipedalis et ultra, tricueter. Folia altitudine fere culmi, lineas duas lata, laxa, linearia, margine lavia: vagina interior semipedalis, in folium desinens. Involucrum triphyllum: foliola ornia umbella langiora, longizss pedale, unicum vel nullum interius: partiale nullum. Ochreae unidentatie, fuscae. Umbella composita; radii circiter octo, longior subtripollicaris: partiales tres-quingue, distarb- 


\section{TRIANDRIA. MONOGYNIA.}

tes, semipollicares. Spiculae quinque-octo, distantes, distichae, semipollicares, remotiusculae, patentissimae, adultiores curvatae, vigintiflorae: valvulae oblongae, abtusissimae, substriatae, concavae, apice imbricatae, basi hiantes, fusco-virescentes, margine membra. naceae.

planifolius. 120. CYPERUS spicis corymbosis, spiculis linearilanceolatis confertis convexis, involucro subpentaphyllo longissimo.

Cyperus planifolius; triqueter; foliis praelongis, planissimis: umbella composita: spiculis confertis, linearibus, acutis, saturate castaneis. Act. soc. h. n. par. 1. p. 106. fide herbarii Richardi.

Habitat in Cajenna v. Rohr, in insula St. Crucis VIest: 24

Culmus altus, crassitie pennae cygneac, acuts angulatus, apice fusco-ferrugineus. Folia semipollicem lata, extus carina margineque serrulato-scabra. Involucrum structura foliorum: partiale nullum, nisi setae duae vel tres, unguiculares. Ochreae ligula truncata, brevissima, vix dentata. Umbella dęcomposita: radii sex-novem, longiores fere spithamaei: partiales quinque-sex; ultimi quatuor - quinque brevissimi, patentes. Spiculae plures, unguiculares, octodecimflorae, convexae, linearilanceolatae: valvulae oblongae, obtusiusculae, concavae, striatae, juniores carina virides, fructiferae totae castaneae.

$V$ ariat umbellis compositis, radiis brevioribus, ut spicae fere glomeratae appareant.

In Barbados legit Dn. Martfelt et mihi una cum tota sua collectione plantarum americarum donavit. Anne ad hanc varietatem pertinst Sloanaei: Cyperus rotundus, panicula sparsa, spicis strigosis ferrugineis. Cat. 35. hist. I. p. I16.

t. $74 . f .2$. 3. certe enim magnam habet similitudinem.

pilosus., 1 21. CYPERUS spicis sessilibus radiatis lanceolatooblongis, spiculis patentibus distichis remotiusculis, rachi ciliata.

Habitat in India orientali. 4 
Culmns sesquipedalis, penna columbina crassior, iriqueter. Folia altitudine culmi, lineas duas lata, extrorsum margine carinaque serrulata. Involucrum pentaphyilum, umbella longius: partiale mono-diphyllum, setaceum, umbella brevius. Ochrea unidentata, puipureo punctata. Umbella composita, sex-septemradiata: radii quadripollicares. Spicae quatuor-sex, sessiles, confertae, alternae, horizontales, brevissimae. Rachis flexuosa, angulis ciliatis. Spiculae sedecim-triginta, parum distantes, duas lineas longae, horizontales, duodecimflorae, lineari-lanceolatae: valvulae ovatae, mucronatae, purpurea striatae, margine membranaceae.

$A b$ omnitus mihi notis dignoscitur rachi inter spiculas angulis piloso-ciliata.

222. CYPERUS spicis sessilibus imbricatis spicu- canescens. lisque oblongis teretiusculis reflexis.

Wrara pullu. Rheed. mal. 12. p. 77. t. 42.

Habitat in India orientali. König. 24

Virescenti-glaucus. Culmus bipedalis et ultra, penna columbina crassior, obtuse angulatus, sub umbella ferrugineus. Folia altitudine fere culmi, unguem lata, margine scabra, Involucrum hexaphyllum: foliola structura foliorum, unicum sesquipedale: partiale nullum. Ochreae oblique truncatae, altero latere bidentatae. Umbella composita; universalis circiter octoradiata: radiis patentibus, longior bi-s-tripollicaris: partialis quadriradiata: radii semipollicares, horizontaliter patentes, dıo altiores. Spiculae copiosae, vix semiunguiculares, serflorae, confertae, acutae: valuulae ovatae, obtusiusculae, 'striatae. Semen triquetrum, nigrum.

123. CYPERUS spicis corymbosis imbricatis, spi- racemosus, culis linearibus, involucro polyphyllo. +

Cyperus racemosus; culmo triquetro nudo, umbella supradecomposita, pedunculis ramosis racemosisque, involucro polyphyllo longo. Retz.obs. 6. p. 20.

Habitat in India orientali. 
Culmus pedalis, crassus. Folia radicalia, culmo altiora. Involucrum decaphyllum et ultra; foliolo exteriore umbella duplo longiore, reliquis sensim minoribus: partiale foliolis nonnullis filiformibus, umbellula brevioribus. Ochreae. breves, albae, truncatae, folio subulato terminatae. Umbella supradecomposita, decempollicaris. Spiculae densae, duodecimflorae, rufescentes. Retz. l. c.

odoratus. I24. CYPERUS spicis corymbosis, spiculis subulatis remotis distichis, valvulis subdistantibus, umbellulis patentissimis involucellum subaequantibus.

Cyperus longus odoratus panicula sparsa, spicis strigosioribus viridibus, Sloan. cat. 35 . hist. г. p. I 16. t. ? 4. f. I. et t. 8. f. т.

Cyperus odoratus; culmo triquetro nudo, umbella decomposita, simpliciter foliosa, pedicellis distiche spicatis. Lin. spec. pl. 68 .

Habitat in Caribacis ad ripas fluviorum. $v$. Pohr. 2

Culmus altus, crassitie pennae anserimae, acute trigonus. Folia culmo breviora, unguem vel parum ultra lata, margine carinaque scabra. Involucrum subpentapliyllum: foliola quatuor zumbella longiora, structura foliorum: partiale diphyllurn, longitudine umbellulae; inicum brevius ad singulum radium. Ochreae pollicares, bifidae; laciniae lineari-subulatae, margine serzulatae: partiales aristatae. Umbella magna diffusa, composita: radii septern, longior spithamaeus: partiales tres-quinque, alterni, semipollicares, sensim minores, remoli, horizontaliter patentes, flexusi. Spiculae pollicares, duodecim-novendecim, horizontales, aetute reflexae, teretes, valde attemuatae, vigintiflorae, viridi flavescentes: valvulae oblongae, obtusae, dorsu-striatae.

Linnaei C. odoratum hiuc retuli propter Synonymum Sloanaei. A sequentibus differt: longitudine et crassitie spicularum. Specimen in toto minus umbella contractiore ceterum ommino C. odorato consimile e Senegal mecum communicavit Dn. Dupuis. 
25. CYPERUS spiculis filliformi-subulatis confer-ferox. tissimis flexuosis reflexis, involucro partiali subnullo.

Cyperus ferox; foliosus triqueter majusculus, umbella spatiosa composita, spiculis copiosissimis confertis patulis filiformi subulatis. Act. soc. h. n. par. 1. p. 1o6.

Habitat in America meridionali v. Rohr, Richard, in Monserrat Ryan.

Culmi pedales, penna columbina crassiores, acute trigoni, angulis laevilus, rigidi. Folium unicum vel duo inferne in culmo, graminea, altitudine culmi, vix sémiunguem lata, carinata, extrarsum margine scabra, carina laevia. Involucri quatuor foliola umbella plerumque longiora, saepe foliis latiora, extrorsum margine scabra. Ochreae bimucronatae, compressae. Umbella composita, diffusa; radii universales plerumque septem, longiores bi-quadripollicares, semiteretes: partiales triradiatae; raclii breves, horizontales. Spiculae plurimae, pollicares, primum patentes demum reflexae, sedecimflorae, acutae: valvulae oblongae, obtusae, parum distantes, dorso virides, substriatae, latere laeves, mipureae, hinc spicula quasi alternatim rubro viridique maculata apparet.

Umbella interdum simplex, radiis paucis brevibus.

126. CYPLRUS spiculis teretibus globoso-capitatis, croceuz. involucro subpentaphyllo umbella longiore.

Habitat in Puertorico? Tx herbario Jussiagi. 4

Radix repens, penna columbina crassior. Culmi pedales, filiformes, acute angulati. Folia radicalia, tripollicaria, rigidiuscula, margine scabra, viridi-flavescentia. Involucrum subpentaphyllum, umbella longius. Ochreae transversim truncatae. Umbella simplex, sex-septemradiata: radii capillares, longior policaris. Spiculae confertissimae in capitulum, piso parum majus, lineam longae, quadri-sexflorae flavescerti-ferrugineae: valvulae oblongae, acutae.

27. CYPERUS spiculis subulatis teretiusculis con- dilutus. fertissimis subgloboso-capitatis, involucellis umbellam aequantibus.

Habitat in India orientali Röttler. 2 


\section{TRIANDRIA. MONOGYNIA.}

Culmi bipedales et forte ultra, superne acute angulati. Involucrum subhexaphyllum: foliola omnia umbella longiora, unicum sesquipedale, margine a basi ad apicem scabra: pertiale tritetraphyllum. Ochreae acuminatae. Umbella decomposita, longior tripollicaris : partialis triquinqueradiata; radii pollicares, patentes: ultimi brevissimi, duo-tres confertissimi. Capitulum piso duplo vel triplo majus. Spiculae copiosae, undique patentes, semiiunguiculares, octoflorae, angustissimae, acutissimae: valvulae lineari-oblongae, acutiusculae, versus carinam substriatae.

congestus. 128. CYPERUS spicis capitato-subglobosis, spiculis subulatis confertissimis reflexis rectis, ligula ochrearum bidentata, involucro triphyllo.

Habitat in Cap. b. spei. 4

Culmus bi-tripedalis, acute trigonus, basi foliosus. Folia culmo breviora, unguem lata, extrorsum margine scabra. Involucrum subtriphyllum, structusa foliorum, duo umbella longiora: partiale nullum vel monopliyllum, setaceum, capitulo brevius. Ochreae truncatae. Umbella composita: radii quatuor, longior tripollicaris; partialis biradiata, radiis sessilibus, confertis. Capitula magnitudine nucis juglandis. Spiculae reflexae, undique patentes, semipollicares, circiter sedecim, acutissimae, inferiores reflexae, duodecimflorae: valvulae oblongae, acutae, concavae, striatae, virides, apice purpurascentes.

Affinis antecedenti, at diversus: Culmo inde ad basin acutangulo: Involucri foliolis radiisque Umbellae paucioribus: Capitulis triplo majoribus: Spiculis duplo longioribus. Anne huc pertinet C, ligularis Thunbergii?

strigosus. 29. CYPERUS spicis oblongis laxis, spiculis subulatis patentibus remotiusculis, involucellis subnullis, umbellulae radiis alternis.

Cyperus strigosus; culmo triquetro nudo, umbella.simplici, spiculis linearibus confertissimis horizontalibus. Lin. spec. pl. 69 .

Habitat in Virginiae paludosis.

Radix fibrosa. Culmi semipedales, acute trigoni, basi foliosi. Folia altitudine culmi. Involucri 
foliola quatuor-quinque umbella longiora, unicum longitudine culmi: partiale vix ullum. Umbella composita: radïi tripollicares vel breviores; partiales tres-quinque brevissimi, remotiusculi, patentissimi. Spiculae circiter vigin$t i$ in singulo radio, vix semiunguiculares, angustissimae, acutae, octoflorae: valvulae lineares, substriatae, carina virides, marginem versus flavescentes.

De synonymo Linnaei omnino certus sum, specimen enim e proprio herbario propria manu inscriptum mihi donavit, toto coelo discrepans a Sioanaei et Rottböllii C. strigoso, quod quoque satis patebit conferenti descriptiones et icones horum auctorum cum descriptione Linnaei.

30. CYPERUS spicis oblongis retrorsum imbrica- fexuosus. tis, spiculis subulatis flexuosis, involucellis pentaphyllis longitudine umbellulae.

Habitat in America meridionali v. Polhr.

Culmus tripedalis, basi crassitie pennae cygneae, acute trigonus, inferne foliosus, apice ferrugineus. Folia culmo breviora, interdum semipollicem lata, margine scabra. Involucrum subpentaphyllum: foliola umbella longiora, inieriora breviora, structura foliorum: involucella pentaphylla: foliola plurima longitudine umbellulae. Ochreae oblique hiantes, desinentes in laciniam lanceolatam, bifidam: partiales truncatae, bidentatae. Umbella composita, radiis circiter decem-duodecim, longiores spithamaei: partiales septem-octo, patentissimi, saepe reflexi, longiores pollicares. Spicae pollicares, undique imbricatae. Spiculae numerosae, semiunguiculares, sexflorae, virides, primum patentes; demum sensim reflexae, angustissimae, apice purpurascentes: valvulae oblongae, obtusae, convexae, striatae, interdum alternatim purpureae et virides.

Hunc, uti sequentem et ylurimos alios sub nomine Cyperi ligularis accepi, qui tamen meo judicia a Linnaei specie differunt. Varietas clatur spiculis paucioribus.

¥31. CYPERUS corymbis ovatis fasciculatis, spicu- purpuralis lineari-subulatis convexiusculis, involucro longissimo scaberrimo. 
Habitat in instila St. Crucis. West. 4

Culmus altus, acute trigonus. Folia semipollicem lata, margine carinaque scabra. Involucrum pentaphyllum; foliola omnia praeter unicum Umbella longiora, unicum sesquipedale unguem latum, margine carinaque scaberrima: partiale nullum nisi squamula minuta ad basin radiorum. Ochreae bidentatae. Umbella decomposita: radii subdecem, longiores fere spithamaei: partiales sex-septem, brevissimi, contracti in capitulum laxum. Spiculae conferfae, circiter decem, unguiculares, distichae, lineari-subulatue, convexiusculae, quatuordecimflorae, purpurascentes: valvulae lanceciatae, acutae, concavae, versus dorsum striatae, basi pallidiores, carina vix virides.

Aavicomus. 32. CYPERLS spiculis lineari-lanceolatis, valvulis oblongis obtusis, fructiferis patentibus, involucro longissimo.

Cyperus flavicomus; majusculus, basi foliosus; involucro longissimo, reflexo: umbella composita; ramulis ab ipsa basi floridis; spiculis patentibus, flavis, oblongis, septemfloris. Nich. fl. bor. am. т. p. $2 \tau$.

Habitat in Carolina. Bosc.

Culmus semipedalis et ultra, acute trigonus. FoIia radicalia culmo breviora, linearia, angusta. Involucrum tri-pentaphyllum: partiale radiis intermediis triphyllum, lateralibus diphyllum. Ochreae truncatae, ferrugineae, apice mentBranaseae. Umbella composita, quinqueradiata: radii partiales pollicares. Spiculae frequentes, distinctae, patentes, semiunguiculares, septem-duodecimflorae, acutae, flavo-ferrugineae: valvulae parum clistantes, oblongae, obtusissimae, nitidae, margine membranaceo, niveo.

Specimina humiliora rumbellam habent simplicem, quadriradiatam, absque involucro partiali. Sequenti maxime affinis.

dria. 33. CYPERUS spicis corymbosis, spiculis linearibus, valvulis remotiusculis ohovatis obtusissimis, fructiferis patentibus, umbellis laxis. 
Gramen cypernides Indiae orientalis elatius, panicula sparsa pallescente. Plukn. alm. 179. $t$. 191. $f . \tau$.

Cyperus maderaspatanus, paniculis semen Santonici aemulans Petiverii. Scheuchz. gram.9o. t. o. f. 2. junior.

Cyperus Borneaceus, limonii panicula. Broven. in act. Lond. Scheuchz. gram. 39=. t. 9. f. A. adlultior.

Cyperus Iria; culmo triquetro seminudo, umbella foliosa diccomposita, "spiculis altornis granis distinctis. Lin spec. pl. 6\%. Rotib. gram. $4 \mathrm{r}$.

Cyperus Santonici; paniculis sessilibus et pedunculatis; spicis linearibus; flosculis alternis remotis obtusissinis. Rottb. gram.+1.t.g.f. 1 .

Cyperus panicosdes; culmo triquetro, umbella decomposita triplyy ria, spiculis linearibus, floribus alternis remotis obtusiusculis. Lamarck. illustr. 1. p. 145 .

Haljitat in India orientali. China.

Culmus pedalis et ultra, laxus, acutangulus, basi foliosus. Folia culmo breviora, fiaccida, linearia, extrorsum margine scabra. Involucrum subtriphyllum, unicum semipedalc: partiale nullum nisi squamae setaceae. Ochreae compressae, obtusae, mucionatae. Unhella decomposita: radii sex-septem, lungiores saepe spithamaei, filiformes: partiales distantes, ruatuor-ruinque, capillares, infimi bi-trisiachyi, reliqui monostacizi, ,brevissimi Spicae infimae sesquipollicares. Spiculae approximatae, vigintiflorae, floriferae lineam longae, fructiferae unguicrilares, oftusae: valvulce remotizesculae, conduplicatae, parvae, stria utringre prope dursum, latere membranaceae, flavescentes, sensim deciduae, rachi denticulata superstite.

Specimen Cyp. Iriae herbarii Rottböllii a C. Santonici ejusdem non differt misi guod junior, humilior, umbella minus ramosa et spicuiae floriferae non vero fructiferae ut in speciminibus C. Santonici; praetera, quantun recordor. Cyp. Iria herbarii Linnaei ident est ac C. Santonici Rottböllii. 


\section{TRIANDRIA. MONOGYNIA.}

distans. 34 . CYPERUS spicis distichis, spiculis filiformibus patentibus, flosculis distantibus, umbella stricta.

Cyperus elatus; culmo triquetro, nudo; umbella foliosa, supradecomposita; spicis alternis, longissimis, filiformi-subulatis. Rottb. gram. 37. $t$. 10.

Cyperus distans; culmo triquetro nudo, umbella foliosa supradecomposita, spicis alternis filiformibus, flosculis distantibus. Lin. suppl. p. 103. Jacqu. collect. 3. p. 189-Ic. rar. 2. t. 299.

Habitat in Caribaeis, Guinea Thonning, in India orientali Röttler. 4

Culmi bi-tripedales et parum ultra, penna anserina tenuiores, acute angulati. Folia graminea, culmo breviora. Involucrum subhexaphyllum, plurima umbella longiora, unicum sesquipedale, nervi duo parum elevatiores, supriz extrorsum scabriuscula: partiale triphyllum, unnbellula brevius. Ochreae in setam attenuatue. Umbella decomposita, subnovemradiata; radii longiores spithamaei: partiales tres-quinque; ultimi subterni, subsessiles. Spicae sesquipollicares, patentes. Spiculae plures, interdum triginta, unguiculares, distantes, decem-quatıordecimflorae, teretes, parum flexuosae: valvulae oblongae, convexae.

umbeliatus. 35 . CYPERUS spicis corymbosis, spiculis linearibus, umbellae radiis elongatis involucro diphyllo longioribus. $\frac{1}{1}$

Cyperus umbellatus; culmo triquetro nudo, umbella diphylla, pedunculis longissimis spicatis. Burm ind. 2 I. $t$. 9. $f$. I.

Habitat in India orientali.

Folia longitudine culmi. Umbellae radii circiter septem.

lasus. 136. CYPERUS spicis corymbosis, spiculis filiformibus, umbellulis fastigiatis laxis.

Habitat in India orientali. 4

Culmus bipedalis, crassitie pennae anserinae, acute trigonus. Folia altitudine culmi, semipollicem lata, extrorsum margine carinaque scabra. Involucrum subpentaphyllum, umbella longius : partiale foliolum sub radiis quin. 


\section{TRIANDRIA. MONOGYNIA. 363}

que inferioribus, lineari-subulatum, umbellula iongius Ochreae ligula fere pollicaris, lineariianceolata, valde attenuata, serrulata. Umhella decomposita sex-octoradiata: radii bi-quadripollicares, laxi: partiales quatuor-sex capillares, vix pollicares, ultimi breves, remotiusculi. Spiculae remotiusculae, unguiculares, teretes, tenuissimae, sex-octoflorae: valvulae lineares, obtusae, concavae, latere membranaccae, pallide ferrugineae, dorso virentes, utrin. que unisulcatae.

137. CYPERUS corymbis contractis subnutantibus, nutans. spiculis linearibus erectis, flosculis distantibus, umbella laxa.

Habitat in India srientali König.

Viridi-glaucus. Culmi triquetri. Folia carinata, extrorsum margine carinaque scabra. Involucri foliola tria umbella longiora, unicum sesquipedale, facie foliorum: partiale sub spiculis infinis di-tetraphyllum, setaceum, spiculis brevius. Ochreae oltusae, pallidae, purpureo punctatae. Umbella composita, radii circiter sex; treslongiores filiformes, subspithamaei vel breviores, erectiusculi, laxi; reliqui capillares, saepe penduli. Spiculae circiter decem, approximatae, rachidi subadpressae, unguiculares, angustae, sedecim-vel octodecinflorae, acutae: valvulae lineari-oblongae, acutae, apice patulae, fusco-virescentes, margine membranaceae.

Diversissimus a Cypero distante.

338. CYPERUS spicis distiche imbricatis, spiculis elatus. subulatis. +

Cyperus elatus; culmo triquetro nudo, umbella foliosa supradecomposita, spicis dicitalibus imbricatis, spiculis subulatis. Lin. am. acad. 4. p. 301 .

Habitat in Jndia orientali.

Gramen magnum. Involucrum universale poly. phyllum, longissimum: partiale spicis brevius. Spicae sessiles non modo ad umbellas universales, sed et ad proprias et partiales, longitudine digiti, ferrugineae, imbricatae ex spiculis te. neris, subulatis, distichis. Liu. $l$. c. 


\section{TRIANDRIA. MONOGYNIA.}

Mili ignotus, Cyperum enim ex India sub nomine elati missum a distante distinguere nequeo.

speciosus, 339. CYPEPUS spicis corymbosis, spiculis subulatis distichis, umbellulis involucello brevioribus, ochreis biaristatis, culmo acutangulo.

Cyperus culmo triquetro nudo, umbella duplicata foliosa: pedunculis propriis distiche spicatis. Poycn. Lugdb. 50. n. 6.? Gron. virg. 131.

Gyperus virginianus, panicula sparsa speciosa. Herbarium vaillantii.

Fiabitat in Virginia. Ex herbario horti parisini.

Involucrum subpentaphyllum, paters: foliola margine sccbriuscula, quinque picrumque unbella longiora, lineas duas lata: juartiale subtetrapliyllum; foliola linewri-subulata, umbelluia longiora. Umbella subdecomposita; radii circiter octo, longiores poliicares, patentes, apicem versus altero latere carinati: partiales bieves, quinque, aiterni, -ulimi gemini, solitarii vel rulli. Spicae vix pollicares. Spirulae circiter triginta duas, vix serniunguiculares, teretes, sexflorae, acutae, viridi-flavescentes: valvulae lineares, acutae.

A sequente differt, practer allata: culmo teneriore, vix crassitie penare columbinae: involucris radisque unbellae minus rigidis : umisellae universalis radiis paucioribus, patentioribus, brevioribus; partialis brevissimis: spicis vix pollicaribus, paucis, basi pedicello uno alterove auctis.

Tam ex orientaii quam occidentali India diversos sub nomine odorati accepi Cyperos, ex his vero genuinuin distinguere $\mathrm{C}$. cdoratum Linnaei difficile erit; credidi tamen figuram Sloanei $t$. $7 \cdot f$. r. ad C. odoratum Linnaei pertinere, ideoque ejus nomen iluc transtuli, praecipue cuim dicta figura a C. giganteo et specioso nostro plane differat. Cum nullum alium e Virginia Gyperum, C. odorato adfinem, vidi, C. Gronovii huc collocavi; num vero C. Proyenii huc. pertineat, in suspenso relinquo.

giganteus 1 fo. CXPEPUS spicis umbellatis, spiculis subulatis, umbellulis involucellum aequantibus, ochreis bifidis, culmo obtusangulo. 
Cyperus culmo triquetro, nudo; umbella supradecomposita, sesquipedali; spicis confertissinis, subulatis. Rottb. gram. 38. n. $4 \%$.

Habitat in Puertorico West, von Rohr e Surinamo. 2\%.

Similis praecedenti, at: culmus apice scepe crassitie fere digiti minimi, obtuse angulatus: involucri universalis foliola octo decem, longiora umbellam aequantia, uti et involucelii foliola quina longitudine umbellulae: umbella maxi$m a$, selecim radiata; radiis spithamceis: partiales bipollicares, omnes ex uno centro, uti zuniversales erecto-patentes. Ceterum Culmus altitudine ho:ninis. Folia radicalia nulla. Involucri foliola margine scabra. Umbellae radii trigoni, rigidi. Spicae bipollicares. Spiculae plurimae, sparsae, decemflorae, tenues, flavescentes: valvulae oblongae.

$V$ ariat culino parum teneriore, radiisque umbellas paucioribus.

I4r. CYPERUS spicis umbellatis, spiculis subula- Papyru. tis, umbellulis involucello longioribus, ochreis truncatis, culmo obtusangulo.

Papyrus syriaca et siciliana. Bauh. theatr. 333.

Cyperus enodis nudus, culmis e vaginis brevibus prodeuntibus, spicis tenuioribus. Scheuchz. gram. $38 \%$. t. $8 . f . \quad 14$.

Cyperus omnium maximus Papyrus dictus locustis minimis. Mich. gen. $44, t$. I 9 .

Cyperus Papyrus; culmo triquetro nudo, umbella involucris longiore, involucellis tekaphyllis setaceis longioribus, spiculis ternis. Lin. syst. veg. 6,9. Rottb. gram. 32 .

Papyrus. Bruce it. 5. p. i. t. r.

Hubitat in fiuviis Calabriae, Siciliae 2. Syriae, Esypti, Madagascariae. 24

Glancus. Culmus sacpe crassitie digiti. Involucri foliola quatuor praeter interiora, lanceolata, basi semipollicem fere lata, margine laevia: partiale tetraphyllum, umbellula adultiore brevius, setaceum. Ochreae transversim truncatae; partialium oblique truncatae. Umbella composita: radii numerosi, saepe quadraginta, spithamaei, filiformes: partialis bi- 


\section{¡66 TRIANDRIA. MONOGYNIA.}

triradiata, brevis. Spiculae usque fere a basi radii, ternae, geminae vel solitariae, teretes, minimae, sexflorae: valvulae concavae, lineares, dorso fuscae, latere flavae.

Specimina e Madagascaria duplo vel triplo majora; involucri foliola ferruginea; radii umbellae partialis saepe sesquipollicares, supra medium floriferi.

exalcatus. 42. CYPERUS spicis laxis, spiculis linearibus subdistichis, umbellulae terminales trifidae, ochreae biaristatae.

Cyperus longus maderaspatanus panicula rufescente speciocissima. Petiv. mus. 55. n. 539. fide herbarii Vaillantii a Petiverio missus.

Cyperus exaltatus; culmo triquetro basi monophyllo, umbella supradecomposita polyphylla; spiculis linearibus pedunculatis. Retz. obs. 5. $p$. i I.

$\beta$. Cyperus canaliculatus; culmo triquetro canaliculato nudo, umbella decomposita, pedunculis racemosis, involucro polyphyllo longissimo. Retz. obs. 6. p. 20.

Habitat in India orientali ad margines rivulorum, in paludosis König, Röttler. 4

Culmus superne crassitie pennae anserinae, basi vaginatus, obtuse angulatus. Folium bipedale et ultra, inferne semipollicem latum, margine-carinaque serrulato-scabrum. Involucrum triphyllum, praeter minora interiora: foliola u:abella longiora, structura foliorum modo anglestiora: partiale di-triphyllum, angistissimum, umbellula brevius. Ochreae bifirlae; laciniis pollicaribus, subulatis, margine serrulatis. Umbella decomposita, maxima: ratii uriecim vel duodecim, longiores pedales; particles quinque-sex, bipollicares; terminales tres. Spicae bipollicares vel breviores, subfastigiatae. Spiculae circiter triginta, qvinquagintaflorae, fructiferae elongatae, latere purpureae, dorso virides: valunlae ovatae, acutae, dorso substriatae, sensim deciduae.

C. canaliculatus Retzii vix nisi aetate a C. exaltato differre credo, umbella enim in juniore minor et spiculae parvae, in adultiore umbella magna evadit et spiculae sensim majores. 


\section{TRIANDRIA. MONOGYNIA. $\quad 367$}

Specimen C. exaltati possideo ubi spicae et spiculae nonnullae ut in C. canaliculato, aliae ut in C. exaltato in una eademque umbellula, praeterea tam C. exaltati quam C. canaliculati specimina culmo cum vel absque sulcis vidi.

143. CYPERUS spicis cylindricis imbricatis erectis fastigiatus. subfastigiatis, spiculis teretibus

Cyperus fastigiatus; culmo triquetro; umbella decomposita; pedunculis longissimis filiformibus subquinquefidis, spicis plurimis linearibus sparsis. Rottb. gram. 32. t.,$- f .=$.

Cyperus fastigiatus; culmo triquetro cubitali, basi folioso; umbelja foliosa, denuo umbellifera; spicis cylindricis: spiculis utrinque convexis flavidis. Forsk. descr. $p$. 14.

Cyperus imbricatus; culmo triquetro nudo, umbella decomposita, umbellularum radiis imbricatis, involucris hexaphyllis: foliis tribus longissimis, tribus brevissimis. Retz. obs. 5 . p. 12 .

Habitat in Aegypto Forskâl, in India orientali Röttler. 4

Culmus cubitalis et ultra, crassitie pennae cygneae, acutangulus. Folia pollicem lata, extrorsum margine carinaque scabra. Involucri foliola tria longissima: unico bipedali, pollicem lato; supra trinervia, margine, carinaque e denticulis ferrugineis scabra: partiale triphyllum: foliola subulata, umbellula breviora. Ochreae semipollicares, oblique truncatae, integrae, obtusae. Umbella maxima, pedalis, decomposita, septem-octoradiata: radii triquetri, laxi: partiales octo, brevissimi, di-tristachyi. Spicae interdum longitudine digiti minimi, penna columbina parum crassiores, laxe imbricatae. Spiculae numerosae, confertissimae, vix semiunguiculares, decemflorae, acutae, flavae: valvulae oblongae, mucronatae, lateribus membranaceis, vix striatae.

Species pulcherrima, a C. esculento uti $a b$ antecedente toto coelo diversa. Aegyptiacus ab Indico differt colore viridi-glauco nec flavescente; culmo, foliis involucrisque triplo quadruplo angustioribus. In speciminibus Indiae anguli 
culmi snperne ferrugineo-denticulati, scabri, an sic serizer?

ainpeck:oi- 44 . CYPEPUS spicis subsessilibus imbricatis tedes.

retibus spiculisque ovato-oblongis patentibus.

Cyperus maderaspatensis maximus panicula cristata contractiore. Petiv. 55. n. 59! fide herbarii Vaillantii qui eum a Petiverio verosimile habuit.

Cyperus alopecuroides; culmo triquetro, umbella supradecomposita, spicis digitatis oblongis, spiculis confertissimis imbricatis erectis. Rottb. gram. 38. t. \&. f. =.

Habiat in Arabia Forsiâl, in India orientali. Röitler: 24

Culmus crassitie pennae anserinae, acute angulatus. Folia semipollicem lata, margine scabra. Involucrum subtriphyllum: foliola ungüem lata, duo umbella longiora: partiale triphyllum, umbella brevius. Ochreae lamina bifida. Umbellae radii septen - octo, longiores spithamaei et ultra: partialis tri-septemradiata. Spicae tres-quinque, pollicares vel bipollicares, interdum crassitic digiti minimi, oblongae vel cylindricae, obtusae. Spiculae numerosae, conferlissimae, primum erectae, dein patentes duodecin-vigintisexflorae, duas lineas longae, ovalo. oblongae, aculae: valvulue ovatae, obtusae mucronatae, concavae, sensim deciduae.

bicep3. I 45. CYPERUS spicis teretibus compactis, spiculis linearibus confertissimis, valvulis oblongis acuminatis, umbella subuniradiata, culmo obtusangulo.

Habitat in Galam. Fx heri,ario Jussiaei.

Culnus pedalis, vel brevior, obtuse trigonus, rigidus. Folia radicalia, copiosa, altitudine culmi, linearia. Involucri foliola quinque, umbella triplo quadrupio longiora. Capitulum alterum sessile, nuce juglandis majus, compositum e plutrinis minoribus; alterum pedunculatum cluplo minus: radius longitudine capituli, contralis. Spiculae numerosissimae, semipollicares, tringintasex-quadragintaflorae, obtusiusculae, flarescentes, nitidac: valvulae acumina. tae, acumine patulo. 


\section{TRIANDRIA. MONOGYNIA. 369}

An radii plures et longiores in speciminibus perfectioribus?

$x_{4}$ 6. CYPERTS spicis sessilibus patentibus imbri- radiatu. catis teretibus, spiculis oblongis subsquarrosis, involucro triphyllo, culmo acutangulo.

Habitat in India orientali König, in Guinea Isert. Culmus sesquipedalis, inferne crassitie pennae anserinae, basi foliosus. Folia plura, altitudine culmi, linearia, margine carinaque scabra, glauca. Involucri foliola tria, umbella longiora, unicum pedale: partialis mulla nisi squamae setaceae, brevissimae. Ochreae unidentatae. Umbellae compositae, radiis sex-septem, longiore pollicari. Spicae quatuor-sex sessiles, intermedia erecta, reliquae horizontales, pollicares vel parum breviores, undique laxe imbricatae. Spiculae nume. rosae, quaiuordecin-vigintiflorae, lineam longae, convexiusculae, confertissimae: valvulae ovatae, acuminatae, acumine patente, membranaceae, prope carinam striatae, sordide flavescentes, sensim deciduae. Spiculae uti in specie antecedente, ex acumine valvularum tenuissimo patente, primo intuitu ciliatae apparent.

74. CYPERUS capitulis oblongis, valvulis caly- aristatus. cinis subulatis recurvis.

Scirpus capitatus, culmo tereti folioso, capitulis arillaribus pedunculatis; involucro diphyllo lineuri. Burm. ind. 21 .

Scirpus intricatus, culmo triquetro nudo, umbella foliosa simplici, squamis calycinis recurvis. Lin. mant. 182.

Cyperus aristatus, capitulis oblongis sessilibus et pedun ulatis, spiculis linearibus minimis, flosculis subulatis reflexis. Rottb. gram. 23 . t. i. $f$. i.

Scirpus lappaceus; culmo triquetro subnudo, capitulo terminali solitario involucrato, glumis striatis recurvis. Lamarck. illustr. I. p. I 3 \%

Habitat in India orientali et Cap. b. spei.

liadix capillaris. Culni plures, fasciculati, digitales, palmares vel paruin ultra, trifiuetri. Folia longitudine culmi, linearia, carinata,

Tom. II.

A a 


\section{TRIANDRIA. MONOGYNIA,}

margine laevia. Involucrum tetraphyllum; foliola duo umbella duplo vel triplo longiora, guartum brevius. Ochreae truncatae, ferrugineae. Umbella simplex bi-triradiata; radius longior interdum pollicaris. Capitula vix unguicularia, obtusissima, ferruginea. Spiculae copiosae, lineam fere longae, alternae, confertissimae, patentes, octo-decemflorae: valvulae in aristam uncinatam attenuatae, striatae.

$V$ ariat culmo pollicari vel sesquipollicari: capitulo globoso vel cylindrico, solitario absque radiis lateralibus.

glomeratus. 148. CYPERUS spicis glomeratis oblongis imbricatis, spiculis valvulisque linearibus, involucris involucellisque triphyllis umbellis longioribus,

Cyperus aquaticus italicus procerior, locustis tenuissimis in racemum dense congestis. Mich. gen. 45. Segu. ver. 3. p, 68. t. 2. f. 2.

Cyperus capitulis glomeratim congestis, seminibus aristatis. Mont. gram. 1 +. t. I. $f .1$.

Cyperus culmo triquetro nudo, umbella triphylla supradecomposita, spicis glomerato rotundatis, spiculis subulatis. Lin. am. acad. 4. p. $30 \mathrm{I}$,

Cyperus cinnamomeus; culmo triquetro foliog, umbella spiculis capitatis pedunculatis sessilibusque, involucro pentaphyllo serrulato-scabro. Retz. obs. 4.p. 10.

Habitat in Italiae paludosis, an ex India advena?

Culmus bipedalis et ultra, crassitie pennae cygneae, acute angulatus, inferne foliosus. Folia duv-tria, culmo aliora, longe vaginantia, extrorsum margine carinaque scabra. Involucri foliola tria vel quatuor, praeter interiora, umbella longiora: partialis duo vel tria, umbellula longiora. Ochrea oblique truncata, ligula lanceolata, integra. Umbella subdecomposita, radii interclum novem, longiores spithamaei. Spicae omnes interclum sessiles, interdum tres vel quatuor pedicellatae, basi gloneratae. Spiculae numerosissimae, patentes, semitunguiculares, compressae, quatuordecimflorae, acutae, ferrugineae: valvulae lineares, angustae, obtusiusculae, vix striatae. 
A C. alopecuroideo Rotthöllii distinctissimus. Specimina culta vidi interdum capitulo solitario sessili, interdum umbella simplici, radiis unicapitatis.

149. CYPERUS spicis oblongis subsessilibus retror- ligularis. sum imbricatis, spiculis oblongis rectis, ligula ochrearum integra.

Cyperus maximus panicula minus sparsa ferruginea, capitulis compactis crassioribus. Sloan. cat. 35. hist. I. p. $3^{\%}$ t. 9 .

Cyperus ligularis culmo triquetro nudo, umbella spiculis capitatis oblıngis sessilibus, involucris longissimis serrato-asperis. Lin. am. acad. 5. p. 31. Rottb gram. 35. t. I r. f. 2 .

Cyperus major subtriqueter paniculis oblongis strictioribus. Brown. jam. 123. n. 6.

Habitat in Caribaeis, Cap. b. spei, Guinea. Thonning. 4

Viridi-glancescens. Culmus tripedalis et ultra, acute angulatus. Involucrum pentaphyllum, foliola quatuor. umbella longiora, unicum bipedule, semipollicem lata, margine carinaque serrulato-scabra, partiale nullum. Ochreae oblique truncatae, ligula obtusa, integra. Umbellae compositae : radii octo-novem, longiores quinquepollicares: partiales vix ulli. Spicas tres-quinque, alternae, approximatae, intermedic erecta pollicaris, penna cygnea crassior, laterales minores, sessiles vel subpedunculatae, horizontaliter patentes. Spiculae copiosissimae, parvae, sexflorae, primum patentes, acutae: valvulae ovatae, acutae, concavae, striatae, fusco-virescentes.

150. CYPERUS spicis oblongis glomeratis imbri- Thunbergit. catis sessilibus, spiculis subulatis erectis, ligula ochreae hifida: laciniis divaricatis.

Cyperus alopecuroides; culmo trigono, umbella decomposita involucro polyphyllo serrato breviore, spiculis cylindricis. Thunb. prodr. 18 .

Habitat in Cap. b. spei. 4

Viridi-glaucus. Culmus altus, crassitie fere pennae anserinae, acute-angulatus. Involucrum penta-hexaphyllum: foliola omnia umbella longiora, longuius, sesquipedale, margine carina- 


\section{TRIANDRIA. MONOGYNTA.}

que serrulato-scabra: partiale ad singulum capitulum, monophyilum, capitulo longius, lineari-subulatum. Ochreae pollicares, trigonae, oblique truncatae; ligula serrulatoscabra. Umbella composila, radii quinquesex, longiores quinque-sexpollicares. Spicae quinque-octo, intermedia pollicaris vel sesquipollicaris, crassitie saepe digiti, erecta; laterales radiatim patentes, breviores, tenuiores, omnes obtusissimae, undique spiculis copiosisșimis tectae. Spiculae parvae, bi-sexflorae, vix semiunguiculares, acutae: valvulae lineares, attenuatae, concavae, dorso striatae, virides, margine putpureae.

Hunc in herbario Lamarckii vidi sub nomine C. ligularis. Thunbergii C. alopecuroidem huc retuli propter figuram spicularum.

Habitus. Padix fibrosa, in paucis tuberibus zonatis. Culmi enodes, basi et apice foliosi, in paucis, pracsertim primac divisionis, aphylli. Inflorescentia simplicissima-supradecomposita.

122. Mariscus. Cal. 2-valvis, subtriflorus. Cor. Glumae imbricatae, inferior supefiorem inferne amplectens. Stylus 3 -fidus. Setae nullae vel brevissimae.

capillaris. I. MARISCUS spica oblonga retrorsum imbricata, involucro diphyllo, culmo basi folioso.

Schoenus capillaris; culmo triquetro nudo foliisque capillaribus, spiculis fasciculatis reflexis involucratis: involucro diphyllo. Swarz. prodr. 20. Fl. ind. occid. т. p. 106.

Cyperus nanus; culmo triquetro setaceo, umbella sessili capitata diphylla, glumis nervosis. Wild. spec. pl. 1. p. 272 .

Habitat in Caribaeis. West.

Gulmi caespitosi, digitales-pedales, filiformes, inferne foliosi, basi subbulbosi. Folia setacea, culmo interdum longiora. Involucrum tripentaphyllum, reflexum; foliolum unicum tripollicare, reliqua sensim minora. Spica solitaria, magnitudine Piperis nigri, interdum duplo vel triplo minor, flavo-ferruginea, retrorsum imbricata. Spiculae teretiusculae, triflorae, 
basi valvulis duabus, minutis, ovatis calyculatae: valvulae floriferae oblongae, striatae.

$A b$ Isertio verosimile habuit Cel. Wildenowius ideoque Guineam uti patriam ei assignavit; Isertius vero fide herbariis ejus eum in insula Martinica legit. Synonymum Plucknetii dubium videtur. Spiculae majores vel minores ratione magitudinis spicae.

2. MARISCUS aphyllus, spica subglobosa sessili, gracilis. involucro diphyllo setaceo.

Habitat in America mericlionali. Richard.

Culmi pedales et ultra, subsetacei, basi vaginis duabus vestiti, monophylli. Folium angusfum, bi-tripollicare. Involucrum triphyllum; foliola duo bi-tripollicaria, tertium semiunguiculare. Spica semine coriandri parum major, flava. Spiculae ovatae, acutae, fructiferae trigonae. Corvllae glumae ovatae, acutae. Semen trigonum. Stamina duo. Stylus trifidus. Richard.

3. MARISCUS aphyllus, spica globosa sessili, in- aphyllus. volucro brevissimo.

Juncus cyperoides; culmo compresso striato, radice odorata tuberosa, capitulo rotundo compacto. Sloan. cat. 36. hist. I. p. I21.t. 81. f. 2. Habitat in arenosis ad sinum maris Americani Honduras dictum, in Senegal. Dupuis. 4

Padices repentes. Culmi pedales, trigoni, basi vaginati. Vaginae loco foliorum, plures, interiores longiores, oblique truncatae, obtusae, griseae, apice ferrugineo-marginatae. Involucrum di-triphyllum, spica brevius: foliolis ovatis vel ovato-lanceolatis. Spica piso dicplo major, globosa. Spiculae copiosissimae, parvae, lineari-tanceolatae. Glumae purpureo punctatae. Stamina tria.

Specimen e Senegal differt magnitudine duplo majori.

4. MARISCUS spicis cylindricis, spiculis oblongis, paniceus. bracteis setaceis spiculis brevioribus.

Kyllinga panicea; culmo setaceo, triquetro; spicis cylindricis, imbricatis; floribus triquetris, subulatis erecto-patentibus. Rottb. gram. 15 . t. $t, f$. I. Guertn. de fruct. I. p. I 2. t. 2. f. 8 . 


\section{TRIANDRIA. MONOGYNIA.}

Kyllinga panicea; "rmbella terminali : spicis sessilibus pedunculatisque cylindricis imbricatis, involucro universali subtetraphyllo, partiali nullo. Lin. suppl. to:.

Habitat in Arabia felici Forskâl, in India orientali. König.

Culmi pedales, rigidi, basi bulbosi. Folia plura, unum vel alterum altitudine culmi. Involucrum tetraphyllum, unicum semipedate et ultra. Umbella quinque-sexradiata, radii vix semipollicares. Spicae semipollicares: spiculae triflorae, seminiferae trigonae. Bractea setácea. Calycis valvulae oblongae, membranaceae. Corollae glumae saepe fusco irroratae, frequenter margine et apice flavescentes, carina virides.

tavus. 5. MARISCUS spicis cylindricis, spiculis oblongis, bracteis setaceis serrulatis spiculas aequantibus. Habitat in America meridionali v. Rohr, Richard. Culmi approximati, sesquipectales. Folia duotria, culmo breviora. Involucrum tetraphyllum; foliolum longius quadripollicare. Umbella quadri-quinqueradiata; radii brevissimi. - Spicae semipollicares. Calycis valvulae oblongo-ovatae. Corollae glumae flavescentes, purpureo lineolatae.

Affinis praecedenti: diversus bracteis, glumis latioribus magisque striatis.

ovularis. 6. MARISCUS spicis ovali-subrotuntis, involucris polyphyllis.

Gramen cyperoides americanum, spicis grundioribus oblongo-rotundis, sparganii in modum echinatis, ad summum caulem pediculis longis innitentibus. Plukn. alm. 179. t. 9 I. f. 4.

Cyperus floribus capitatis erectis pedunculatis. Gron. virg. 12.

Schoenus umbellatus; culmo triquetro folioso, spicis umbellatis. Jacqu. collect. I. p. I1 3 . Ic. rar. 1. t. 10 .

Kyilingia ovularis; spicis umbellatis, sessilibus pedunculatisque, globoso-ovoideis: glumis rectis, lanceolatis: valvulis exterioribus ovalihus: staminibus tribus: stylo tripartito. Mich. fl. bor. amer. 1. p. $=9$.

Habitat in Georgia et Carolina. Bosc. 24 
Culmi plures, pedales et sesquipedales, acute trigoni, Folia culmo breviora, tri-quatuor lineas lata, linearia, plana, basi vaginantia. Involucrum subhexaphyllum umbella longius: foliola structura foliorum, longius spithamaeum, margine carinaque scabra. Umbellae radii sex-septem, longior tripollicaris. Spica piso major, interdum foliola duo ad basin, interclum nulla: spiculae subulatae: squamae striatae. -

Nullum discrimen inter Sch. umbellatum et Kylling. ovularem invenio, ideoque eos conjunxi, nec dubito de synonymis reliquis cum et patria et icone Pluknetii conveniunt.

An Scirpus echinatus Lin. fl. zeyl. n. 39. huc pertineat? possideo specimen hujus generis, oblitus unde habeo, sub nomine Scirpi echinati, simile descripto, nisi quod culmus tenerior, brevior: pedunculi breviores, spicis minoribus, sic quoad magnitudinem quadrans cum Sc. echinato Lin., diversum modo spicis globosis, nec subovatis, si vero Plukn. figura genuinum Sc. echinatum rapresentat, idem erit ac. Mariscus avularis,

7. MARISCUS spicis retrorsum subimbricatis, retrofractus. spiculis subulatis retrofractis; involucro triphyllo.

Cyperi genus indianum, panicula speciosa, spiculis propendentibus atris. Plukn. t. 4 I 5. $f \cdot 4 \cdot$

Scirpus retrofractus; culmo triquetro, umbella simplici, spicarum flosculis retrofractis. Lin. syst. veg. 102. Gaertn. de fruct. I. p. 12. t. 2. f. 5 .

Habitat in Virginia. Ex herbario Vaillantii et Lussiaei.

Glaucus. Culmi sesquipedales, graciles. Folia carinata. Involucrum triphyllum, foliola duo umbella longiora. Ochreae bidentatae, purpureo punctatae. Umbellae radii quinque, longior sesquipollicaris, erecti. Spicae vix semipollicares. Spiculae viginti quatzor, omnes retrofractae praeter terminalem quae erecta, infimae radio adpressae, unguiculares, tereti-filiformes, biflorae. Corollae glumae lineares sub- 


\section{TRIANDRIA. MONOGYNIA.}

tilissime striatae, purpureo punctatae. Germen lineare.

umbellatus. 8. MARISCUS spicis cylindricis retrorsum imbricatis, involucris polyphyllis.

Kollpullu. Rheed. mal. i2. p, I I9. t. 63.

Scirpus cyperoides; culmo triquetro nudo, umbella simplici; spicis oblongis; flosculis subulatis unifloris reflexis. Lin. mant. I $8 \mathrm{I}$.

Kyllinga umbellata; culmo triquetro; umbella strictissima, simplici; spicis terminalibus, solitariis; floribus confertis reflexis. Rottb. gram. I 5. t. 4. f. $=$.

Kyllingia umbellata; umbella terminali: spicis sessilibus pedunculatisque squarrosis, involucro universali polyphyllo, partiali diphyllo. Lin. suppl. 105 .

Kyllingia sumatrensis; umbella terminali, spicis sessilibus pedunculatisque cylindricis squarrosis, involucro universali polyphyllo, partiali nullo. Retz.obs. 4. p. г.3.

Habitat in India orientali. 4

Culmi pedales et ultra. Folia plure, culmo longiora. Involucrum subdecaphyllum, umbella triplo vel quadruplo longius: partiale triphyllum vel nullum, setaceum. Ochreae truncatae, mucronatae. Umbella quadri-quinqueradiata; radius Iongior Lipollicaris et ultra. Spicae cylindricae, semipollicares: spiculae parvae, confertae, primum patentes dein reflexae, subulatae. Calycis valvulae minutae, oblongae.

Duo specimina, unicum sub nomine Kyllingae bulbosae, aiterum absque nomine, misit Koenigius, ztrumque a M. umbellato diversum spicis pluribus brevius pedunculatis et structura robustiori, quoad habitum vero omnino consimilia sunt, nisi quod specimen innominatum gaudet foliis non glaucis et spiculis viridi-fuscis parum curvatis, quod quoque in spiculis nonmullis M. umbellati observavi, ideoque ea nonnisi varietates esse suspicor. Tarietatem quoque habeo speciminis innominati culmo foliisque filiformibus, spicis tantum duabus-quatuor.

alternifolitus. 9. MAPISCUS spicis cylindricis retrorsum imbricatis, involucris pedunculisque alternis.

Habitat in Guinea. Thonning. 4 
Culmi pedales et ultra, crassitie pennne columbinae. Folia culmo breviora. Involucruin decaphyllum; foliola alterna, conferta, nonnulle: longitudine fero culmi, latitudine foliorum. Ochreae vix pollicares, truncatae, superne purpureo punctatae. Pedunculi tot qieot involucri foliola, unicus inter singulum foliolum, bipallicares et ultra. Spicae semipollicares. Spiculae subulatae, virides; folioluin setaceum, brevissimum ad spicularum basin. Calycis valvulae brevior ovata, longior lineari-lanceolata. Corollae glumae oblongae.

30. MARISCUS spicis cylindricis, spiculis erectis, cyperimus. bracteis spiculis brevioribus.

Kyllingia cyperina; culmo triquetro striato hasi folioso, umbella simplici, spicis strictis sessilihus, involucro universali polyphyllo longissimo, partiali nullo. Retz. obs. 6. p. 2 i. ?

Habitat in India orientali. König, in Guinea. Thonning. 26

Culmi pedales vel parum ultra. Folia nonnulla culino alitiora Involucrum hexa-heptaphyllum: folisia longissima. Ochreae obtique truncatae, obtusae. ,Umbella sex-sentenradiata; radii semipollicares. Spicae pollicares: spicılae subulatae, erectae. Calycis valvulae oblongae. Corollae glumae oblongab, margine pallidae, carina virides.

Quamvis spicae sessiles in Retzii Kyll. cyperina, forte tamen eadem ac mea cum reliqua descriptio quadrat et in nonnullis affinibus vidi spicas sessiles in aliis individuis vero pedunculatas

I. MARISCUS spicis cylindricis, spiculis paten- elstus. tissimis, bracteis spiculis longioribus.

Kyllingia incompleta; culmo triquetro folioso, umbella terminali composita, spicis cylindricis, calyce monophyllo. Jacqu. collet. 4. $p$. то. ic. rar. 2. t. 300 .

Kyllinga cajarensis; umbella terminali: spicis sessilibus pedunculatisque, flosculis reflexis, involucro longissimo suboctophyllo. Lamarck. illustr. I. p. $1+9$.

Habitat ad Carracas locis udis, in Cajenna. v. Rohr. 
Culmi bi-tripedales, interdum crassitie pennae anserinae, nitidi- Folia altitudine fere culmi, semiunguem vel ultra lata. Involucrum universale subhexaphyllum: foliolumt unicum pedale vel bipedale. Umbellae radii plures, longiores bipollicares: partialis quadriradiata. Spicae crassitie pennae anserinae, pollicares-bipollicares: spiculae triflorae. Corollae glumae ovatae, margine tenuiores.

Spontanea, uti et culta, variat spiculis omnibus sessilibus, quinque ad septem, lateraibibus horizontaliter patentibus, intermedia erecta vel umbellis simplicibus vel compositis. Calyx certe bivalvis, si enim spicula mediante acicula levi manu abraditur, ambae in conspectu veniunt. Habitus. Radix stolonifera. Culmi erecti, acute trigoni, basi subbulbosi, inferne foliosi, Folia linearia, latiora vel angustiora, carinata, basi vaginantia, margine carinaque serrulatoscabra; vaginae purpureae- Involucri foliola foliis simillima. Spicae in umbella terminali, zenica in singulo rallio, centrali sessili. Spiculac alternac, remotiusculae, teretes, imbricatae. Bractea ad basin singulae spiculae, extrorsum sensim minor. Corollae glumae striatae. Rachis angulata, dentata.

Hos a Kyllingis separavi tam ob habitum, quam ob fructificationem diversam Spiculae enim teretes, subulatae sunt, nec ovatae, compressae. Calyx non unicum flosculum continet, sed minimum duos, plerumque vero tres. Corollae glumae alio modo disponuntur, non enim paralellae positae sunt, sed unia supra alteram, singula interiorem plerumgue vix ad dirnidiam partem includens, omnes suis pistilis gaudentes, quod etiam in speciminibus exsiccatis fucile apparet; florente gluma inferiore, superior convoluta est, nil commune habens cum inferiore praeter receptaculum. Sunt igitur tot flosculi quot glumae. Stylus semper trifidus, nec bifidus. Si flosculi tres adsunt, secundus pedicellatus est, inque fundo singulae glumae semen invenitur.

Affiniores Cyperis videntur, et forte non absomum foret hos cum iis conjungere, glumae enim disti- 
chae sunt et spiculae tantummodo paucitate florum diversae. Quod glumae duae infimae steriles sint ideoque calycis valvulae dictae, nil impedit, dum in quam plurimis Cyperis idem accidit. Si vero uti genus distinctum assumitur vel ob paucitatem flosculorum, vel quia Cyperi genus jamdudum satis vastum est, character naturalis sequens erit.

Character naturalis:

CAL. valvulae duae, inaequales, subtriflorae, membranaceae.

COR. uniglumi.: Gluma inferior superiorem inferne amplectens.

STAM. tria." Antherae lineares.

PIST. Germen angulatum. Stylus trifidus. Stigmata simplicia.

SEM. trigonum. Setae nullae.

123. Kyllinga. Cal, 2-valvis, 1 -florus. Cor. 2-valvis. Stylus z-fidus.

1. KYLLINGA capitulo globogo sessili solitario, monocephainvolucro longissimo.

Pee matenga. Rhieed. mal. is. p. oq. t. 53.

Gramen capitatum. Kumph. amb. 6. p. 8. t. 3. f. 2 .

Schoenus coloratus; culmo triquetro, capitulo globoso sessili; involucro longissimo plano variegatu. Lin. spec. pl. 64.

Kyllinga monocephala; culmo filiformi, triquetro; capitulo globoso sessili; involucro subtriphyllo longissimo. Rotth. gram. I.. t. A. f. 4 . Kyllinga monocephala; culmo filiformi-triquetro, capitulo globoso sessili, involucro triphyllo longissimo. Lin. suppl. 104.

Scirpus cephalotes. Jacq. hort. vind. ז. p. 42. t. 97 .

Habitat in Indiae orientalis umbrosis, graninosis. König.

Radix repens, Culmi solitarii, distantes, palmares et spithamaei, basi foliosi. I'vlia culmo saepe longiora, linearia. Involucrum tri-tetraphy.llum, foliolum unicum saepe longinudine culmi. Capitulum magnitudine pisi, niventm. Spiculae acuminatae. Corollae glumae ova- 
tae, lanceolatae, acutae, altera carina serrulato-cìilata. Semina compressa.

In olla satae culnii caespitosi, in speciminibus spontaneis distincti sunt.

pumila, 2. KYLLINGA capitulo globoso sessili solitario, inrolucro brevi, culmo setaceo, flosculis diandris.

Ky-1lingia pumila; subtriuncialis, glabra: foliis angusto planis: involucro triphyllo, plano, patulo: capitulo simpliusculo, subgloboso: glumis minutis: valvulis exterioribus interiores superantibus: staminibus duobus: stylo bifido. Mich. fl. bor. amer. т. p. 28.

Habitat in Shavanensium regione, ad amnem Scioto. Bosc et Richard.

Culmi plures, tri-quadripollicares, acute angulati, filiformes. "Folia culmo breviora, linearia, angusta. Involucrum iriphyllum; foliolum unicum bipollicare vel par̃um ultra. Capitulum vix magnitudine Piperis nigri. Glumae oratae, acutae. Stamina duo.

brevifolia. 3. KYLLINGA capitulo globoso sessili sulitario, involucro brevi, culmo filiformi, flosculis triandris.

Kyllinga brevifolia; culmo setaceo monophyllo, involucro triphyllo brevi, capitulo terminali sessili. Rottb. gram. 12. t. 4. f. 3.

Habitat in India orientali. König, in Caribaeis. West.

Radix repens. Culmi conferti vel distincti, saepe bipedales, filiformes, acute angulati, basi vaginis purpureis vestiti. Folium unicum e vagina, longius, pollicare. Involucrum triphylIum; foliola bi-quadripollicaria. Capitula magnitudine piperis nigri. Spiculae ob̉ongae. Calycis z:alvula longior lanceolata. Corollae glumae ovatae, acutar, subaequales, carina ciliatae, apice saepius reflexae.

Stamina tria. Rotth.

Est minime varietas $\mathrm{K}$. monocephalae: spiculae pauciores, magis distinctae et horizontales, virides. 
4. KYLLINGA capitulo ovato sessili solitario, in- squamulata. volucro elongato, spiculis carina squamulosospinosa.

Halitat in Guinea. Thonning.

Facies Kyllingae monorephalae. Culmi plures, palmares et ultra, filiformes, acuie trigonit, basi foliis vaginati. Folia culmo breviora, linearia, planiuscula, laxa. Involucrum tetraphyllim, capitulo multoties longizss; duo-tria folia saepe longitudine culmi. Capitulium magnitudine pisi globosum. Spiculae copiosae, magnitudine seminis milii, ovatae, acutae. Corollae glumae ovatae, naviculares, latere flavae, membranaceae, carina virides, squamulis compressis albis, modo seminis Artediae, aculeatae. Sta. minz tria. Semen subrotundum, complanatum, nigrtem, laeve.

5. KYLLINGA aphylla, capitulo globoso sessili vaginata. solitario, involucro brevi.

Kyllinga peruviana. Lamarck. dict. bot. 3. p. 366. Kyllinga vaginata; culmo inferne vaginato, capitulo globoso sessili, involucro brevi triphyl1o. Lamarck. illustr. i. p. เия.

Habitat in Peru et Senegal. Ex herbario Lamarck. Cuini pedales et ultra, inferne vaginati, acute angulait. Folia nulla nisi unicum breve e vagina longiore. Involucrum triphyliun: foliola duo quadri-quinque pollicaria, vix semiunguem lata. Capitulum piso dluplo majres. Spiculae ovatae. Calycis valvulae ovatae, altera brevissima acuta, altera longior acuminata. Corollae glumae lineaires. Semen oblongum, compresso-triquetrum, cinereum.

Distinctissima a K. monocephala.

6. KYLLINGA icapitulis subternis sessilihus glo- triceps. meratis, spiculis confertissimis subimbricatis. Motenga. Rheed. mul. 12. p. 97. t. 52 .

Juncellus maderaspatensis capitulis compactioribus, acumine bifido longior:, Pluclin. alm. 200. t. 197. f. 7.

Scirpus glomeratus; culmo triquetro folioso, capitulo glomerato, involucro folioso, Lin. spec. pl. ed. 1. p. 32 . 


\section{TRIANDRIA. MONOGYNIA.}

Kyllinga triceps; capitulis terminalibus subternis glomeratis sessilibus. Rottb. gram. 14. $t$. 4. f. ศ. Lin. suppl. 10.4.

Thryocephalon nemorale, Forst.

Habitat in Indiae orientalis pascuis subaridis. König. 4

Culmi plures, erecti, digitales, palmares vel spithamaei, debiles, filiformes, basi vaginis foliorum tecti. Folia plura culmo breviora vel longiora, laxa. Involucrum tri-tetraphyllum, majus longitudine culmi, sensim minora. $\mathrm{Ca}$ pitula tria, e spiculis mumerosis densissime compacta. Spiculae patulae, minime vero horizontaliter patentes, lanceolatae, prinum niveae, dein apice purpurascentes. Calycis valvulae lanceolatae, acutae, altera breviore. Corollae glumae lanceolatae. Stamina tria.

An a K. monocephala diversa, vidi enim specimina tam spontanea quam culta K. tricipitis capitulis solitarius, geminiš vel ternis.

olorata. 7. KYLIINGA capitulis subternis sessilibus glomeratis, spiculis distinctis patentissimis.

Gramen, secunda species. Marcgr. hist. 1. fide herbarii ejus.

Habitat in America meridionali. v. Rohr, Richard. Culmi palmares, uti folia et involucrum, rigidi. Folia plura, culmo breviora, subtus punctis elevatis sparsis mixiutis. Involucrum triphyllum; foliola uti folia. Capitula tria, lateralia subglobosa, horizontaliter patcntia, Pipere nigro parum majora; intermerlium erectum, oblongum, dimidio majus. Spiculae patulae, ovatae, acutae, virides. Corollae glumae ovatae, acutae, aequales. Semen oblongum, compressum, flavum. Stamina duo. Richard. Differt eodem modo a K. tricipite, ut K. brevifolia a K. monocephala. An Cel. Swartzii, K. triceps obs. bot. 33 . huc pertineat.

filiformis. 8. KXLLINGA? spicis umbellatis sessilibus pedunculatis. +

Kyllinga filiformis; umbella terminali simplici, spicis sessilibus pedunculatisque ovatis acutis, involucro triphyllo, partiali nullo. Swartz. prodr. 20. Fl. ind. occid. 1. p. 121. 
Habitat in siccis campis graminosis Jamaicae et Hispaniolae.

Culmus pedalis, filiformis, laxus. Folia longitudine saepe culmi, linearia, convoluta, carinata: vaginae minutae. Involucrum triphyllum, foliolo uno alterove umbella longiore. Spicae parvae, oblongae, obtusue, flavae: spiculae subimbricatae, oblongae, acuminatae, subcompressae, minutae. Calycis glumae ovatae, carinatie, subaequales. Corollae glumae sub. aequales, acuminatae, carinatae. Sivartz. l. c. An potius Cyperi species?

Habitus. Culmi acuto trigoni, inferne foliosi. Folia linearia, carinata, margine carinaque serrulato scabra. Involucra capitulo longiara, reflexa, foliis simillima. Capitula terminalia. Spiculae compressae. Corollae glumae carina sermulatae. Rachis teres.

124. Furrena. Squamae glumae undique imbricatae, aristatae. Cor. glumae tres, petaliformes, unguiculatae.

1. FUIRENA umbellis axillaribus terminalibusque umbellata. compositis decompositisque, spiculis glomerato-capitatis, culmo foliis glabris.

Fuirena umbellata; culmo angulato; foliis lanceolatis striatis remotis; floribus umbellatis. Rotth. gram. $70, t .190 . f .3$.

Fuirena paniculata. Lin. suppl. 105.

Fuirena paniculata; pedunculis ramosis, paniculis lateralibus et terminalibus, Lamarck. illustr. i. p. 150. t. 3\%.

Habitat in Surinamo et Cajenna.

Culmus altus, penna columbina crassior, tetragonus, superne lateribus duobus oppositis sulco excavatis, duobus flanis, pallide virens. Folia spithamaea et ultra, pollicem fere lata, internodiis longiora, sensim minora, vix scabra, nervosa: vaginae bipollicares, inferiores glabrae, superiores pilosae; ligula subciliata. Pedunculi axillares ot terminales, gemini, ra- ro terni, alter longior, vagina duplo vel triplo longiores. Involucrum umbella multoties bre. vius, unicum senipollicare: partials setaceum. 
Umbclla terminalis decomposita, laterales compositae, plerunque quinqueradiatae: partialis biradiata: radii patentes, longiores sesquipollicares, compressi, villoso-cinerei. Spiculae quatuor-sex in singulo capitulo, parvae, oblongae, villoso-cinerascentes: squamae obovatae, concavae. Petalorum lanina obcordata. Semen minutum, trigono-subgrlobosum, mucronatum, laeve, fusco-flavescens.

simplcx. 2. FUIRENA umbellis simplicibus compositisque, spiculis ovato-oblongis solitariis.

Fuirena sinplex; umbellis simplicibus: radiis ternis quinisve monostachyis, spiculis ovatooblongis, foliis lineari-lanceclatis. Ecl. amer. 2. p. S.

ß. Fuirena obtusiflora; umbella subcomposita, spicis cylindricis utrinque obtusis. Ecl. amer. 2. p. s,

Habitat in America meridionali. v. Rohr.

Culmi teiragoni, glabri. Folia sesquipollicaria, vix semiunguem lata, glabra, superiora ciliata: vaginae foliis dimidio breviores, inferiores glabrae, superiores pilosae; ligula ciliata. Pedunculi duo ex ultima vagina, alter quadripolicaris, alter dimidio brevior. Involucri foiiola pilosa, alterum vix pollicare, alterum brevius. Umbella pedunculi longioris composita, quinqueradiata; radii semiteretes, pilosi; partialis uti umbella pedunculi brevioris, iniquadriradiata, radiis brevibus recurvatis. Spiculae solitariae in singulo radio, unguiculares, tereles, piliosne; foliola duo brevia ad basin spiculae, ovatr, in aristam foliolo ipso longiorem desinentia: squamae obovatae. Petalorum Inmina oblonga, mucronata, fusco-ferruginea. Siamina petalis longiora. Germen pedicellatum. Semen trigonum. Setae trés, inter ungues petalorum exsertae.

Quamvis Fuirena obtusiflora Ecl. aner. discrepat a Fuir. simplici ibidem spiculis cylindricis nec ovato-oblongis, apice obtusis in junioribus magis squarrosis nec acutis, tamen iterum accuratius examinatam pro varietate F. simplicis habeo. Setae inim in hac quoque adsunt. 
ot facile uti extra corollam positae videntur, cum ungues crassitie aequant et inter eas exsertae sunt, ut difficile dictu num interiores vel exteriores sint. Observavi quoque in $\beta$. squamas tres minutissinas ad basin corollae, quas in altera forte ob parvitatem haud observare potui.

3. FUIRENA spiculis glomerato-capitatis, culmo canescens. foliisque villoso incanis.

Habitat ad Senegal. Ex herbario Richardi.

Tota villoso-incana. Culmi trigoni. Folia bipollicaria. Bractea capitulo brevior. Capitulum compositum e quatuor minoribus brevissime pedicellatis. Spiculae minores quam in reliquis. Squamae oblongae, aristatae, trinerves.

4. FUIRENA umbellis simplicibus, spiculis ovatis, squarrosa. culmo glabro; foliis ciliatis, vaginis pilosis.

Fuirena squarrosa; foliis ciliatis: spiculis ob squanarum mucrones longos horride squarrosis: paleis pistillinis petiolato-spathulatis, muticis; interjectis totidem setulis brevibus. Mich. fl. bor amer. r. p. $37^{\circ}$

Habitat in paludosis Georgiae et Carolinae. Richard.

Culmi sesquipedales, basin versus penna columbina crassiores, angulati, inferne aphylli vaginati, glabri, summitatem versus pilosi. Folia versus medium culmi, duo-tri-quinquepollicaria, semiunguem lata, remota plana, inferne ciliata, supra ad lentem pubescentia: vaginae inferiores duae, ore obliquo, aphyllae, ferrugineae, pilosissimae; foliiferae glabrae. Pedunculi saepe duo ex ultima vagina, alter longior: Involucrum umbella brevius, vix pollicare, rigidum. Umbella pedunculi longioris birudiata: radii unguiculares, villosi. Capitulum pedunculi brevioris absque involıcro et radiis. Spiculae tres quatuor in singulo radio, sessiles, plures in capitulo sessili centrali, semiunguiculares; ovatae, obtusae: squamae oblongae, obtusissimae, membranaceae, purpurascentes, subciliatae, dorso virides, nervosae, in aristam squama ipsa longiorem re- 


\section{TRIANDRIA. MONOGYNIA.}

curvatam desinentes, infimae pubescentes, re7iquae glabrae. Petalorum lamina oblonga mutica. Styli pubescentes. Germen triquetrum, semimaturum niveum.

Valde affinis F. glomeratae: folia vero latiora et petala non tridentata.

glomerata 5. FUIRENA umbellis simplicibus axillaribus terminalibusque spiculis subternis aggregatis ovato-oblongis, culmo vaginisque glabris.

Gramen cyperoides indiae orientalis, foliis hirsutis pubescentibus, intervallata panicula pulchra. Poona repille malabarorum. Plukn. mant. 98. t. 4 I ? $f$. 6 .

Scirpus ciliaris; culmo triquetro folioso, umbellis sparsis; squamis calycinis aristis ciliatis. Lin. mant. I 82 .

Scirpus pedunculis lateralibus et terminalibus, multifloris; spicis oblongis, hirsutissimis; squamis tricarinatis aristatis. Rottb. gram. 55 . t. I . f. r.

Fuirena glomerata; pedunculis indivisis, spiculis conglomeratis, glomerulis pedunculatis sessilibusque. Lamarck. illustr. 1. p. 150.

Fuirena scirpoides. Rötler in litt.

Habitat in India orientali.

Culmi plures, pedales, tenues, angulati, inferne vaginati. Folia tri-sexpollicaria, plana, ciliata, suprema pilosa: vaginae pollicares, glabrae. Pedunculi plerumque ierminales gemini, interdum ex axillis superioribus solitarii vel gemini, villosi. Involucrum diphyllum, patens, pilosum, sub umbella pedunculi longioris, nullum sub brevioris, foliolum alterum pollicare. T!mbella biradiata; radii brevissimi, tristachyi; spiculae tres-sex in pedunculo breviore, glomerato-capitatae. Spiculae semiunguiculares, obtusae: squimae oblongae, obtusae, fusco-virides, dorso trinerviae; arista longitudine squamae. Petalorum lamina subrotunda, tridentata, trinervis, purpurea. Reliqua ut in Rottböllio.

Singulare est Rottböllium, qui alias Cyperoides tam egregie enucleavit, hanc ad Scirpos retulisse, et petala pro valvulis capsulae assum- 
sisse; totus enim habitus monstrat cujus generis sit', nec quoad fructificationem nisi figura squamarnm et petalorum a congeneribus differt.

6. FUIPENA capitulis globosis hirsutis, foliis sub-hirta. tus pilosis.

Scirpus hottentottus; culmo triquetro folioso, squamis calycinis hirtis. Lin. mant. I 82.

Scirpus capitulo terminali, glomerato, subnudo. Rottb. gram. 54. t. r6. f. 4 .

Habitat in Cap. b. spei. locis paludosis ad rivulos. Culmus bi-tripedalis, trigonus, glaber. Folia tripollicaria, erectiuscula, rigida, carinata: vaginae ore membranacco, fusco, uti folia pilosae. Pedunculus terminalis, solitarius, pilosus. Involucrum capitulo brevius. Capitulum globosum, magnitudine fere cerasi, e spiculis numerosissimis congestum. Spiculae $a b$ longae: squamae oblongae, hirsutissimae, viridi-nigricantes. Petala subrotundo-ovata, mutica, rufa.

Etiam hanc ad Scirpos retulit Rottböll qui petala vidit et depinxit.

7. FUIRENA aphylla, spiculis terminalibus sub-scirpoidea: ternis.

Fuirena scirpoides; radice repente: culmis aphyllis, vaginis distincte alternis: spica terminali subunica, ovata: squamis puberulis, mucrone brevissimo, recto: paleis pistillinis lanceolato-spathulatis; interjectis totidem setulis tenuissimis. Mich. fl. bor. amer. x. p. $3 \mathrm{~s}$. Habitat in paludosis aestate exsiccatis Floridae. Richard.

Radix repens, crassitie fere pennae anserinae, nodosa. Culmus semipedalis, gracilis, apice trigonus, glaber, articuli superiores longiores. Folia nulla nisi acumen vaginarum superiorum vix semiunguiculare, lanceolatum: vaginae remotissimae, semipollicares, culmo parum ampliores, glabrae. Bractea sub spicula, subulata. Spiculae terminales solitariae, geminae vel ternae, sessiles, vix semiunguiculares, oblongae, villosae: squamae ovatae, acuminatae. Petalorum lamina oblonga, mutica. 
Habitus. Culmi simplices, erecti, articulati, ad geniculos crassiores, angulati, rigidi, striati. Folia remota, lineari-Lanceolata, striata: vaginae integrae, culmo parum ampliores, articulis breviores, striatae; ligula brevis, membranacea, ferruginea. Pedunculi sulco unico vel duplici exarati. Involucrum diphyllum patentissimum; foliolum alterum longius, lineare, alterum brevius, setaceum. Spieulae squarrosae ex arista squamarum recurvata. Petala unguiculata.

125. Eriophoruni. Glumae paleaceae undique imbricatae. Cor. o. Sem. i. lana longissima cinctum.

vaginatum. ז. ERIOPHOPUM culmis vaginatis teretibus, spica scariosa. Lin. fl. svec. 45. 5\%. Fl. dan. 236. Pollich. pal. n. 5 r.

Juncus alpinus capitulo łanúginoso seu schaeno. lagurus. Bauh. prodr. 23. Theatr. 187. Scheuchz. gram. 302. t. $7 \cdot f$. . app. t. 7 .

Habitat in Europae frigidis sterilibus.

Culmi pedales, vaginis duabus vel tribus superne ampliatis. Folia culmo saepe altiora, trigona, subulata, medullosa. Spica oblonga, semipollicaris. Squamae ovatae, acutae.

Scheuchzeri. 2. ERIOPHORUM culmis basi vaginatis teretibus, foliis tereti-canaliculatis, spica florifera subrotunda. Roth. neue beitr. r. p. 93.

Juncus alpinus capitulo tomentoso majori. Scheuchz. gram. 20 * app. $t$. 7 .

Eriophorum Scheuchzeri; culmis teretibus vaginatis, inferne foliosis, foliis canaliculatis, spica subrotunda. Hoppe taschenb. IS00.p. I0\%. Habitat in alpibus Salisburgensibus et Rhaeticis. Radix fibrosa Culmus pedalis, inferne foliosus, superne nudus. Folia culmo breviora. Squamae coloratae, margine scariosae.

alpinum. 3. ERIOPHOPUM culmis nudis trigonis, spica pappo breviore. Syst. veg. 104. Fl. dan. 620. Roth. fl. germ. 2. p. 64 .

Juncus alpinus bombycinus. Bauh. prodr. 6. 
Linagrostis juncea alpina, capitulo parvo tomentoso rariore. Scheuchz. gram. 305. t. 7 . f. 4. app. t. 8 .

Eriophorum hudsonianum; culmo nudissimo, acute triquetro: foliis radicalibus paucis, subtrigone canaliculato setaceis: spica unica: villis paucioribus. Michaux fl. bor. Am. т. p. I34. Habitat in Europae et Americae alpibus, locisque affinibus. 4

Culmi spithamaei, aphylli, filiformes, basi vaginati. Spica parva oblonga: Squamae lanceolatae ferrugineae, infima in aristam attenuata, longitudine spicae.

Specimen Erioph. hudsoniani, quod in herbario Aichardi vidi, vix diversum ab Er. alpino apparet.

4. ERIOPHORUM culmis foliosis teretibus, foliis planis, spicis pedunculatis, seminibus ovatis. polystachy* on. Roth. neue Beytr. 1. p. 74.

Gramen eriophorum. Dod. pempt. 562.

Gramen pratense tomentosum, panicula sparsa. Bault. theatr. 60.

Linagrostis panicula ampliore. Vaill. bot. par. t. in. $f$. i.

Eriophorum polystachyon; culmis teretibus, foliis planis, spicis pedunculatis. Lin. syst. veg。 1 0 . Leers fl. herb. n. 36. t. I. f. 5. Smith. engl. bot. t. 563 .

Eriophorum latifolium; culmis teretibus foliosis, fuliis planis, apice triquetris, spicis pendulis subramosis. Hoppe bot. Taschenbuch 1800. p. 109 .

Habitat in Europae uliginosis turfosis. 4

Radix fiurosa. Culmi interdum sesquipedales. Folia cuilina culmo breviora plura, apice trigona: vaginae inferne saepe fusco-nigricantes. Involucrum mono-triphyllum, umbella brevius. Spicae plurimae, floriferae ovatae, erecitusculae; fructiferae oblongae, pendulae. Squamae scariosae.

5. ERIOPHORUM culmis foliosis teretibus, fuliis canaliculato-triquetris, spicis pedunculatis, angustifoliun. seminibus ovatis. Roth. neue Beitr. 1. p. ot.

Eriollorum angustifolium; cu!mis foliosis teretibus, foliis canaliculato-triquetris, spicis 


\section{TRIANDRIA. MONOGYNIA.}

pedunculatis erectis. Reich. fl. moeno-francof. 7. 34. app. т65. Roth. fl. germ. 1. p. 24. Dichs. act. soc. Lin. 2. p. 289. Smith. engl. bot. t. 564. Linagrostis palustris angustifolia, panicula sparsa, pappo rariore. Scheuchz gram. 308.

Eriophorum polystachyon. Curt. fl. lond. fasc. 4. t. 9 .

Habitat in Daniae, Germaniae, Angliae uliginosis turfosis. 4

Radix repens. Folia culmo longiora, angustiora quam in anteedente, apice triquetra. Involucrum bi-triphyllum, umbella longius, foliolum unicum saepe tripollicare. Pedunculi scabriusculi.

E. angustifolii discriptio in florae brittanicae $1 . p$. 60. potius ad E. gracile pertinet.

gracile. 6. ERIOPHORUM culmis teretihus foliosis, foliis triquetris sursum canaliculatis, spicis pedunculatis, seminibus linearibus. Rotl. catalect. 2. app. neue Beytr. 1. p. 95.

Linagrostis panicula minore. Vail. bot. par. $t$. I6. $f$. 2 .

Eriophorum triquetrum; culmis subtriquetris foliosis, foliis triquetris, spicis erectis simplicibus. Hoppe bot. Taschenb. r 800 . p. 106.

Habitat in Europae uliginosis, turfosis. 4

Radix repens. Culmus pedalis, tenerior quam in E. angustifolio, ultra medium anceps. Folia culmi dun-tria, tri-quadripollicaria. Involucrum diphyllum, limbella brevius. Pedunculi scabriusculi. Spicae dluae-tres, erectae, oblongae.

virginicum. 7 . ERIOPHORUM culmo tereti folioso, foliis planis, spicis congestis subsessilibus involucro brevioribus.

Gramen tomentosum virginianum, panicula magis compacta, foliacea, aureo colore perfusa. Plukn. alm. 179. t. 299. f. 4 .

Gramen tomentosum, capitulo ampliori fusco et foliaceo. Moris. hist. 3. p. 224. s. 8. t. 9. f. 2 .

Eriophorum virginicum; culmis foliosis teretibus, foliis planis, spica erecta. Lin. syst. veg. I04. 
Eriuphorum virginicum; culmo tereti, folioso: foliis angusto-planis; caulinis plerumque duobus: spicis pluribus, subsessilibus, conǵestis: floribus diandris : lana fulvescente. Mich. $f$. bor. Amer. x. p. 34 .

Habitat a Canada usque ad Carolinam. 4

Culmus teres. Folia plana. Involucrum triphyllum; foliolum unicum tripollicare. Lana albido-gilva. Capitulum fructiferum hemisph.zericum. Stamina duo. Stigmata tria. Richard.

Habitus. Culmi erecti, striati. Vaginae foliorum integrae.

I26. Mapania. Cal. 6-valvis. Cor. o. Sem. r. sylvestris.

I. MAPANIA. Aubl. fl. guian. 47. t. г 7 .

Habitat in sylvis paludosis Guianae. Ex herbario Jussiaei et Richardi. 4

Culmi triquetri, semipedales et ultra, striati, basi imbricati. Squamis nonnullis lanceolatis. Involucrum triphyllum: foliola sessilia, bitripollicaria, pollicem fere lata, lanceolata, acuminata, trinervia. Flores in capitulum collecti: squama ad basin singuli. Calycis valvulae lineari-lanceolatae, obtusiusculae, dorso ciliatae, integerrimae, nec serratae ut habet Aubletius. Semen unicum.

127. Remirea. Cal. 2-valvis, uniflorus. Cor. 2-maritima. valvis, calyce minor.

1. REMIREA.

Paratura. Pis. hist. nat. br. 238.

Remirea maritima. Aubl. fl. guian. 45. t. i6.

Habitat in Cajennae maritimis, in Guinea. Thonning. 4

Radices longe repentes, teretes, articulati, striati. Culmi ex articulis radicis, palmares vel semipedales, erecti, rigidi, glabri, inferne basi foliorum persistenti tecti, superne in ramos tres vel quatuor divisi: Rami vaginis foliorum tecti. Folia conferta, disticha, patentia, pollicaria, infima longiora, subulata, rigida, subpungentia, supra canaliculata, subtus convexa, mar- 


\section{TRIANDRIA. MONOGYNIA.}

gine scabriuscula, basi striata: vaginae fuscoferrugineae. Capitulum terminale, vix semipollicare, subsessile, spiculis imbricatum, oblongum, foliis brevius. Spiculae lineari-lanceolatae, valvulae striatae, altera parum longior.

128. LYGEUm. - Flores intra spatham convolutam gemini. Cal. basi in tubum $=$-locularem villosum concrescens, 2 -valvis.

spareum. I. LYGEUM. Loefl. it. 285. f. 2. Lin. syst. veg. 105. Richard. in act. soc. par. $28 . t .3$.

Spartum herba altera. Clus. hisp. 506. hist. 2. p. 220. $f .2$.

Habitat in Hispaniae et Africae borealis campis argillosis. 4

Culmi erecti, pedales et ultra, teretes, tenaces, glabri, binodes, terminati involucro pollicari, filiformes, apice subaristata longitudinaliter dehiscente flores obvolventer Folia convoluta, altitudine culmi, rigida, recurva: ligula lanceolata, bifida. Flos sub florescentia erectus dein magis minusve inclinatus, sesquipollicaris, ovato-lanceolatus, attenuatus. Spatha biflora, interdum trifiora, bivalvis: valvula exterior interiorem involvens, - lineari-lanceolata, carinata; interior longior, angustior, apice bifida. Calycis valvulae cxteriores inferne coalitae in tubum bilocularem, maturitate cartilagineum, valvulis aridis coronatum, turbinatum, pilosissimum. Stamina e fundo tủia, ad latus valvulae exterioris, sub germine inserta, valvula longiora. Germinis situs ut staminum, subpedicellatus. Stylus longus, inferne triangularis, sensim angustior, compressus. Sernen unicum in singulo loculo, lineari-oblongum, extus convexum, intus planum sulcogue exaratum.

I29. Cornucopiae. Invol. infundibuliforme, multiflorum. Cal. z-valvis. Cor, $\mathrm{r}$-valvis.

suculasur. I. CORNUCOPIAE spica mutica, cucullo crenato. Lin. S. $V$.

Juncus clavatus vaginatus polycephalus, Pet. gar. t. $73 . f .5$. 
Gramen orientale vernum in udis proveniens, capitulo inflexo. Scheuchz. gram. I I ?

Habitat Smyrnae.

Culmi erecti, pedales, striati. Folia lineari-lanceolata, attenuata; siperiora breviora. Vaginae superiorum ampliatae, supremae obovatae, spathaceae. Pedunculi duo-tres, sursum incrassati, unguiculares, apice terminati cucullo campanulato, margine crenato. Involucrum cucullatum; intra involucrum Capitulum ovatum, floribus imbricatis hermaphroditis. Flosculi lineares, apice obtuso, tricrenulato. Gluma trivalvis, duae exteriores aequales, marginem interioris amplectentes, oblongae, obtusae, inferne pubescenti-scabratae. Stamina tria. Germen ovatum, extus convexum, intus planum, latvissimum. Stylus brevis, glaber. Stigmata duo, hirsuta. Semen gluma involutum et duplo brevius, obovato-oblongum, absque sulco, antice convexiusculum, postice subplanum. Richard.

2. CORNUCOPIAE spica aristata. Lin. mant. 29. alopecuroisyst. veg. p. 103.

Habitat in Italia.

Culmus palmaris, binodis, infractus. Folia graminea, pollicaria. Vaginae striatae, laxae, suprema sensim ampliata, pollicaris vel parum ultra. Pedunculus terminalis, incrassatus, dilatatus in cucullum campanulatum, margine integro. Flores in spica cucullo dimidio longiore. Flosculi aristati.

Frabitus. Culmus articulatus, subsimplex. Foliorum vaginae superiores sensim iurgidiores, inflorescentiam in formam spathae cingentes.

130. Pommereulr. Cal. turbinatus, bivalvis, 3-4 florus. Valv. 4-fidae, dorso aristatae. Cor. bivalvis, aristata.

э. POMMEREULLA. Lin. nov. gen. gram. p. 3 т. Cornucopiae. suppl. plant. p. 105.

Habitat in India orientali. König.

Gliuca. Radix fibrosa, alba, stolonifera. Culmi plures, pollicares vel digitales, vaginis foliorum bifariam imbricati, parum ramosi. Fo. 


\section{TRIANDRIA. MONOGYNIA.}

lia unguicularia, raro pollicaria, equitantia, lanceolata, obtusiuscula, facile a vagina secedentia, basi interdum pilis nonnullis ciliata: Vaginae compressae, folio breviores vel longiores, apice margine flavescentes; ultima spathacea, reliquis amplior. Flores breviter pedicellati, alterni. Calyx ope lentis pubescens.

I3I. Cenchrus. Invol. laciniatum, echinatum, 3-4 florum. Cal. 2-valvis, 2 -florus; altero masculo altero hermaphrodito. Cor. 2 -valvis, mutica.

capiratus. 1. CENCHRUS spica ovata simplici. Loefl. it. r72. Lin. syst. veg. 947.

Gramen montanum echinatum tribuloides capitatum. Col. Ecphr. r. p. 3ょc. t. 338. f. г.

Gramen spica subrotunda echinata. Bault. prodr. 16.

Gramen minimum spica globosa echinata. Barr. ic. $28 . f$. 1. et 862. f. 2 .

Habitat in Europa australi et Africa septentrionali. $\odot$

Culmi plures, saepe vix pollicares, interdum palmares, basi foliosi. Folia pollicaria, uti vaginae pubescentia. Capitulum floriferum ovato-oblongum; fructiferum interdum piso fere duplo majus, undique echinatum.

rribuloides, =. CENCHRUS spica spiculis alternis, involucris integris spinosis.

Gramen trihuloides spicatum maximum virginianum. Plukn. alm. I 7. .

Gramen echinatum spicatum, locustis crassioribus tribuloides virginianum. Moris. hist. 3. $p$. 195. s. 8. t. $5 . f$. 4 .

Cenchrus tribuloides; spica glomerata, glumis foemineis globosis muricato-spinosis hirsutis. Lin. syst. veg. $9+9$.

Cenchrus spinifex; culmo ramoso; foliis brevibus, cordato-lanceolatis: calyce communi integerrimo, spinis echinato. Cavan. ic. 5.p. 38 . t. $46 \mathrm{I}$.

Habitat in Virginia, Florida. 24

Culmi teretes, ramosi, glabri: geniculis atropurpureis. Folia spithamaea, superiora culmo 


\section{TRIANDRIA. MONOGYNIA.}

altiora, lanceolata, basi subcordata, glabra, glauca: vaginae laxae, superne margine villosae. Spica bipollicaris. Spiculae floriferae oblongae; fructiferae globosae, magnitudine pisi. Involucrum integrum, villoso-subtomentosum, armatum spinis validis, in floriferis erectis; in fructiferis divergentibus, distantibus.

C. Spinifex Cavan. non videtur differre nisi foliis brevioribus, subvillosis. C. Carolinianus. IValt. fl. car. 79. huc quoque forte spectat.

3. CENCHRUS spica spiculis approximatis, invo- echinatus. lucris decempartitis villosis.

Gramen americanum, spica echinata, majoribus locustis. Plukn. alm. i $77 . t .92 . f .3$.

Gramen locustis tumidioribus echinatis. Scheuchz. gram. 77.

Cenchrus echinatus; spica oblonga glomerata. Lin. syst. veg. 948. Schreb. gram. 9. t. 23. f.1.

Cencirus echinatus; calyce communi subgloboso, coriaceo monophyllo, semidecempartito, fissura rachidi opposita profundissima: floribus dense spicatis. Cavan. ic. 5. p. 39. t. 462 .

ק. Elymus caput medusae. Forsk. descr. p. 25 .

Habitat in Caribaeis, $\beta$. in Arabia. ()

Culmi basi repentes, pedales et ulira, teretes, ramosi, nitidi: geniculi inferiores infracti. Folia spithamaca, lanceolata, basi cordata. Vaginae laxae, conduplicatae, ad frucem intus villosae. Spica bipollicaris. Spiculae approximatae, fructiferae subglobosae, minores quam in C. tribuloide, spinis patentibus.

C. Forskâlaei minor involucris glabris, caeterum non videtur diversa.

4. CENCHRUS spica spiculis approximatis, invo- setige us. lucris setacea-mult: ifidis glabris.

Habitat in Arabia. Forskâl.

Culmus pedalis. Folia plana, glabra, bipollicaria et ultra. Spica tripollicaris. Spiculae ovatae, in rachi flexuosa sessiles, solitariae, approximatae. Involucrum multifidum: laciniis setaceis, rigidiusculis. Calyx bivalvis, biflorus: flosculo interiore hermapilrodito, exteriore masculo.

Affinis C. ciliari. 


\section{TRIANDRIA. MONOGYNIA.}

muricatus, 5. CENCHRUS spicis spiculisque geminatis, involucris polyphyllis mucronatis.

Cenchrus muricatus; spica muricata, squamis variis mucronatis. Lin. mant. 302. Schreb. gram. 2. p. 69. t. 34 .

Panicum squarrosum; spicis geminis horizontalibus, involucris florum squarrosis, culmis decumbentibus. Retz. obs. 4. p. I5.fasc. 5. t. I. Habitat in India orientali. König.

Culmi repentes, teretes, glabri: geniculis infractis. Folia et Rami interdum ad genicula congesta, bipollicaria, lanceolata, basi cordata, undulata, uti vaginae villosa. Spicae geminae, raro solitariae, pedunculatae, horizontales. Spiculae approximatae, geminae ad singutum dentem rachidis, biflorae. Involucri foliola patula, mucronata, ovata vel subulata.

frutescens. 6. CENCHRUS capitulis lateralibus sessilibus, foliis inucronatis, caule fruticoso. Lin. syst. veg. $948 .+$

Arundo graminea aculeata. Alp. exot. 105. t. 104 . Gramen orientale spicatum fruticosum, spinosum, spicis echinatis in capitulum congestis. Tournef. cor. 39 .

Habitat in Armenia. 5

Habitus. Spiculae in spicam racemosae.

132. NARDUS. Cal. I-valvis, I-florus. Cor. I- , valvis. Stigma simplex.

stricta r. NARDUS spica setacea recta. Lin. syst. veg. Schreb. gram. 65. t.7. Pollich. pal. $n$ 5. Leers. fl. herb. n. 39. t. 1. f. z. Cavan. ic. 3. t. =04.

Spartum nostras parvum. Lob. ic. 90.

- Gramen sparteum juncifolium. Bauth. theatr. 69 . Scheuchiz. gram. 90.

ß. Gramen sparteum hrasiliense, capillaceo folio majus. Bauh. prodr. '29.

Habitat in Europae asperis, sterilibus, duris. 4 Radix fibrosa. Culmi caespitosi, palmares-pedales, filiformes, rigidi, retrorsum scabriusculi, inferne uni-trinodosi. Folia radicalia copiosa, longa, setacea superne canaliculata: ligula membranacea, alba. Spica bi-tripollicaris. Pachis margine scabra. Flosculi subulati, pubescentes, subviolacei. 
2. NARDUS spica setacea incurva glabra.

indica.

Nardus indica; spica setacea secunda subincurviata. Lin. sumpl. 105.

Habitat ad Tranquebariam.

Culmi digitales vel minores, setacei. Folia vix unguicularia, setacea. Spica longitudine culmi. Flosculi subulati, glabri, uti totum gramen flavescentes.

3. NARDUS spica incurva ciliata. Lin. spec. $78 .+$ ciliaris. Habitat in India.

Culmus spitamaeus. Folia graminea plana. Flosculi duodecim-quindecim: valvula exteriore ovato-oblonga, mutica, margine ciliata pilis scabris numerosis.

Habitus. Cuimi caespitosi. Spica secunda. Flosculi alterni. Rachis altero, latere convexa, altero excavata; denticulo pro singulo flosculo.

133. Oryzopsis. Cal. =-valvis, I-florus. Cor. 2-valvis; exteriore aristata. Nect. 2phyllum.

I, ORYZOPSIS. Mich. fl. bor, amer. r. p. 5 r. t. 9. Habitat a sinu Hudsonis ad Quebec, per tractus montium. Ex herbario Pichardi.

Culmi plures, uni-binodes, basi foliosi. Folia infima longitudine fere culmi; superiora remota, vagina breviora, angusta, planiuscula, rigidula, subpungentia, margine aspera. Flores subracemosi: pedicellis uni-bifloris. Calycis glumae corolla ampliores, oblongae, obtusae, quinquenerviae, glabrae. Corolla basi annulo barbato cincta, pubescens: valvula exterior teretiuscule oblonga, coriacea, aristata; arista calyce longior, villosa: interior $a b$ exteriore inclusa, angustior. Nectarium lineare, planum, filamentis brevius. Germen lineare. Stylus trifidus. Stigmata duo, villosa. Richard. 


\title{
ADDENDA ET CORRIGENDA
}

\author{
I N \\ VOLUMINE PRIMO.
}

Pag. XV. Act. harlem. Maatscappy lege Maatschappy

Pag. XVI. Act. palat Manhem l. Manheim

- - Act. soc. bengal. in to 1. into

Pag. XVII. add. Afzel. gen. $p l$. Ejusdem-genera plantarum Guineensium revisa et aucta, pars I. Ups. 1804. 4 to.

- - Afzel. ros. svec. Ejusdem de rosis svecanis tentamen i. Ups. 1804.4 to.

Pag. XVIII. Andr; eric. Heads l. Heaths

- Ann. mus. h. nat. Cohier. 1. Cahier.

Pag. XX. Lin. 20. Blanckiv. 1. Blackiw.

- Besl. hort. eyst. Norib. 1. Norimb.

Pag. XLIII. ad Lin. $=0$. add. Pall. illustr. pl. Ejusdem illustrationes plantarum, imperfecte vel nondum cognitarum cum centuria iconum. Fasc. I。 Lipsiae is 84 . fol.

Pag. XLVI. ad Lin. 2-. add. Roth. neue Beitr. Ejusd. neue Beiträge. erst. Theil. Frankf. am Mayn 1802. S.

Pag. 5. ad Lin. 34. add. Usteria volubilis. Afzel. gen. pl. P. i. $p$. 3 .

Pag. 10. ad Lin. 5. add. Salicornia acetaria; annua strictim erecta, subramosa, amentis oppositis cylindricis lateralibus terminalibusque, Pallas illustr. 1. fasc. p. . . t. т. f. ז.

- - ad. Sal. herb. d. Pallas illustr. fasc. r. p. 7. t. 2. f. I. 


\section{ADDENDA ET CORRIGENDA.}

Pag. I0. ad. Lin. 14. add. \& Salicornia acetaria humilior ruberrima, digitalis vel palmaris. Pall. illustr. I. fasc. p. . . t. I. f. 2 .

Pag. Ir. ad. Lin. 9. Salicornia prostrata caule ramosissimo, divaricato trifariam prostrato, articulis apice subsinuatis, amentis scabris, oppositis terminalibusque. Pallas illustr. r. fasc. p. s. t. 3.3 .

Radix annua. Stirps a radice trifida, modo terrae adpressa, modo subassurgens: Pami oppositi, divaricati; Articuli teretiores, turgidiores et carnosiores quâm in herbacea. Pall. $l$. c.

Pag. I2. ad Lin. 3. Salicornia strobilacea; sufruticosa ramosissima assurgens, aphylla, amentis creberrimis, oppositis, cylindricis, extremorum ramorum sensin minoribus. Pallas illustr. т. fasc. p. 9. t. 4 . Truncus fragilis, rudis nodulosus, prostratus, a quo surculi creberrimi, stiberecti, ramosi, saepe lignescentes. Amenta cruciatim opposita. Flosculi ternati; spatiis inter se latis trapeziformibus dispositi, trituberculati, monandri. Semen plerumque unicum, ovatum. Pall. $l$. $c$.

- - ad. Lin. r2. add. Salicornia caspica; frutescens, ramis oppositis, amentis pedunculatis elongatis. Pallas illustr. fasc. I. t. 12. f. ?.

Truncus fere tripedalis; rami annui. Flosculi crebri, terni, transversim quasi lineam lati.

In illustrationibus huc refert Pallas itin. sua t. $A$. $f$. 2. forte errore typographi.

Salicornia foliata $\alpha$. Pallas illustr. fasc. I. $p$. го. -f. 5 .

- - ad Lin. 34. add. Salicornia foliata f. Pall. illustr. x. fasc. p. เо. t. 6.

Varietas prioris secundum Pallas.

Pag. I3. ad Lin. 5. add. Salicornia pygmaea, caule pausillo monilifero, articulis globosis, amentis confertis, crassissimis, cylindricis. Pallas illustr. fasc. i. p. 9. t. 2. f. 2 .

Caulis interdum vix bipollicaris, a basi ramasus; articuli globoso-turgidi, filo sicco colzaerentibus. Spicae confertae, per paria oppositae, sessiles, obtusae.

Pag. 42. Olea apetala add. Olea apetala; foliis ellipticis, floribus racemosis apelatis. Andr. repos, t. 316 . 


\section{0 \\ ADDENDA ET CORRIGENDA.}

Pag. 45. Lin. 4. Calycis 1. Calyces

Pag. Iog. Lin. $=\frac{1}{4}$. crassiore 1 . crassiores.

Pag. $13 \div$.

59-50!acida. JUSIICIA; dianthera calycibus simplicibus, spicis terminalibus subcapitatis, foliis ellipticis nerrosis bullatis luciäis, labio corollae superiore lanceolato. Antr. repos. f. 3 r 3 .

Habitat in India orientali.

Pag. 204. Utric, tenuis add, eadem, est ac aphylla secundum fictores florae perurianae.

Pag. 233. Lin. 2-. veris 1 , vectis

Pag. 259. Salvia rugosa: add. Tota villoso-viscosa. Folia cordato-lanceolata, duo suprema sessilia, inaequaliter dentato-erosa, obtusiuscula. Corolla calyce parum longior, alba cum tinctura purpurea. Labia aequalia: inferioris lacinia media concava, emarginata, laterales breves. erectae, ovatae. Stamina longitudine tubi. Pistillum staminibús parum longius. ‡-

Pag. 267. inter Salriam nemorosam et amplexicaulem collocátur SALVIA pendula

Pag. 270. Lin. 32. culta indivisa: add. vidi tamen semel cultam in olla foliis palmatis

Pag. 282. SALVIA pendula - collocarda prope S. nemorosam, a. qua differt, follis minuribus, sinu baseos clauso.

Pag. 302. CODARIUMI nitidum, add. foliis oralibus acuminatis, interioribus minoribus.

- - Lin. s. ad finem Lineae: add. Codarium acutifolium, fuliolis inaeqralibus acuminatis. Afz. gen. plo i . p. $2 \vdots$.

Habitat quoque ad Sierram Leonam.

- Lin. 2.. ad finem. Arbor sedecim-vel viginti pedalis. Folia raro ovali-oblonga. Panicula plerumque stupradeconiposita. Flores plurimi abortientes. Bracteae majusculae, oblongas, acuminatae, obtusae. Calyx monophyllus: tubus brevis, cyathiformis, ore obliquo: laciniis aequalibus, deciduis. Petalum tubo calycis infertum uti filamenta. Germen subovatum. Stigma hemisphaericum. Semen unicum. Perisnermum magnum, conchiforme. Cotyledones ellipticae. Corculum radicula hemisphaerica: Plumula ligulata, acuta. Iegumen cortice duplici, 


\section{ADDENDA ET CORRIGENDA.}

exterius univalve, crustaceo. fragili; interiore tenuissimo, membranaceo, pellucido, bivali i, pulpa intermedia terrea, granulosa. Afzel. l. c. p. $=1$.

Pag. 303. ante DIALIUM adde:

cbensifolium, =. CODARILM foliolis apice rotundatis aequa. libus. Afz. gen. pl. 1. p. 25 .

Habitat in Guinea. $\hbar$

Arbor praecedenti minor, cortice cinereo. Foliola minora, saepius opposita, angusto-oblonga. $\mathrm{Pe}$ tioli quasi pulverulenti. Panicula minor. $\mathrm{Pe}$ dunculi partiales omnes simplices, compressi; proprii pauciflori, brevissimi. Bracteae minores. Afz. l. c.

Habitus. Arbores humiles. Iignum durum album saepe in brasiliantum migrans. Pami $e \downarrow f o-$ lia alterna. Folia impari-pirnata: foliola infima opposita.

- - ad DIALIUM indum add. Afzel. gen. pl. т. p. I3. Pag. 304. Lin. 4. add. an species Codarii? habitu similis est. Pag. 37\%. sub Salvia mexicana add. mia antha 235.

\section{ADDENDA ET CORRIGENDA}

I $\mathrm{N}$

VOLUMINE SECUNDO.

Pag. 26. HIPPOCRATEA rata 1. HIPPOCRATEA orata Pag. 33. L. 10. foliola 5-linearia l. foliola 5, linearia. Pag. 58. ad Ix. recurr. syn. Jaquinii deleatur.

Pag. $17 \mathrm{r}$, ad Commelinam turbinatam syn. Jaqrinii deleatur. Pag. 185. Ficus renosa add. Wildenow. Hort. berol. fasc. 3. tab. $3 f$.

Caulis arboreus, ramis tereitihus annulatis brunneis, junioribus viridibus ad basin cujusque petioli annulo membranaceo purpurascente cinctis, sub̉ quo puncta alba. Folia alterna, petiolata, semipedalia usque pedalia, ovata, integerrima, acuta, basi subcordata, glabra, supra saturate viridia, venosa, venis cardidis et punctis albis impressis picta; infra pallidiora, reticulato-venosa, venis majoribus niveis. Petioli teretes, glabri. Stipula solitaria, ovato lanceolatu, acuminata, deciduce. Re-

Tom. II.

$\mathrm{C} c$ 
ceptacula pyriformia in ramis praeteriti anni, magnitudine cerasi, pedunculata, juniora sulcata et punctata, adulta laevia non punctata. Wild. $l . c$.

Pag. 193. sp. 51. Rami teretes, cinereo punctati l. Rami cinereo punct.

Pag. 197. sp. 67. axasperata 1. exasperata

Pag. 204. Lin. 7. carica l. Carica.

Pag. 206. Lin. 28. magricans 1 . nigricans

Pag. 207. Lin. 17. Capitula 1. Capitulum.

Pag. 209. sp. 4. breviopibus l. brevioribus

Pag. 215. Lin. 18. Schotiae I. Scotiae.

Pag. 217. Lin. 27. baevioribus 1. brevioribus

Pag. 223. Lin. 18. differet l. differt.

Pag. 226. deleatur Habitus.'

Pag. 227. Lin. 22. ad finem lin. add. sub nomine Schoen.
spicati.

Pag. 229. post. Lin. 6. add. Habitus v. p. 226.

Pag. 239. Lin. 15. saespitosi l. caespitosi

Pag. 273. Lin. I. deleat. culmi breviora

Pag. 275. Lin. 7. infra, menbranaceae 1. membranaceat

Pag. 281. Lin. I. eulmo 1. culmo.

Pag. 286. sp. 5. scỉaenoides 1 . schoenoides

Pag. 300. Lin. 9. infra, spicigetus 1. spicigerus

Pag. 325. Lin. I. Jeminicus I. jeminicus

Pag. 326. Lin. 16. Mönch. adıl. Metlıod. 3 17.

Pag. 332. Lin. 10. amaenitat. 1. amoenitat.

- - Lin. 16. verisimile 1. verosimile 


\section{I $N \quad D \quad E \quad X$ :}

A.

Abildgaardia monostachya . 296 $\therefore$ tristachya - 297 Anthodon decussatum 30 Antholyza-aethiopica $\mathbf{2} 2 \mathbf{I}$ aletroides . . 96 caryophyllacea' 123 caryophyllea . ib. Cunonia . $\because 28$ hirsuta . 119 lucidor . $\quad 122$ maura • 47
Antholyza Meriana $9 \overrightarrow{4}$ Merianella . 95 nervosa . 122 plicata . . ib. quadrangularis $\mathrm{I} 23$ revoluta . . 93 ringens.,$\therefore \quad$ I $2 \mathrm{E}$ spicata . I 105 Aristea coerulea . I 27 cyanea - I 23 spiralis . . 124 Axia cochinchinensis 38
Biaslia 180 Bobartia indica , $\quad 156$ Bulbocodium crocifo- lium . 5 I
C.

Callisia repens . I80 Calyxhymenia ovata 40 umbellulata . ib.

Calyxhymenia aggreprostrata . . 4 I gata : 4 I Carex pubescens . 274 expansa . ib. uliginosa . . 214 glabrifolia " 40 Cenchrus capitatus , 394 
Cenchrus echinatus 395 frutescens . 396 muricatus . ib. setigerus • 395 spinifex . 394 tribuloides $\because$ ib.

Cipura paludosa . 48

Cneorum pulverulentum . 34 tricoccon . . ib.

Codarium acutifolium 400 obtusifolium - 40 I

Commelina africana 167 angustifolia . 165 attenuata . 168 barbąta .. . 173 benghaleusis . I74 benghalensis . 169 bracteolata - 176 cajenensis . 169 canescens $\quad 173$ communis . I70 cucullata, I74 diffusa . 169 divaricata . ib. elata . $\quad 178$ erecta . . 172 fasciculata . 167 Forskâlei . I $7 \mathbf{2}$ gigantea . 177 gracilis . 174 hirtella . . 166 hispida . . $\quad 169$ japonica . , 178 longicaulis . $\quad 6_{5}$
Commelina longifolia 165 longifolia . 166 medica . 175 micrantha - 178 mollis • . 173 nervosa . . 166 nervosa . . 174 nudicaulis . 175 nudiflora . 176 obliqua . . 172 obtusifolia . 168 pacifica . ib. paniculata. $\quad 179$ pilosula . $\quad 168$ polȳgama . 170 serrulata •. I 7 ? simplex . . ib. spirata . 176 tụberosa . . I 17 tuberosa ... 179 turbinata . 175 umbrosa : . 179 vaginata $\cdot 175$ virginica . 16 ? virginica . . 168

Comocładia dentata. 35 ilicifolia - 36 integrifolia . 35 tricuspidata . 36

Cornucopiae alopecuroides - 393. cucullatum . 392

Crocus autumnalis . 45 capensis - . 49 multifidus • 46 
Crocus nudiflorus - 46 sativus • 45 vernus . 46

Cyperus aegyptiacus 213 aequalis . 320 albidus : 352 albidus - $35 \mathbf{I}$ alopecuroides $\quad 368$ alopecuroides - $37 \mathbf{I}$ alternifolius $\quad 32$ r amabilis . 318 aphyllus . 320 arenarius . 298 aristatus . 369 articulatus . $30 \mathrm{I}$ nrundinaceus . 339 autumnalis . 318 ater . . 335 badius . 346 biceps . 368 bicolor .' 340 bidentatus . 330 brizaeus . . 316 brunneus . ib. bulbosus . 342 canaliculatus . 366 canescens - 355 capitatus . 314 capitatus . 213 castaneus . $3 \mathbf{I}$ cephalotes - $3 \mathbf{I}$ I cinnamomeus , $37^{\circ}$ collinus . $30 x$ coloratus . 312
Cyperus compactus, 30,4 $\begin{array}{ll}\text { compactus } & 312 \\ \text { complanatus } & 319 \\ \text { compressus } & 324 \\ \text { compressus } & 326 \\ \text { confertus } & 329 \\ \text { congestus } & 358 \\ \text { conglomeratus } & 339\end{array}$ conoideus - 328 corymbosus . 347 crassipes of 299 croceus - 357 cruentus - 35 I cruentus - 322 curvatus - 338 declinatus - . 326 denudatus . 324 depauperatus . 305 difformis - $\quad 33$ ? diffusus . 32 I dilutus . . 357 diphyllus . 348 distachyos 306,307 distans . 362 divaricatus . 334 dubius . 312 effusus . 300 elatus - 363 elatus. - . 362 elegans - . 323 elegans . . 303 Eragrostis . . 322 eragrostis . $\quad 326$ esculentus . 345 
Cyperus exaltatus 366 fascicularis 315,316 fastigiatus . 367 ferox - . 357 ferrugineus 225,337 filicinus . 332 filiculmis . 328 filiformis . . 3 I 4 flabelliformis . $\mathbf{3 2 2}$ flavescens . 335 flavicomus $\quad 360$ flavidus . 334 flexuosus $\quad 359$ formosus . 327 fuscus - . 336 giganteus . 364 globosus . 309 globosus - . 35 ⿷ glomeratus : 370 glomeratus 299,326 gradatus . 322 Haspan . 320 hexastachyos . $3+4$ hyalinus : 329 Hydra • 344 jeminicus . 325 imbricatus . 367 intactus . 332 Iria ! . . 360 junciformis . 306 juncoides . 3 I9 Koenigii . 302 kyllingaeoides 3 I 2 laevigatus : 3 ro Ianceus . 350
Cyperus lateralis 305,306 laxus . . 362 laxus . . 323 leucocephalus $3 \mathbf{I 3}$ figularis . $\quad 37^{\mathrm{x}}$ longus . 346 Luzulae - . 328 'macrostachyos' 349 maderaspatanus $33 \mathrm{E}$ malaccensis - 353 margaritaceus 307 marginatus • 303 'membranaceus' 330 microstachyos 318 minimus . 253,306 minutulus . 314 monandrus . $3=6$ monophyllus . 352 monostachyos. 296 monti ¿ $\therefore 350$ muicronatus . 306 nanus - . 372 niloticus . 362 nitens - $33 \mathrm{I}$ nitidus . 335 niveus - . 308 nutans . . 363 obtasiflorus . 308 ochraceus . 325 odoratus . . 356 olidus . . 333 olivaceus . 332 pallescens. . 342 Pangoraei : 345 panicoides, $36 \mathrm{r}$ 
Cyperus paniculatus 333

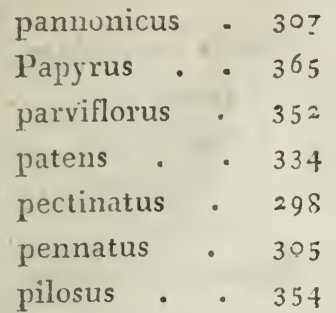
planifolius . 354 polycephatus . 328 polyphyllus . 317 polystachyos - 3 I 5 prolifer . . 299 prolifer . $32 \tau$ pulcher . 349 pumilus . 330 punctatus . . 266 puncticulatus - 348 purpurascens . 359 pusillus . 303 pusfulatus . $3 \div \mathrm{r}$ pygmaeus - 3 г 3 pygmaeus 303, 306, 3 I4 racemosus - 355 radiatus . 369 recurvus . 3 го reflexus . 299 rigidulus . 342 rigidus : 309 rotundus . 343 rubicundus $\quad 30 \$$ sanguinolentus $35 \mathrm{I}$ Santonici . $36 \mathbf{x}$
Cyperus scirpoides . $3 \mathbf{I}$ scopellatus - 333 serotinus . 350 serrulatus . 360 setaćeus . . 305 spadiceus . 338 spathaceus . 225 speciosus . 364 sphacelatus . $34 \mathbf{I}$ sphaerocephalus 310 spicigerus $\quad 300$ squarrosus - $33 \mathbf{I}$ stoloniferus . 338 striatulus ... 3 II striatus - $30 \mathbf{r}$ strictus - . 339 strigosus - 358 surinamensis - 327 tenellus . 305 tener . - 299 tenuiflorus - 34 ? tenuis. . 315 tetrastachyos . 343 textilis . 304 Thunbergii . $37 \mathrm{I}$ torosus . 339 triflorus . 297 tuberosus - 340 umbeliatus - 362 vetgetus . $\quad 3=6$ virens . . 353 virescens - . 36 virginianus $\cdot 364$ viscosus ‥ 303 
D.

Dichromena ciliata 240 leucocephala . ib. nervosa • $24 x$ pubera . . ib. repens . . ib.

Dilatris caroliniana ${ }_{162}$
Dilatris corymbosa 168 ixioides . . ib. paniculata . ib. umbellata . . ib. viscosa . . ib. Diplarrena moraea $\quad 154$

E.

Elymus Caput medusae 395

Eriocaulon spadiceum 210 Eriophorum alpinum 388 angustifolium 389 cyperinum . 282 gracile - 390 Hudsonianum 389
Eriophorum latifolium 389 polystachyon . 390 polystachyon - 389 triquetrum • 390 Scheuchzeri • 388 vaginatum . ib. virginicum $390^{\circ}$

F.

Fedia cornucopiae . 19 coronata . . 20 dentata . . ib. discoidea . . 2 z echinata . 19 mixta . . . 2 I olitoria . . I9 pumila . $2 x$ radiata . . ib. rupestris . . 22 sibirica - . ib. vesicaria . 20

Ficus aggregata . I9 I americana . 188 Ampelos . . 186
Ficus aspera . 200 auriculata . 196 benghalensis 187 benjamina : $\mathbf{8 7}$ callosa . . 188 calyptrata . . 186 cannabina . 203 capensis . 197 Carica • . 204 Chanas . I 183 citrifolia . . ib. cordata . . 182 coriacea . . 192 costata . : $183^{\circ}$ cotoneaefolia $\quad \$ 89$ 
Ficus Daemonum 198 denticulata" . 202 difformis . . $=00$ drupacea - I93 erecta . 192 exasperata - 197 excelsa . $\quad 195$ falcata - 193 Forskâlaei • 196 granatum • 186 grisea . 194 grossularioides $\mathbf{3} 97$ heterophylla . 202 heterophylla . 203 hirta. . . 201 hispida • 198 indica . . 195 indica . . 189 laevigata - 183 lateriflora . 19 ? laurifolia . 194 lentiginosa . $\quad \mathbf{8 3}$ lucida . $\quad 184$ lutea . . I85 maculata • . 198 mauritiana - 196 microcarpa - 188 mollis . - 192 montana . . 198 morifolia ' 203 morifolia $\quad$ 96, 19? nitida . . $19 \mathbf{1}$ nymphaeifolia $\quad 182$ obliqua . . 195 ovatá . . 185
Ficus pallida • 194 palmata . 200 parasitica . 188 pedunculata . 184 pertusa . . 189 polita . 182 politoria . - 19 I politoria - . 186 populifolia - $\mathbf{1 8} \mathbf{z}$ prolixa . . 193 pumila . 190 punctata . 189 punctata . . $19 \mathbf{x}$ pyrifolia . . 187 pyrifolia.. . $19 \mathrm{I}$ racemosa $\quad 188$ reflexa - . 190 religiosa - $18 \mathbf{1}$ reticulata - 199 retusa . . 193 rhomboidalis $\quad 199$ rostrata . 200 rubra . . $19 \mathrm{x}$ rufescens . 202 sagittata . 184 salicifolia - 195 scabra • . 183 scabra - . 192 scandens . 184 septica . , 186 septica . $\quad \times 92$ serrata . . 202 simplicissima $\quad 203$ sinuata . . 200 stipulata . 184 
Ficus Sur - . . I99

Sycomorus . I9? symphytifolia . ib. Taab • . 186 Toka . . 189 toxicaria . 202 trigona . 190 truncata . $20 I$ ulmifolia . . $\mathbf{I} 9$ ? umbellata . 182 vasta . . 187 venosa. . 185 verrucosa . 192 virens . . 194

Fimbristrlis acuminatum . 285 aestivale . . 288 argenteum . 294 arvense • $\quad 29 \mathrm{I}$ castaneum . 292 cylindricum . 293 dichotomum . $28 \mathrm{z}$ diphyllum . 289 ferrugineum . $29 \mathrm{I}$ glaucum . $\quad 28 \mathrm{~s}$
Fimbristylis hirtellum $=36$ laxum . : 292 miliaceum . 287 mucronatum $\quad 293$ nutans . : 285 pilosum . 290 puberulum . 289 pygmaeum • 285 schoenoides . 286 serrulatum . 285 spadiceum . 294 squarrosum . 289 tomentosum . 290 _umbellare . $29 \mathrm{I}$ Fissilia psittacorum . 33 Fuirena canescens . 385 glomerata . 386 hirta . . 387 obtusiflora . 384 paniculata . 383 scirpoidea . 387 scirpoides 386,387 simplex . 384 squarrosa $\because 385$ umbellata . 383

G.

Galaxia obscura . 48 plicata - . 57 Gladiolus alatus . roo

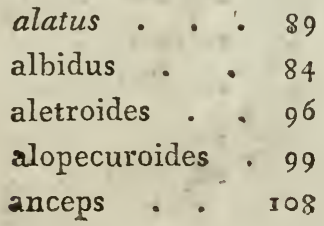

Gladiolus angustifolius

\begin{tabular}{|c|c|c|}
\hline . & 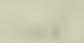 & I I 3 \\
\hline gustus & . . & 103 \\
\hline angustus & . & 86 \\
\hline bicolor . & . & 106 \\
\hline biflorus & . $\quad$. & 97 \\
\hline bimaculatu & & 102 \\
\hline blandus & - & 103 \\
\hline
\end{tabular}


Gladiolus bracteatus 107

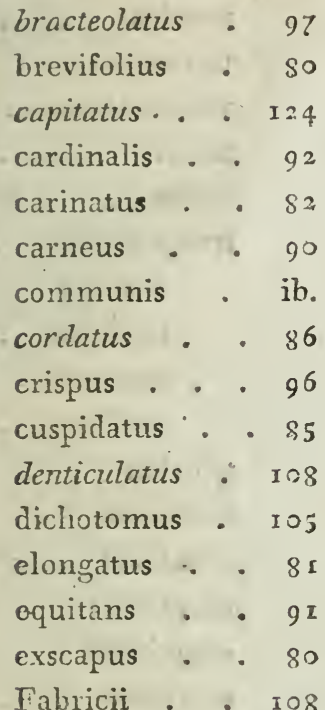

falcatus . 97

fissifolius . . 107

fistulosus . 78

flavus . . I Iо

flexuosus . 79

floribundus 1 II

fragrans . IIZ

galeatus . . 89

glumaceus . 10.5

gracilis . 82

gramineus 1 IOI

grandis . 87

hastatus . 86

hirsutus . 88

hyalinus .. . ib.

imbricatus . 79

inflatus . 87

involutus . 102

iridifolius
Gladiolus junceus . 104 laccatus . 94 laceratus . I 120 laevis . ¿ 83 latifolius . IIT liliaceus . $\quad x=0$

lineatus - 73

longiflorus . III longiflorus . $\mathrm{II} 3$ luteus . . 109 marginatus 104 marmoratus . ib. Merianellus . 95 Merianus . 94 mollis - II9 montanus • 77 mucronatus jacqv.

mucronatus Lam.

I 20

nervosus . . 118 paleaceus . . II8 paniceus . . I 20 parviflorus' 79 parviflorus $\quad 78$ permeabilis . Iо plicatus • . 116 praecox - 94 punctatus . 83 punctatus? 82 purficeus . I14 puniceus Lam. 120 purpureus . . 114 pyramidalis . $\mathrm{x} 20$ pyramidalis - $9 \mathbf{I}$ recurvus , 86 
Gladiolus refractus . I09 ringens . 83,115 roseo-albus $\quad 93$ roseus . . I10 roseus . . 88 rubens • . 98 rubro-cyaneus 98 sambucinus . II? secundus . . ib. securiger . 109 setifolius . 100 silenoides . 106 spathaceus . I I 8 spicatus . 78 spicatus . 79 striatus , . 89 strictus - . II 8 strictus . . 88 subulatus . 97 sulcatus • . II
Gladiolus sulphureus 99 tenellus . $8 \mathrm{I}$ testaceus . . 105 ţrimaculatus $\quad 85$ triștis . . 84 tristis - . $80,8 \mathrm{I}$ tristis grandis . 87 hastatus $\quad 86$ inodorus $\quad 83$ punctatus $\cdot 82$ violaceus $\quad 87$ tubatus . . II 3 tubiflorus $\quad 112$ tubulosus - 78, 96 undulatus $\quad 102$ ventricosus $\quad 9 \mathrm{I}$ versicolor - 87 villosus . . II5 viridis . . 96 Watsonius . 93

$\mathrm{H}$.

Haemodorum corymbosin 179

Hapalanthus repens 180 Hedycrea incana $\quad 37$ Heteranthera acuta 42 cordata . $4 \frac{4}{4}$ diversifolia $\quad 47$ graminea : 45 limosa . . 44 pubescens . 43 reniformis . ib.

Hippocratea aspera . 29 comosa . ib.
Hippocratea disperma 28 indica . . ib. laevigata . $\quad 27$ macrophylla . 28 madagascariensis 32 multiflorus . ib. obcordata . 26 obovata . : 32 ovata . . 26 paniculata $\quad 28$ scandens . 26 senegalensis . 31 viridis . . 27 volubilis . . ib. 
Hypaelyptum argen-

$$
\text { teum . } 283
$$

filiforme . 284
Hypaelyptum pungens sphacelatum . ib.

I.

Ilex Dodonaea . . 36 Iris alata . ... 143 angusta . . I 46 aphylla . . 133 arenaria . I 34 biflora . . $I_{j} 2$ biglumis, . 149 bituminosa . 150 capensis . $\quad 153$ chinensis . . 133 ciliata - . I37 compressa . ib. crispa . . $\mathbf{I}_{52}$ cristata - 132 dichotoma . 136 ensata . . 148 fimbriata . I 133 flavissima : 135 flexuosa - . I3 I florentina . . 126 foetidissima . 139 germanica . $\quad 126$ germanica - 127 graminea $\quad 149$ graminea - 148 Gyldenstädtii . I 4 ז halophila . I4I hexagona . 140 japonica 329
Iris juncea . . 145 lacera .. I 50 lactea? . I49 longifolia . . ib. lurida . . $\quad 1=8$ lutescens . $\quad$ I34 microptera . 142 , minuta - 138 nudicaulis . $\quad 133$ ochroleuca . I4I odoratissima . I 27 orientalis . : ib. pallida . - ib. papilionacea . $15 \mathbf{I}$ persica - : 147 plicata ... I3I plumaria . 158 polystachya - I5a pratensis . . 148 Pseud-Acorus 138 pumila . 135 ramosa . 142 ramosissima . ib. sambucina . 128 scorpioides - $\mathrm{I}_{43}$ setacea! . . 145 setifolia . . ib. sibirica . 348 Sisyrinchium : It4, 
Iris spathacea $\cdot 142$ Ixia campanulata $\quad 49$ spathulata I4I, ${ }_{42}$ capillaris . . 60 - spuria . $\because 140$ - cartilaginea I I04 squalens . I 129 stylosa - . I 43 susiana . . 125 Sivertii . I 130 tenuifolia. ' 146 tripetala Thumb. 138 tripetala Walth. 153 tristis . . I I I tuberosa . I 52 unguicularis . I 43 variabilis : 144 variegata . 129 ventricosa . 147 verna . . ib. versicolor . . 139 virginica . 140 viscaria - I50 xiphioides . I 44 Xiphium . . 43 Justicia lucida • . 400 Ixia alopecuroidea $\because 78$ anemonaeflora 58 angusta . 59 arcuata . 77 aristata . 7 I aristata . . 63 aruica . 60 bicolor ... 72 bulbifera . $7^{2}$ bulbocodioides . 53 Bulbocodium - 50 Bulbocadium .. 49 caryophyllacea 77 chinensis . I59 cinnamomea . 56 coelestina @ 58 coerulea . 64 corymbosa . 56 crispa : : 55 crocata . 73 crocata. 74 crocata variet. . 76 cruciata - : $5 \mathrm{E}$ -deusta . 74 elungata . 5 I emarginata . 70 erecta . . 65 excisa. . 69 Fabricii . . 108 falcata. . 69 fastigiata . 56 fenestrata - 75 filiformis . .63 fimbriata . . 7 I fistulosa : : 58 flabellifolia . I I flabellularis . $6 \bar{T}$ flava? . . 53 fragrans . 52 fruticosa • $\cdot 47$ geminata . 68 gladiata - I 55 gladiolaris . . 110 grandiflora , : 7 I 
Ixia heterophylla $\quad 57$ hirsuta . 16 I hirta . .. 54 holosericea $\quad 7^{2}$ humilis • 53 hyalina . 75 imbricata . 6 I incarnata , 60 inflexa . . 54 lancea . . 62 lancea . . 60 leucantha . 63 linearis . . 6 I linearis . 59 longiflora . I I I longifolia . ${ }_{156}$ maculata . 64 maculata viridis ih. magellanica - 48 marginata 104 Milleri . $\quad 73$ miniata • 74 minuta • 49 monanthos $\because 72$ ochrỏleuca 50 paniculata . . III patens $\cdot$ : $7 x$ pectinata . 62 pendula . 66 pentandra . 67 pilosa . . 54 plantaginea . 99 plicata . . I I 6 polystaclas 65,67
Ixia pumila . . 48 punicea . II 4 purpurea . $7^{6}$ purpurea - . II pygmaea . $\quad 7^{6}$ pyramidalis . 53 quadrargula $\quad 52$ radians . $7 j$ radiata . . $6 \mathrm{~s}$ recurva . . 58 rosea - . 49 rubra. . 64 rubro-cyanea • 98 scillaris , 59 scillaris . 67 secunda. 55 setacea . 68 spicata - 77 squalida . 73 striata . . $6 \frac{5}{5}$ sublutea? - 53 -tenuiflora . . 66 tenuifolia . 62 thyrsiflora . 65 tricolor . 74 triticea . $7^{6}$ tubulosa . . ib. undiclata . $\quad 55$ uniflora $\quad: \quad 75$ villosit $\quad 98$, I I 5 violacea . . 64 viridiflora . . ib. virgata . . 59 Xiphadium . . 162 


\section{K.}

Kyllinga brevifolia 350 cajanensis . 377 cyperina - 377 filiformis . 382 incompleta • 377 monocephala • 379 odorata . . 382 ovularis . 374
Kyllinga panicea • 373 peruviana . 38 ז pumila . 380 squamulata - $38 \mathrm{I}$ sumatrensis . 376 triceps . . 38 I umbellata . 376 vaginata . $38 \mathrm{I}$

\section{L.}

Lapeyrousa compressa 108 Leptanthus gramineus 45 ovalis . . 44 reniformis . 42
Licania incana . . 37 Loeflingia hispanica 24 pentandra . . 25 Lygeum spartum . 392 M.

Machaerina restioides

Mariscus ovularis . 374 238

Macrolobium Hymeretrofractus - 375 naeoides $\quad 37$ sphaerócarpon ib. Mapania sylvestris . 39 I Marica paludosa . 48 Mariscus alternifolius 376

aphyllus . . 373 capillaris . 372 cyperinus - 377 elatus . . ib. flavus . . 374 gracilis • 373 paniceus . ib. setaceus - 253 umbellatus .376 Mayaca fluviatilis . 18.0 Melancranis radiata 239 scariosa . . ib. Mirabilis aggregata 4 I corymbosa . . 40 viscosa . . 39 Moraea africana . 124 alata . . 154 aphylla . . 155 chinensis . 159 coerulea • 125 corniculata . 157 
Moraea crispa . 158 Moraea palmifolia . 160

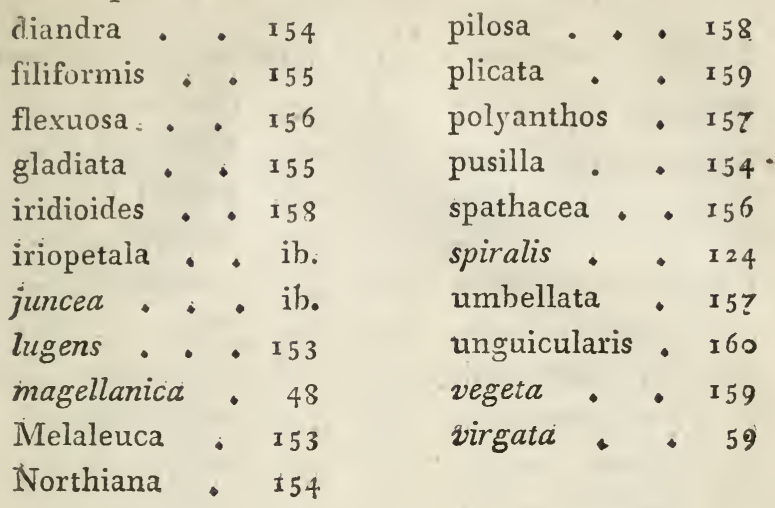

N.

Nardus ciliaris - . 397 Nardus stricta . - 396 indica . . ib.

O.

Olax Psittacorum . 33 Oxybaphus aggregatus 4 t zeylanica . . ib. expansus . . ib. Ortegia dichotoma . 25 glabrifolius 440 hispanica . ib, ovatus . . ib. Oryzopsis asperifolia 397 prostratus . . ib. Outea guianensis - 38 viscosus : . 39

P̈。

Panicum squarrosum 395 Polycnemum sclerospePapyrus . . 365 Polycnemum arvense 23 mum . . 24 monaudrum - ib, Pomereulla Cornucooppositifolium 24 salsum - 23 Pontederia limosá : 44 
Remirea maxitima . 39 I Romulea . . 51 Rotala verticillaris . 26 Rumphia amboinensis 36 Rynchospora alba . 236 aurea . . 229 capitellata • 235 cephalotes . 237 ciliata . 235 distans . ib. fascicularis، $\quad 234$
Rynchospora filiformis 232

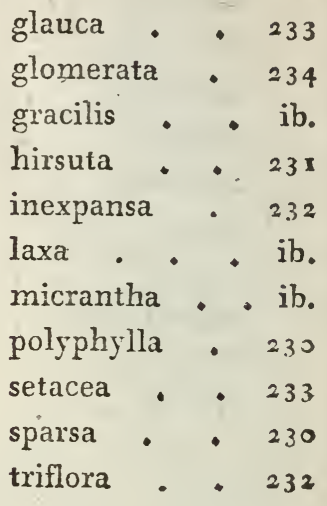
S.
Salicornia acetaria . 398 foliata a . . 399
foliata $\beta$.
prostrata.$\quad$ ib.
pygmaea . . ib.
strobilacea.$\quad$ ib. Schoenus albus . $\quad 236$ angustifolius . 225 aphyllus . 209 aristatus . . 215 arundinaceus . 220 axillaris . . 235 Bobartiae - 213 bromoides • . 223 bulbosus . . 22 6 bulbosus . 215 Burmanni . . 22 ? capillaceus . 218 capillaris , 372
Schoenus capitellatus 235 Capitellum . 212 cephalotes - 237 ciliaris • 236 Cladium . . 221 coloratus . 379 compar . . 216 compressus . 214 corniculatus . 23 I cuspidatus . 217 cymosus • . 228 cyperoides - 22 ? cyperoides . 297 dactyloides . 224 deustus . 210 distans . . 235 Fabri . . 229 fasciatus . 219 fascicularis . 234 
Schoenus ferrugineus 207 filiformis . 2 I I flexuosus . . 225 fuscus . 236 glomeratus 224, 234 gracilis . . 234 hirsutus . 23 I hispidulus $\quad=19$ Hystrix • 226 inanis . 218 incanus . . 229 indicus . 212 inexpansus . 233 involucratus . 223 junceus . . 257 juncoides . 2 I I laevis . 2 I8 lanceus • 222 lateralis . . 2 II latifolius . . 226 longirostris . $\quad 232$ Mariscus . $22 \mathrm{I}$ microstachys . 220 miliaseus . 230 mucronatus . 213 nemorum • 227 nigricans . 208 pilosus . . ib. polyphyllus - 230 punctorius . 2rz pusillus . . 209 radiatus . 220,262 rariflorus $\quad 23 \mathrm{I}$ restioides . . 238 ruber $\cdot \quad=253$
Schoenus rufus . $\quad 215$ rugosus . . 233 scariosus . 210 scarioszs • 239 secundus . 215 setaceu's . 219 setaceus . $\quad 236$ spadiceus $\quad 212$ sparsus . . 230 spathaceus . 225 spicatus . . $2 \pi 6$ spicatus . $\quad 22$ ? stellatus . . 249 striatus . 2 ro surinamensis . $\quad 2=9$ thermalis . $\quad 223$ tristachyos: 254 umbellatus $\quad 374$ ustulatus $\quad 222$ Scirpus acicularis . $2+5$ acicularis . 246 annuus - 249, 287 anomalus . $28 \mathrm{I}$ antarcticus . $26 \mathrm{I}$ argenteus $\quad 297$ aristatus . . $27 \mathrm{I}$ articulatus . 258 arvensis . . $29 \mathrm{x}$ atropurpureus $=49$ australis . . 267 autumnalis . $3 \pm 9$ Baeothryon . 244 barbatus . $.26 x$ bisumbellatus $\quad 28$ ? bivalvis . . $27 \%$ 
Scirpus bulbosus - 2 ro caespitosus . 242 campestris . 243 capensis . 280 capensis . . 216 capillaris.. 276 capillaris . 246 capitatus . 250 capitatus 249,369 capsularis . 280 caribaeus . 250 caricis . 214 carolinianus , 292 castaneus . . ib cephalotes . 263 cephalotes - 379 cernuus . 245 chinensis . 259 ciliaris . . 386 cinnnamometorum

278

complanatus : 279 compressus . 249 coronarius . $26 \mp$ corymbosus 229,269 cymosus . $\quad 275$ cyperoides . 376 debilis . . 292 dichotomus . 28 ? diphyllus . . 290 dipsaceus . 276 chinatus? $\quad 375$ ellychniarius , 289 eriophorus . 282 falcatus $\quad 275$ fthstigiatus $\quad 260$
Scirpus ferrugineus $29 x$ filamentosus . 262 filiformis . 248 fistulosus . 258 fluitans . . 246 fragrans . 277 geniculatus 250 glaucus . 269 globiferus . 266 globulosus • 277 glomeratus . 274 glomeratus - $38 \mathrm{I}$ grossus . 270 Halleri • 244 hispidulus . 276 Holoschoenus 264 hottentottus . 387 Hystrix - 259 intermedius? - 247 interstinctus . $25 \mathrm{l}$ intricatus . 369 junceus . 285 junciformis , 272 Kalli . . 213 laciniatus $\quad 260$ lacustris . 267 lappaceus . $\quad 369$ lateraliss . . 280 lateralis . 257 lineatus,$\quad 273$ longifolius , $28 \mathrm{I}$ luzulae : 266 maculosus : 247 marginatus : 255 maritimus : 269 membranaceus $26 \mathrm{r}$ 
Scirpus michelianus 263 micranthus . 254 miliaceus $\quad 287$ minimus . 253 monander $\quad 294$ mucronatus . 256 mucronulatus $\quad 278$ multicaulis . 246 mutatus - 252 natans . 254 nitens • 272 nodosus . 258 numidianus , 254 nutans • $\quad 285$ obtusifolius . 275 - ovatus . . 249 palustris - 24 ? palustris . 246 paniculatus . 282 pauciflorus . 244 pilosus . 263 pilosus • $\quad 27 \mathrm{I}$ plantagineus . 25 I plantaginoides ib, polyphyllus • 274 polytrichioides 248 prolifer . 265 puberulus . 289 pubescens $\quad 277$ pumilus : $\quad 243$ pungens . 255 pusillus . 246 pygmaeus . $2 t^{2}$ quadrangulatus 252 quinquangularis $27 ?$
Scirpus radiatus . 262 radicans $\cdot 272$ reptans - $24 \mathrm{I}, 24$ ? reticulatus . $28 \mathrm{I}$ retrofractus $\quad 375$ romanus . 264 scariosus . 210 schoenoides . 286 senegalensis . 283 setaceus . 253 spadiceus . . 294 Sparmanni . 260 spiralis . 252 squarrosus . 259 stolonifer , , 246 subulatus . 268 supinus . $\quad 257$ sylvaticus . . 27 I trigynus, , 210 triqueter ... 270 triqueter . 256 trispicatus . 260 tristachyos - 254 truncatus . 260 tuberculosus - 248 umbellaris * 290 umbellatus : 292 uncinatus $\quad, \quad 259$ vaginatus . 258 Vahlii . 263 validus . $26 \mathrm{~s}$ Sisyrinchium palmifo.

lium 154,160 viperatum . 89 Syena fluviatilịs . $\quad 180$ 


\section{$\mathrm{T}$.}

Tapeinia

48

Tonsella multiflora 32

Thryocephalon nemo-

$$
\text { rale . } 328
$$

Tonsella africana 30

decussata . ib. madagascariensis 32

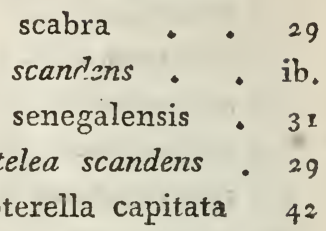

\section{U.}

Usteria volubilis . 398

\section{V.}

Valeriana alliariaefolia I $\mathbf{z}$ angustifolia . I calcitrapa . i ib. capensis $\because 7$ carnosa . I 12 celtica . . 15 coarctata - . $\mathbf{r}$ connata • 16 cornucopiae - I9 crispa • . 3 decussata . . 8 dentata . 20 dioica . . 2 echinata . I elongata . . I3 globifera .. . 5 hyalinorhiza . 3 jetamansi . • 13 intermedia . 9 interrupta . 4 italica . . 6 lapathifolia . I I locusta . . Ig
Valeriana locusta coro-

\begin{tabular}{ll}
\multicolumn{1}{c}{ nata } & 20 \\
dentata & ib. \\
discoidea & 2 I \\
olitoria & I9 \\
pumila & 2 I \\
radiata & ib. \\
vesicaria & 20
\end{tabular}

lyrata • . 4 magellanica . 12 mixta .. . 2 I montana - 9 multifida . 2 I oblongifolia . 2 officinalis . 6 orientalis $\quad 7$, I I paniculata . 7 pauciflora • 5 phu . . . 3 pilosa . . 16 pinnatifida . 4 polystachya 5 pyrenaica . II 
Valeriana rigida . Is Valerianella annua . 2 I rubra . 1 I rupestris + $2=$ ruthenica . . ib. salicariaefolia . 16 saliunca . . ${ }^{5}$ sanguisorbaefolia 8 saxatilis . I 7 scandens . . 8 serrata . . I? sibirica $\cdot \quad 2=2$ sisymbriifolia, 7 spathulata . . 15 spica . . 13 supina . . ib. tenuifolia . I 8 tripteris . . 10 tuberosa . I 12 tuberosa . . 6 villosa . . то virgata . . 9 cretica . . 20 marilandica . $2 x$ procera . 22 tetrastemon. ib. Vogelia capitata $\quad 42$ Vouapa bifolia . . 37 Simira • . 38 Wachendorfia grami-

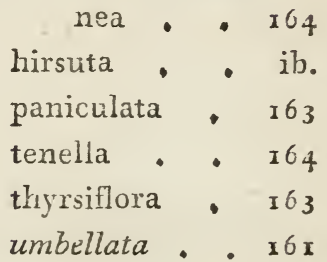
Watsonia humilis . 95 Meriana . 94 Willichia repens • 39 Witsenia maura • 4 ? pumila • . 48 ramosa . . 47

\section{$\mathrm{X}$.}

Xiphidium albidum $\mathrm{I}_{2}$ Xyris capensis . 206 coeruleuin . . ib. floriburdum . ib. Xiphium latifolium 144 vulgare . . ib. Xyris americana . 205 anceps . . ib. brevifolia eof caroliniana . ib. filiformis $\quad 207$ indica . . 204 jupicai . 205, 206 macrocephala 204 pauciflora . 20 ? subulata . . ib. 


\section{3} (2)

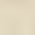

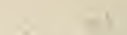

+
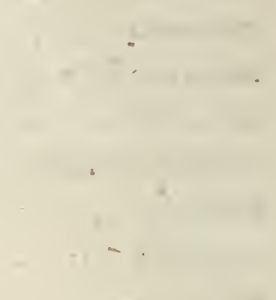

$+$
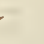

$\because$

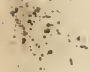
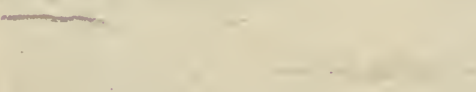

$$
\text { r }
$$




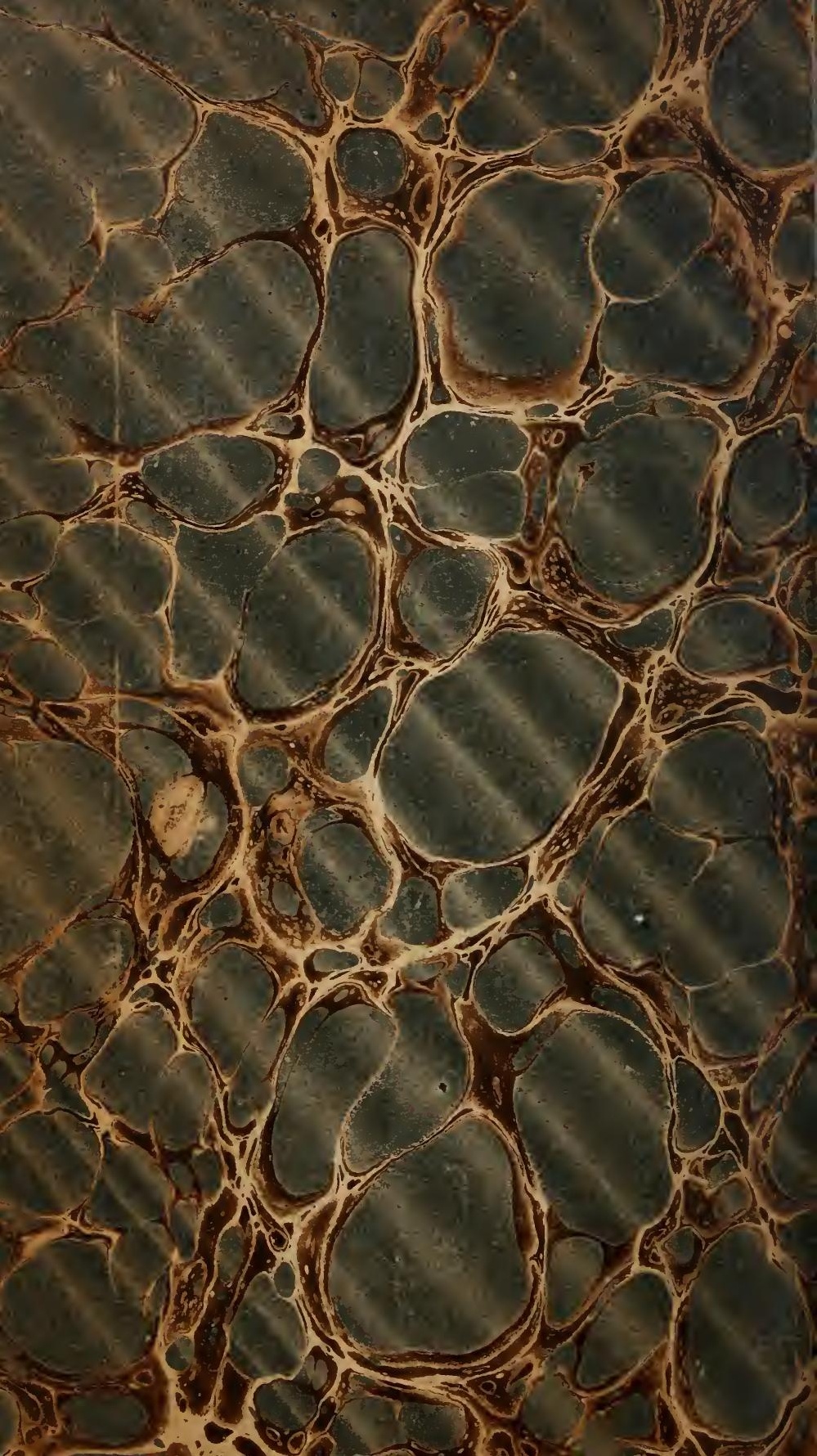




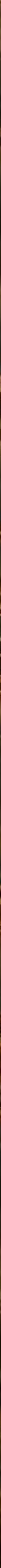


